
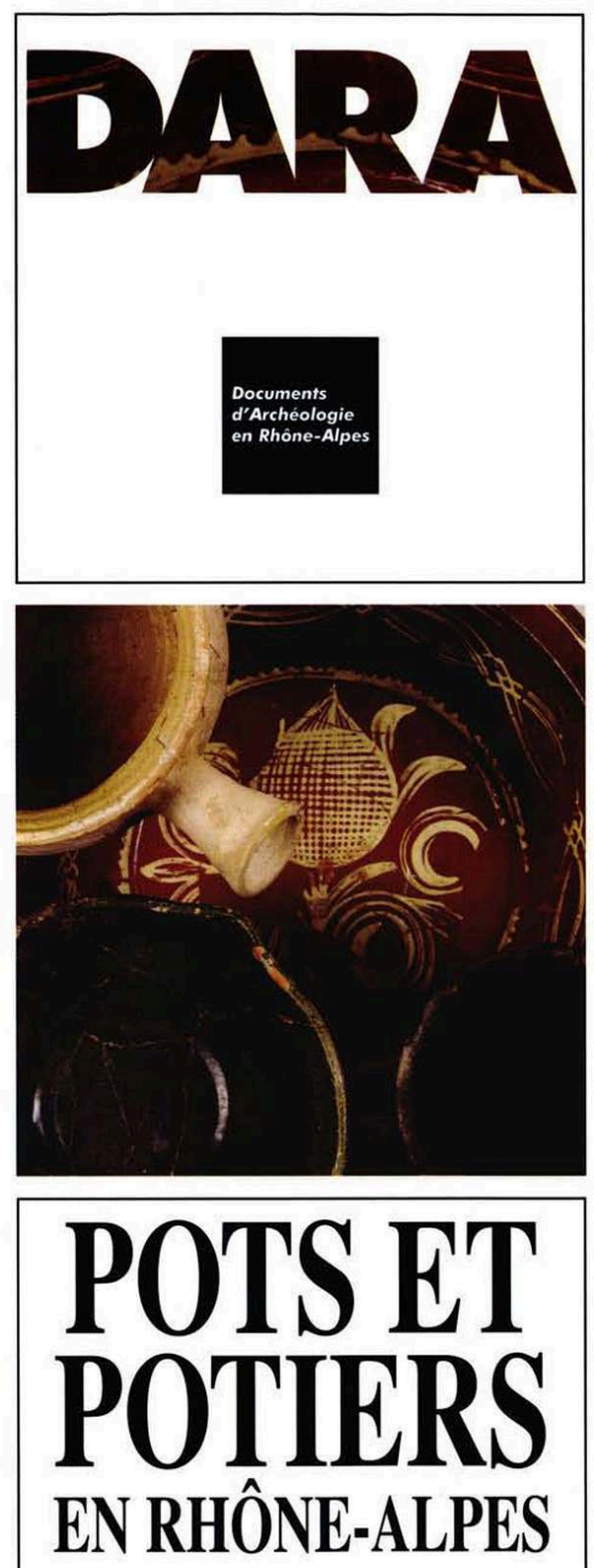

ÉPOQUE MÉDIÉVALE ÉPOQUE MODERNE

E. FAURE-BOUCHARLAT, T. VICARD

B. MACCARI-POISSON, S. SAVAY-GUERRAZ 


\title{
Pots et potiers en Rhône-Alpes
}

Époque médiévale, époque moderne

\author{
Élise Faure-Boucharlat, Tommy Vicard, Bruna Maccari-Poisson et Sophie \\ Savay-Guerraz
}

DOI : 10.4000/books.alpara.1029

Éditeur : Alpara

Lieu d'édition : Lyon

Année d'édition : 1996

Date de mise en ligne : 2 juin 2016

Collection : DARA

ISBN électronique : 9782916125312

\section{Qbooks}

http://books.openedition.org

Édition imprimée

ISBN : 9782906190160

Nombre de pages : 316

Référence électronique

FAURE-BOUCHARLAT, Élise ; et al. Pots et potiers en Rhône-Alpes : Époque médiévale, époque moderne. Nouvelle édition [en ligne]. Lyon : Alpara, 1996 (généré le 12 janvier 2021). Disponible sur Internet: <http://books.openedition.org/alpara/1029>. ISBN : 9782916125312. DOI : https://doi.org/10.4000/ books.alpara.1029.

Ce document a été généré automatiquement le 12 janvier 2021. Il est issu d'une numérisation par reconnaissance optique de caractères.

(C) Alpara, 1996

Conditions d'utilisation :

http://www.openedition.org/6540 
Pot à cuire ou pot à boire, vaisselle de table ou vaisselle de cuisine, la céramique constitue, en raison de son caractère inaltérable, l'essentiel des objets découverts lors d'une fouille archéologique. Indispensable donc généralisé, de faible valeur donc abondant, de durée éphémère donc souvent renouvelé, ce mobilier est riche d'informations sur la culture matérielle d'une époque, sa façon de produire et de consommer, ses modes alimentaires et ses goûts.

L'équipe pluridisciplinaire, à qui l'on devait déjà la remarquable exposition "À la fortune du pot" présentée en 1990 au Musée de la civilisation gallo-romaine de Lyon, s'attache ici à retracer l'évolution de la vaisselle de terre sur plus d'un demi-millénaire, à travers les techniques de fabrication et le répertoire des formes des diverses catégories de récipients. Cette démarche permet de suivre le parcours de ces vases, depuis l'atelier du potier jusqu'au vaisselier domestique, par un va-et-vient permanent entre les sites de production et ceux de consommation, entre le travail du typologue et celui de l'historien de l'artisanat, entre les analyses de laboratoire et les enquêtes de terrain.

La première partie de ce volume est consacrée aux ateliers régionaux, à travers trois secteurs privilégiés de production, en Bresse, dans la vallée du Rhône et en Beaujolais. Une seconde partie expose, au plan régional, le répertoire des formes et la variété de leurs usages entre le XII et le XVIII's. 
SOMMAIRE

Avant-propos
Élise Faure-Boucharl

Introduction : la céramologie médiévale, une discipline à part entière

Élise Faure-Boucharlat

La naissance d'une discipline

La céramologie au service de l'archéologie

Les champs de la discipline et leur diversification progressive

Vers une pluridisciplinarité

L'élargissement du champ chronologique

Du tesson à l'histoire?

Première partie. Aux origines de quelques poteries : trois groupes d'ateliers Rhône-Alpins

Chapitre 1. En Bresse, les ateliers de Meillonnas-Treffort, une belle réussite économique Élise Faure-Boucharlat, Bruna Maccari-Poisson, Sophie Savay-Guerraz et Anne Schmitt

Origine des recherches

Les ressources en argiles de Meillonnas

L'artisanat potier : une histoire peu écrite

Les produits de Meillonnas-Treffort

La répartition des ateliers d'après l'enquête de terrain

La diffusion du service vert

Conclusion

Chapitre 2. Dans la moyenne vallée du Rhône : le secteur d'Érôme et de Larnage, un exemple parmi d'autres

Élise Faure-Boucharlat, Bruna Maccari-Poisson, Sophie Savay-Guerraz et Anne Schmitt

Objectif des recherches

Environnement naturel et ressources en argiles

Une enquête historique fructueuse

Les données archéologiques

La diffusion du service jaune de Larnage

Conclusion

Chapitre 3. Les ateliers du Beaujolais : la tradition du Val de Saône

Élise Faure-Boucharlat, Georges Ducomet, Bruna Maccari-Poisson et Anne Schmitt

Origine des recherches

Environnement et ressources en argiles

Cartographie des vestiges d'ateliers

Production et chronologie des ateliers

Conclusion

\section{Synthèse}

Élise Faure-Boucharlat et Sophie Savay-Guerraz

Les méthodes d'investigation

Trois études de cas

Une enquête à poursuivre 
Seconde partie. Répertoire illustré des céramiques domestiques en lyonnais (XII - XVIII ${ }^{\mathrm{e}}$ siècle)

Avant-propos

Introduction

Chapitre 1. Pour une typologie des récipients

Tommy Vicard

Fonction

Morphologie

Typologie

Vases incomplets

Technologie

Chapitre 2. Les critères de datation à partir des données archéologiques

Du XIIe au XIVe siècle

Au XVe siècle

Les XVIe, XVIIe et XVIIIe siècles

Chapitre 3. L'évolution du vaisselier régional du XII au XVIII siècle

Synthèse fonctionnelle

Synthèse technologique

Synthèse chronologique

Annexe

Conclusion

Tommy Vicard

Bibliographie

Crédits illustrations 


\title{
Avant-propos
}

\author{
Élise Faure-Boucharlat
}

1 En 1986 se constituait un " groupe de travail sur la céramique médiévale et moderne de la région Rhône-Alpes ", officieusement d'abord, puis officiellement en apparaissant, de 1987 à 1991, comme " projet collectif de recherche » dans le cadre du programme H30 (devenu H19 depuis) défini par le Conseil supérieur de la recherche archéologique : les ateliers médiévaux et modernes, l'archéologie industrielle, organisation et diffusion.

2 Plus prosaïquement, une poignée d'archéologues lyonnais, sensibles à l'intérêt offert par le mobilier céramique médiéval, s'assignait pour tâche de "démêler l'écheveau " que représentaient alors les ensembles de poteries médiévales et modernes restitués par les fouilles régionales toujours plus nombreuses. C'est ainsi que Bruna MaccariPoisson, Tommy Vicard, Jean-Paul Lascoux et moi-même nous lançâmes dans l'entreprise. Sophie Savay-Guerraz rejoignit bien vite nos rangs lorsque la nécessité se fit sentir du recours aux sources écrites, notamment lorsque nous abordâmes la question des lieux de fabrication. Sa contribution apporta une salutaire "bouffée d'humanité " dans nos travaux de collectes, d'inventaires, de comptages, de classifications. Dès l'origine, la collaboration avec le Laboratoire de céramologie de Lyon (CNRS, UPR 7524) fut l'un des atouts de cette aventure collective. Impliqués sur le terrain de nos enquêtes, tout autant que dans leur laboratoire, Maurice Picon, Anne Schmitt, Eliane Meille et Michèle Vichy nous apportèrent la paisible assurance des sciences exactes là où nous progressions par impressions, comparaisons, analogies et hypothèses. Tous acceptèrent que je me charge de la coordination scientifique et administrative de ces recherches pluridisciplinaires. Tous savent combien j'ai apprécié leur compétence et leur disponibilité. Ils savent aussi combien ils m'ont appris. Qu'ils trouvent ici l'expression de mon amicale gratitude.

3 Il est tout à fait certain que notre " projet collectif de recherche " aurait vite tourné court sans la confiante complicité de tous nos collègues archéologues qui, patiemment, répondirent à nos enquêtes, ouvrirent leurs réserves, fournirent les informations archéologiques nécessaires aux datations... Plusieurs d'entre eux, en nous confiant l'étude d'ensembles importants (provenant de Lyon, Vienne ou Condrieu, de l'Ain, de Savoie, etc.) favorisèrent l'harmonisation des méthodes d'approche, la mise en commun des informations et par conséquent les progrès de la céramologie régionale. Je 
les remercie tous très sincèrement. Ma reconnaissance va également aux responsables successifs du Service régional de l'archéologie qui dégagèrent régulièrement les moyens matériels et financiers nécessaires à nos travaux. Aux crédits du ministère de la Culture s'adjoignirent des subventions des départements de l'Ain, du Rhône et de la Drôme. Bref, nous voici donc redevables d'une infinité de collaborations. L'exigence de diffuser dignement les résultats de ce travail collectif n'en était que plus pressante. Les Documents d'Archéologie en Rhône-Alpes nous ont tout naturellement proposé de s'en charger.

Lorsque débutèrent les recherches que cet ouvrage relate, la céramologie médiévale jouissait déjà de solides acquis. La région Rhône-Alpes, et plus particulièrement le Lyonnais et le Dauphiné, avaient été le cadre d'études, qui avec le recul, peuvent être qualifiées de pionnières. Dès les années soixante-dix en effet, l'originalité des poteries "à fond marqué » des Xe-XIe s. avait suscité un important travail de la part des équipes lyonnaises et grenobloises regroupées autour de Jean-François Reynaud et de Michel Colardelle. Un peu plus tard, l'intérêt se porta vers des catégories de vaisselles bien typées, facilement identifiables parmi les monceaux de tessons exhumés par les archéologues de la région : les "pichets ornés ", approximativement placés au XIIIe s., puis les récipients en pâte blanche recouverte d'une belle glaçure vert vif attribuées à la Bresse ou encore les productions décorées aux engobes polychromes globalement qualifiées de modernes et traditionnellement attribuées au Val de Saône.

Mais à l'évidence, le tableau comportait plus de zones d'ombre que de lumière. Tout au long de ces six années de travail, nous nous sommes attachés à réduire ces zones d'ombre en visant un double objectif : tracer l'évolution de la vaisselle de terre sur près d'un millénaire à travers les techniques de fabrication et les formes des récipients, tout en explorant les lieux de fabrication potentiels de quelques productions caractéristiques; en d'autres termes, nous tenions pour important de fonder nos recherches relatives à la diffusion de l'artisanat de la poterie sur une connaissance approfondie des produits utilisés par les consommateurs. Tout naturellement la ville de Lyon devint notre champ d'observation privilégié en raison de la quantité et de la qualité des collections archéologiques mises au jour régulièrement. Notre publication est donc le reflet de cette répartition des tâches : tandis que se forgeait graduellement une typologie régionale, objet de la seconde partie de ce volume, l'enquête sur les ateliers de potiers dégageait trois secteurs privilégiés, en Bresse, dans la vallée du Rhône et en Beaujolais, sensés approvisionner les marchés lyonnais et régionaux ; cette enquête est présentée dans la première partie du volume. Deux ouvrages en un penseront certains, à juste titre, tant il est vrai que nos recherches s'attachèrent à privilégier le va-et-vient permanent entre les sites de consommation et les sites de production, entre le travail du typologiste et celui de l'historien de l'artisanat, entre les analyses en laboratoire et l'enquête de terrain.

6 Si l'impression d'ensemble reste celle d'un tableau encore disparate, n'est-ce pas à la nature même du sujet traité ici que cela incombe? Les céramologues médiévistes, confrontés à un matériel lui aussi disparate procèdent par petites touches successives comblant patiemment les hiatus d'une typologie, retrouvant progressivement le fil conducteur du vaisselier domestique à l'atelier du potier. Cette publication n'est autre qu'un portrait partiel et provisoire d'une réalité complexe et foisonnante. C'est un état de la recherche régionale, que nous pensons utile de proposer à nos collègues archéologues mais aussi à tous ceux qu'intéresse l'histoire de l'artisanat potier. 
7 Il convient de préciser que depuis le début de nos travaux, les publications en matière de céramologie n'ont pas manqué pour la région Rhône-Alpes. Bien souvent tel ou tel d'entre nous, membre du projet collectif, en est l'auteur ou y est largement impliqué. Le groupe de travail rhônalpin fut par ailleurs actif au sein des structures de recherches nationales comme le Groupe de recherches coordonnées (GRECO du CNRS) sur les sociétés artisanales. Mais de tout cela nous retiendrons ici deux temps forts. La parution en 1985 d'un rapport collectif intitulé "Etudes céramologiques, région RhôneAlpes » : à la fois bilan des connaissances et déclaration d'intention, il marquait le coup d'envoi de notre programme de recherche. Puis en 1990 nous visions le grand public avec l'exposition créée au Musée de la Civilisation gallo-romaine de Lyon et son catalogue "A la Fortune du Pot». La diversité des thèmes abordés alors montrait le chemin parcouru en quatre ans grâce à la constitution d'une équipe pluridisciplinaire particulièrement soudée. Enfin ce volume des Documents d'Archéologie en RhôneAlpes témoigne encore de ce que furent la permanence de nos préoccupations et la tranquille progression de nos connaissances.

8 Si je n'avais acquis qu'une seule conviction au cours de ces années d'obsession "tessonnière ", c'est bien celle que la culture matérielle du Moyen Âge et des temps modernes ne peut être appréhendée qu'au travers d'enquêtes minutieuses et de longue haleine, comme celles dont nous présentons les résultats ici. 


\title{
Introduction : la céramologie médiévale, une discipline à part entière
}

\author{
Élise Faure-Boucharlat
}

1 En replaçant le travail réalisé depuis la constitution, en 1987, du projet collectif de recherche «les ateliers céramiques du Moyen Age et de l'époque moderne dans la région Rhône-Alpes » dans le contexte plus large de la recherche nationale, le lecteur saisira mieux la démarche parcourue, les modes d'approche et les méthodes employées, les objectifs recherchés, bref, les tenants et aboutissants de cet ouvrage qui n'est autre qu'une étape dans le domaine si vaste et si varié de la céramologie médiévale.

2 Campons le décor : l'intérêt et la spécificité de cette discipline se sont affirmés au fil des ans grâce au patient travail des chercheurs et à la reconnaissance des archéologues médiévistes. Mais dès 1982, la céramique est mise en avant comme une source d'information historique à part entière, par J.-M. Pesez, dans sa réflexion sur les relations parfois polémiques entre historiens et archéologues (Pesez 1982, pp. 301-302). Affirmation susceptible de réconforter bien des céramologues aux prises avec un mobilier envahissant, répétitif, voire rébarbatif : l'intérêt documentaire de la vaisselle de terre cuite, qui n'a d'égal que la faible valeur intrinsèque du matériau, justifie ainsi pleinement l'énergie que lui consacrent les spécialistes. Mais que recherchent-ils donc?

Durant les décennies soixante-dix et quatre-vingt, les études céramologiques médiévales connaissent en France une rapide progression. Celle-ci est en grande partie liée à l'augmentation régulière du nombre des témoins archéologiques livrés à l'étude, elle-même tributaire de l'intérêt grandissant porté au Moyen Age, tant en milieu rural qu'en milieu urbain. De toute entière vouée à l'analyse des objets en vue de la description de leurs caractéristiques morphologiques et technologiques, indices présumés d'une évolution chronologique continue, la céramologie connaît peu à peu d'autres préoccupations comme l'origine et la diffusion des productions, l'organisation des communautés artisanales, les goûts des utilisateurs. Les spécialistes cherchent à renouer le fil entre le dépotoir et l'atelier, entre le consommateur et le producteur. Des 
regards complémentaires sont alors portés à ces témoins privilégiés des activités de nos proches ou lointains prédécesseurs : les recherches se doublent d'enquêtes de terrain, d'archives et de laboratoire. Le travail mené dans la région Rhône-Alpes s'inscrit tout à fait dans cette évolution générale.

\section{La naissance d'une discipline}

4 L'intérêt des archéologues médiévistes pour le mobilier céramique se fait jour, dans notre région, dès le début des années soixante-dix. Avec le recul du temps, il n'est pas faux de dire que le fait apparait relativement précoce, comme il le fut dans quelques autres régions, grâce aux recherches d'équipes constituées. Citons par exemple les travaux du Centre de recherches archéologiques médiévales de Caen pour le NordOuest de la France ou bien ceux du laboratoire d'archéologie médiévale d'Aix-enProvence, pour le secteur méridional, alors respectivement placés sous la responsabilité de M. de Boüard et de G. Démians d'Archimbaud. Entre ces pôles normand et provençal, les recherches conduites en Saintonge, en Bourgogne, dans la région bordelaise, à Paris et en Ile-de-France, et enfin en Lyonnais et Dauphiné sous l'impulsion de J.-F. Reynaud et $\mathrm{M}$. Colardelle complètent les données pour le territoire français et jettent les bases d'une véritable discipline.

Mais les céramologues médiévistes français ont quelques difficultés à bousculer l'ordre établi : l'étude des lots de mobilier médiéval est souvent considérée comme secondaire tandis que les productions de l'Antiquité monopolisent l'attention et les moyens. Il faut attendre le milieu des années quatre-vingt pour que l'on considère comme "normal » d'associer un céramologue médiéviste à part entière aux équipes en charge des grandes fouilles métropolitaines. Les fouilles de Saint-Denis montrent l'exemple. A Lyon, les fouilles préalables à la ligne $\mathrm{D}$ du métro inaugurent cette pratique en 1981-1982. Jusque-là, la céramique médiévale est « sélectionnée » après la fouille parmi l'ensemble du matériel recueilli et est appréhendée par les chercheurs davantage comme une collection de musée que comme partie intégrante d'un gisement archéologique. C'est, il faut l'avouer, le péché de jeunesse des recherches rhône-alpines.

Quoiqu'il en soit, quelques études pionnières montrent à la communauté scientifique française l'intérêt d'une analyse précise et exhaustive du mobilier archéologique et, au premier chef de la céramique. Citons les exemples d'Andonne (Debord et Leenhardt 1975), de Doué-la-Fontaine (de Boüard 1976), de Beauvais (Chami 1963), de Condorcet (Gayraud 1975), de Paris (Nicourt 1974 et 1986).

\section{La céramologie au service de l'archéologie}

7 Fascinés en quelque sorte par les résultats des céramologues antiquisants qui, depuis fort longtemps, avaient doté les archéologues de «fossiles directeurs » extrêmement efficaces, les médiévistes cherchent à œuvrer dans le même sens. Le matériel fait d'abord et avant tout l'objet de classifications typologiques très détaillées, à vocation générale. La codification des critères morphologiques, s'appuyant sur la normalisation des termes descriptifs est l'objectif de cette première "génération" de travaux. Le nouvel outil informatique favorise de telles entreprises. A l'instar du Code pour l'analyse des formes de poteries de J.-C. Gardin paru sous sa première forme dès 1962, M. Leehnardt, au sein de l'équipe du Centre de recherches archéologiques médiévales de 
Caen, propose un Code pour le classement et l'étude des poteries médiévales adapté au Nord et Nord-Ouest de l'Europe. Si la valeur « universelle »le » de telles approches est depuis longtemps contestée, du moins ces travaux ont-ils le mérite d'attirer l'attention sur la nécessité d'une terminologie adaptée ainsi que sur l'intérêt des méthodes statistiques.

Durant cette période de tâtonnements fructueux, les recherches et les méthodes mises en œuvre dans les pays voisins d'Europe occidentale (Allemagne, Belgique, Pays-Bas, Grande-Bretagne...) servent souvent de référence aux médiévistes tentés de bâtir une sorte "d'internationale céramique». C'est l'époque où les céramologues, d'abord intéressés par le matériel des sites castraux ou religieux du haut Moyen Age ou du Moyen Age classique, le plus souvent vaisselle commune ou grossière, mènent de front, paradoxalement, des analyses typologiques détaillées à l'extrême et des rapprochements morphologiques transfrontaliers particulièrement hardis, dépassant largement, la plupart du temps, l'échelle probable des échanges technologiques ou commerciaux. Dès 1976, M. de Boüard met en garde contre le danger de telles analogies (de Boüard 1976, p. 247). Cependant, plusieurs typologies régionales offrent aux archéologues médiévistes français des critères de datation fort attendus. Citons à titre d'exemple, la Provence (Démians d'Archimbaud 1980), le Val de Saône (Renimel 1974), le Lyonnais et le Dauphiné (Reynaud et alii 1975).

\section{Les champs de la discipline et leur diversification progressive}

\section{La notion de faciès régionaux}

Tandis que la céramologie médiévale trouve ses lettres de noblesse et compte désormais ses "spécialistes", de nombreuses équipes, encouragées par le Conseil supérieur de la recherche archéologique dans le cadre des programmes H30, puis H19: Les ateliers médiévaux et modernes, organisation et diffusion, abordent avec succès le sujet à l'échelle régionale. Cet intitulé, formulé en 1985, indique qu'alors la complexité et la variété des champs scientifiques offerts aux céramologues sont envisagées par l'ensemble de la communauté scientifique. Des projets collectifs de recherche voient le jour dans plusieurs régions comme en Normandie, en Bretagne, en Bourgogne, dans le Nord-Pas-de-Calais, et aussi en Rhône-Alpes...

Dans le même temps apparaît nettement le caractère régional, voire micro-régional, des productions céramiques, conduisant à réduire notablement l'aire géographique des études de synthèse et invitant à manipuler avec prudence les notions "d'influences ", "d'échanges ", « d'importations ", « d'exportations », tout autant que les comparaisons typologiques tous azimuts. On admet désormais le concept de faciès régional et chaque groupe de chercheurs se doit de forger l'outil typologique adapté à sa zone de travail. A la vision européenne des années soixante-dix succède une approche plus nuancée de l'histoire des produits céramiques, en relation plus concrète avec la diversité des cultures matérielles et techniques du Moyen Âge. Parallèlement, le rêve d'une évolution morphologique univoque et régulière, si commode pour les archéologues, s'effondre. Une deuxième génération de typologies vit le jour dans les décennies 80 . Les travaux qui se développent en Ile-de-France sur le fabuleux échantillonnage fourni par les fouilles de Saint-Denis montrent la voie (de Bouärd et alii 1987). 


\section{Vers une pluridisciplinarité}

11 A partir de cette période, mais plus d'une décennie après l'exploration des grands centres de production anglo-saxons et rhénans, les recherches s'orientent en France vers les structures artisanales. Après des opérations pionnières, comme les fouilles de l'atelier carolingien de Saran (Loiret) (Chapelot 1970 et 1971), l'impulsion est, là encore, donnée par les équipes de Normandie et de Provence. A partir des recherches extensives en Uzège et dans le Bas-Rhône sont dressées les premières typologies des structures de cuisson (Thiriot 1985 et 1987). Les enquêtes de terrain et de laboratoire conduites en Basse-Normandie mettent en évidence l'origine et la diffusion de produits caractéristiques tels le grès (Bucur et alii 1989; Dufournier et Flambard 1987). D'importants centres potiers sont également explorés en Ile-de-France, Bretagne ou en Aquitaine pour ne citer que ceux-ci. Les préoccupations méthodologiques des chercheurs sont constantes comme en témoigne nombre de publications (Thiriot 1990).

12 Aucune enquête sérieuse sur la détermination de l'origine des terres cuites, sur la localisation des ateliers ou sur la circulation des produits ne saurait désormais se dérouler sans recourir aux travaux de laboratoire. Analyses minéralogiques et chimiques permettent de constituer des groupes de référence, de comparer la composition de différents lots, de déterminer les lieux d'approvisionnement en matière première. Longues et coûteuses, ces interventions spécifiques s'intègrent à des problématiques de mieux en mieux maîtrisées dans les domaines de l'histoire des techniques ou des échanges commerciaux durant le Moyen Âge.

La dynamique créée grâce aux travaux conjoints du Laboratoire de céramologie de Lyon et du Laboratoire d'archéologie médiévale d'Aix-en-Provence profite à tous. Les colloques internationaux consacrés tous les quatre ans à « la céramique médiévale en Méditerranée occidentale " depuis celui de Valbonne en 1978, donnent lieu à d'importantes publications au fil desquelles les réseaux d'échanges de produits artisanaux se dessinent grâce au travail d'équipes interdisciplinaires : archéologues, céramologues, historiens des textes, archéomètres. Si la démonstration est particulièrement frappante pour les échanges de vaisselle de luxe entre les pays du bassin méditerranéen, elle n'en demeure pas moins valable pour des produits plus modestes, aux aires de diffusion plus limitées (Amouric 1987). C'est dans cet esprit que travaillent désormais bien des équipes régionales.

Pour la région Rhône-Alpes l'enquête sur les moyens de production débute par deux travaux universitaires (Chemorin 1984 ; Faure-Boucharlat 1980). Mais c'est en 1988 que notre groupe de travail s'oriente plus fermement vers les thèmes de la localisation des ateliers de terre cuite et de leur diffusion (fig. 1). Aux enquêtes documentaires larges (plusieurs départements) réalisées dans le cadre des ouvrages cités ci-dessus (toponymie, archives artisanales et industrielles), se substitue résolument le travail de terrain (prospections, prélèvements) à l'échelle micro-régionale, accompagné des déterminations de composition des matières premières et des produits manufacturés. La première partie de cet ouvrage présente donc les résultats des enquêtes consacrées à trois zones de production de terre cuite: Bresse, moyenne vallée du Rhône et Beaujolais. 
1- Sites de production céramique étudiés dans le cadre du projet collectif de recherche

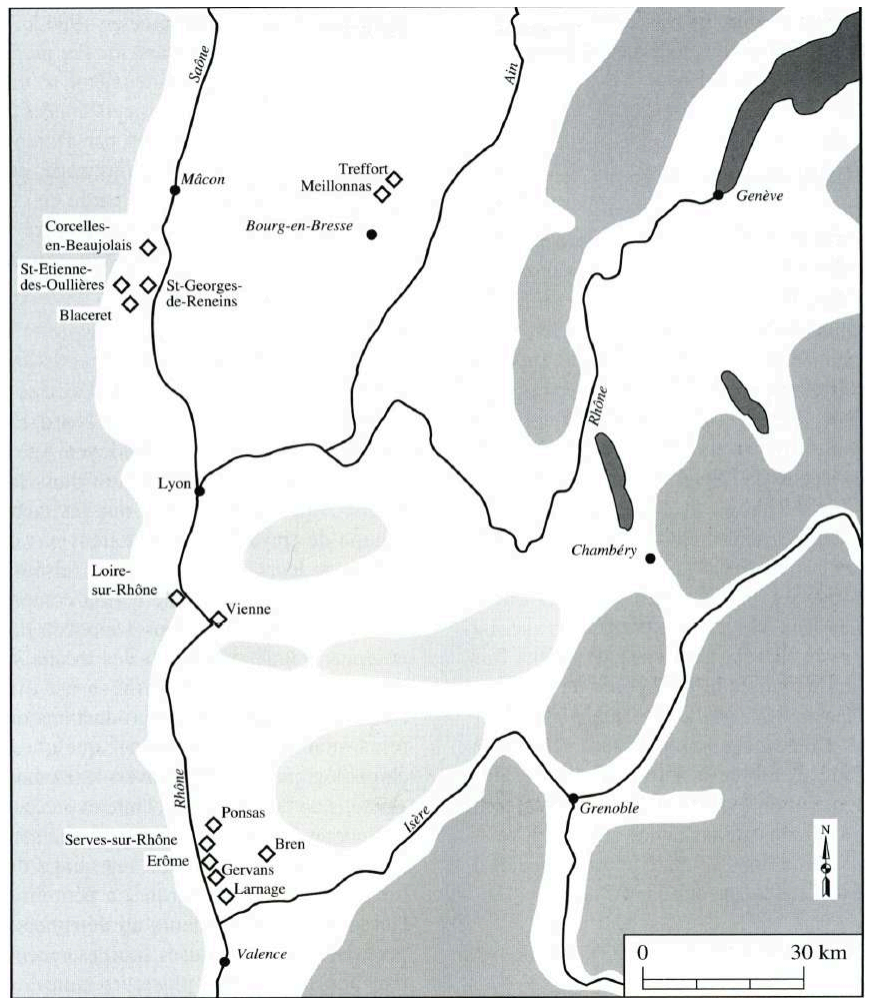

\section{L'élargissement du champ chronologique}

La diversification des modes d'approche s'accompagne d'un élargissement du champ chronologique des études comme en témoignent au fil des ans les publications spécialisées. Jusqu'en 1980 environ, peu de travaux portent sur des productions postérieures à $1400 \mathrm{ou}$, à l'inverse, antérieures à 900 . Vingt-cinq articles de céramologie publiés par la revue nationale "Archéologie Médiévale» depuis 1972 permettent de suivre, peu ou prou, l'évolution de la discipline. Jusqu'en 1982, trois articles seulement intéressent les XVe-XVIe s., tandis que dix autres concernent la période 850-1400. En 1986, paraît l'unique étude consacrée au haut Moyen Âge par cette revue. La période post-médiévale n'est évoquée qu'une fois en 1982. La même enquête à partir de la revue "Archéologie du Midi médiéval " amène à nuancer ce constat. Créée onze ans plus tard (1983), la revue reflète d'emblée la curiosité élargie des céramologues médiévistes: onze articles sont consacrés à des ensembles situés entre le XVe et le XVIIIe s. En amont, le matériel haut médiéval est abordé dès 1987 dans plusieurs études.

\section{Des acquis dans notre région...}

Durant cette période, le travail réalisé dans notre région traduit une évolution analogue : entièrement consacré aux poteries des Xe et XIe s. jusqu'en 1980, le champ chronologique s'élargit au bas Moyen Âge avec l'étude consacrée à la vaisselle issue des fouilles du Château d'Anse (Vicard 1984) ainsi qu'aux vases funéraires de l'église SaintGeorges de Vienne (Faure-Boucharlat 1986). A partir de 1985, le mobilier des niveaux post-médiévaux et modernes est quasi systématiquement pris en compte. Le travail 
porte ses fruits avec deux publications en 1988 et 1989 (Maccari-Poisson 1988, Becker et alii 1989). La synthèse collective présentée en 1990 à l'occasion de l'exposition A la Fortune du Pot profite largement des résultats de ce "deuxième souffle" de la céramologie régionale. Plusieurs années de travail supplémentaire mené à bien par Tommy Vicard sur un très important échantillonnage, permettent de proposer dans la seconde partie de ce volume une nouvelle synthèse (argumentée et révisée) des terres cuites en usage entre le XIIe et le XVIIIe s. dans la région lyonnaise.

\section{Mais aussi des points faibles}

Contrairement à nombre d'autres régions (Provence, Centre, Nord et Nord-Est de la France), la vaisselle du haut Moyen Age reste, en revanche, encore mal connue dans la région Rhône-Alpes. Outre le fait que les membres du groupe de travail ne souhaitaient pas disperser davantage leurs efforts, plusieurs raisons peuvent être invoquées : dans une région comprise entre les courants méditerranéens d'une part, rhodaniens et alpins d'autre part, les faciès locaux sont multiples et la moindre synthèse est difficile à construire. Peu ou pas de productions ou formes remarquables pour constituer quelques repères chronologiques dans un univers assez uniforme de vaisselle commune. Enfin, l'intérêt précoce pour la céramique des Xe-XIe s., longuement soutenu par l'énigmatique pratique du marquage des fonds (céramiques à fond marqué) a peutêtre captivé l'attention des chercheurs au détriment d'autres périodes. De nombreuses fouilles récentes révèlent pourtant depuis plusieurs années d'importantes séries du haut Moyen Age (fouilles préventives dans l'Ain, le Rhône, l'Isère, la Drôme), mais les éléments stratigraphiques en milieu rural sont souvent indigents et les datations restent mal assurées, voire faussées par des attributions typo-chronologiques du matériel céramique un peu hâtives. A cet égard, le fameux rebord en bandeau constitue un «faux-ami » redoutable pour les médiévistes de la région : il est présent du VIe au XIIIe s. et ne saurait à lui seul caractériser une période. Il serait sans doute utile de proposer une « relecture " globale du mobilier issu de ces fouilles. Plusieurs avancées sont cependant sensibles pour le début du Moyen Age. A partir du matériel des sites funéraires, quelques points de repère sont établis relativement tôt : tout d'abord pour les régions alpines (Colardelle 1983; Bizot et Serralongue 1988, pp. 40-44); puis les connaissances progressent grâce à plusieurs fouilles urbaines bien stratifiées à Lyon, Vienne et Grenoble par exemple. Quelques ensembles lyonnais font l'objet d'études monographiques détaillées: le mobilier funéraire de Saint-Laurent et les rejets domestiques du quartier Saint-Jean (Faure-Boucharlat et Reynaud 1986; MaccariPoisson 1991).

Par ailleurs, l'étude du matériel céramique de l'Antiquité tardive n'est abordée sérieusement dans la région que vers 1985. Cette période, qui offre des problématiques bien particulières, est le point de rencontre des antiquisants et des médiévistes. Elle pourrait à très court terme dans notre région, être le champ d'études prometteuses grâce à la méthodologie mise en place à l'occasion des fouilles du métro de Lyon (Ayala 1994), à l'instar du travail gigantesque fourni par les chercheurs méridionaux regroupés dans l'Association pour l'étude de la céramique de l'Antiquité tardive et du haut Moyen Age (CATHMA 1986 et 1993) ou des patientes enquêtes conduites par nos voisins genevois (Haldimann 1994). On l'aura compris, l'auteur de ces lignes plaide pour un "troisième souffle » de la discipline dans la région Rhône-Alpes en faveur du 
mobilier antérieur à l'An Mil. Les données recueillies sont nombreuses et de qualité : elles offrent les conditions d'un travail fructueux.

\section{Du tesson à l'histoire?}

19

a vu plus haut, tandis que le champ chronologique de la discipline s'élargit, l'angle d'approche se modifie, ou plutôt se diversifie, notamment lorsque le céramologue s'intéresse aux périodes du bas Moyen Age et moderne. Bien des questions relatives à l'origine, à la commercialisation, à l'usage des poteries sont plus aisées à aborder pour ces périodes : les poteries présentent des caractéristiques techniques, morphologiques ou décoratives plus marquées, susceptibles de guider les recherches; mais surtout les textes offrent un complément d'information qui, confronté aux données archéologiques, permet de pousser la démarche bien au-delà des limites de la céramologie classique. La diversité et l'imbrication de ces thèmes de recherche sont fort bien résumées par D. Dufournier auquel sont empruntées les lignes qui suivent :

«ainsi l'objet céramique contribue-t-il à nous renseigner tout à la fois sur les usages, les goûts, les techniques de fabrication mises en œuvre, les structures sociales et la conjoncture économique à une époque et dans un espace bien définis. Ce faisant, il nous renseigne sur les exigences réciproques de l'utilisateur et du fabricant, sur la perpétuelle confrontation entre les besoins exprimés par les uns, les initiatives et les contraintes techniques prises et assumées par les autres » (Dufournier 1989, p. 10).

Sans abandonner les travaux d'inventaire, de classification typologique et chronologique, fondement de toute recherche, les spécialistes abordent les activités humaines dont les poteries sont les modestes, mais omniprésents témoins matériels. Pour en juger, il suffit de suivre l'évolution du vocabulaire appliqué au mobilier à travers la littérature ces dix dernières années : aux mots abstraits tels que "formes ", " types » sont préférés des mots évocateurs, tels que " récipients ", " vais » vaisselle », «équipement domestique». Influence indéniable des sources écrites! Le premier Congrès international d'archéologie médiévale, organisé en 1985 par la Société d'archéologie médiévale à Paris, consacre en quelque sorte la démarche. D'une part, par son titre évocateur, La céramique (Ve-XIXe s.), fabrication, commercialisation, utilisation, qui comporte tous les «ingrédients» de la céramologie moderne: l'étendue du champ chronologique, la diversité des approches thématiques (typologique, technologique, socio-économique). D'autre part, en posant la double question : «Comment traiter un matériel en masse imposante? Comment en faire un document d'histoire? " (Chapelot 1987, p. 7).

Depuis, la part consacrée aux aspects « humains du sujet » s'est sans cesse développée. Tout d'abord utilisant les données de la céramologie dans le cadre de l'appréhension globale des sites d'habitat: le mobilier n'est pas seulement une collection à étudier, il est aussi un témoin ethnographique pour l'interprétation du contexte archéologique (organisation de l'espace, nature des activités, statut des occupants...). Des cas d'école comme ceux de Brucato (Maccari-Poisson 1980) et de Rougiers (Démians d'Archimbaud et Picon 1987) montrent l'intérêt d'une telle démarche pour la connaissance des communautés concernées. Parallèlement, la consultation généralisée des sources écrites infléchit considérablement l'esprit même de la discipline. Comment se passer désormais de l'éclairage fourni par les archives artisanales, commerciales ou privées. L'équipement de la maison médiévale apparaît aussi à travers les textes, en particulier 
des inventaires des biens (Démians d'Archimbaud 1982, Piponnier 1987) qui amènent les céramologues à relativiser la place du document archéologique qui, le plus souvent, reste le seul témoin matériel qui nous soit parvenu.

De même, les hommes et les femmes à la tâche ne peuvent être ignorés de qui s'intéresse au fonctionnement et à l'organisation des ateliers céramiques. A cet égard, la constitution en 1988 au sein du Groupe de recherches coordonnées (GRECO du CNRS : Sociétés et cadre de vie au Moyen Age) du thème consacré " aux sociétés artisanales » (animé successivement par $\mathrm{J}$. Chapelot et $\mathrm{H}$. Amouric) reflète certainement une certaine maturité de la céramologie médiévale en faisant largement place aux préoccupations d'ordre historique telles que nous venons de les évoquer. En adhérant à ce programme, les auteurs de cet ouvrage ont beaucoup appris. Leur travail doit beaucoup aux expériences échangées, aux conseils prodigués, aux incitations stimulantes des collègues côtoyés plusieurs années durant. Les enquêtes archéologiques et historiques conduites dans cet esprit un peu partout en France, depuis le travail pionnier réalisé sur la Saintonge (Chapelot 1975) ne sauraient toutes être mentionnées ici. Citons, à titre d'exemple et pour des régions fort diverses, les travaux consacrés aux communautés artisanales de Lille pour le Nord (Blieck 1989), de Saint-Jean-de-Fos pour le Languedoc (Vayssettes 1987), d'Apt ou de Manosque en Provence (Amouric 1986) et encore de Sadirac en Bordelais (Hanusse 1982 et 1987). Ainsi, la première partie de cet ouvrage livre les informations réunies sur les potiers de terre des centres de MeillonnasTreffort (Ain) et d'Erôme-Larnage (Drôme), deux des trois secteurs de production étudiés ces dernières années par l'équipe rhônalpine.

Enfin, depuis quelques années, l'exploration de sources iconographiques médiévales et postmédiévales accompagne le travail des céramologues. Les objets étudiés retrouvent ainsi leur contexte d'utilisation de façon vivante et souvent édifiante. La confrontation avec les images conforte le céramologue lorsqu'il se fait « ethnologue » et qu'il cherche à retracer les modes et usages domestiques à travers les ustensiles de terre cuite. Cette méthode d'approche a été particulièrement mise en évidence à l'occasion d'une série d'expositions et de catalogues d'accompagnement consacrés à la vaisselle médiévale et moderne qui, fondés sur le travail rigoureux des spécialistes, ont retracé de façon attractive les pratiques culinaires et alimentaires des utilisateurs, les phénomènes sociaux, économiques et techniques expliquant l'évolution des formes et des décors des récipients. Ainsi : Le banquet du Damoiseau à Avignon en 1989, Se nourrir à Besançon au Moyen Age à Besançon en 1990, et Plaisirs et manières de la table aux XIVe et XVe s. à Toulouse en 1992. Tel fut l'un des objectifs recherchés par le groupe des chercheurs rhônalpins et présenté en 1990, grâce à la contribution de D. Alexandre-Bidon (A la Fortune du Pot 1990, pp. 25-48).

Rappeler l'évolution de la discipline sur plusieurs décennies, souligner la diversité et la complémentarité des approches auxquelles se livrent les céramologues, c'est mettre en lumière la part irremplaçable que tient la céramique pour la connaissance des sociétés médiévales et postmédiévales. On l'a vu, le céramologue ne se cantonne pas au domaine du matériel; il aborde aussi le culturel, l'économique et le social. Nul doute: la céramique est bien " un document d'histoire »! 
Première partie. Aux origines de quelques poteries : trois groupes d'ateliers Rhône-Alpins 


\title{
Chapitre 1. En Bresse, les ateliers de Meillonnas-Treffort, une belle réussite économique
}

\author{
Élise Faure-Boucharlat, Bruna Maccari-Poisson, Sophie Savay-Guerraz et \\ Anne Schmitt
}

1 Les premières recherches sur la poterie à pâte blanche, recouverte de glaçure verte, ont débuté dès 1984, lorsqu'on s'est aperçu qu'une importante quantité de mobilier de ce type, provenant des fouilles du Métro à Lyon (avenue Adolphe Max), ${ }^{1}$ présentait de remarquables similitudes avec les céramiques issues des fouilles du château de Vuache à Vulbens (Haute-Savoie) ${ }^{2}$.

\section{Origine des recherches}

Ces deux ensembles de céramiques étaient quasi contemporains. Les datations fournies par la stratigraphie (Lyon) et les sources écrites (Vulbens) permettaient de situer le moment de plus grande diffusion de ce matériel entre la fin du XVe s. et la première moitié du XVIIe s. Les formes, à quelques exceptions près, présentaient une répétition constante et remarquable de tous les éléments fondamentaux du profil : la lèvre, les anses, les fonds. Mais, surtout, les céramiques mises au jour à Lyon et à Vulbens frappaient par leur pâte blanche, fine, parfois très fine et recouverte d'une glaçure verte, brillante, homogène et bien couvrante.

3 Sur la base de ces trois premiers éléments de rapprochement (chronologique, typologique et technique), le laboratoire de céramologie de Lyon (CNRS, UPR 7524) a effectué les analyses physico-chimiques de quelques échantillons, confirmant que la composition des pâtes des poteries de Lyon et de Vulbens présentait de telles ressemblances qu'il pouvait s'agir de la production d'un même atelier, ou, du moins, d'un même groupe d'ateliers.

4 Ce premier constat nous a conduit à rechercher l'origine de cette céramique. D'une part, l'éventail des formes répertoriées, soit à usage culinaire, soit pour le service de 
table, produites par un ou plusieurs ateliers utilisant la même argile, témoignait d'une activité artisanale importante. D'autre part, la présence de poteries issues d'un même centre producteur dans deux sites aussi éloignés que Lyon et Vulbens incitait à mieux cerner la diffusion commerciale de ces produits et à rechercher leur lieu de fabrication.

\section{2- Carte de situation du secteur étudié}

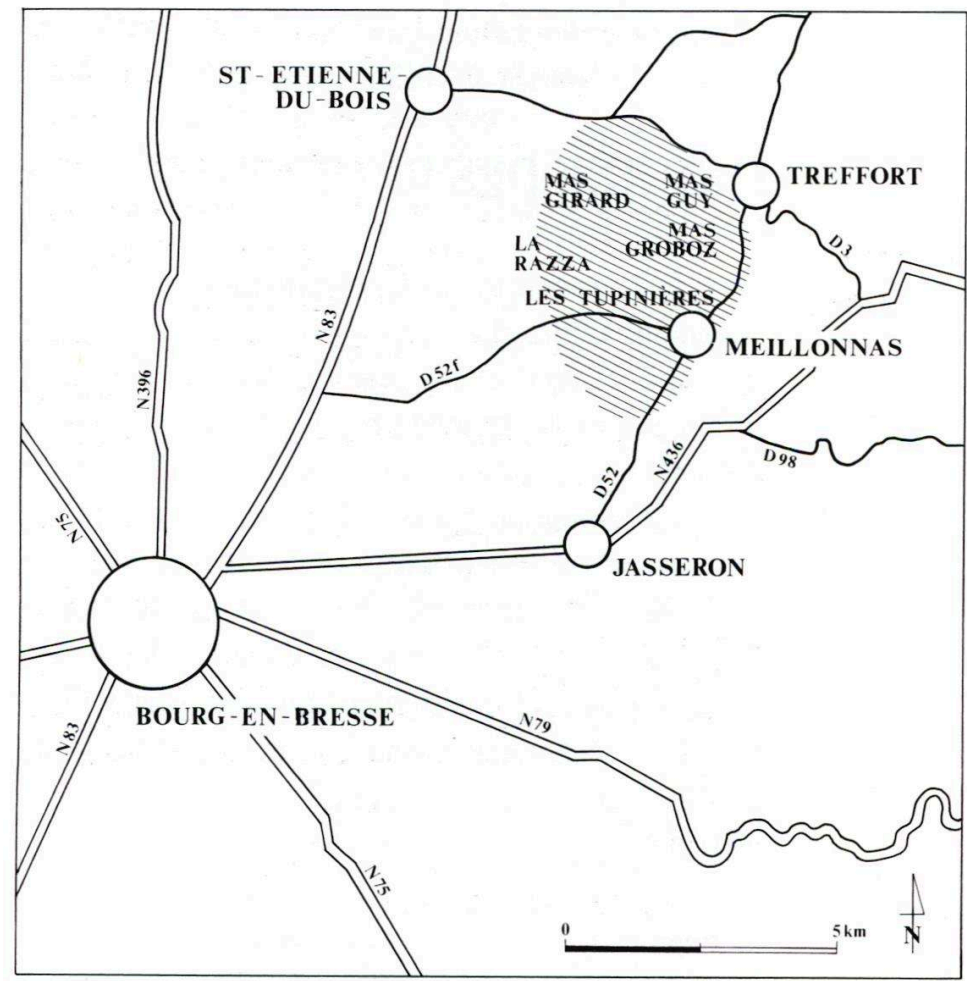

Plusieurs indices nous ont amenés à prendre en considération la région de Meillonnas dans l'Ain, à une dizaine de kilomètres au nord-est de Bourg-en-Bresse (fig. 2) :

- la concentration des trouvailles dans la plaine de l'Ain était probablement un indice en faveur de la localisation du centre de diffusion au nord-est de Lyon.

- dans la région bressane, les communes de Meillonnas et de Treffort (Ain) possèdent sur leur territoire des argiles réfractaires réputées et exploitées en carrières à ciel ouvert jusqu'à une date récente. Cette terre est connue également comme "terre d'engobe», utilisée notamment aux XVIIIe et XIXe s. pour orner les poteries à décor blanc sur fond brun, produites dans la vallée de la Saône: terre réfractaire blanche que l'on trouve en Bresse et notamment à Treffort et à Meillonnas (Jeanton 1943). L'achat de terre de Meillonnas par les potiers lyonnais est également mentionné dans les textes depuis le XVIe s.

- les sources écrites signalaient la présence de potiers et l'extraction de l'argile dans cette zone dès le XVes.

- au cours du XVIIIe s., Meillonnas fut un centre de production de faïences (La faïence de Meillonnas 1993, pp. 25 à 54); traditionnellement on admettait que ce fut aussi un lieu de fabrication de poteries « rus » rustiques », bien avant cette date.

Il y a plus de 800 ans que les poteries de Meillonnas fournissent de terre à feu le tiers du Royaume; c'est par ces mots, qu'en 1761, Hugues de Marron, seigneur de Meillonnas, commençait un mémoire destiné à obtenir des subventions pour la création de sa faïencerie. Si l'ancienneté proclamée relève plus de la figure de style que de la réalité 
historique, il n'en demeure pas moins que le seigneur de Marron signait là la première «notice» jamais consacrée à la poterie de Meillonnas ${ }^{3}$. Plusieurs auteurs ont par la suite évoqué cette activité, qu'il s'agisse des artisans et de leurs productions (Tardy 1971, p. 786 à 788, 1721 et 2006; Cattin 1984 ; Tupins et carrons 1994) ou des carrières d'argiles qui affleurent sur le territoire de la commune (Philipon 1913), mais sans étude détaillée.

Guidés par la convergence de ces indications, qui justifiaient une étude approfondie du site de Meillonnas, les recherches ont été lancées dans trois directions: dans la documentation écrite, sur le terrain et en laboratoire afin de déterminer si la vaisselle à revêtement vert, désormais bien individualisée, et dénommée par commodité « service vert », en était originaire, et de retracer plus globalement l'histoire de l'activité céramique de la commune $e^{4}$.

\section{Les ressources en argiles de Meillonnas}

Le village de Meillonnas se situe à la limite de la plaine de Bresse et des contreforts du Jura dans un contexte très favorable à l'implantation d'un centre de production céramique. En effet, toutes les matières premières sont disponibles à proximité immédiate: la plaine de Bresse est riche en gisements argileux et le Revermont jurassien est abondamment boisé (fig. 3).

3- Les formations argileuses du secteur de Meillonnas et Treffort

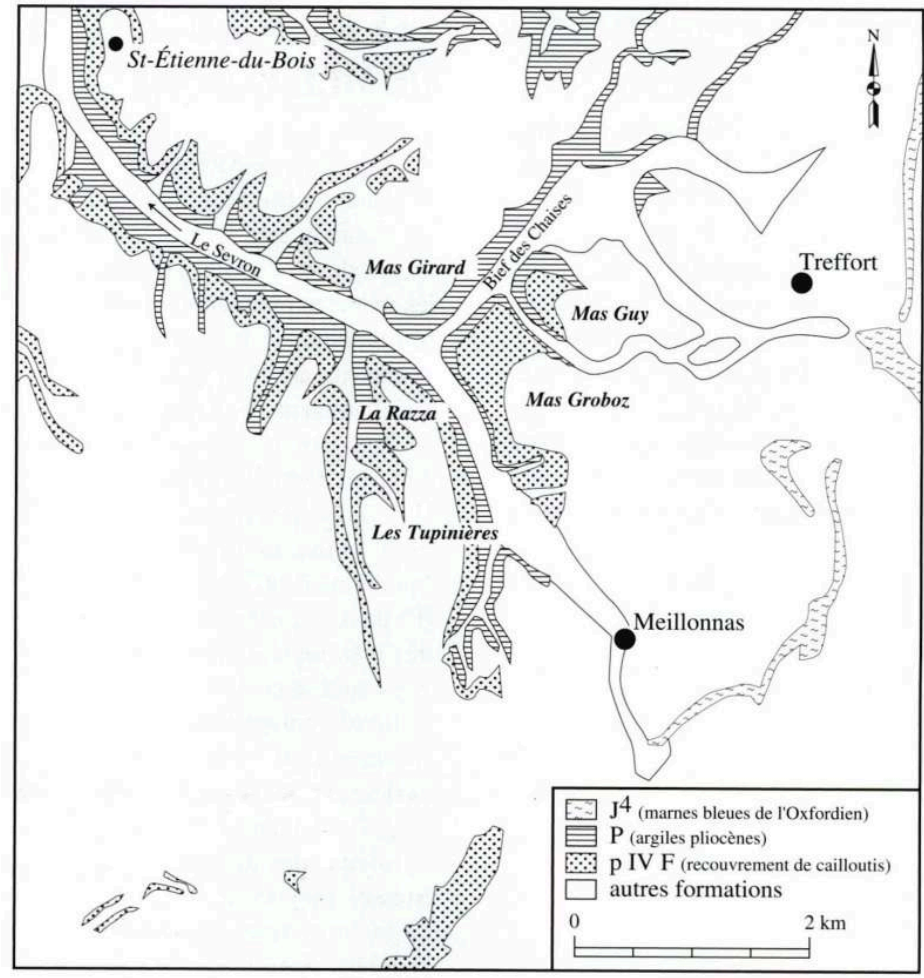

D'après les cartes géologiques au 1/50 000 de Bourg-en-Bresse et de Saint-Amour BRGM 
Il existe, d'une part, des argiles marneuses dans les formations jurassiques du Revermont (J4: Oxfordien, marnes bleues fossilifères, notamment dans la vallée du Sevron proche de Meillonnas), et, d'autre part, des argiles pliocènes (P) dans la plaine de Bresse $^{5}$. Ces dernières sont très bien représentées à l'Ouest de Meillonnas où elles sont accessibles sous un recouvrement de cailloutis polygéniques ( $\mathrm{p} \mathrm{IV} \mathrm{f)} \mathrm{assez} \mathrm{faible.}$ La formation pliocène $P$ comprend des bancs très variés avec des argiles réfractaires bigarrées rouges et jaunâtres, des niveaux gris, des niveaux ligniteux, des argiles blanches dites «blanc de Bresse » ou encore "terre d'engobe » et, à la base de la formation, des argiles grises et bleutées appelées dans la région « marnes bleues », bien que, d'après les analyses, leur teneur en chaux soit très faible. Cette stratigraphie est parfaitement observable dans la carrière de la Razza à Meillonnas, carrière exploitée jusqu'en 1989 pour sa terre à poterie réputée (fig. 4 et 5). La figure 5 présente un diagramme stratigraphique simplifié de cette carrière ${ }^{6}$.

\section{4- Carrière à ciel ouvert de la Razza à Meillonnas}

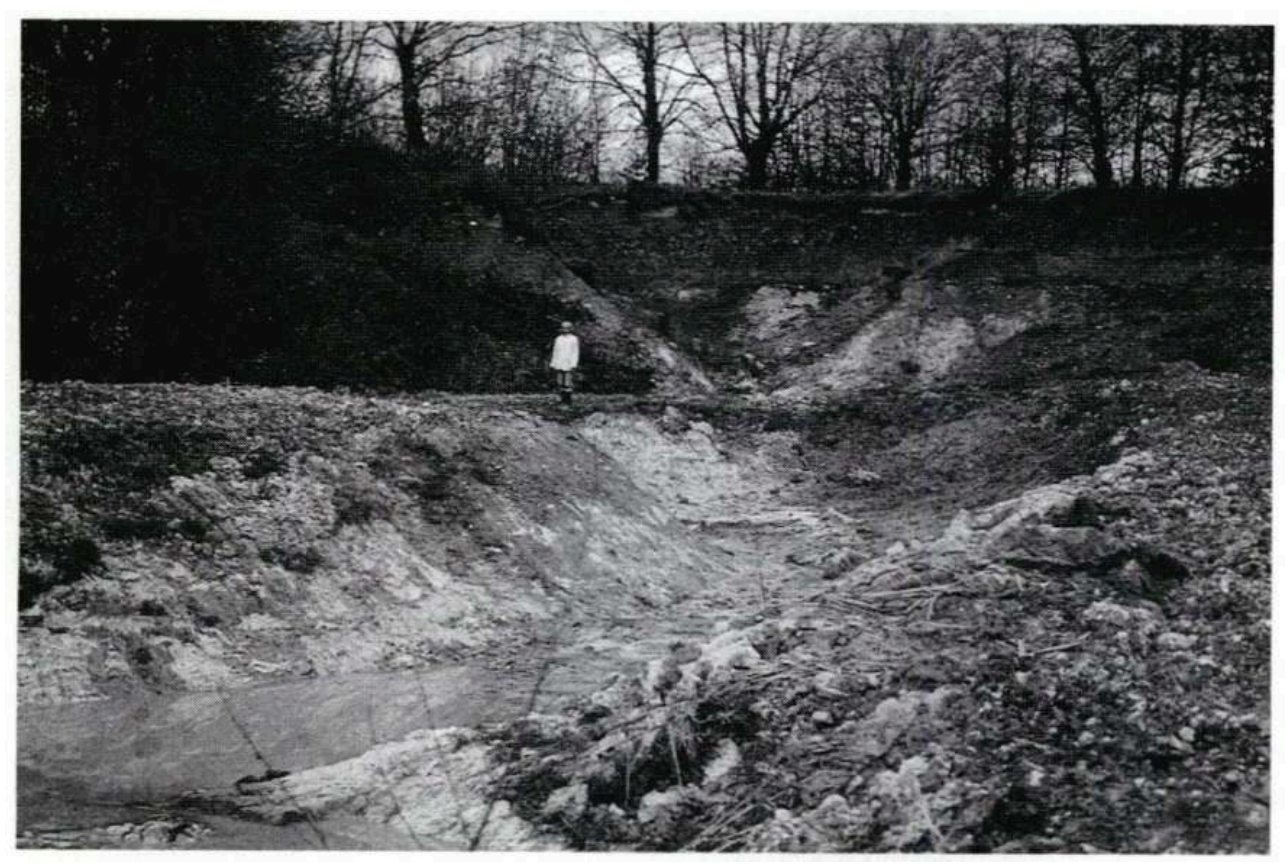




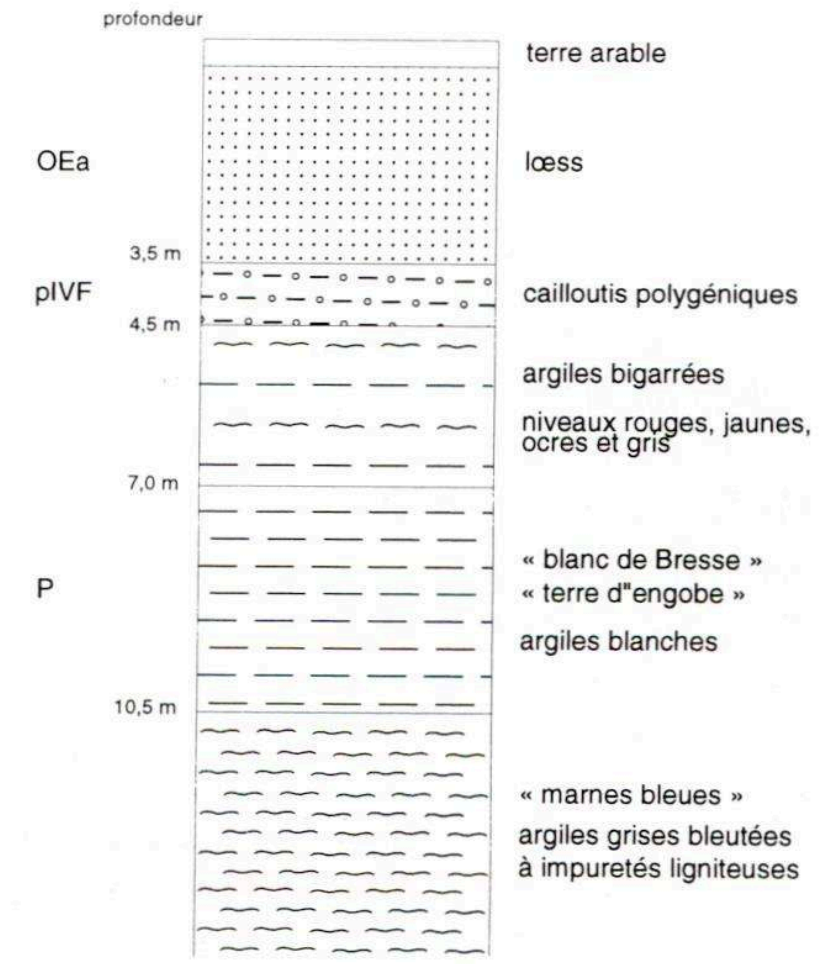

D'après P. Darnand

11 Les prélèvements réalisés dans la région ont permis de préciser les compositions chimiques de ces diverses argiles et d'identifier celles qui ont été utilisées pour les différentes productions céramiques.

12 Les deux principaux groupes de céramiques rencontrés lors des ramassages de surface aux environs de Meillonnas sont les céramiques communes à pâte grise et les céramiques à pâte blanche revêtue d'une glaçure verte. Le premier groupe correspond à la phase la plus ancienne des productions de Meillonnas-Treffort. Lui succèdent des produits plus élaborés et glaçurés.

Les différences de compositions chimiques entre les céramiques à glaçure verte et les céramiques grises sont très marquées, surtout dans le cas du fer et du titane. C'est pourquoi les histogrammes des teneurs de ces deux constituants sont présentés ici (fig. 6 et 7). Sur ces graphiques figurent les exemplaires de céramiques à glaçure verte et les exemplaires de céramiques communes grises collectés lors des ramassages de surface aux environs de Meillonnas, ainsi que les argiles prélevées dans divers affleurements de la région. On observe un net décalage des distributions des céramiques à glaçure verte et des céramiques grises ; les céramiques à glaçure verte ont des taux de fer et de titane inférieurs à ceux des céramiques grises. 
6- Histogramme des teneurs en fer des céramiques de Meillonnas

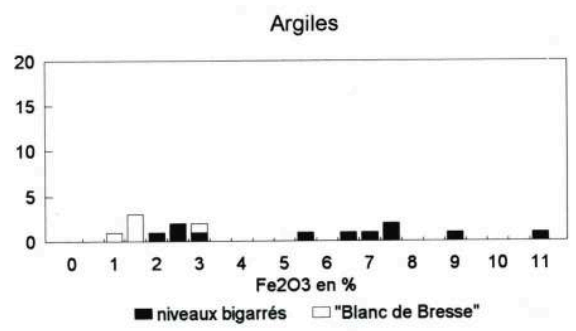

Service vert

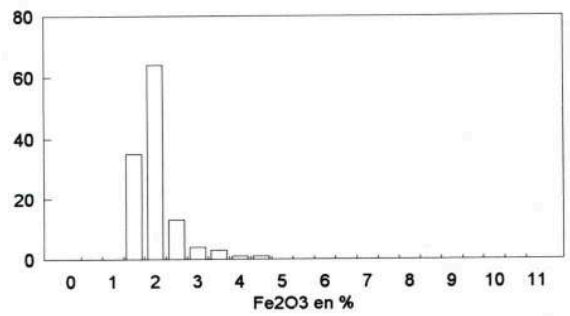

Communes grises

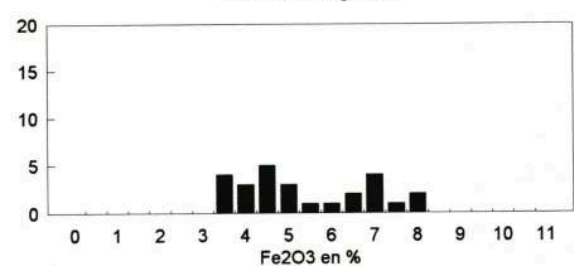

7- Histogrammes des teneurs en titane des céramiques de Meillonnas
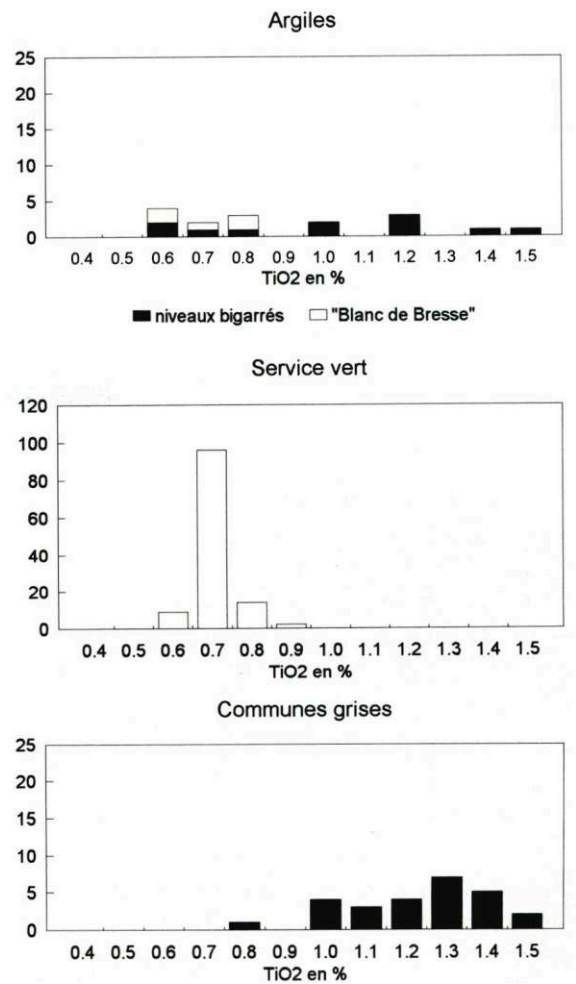

14 Les céramiques communes grises présentent des taux de fer plus ou moins élevés dont les teneurs sont similaires à celles des argiles bigarrées, avec cependant des 
fluctuations légèrement plus faibles. Les argiles bigarrées ont en effet des taux de fer et de titane très dispersés. Ceci s'explique aisément, car dans cette formation on peut observer diverses lentilles au sein desquelles existent des variations de couleurs très rapides, révélatrices des changements de concentration en oxydes de fer. Les prélèvements réduits et ponctuels qui ont été réalisés ont nécessairement des compositions chimiques plus dispersées que celles de céramiques réalisées à partir d'une pâte travaillée et homogénéisée. Quant aux échantillons de "blanc de Bresse », ils présentent des taux d'oxydes de fer et de titane faibles proches de ceux des céramiques à glaçure verte.

Le diagramme de corrélation entre les teneurs en titane et en fer (fig. 8) met très bien en évidence la séparation entre les deux groupes. De grandes différences ont également été notées dans les taux de chrome et de nickel (fig. 9). Sur les deux diagrammes de corrélation, on note le regroupement des échantillons de «blanc de Bresse » avec les céramiques à glaçure verte. Quant aux argiles bigarrées, dont les compositions chimiques sont plus fluctuantes, elles se classent cependant toujours du côté des céramiques grises.

8- Diagramme de corrélation entre les teneurs en titane et en fer des céramiques de Meillonnas

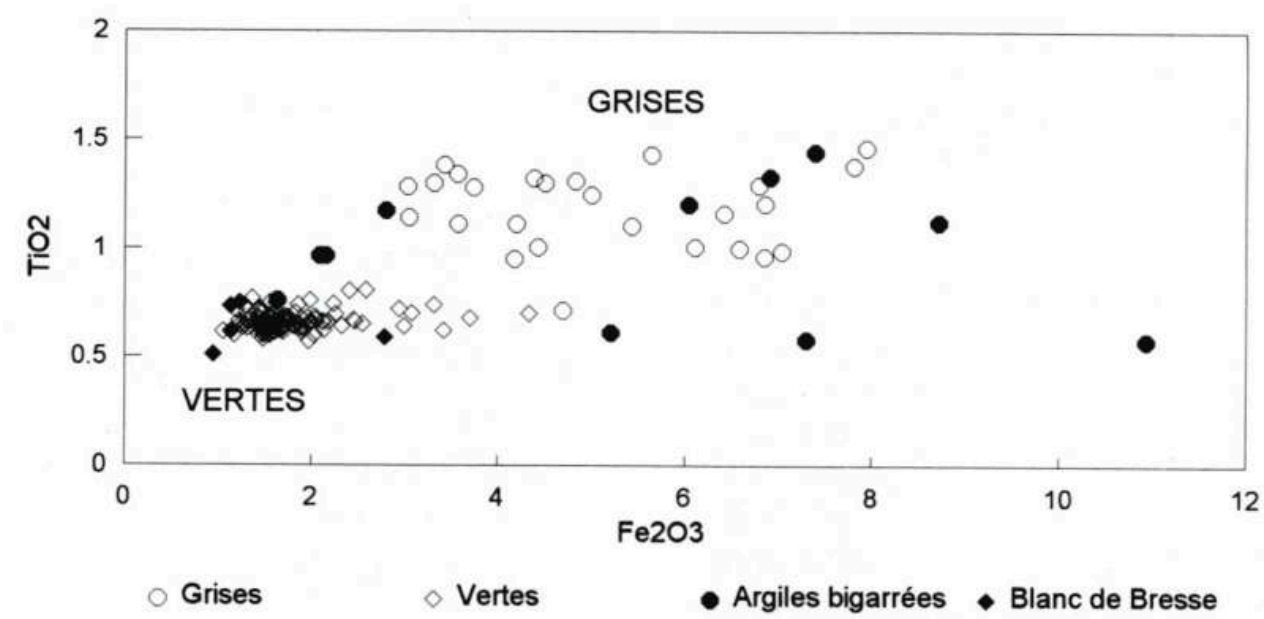


9- Diagramme de corrélation entre les teneurs en chrome et en nickel des céramiques de Meillonnas

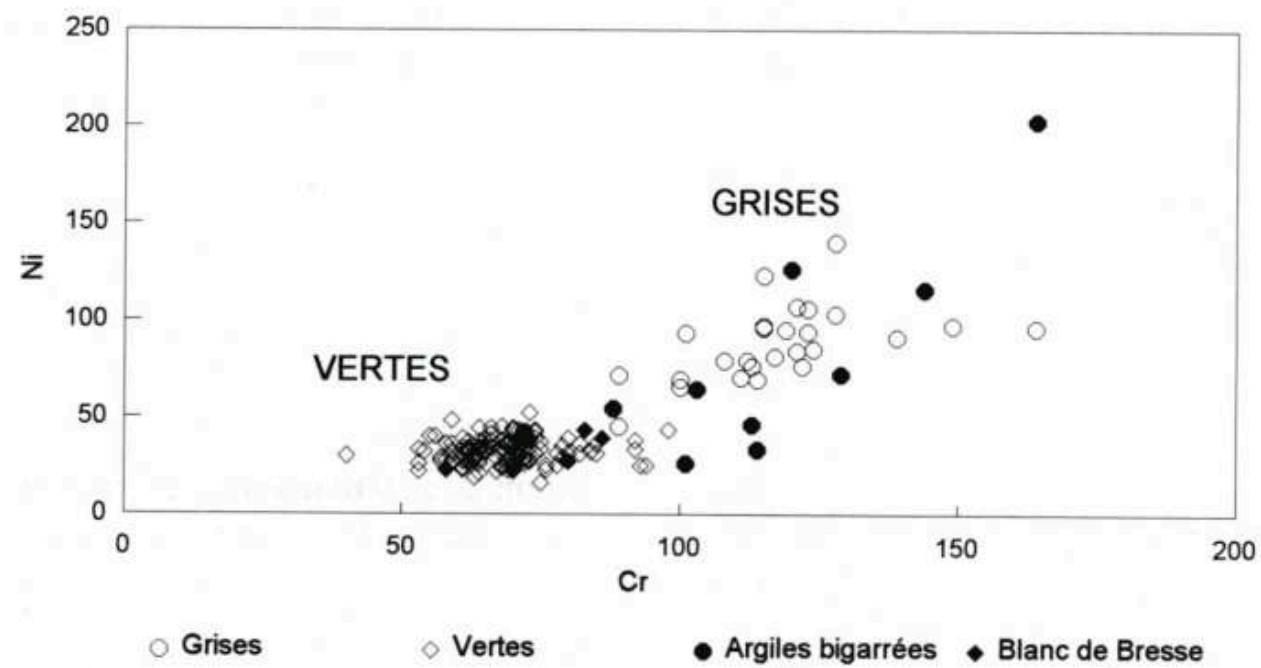

D'après l'examen général des compositions chimiques, on peut donc dire que les niveaux bigarrés des argiles pliocènes ont servi à la fabrication des céramiques grises, et que le «blanc de Bresse » a été utilisé pour les céramiques à glaçure verte.

On signalera rapidement les argiles utilisées pour les autres types de productions des ateliers de Meillonnas. Pour la fabrication des grès, ce sont les pseudo «marnes bleues » qui semblent avoir été employées ; pour les faïences, la pâte employée résulte d'un mélange complexe entre les marnes du Sevron et les argiles pliocènes ${ }^{7}$

On remarque donc à Meillonnas une évolution dans l'exploitation des argiles au cours du temps. Aux périodes les plus anciennes, seuls les niveaux ferrugineux ont été utilisés pour la fabrication des céramiques grises. Ces argiles constituées de kaolinite mêlée d'illite ont de bonnes qualités réfractaires adaptées à la fabrication de céramiques grises culinaires, mais moins bien adaptées à la production de céramiques glaçurées de bonne qualité. Les niveaux de "blanc de Bresse" ont alors été utilisés pour la fabrication du service vert. Ces argiles blanches moins riches en kaolinite, mais pauvres en fer, permettent en effet l'obtention de pâtes claires homogènes sur lesquelles l'application d'une glaçure verte donne des tons uniformes. Enfin, avec l'apparition des faïences, la préparation de la pâte devient plus complexe; les mélanges d'argiles deviennent nécessaires pour obtenir des faïences répondant à divers critères fonctionnels.

A.S.

\section{L'artisanat potier : une histoire peu écrite}

Durant le Moyen Âge, les anciennes paroisses de Meillonnas et Treffort dépendaient des châtellenies de Jasseron et de Treffort qui relevaient du Duché de Savoie. Celles-ci furent ensuite réunies aux États de Bourgogne par le traité de Lyon en 1601, à l'instar de la quasi totalité des anciennes possessions savoyardes en Bresse et en Bugey. Au cours de la Révolution, les communes de Meillonnas et de Treffort furent rattachées au département de l'Ain. 


\section{Les ateliers médiévaux des Tupinières}

\section{Les sources}

21 Fruits de la minutieuse gestion savoyarde, les très complètes et très abondantes séries de comptabilités tenues par les officiers châtelains constituent de remarquables indicateurs de la vie économique du terroir, tout au long des derniers siècles de la période médiévale. Plus particulièrement, ils consignent les denrées et les produits échangés sous les halles du siège de la châtellenie de Treffort ${ }^{8}$ En revanche, il ne subsiste que quelques registres terristes de la seigneurie de Treffort, datant tous de la première moitié du XVe s. S'ils mentionnent effectivement la présence d'ateliers de potiers (operatorii) sur le territoire de la paroisse de Meillonnas, la rareté de ces « classiques » de l'histoire de l'occupation des sols limite l'étude géographique et, plus encore, l'analyse de l'évolution de la composition des ateliers au cours du Moyen Âge.

\section{Une petite communauté artisanale : image ou réalité ?}

Les operatorii des Tupinières au XVe s. : en 1416...

Les premières reconnaissances relatives à des installations de potiers datent de 1416 . Les articles, au nombre de quatre, sont brefs; chacun concerne un ou plusieurs censitaires pour lesquels il est parfois difficile de distinguer le nom de famille du surnom 9 .

23 - Seul Johannem, filium quondam Girardi passe reconnaissance pour une maison et un four à fabriquer et cuire les «tupins". (pro domo (...) cum furno pro tupini faciendum seu dequoquendum). La maison est localisée à proximité du bois qui confine à Meillonnas.

24 - Deux frères, Pierre et Jean, fils d'André Tupinier (Petrum et Andream filios quondam Andree Tupinerii) reconnaissent conjointement deux maisons, une moitié de four et des ateliers pour confectionner les poteries (cum medietate furni et operatorii per tupinis faciendis).

25 - Trois autres frères, fils de Jean Tupinier, jouissaient d'une maison et d'un four pour cuire les "tupins et les vases en terre ", situés aux Tupinières (furno pro dequoquendo, ut alii super, et vasa terrea, versus tupinerias).

26 - Enfin, Jean, fils de Pierre Tupinier dit Oddet, reconnaissait une maison et une moitié de four.

27 Trois fours au moins, dont deux indivis, sept potiers peut-être, quelques ouvroirs ou ateliers de poterie constituent les premiers indices écrits d'une activité qui allait devenir florissante. Il n'est d'ailleurs pas exclu que d'autres potiers aient exercé à Meillonnas ou à Treffort, mais le terrier n'en fait nulle part mention.

28 Le lieu-dit les Tupinières n'est mentionné qu'une fois, mais le manuscrit suivant permet d'assimiler le lieu-dit et le bois puisque, en 1449, ce dernier est appelé Tupinier (versus nemus... vocati Tupinier). S'agit-il des bois qui bordaient la frange occidentale de la commune et qui sont encore visibles sur la carte de Cassini?

... et en 1449

Bien que plus détaillées, les reconnaissances du terrier de 1449 ne fournissent guère de renseignements complémentaires par rapport au précédent ${ }^{10}$ Plus encore qu'en 1416 , 
fours et ateliers sont exploités dans l'indivision; ainsi certains redevanciers reconnaissent tenir le tiers d'un four ou le quart et le huitième d'un (seul ?) four et, par ailleurs, le tiers ou la moitié d'ateliers. Au terme du recollement de toutes ces fractions, on obtient un nombre minimum de quatre fours, mais aucune certitude quant aux ateliers qui sont toujours cités au pluriel. Peut-on pour autant conclure à l'ancienneté de l'implantation de l'artisanat de la poterie, le morcellement des structures résultant de plusieurs partages successoraux, ou bien traduit-il plutôt l'association d'artisans soucieux d'investir et de gérer au mieux des outils de travail communs? Un argument, d'ordre archéologique, plaiderait en faveur de la première hypothèse : on verra cidessous que les prospections ont livré, au lieu-dit les Tupinières, des indices de la fabrication de poteries communes dès le XIIIe s.

Neuf censitaires sont mentionnés par le texte, étaient-ils tous potiers? Sans doute, mais ce n'est pas une certitude, de même qu'on ne peut exclure de possibles ouvriers les secondant. Parmi ceux-là, le nom ou surnom de Tupinier semble dominant (par exemple : Jean, fils de Jean Tupinier alias Odet ou Jean, fils de Jean Girard alias Tupinier ou enfin Jean, fils de Jean Tupinier alias Jan) mais il est bien risqué de chercher à établir des filiations, même si des parentés sont parfois assurées. Tout au plus peut-on remarquer que l'on retrouve les patronymes Odet, Girard et... Tupinier déjà mentionnés en 1416. La mention de domo tuppineriorum qui accompagne l'un des artisans n'est guère interprétable.

31 Les cens étant dus globalement, pour l'ensemble des biens reconnus, il n'a pas été possible de déterminer la charge fiscale qui pesait sur l'outil de travail bâti. Ce dernier est ainsi généralement accompagné de terres, vignes et très souvent de maisons. Enfin, les structures (fours, ateliers) sont toutes précisément localisées au lieu-dit les Tupinières, jouxtant les unes aux autres, définissant l'embryon d'un quartier artisanal spécialisé. Certains ateliers sont d'ailleurs clairement situés au sud-ouest du carrefour des routes de Jasseron à Marboz et de Meillonnas à Bourg-en-Bresse, à l'emplacement d'une partie du hameau actuel (versus Tuppinierias, juxta viam publicam tendentem de Jasserone versus Marbosium, ex oriente (...) carreriam tendenten de Mellionaco versus Burgum ex bore).

\section{Les « bancs » des potiers à Treffort}

32 Les comptes de la châtellenie de Treffort consignent les redevances dues pour le louage, sous les halles de la ville, de places ou «bancs » pour la vente réservés aux potiers (locagium bancharum). Perçus de 1349 à 1525 au moins, les droits acquittés par les potiers s'élevaient à vingt sous viennois pour chaque banc. Primitivement au nombre de deux, puis trois à partir de 1356 et enfin cinq au début du XVIe s. ${ }^{11}$ ces bancs de potiers étaient certes les moins nombreux parmi ceux des autres artisans, mais ils étaient aussi les plus onéreux : en 1349, on comptait ainsi six bancs de bouchers et six de tanneurs à six sous, cinq de merciers à dix-huit sous, quatre de cordonniers à trois sous, six de sauniers à dix-huit sous (Cotton 1984, p. 78). La cherté du bancheagium et la bonne représentation des potiers face à des métiers de première nécessité (bouchers, sauniers) ou importants à l'époque médiévale (cordonniers, tanneurs, merciers) traduit indéniablement une activité dynamique, tout au moins sur le plan local. En outre, l'augmentation du nombre des bancs de potiers pourrait bien témoigner de l'intensification du commerce des poteries et, par voie de conséquence, de celle de leur 
production, même si ce mouvement s'inscrit par ailleurs dans une croissance économique plus générale.

\section{Les ateliers de terre cuite à l'époque moderne}

33 L'époque moderne est en général bien mieux documentée que les périodes antérieures. L'enquête d'archives, menée sur la fabrication de la céramique en Bresse, nuance cette vision. Il apparaît en fait que ce type d'activité artisanale n'a pas toujours laissé les traces écrites à la mesure des empreintes qu'elle a laissées dans le sol.

\section{Une activité ignorée à l'échelon régional}

Les séries à vocation économique (série $\mathrm{C}$ des archives départementales) ne détiennent, semble-t-il, aucun texte concernant les potiers de Meillonnas. Outre les problèmes d'éventuelles disparitions de documents, il est probable que l'artisanat céramique n'ait guère généré d'archives, parfois faute de considération de la part des rédacteurs. A cet égard, il est intéressant d'évoquer la remarquable enquête de 1561 qui recense, maison par maison, les habitants de chaque hameau des paroisses de Treffort et Meillonnas ${ }^{12}$ Elle signale, çà et là, quelques professions notables, mais jamais de potiers, non plus que de fours ou d'ateliers d'ailleurs, ni aux Tupinières (vingt et une maisons dont une grange), ni à la Razza (la Rase du Bois, dix-huit maisons). Les serviteurs de sexe masculin, originaires de Treffort, recensés au sein de certaines maisonnées des Tupinières, pourraient tout au plus être considérés comme des ouvriers, mais sans spécialisation connue. Les datations archéologiques du service-vert attestent pourtant bel et bien, dès cette époque, la fabrication de céramiques à Meillonnas et leur diffusion jusqu'à Lyon au moins. Les contemporains des artisans n'en ignorèrent pas moins les fours à poteries et tout l'environnement d'un centre, encore modeste peut-être, de production.

Cet artisanat est tout autant oublié des articles des déclarations des biens des communautés, requises par l'intendant de la province, Bouchu, en 1665 (Bouchu 1978, pp. 278 et 513). La paroisse de Meillonnas abritait environ soixante habitants (...). Estimés pauvres. La mise en valeur du terroir (une partie en forêt ruinée, une partie en plaine) est rurale (seigle, froment, prés et vignes), le revenu de la seigneurie à l'avenant (rente sur des prés, vignes, moulins, maisons et pressoirs, canaux au pied de la montagne du comté de Bourgogne). Nulle part il n'est fait allusion à l'activité céramique. Les réponses de la paroisse de Treffort sont à l'identique, excepté l'exercice d'un péage (sur les chariots qui passent) et d'un octroi sur le vin, mais il n'y a ni peut avoir aucun commerce dans la ville.

\section{Des archives locales plus disertes}

Les archives provenant des justices de Meillonnas (justice seigneuriale) ${ }^{13}$ et de Treffort (bailliage $)^{14}$ sont peu fournies. Ni dossiers d'inventaires après décès, ni registres de délibération des communautés d'habitants n'ont été conservés pour Meillonnas. Incendiées par les troupes espagnoles au cours de la Guerre de Trente ans, les archives du marquisat de Treffort renferment néanmoins quelques actes de procédure civile (1638-1688) et un petit nombre d'inventaires après décès, mais aucun de ces derniers ne concerne d'artisan potier. Les greffes du bailliage présidial de Bresse, sis à Bourg-enBresse, ne livrent quant à eux que quelques noms de potiers engagés dans des procédures diverses ${ }^{15}$. 
37 En dépit de la disparition de la presque totalité des archives des études sises à Meillonnas même (seul subsiste un registre, daté de 1584, issu de l'étude de Saddet, notaire à Meillonnas ${ }^{16}$ l'essentiel de la documentation repose sur le dépouillement d'archives notariales: celles des tabellions de Treffort. Les premières minutes ne sont pas antérieures à 1615 et leur nombre s'accroît notablement au cours de la seconde moitié du XVIIe s. Loin d'être exhaustifs, les dépouillements ont porté sur des registres datés des XVIIe et XVIIIe s. ${ }^{17}$.

38 La majorité des actes notariés relatent des événements de la vie privée des artisans potiers (contrats de mariage, testaments, reconnaissances de dettes, ventes, quittances...). La vie professionnelle n'a été que très exceptionnellement l'objet de contrats conclus devant notaire et quelques documents seulement enregistrent des accords ou partages professionnels entre artisans ; cela dit, la découverte fortuite d'un acte de cette teneur dans les archives de la commune de Pont-de-Veyle indiquerait qu'ils existent en fait en plus grand nombre, mais conservés dans des fonds dispersés géographiquement. A la suite de cette lecture, les archives communales de cette ville ont d'ailleurs été dépouillées succinctement, mais sans révéler d'activité particulière liée à la poterie de Meillonnas ou à son commerce ${ }^{18}$.

\section{Des ateliers et des hommes : une évocation plus qu'une histoire}

Le tableau ci-contre (tableau 1) livre les noms et parfois la localisation de quelques artisans potiers repérés dans les registres notariaux de Treffort. Cette liste n'est exhaustive ni des dépouillements effectués et moins encore des potiers cités par ces sources. Elle résulte de sondages pratiqués dans les registres de notaires qui parurent plus rentables que d'autres, pour une période, le XVIIe s., qui intéressait particulièrement l'archéologie (cf. note 17). 
Tableau 1. Liste des artisans potiers par commune au XVIle siècle

\begin{tabular}{|c|c|c|}
\hline noms & lieu-dit & date \\
\hline \multicolumn{3}{|c|}{ Meillonnas } \\
\hline Bignet Claude & & 1654 \\
\hline Dufourt Pierre & La Raxza & 1660 (décúćlé) \\
\hline Gamoz Claude & La Razza & 1635 \\
\hline Maire Benoît & La Razza & \\
\hline \multicolumn{3}{|c|}{ Treffort } \\
\hline Bignet Gaspand & & 1677 \\
\hline Blanc Jacquemet & Les Girards & 1654 \\
\hline Bonjour Claude & & 1681 \\
\hline Bouillioxd Denis & & 1680 \\
\hline Callend Pierre & & 1696 \\
\hline Cassand Philibert & & 1679 \\
\hline Cassand Benoît & & 1681 \\
\hline Chèvre Jcan & & 1678 \\
\hline Cottier Henri & Mas-Gaillard & 1679 \\
\hline Cottier Joseph & Mas-de-Guy & 1681 \\
\hline Cotticr Philippe & Mas-Gaillard & 1679 \\
\hline Filliot Hector & Le Villard & $1660-1675$ \\
\hline Filliot Pierre & & 1679 \\
\hline Fromon Philiberr & & 1680 \\
\hline Gaillani Claude & & 1660 \\
\hline Gaillard Philibert & & 1682 \\
\hline Girard Benoît & & $1660)$ \\
\hline Girard Claude L'ainé & & 1698 \\
\hline Girard Claude le Jeune & & 1696 \\
\hline \begin{tabular}{|l|l} 
Girard Denix \\
\end{tabular} & & 1678 \\
\hline Girard François & & 1680 \\
\hline Girard Thamas & & 1682 \\
\hline Groboz claude (fils) & & 1681 \\
\hline Groboz Laurent & & 1682 \\
\hline Guillermaz Claude & & 1682 \\
\hline Prely Antoine & & 1678 \\
\hline Segucy Benoit & Plantaglay & $1660-1690$ \\
\hline Taboret Claude & & 1679 \\
\hline Taboret Jcan-Claude & Le Villard & 1697 \\
\hline Taboret Pierre & & 1677 \\
\hline Villetan Claude & & 1677 \\
\hline Villetan Denis & & 1677 \\
\hline Villetan jean & Mas de Guy & 1689 \\
\hline
\end{tabular}

40 La disproportion flagrante entre le nombre des artisans localisés à Treffort et ceux résidant à Meillonnas résulte de la disparition des archives notariales de Meillonnas. Cette absence traduit-elle une réalité historique, ou peut-on supposer une démographie artisanale équivalente, ou à peu près, pour les deux paroisses ? La réponse est malaisée, mais il est curieux de noter que le site des Tupinières n'est pas mentionné, à l'inverse de celui de la Razza.

\section{Des familles de potiers}

41 Comme au XVe s., la structure familiale pèse fortement sur l'artisanat de la poterie : des dynasties de potiers semblent avoir assuré la transmission du savoir et peut-être même du patrimoine professionnel. Ainsi le seigneur du lieu soulignait-il qu'en 1761, la poterie occupe trente familles entières ${ }^{19}$. Les textes le confirmant sont pourtant rares et il faut parfois déduire ces fratries artisanales d'indices bien ténus, comme, à l'occasion de transactions, le recours à des témoins ou à des créanciers eux aussi potiers. Quelques actes de mariage consignent des alliances d'où l'intérêt professionnel n'est sans doute pas absent, mais sans détail effectif. Seul un acte de cession, daté de 1679, définit le partage de l'hoirie d'un potier du Mas Guy, à Treffort. Son fils, potier de terre, reçut une grande maison avec les cours devant et derrière, ensemble les bastiments propres à cuire pain et pots de terre ${ }^{20}$.

\section{Le métier de potier}

42 L'exercice du métier est encore plus rarement évoqué. Un acte notarié daté de 1683 rappelle néanmoins que les potiers de la Razza exigeaient certain droict de terre propre à fabricquer des pots et plats dans une pièce de terre proche du moullin Taboret ${ }^{21}$. De nos 
jours encore des carrières d'argile sont creusées au lieu-dit Moulin Tabouret. Enfin, une convention passée en 1677, associe, selon les termes du contrat, Denis Girard de Treffort et Joseph Camus de la Razza, tous deux potiers de terre ${ }^{22}$ (fig. 10). En fait, le premier embauche le second pour exercer son métier deux jours par semaine (le mardi et le mercredi). J. Camus travaillera dans la boutique de D. Girard et percevra le salaire de sept livres par grande douzaine de pots, la terre utile à leur fabrication et sa nourriture. Le contrat fut établi pour une année, en présence d'un potier de terre requis comme témoin; il prévoit en outre une amende de cinq livres en cas de manquement de l'une ou l'autre des parties.

10 - Convention entre Denis Girard, potier de terre de la paroisse de Treffort, et Joseph Camus, potier de terre de la Raza, paroisse de Meillonnas

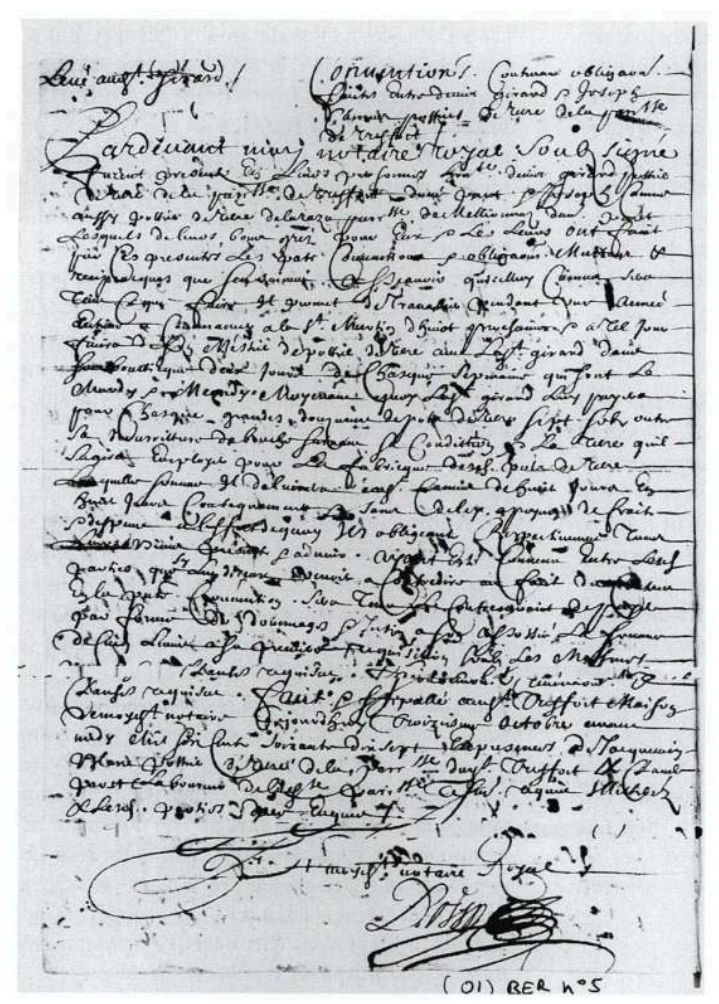

A.D. Ain. Versement de Me Berger, $n^{\circ} 5, f^{\circ} 92 v^{\circ}, 3$ octobre 1677

\section{Les lieux de production}

Si l'on compare à la période médiévale, on note plusieurs nouveaux lieux de production: Mas Guy, Mas Gaillard, Le Villard, les Girards et Plantaglay. Cette dispersion révèle bien l'extension prise par l'artisanat de la terre cuite, même si la famille des Girard offre un bel exemple de tradition professionnelle : déjà présents en 1416, leur souvenir est en outre perpétué par le toponyme Mas Girard ou Les Girard. Sur le cadastre de 1826, ce lieu-dit abritait encore un four et une aire pour la fabrication de la poterie ; ce document ne mentionne en revanche qu'un seul autre four de potier sur la commune de Treffort, au lieu-dit le Pelot. A la même date, cinq fours à poteries sont recensés à Meillonnas (lieux-dits : Plantaglay, en Buscard, aux Tupinières, à la Rasa, aux Avocats) ${ }^{23}$. 


\section{Les modalités de la commercialisation des produits : une enquête difficile} Meillonnas et Treffort qui fournirent en terre à feu le tiers du Royaume et même la Suisse et la Savoye; cette activité occupant par ailleurs beaucoup de voituriers ${ }^{24}$. Excepté ces affirmations d'ordre général, peu de textes concernent le commerce de la poterie. Ce dernier est néanmoins attesté par un contrat passé à Pont-de-Veyle, en 1635, entre un marchand de la ville et un potier de la Razza à Meillonnas ${ }^{25}$ Le potier s'y engageait à fournir et entretenir, pendant une année (...) toute la vesselle de terre (que le marchand) pourra débiter. Dès réception de la marchandise, le potier serait payé pour chascune grande douzaine de pots, deux livres tournois. Le marchand était tenu par le contrat de ne pas revendre les céramiques livrées à aucun marchand en gros; l'acte stipule en outre que c'est telle marchandise que d'accoustumé se débite dans ladite ville. Doit-on comprendre alors que le marchand était peut-être lui-même grossiste et, d'autre part, que les poteries de Meillonnas avaient coutume de transiter par Pont-de-Veyle avant d'être redistribuées ? La proximité de la Saône plaide en faveur de cette hypothèse, mais elle n'a pas pu être confortée faute de textes similaires.

alons en outre, qu'au XVIIIe s. la terre brutte (se transportait) dans toutes les manufactures pour y servir d'engobage (cf. note 24 et que les acquisitions répétées qu'en firent les potiers de Bourg-en-Bresse accélérèrent peut-être le déclin de MeillonnasTreffort comme centre producteur. Actuellement, seul le commerce de la terre rappelle le souvenir de cette activité.

Faute d'information sur les modalités de la commercialisation, les données archéologiques nous permettent de retracer l'aire de diffusion des ateliers, du moins pendant la période de prospérité, aux XVIe et XVIIe s. (cf. infra).

S. S.-G.

\section{Les produits de Meillonnas-Treffort}

Les résultats de l'enquête archéologique menée à Meillonnas-Treffort sont fondés surtout sur l'analyse quantitative et qualitative du produit des ramassages de surface. Avant d'entraîner le lecteur dans le dédale de la topographie et de la chronologie des ateliers repérés, il est important de présenter les grandes étapes des productions bressanes. Faute de critères de datation fournis par les prospections, il a fallu faire largement appel aux comparaisons typologiques, dans le cadre régional, pour tenter de caler dans le temps les produits de Meillonnas-Treffort. La classification établie ici est reprise tout au long du texte.

Les ramassages ont permis de réunir une imposante quantité de matériel, soit 12860 tessons susceptibles de fournir un échantillonnage fiable de la production des ateliers à travers les siècles. Comme nous l'espérions, le service vert est largement représenté, mais n'est pas isolé. Parfois il est accompagné de productions plus récentes. Mais l'intérêt réside surtout dans le fait que, en certains points, domine nettement une catégorie de poteries très homogène, plus ancienne que le service vert: il s'agit de poteries communes le plus souvent à pâte grise.

50 Sans entrer chaque fois dans les détails de description des différents types rencontrés, les céramiques des ramassages de surface ont été, par simplicité, classées en trois 
groupes présentés successivement dans les pages qui suivent :

groupe 1 - céramiques sans revêtement, poteries communes, attribuables en majorité au bas Moyen Age (XIVe-XVe s.),

groupe 2 - céramiques à glaçure verte plombifère sur pâte blanche dites service vert (fin XVe, XVIe et XVIIe s.).

groupe 3 - céramiques recouvertes d'autres sortes de glaçures monochromes, attribuables à la période moderne (XVIIIe et XIXe s.).

51 La faïence, quant à elle, est pratiquement absente des ramassages. Cela peut paraître étonnant, si l'on considère que Meillonnas fut un gros centre de production de faïences. Mais la faïencerie était installée en plein centre du village, dans le château, tandis que les ateliers localisés sont dispersés dans les hameaux environnants (cf. note 4).

\section{Groupe 1 : les poteries communes}

52 Ce premier groupe réunit les céramiques dépourvues de revêtement, tournées en pâte grise à brun clair, ou uniformément rouge, ou rouge avec surface noire. Les pâtes grises sont les plus nombreuses (environ 2000 tessons); plus ou moins bien cuites, elles sont en général assez fines, compactes. Les pâtes de couleur brun clair sont légèrement moins nombreuses (1 305 tessons); elles sont généralement plus grossières, à surface rugueuse et, dans l'ensemble, utilisées pour des vases à parois plus épaisses que ceux en pâte grise. Beaucoup plus rares sont les pâtes franchement rouges (173 tessons), également grossières et à surface rugueuse. Un dernier type regroupe les pâtes type « sandwich ", rouges à surface noire, qui sont très dures et compactes (179 tessons).

\section{Catalogue}

Les éléments morphologiques identifiés appartiennent à deux types de vaisselle : les formes fermées, pour la cuisson ou les liquides, et les formes ouvertes pour la table et la préparation. La marmite se caractérise par un col court, cylindrique, concave à l'intérieur, parfois cannelé à l'extérieur. La lèvre est toujours rectangulaire, plus ou moins saillante vers l'extérieur (fig. $11 \mathbf{n}^{\circ} \mathbf{1}$ à 5). L'anse est attachée sur le col. Plus rares sont les formes de marmite avec un col court, légèrement évasé qui se termine, le plus souvent, par une petite lèvre plate à peine saillante ou, plus rarement, par une lèvre confondue avec un col muni d'une extrémité arrondie (fig. $11 \mathbf{n}^{\circ} 6$ et 7). Les anses, très nombreuses et très variées, sont de type rubané et toujours caractérisées par un repli interne. Parfois, elles ont un profil simple (fig. $12 \mathbf{n}^{\circ} 1$ à 5 ), ou très asymétrique (fig. $12 \mathrm{n}^{\circ} \mathbf{6}$ à 9). Un nombre relativement important présente une incision plus ou moins profonde et, dans un seul cas attesté, deux incisions (fig. $12 \mathbf{n}^{\circ}$ 10 à 13). Nombreuses sont aussi les anses de type cannelé (fig. $12 \mathrm{n}^{\circ} 14$ à 17). Rares, en revanche, sont celles présentant deux replis latéraux ou de section ronde et de profil coudé, (fig. $12 \mathrm{n}^{\circ} 18$ et 19). 
11 - Céramiques communes à pâte grise ou brune : marmites et autres formes fermées

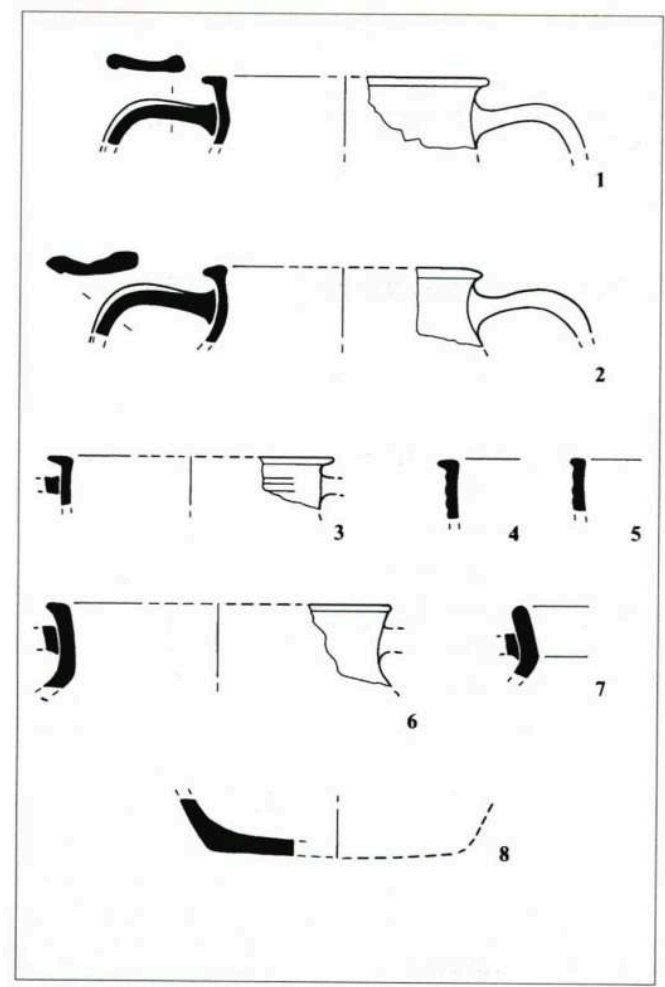

12 - Céramiques communes à pâte grise ou brune : anses et lèvres (de pichets ou cruches ?)

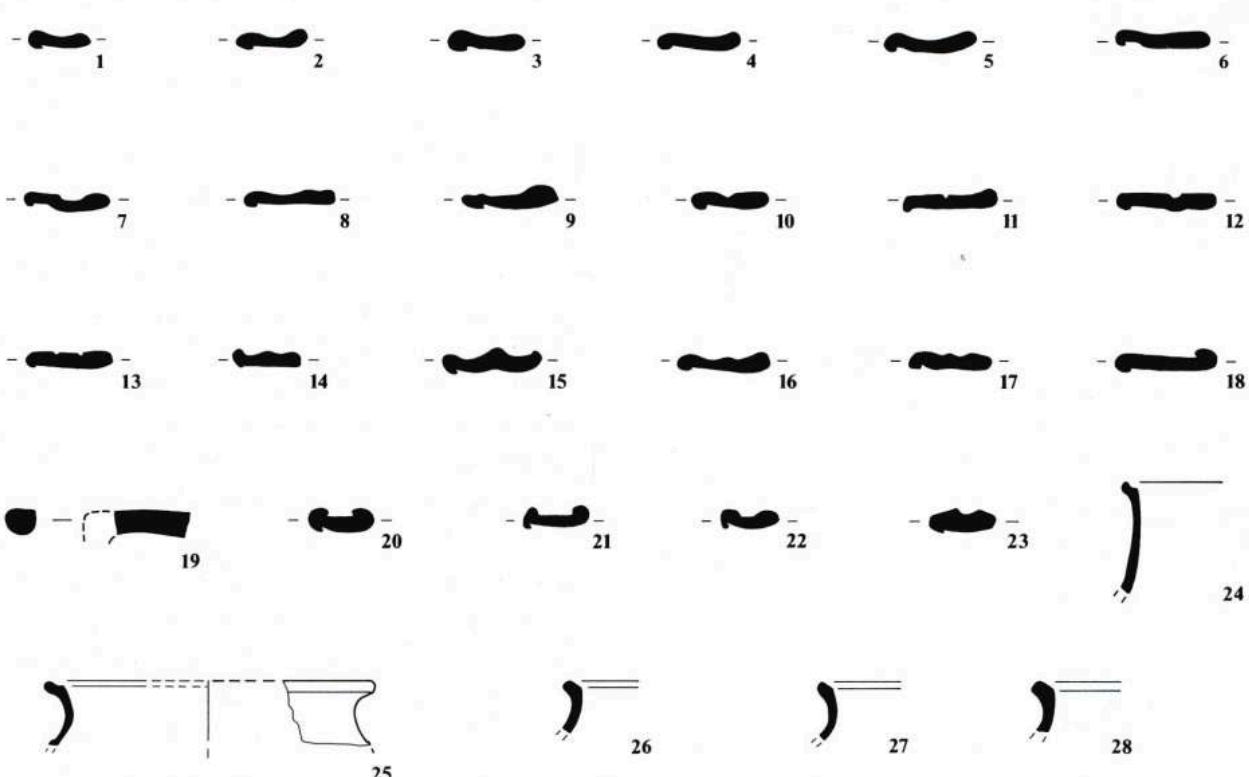

54 Les fonds bombés sont nombreux (75,8 \% - 69 tessons), tandis que les fonds plats sont plus rares (20,9\% - 19 fragments). Dans seulement trois cas nous avons pu constater l'existence d'un fond globulaire confondu avec la panse. Mais le nombre relativement réduit de tessons de fonds par rapport au nombre total de tessons indique que la forme globulaire devait être très répandue : en effet il est impossible de distinguer, lors du tri, les tessons de panses des tessons de fonds, lorsqu'il s'agit d'un profil hémisphérique. 
Une dernière série d'anses, de plus petite taille et de section presque bifide semblerait se rattacher à une autre forme fermée (fig. $12 \mathbf{n}^{\circ} 20$ à 23). La lèvre de ces récipients est à peine saillante, plus ou moins épaisse, et elle est reliée à un col évasé, apparemment court mais, dans un cas, suffisamment haut pour laisser envisager une sorte de pichet ou de cruche (fig. $12 \mathrm{n}^{\circ} 24$ à 28 ).

A côté de ces formes fermées, on a pu identifier de nombreux fragments de formes ouvertes et basses, parfois de grande taille, qui semblent appartenir à des bassins ou à de larges terrines. Le rebord est en forme de marli oblique ; il présente des extrémités très variées : verticales et légèrement bombées (fig. $13 \mathrm{n}^{\circ} \mathbf{1}$ et 2 ); en forme de bandeau couché (fig. $13 \mathrm{n}^{\circ} \mathbf{3}$ et 4 ); ou encore, en amande ou en bourrelet arrondi (fig. $13 \mathrm{n}^{\circ} 5$ à 8). Ce dernier type de lèvre en amande est associé, une fois, à un décor horizontal de bande rapportée et digitée sur un récipient de très grande taille (fig. $13 \mathbf{n}^{\circ}$ 9). Ces sortes de bassins ont en général un très large diamètre $(26$ à $30 \mathrm{~cm})$.

13 - Céramiques communes à pâte grise ou brune : rebords de formes ouvertes

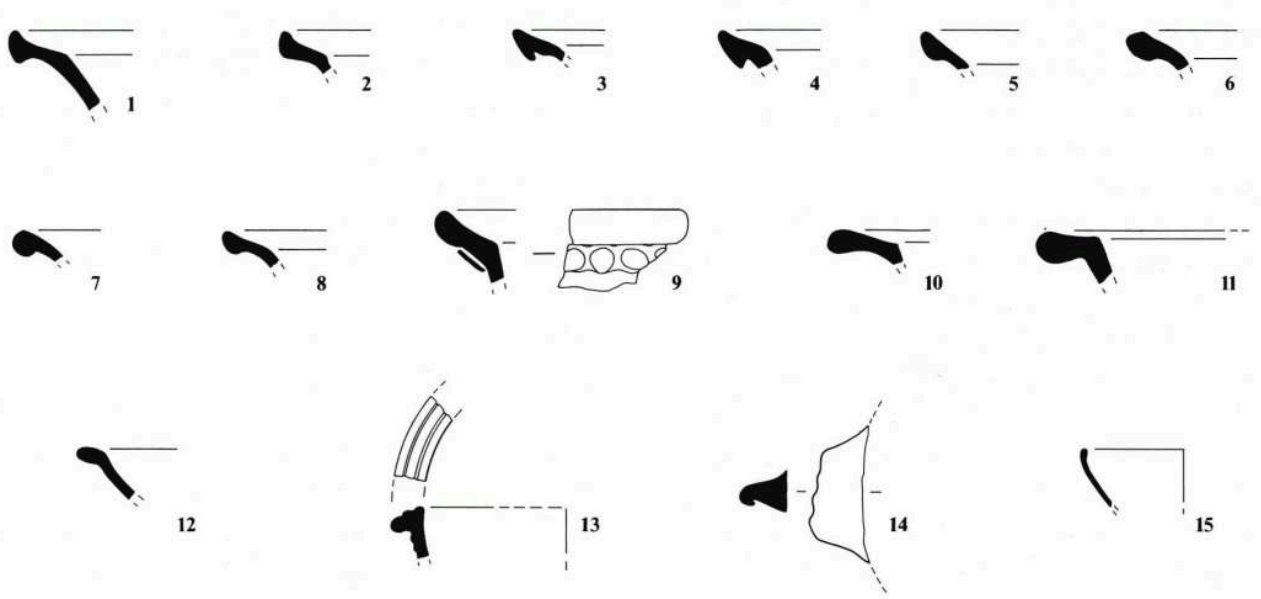

Des éléments de plus petite taille semblent se rapporter plutôt à une forme d'écuelle (fig. $13 \mathbf{n}^{\circ} 10$ à 12). Leur rebord est le plus souvent en forme de large lèvre horizontale et, d'après l'amorce du profil, il semblerait qu'il s'agisse de pièces plus ou moins hémisphériques.

Une lèvre à rebord oblique pendant vers l'extérieur et marquée par des incisions parallèles est tout à fait unique (fig. $13 \mathbf{n}^{\circ} \mathbf{1 3}$ ), ainsi qu'un grand rebord avec tenon (ou probablement deux) horizontal, à extrémité ondulée (fig. $\left.13 \mathbf{n}^{\circ} \mathbf{1 4}\right)$. Enfin, il a été possible d'identifier un rebord d'écuelle hémisphérique muni d'une extrémité arrondie, repliée vers l'intérieur qui, bien qu'en pâte grise, rappelle la forme largement attestée dans le service vert, postérieur (fig. $13 \mathbf{n}^{\circ} \mathbf{1 5}$ ).

14- Céramiques communes à pâte grise ou brune : rebords de grandes formes fermées (1 et 2) ; pieds de réchaud (3 et 4 ); couvercle (5) 


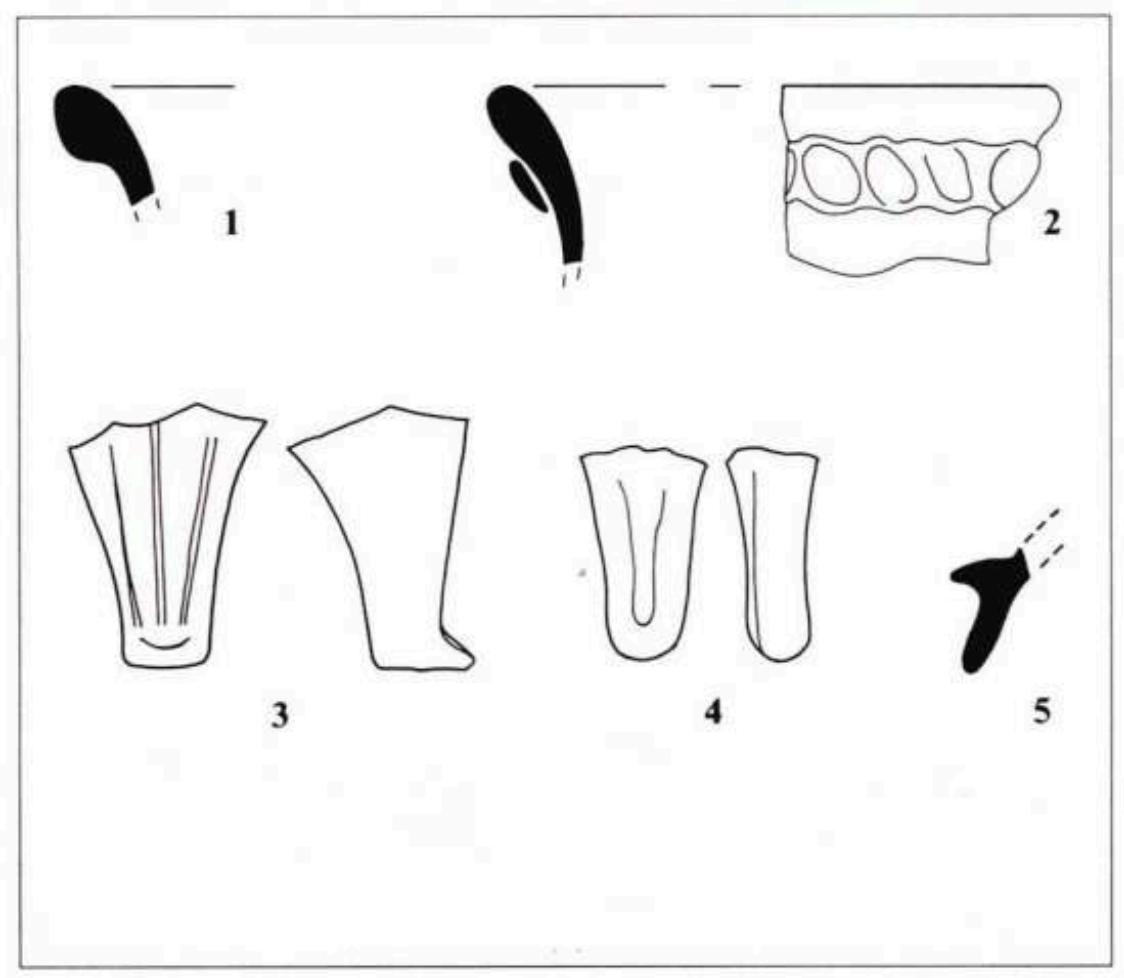

Parmi les formes rares, nous pouvons aussi citer les rebords de récipients fermés du type jarre, soit avec bourrelet, soit avec un profil en amande, souligné à l'extérieur par un décor de bande rapportée et digitée (fig. $14 \mathbf{n}^{\circ} 1$ et 2 ). Sont également intéressants deux pieds très hauts ayant appartenu fort probablement à des réchauds ou à des trépieds en terre cuite (fig. $14 \mathbf{n}^{\circ} 3$ et 4 ).

Un décompte minutieux effectué sur tous les fragments identifiables n'a pas permis de constater la prédominance de la forme fermée ou ouverte selon qu'il s'agisse de pâte grise ou brun clair. Apparemment deux sortes de cuisson ont été utilisées indifféremment pour l'une ou l'autre catégorie de formes : en atmosphère réductrice et en atmosphère oxydante. Les pourcentages s'écartent de très peu et dans les deux cas les formes fermées sont largement majoritaires ( 88,7 \% pour les pâtes grises et $80,2 \%$ pour les pâtes brun clair).

Rares, mais non absents, sont les indices d'autres formes qui, en l'état actuel des connaissances, semblent plus anciennes. Il s'agit surtout de quelques lèvres évasées (fig.15 $n^{\circ} 1$ à 3), d'une lèvre en bandeau (fig. $15 n^{\circ}$ 4) et d'un nombre assez important de becs pontés ( 31 fragments). Dans ce groupe de céramiques plus anciennes, on peut inclure également le seul fragment de céramique recouvert de glaçure non couvrante, rugueuse et parsemée, typique du Moyen Age, retrouvé aux Tupinières. L'analyse de la composition de quelques uns de ces échantillons anciens montre qu'ils ont bien été fabriqués avec les argiles locales. 


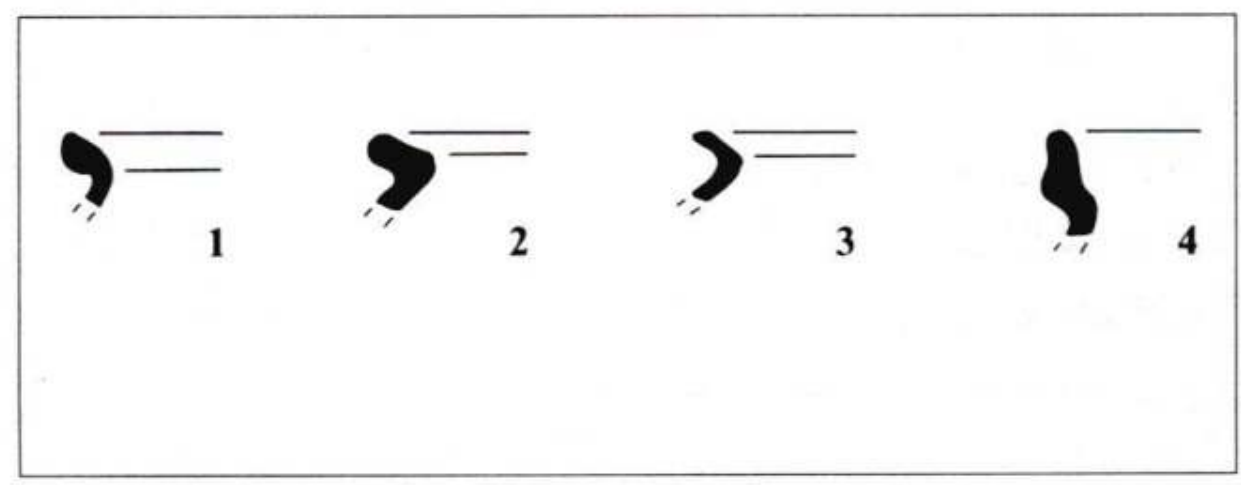

\section{Datation}

Les poteries communes restent difficiles à dater en l'absence de critères absolus, mais le groupe 1 des productions de Meillonnas trouve des éléments de comparaison régionaux. Les formes les plus significatives sont bien les marmites globulaires à deux anses symétriques et les bassins, formes désormais bien repérées et datées sur quelques sites utilisateurs. Ceux-ci sont mentionnés dans la seconde partie du volume.

L'usage des formes basses, ouvertes, en terre cuite, tant pour la table que pour la cuisine, ne se répand pas avant la deuxième moitié du XVe s (A la Fortune du Pot 1990, pp. 87-111 et Maccari-Poisson 1988, p. 234). Ce n'est qu'à partir de ce moment que les couches archéologiques livrent des quantités significatives de jattes et/ou bassins à rebord en marli et à fond plat ou bombé comme à Lyon, quartier Saint-Vincent, rue Tramassac, place Antonin Poncet (Becker et alii 1989, p. 156).

La datation des marmites à deux anses est moins précise. Ce récipient, en pâte grise, sans revêtement aucun, apparaît dès le milieu du XIIIe s. (à Anse, Rhône). Mais il n'est vraiment omniprésent sur les sites qu'à partir du XVe s. où il connaît une certaine variété avec l'apparition des pâtes oxydées et de la glaçure, ainsi que des anses coudées et les fonds tripodes, destinés à imiter les chaudrons métalliques. Cependant le type plus classique, fabriqué à Meillonnas, avec son col légèrement évasé et ses anses rubanées, connaît des exemples dès le XIVe s. (bastide de Gironville, à Ambronay, Ain, par exemple). Il est adopté très généralement dans le courant du XVe s. (MaccariPoisson 1988). Par bien des points, les marmites de Meillonnas rappellent la production de l'atelier rural de Saint-Romain-de-Surieu (Isère), dont l'activité a été datée des XVeXVIe s. (Faure-Boucharlat et Vicard 1986, pp. 120-121).

Ces formes largement majoritaires dans les rejets d'ateliers, invitent à placer au XVe s., la phase florissante de la production de céramiques communes à Meillonnas (hameau des Tupinières essentiellement). Des indices incontestables d'une activité plus ancienne, certes plus réduite, sont fournis par des éléments de pots à cuire et cruches à bec ponté. On sait désormais que de tels récipients ont eu une remarquable longévité : majoritaires sur les sites des Xe et XIe s., on les retrouve encore, en faibles proportions, dans des niveaux de la première moitié du XIIIe s. (Anse et Lyon, rue Palais-Grillet et îlot Clément V). L'artisanat de la poterie apparaît donc à Meillonnas au moins dès le XIIIe $s$. avec des productions communes, de tradition médiévale. Le mobilier assurément datable du XIVe $\mathrm{s}$. fait défaut, mais alors les textes prennent la relève pour 
signifier une continuité des ateliers jusqu'à l'apparition du service vert au début du XVIe s.

\section{Groupe 2 : le service vert}

Cet ensemble réunit toutes les formes reconnues comme service vert, caractérisé par une pâte très claire et fine, recouverte de glaçure plombifère vert vif, bien couvrante, appliquée directement. Cette catégorie de vaisselle est dénommée « famille B1 » dans la nomenclature présentée dans la seconde partie de cet ouvrage. Les lignes qui suivent se réfèrent donc à cette étude, tant pour la typologie (renvoi au numéro de type entre parenthèses) que pour la datation. Le service vert est désormais bien connu grâce aux ramassages sur les sites producteurs, mais aussi et surtout, par l'étude du mobilier, moins fragmenté, issu de nombreux sites utilisateurs fouillés dans la région (cf. infra) (fig. 55). Le mobilier provenant du remplissage d'un four du hameau des Tupinières (point de ramassage T 29, sur la commune de Meillonnas) (fig. 16) a largement enrichi notre inventaire ${ }^{26}$. On peut désormais dresser un catalogue assez fourni des récipients fabriqués dans la région de Meillonnas. Les fouilles de Lyon livrent encore, au moment où ce texte est rédigé, d'importants lots de service vert. Aussi, le catalogue présenté cidessous n'est-il pas exhaustif.

\section{6- Service vert : une partie du mobilier provenant du remplissage d'un four}

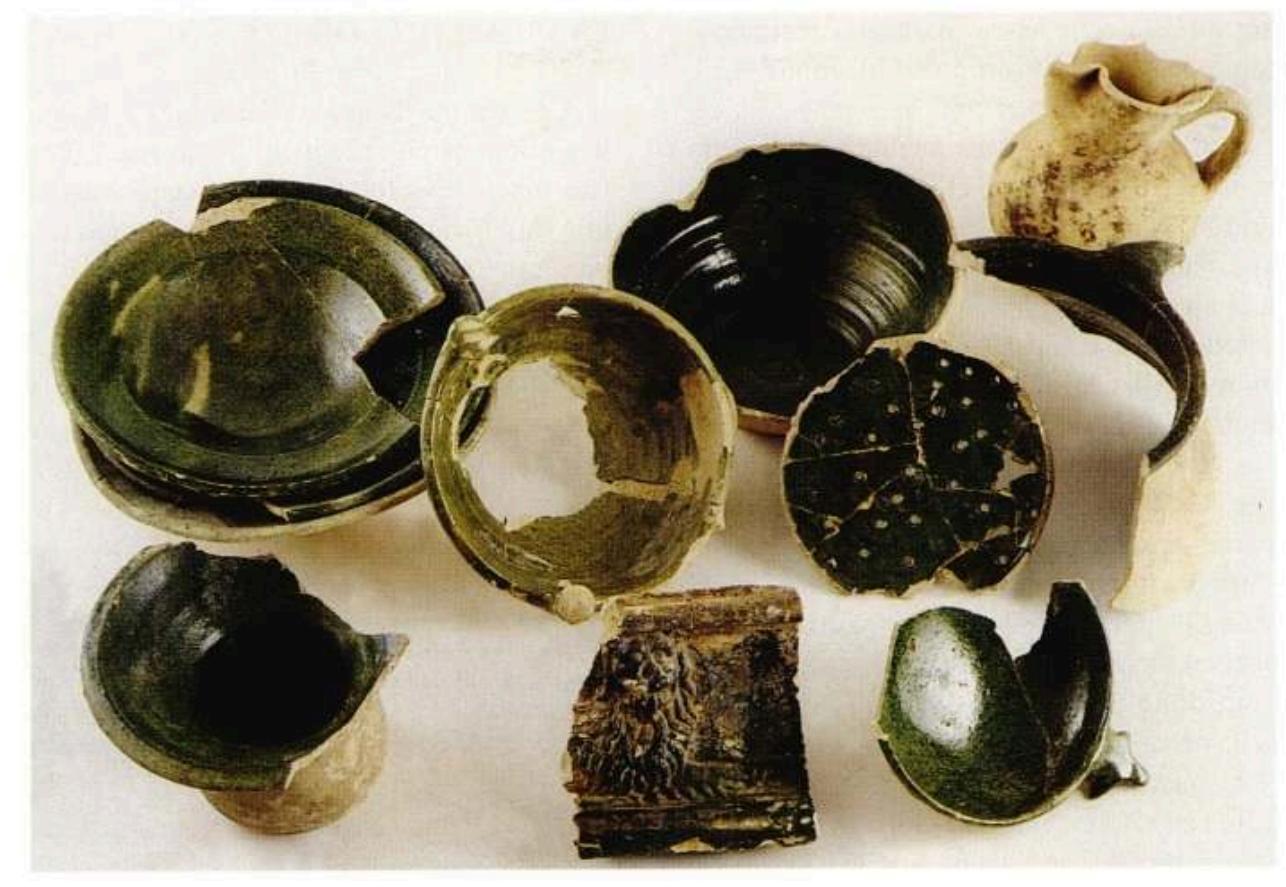

Point de ramassage T 29 sur la commune de Meillonnas

Apparemment, et les analyses de pâte le montrent, il s'agit d'une production très homogène. Mais l'étude et la comparaison de nombreux fragments recueillis lors des prospections ont fait apparaître, à l'œil nu, plusieurs nuances de vert pour le revêtement et également deux catégories de pâte. Celle-ci, généralement blanche, fine et compacte, présente parfois une nuance plus rosée, peut-être à cause d'une cuisson 
différente, mais sans que l'on puisse exclure l'hypothèse d'ateliers différents. Les comptages des ramassages de surface ont donc pris en considération ces deux sortes de pâtes. Quant à la glaçure, on peut distinguer cinq nuances de vert :

- glaçure vert vif, brillante, très couvrante,

- glaçure vert pâle, parfois plus opaque,

- glaçure vert bronze, résultant peut-être d'une surcuisson,

- glaçure vert maculé, caractérisée par la présence d'une myriade de minuscules petits points plus sombres,

- glaçure verte comportant des coulures plus sombres,

- biscuit; ce dernier groupe réunit, sans que l'on puisse toujours le déterminer, soit les biscuits de dégourdi, soit des fragments de vases qui ne recevaient pas de glaçure : c'est le cas des anses, des pieds des vases tripodes et des parties de panse des récipients qui ne recevaient que partiellement le revêtement vitreux.

La répétition des formes de récipients reconnues actuellement nous autorise à penser que les ateliers de Meillonnas et Treffort ont produit essentiellement trois catégories de poteries en pâte blanche: de la vaisselle culinaire, de la vaisselle de table, des ustensiles domestiques ou artisanaux divers, auxquelles il faut ajouter une production de céramiques architecturales.

\section{La vaisselle culinaire}

Les récipients qui sont destinés à la cuisson des aliments comprennent des formes fermées (marmites, casseroles hautes et coquemars) ainsi que des formes ouvertes (poêlons, casseroles basses et lèchefrites).

\section{Les marmites}

70 Elles sont les plus nombreuses et les plus diversifiées par leur profil, mais sont toujours munies de deux anses verticales opposées.

71 - marmite globulaire, sans col (type 1352). La lèvre est évasée et arrondie; les deux anses, de section ovale, ont leur attache sur le diamètre maximum et sur la lèvre; le fond est plat. Il devait exister plusieurs tailles. La plus petite présentée ici mesure 133 $\mathrm{mm}$ de haut et la plus grande $195 \mathrm{~mm}$. Ces deux exemplaires provenant du four des Tupinières sont des pièces inachevées puisqu'encore à l'état de biscuit de dégourdi. Le produit fini était très probablement glaçuré à l'intérieur (fig. $17 \mathrm{n}^{\circ} 1$ et 2). 

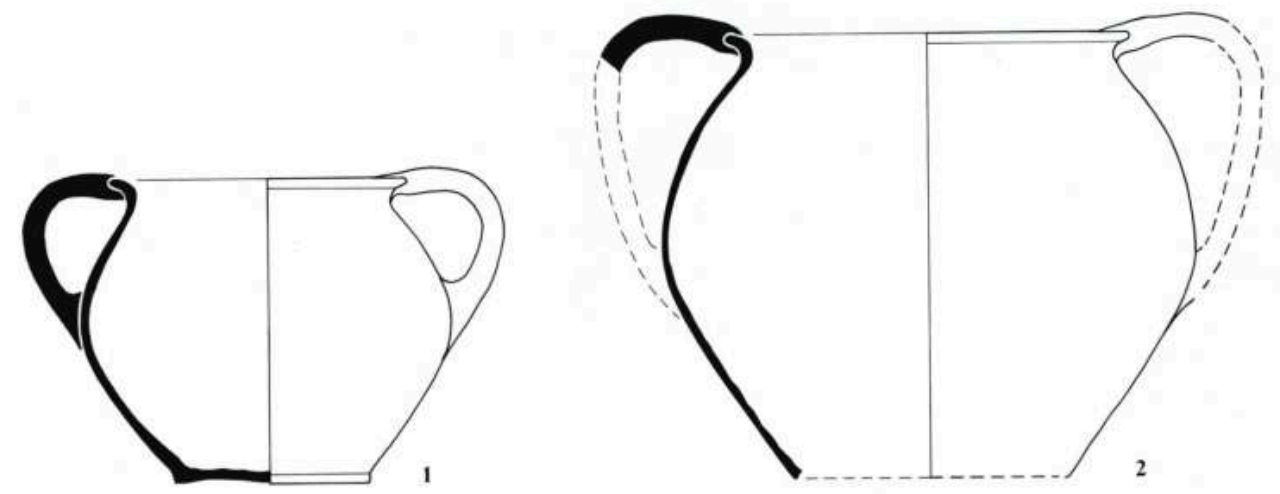

Meillonas, four Giroud

- marmite globulaire à col court (type 1811). Les lèvres présentent des profils légèrement différents, mais sont toujours saillantes à l'extérieur. Les anses, ovales, englobent la lèvre en haut et se rabattent sur le diamètre maximum. Les fonds sont concaves. Un fragment de forme présente à l'extérieur une bande rapportée et digitée, disposée verticalement. La glaçure recouvre toute la surface interne, sauf dans un exemplaire qui est à l'état de biscuit de dégourdi (fig. $18 \mathbf{n}^{\circ}$ 3), provenant du four des Tupinières. La hauteur des exemplaires connus varie entre $152 \mathrm{~mm}$ et $197 \mathrm{~mm}$ (fig. 18 $\mathbf{n}^{\circ} 3$ et 1).

18 - Service vert : marmites globulaires avec col court
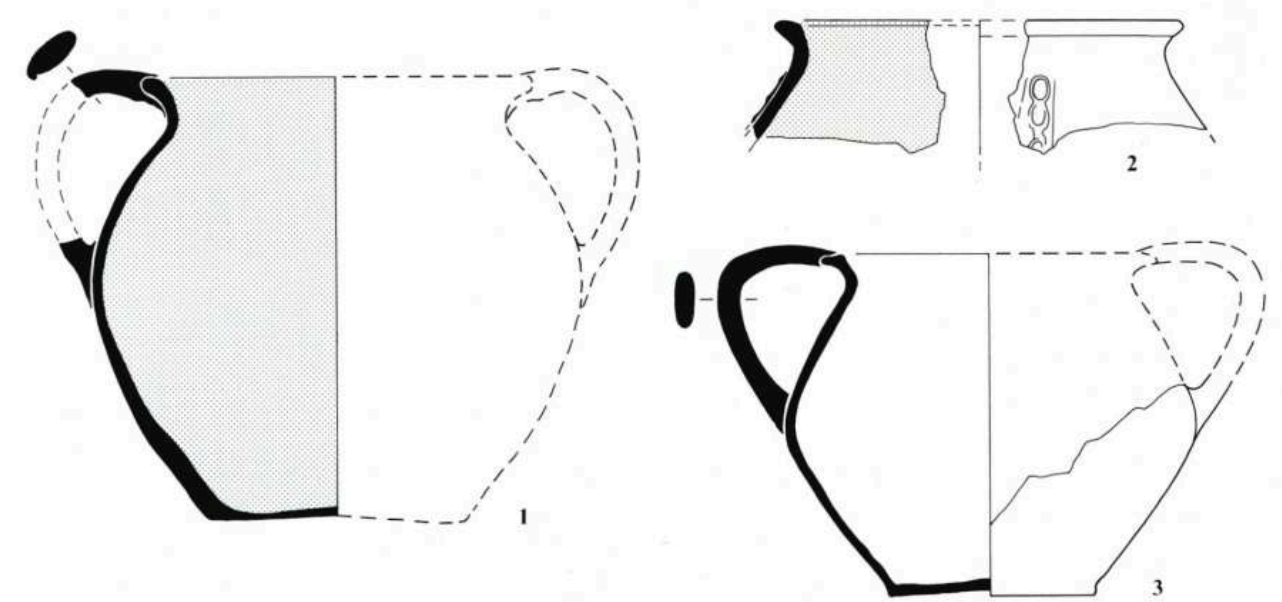

1 et 2 : Lyon, avenue Adolphe Max ; 3 : Meillonas, four Giroud

- marmite globulaire à col oblique (type 1321). Cet unique exemplaire de marmite est de très grand gabarit : h. : $280 \mathrm{~mm}$, diamètre de l'ouverture : $350 \mathrm{~mm}$ et diamètre du fond : $230 \mathrm{~mm}$. La paroi est renforcée par des cordons en relief disposés verticalement. Le fond est bombé et les deux anses verticales ont leur point de départ au-dessus du diamètre maximum (fig. 19). 


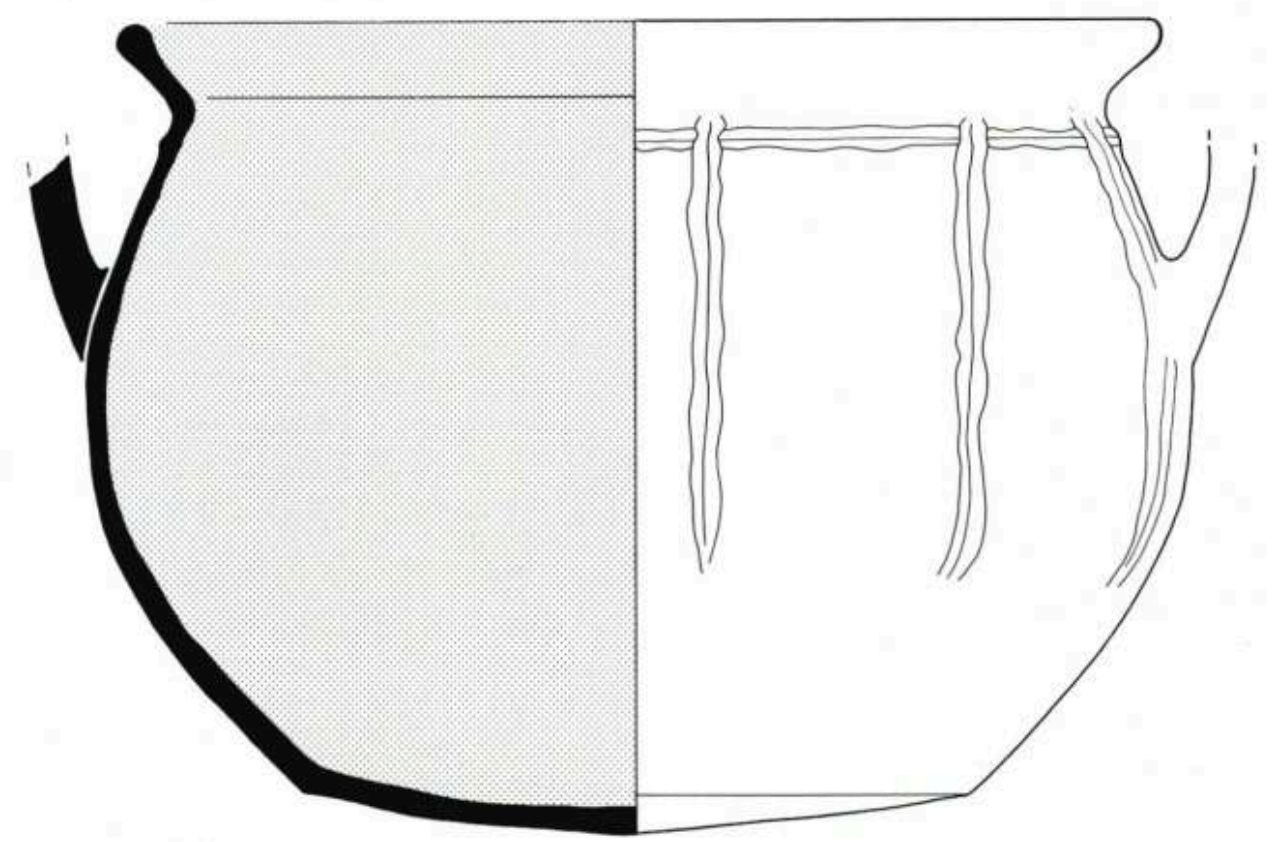

Nerciat, Ain

- marmite à anses « coudées » (type 1311). Les exemplaires de marmites munies d'anses coudées à section cylindrique sont fragmentaires. Par leur profil, ils s'apparentent, semble-t-il, aux marmites globulaires à col court et lèvre saillante ; celle-ci présente parfois une extrémité plate (fig. $20 n^{\circ} 1$ ) ou concave (fig. $20 n^{\circ} 2$ ). Il s'agit de vases de grande taille, puisque les diamètres de l'ouverture mesurent respectivement 200 et 220 $\mathrm{mm}$. Le fragment le mieux conservé possède une bande côtelée rapportée sur la panse, probablement en guise de renfort. La glaçure interne déborde à l'extérieur sur la lèvre et une partie des anses.

20 - Service vert : marmites à anses coudées

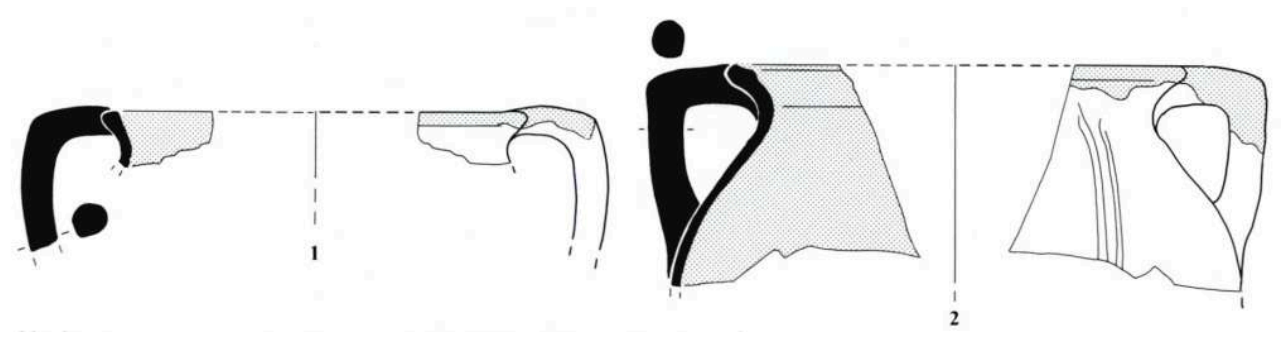

Vulbens, Haute-Savoie

- marmite ovoïde (fig. 21, type 1521). Le col court est cylindrique et la lèvre, saillante, a une extrémité plate. Les deux anses de section ovale englobent la lèvre et se recourbent très au-dessus du niveau de l'ouverture. Le fond est plat avec une base étalée. La glaçure recouvre entièrement la face interne et déborde à l'extérieur sur la lèvre et les anses (h. : $204 \mathrm{~mm}$ ). 


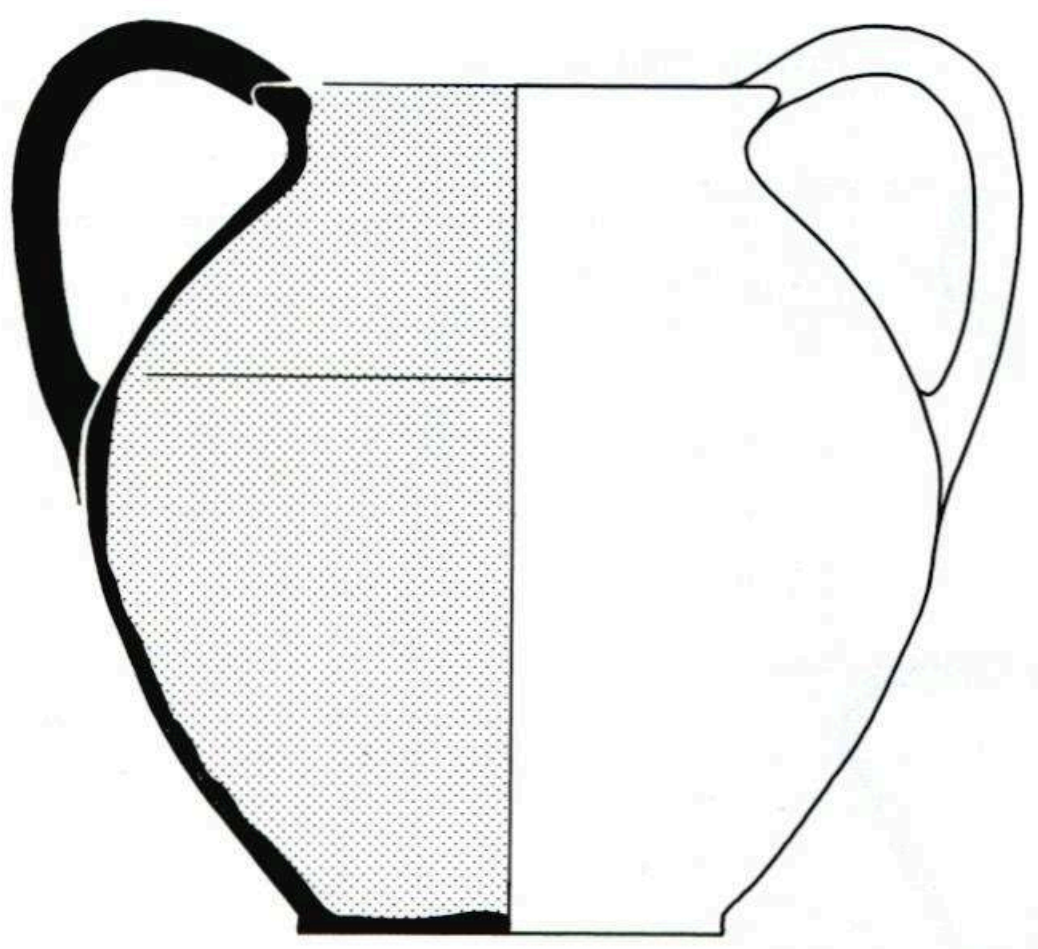

Lyon, place Antonin Poncet

76 - marmite cylindrique et tripode (type 1711). La panse est, dans cette forme, haute et cylindrique et se rattache à la lèvre par un épaulement plus ou moins marqué. Les anses, de section ovale, très en relief et asymétriques, s'attachent sur le haut et le bas de la panse. Le fond plat repose sur trois pieds formés d'un boudin replié ou vaguement conique (fig. 22). La glaçure recouvre toute la surface interne et déborde sur la lèvre. Un des exemplaires répertoriés a été percé, après cuisson, d'une série de perforations rondes ou carrées, afin de l'utiliser, semble-t-il, comme une chaufferette. 


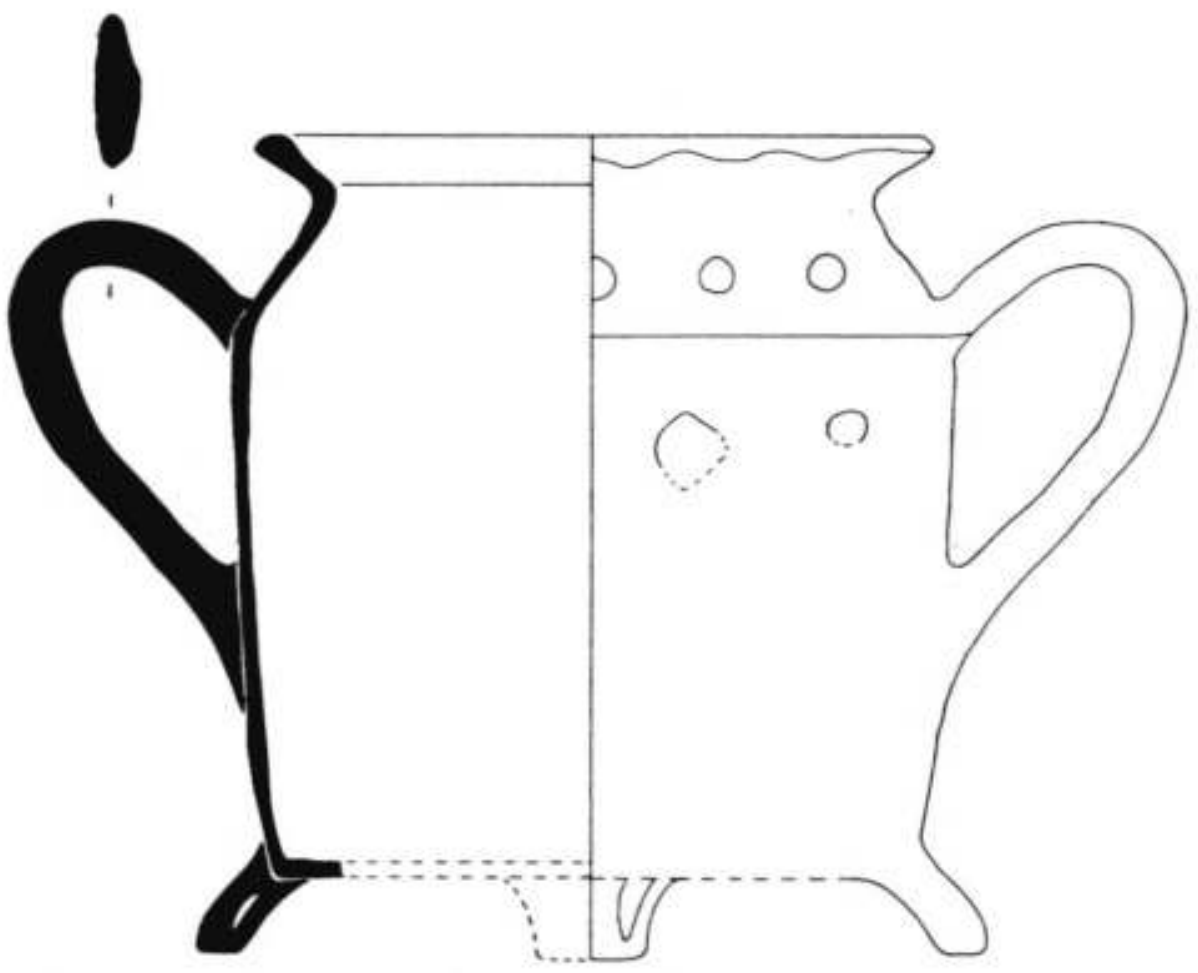

Lyon, quartier Saint-Vincent

77 - petite marmite tripode (fig. 23). Cette petite forme culinaire a un fond bombé posé sur trois pieds coniques; la panse est globulaire et le rebord haut forme une sorte de col confondu avec la lèvre arrondie. Les anses, de section ronde, sont plaquées contre le rebord et retombent au-dessus du diamètre maximum. La glaçure recouvre toute la surface interne et déborde sur la lèvre et les anses (h. : $132 \mathrm{~mm}$ ). 


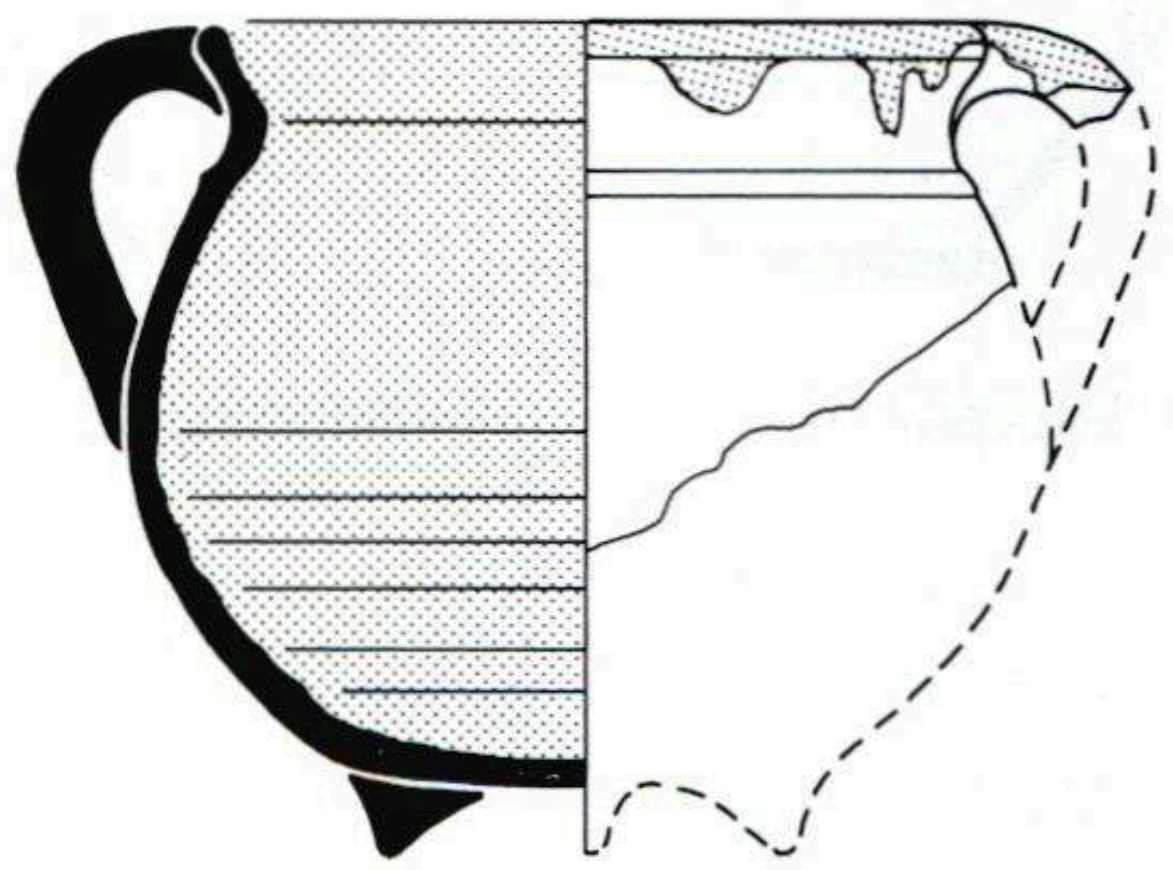

Vulbens, Haute-Savoie

\section{Les casseroles hautes}

78 A la différence des marmites, les casseroles hautes ne possèdent pas d'anse, mais un manche creux plaqué soudé à la panse. Ce récipient culinaire est rare ; il n'en existe que deux exemplaires différents par leur taille et par le profil de la lèvre.

- petite casserole haute (fig. $24 \mathbf{n}^{\circ}$ 1). La panse globulaire se rattache directement à la lèvre qui est évasée et large. Le fond plat est posé sur trois pieds pleins et cylindriques. $\mathrm{Du}$ manche creux il ne reste que l'attache contre le diamètre maximum. La glaçure recouvre toute la surface interne (h. : $105 \mathrm{~mm}$ ).

- grande casserole haute (fig. $24 \mathbf{n}^{\circ}$ 2). Dans cette forme, très fragmentaire, le manche creux est collé contre le haut de la panse. La lèvre est repliée vers l'extérieur, formant un anneau circulaire autour de l'ouverture et que l'on peut supposer destiné à recevoir un couvercle. La glaçure recouvre toute la surface interne.

\section{4 - Service vert : casseroles hautes}
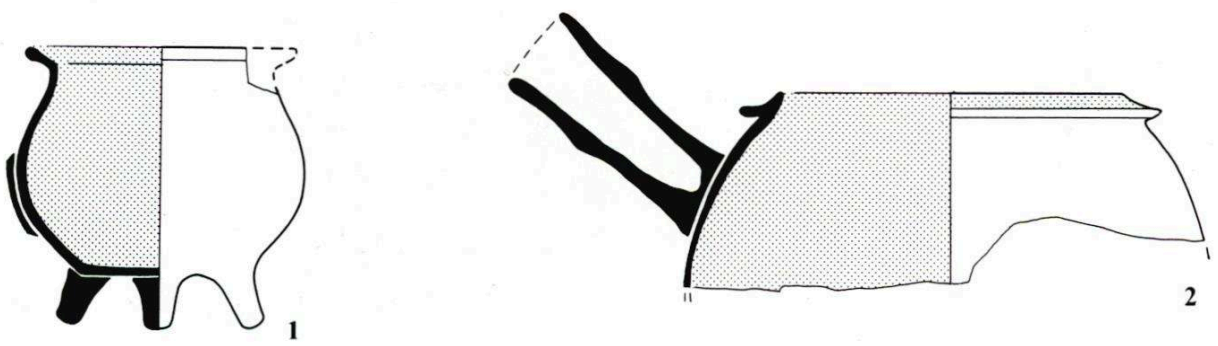

Meillonnas, four Giroud 


\section{Les coquemars}

81 Ils se caractérisent par la présence d'une seule anse sur des récipients de petite taille. Tous les coquemars du service vert frappent par la forme étrange de l'anse qui, placée de part et d'autre du diamètre maximum, dessine une préhension très saillante et très détachée du profil du vase. Il existe plusieurs variantes de coquemars :

82 - coquemar globulaire, sans col (fig. $25 \mathbf{n}^{\circ}$ 1) (type 1821). La lèvre évasée est plus ou moins épaissie à l'extrémité ; le fond est plat et la glaçure recouvre entièrement la surface interne, sauf dans l'exemplaire incomplet qui est à l'état de biscuit de dégourdi (h. : $138 \mathrm{~mm}$ ).

83 - coquemar globulaire avec col court (fig. $25 \mathbf{n}^{\circ}$ 2). La lèvre très saillante forme presque un rectangle par rapport à l'axe du col. Le fond, dans l'exemplaire complet, est plat avec une base étalée. On dispose d'un exemplaire achevé, avec glaçure à l'intérieur, et d'un fragment qui est resté à l'état de biscuit. Le vase complet atteste l'existence de très petits gabarits (h. : $93 \mathrm{~mm}$ ).

84 - coquemar ovoïde (fig. $25 \mathbf{n}^{\circ} 3$, type 1821). Le fond, plat, est plus étroit que l'ouverture et cela confère au profil une allure élancée. Le rebord, oblique, se termine par une extrémité plate. La glaçure recouvre entièrement la surface interne et, cas assez rare dans le service vert, la moitié supérieure de la face externe (h. : $120 \mathrm{~mm}$ ).

- coquemar tripode (fig. $25 \mathbf{n}^{\circ}$ 4). La panse, très large et trapue, se termine en haut par un rebord évasé avec l'extrémité à peine arrondie. Le fond plat est très large (son diamètre est supérieur à celui de l'ouverture) et devait reposer sur trois pieds dont il ne reste que l'arrachement. La glaçure recouvre toute la surface interne (h. : $108 \mathrm{~mm}$ ).

\section{5 - Service vert : coquemars}
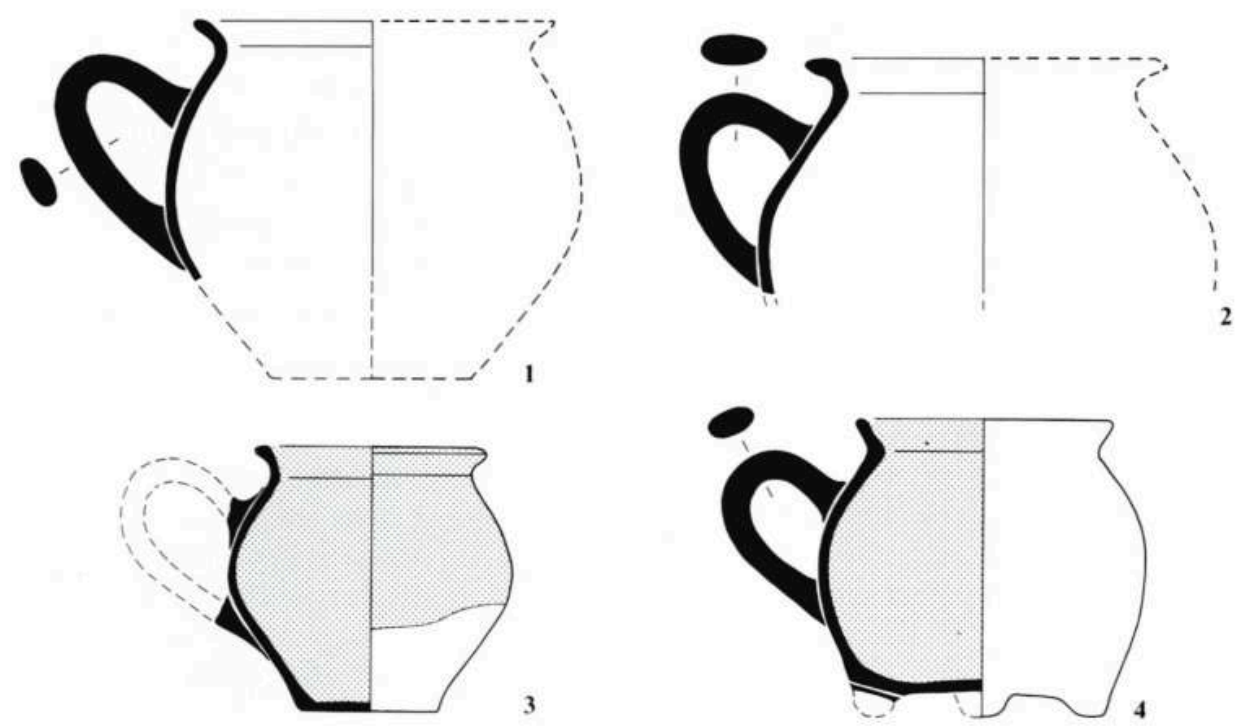

1 et 3 : Lyon, quartier Saint-Valentin ; 2 : Meillonas, four Giroud ; 4 : Vulbens, Haute-Savoie 


\section{Les petits poêlons}

Ils sont tous hémisphériques et munis d'un manche creux, posé obliquement contre la lèvre (fig. $26 \mathrm{n}^{\circ} 1$ et 2 , type 3832). Le rebord forme un petit marli horizontal ; l'ouverture est circulaire, sans trace de bec pincé ; le fond est toujours, semble-t-il, plat comme dans l'exemplaire complet (h.: $65 \mathrm{~mm}$ ). La panse, plus large que haute, est recouverte de glaçure à l'intérieur pour les produits finis, tandis qu'un fragment (trouvé dans le four des Tupinières) est en biscuit de dégourdi.

\section{Les casseroles basses}

Elles sont des formes ouvertes munies d'une ou plusieurs anses verticales. Le seul exemplaire complet est tripode (fig. $26 \mathbf{n}^{\circ}$ 3). La panse, cylindrique, est très large par rapport à la hauteur (respectivement $190 \mathrm{~mm}$ et $85 \mathrm{~mm}$ ). La lèvre, simplement arrondie à son extrémité, se dédouble à l'extérieur, formant une corolle saillante, sans doute destinée à recevoir un couvercle. L'anse, verticale, est plate et le fond, plat également, repose sur trois pieds formés par des boudins de pâte repliés sur eux-mêmes.

26 - Service vert : petits poêlons, casseroles basses et lèchefrites
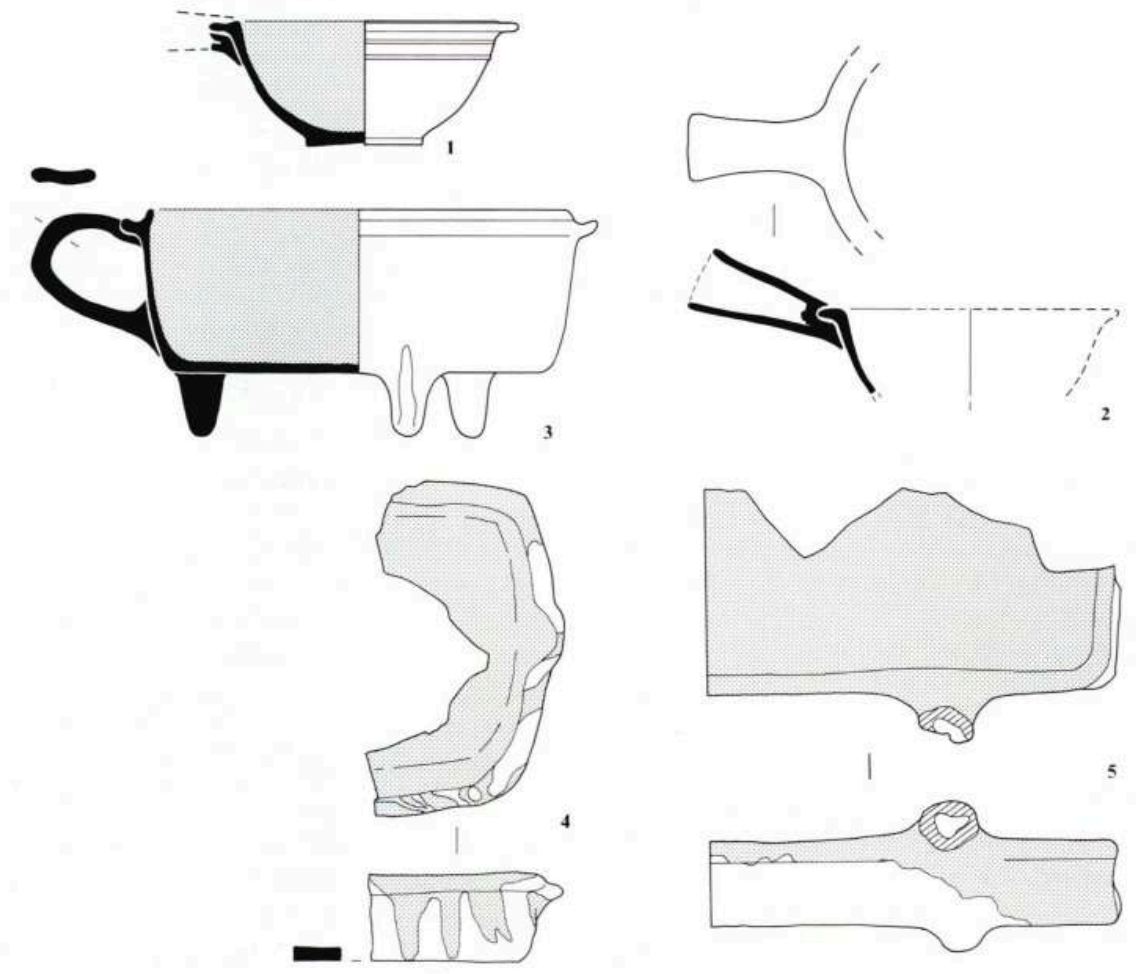

1 et 2 : Meillonas, four Giroud ; 3 : Lyon, avenue Adolphe Max ; 4 : Valence, Drôme, 5 : Nantua, Ain

\section{Les lèchefrites}

Ce sont des récipients très bas, munis d'un ou plusieurs manches et d'un bec verseur pincé (fig. $26 \mathrm{n}^{\circ} 4$ et 5). L'exemplaire $\mathrm{n}^{\circ} 5$ est un récipient rectangulaire qui porte sur son côté long $(320 \mathrm{~mm})$ deux manches creux (l'un des deux est arraché). Du côté opposé se trouve le bec pincé. Le fond repose sur des pieds ( 3 ou 4 ?). Le fragment $n^{\circ} 4$ n'est 
conservé que sur le côté court du rectangle où se trouve un bec pincé. Apparemment il n'avait pas de pied et nous ne connaissons pas l'emplacement des éléments de préhension (larg. : $180 \mathrm{~mm}$ ).

\section{La vaisselle de table}

Les récipients destinés au service de table sont également très nombreux et se regroupent en quatre séries: les assiettes creuses, les écuelles, les cruches et les pichets.

\section{Les assiettes creuses}

Ce fut, semble-t-il, le produit qui a eu le plus de succès et on les retrouve pratiquement sur tous les sites (fig. 27, type 3311). Plus ou moins profondes et plus ou moins larges, elles correspondent toutes à une même forme basse, avec de petites variantes au niveau de la lèvre et de l'inclinaison du rebord. Dotées d'un marli très large, les assiettes creuses ont une paroi relativement profonde et un fond plat, parfois légèrement concave. La glaçure recouvre toute la surface interne, avec des coulures irrégulières sur la surface externe. Signalons, comme unique cas, l'exemplaire doté d'une marque de potier sur le fond, potier qui, pour le moment, n'a pas pu être identifié (fig.27 $\mathbf{n}^{\circ}$ 6) (hauteur moyenne : $50 \mathrm{~mm}$ et diamètre d'ouverture se situant entre 150 et $190 \mathrm{~mm}$, sans le marli).

\section{7 - Service vert : assiettes creuses}

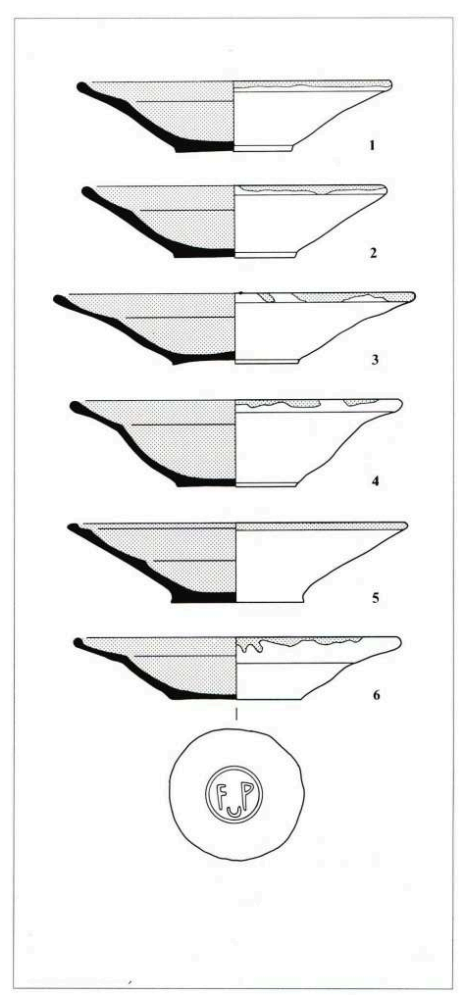

1 à 4 : Meillonas, four Giroud ; 5 : Nerciat, Ain ; 6 : Lyon, quartier Saint-Vincent 


\section{Les écuelles}

91 Elles sont moins nombreuses et moins répandues que les assiettes, mais présentent plusieurs variantes. Le profil de base est constant: paroi hémisphérique avec lèvre arrondie, légèrement refermée vers l'intérieur; le fond plat forme un petit socle cylindrique (fig. 28, type 3411). Les différences se retrouvent surtout au niveau des éléments de préhension collés horizontalement contre la lèvre :

92 - oreilles festonnées (fig. $27 \mathbf{n}^{\circ} \mathbf{1}$ ),

93 - oreille cylindrique, aplatie à l'extrémité (fig. $28 \mathbf{n}^{\circ} 2$ ),

94 - oreille rectangulaire plaquée contre la lèvre (fig. $28 \mathbf{n}^{\circ}$ 3),

95 - petite poignée annulaire de section ronde (fig. $28 \mathbf{n}^{\circ} 4$ ),

96 - prise annulaire torsadée (fig. $28 \mathbf{n}^{\circ}$ 5).

28 - Service vert : écuelles

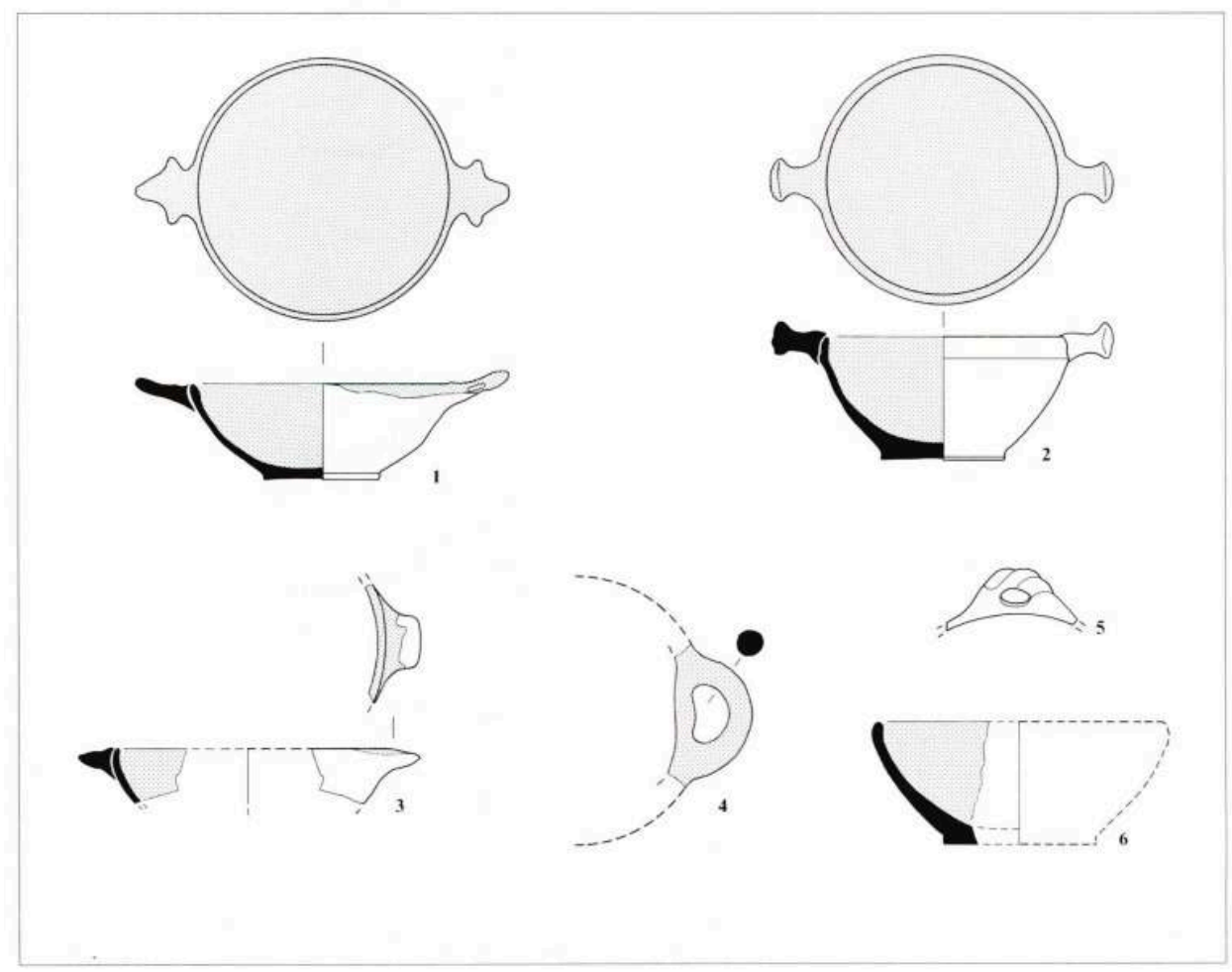

1 et 5 : Meillonnas, four Giroud ; 2 : Nerciat, Ain ; 3 : Vulbens, Haute-Savoie ; 4 : Treffort ; 6 : Lyon, rue Tramassac

Dans l'exemplaire complet les dimensions sont comprises entre 51 et $66 \mathrm{~mm}$ pour la hauteur et $140 \mathrm{~mm}$ au maximum pour le diamètre d'ouverture.

\section{Les cruches de table}

Ce sont des formes très rares, encore peu rencontrées sur les sites utilisateurs, mais présentes dans le mobilier du four retrouvé aux Tupinières. Elles se divisent en deux groupes : cruches à bec pincé et cruches à bec tubulaire. 
99 à bec pincé (fig. $29 \mathrm{n}^{\circ} 1$ et 2). De tailles variables, les cruches de ce type ont une panse globulaire et un fond plat avec base étalée. Le col est haut et se termine par une lèvre, largement évasée. Le bec est très festonné, largement pincé, donnant ainsi à l'ouverture une forme trilobée. Du côté opposé au bec, l'anse verticale, et ovale, s'attache au bas du col et au-dessus du diamètre maximum. On imagine les produits finis avec de la glaçure à l'intérieur, mais nous ne connaissons que des vases encore à l'état de biscuit de dégourdi (h.: 160 et $210 \mathrm{~mm}$ ).

100 - cruches à bec tubulaire. Deux récipients incomplets illustrent cette forme pour la table. Le premier, globulaire, présente un col haut et un long bec cylindrique placé sur le milieu du vase ; la glaçure recouvre toute la surface interne et, en guise de décor, elle forme une large tache ovoïde sur la face antérieure de la panse (fig. $29 \mathbf{n}^{\circ}$ 3) (hauteur conservée $140 \mathrm{~mm}$ ). Le deuxième, encore plus fragmentaire, est sans col avec un petit rebord oblique ; le bec, court, est placé sur le haut de la panse. Le vase est glaçuré à l'intérieur et à l'extérieur (fig. $29 \mathbf{n}^{\circ} \mathbf{4}$ ).

29 - Service vert : cruches de table
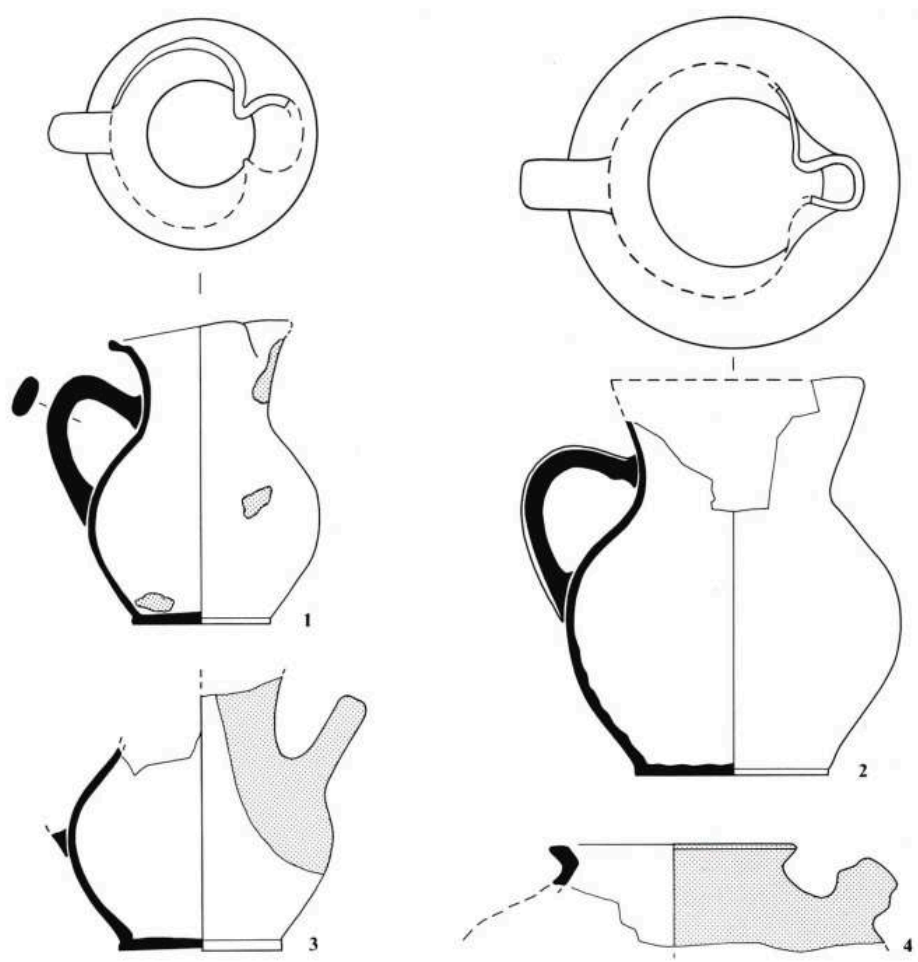

Meillonas, four Giroud

\section{Les pichets}

Vases de table sans élément verseur, ils sont également très rares. Trois exemplaires, dont un très fragmentaire, sont actuellement connus. Ils sont assez différents les uns des autres.

Le premier a un profil ovoïde, accentué par le fait que le fond est plus étroit que l'ouverture. Le col, court, est évasé et se termine par une lèvre en bourrelet. L'anse a son départ supérieur contre la lèvre et est de section circulaire $\left(f i g .30 \mathbf{n}^{\circ} 1\right)$. La glaçure 
recouvre uniquement la surface interne mais, le vase étant incomplet, il n'est pas exclu qu'il ait eu une tache décorative à l'avant (h. : $160 \mathrm{~mm}$ ).

La deuxième forme complète est, en revanche, globulaire et trapue à cause d'un fond plus large que l'ouverture (fig. $\mathbf{3 0} \mathbf{n}^{\circ} \mathbf{2}$ ); le col, court et évasé, se termine par une lèvre plate; l'anse est rubanée et ses attaches sont apposées sur le col et sur la moitié inférieure de la panse ; la glaçure recouvre entièrement les surfaces interne et externe, sauf le fond (h. : $138 \mathrm{~mm}$ ).

Il existe, enfin, un fragment de col haut et évasé qui s'apparente à la forme du pichet ; le rebord est biseauté vers l'extérieur et l'anse, placée sur le col, est de section ovale; la glaçure recouvre les surfaces interne et externe (fig. $30 \mathbf{n}^{\circ} \mathbf{3}$ ).

30 - Service vert : pichets
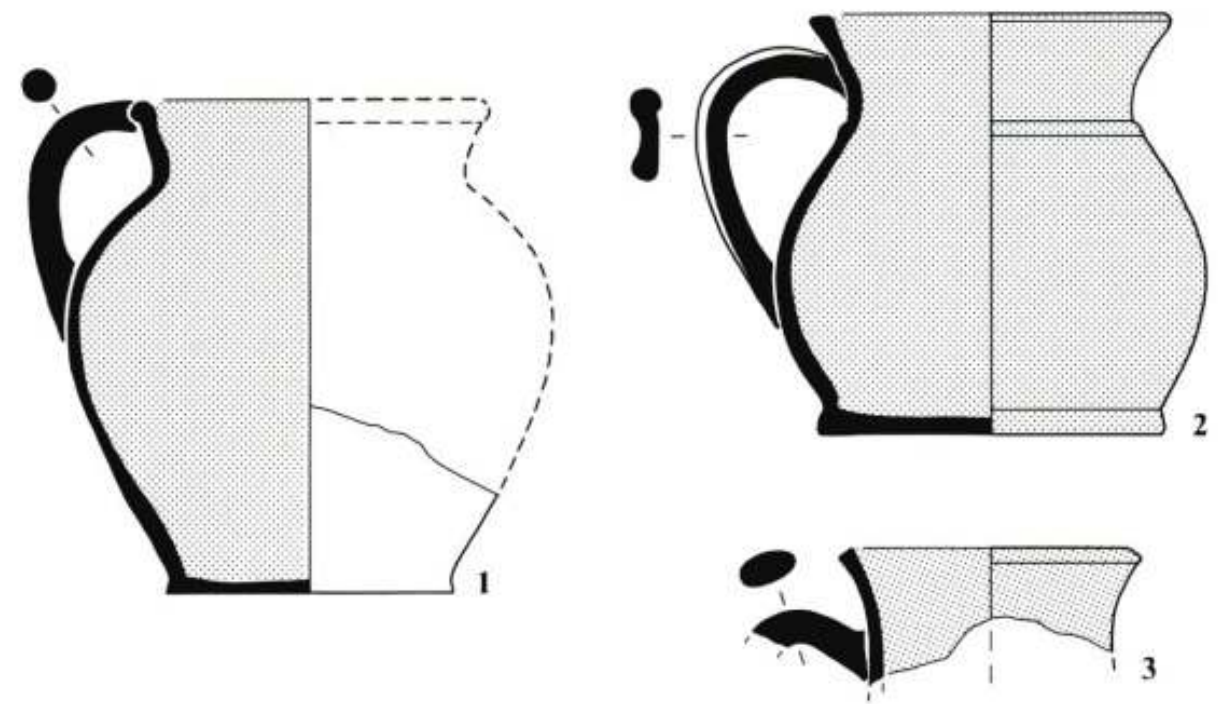

1 : Vulbens, Haute-Savoie ; 2 : Lyon, rue Tramassac ; 3 : Lyon, avenue Adolphe Max

\section{Ustensiles domestiques ou artisanaux}

Les poteries domestiques, incluant également d'autres formes non directement liées à la cuisson ou à la consommation des aliments, ont été considérées comme formant un groupe à part : celles qui servent à la préparation des aliments, comme la faisselle et le porte-faisselle; les accessoires tels que les réchauds et les couvercles; et enfin les fragments de formes plus particulières qui laissent deviner la multiplicité des vases produits à Meillonnas-Treffort et dont il est difficile d'entrevoir l'utilisation. Dans ce dernier groupe d'ustensiles divers ont été également inclus quelques fragments de creusets, bien qu'il ne s'agisse pas de poteries domestiques à proprement parler, mais de récipients destinés à l'artisanat.

\section{Les vases porte-faisselle}

Ils ont un profil tout à fait particulier et caractéristique (fig. $31 \mathbf{n}^{\circ} \mathbf{1}$ et 2). La panse, trapue, repose sur un large fond plat; le rebord, oblique et largement développé, forme une grande corolle circulaire permettant de recueillir le petit lait. Les seuls exemplaires connus proviennent du four des Tupinières et ils sont tantôt avec de la glaçure interne, 
tantôt encore à l'état de biscuit de dégourdi. Ils existent en deux tailles, la plus petite de $108 \mathrm{~mm}$ de haut et la plus grande de $162 \mathrm{~mm}$ de haut.

31 - Service vert : vases porte-vaisselle, faisselle et forme à sucre (?)
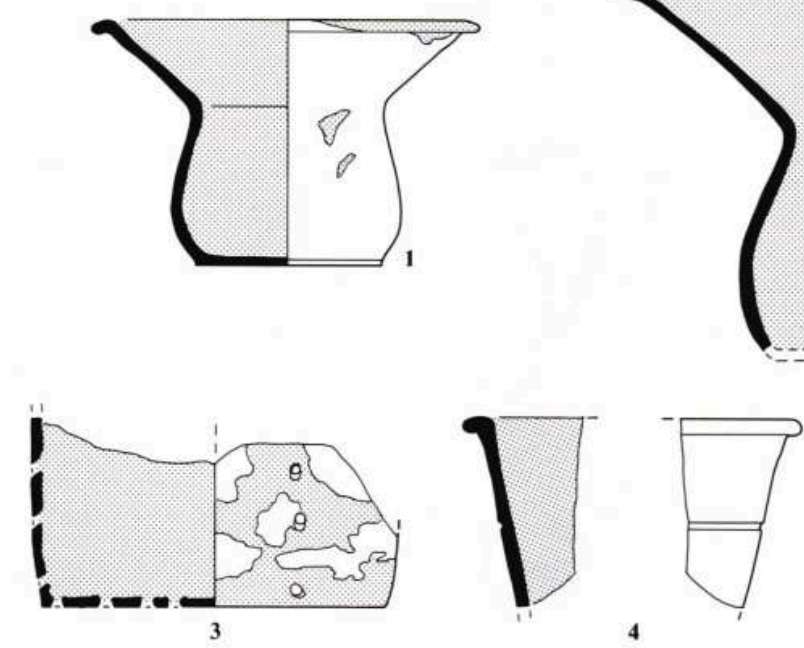

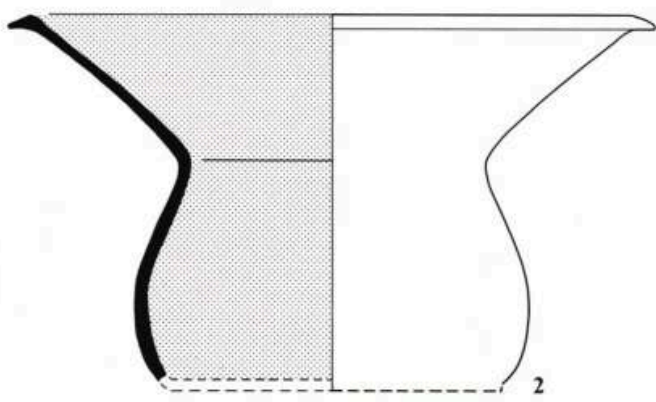

1 à 3 : Meillonas, four Giroud ; 4 : Sanciat, Ain

\section{Les faisselles}

Elles sont en forme de cylindre à fond plat (fig. $31 \mathbf{n}^{\circ} \mathbf{3}$ ). Les fragments retrouvés sont entièrement glaçurés à l'intérieur et partiellement à l'extérieur. Les perforations sont disposées en ligne verticale et à distance régulière sur la panse, tandis que sur les fonds elles forment des cercles concentriques.

\section{Moule à sucre?}

Un seul fragment de récipient évoque l'existence d'un tel ustensile en poterie. Son profil en tronc de cône renversé semble bien correspondre à cette forme très typique ; il s'agit d'une hypothèse. La glaçure ne recouvre que la face interne (fig. $31 \mathbf{n}^{\circ} \mathbf{4}$ ).

\section{Les réchauds}

De nombreux exemples de réchauds de table attestent l'uniformité de ce genre d'ustensile: à quelques détails près, ils sont tous identiques. La panse, évasée, est montée sur un piédouche assez haut, de profil conique. Le rebord forme une collerette évasée qui se termine par une lèvre plate. La jonction entre panse et rebord est soulignée par un fort ressaut. Sur le rebord sont posés verticalement trois boutons cylindriques, aplatis sur le haut, qui servaient à caler les récipients à maintenir au chaud. Un arrachement latéral sur la panse témoigne de la présence d'un manche. L'exemplaire le plus complet, (fig. 32, type 7113) est encore à l'état de biscuit (et très déformé), mais généralement les réchauds sont entièrement glaçurés à l'intérieur. 


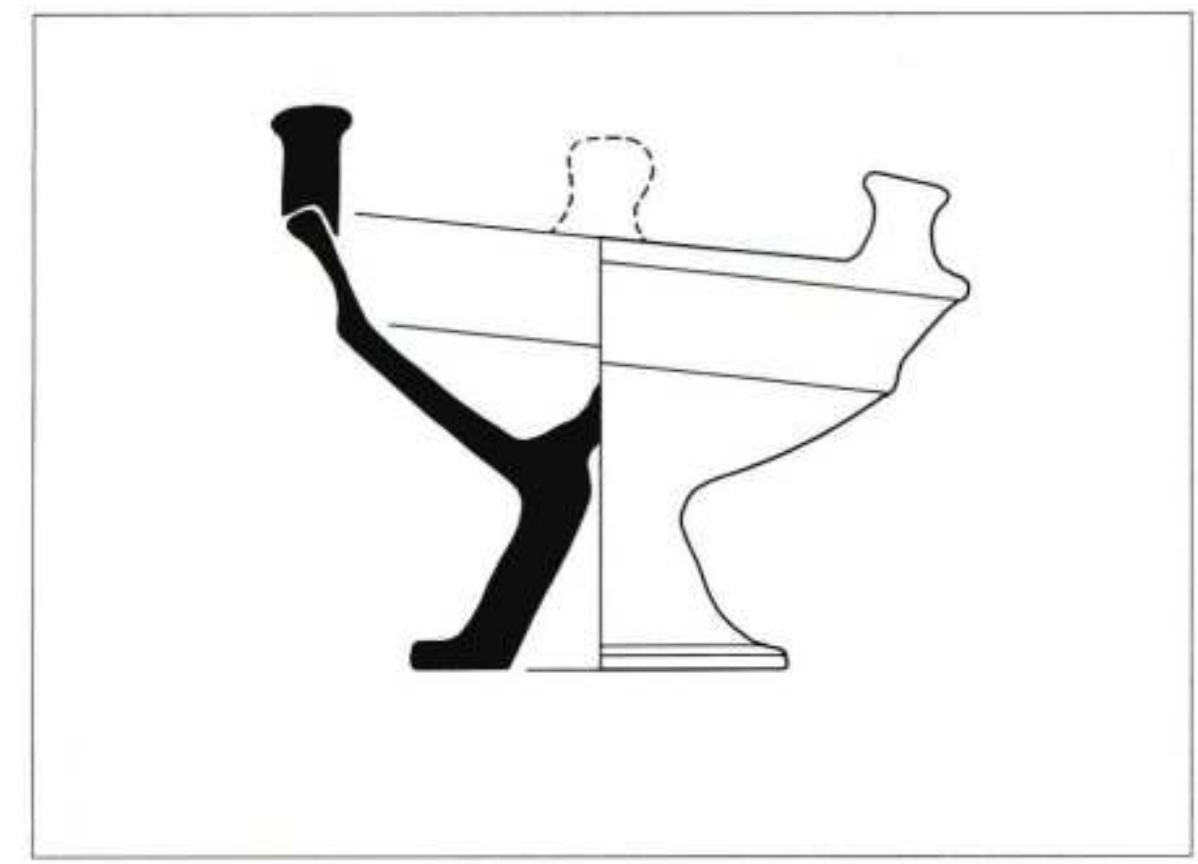

Meillonas, four Giroud

\section{Les paniers}

110 Ils ont un profil en tronc de cône renversé (fig. $\left.33 \mathbf{n}^{\circ} \mathbf{1}\right)$. Le seul exemplaire complet répertorié est d'assez grande taille : h. : $145 \mathrm{~mm}$, diamètre de l'ouverture : $290 \mathrm{~mm}$. L'anse, qui part de la lèvre, est plate, mais se replie sur elle-même au sommet (fig. 33 $\mathbf{n}^{\circ}$ 2). D'autres anses, torsadées ou avec cordons en relief sur une âme cylindrique, évoquent la même forme (fig. $\left.33 \mathrm{n}^{\circ} 3,4\right)$. 


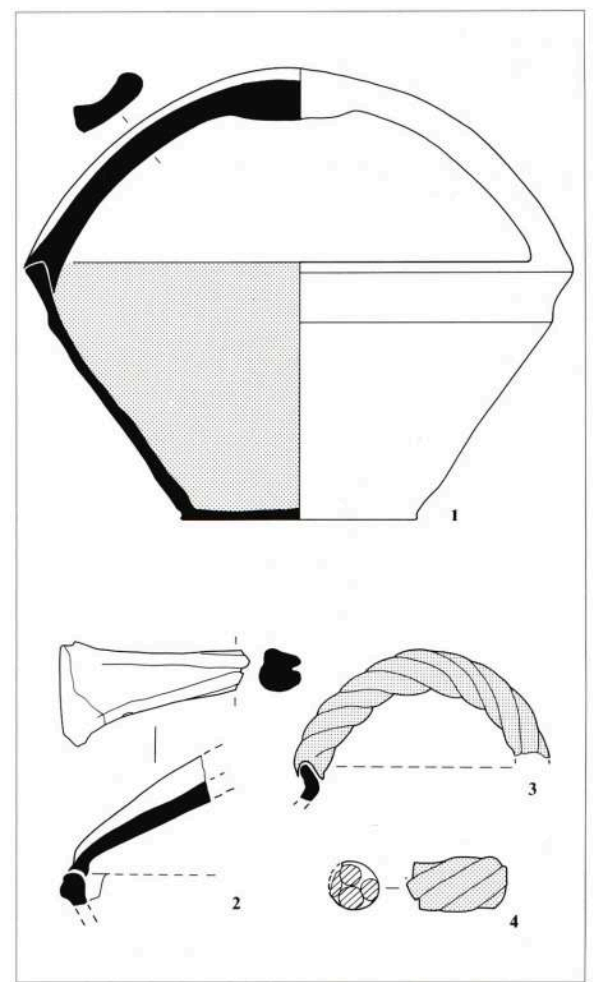

1 : Nerciat, Ain ; 2 : Treffort, T $14 ; 3$ : Meillonnas, four Giroud ; 4 : Nantua, Ain

\section{Les couvercles}

111 Ils constituent une production bien attestée dans le service vert, mais les exemplaires retrouvés sont tous très fragmentaires (fig. 34). De différentes tailles, ils se regroupent en quatre formes distinctes, toutes glaçurées à l'extérieur.

112 - couvercle avec base d'appui cylindrique (fig. $27 \mathbf{n}^{\circ} \mathbf{1}$ à 2). Le profil de la calotte est, semble-t-il, hémisphérique, se terminant probablement par un bouton de préhension. Un ressaut très prononcé, situé entre la calotte et la base d'appui servait à le caler sur les récipients à couvrir. Un fragment est enrichi d'un décor de bande rapportée et digitée, disposée horizontalement (fig. $34 \mathbf{n}^{\circ}$ 2).

113 - couvercle conique (fig. $34 \mathbf{n}^{\circ} \mathbf{3}$ ). Ce seul exemplaire est décoré d'une incision verticale coupée de petits traits obliques.

114 - couvercle cylindrique (fig. $34 \mathbf{n}^{\circ}$ 4). Conservé sur la moitié supérieure, ce couvercle est le seul à posséder son bouton de préhension, cylindrique également.

115 - couvercle avec rebord droit (fig. $34 \mathbf{n}^{\circ} 5$ et 6). La calotte, hémisphérique, est très aplatie ; une forte inflexion à angle droit marque la liaison avec le rebord simple ou cannelé. 
34 - Service vert : couvercles

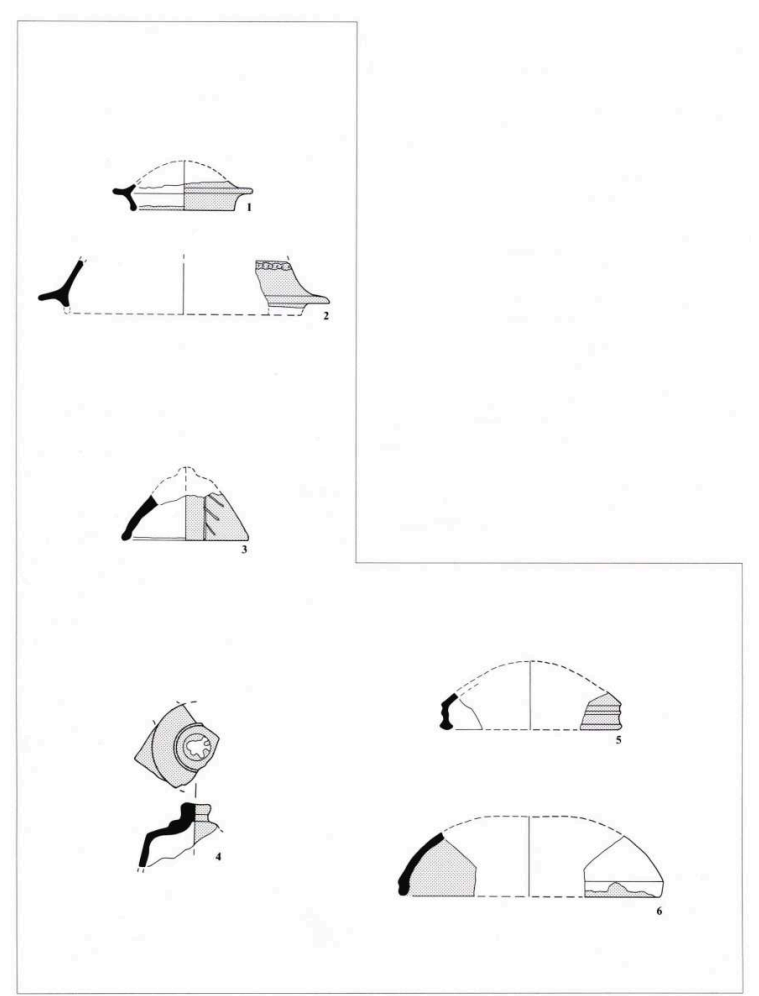

1, 3 et 5 : Vulbens, Haute-Savoie ; 2 et 6 : Nantua, Ain ; 4 : Meillonas, T 4

\section{Les fragments d'autres formes}

116 Ils rassemblent les pièces uniques et disparates :

117 - petit vase en panier et bec ponté avec filtre (fig. $\left.35 \mathbf{n}^{\circ} \mathbf{1}\right)$,

118 - petite gourde (fig. $35 \mathbf{n}^{\circ} \mathbf{2}$ ) ; deux exemplaires en parfait état de conservation ont été récemment trouvés à Lyon dans le remplissage du fossé de la place des Terreaux (ill. dos de couverture),

119 - anse verticale creuse avec perforations (fig. $35 \mathbf{n}^{\circ} \mathbf{3}$ ),

120 - creusets en tronc de cône renversé (fig. $35 \mathbf{n}^{\circ} 4$ et 5). 


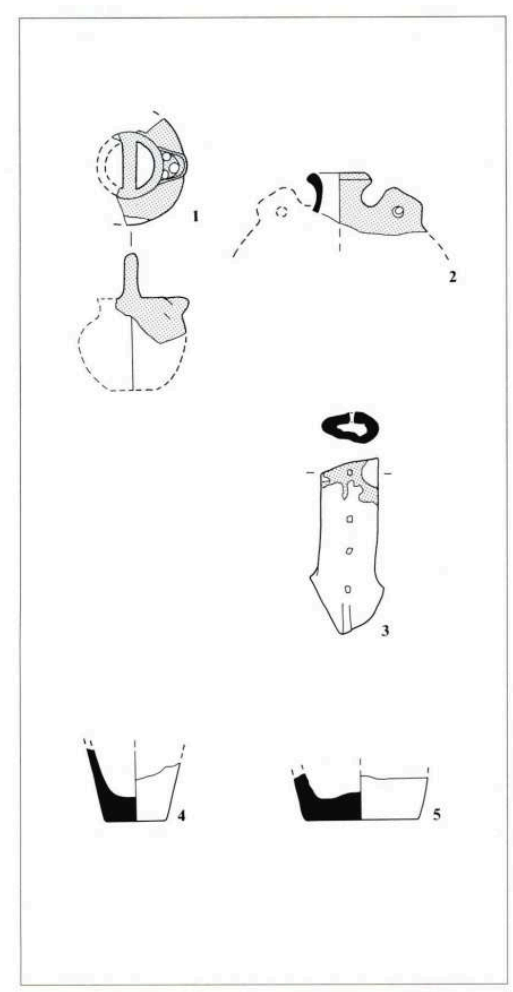

1 : LYON, RUE tRAMASSAC ; 2 : VULbenS, HAUTE-SAVOIE ; 3 : NeUVILLE, AIN ; 4 : TREFFORT, 14 ; 5 : TREFFORT, T 17

\section{Datation du service vert}

Les nombreuses découvertes de service vert dans une vaste région ont permis d'évaluer la vitalité économique des ateliers de Meillonnas-Treffort, mais n'ont que très rarement fourni des arguments de datation. Cependant, les chantiers urbains, à Lyon en particulier, qui restituent en grande quantité du mobilier bien stratifié, concourent à établir la chronologie de cette production. Il est désormais possible de "suivre » le service vert depuis ses premières manifestations jusqu'à son déclin, en passant par l'époque de sa plus grande diffusion. Quelques chiffres suffiront à mettre en évidence l'ampleur des importations bressanes sur le marché de la capitale régionale, par rapport aux autres catégories de vaisselle. La chronologie qui s'affine au fur et à mesure des découvertes n'est pas sans intérêt pour les chercheurs régionaux, puisque la proportion relative du service vert constitue désormais un critère de datation assez précis (cf. seconde partie de ce volume, la synthèse consacrée à la « famille B1»).

A partir d'échantillonnages aussi étoffés et d'études détaillées, il est possible de situer les premières apparitions du service vert à Lyon dès la fin du XVe s. Par exemple, dans les fouilles de l'Hôtel-Dieu, le mobilier est attribuable à la fin du XVe s. ou au début du XVIe s. : les classifications mettent alors en évidence la très faible proportion du service vert de Meillonnas (1,8 \%). Durant la première moitié du XVIe s., les produits de Meillonnas-Treffort occupent encore une place réduite $(3,5 \%)$ sur divers sites lyonnais datés par des monnaies. Mais au milieu du XVIe s. le service vert représente près de $15 \%$ du vaisselier en usage à Lyon. 
Le moment de la plus grande activité des ateliers se situe dans la première moitié du XVIIe s. Cette datation est confirmée, sur plusieurs sites lyonnais, par des séries monétaires. Ainsi le service vert représente 42,8 \% dans une cour, avenue Adolphe Max, et 30 à $40 \%$ dans la plupart des autres sites urbains reconnus jusqu'à présent.

Dès la fin du XVIIe s., le service vert se raréfie dans les ensembles céramiques étudiés. A la période charnière, entre le XVIIe et le XVIIIe s., le service vert accuse un important recul sur le marché lyonnais et ne représente que 5 à $10 \%$ de l'ensemble du matériel céramique. Enfin, dans une fosse de la rue de la Vieille, par exemple, datée du milieu du XVIIIe s., il n'y a plus que 2 tessons du service vert sur un total de 46 (4,3\%).

Parmi les autres sites d'utilisation, le château de Vuache à Vulbens (Haute-Savoie) fournit des arguments de datation complémentaires: les productions de MeillonnasTreffort (qui atteignent $73,7 \%$ de l'ensemble du mobilier, toutes périodes confondues) se situent dans une fourchette chronologique assez précise : après 1536 et avant 1612 (Raynaud 1992, pp. 106-108).

126 Compte tenu de la longue durée de la fabrication du service vert (de la fin du XVe au début du XVIIIe s.), il était intéressant de mettre en évidence l'évolution du répertoire des formes durant cette période. A titre d'exemple, ont été choisis deux ensembles bien datés et quantitativement bien représentatifs : celui du château de Vulbens (fin XVIedébut XVIIe s.) et celui de l'avenue Adolphe Max à Lyon (première moitié XVIIe s.). D'autres observations devront être faites pour renforcer la portée d'une telle comparaison entre deux sites de nature très différente. Néanmoins la diversification du catalogue des poteries de Meillonnas-Treffort est très nette tout au cours du XVIIe $s$. (cf. infra, seconde partie de ce volume, chap. 3).

$127 \mathrm{Au}$ décompte des tessons, en nombre absolu, on constate un écart important entre formes fermées et formes ouvertes. A Vulbens, sur 322 tessons identifiables (lèvres, fonds, anses), 320 correspondent à des récipients fermés (99\%). Pour l'ensemble des 859 tessons identifiables de Lyon, 62,7 \% appartiennent à des formes fermées et 37,3 \% à des formes ouvertes. Lorsqu'on prend en compte les vases restitués après collage, la différence est également frappante. A Vulbens, il y a 15 formes fermées contre 2 formes ouvertes. A Lyon en revanche, on dénombre 12 formes fermées contre 10 formes ouvertes ( $54,5 \%$ contre $45,5 \%$ ).

La mise en évidence de nuances porte également sur les types de formes, surtout en ce qui concerne les vases fermés, constitués essentiellement de récipients culinaires. Ainsi le lot le plus ancien (Vulbens) comporte des marmites à anses coudées, de petites marmites tripodes, un coquemar, autant de formes qui se rapprochent des récipients culinaires en pâte grise commune, très répandus dans la région à la fin du XVe s. et durant une partie du XVIe s. En revanche, le groupe provenant de l'avenue Adolphe Max (Lyon), plus récent, montre une forte proportion de récipients de table, dont des assiettes individuelles, guère populaires à Lyon avant le plein XVIIe s. Le catalogue du service vert semble donc suivre l'évolution des goûts de la clientèle, les potiers de Meillonnas-Treffort montrant une grande capacité d'adaptation aux modifications des pratiques culinaires et des manières de table. D'autres comparaisons entre lots de diverses périodes devront conforter ces premières constatations avant que ne soit dressée une typo-chronologie plus précise du service vert sur plus de deux siècles. 


\section{Groupe 3 : les autres céramiques glaçurées monochromes}

Les ramassages de surface livrent, outre les poteries communes sans revêtement et outre l'abondant service vert, des lots plus ou moins fournis de poteries au revêtement vitreux brillant et couvrant, parfois posé sur un engobe coloré.

Il s'agit toujours de glaçure monochrome sur une pâte de couleur rose ou rouge, rarement blanche. Sur un total de 3707 tessons, les types les plus représentés sont :

- glaçure incolore légèrement teintée de vert (13,3\% de l'ensemble),

- glaçure jaune vif posée directement sur la pâte $(26,1 \%)$; parfois cette glaçure comporte des taches vertes (115 tessons) ou des taches brunes (30 tessons),

- glaçure de couleur orange obtenue probablement par la pose du revêtement vitreux sur une couche d'engobe brun ou rouge (27,1\%),

- glaçure brun clair (13,2\%),

- glaçure marron ou brun très sombre, proche du noir (20,3\%).

Les couleurs vives, jaune et orange, dominent, tout comme les formes culinaires, en raison des qualités réfractaires des argiles utilisées et probablement de la concurrence exercée par la faïence de table, de plus en plus populaire.

Ces produits, apparemment très standardisés, se rapportent à la phase pré-industrielle de la fabrication des «terres vernissées » domestiques qui ont fait la réputation des ateliers bressans aux XVIIIe et XIXe $s$. La réponse, très circonstanciée que firent les maires de Meillonnas et de Treffort, en 1809, à «l'enquête des Préfets », pilotée par l'ingénieur Brongniart, nous renseigne sur cette activité florissante. Voici une partie de la réponse de M. Salazard, Maire de Meillonnas ${ }^{27}$ :

Depuis plus de huit siècles les fabriques de poteries sont établies dans la commune de Meillonnas; c'est de leur établissement qu'un des hameaux se nomme Les Tupinières.

Le premier potier fut, dit-on, un appelé Gamos, piémontais dont deux familles de ce nom existent et fabriquent. Les terres employées à la fabrication sont de trois qualités différentes, chacune d'elle reçoit la couverture ou vernis qui lui est propre. La première qui a une qualité supérieure est d'un jaune foncé et s'emploie sans mélange pour la fabrication des vases pour le laitage.

Sa couverture ou vernis noir se compose de $5 \mathrm{~kg}$ de mine de plomb et de $5 \mathrm{hg}$ de manganèse.

Mais pour rendre ce vernis plus brillant et meilleur, il faut y ajouter un peu de verre blanc pilé et un peu de sel marin en augmentant tant soit peu la dose de manganèse. La deuxième, moins jaune, s'emploie avec l'argile. Sur $3 / 4$ on ajoute $1 / 4$ d'argile de creusets.

Sa couverte ou vernis est jaune se compose de $5 \mathrm{~kg}$ de mine de plomb, de $5 \mathrm{hg}$ de crasse de pierre de grès prise sous la meule du maréchal taillandier. On la laisse bien sécher pour la réduire en poudre.

Pour avoir un beau jaune, la pierre de grès rouge est la meilleure. Par un autre procédé, quelques ouvriers le composent de $5 \mathrm{hg}$ de plomb et de $20 \mathrm{~g}$ de poudre jaune provenant d'un caillou qui se trouve dans le bief de Rhin à peu de distance du hameau des Tupinières. D'après tous les renseignements, le meilleur procédé est le premier, en ce que la crasse de pierre de grès contient des parties ferrugineuses qui sortent des outils passés sur la meule car, par expérience, la pierre de grès réduite en poudre ne donne pas un résultat aussi avantageux que la crasse.

La troisième, est l'argile de Treffort, qui, ainsi que pour la fabrication des creusets s'emploie sans mélange.

Sa couverte ou vernis est vert et se compose de $5 \mathrm{~kg}$ de mine et plomb et de $5 \mathrm{hg}$ de calamine. 
Toutes les terres à poterie ne reçoivent d'autre préparation que celle d'être fortement battues sur un banc avec une barre enfer.

Elles résistent au feu, mais principalement la terre jaune foncé.

La couverte vernis de poterie est simplement broyée par le moyen d'un moulin à bras et s'emploie sur des vases crus.

$\mathrm{Au}$ début du XIXe s., la production de vaisselle populaire est donc encore bien implantée, laissant penser que la gamme des produits s'est progressivement mise en place après le déclin du service vert. Ces observations plaident en faveur d'une évolution continue de l'artisanat, d'une adaptation des potiers de Meillonnas et de Treffort au marché régional, sans interruption, depuis le XIVe s., voire le XIIIe s.

Un autre aspect de la production des terres vernissées traditionnelles nous est connu, presque cinquante ans plus tard, de façon tout à fait pratique, par la découverte, sur les lieux de la faïencerie du château de Meillonnas, du tessonnier de Benoît Joly, maîtrepotier, qui racheta une partie des installations du château en 1854. Son atelier fut actif jusqu'en 1867 (Rosen 1993). On peut penser que l'ensemble découvert est représentatif de la production des autres ateliers dispersés sur le territoire de Meillonnas et de Treffort. Les poêlons à manche creux sont très fortement majoritaires (80 \%). Le reste de la production se répartit entre soupières et couvercles, jattes et coupes. Les tasses et bols sont en faible nombre. Pour information, signalons que des pièces issues de l'atelier Joly ont été retrouvées dans les couches supérieures de certains sites lyonnais (fig. 36).

\section{6 - Céramique moderne : poêlon à glaçure jaune}

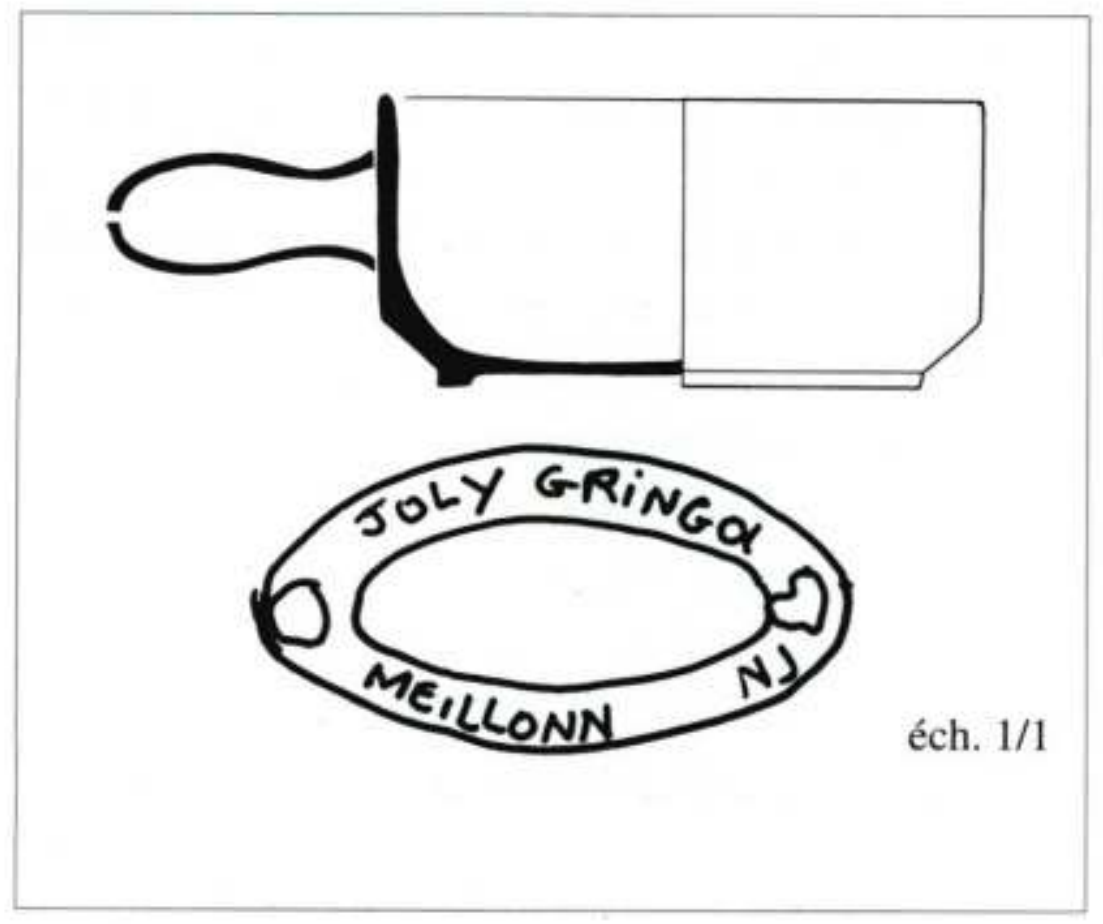

LYON, RUE TRAMASSAC

Les autres catégories de vaisselles modernes (faïence blanche, faïence fine, faïence brune, grès) sont quasi absentes de nos ramassages. On sait pourtant qu'elles étaient produites aux XVIIIe et XIXe s. à Meillonnas même, à la faïencerie du château (Rosen 
1993). Il semble donc que ces activités n'aient pas tenté les artisans répartis alentour, sans doute peu enclins à se lancer dans des innovations qui nécessitaient probablement des équipements spécifiques.

Les potiers de Meillonnas ne cherchèrent pas, non plus, à fabriquer une vaisselle pourtant très en vogue dans la région, et dans toute la France, du XVIIe au début du XIXe s. : les poteries aux motifs géométriques ou floraux réalisés aux engobes clairs sur fond sombre, ou sombres sur fond clair. Il est vrai que les poteries décorées aux engobes étaient plus particulièrement réservées à la table (assiettes, plats, jattes, écuelles, cruches) et au stockage (jarres et pots) : leur fabrication pouvait se satisfaire d'argiles relativement banales à forte teneur en calcaire. La spécificité des argiles de Meillonnas a très certainement conduit les potiers locaux à privilégier la production de poteries destinées au feu, domaine où la concurrence régionale était peut-être moins forte. Les artisans bressans contribuèrent cependant à la vaisselle décorée "aux engobes » par l'exportation de la terre blanche des carrières locales.

\section{Les céramiques architecturales}

Les ateliers de Meillonnas-Treffort n'ont pas négligé les poteries architecturales, malgré la faible quantité d'exemplaires recueillie. Mais à ces rares trouvailles s'ajoutent les sources écrites qui mettent en évidence l'ancienneté de cette activité. Ainsi, le châtelain de Treffort passe commande, entre 1307 et 1309, à un atelier de Treffort de 25000 carreaux de pavement historiés pour le château (Philippe 1925). Des exemplaires de ces carreaux glaçurés, bicolores estampés, sont conservés dans des collections particulières ${ }^{28}$ Les analyses de composition de leur pâte montrent que l'argile utilisée est la même que celle qui compose les poteries communes grises fabriquées aux Tupinières à la fin du Moyen Age. Ces constatations confirment, une fois encore, l'ancienneté et la pérennité de l'artisanat de la terre cuite à Meillonnas-Treffort.

Dans le four à service vert découvert aux Tupinières, plusieurs fragments de carreaux de poêle à décor animalier ont été retrouvés (fig. $37 \mathrm{n}^{\circ} 1$ et fig. 16). Ceux-ci conservent intact, sur le revers, l'élément d'ancrage ovale qui a permis d'en restituer la forme rectangulaire (fig. $37 \mathbf{n}^{\circ}$ 2) $(210 \times 125 \mathrm{~mm})$. Toujours du même four provient un autre fragment de carreau de poêle, cette fois-ci à décor floral et géométrique (fig. 37 $\mathbf{n}^{\circ}$ 3). Enfin, un autre exemplaire provient du lieu-dit Bon Repos, site marginal, mais important en raison de cette trouvaille unique : le décor en relief laisse deviner une monture de cavalier (fig. $37 \mathrm{n}^{\circ}$ 4). 


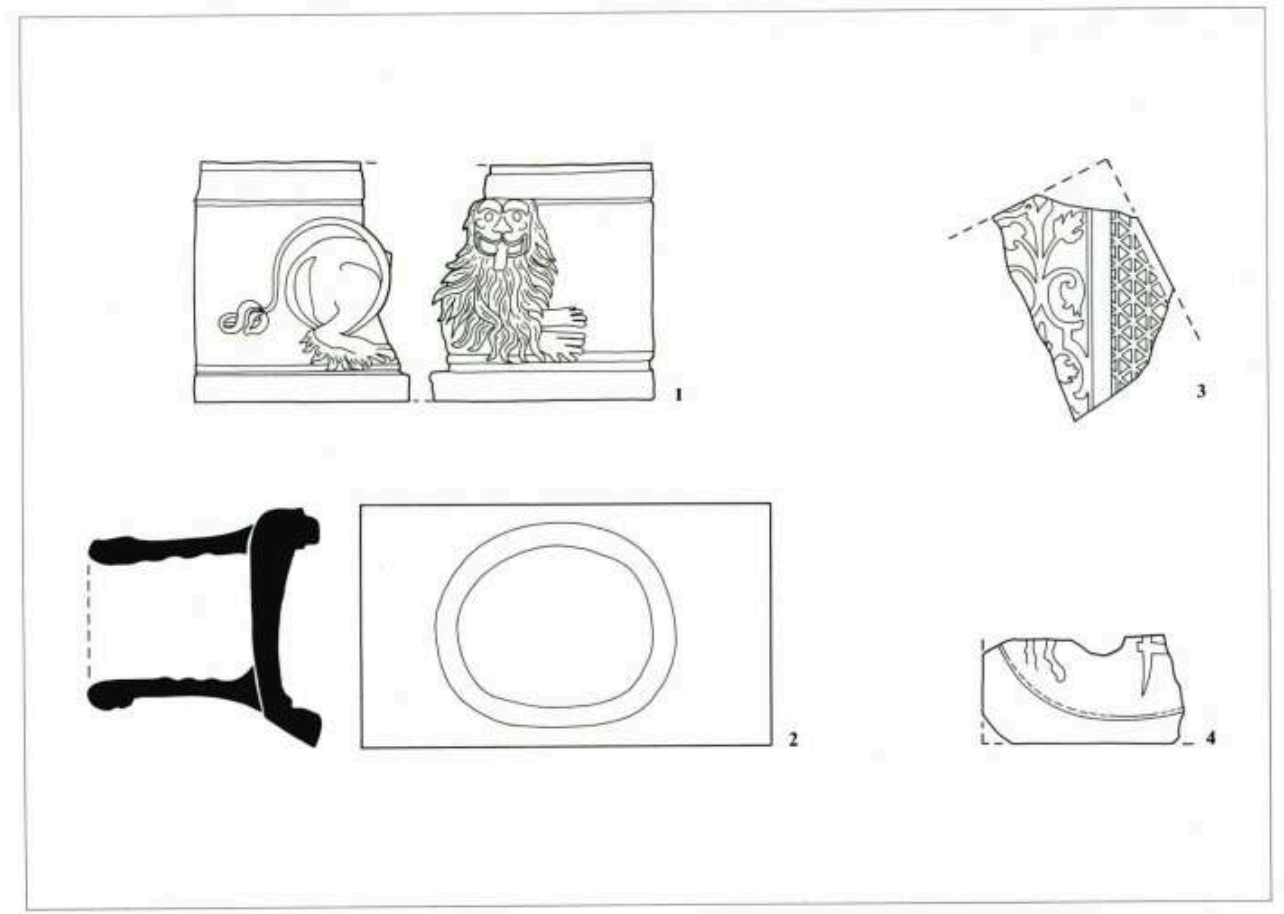

1 à 3 : Meillonas ; 4 : Bon Repos

Mais en dehors de ces données ponctuelles, les recherches réalisées n'ont pas pris globalement en compte les briquetteries et tuileries du secteur de Meillonnas, appelées localement « carronières ». Les mentions textuelles anciennes (XIVe-XVe s.) ont retenu notre attention au début de notre enquête, mais nous avons très vite dû convenir qu'il n'y avait pas de relation entre la localisation des carronières et celle des poteries. Le travail sur les terres cuites architecturales bressanes est en effet un domaine à part entière; notamment les carreaux de pavement médiévaux mériteraient d'être réexaminés à la lumière des inventaires réalisés dans des régions voisines (ChampagneArdennes, Franche-Comté).

B. M.-P.

\section{La répartition des ateliers d'après l'enquête de terrain}

141 L'enquête de terrain a essentiellement consisté en ramassages de surface aussi systématiques que possible. Les parcelles cultivées, à forte proportion céréalière, offrent aux prospecteurs de larges surfaces labourées, d'accès relativement aisé (fig. 38). 


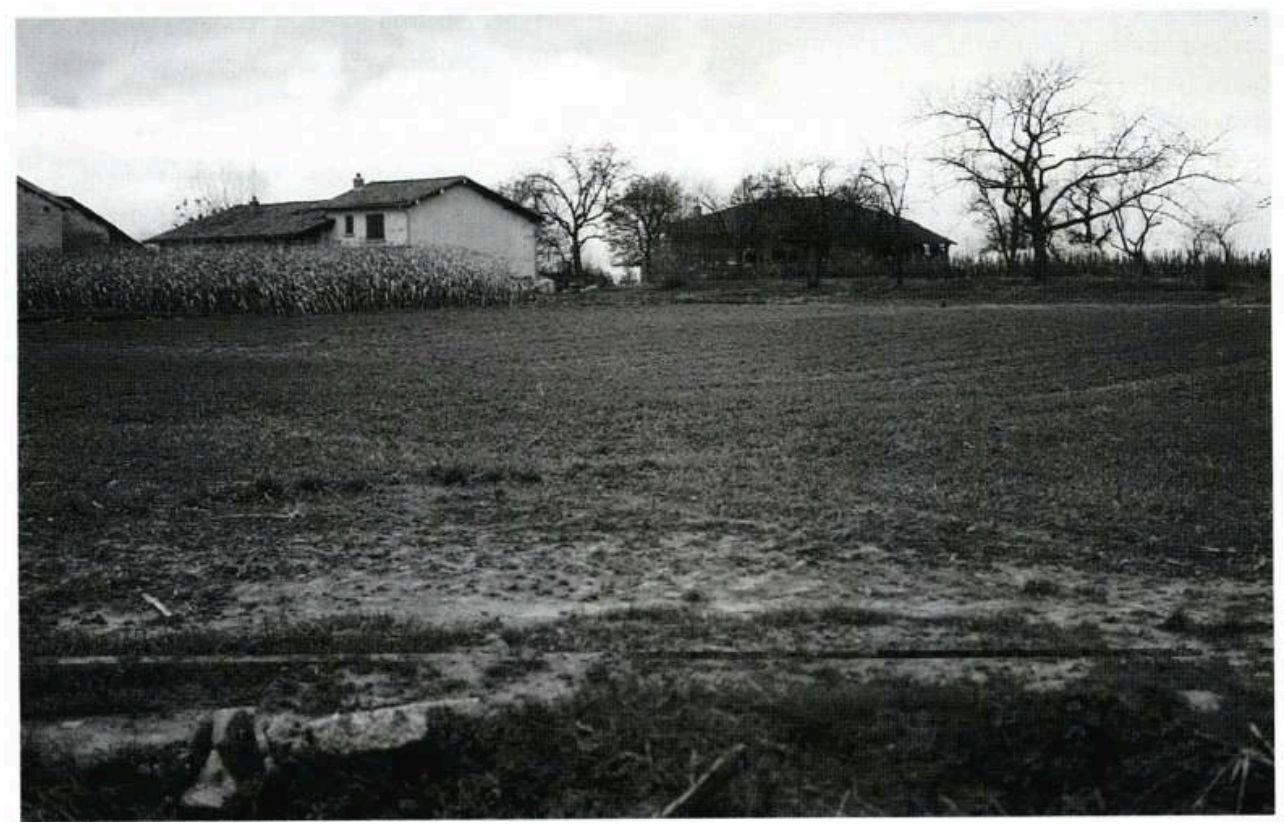

Les ramassages, qui représentent quelques vingt-cinq hectares explorés et 12860 tessons collectés, ont été effectués sans maillage préalable, mais en décrivant des allées et venues régulières dans le sens des labours. La qualité de l'équipe de ramasseurs, leur expérience de terrain et leur connaissance du matériel assurent à ces collectes une certaine homogénéité par des conditions de travail aussi constantes que possible. Pourtant, des difficultés habituelles d'accès aux terrains (prairies, taillis, clôtures) limitent la connaissance des zones réputées positives, faussant en partie l'image restituée à partir des traces au sol, aux abords des ateliers.

Une part des informations provient aussi de l'enquête menée auprès des habitants des hameaux visités. Mais les renseignements obtenus restent très ponctuels et l'on ne saurait prétendre à une enquête orale exhaustive.

Les prospections menées à Meillonnas et Treffort n'avaient pas pour seul objectif de localiser le (ou les) atelier(s). Elles cherchaient aussi à distinguer, à partir de la répartition des tessons et de leur qualité, les phases d'activité et la nature de la production céramique dans ce secteur. Les résultats en sont reportés sur plan cadastral: un jeu de trames rend approximativement compte de la proportion de tessons ramassés par rapport à la surface prospectée. Les zones de ramassage sont signalées par la lettre $\mathrm{T}$ (tessonnière) affectée d'un numéro d'ordre arbitraire. La répartition des tessons collectés entre les trois groupes principaux (cf. supra), qui correspondent aux trois étapes chronologiques de l'artisanat, est également traduite graphiquement sur ces cartes, permettant d'apprécier ainsi le déplacement des centres de production sur le territoire des communes au fil du temps. Les mêmes cartes regroupent les localisations d'ateliers connues d'après les textes, le cadastre napoléonien ou les renseignements oraux.

Le choix préalable des zones prospectées a principalement reposé sur les indications fournies par l'enquête d'archives menée en parallèle. La plupart du temps, les mentions textuelles (potiers, ateliers, fours) se sont traduites dans les faits, nous amenant presque toujours à travailler à proximité des principaux hameaux qui constituaient 
autant de pôles artisanaux. Parfois il n'y a pas eu, apparemment, coïncidence entre les archives et le terrain et les indices de production n'ont pas pu être localisés. Notamment les mentions d'ateliers sur la commune de Saint-Etienne-du-Bois n'ont pu être matérialisées.

Les hameaux (une dizaine sur l'ensemble des deux communes) sont de taille assez constante : deux à quatre exploitations agricoles avec leurs dépendances, relativement groupées et desservies par un réseau très dense de routes et chemins. Probablement, certaines des bâtisses encore en élévation ont abrité des ateliers et des fours de la fin du Moyen Age ou de l'époque moderne. Nous n'en avons retrouvé que peu de vestiges. Le remploi fréquent de briques très calcinées, ayant visiblement appartenu à des parois de four, en garde le souvenir. Les noms de ces hameaux sont souvent formés à partir d'un patronyme. Celui-ci renvoie parfois à des familles de potiers répertoriées dans les textes, comme Gaillard, Girard, Groboz.

Des recherches effectuées sur les sites "mineurs ", là où les ramassages de surface n'ont fourni que peu de matériel ou des résultats négatifs, ne seront pas détaillées et se limiteront à une rapide description.

Le lieu-dit Bon Repos (commune de Viriat ; T 2) avait été signalé dès 1985 ; on avait trouvé des céramiques du type service vert et observé l'existence d'une carronière (tuilerie) dont une partie de la chambre de cuisson restait encore visible ${ }^{29}$ Lors de la prospection, le matériel recueilli dans un champ en face de la maison d'habitation ne s'est pas avéré significatif et, surtout, il était relativement rare (50 fragments), au point qu'il n'est pas envisageable de considérer ce site comme un lieu de production. Le service vert (groupe 2) est présent avec 41 tessons seulement, parmi lesquels il a été possible d'identifier 9 formes fermées du type marmite et 7 formes ouvertes (assiettes et écuelles). Plus intéressante, pour l'histoire des productions de service vert, est la trouvaille d'un carreau de poêle avec un décor en relief (fig. $37 \mathrm{n}^{\circ}$ 4). Six autres tessons se rangent dans le groupe 1 (céramiques sans revêtement), mais il s'agit de fragments non identifiables. Les céramiques modernes (groupe 3), ne sont représentées que par 3 tessons de forme fermée à glaçure marron.

Sur le hameau de Mas Gaillard (commune de Treffort) la prospection a été tout à fait négative. Pourtant les archives notariales signalent, fin XVIIe s., à deux reprises, la présence de potiers dans ce hameau.

150 Les résultats obtenus ont été également fort décevants au lieu-dit Mas Tabouret (commune de Treffort; T 27) où étaient signalées d'anciennes carrières d'extraction d'argile qu'on pensait situées à côté des ateliers. Malheureusement la majorité des champs alentour est en prairie gênant la prospection. Le seul endroit où des tessons auraient pu être ramassés est un champ labouré, isolé, en face d'une ancienne carrière, mais la moisson a été maigre (150 tessons). Le service vert est relativement bien représenté (60 fragments) par la présence d'une dizaine de rebords d'assiettes ou de marmites, ainsi que de 7 anses, 3 boutons de réchaud et le pied d'un récipient tripode. Les céramiques tardives du groupe 3 sont également nombreuses : 70 fragments parmi lesquels domine la glaçure jaune ou marron. La céramique du groupe 1 (sans revêtement) est en revanche très rare : 12 tessons de forme inidentifiable.

Le site de Plantaglay (commune de Meillonnas) est mentionné avec « four et aire » au XVIIe s. et un atelier est signalé au cadastre de 1826. Il peut cependant être considéré comme site mineur (utilisateur plus que producteur), étant donné le petit nombre de 
tessons recueillis lors de la prospection. Sur 142 fragments, 88 sont modernes (glaçure jaune, orange ou brun correspondant au groupe 3). Les céramiques du groupe 1 et celles du service vert (groupe 2) sont minoritaires. Parmi ces dernières, il n'a été possible d'identifier que 2 lèvres de marmite et 2 de forme ouverte (une assiette, une écuelle). La prospection sur le site de Sanciat (commune de Meillonnas) a également été décevante. Soixante seize tessons très dispersés ont été recueillis aux environs du hameau, et sans que l'on puisse déterminer un point de plus forte concentration. Cet ensemble restreint de matériel comprend une douzaine de tessons du groupe 1, 40 tessons du groupe 2, mais non identifiables, et 24 fragments qui se rangent dans le groupe 3.

En revanche, les autres sites prospectés ont fourni des résultats très positifs et très significatifs. Il s'agit essentiellement de cinq hameaux très proches, bien qu'appartenant à deux communes distinctes : Mas Girard, Mas Groboz et Mas Guy sur la commune de Treffort; La Razza et les Tupinières sur la commune de Meillonnas. Les terrains labourés ont restitué plus d'un millier de tessons de poteries à Mas Guy, Mas Groboz et à La Razza. Le hameau des Tupinières, enfin, s'est avéré le plus important des sites prospectés avec 6877 tessons (fig. 39 et tableau 2).

39 - Localisation des points de ramassage (T 1 à T 33) sur les communes de Meillonnas et de Treffort et proportion relative des trois types de céramique collectés pour les cinq hameaux étudiés

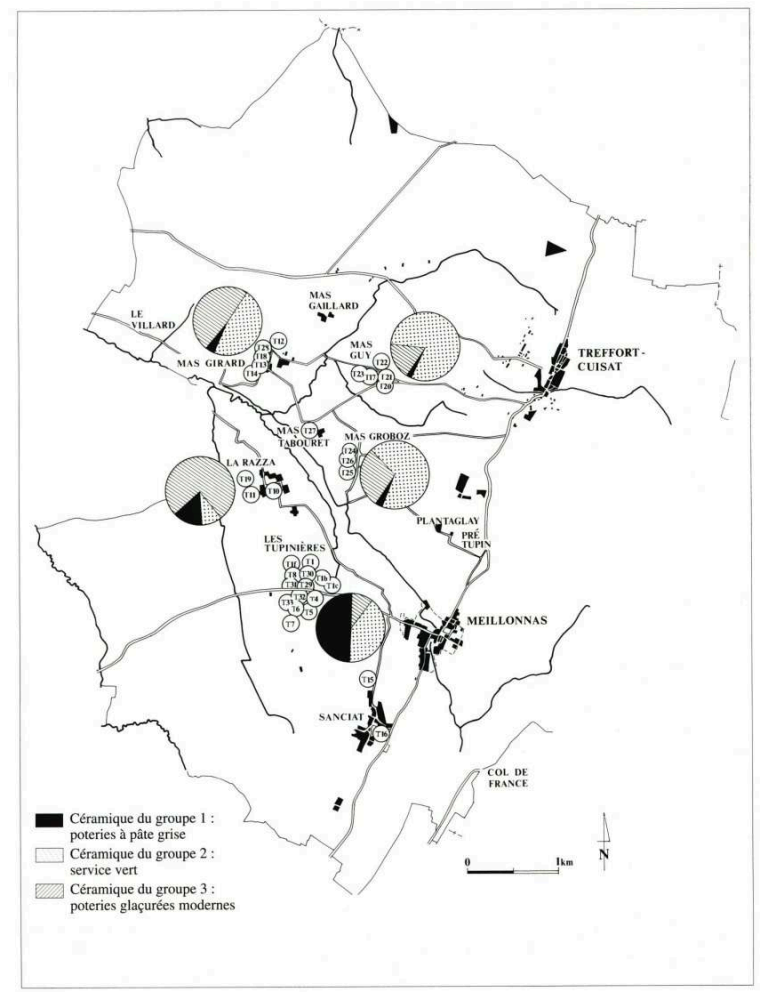


Tableau 2. Localisation des zones de rejets d'ateliers

\begin{tabular}{|c|c|c|c|}
\hline $\begin{array}{c}\text { Point de } \\
\text { ramassage }\end{array}$ & Commune & Lieu-dit & Parcelles \\
\hline $\mathrm{T} 1$ & Meillonnas & Tupinieres nord & $\mathrm{ZB}, 76 \mathrm{c}$ \\
\hline $\mathrm{T} 1 \mathrm{~B}$ & Meillonnas & Tupinières nord & $\mathrm{ZB} .71$ bet $70 \mathrm{~b}$ \\
\hline TI C & Meillonnas & Tupinieres nord & $\mathrm{ZB}, 69 \mathrm{~b}$ \\
\hline T1F & Meillonnas & Tupinières nord & $\mathrm{ZB}, 76 \mathrm{~b}$ \\
\hline $\mathrm{T} 2$ & Viriat & Bon repos & \\
\hline $\mathrm{T} 3$ & Meillonnas & Plantaglay & $\mathrm{ZD}, 20$ \\
\hline $\mathrm{T} 4$ & Meillonnas & Tupinières sud & ZK, 129 et 130 \\
\hline T5 & Meillonnas & Tupinières sud & ZK, 151 (est) \\
\hline T6 & Meillonnas & Tupinières sud & ZK, 150 \\
\hline $\mathrm{T} 7$ & Meillonnas & Tupinières sud & \\
\hline T8 & Meillonnas & Tupinières sud & $\mathrm{ZB}, 76 \mathrm{a}$ \\
\hline T9 & Meillonnas & La Razza & $\mathrm{ZA}, 85 \mathrm{~b}$ \\
\hline T 10 & Meillonnas & La Razza & $\mathrm{ZA}, 46$ \\
\hline $\mathrm{T} 11$ & Meillonnas & La Razza & $\mathrm{ZA}, 69 \mathrm{a}$ et $\mathrm{b}$ \\
\hline T 12 & Treffort & Mas Girard & EI, 1387 \\
\hline T 13 & Treffort & Mas Girard & El, 118 et 121 \\
\hline T 14 & Treffort & Mas Girard & E1, 125 \\
\hline T 15 & Meillonnas & Sanciat & \\
\hline T 16 & Meillonnas & Sanciat & \\
\hline T 17 & Treffort & Mas Guy & $\mathrm{E} 3,810$ \\
\hline T 18 & Treffort & Mas Girard & $\mathrm{El}, 107$ \\
\hline Т 19 & Treffort & Mas Guy & E3, 809 \\
\hline $\mathrm{T} 20$ & Treffort & Mas Guy & E3, 808 \\
\hline $\mathrm{T} 21$ & Treffort & Mas Guy & E3, 805 \\
\hline T 22 & Treffort & Mas Guy & $\mathrm{E} 3,791,792,793$ \\
\hline $\mathrm{T} 23$ & Treffort & Mas Guy & E3, 811 à 814 \\
\hline T 24 & Treffort & Mas Groboz & E2, 438 \\
\hline T25 & Treffort & Mas Groboz & E2, 440 \\
\hline $\mathrm{T} 26$ & Treffort & Mas Groboz & E2, 439 \\
\hline $\mathrm{T} 27$ & Treffort & Mas Tabouret & E2, 279 \\
\hline $\mathrm{T} 28$ & Treffort & Mas Girard & $\mathrm{E}, 104$ \\
\hline T 29 & Meillonnas & Tupinières nord & Four Giroud \\
\hline т 30 & Meillonnas & Tupinières nord & ZB. $76 \mathrm{c}$ \\
\hline $\mathrm{T} 31$ & Meillonnas & Tupinières nord & voieries \\
\hline $\mathrm{T} 32$ & Meillonnas & Tupinières sud & ZK, 184 \\
\hline T 33 & Meillonnas & Tupinières sud & $\mathrm{ZK}, 181$ \\
\hline
\end{tabular}

\section{Mas Girard (commune de Treffort)}

Les textes du XVIIe s. (archives notariales) signalent plusieurs potiers à Mas Girard. Six membres de la famille Girard y exerçaient, mais leur implantation n'est pas localisée précisément. Le plan cadastral de 1826 indique un four dans le hameau. Il est à noter, par ailleurs, que le patronyme Girard est mentionné dès le XVe s. au hameau des Tupinières.

Au total 3010 tessons ont été recueillis, répartis en trois points principaux (fig. 40). Vers le nord, dans un grand champ labouré, une bonne densité de trouvailles se concentre près de la route qui limite celui-ci au sud ( $\mathrm{T} 12$ ). Au centre, d'abord dans un jardin ( $\mathrm{T}$ 18) et, ensuite, dans la terre provenant de l'excavation en vue d'une nouvelle construction ( $\mathrm{T}$ 28). Au sud, un grand nombre de tessons ont été observés dans des jardins proches des maisons et en face de deux anciens fours signalés par un habitant (T 13). Un dernier point de forte concentration a été repéré dans un champ isolé (T 14). Son éloignement de toute construction et le manque de matériel dans les environs laissent imaginer qu'il s'agit de matériaux rapportés ici pour les besoins de la mise en culture. 


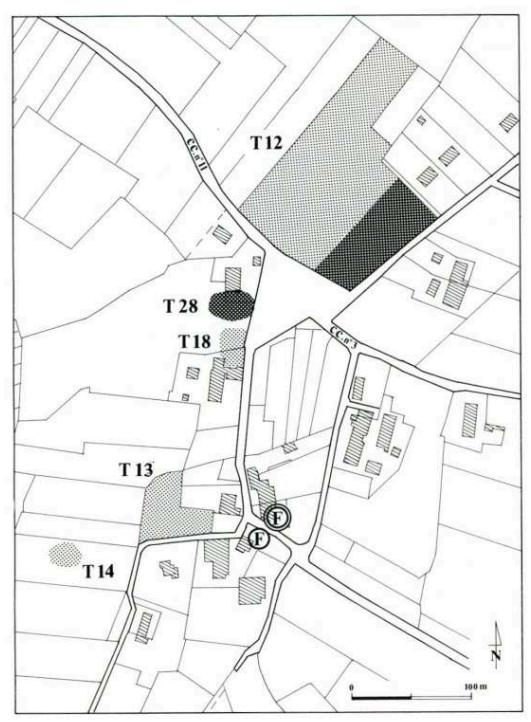

(F) F : Four connu par les textes

(F) F : Four indiqué par les habitants

Densité des tessons collectés : faible

Densité des tessons collectés : moyenne

Densité des tessons collectés : forte

Bâti

Localisation des parcelles prospectées

En ce qui concerne les productions céramiques, on constate que les fragments du service vert (groupe 2) et ceux du groupe 3 (glaçuré monochrome) sont très répandus. Les tessons plus anciens et sans revêtement (groupe 1), qui atteignent au maximum $5,9 \%$ en $\mathrm{T} 12$, sont beaucoup plus rares. Mais les pourcentages ne sont pas uniformes sur chaque point de ramassage. Les céramiques modernes (groupe 3) sont massivement représentées en $\mathrm{T} 12$ et en $\mathrm{T}$ 18, tandis que le service vert domine largement ailleurs ( $\mathrm{T}$ 13, $\mathrm{T} 14$ et $\mathrm{T} 28$ ) (fig. 41 et tableau 3). 


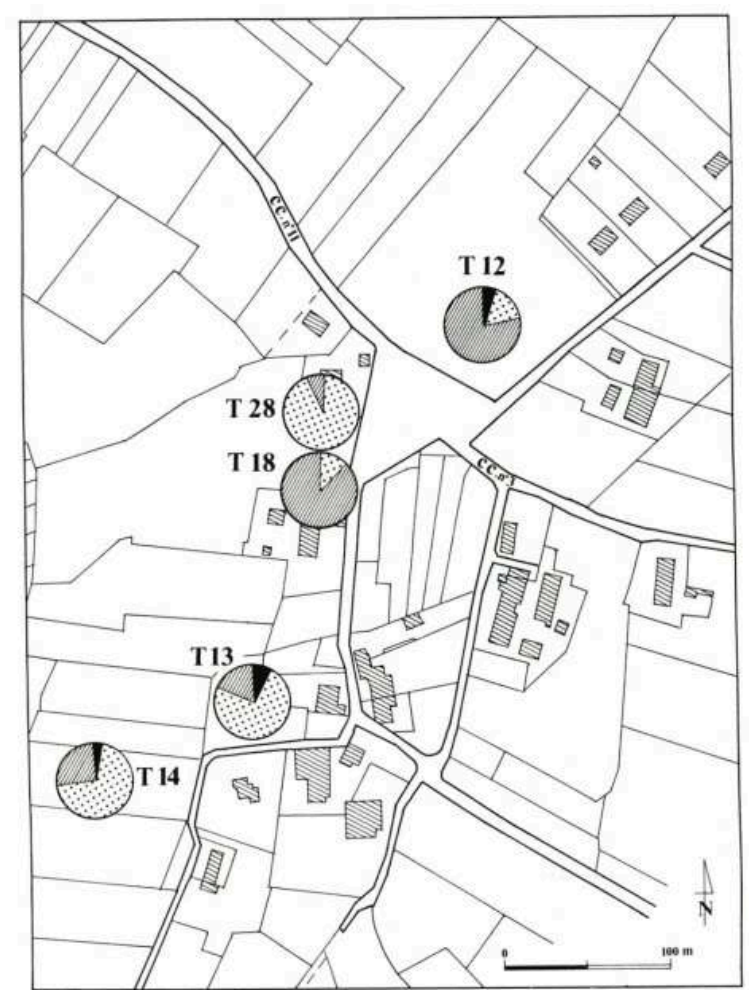

Proportion relative des trois types de céramique collectés (cf. légende fig. 39)

Tableau 3. Résultats des ramassages effectués sur les sites de Mas Girard

\begin{tabular}{|l|c|c|c|c|c|c|c|c|c|c|}
\hline \multirow{2}{*}{} & \multicolumn{2}{|c|}{ T 12 } & \multicolumn{2}{|c|}{ T 13 } & \multicolumn{2}{c|}{ T 14 } & \multicolumn{2}{c|}{ T 18 } & \multicolumn{2}{c|}{ T 28 } \\
\cline { 2 - 11 } & tessons & $\%$ & tessons & $\%$ & tessons & $\%$ & tessons & $\%$ & tessons & $\%$ \\
\hline groupe 1 & 79 & 5,9 & 47 & 5,1 & 6 & 1,9 & - & - & - & - \\
\hline groupe 2 & 239 & 17,7 & 671 & 72,9 & 215 & 68,5 & 14 & 12,3 & 288 & 91,7 \\
\hline groupe 3 & 1030 & 76,4 & 202 & 22,0 & 93 & 29,6 & 100 & 87,7 & 26 & 8,3 \\
\hline TOTAL & $\mathbf{1 3 4 8}$ & $\mathbf{9 2 0}$ & & $\mathbf{3 1 4}$ & & $\mathbf{1 1 4}$ & & $\mathbf{3 1 4}$ \\
\hline
\end{tabular}

Le groupe 1 inclut surtout des pâtes rouges et aucune pâte grise; contrairement à d'autres points de ramassage, il peut s'agir ici de fragments de céramique moderne à l'état de biscuit de dégourdi. Il n'existe d'ailleurs aucun élément identifiable typique de la production du bas Moyen Âge.

La céramique du groupe 2 , là où elle est majoritaire, comprend surtout des pâtes blanches : sauf en T 28 où les pâtes légèrement rosées atteignent $24,3 \%$ du total.

Les comptages effectués mettent en évidence un très fort pourcentage de biscuits appartenant à des vases n'ayant pas reçu la cuisson finale ; surtout en $\mathrm{T} 13$ où le biscuit atteint $34,4 \%$ du total.

Quant aux formes identifiables, on constate, dans tous les points de ramassage où le service vert est majoritaire une prédominance des formes fermées qui constituent environ les 3/4 des fragments identifiables. La marmite globulaire avec un col court légèrement évasé domine incontestablement (fig. 18) tandis que les cruches sont rarissimes. Parmi les formes ouvertes figurent surtout les assiettes (fig. 27) mais les 
écuelles ne manquent pas (fig. 28) ainsi que les petits poêlons à manche creux (fig. 26 $\mathrm{n}^{\circ} \mathbf{1}$ et 2 ).

Parmi les formes rares on peut souligner surtout la présence de plusieurs fragments de creusets, pratiquement absents sur les autres sites.

Dans le groupe 3 (dominant en $\mathrm{T} 12$ et $\mathrm{T}$ 18) les glaçures jaune ou orange sont largement majoritaires. Elles sont surtout appliquées sur des formes de poêlons à manche creux.

163 Sur la base de ces observations, il n'est pas trop hasardeux d'identifier ce hameau comme un site de potiers : le mobilier en surface est très abondant, on note la présence d'un bloc d'argile informe mais cuite en $\mathrm{T}$ 12, d'un raté de cuisson avec de la glaçure éclatée en T 28 et partout de quelques fragments de briques ou carreaux brûlés qui pourraient avoir appartenu à la structure d'un four. Les ateliers semblent relativement récents, puisque la céramique du groupe 1 est extrêmement rare sinon absente. Ils ont démarré avec la production du service vert (XVIe-XVIIe s.) et apparemment ont continué à produire à une époque plus récente (XIXe s.).

\section{Mas Groboz (commune de Treffort)}

Les textes sont peu prolixes sur le Mas Groboz, mais plusieurs potiers (non localisés) dénommés Groboz exerçaient au XVIIe s. à Treffort et/ou Meillonnas.

Dans ce hameau, dont l'habitat est assez dispersé, les ramassages ont procuré 1087 tessons, concentrés surtout en T 25 et en T 26 , sur le bord du chemin qui mène vers les habitations. Ailleurs, d'autres points de prospection possible ont été repérés, mais s'agissant de jardins clos, les tessons de céramiques n'ont pu être ramassés (fig. 42). 


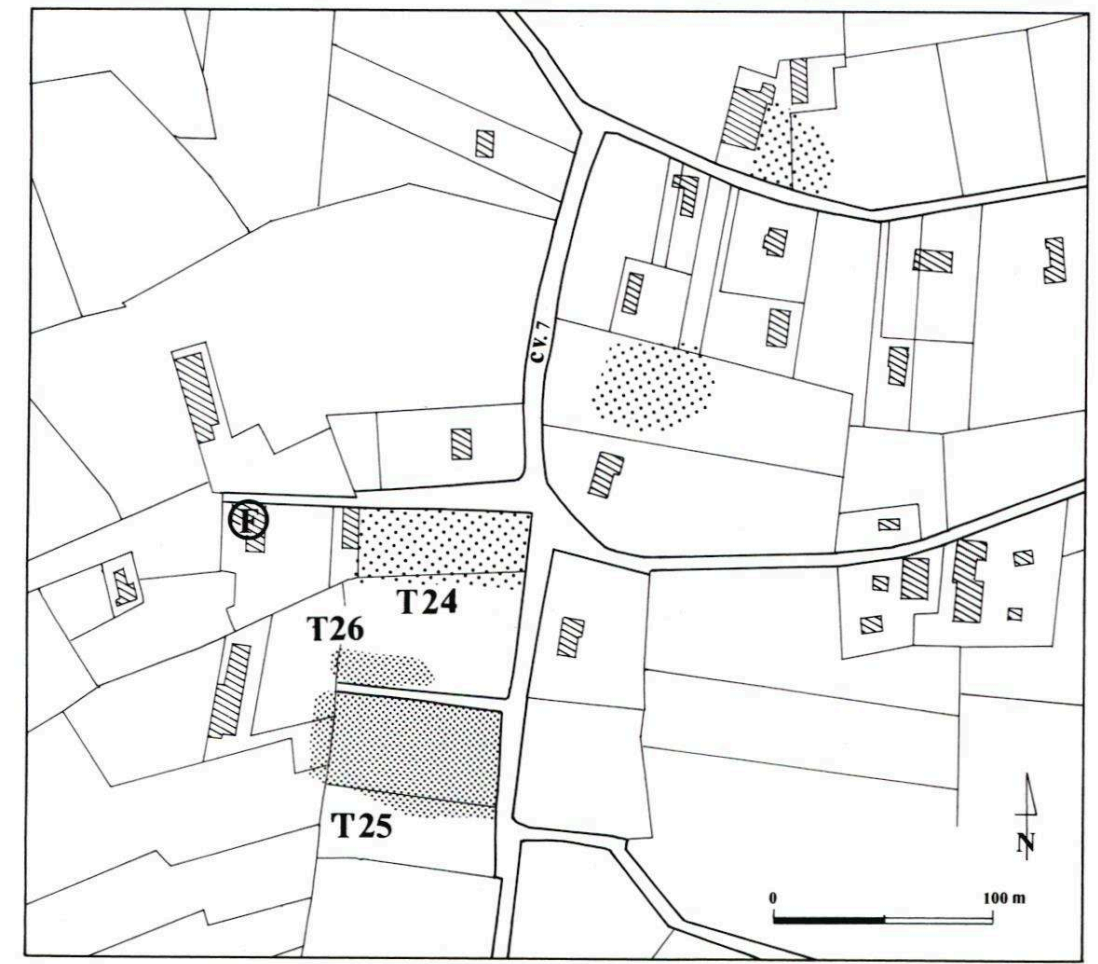

Localisation des parcelles prospectées (cf. légende fig. 40)

Comme sur le site précédent, la catégorie des céramiques sans revêtement est peu représentée. Le groupe du service vert domine largement, suivi de très loin, parfois, comme en T 26, par les diverses glaçures modernes réunies dans le groupe 3 (fig. 43 et tableau 4). 


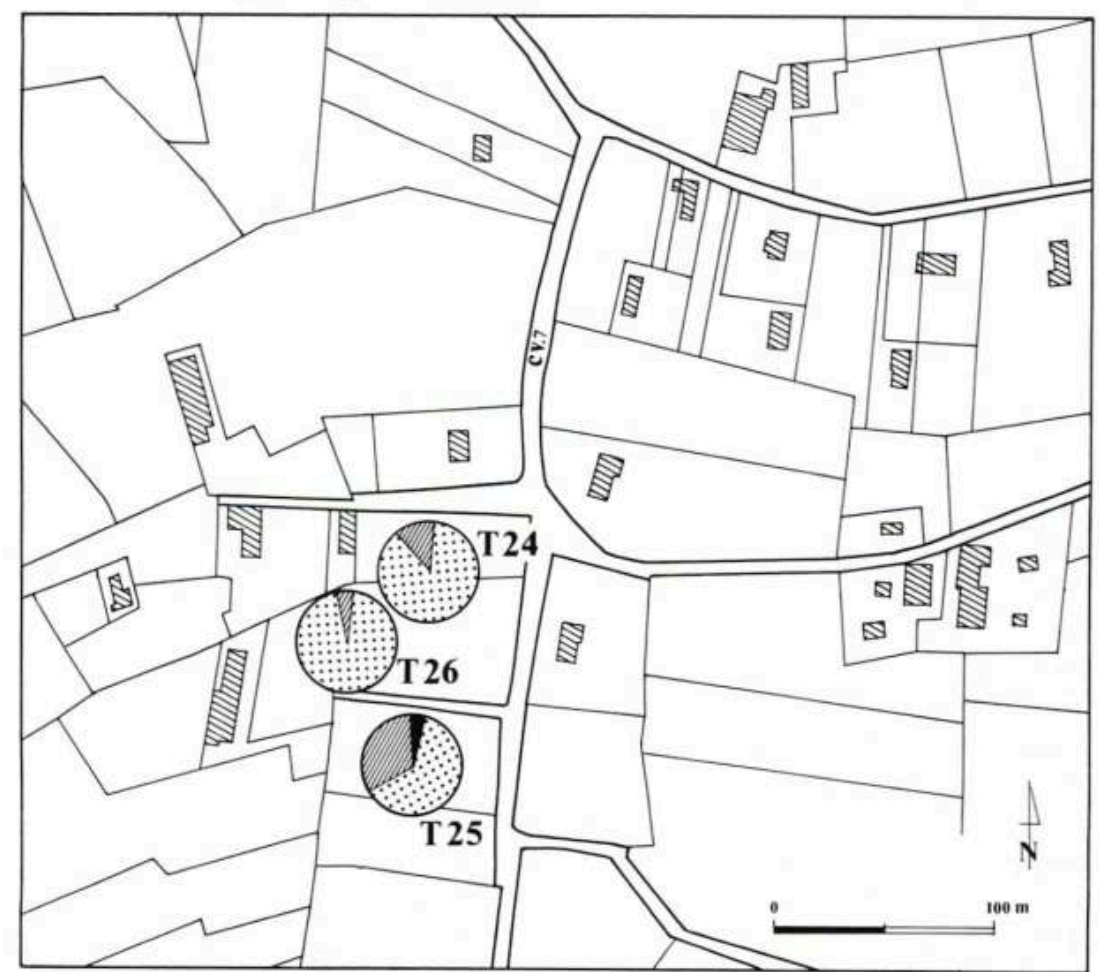

Proportion relative des trois types de céramique collectés (cf. légende fig. 39)

Tableau 4. Résultats des ramassages effectués sur les sites de Mas Groboz

\begin{tabular}{|c|c|c|c|c|c|c|}
\hline & \multicolumn{2}{|c|}{ T 24 } & \multicolumn{2}{c|}{ T 25 } & \multicolumn{2}{c|}{ T 26 } \\
\cline { 2 - 7 } & tessons & $\%$ & tessons & $\%$ & tessons & $\%$ \\
\hline groupe 1 & - & - & 36 & 4,3 & - & - \\
\hline groupe 2 & 53 & 84,2 & 522 & 61,8 & 178 & 98,9 \\
\hline $\begin{array}{c}\text { groupe 3 } \\
\text { TOTAL }\end{array}$ & 10 & 15,8 & 286 & 33,9 & 2 & 1,1 \\
\hline 63 & & $\mathbf{8 4 4}$ & & $\mathbf{1 8 0}$ & \\
\hline
\end{tabular}

Les rares tessons du groupe 1 sont en pâte rouge ou en pâte claire et, d'après leur forme, ils ne sont pas, assurément, du Moyen Âge.

Le service vert (groupe 2) comprend surtout des pâtes blanches : 90,6 \% en T 24, 85,1 \% en T 25 et $95 \%$ en T 26 . Lorsque la pâte est rosée, elle est d'une couleur plus foncée que sur les autres sites. Les tessons en biscuit sont aussi nombreux sur les trois points de ramassage avec une moyenne de $20 \%$. Parmi les formes identifiables du service vert, la seule largement attestée est celle de la marmite globulaire avec un col court (fig. 18) ; 
les assiettes sont également nombreuses. On dénombre quelques écuelles et des fragments de fonds tripodes.

Les céramiques modernes (groupe 3), nombreuses en T 25, reflètent tous les types de glaçure considérés : incolore tendant au vert, jaune, orange, brun et marron.

D'autres indices de la présence d'ateliers de potiers sont à signaler pour ce hameau : plusieurs tessons surcuits (ratés de cuisson?) et des briques ou tuiles fortement calcinées ayant pu appartenir à des parois de four.

\section{Mas Guy (commune de Treffort)}

Les actes notariés du XVIIe s. (cf. supra note 20) signalent plusieurs individus exerçant le métier de potier. En 1679 un atelier avec four est explicitement mentionné dans ce hameau.

Les terrains favorables, fraîchement labourés, ont permis de prospecter largement et fructueusement sur ce site, notamment aux environs d'une maison dont les propriétaires ont signalé le souvenir d'un ancien four situé à l'emplacement d'une grange actuelle. Les plus fortes densités de céramiques ont été constatées dans les champs voisins, tandis qu'on notait une diminution de la densité vers le nord et l'ouest (fig. 44).

\section{4 - Treffort, Mas Guy}

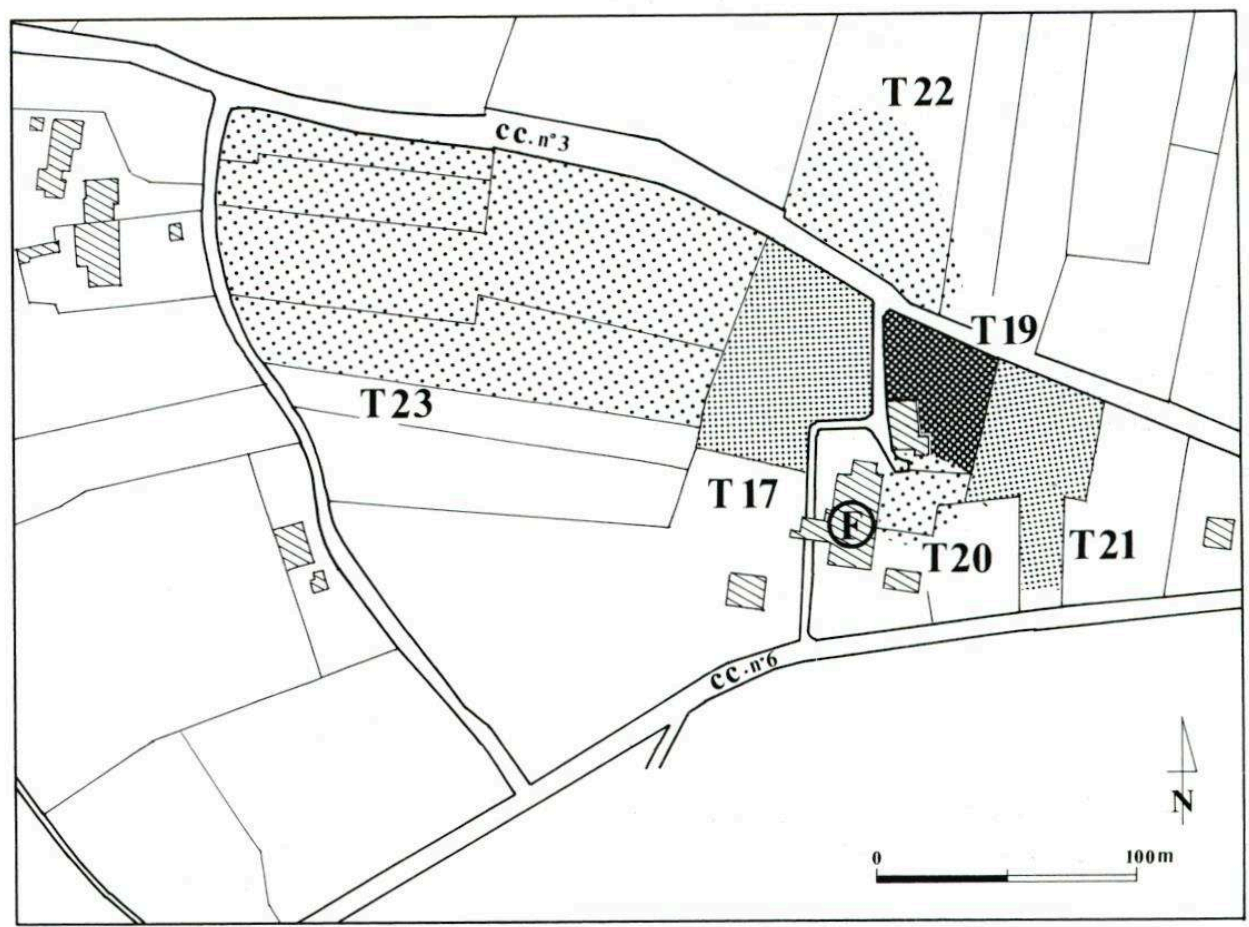

Localisation des parcelles prospectées (cf. légende fig. 40)

Ici, le service vert, domine, dans toutes les parcelles prospectées $(79,5 \%$ sur l'ensemble), tandis que les autres poteries glaçurées, plus récentes, sont minoritaires et probablement issues d'habitats plus que de tessonniers d'ateliers (17\%) (fig. 45 et tableau 5). 


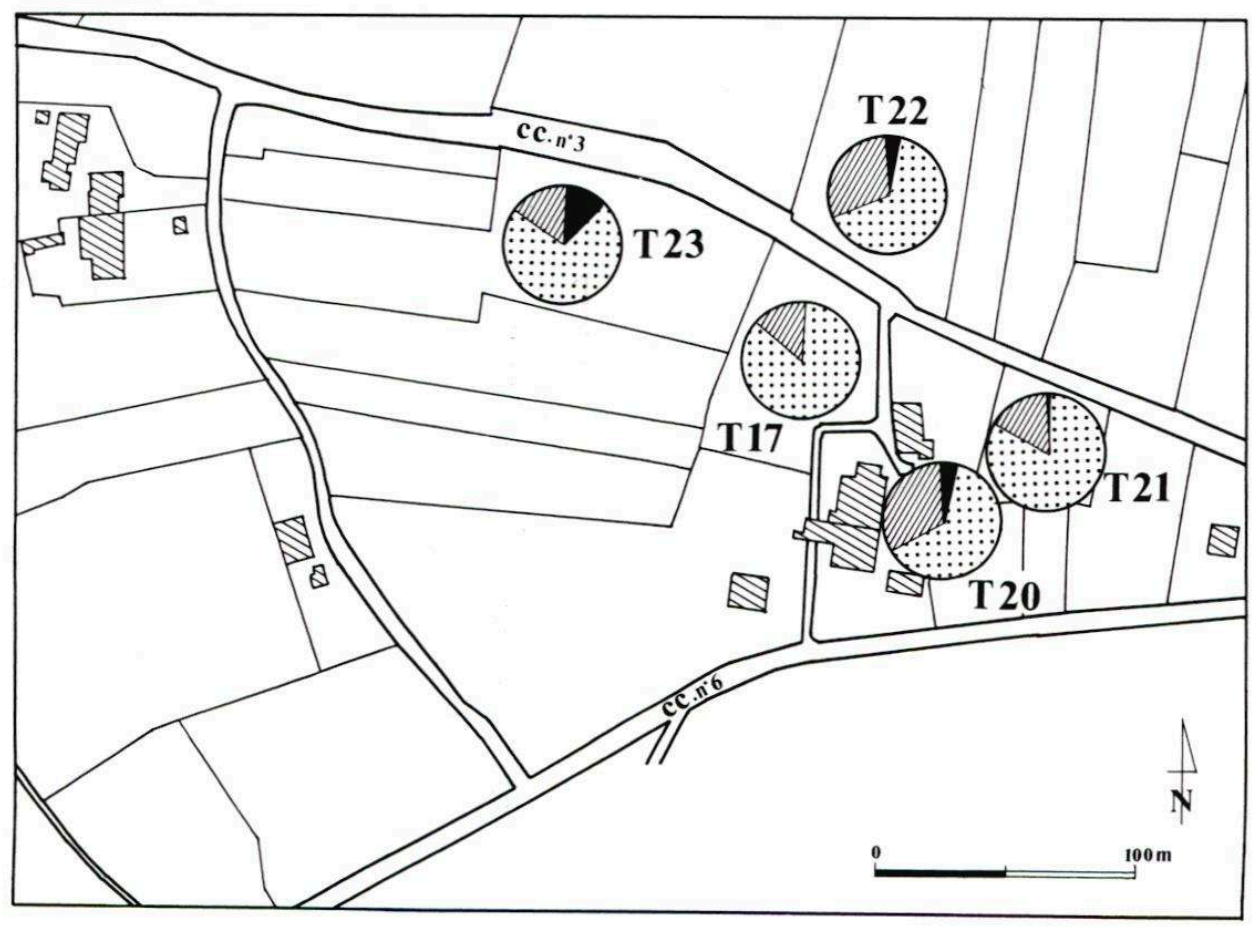

Proportion relative des trois types de céramique collectés (cf. légende fig. 39)

Tableau 5. Résultats des ramassages effectués sur les sites de Mas Guy

\begin{tabular}{|l|c|c|c|c|c|c|c|c|c|c|c|c|}
\hline & \multicolumn{2}{|c|}{ T 17 } & \multicolumn{2}{|c|}{ T19 } & \multicolumn{2}{c|}{ T 20 } & \multicolumn{2}{c|}{ T 21 } & \multicolumn{2}{c|}{ T 22 } & \multicolumn{2}{c|}{ T 23 } \\
\cline { 2 - 14 } & tessons & $\%$ & tessons & $\%$ & tessons & $\%$ & tessons & $\%$ & tessons & $\%$ & tessons & $\%$ \\
\hline groupe 1 & & & & & 1 & 3,0 & 2 & 1,0 & 1 & 2,1 & 46 & 9,0 \\
\hline groupe 2 & 547 & 85,7 & 30 & 55,6 & 21 & 63,7 & 179 & 84,0 & 32 & 69,6 & 392 & 76,9 \\
\hline groupe 3 & 91 & 14,3 & 24 & 44,4 & 11 & 33,3 & 32 & 15,0 & 13 & 28,3 & 72 & 14,1 \\
\hline TOTAL & $\mathbf{6 3 8}$ & & $\mathbf{5 4}$ & $\mathbf{3 3}$ & $\mathbf{2 1 3}$ & & $\mathbf{4 6}$ & $\mathbf{5 1 0}$ \\
\hline
\end{tabular}

Les céramiques du groupe 1 sont rarissimes, comme du reste dans tous les hameaux de la commune de Treffort. Le seul point de ramassage qui en ait restitué un petit nombre est T $23: 34$ fragments en pâte brun clair et cinq tessons en pâte grise se rattachent probablement aux productions du Moyen Age, mais il peut s'agir de rejets d'habitats.

Il est en revanche assuré qu'il s'agit ici d'un lieu de production du service vert (groupe 2) avec un total de 1201 fragments recueillis, tous concentrés aux environs de maisons d'habitation actuelles. Ajoutons qu'ont été retrouvés une vingtaine de tessons surcuits et quelques briques fortement brûlées. Les comptages effectués pour les points ayant fourni le plus grand nombre de tessons montrent que les pâtes blanches sont les plus nombreuses, sauf en $\mathrm{T} 23$ où l'on constate un fort pourcentage de pâtes de couleur légèrement rose.

D'après l'inventaire établi sur les fragments identifiables, la production de Mas Guy ne s'écarte pas de celle des environs. Les formes fermées sont majoritaires par rapport aux formes ouvertes: en $\mathrm{T} 17,151$ contre 84 ; en $\mathrm{T} 21,66$ contre 19 ; en $\mathrm{T} 23,56$ formes 
fermées contre 36 ouvertes. La marmite est la forme la plus répandue, mais exclusivement le type globulaire avec col court. Sur un total de 64 fragments de marmites identifiés, aucun n'évoque d'autres récipients à cuire (marmite globulaire sans col, marmite ovoïde, ou encore de petite taille comme le coquemar). Les assiettes sont, comme toujours, les mieux représentées parmi les formes ouvertes. Les écuelles sont rares. Des différences peuvent apparaître dans les formes plus rares. A Mas Guy, par exemple, comme à Mas Girard, on a retrouvé des fragments de creusets (6 exemplaires) qui indiquent que le ou les ateliers produisaient de la vaisselle et des céramiques utilitaires.

\section{La Razza (commune de Meillonnas)}

On ne relève pas de mention antérieure au XVIIe s., époque à laquelle trois potiers sont signalés. Si l'on admet une relation entre la «Razza », toponyme actuel, et l'expression «la rase du bois ", on pourrait considérer qu'un texte du XVIe s. s'y rapporte. Une carrière d'argile est attestée dès la fin du XVIIe $s$. Habitat très concentré, ce hameau n'a pas permis d'effectuer autant de prospections que souhaité. Seul à l'extérieur du hameau, un champ labouré a restitué une forte concentration de fragments céramiques (T 11). En revanche, la parcelle d'en face n'a restitué qu'un faible ensemble (T 9). Quelques tessons très épars ont été également recueillis dans le terrain déblayé près de la route principale (T 10), (fig. 46).

\section{6 - Meillonnas, la Razza}

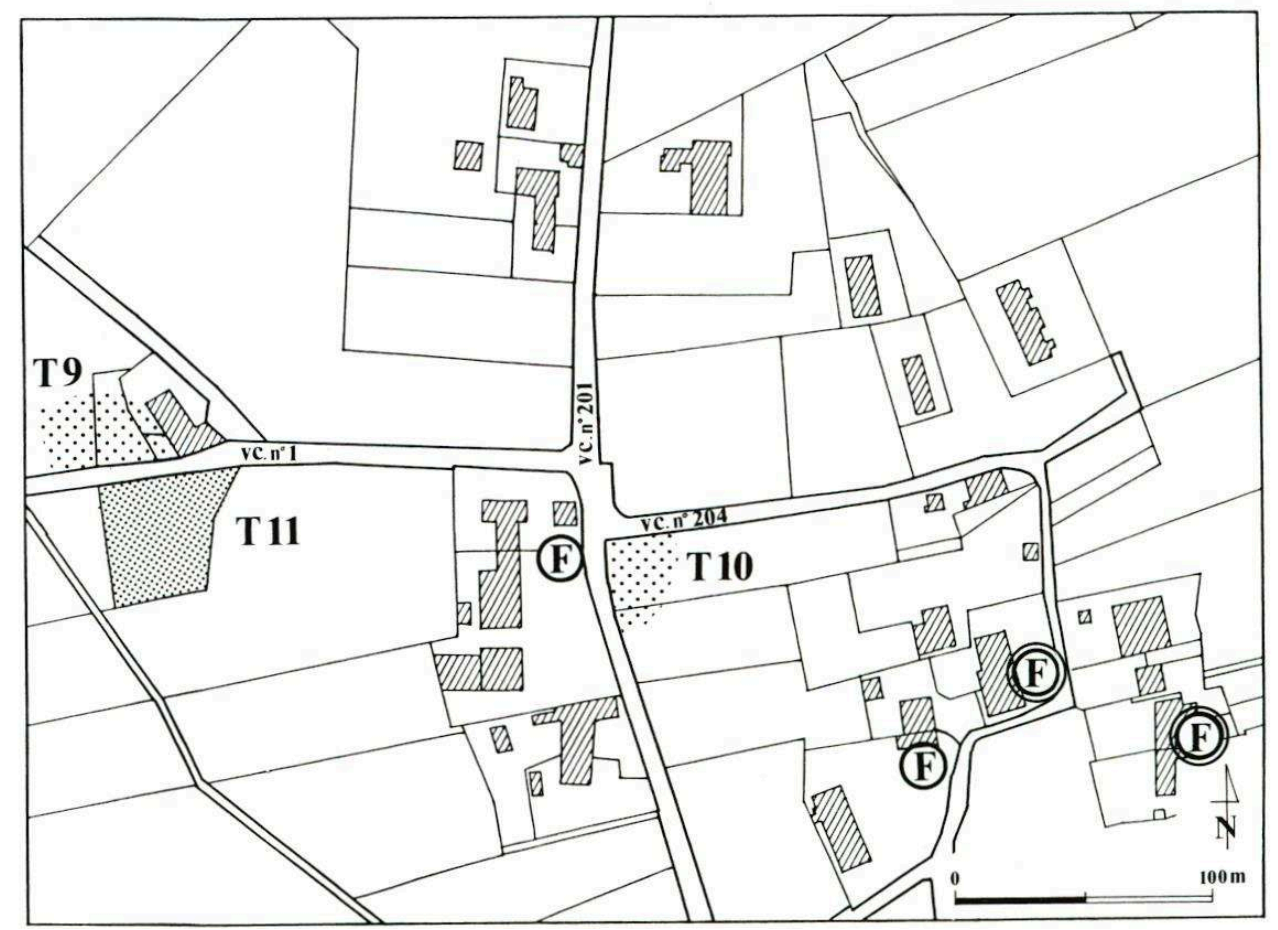

Localisation des parcelles prospectées (cf. légende fig. 40)

La production attestée semble être moderne, avec une importante majorité de glaçures de différents types attribuables au groupe 3 (fig. 47 et tableau 6). 


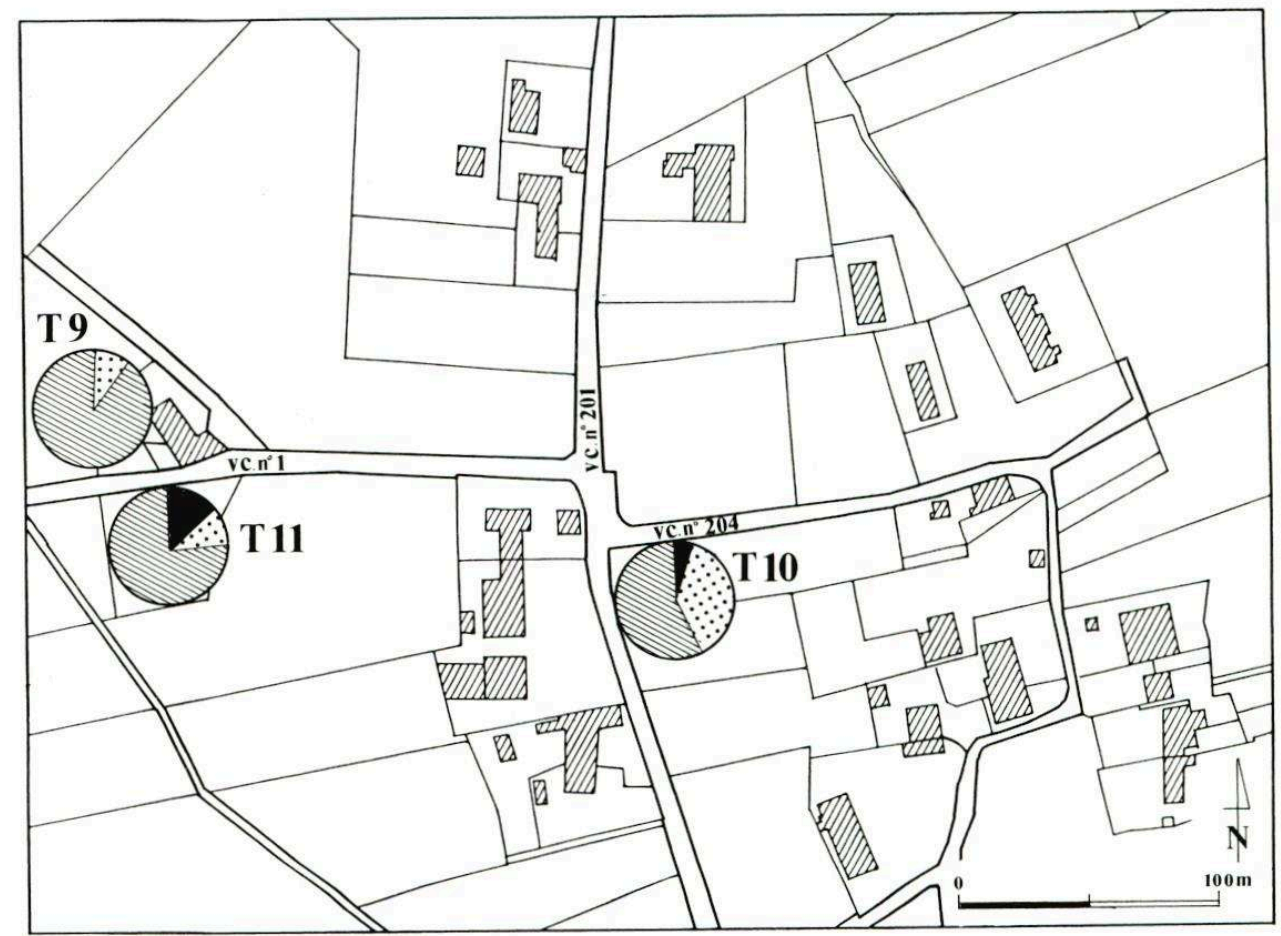

Proportion relative des trois types de céramique collectés (cf. légende fig. 39)

Tableau 6. Résultats des ramassages effectués sur les sites de la Razza

\begin{tabular}{|c|c|c|c|c|c|c|}
\hline & \multicolumn{2}{|c|}{$\mathrm{T} 9$} & \multicolumn{2}{c|}{$\mathrm{T} 10$} & \multicolumn{2}{c|}{$\mathrm{T} 11$} \\
\cline { 2 - 7 } & tessons & $\%$ & tessons & $\%$ & tessons & $\%$ \\
\hline groupe 1 & 1 & 2,3 & 1 & 3,8 & 133 & 13,5 \\
\hline groupe 2 & 4 & 9,3 & 10 & 38,5 & 92 & 9,4 \\
\hline groupe 3 & 38 & 88,4 & 15 & 57,7 & 754 & 77,1 \\
\hline TOTAL & $\mathbf{4 3}$ & $\mathbf{2 6}$ & & $\mathbf{9 7 9}$ & \\
\hline
\end{tabular}

Les tessons sans revêtement (groupe 1), présents en $\mathrm{T} 11$ avec un pourcentage relativement important, sont quasiment tous en pâte rouge ou claire et correspondent à une typologie de formes modernes (poêlons et couvercles). Les tessons en pâte grise, attribuables au Moyen Age, sont peu nombreux (16 tessons sur un total de 133).

Le service vert (groupe 2) n'est abondant qu'en T 10, mais l'ensemble de céramiques recueillies est si faible (26 tessons) que cela est peu significatif. Ont été identifiés : un rebord de marmite globulaire avec un col court évasé, un fragment d'assiette et un 
fragment d'écuelle. Les tessons du groupe 1 et du groupe 2 sont insuffisants pour attester, en ce lieu, la fabrication de poteries communes et de service vert.

L'importante quantité de glaçures modernes (groupe 3) laisse, en revanche, supposer que le site a été productif surtout à partir du XVIIIe s. D'après les comptages effectués pour $\mathrm{T} 11$, seul point de ramassage qui ait restitué un nombre de tessons significatif, tous les types de glaçure moderne sont présents avec une majorité de glaçures orange ou marron.

A cet ensemble assez important de céramiques modernes on peut, en outre, ajouter les fragments sans revêtement qui correspondent à des formes modernes et qui pourraient être des biscuits de dégourdi de vases non achevés. De plus, la présence, en T 11, d'une pernette tachée de glaçure orange est un indice supplémentaire pour confirmer, sans trop de risque d'erreur, la proximité d'un atelier ayant produit entre le XVIIIe s. et le XIXe s.

\section{Les Tupinières (commune de Meillonnas)}

Ce hameau (fig. 48) a été le pôle principal de notre enquête, tant sur le terrain que dans les archives qui mentionnaient en ce lieu les ateliers les plus anciens et les plus nombreux (trois fours au moins et sept potiers, dès 1416 et peut-être neuf, trente-trois ans plus tard). Le toponyme Tupineriae, utilisé dès cette époque et le nom tupinier qui désigne plusieurs artisans de ce hameau, plaident en faveur d'une activité déjà en pleine expansion au XVe s., et probablement plus anciennement installée. Les recherches de terrain, qui englobèrent largement le hameau (Tupinières nord et Tupinières sud) et les champs environnants, confirment cette pérennité (fig. 49). 
48 - Le hameau des Tupinières

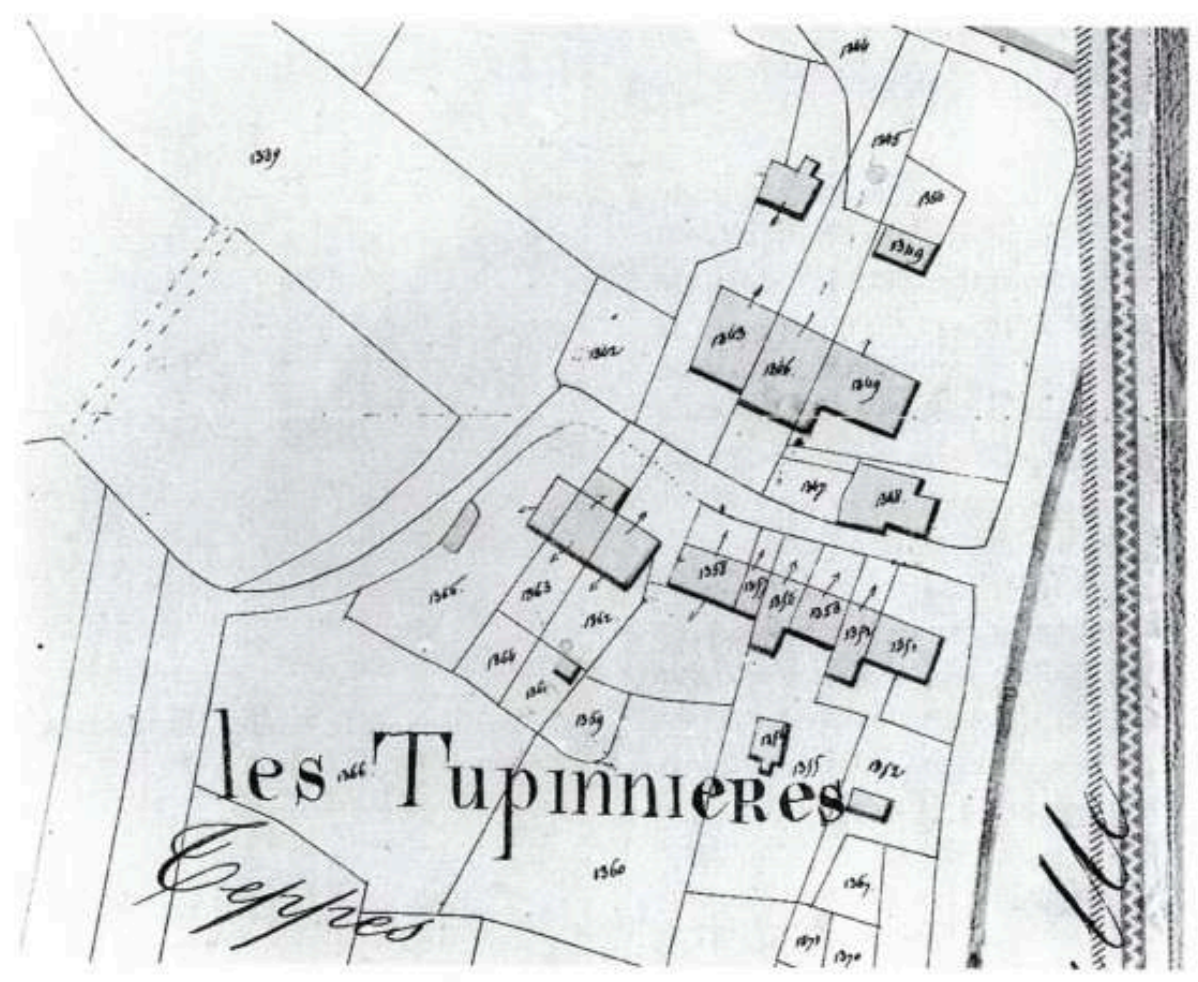

Extrait du cadastre de Meillonnas de 1825. Section A, 5e feuille (Mairie de Meillonnas)

49 - Meillonas, les Tupinières

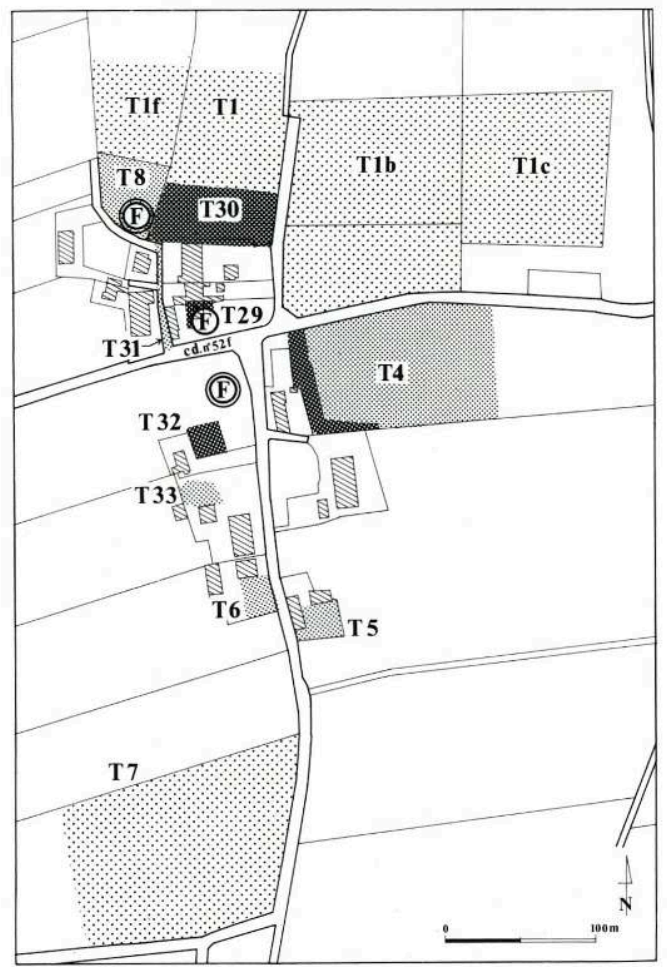

Localisation des parcelles prospectées (cf. légende fig. 40) 
Aux prospections répétées dans le centre du hameau, s'ajoute la collecte faite à l'occasion de la surveillance de la pose du tout-à-l'égout ( $\mathrm{T}$ 31). Enfin, grâce à l'obligeance des habitants, le matériel provenant de la chambre de cuisson d'un four ( $T$ 29) découvert dans une maison en plein coeur du hameau a pu être examiné ${ }^{30}$ Cet échantillonnage de service vert bien conservé est un précieux témoignage de l'activité potière des XVIe et XVIIe s. (fig. 50).

50 - Meillonas : les Tupinières

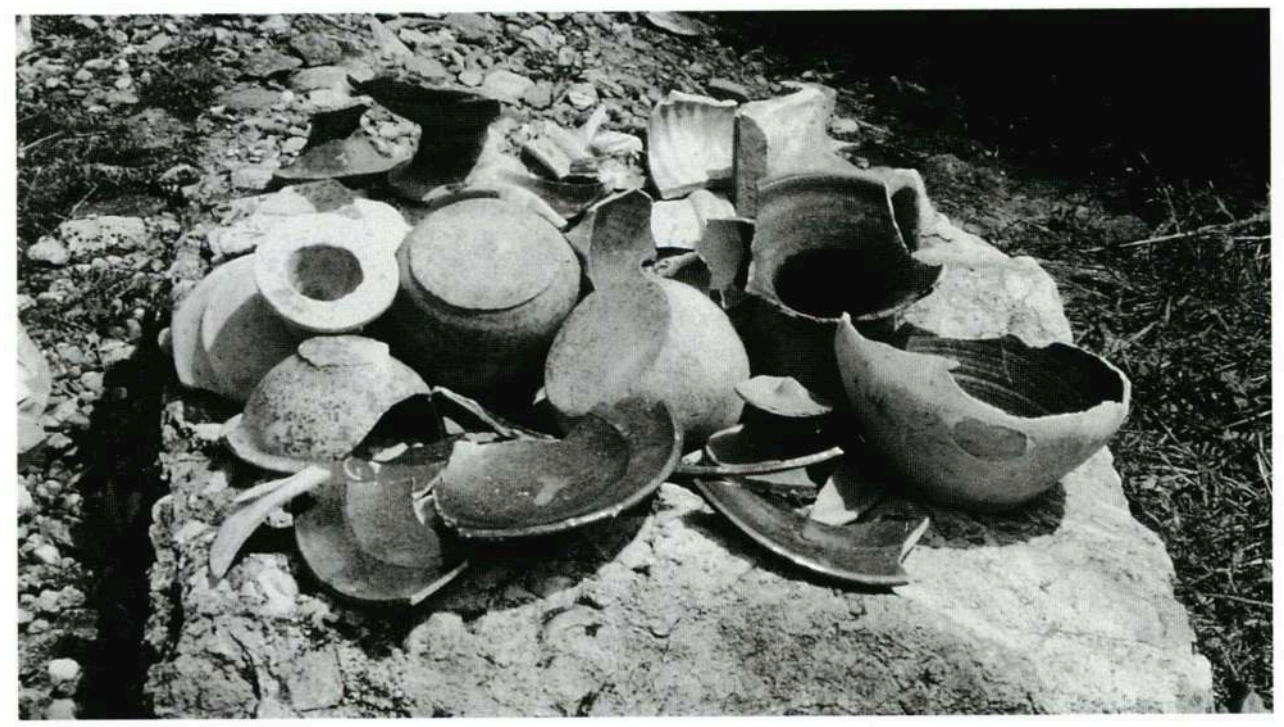

Une partie du matériel provenant du four Giroud

Pour toutes ces raisons, le hameau des Tupinières est celui qui a restitué le plus grand nombre de tessons (6877 fragments). Cet ensemble important correspond essentiellement à deux groupes de productions : celui des céramiques sans revêtement du Moyen Age (groupe 1) et celui du service vert des XVIe-XVIIe s. (groupe 2). Les céramiques plus récentes sont rares, contrairement à ce que l'on a constaté pour la plupart des autres sites prospectés (11,5\% sur l'ensemble du hameau). En revanche, les céramiques plus anciennes dépassent, en proportion, le service vert dans certaines parcelles (fig. 51). 


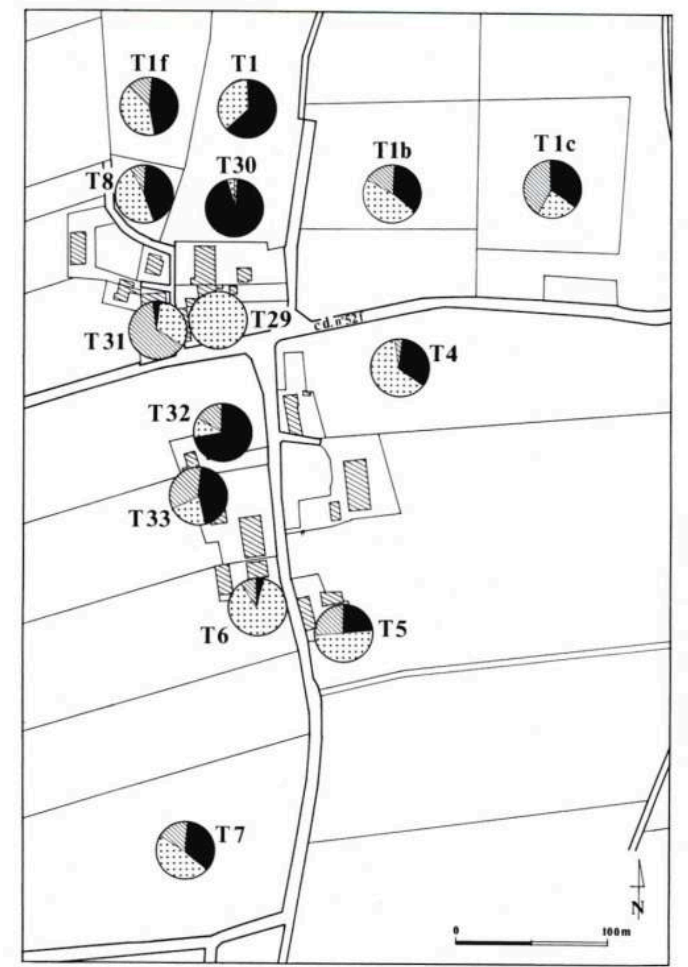

Proportion relative des trois types de céramique collectés (cf. légende fig. 39)

Les comptages ont été faits pour tous les points de ramassage, mais, pour plus de clarté, l'ensemble des tessons peu nombreux provenant des zones marginales ne sera pas détaillé : au nord $\mathrm{T} 1 \mathrm{~F}, \mathrm{~T} 1, \mathrm{~T} 1 \mathrm{~B}$ et $\mathrm{T} 1 \mathrm{C}$, au sud, $\mathrm{T} 7$.

Vers le nord (les Tupinières nord), la plus grande densité des trouvailles se situe dans le rectangle qui correspond à $\mathrm{T} 30$, qui inclut le matériel collecté lors de la surveillance des travaux publics. Ensuite il faut noter, $\mathrm{T} 29$, qui réunit le matériel du four, puis $\mathrm{T} 8$, et enfin $\mathrm{T} 31$ qui comporte le matériel provenant de la surveillance des travaux sur le chemin, entre les maisons.

Ici la situation est particulièrement intéressante en raison de la présence d'une zone n'ayant livré que de la céramique sans revêtement avec des formes typiques du XVe s. (T 30, où le groupe 1 atteint $96 \%$ de l'ensemble); tandis qu'à peu de distance, T 29 (mobilier du four) n'a restitué que des poteries du service vert. Les deux autres points de ramassage présentent, en revanche, soit un mélange des deux groupes ( $\mathrm{T}$ 8), soit une grande majorité de céramiques modernes. Mais il faut souligner que le mobilier moderne provient uniquement de prélèvements effectués lors de la surveillance des travaux publics; il s'agit sans doute de rejets domestiques des maisons avoisinantes (tableau 7). 


\begin{tabular}{|l|c|c|c|c|c|c|c|c|}
\hline & \multicolumn{2}{|c|}{ T 30 } & \multicolumn{2}{c|}{ T 8 } & \multicolumn{2}{c|}{ T 29 } & \multicolumn{2}{c|}{ T 31 } \\
\cline { 2 - 10 } & tessons & $\%$ & tessons & $\%$ & tessons & $\%$ & tessons & $\%$ \\
\hline groupe 1 & 1288 & 96,0 & 106 & 48 & - & - & 2 & 0,8 \\
\hline groupe 2 & 30 & 2,2 & 118 & 48 & 900 & 100 & 82 & 34 \\
\hline groupe 3 & 24 & 1,8 & 24 & 9,7 & - & - & 158 & 65 \\
\hline TOTAL & $\mathbf{1 3 4 2}$ & $\mathbf{2 4 8}$ & $\mathbf{9 0 0}$ & $\mathbf{2 4 2}$ & \\
\hline
\end{tabular}

L'atelier le plus ancien, proche de cette zone de forte densité en T 30, n'a donc produit que des vases sans revêtement (groupe 1) parmi lesquels les comptages mettent en évidence la céramique à pâte grise $(56,7 \%)$, suivie des pâtes brun clair ou rouges (respectivement 18,2\% et 18,1\%). Les pâtes " sandwich ", rouges à surfaces noires, sont rares ( $7 \% \mathrm{du}$ total). Quant aux formes, on y retrouve tout le répertoire des profils qui ont été présentés auparavant; d'ailleurs, cette typologie a été établie en très grande partie avec le matériel ramassé en T 30 (cf. supra) (fig. 11 à 15).

Dans la partie sud du hameau (les Tùpinières sud), de part et d'autre du chemin, en éliminant T 7, qui est marginal et pauvre en matériel (189 tessons sur une assez large surface), il reste cinq points de forte ou très forte densité. Ici encore, les productions modernes du groupe 3 sont rares et, selon les endroits, dominent alternativement les productions du groupe 1 ou du groupe 2 (tableau 8).

Tableau 8. Résultats des ramassages effectués aux Tupinières sud

\begin{tabular}{|l|c|c|c|c|c|c|c|c|c|c|}
\hline & \multicolumn{2}{|c|}{ T 4 } & \multicolumn{2}{|c|}{ T 5 } & \multicolumn{2}{|c|}{ T6 } & \multicolumn{2}{|c|}{ T 32 } & \multicolumn{2}{c|}{ T33 } \\
\cline { 2 - 11 } & tessons & $\%$ & tessons & $\%$ & tessons & $\%$ & tessons & $\%$ & tessons & $\%$ \\
\hline groupe 1 & 308 & 34,5 & 47 & 23,0 & 15 & 2,7 & 1269 & 75,1 & 91 & 49,4 \\
\hline groupe 2 & 539 & 60,3 & 103 & 50,5 & 476 & 87 & 161 & 9,5 & 34 & 18,5 \\
\hline groupe 3 & 47 & 5,2 & 54 & 26,5 & 56 & 10,3 & 261 & 15,4 & 59 & 32,1 \\
\hline TOTAL & $\mathbf{8 9 4}$ & & $\mathbf{2 0 4}$ & & $\mathbf{5 4 7}$ & & $\mathbf{1 6 9 1}$ & & $\mathbf{1 8 4}$ & \\
\hline
\end{tabular}

Le service vert (groupe 2) est densément présent dans les zones de ramassage de surface ( $\mathrm{T} 4, \mathrm{~T} 5, \mathrm{~T} 6$ et $\mathrm{T}$ 7) tandis que les céramiques plus anciennes apparaissent massivement dans le terrain décaissé lors des travaux publics ( $\mathrm{T} 32$ et $\mathrm{T}$ 33). Il y a là, sans doute, matière à réflexion, et ces circonstances de découvertes différentes ont toujours posé un problème d'interprétation des comptages réalisés.

Tout d'abord, on a tenté de discerner si le groupe 1 présentait des différences typologiques entre les points de ramassage où il était majoritaire et ceux dans lesquels le service vert l'emportait. Dans ce cas, on aurait pu avancer quelques hypothèses de datation plus fines. Mais la tentative n'a pas été exploitable. 
193 En $\mathrm{T} 32$ et $\mathrm{T}$ 33, où le groupe 1 domine, les pâtes sont le plus souvent grises (respectivement $62,5 \%$ et $78,8 \%$ ) ; en T 4 , où domine le service vert, elles présentent encore le même pourcentage $(66,2 \%)$. C'est seulement en T 5 que les pâtes claires l'emportent avec $68,2 \%$ contre $31,87 \%$ de pâtes grises. La répartition entre formes fermées et formes ouvertes, pour le groupe 1 , donne à peu près les mêmes résultats. Les formes fermées sont nettement plus nombreuses en T 32 (90,5\%), en T 33 (78,6\%) et en T 4 (77,8\%), mais, malheureusement en T 5 n'a été retrouvée aucune forme identifiable et cela a empêché toute comparaison fructueuse. Notons seulement que T 32 est le seul endroit où, parmi les formes fermées, sont présents les becs pontés qui se rattachent à une typologie plus ancienne (XIIe-XIIIe s.), tout à fait comparables aux 18 exemplaires collectés en $\mathrm{T} 30$, (où les céramiques communes grises représentent quasiment la totalité des trouvailles). Mais cela suffit-il pour avancer l'hypothèse que les ateliers les plus anciens y étaient situés?

194 En ce qui concerne les céramiques du groupe 2, les comptages réalisés pour tous les sites sur le type de pâte n'ont pas fait ressortir d'informations utiles; les pâtes blanches sont partout les mieux représentées. Aucune différence remarquable n'apparaît, également, dans les nuances de glaçure, et, comme toujours, on dénombre une quantité importante de biscuits.

195 Quant aux formes identifiables, elles correspondent à toute la typologie connue et présentée ci-dessus, sans qu'il ait été possible d'isoler une production particulière, sauf pour le matériel retrouvé dans le four. Mais il s'agit là d'un cas tout à fait particulier qui ne peut être comparé aux trouvailles éparses sur le terrain. Un seul détail est à remarquer: le secteur des Tupinières n'a livré aucun fragment de creuset; en revanche, les fragments de terres cuites architecturales à glaçure verte pourraient signaler une particularité du répertoire des ateliers de ce hameau.

Dans l'ensemble collecté aux Tupinières, les 233 formes identifiées reflètent la présence de vaisselle de table et de cuisine à peu près dans la même proportion :

197 - 75 marmites, 4 coquemars, 21 petits poêlons avec manche creux, 10 cruches à bec pincé, 2 cruches à bec tubulaire, 68 assiettes ou plats, 17 écuelles, 4 faisselles, 6 portefaisselle, 13 réchauds, 3 couvercles.

198 Parmi les fragments d'anses, on en dénombre 35 appartenant à des marmites ; 52 anses ont en revanche une section ovale qui rappelle celles identifiées sur les coquemars; 68 autres fragments d'anse à section plate, mais étroite, ont pu appartenir à des formes fermées destinées à la table, comme les cruches; 2 anses torsadées, enfin, semblent correspondre à l'anse en panier des vases portatifs. On dénombre également 15 pieds ayant appartenu à des vases tripodes et 6 fragments de panse avec décor de côtes en relief. Enfin, des éléments de briques et autres fragments calcinés ont probablement appartenu aux parois des fours.

\section{Les trois grandes phases d'activité des ateliers}

199 Si l'on considère l'ensemble des résultats acquis par les prospections et les ramassages de surface dans les cinq hameaux potiers de Meillonnas et Treffort, une image relativement mouvante de l'implantation des ateliers au fil des siècles se dégage (fig. 39 et tableau 9). 
Tableau 9. Répartition des différentes catégories de produits entre les groupes d'ateliers de Meillonnas-Treffort

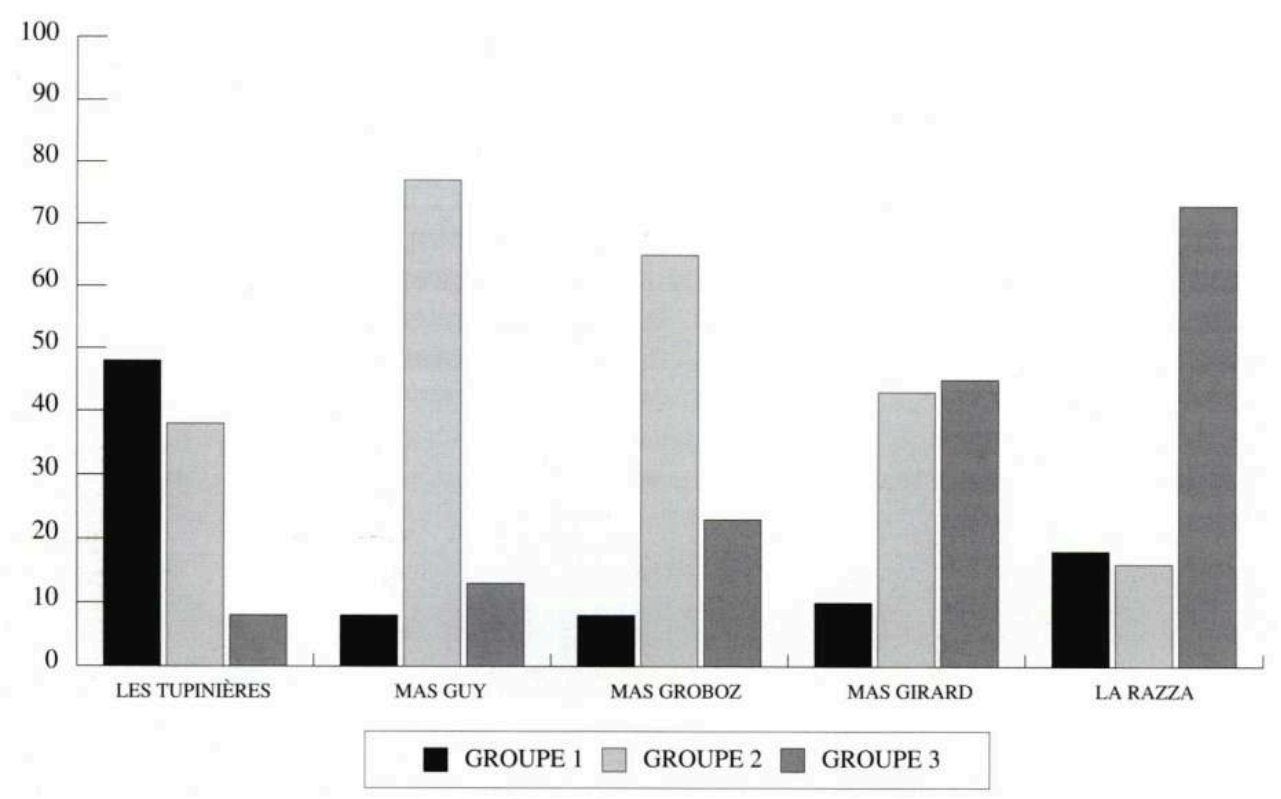

200 Sans conteste, le phénomène apparaît aux Tupinières; tout en témoigne, le toponyme, l'ancienneté des données écrites et les informations archéologiques: les céramiques communes (groupe 1), pour l'essentiel datées du XVe s., dominent mais certaines ne sont pas postérieures au XIIIe s. Les textes et les informations archéologiques concourent à restituer là le premier quartier artisanal spécialisé.

Au moment où la production locale connaît l'essor que nous avons décrit plus haut, depuis le début du XVIe s. jusqu'à la fin du XVIIe s., presque tous les ateliers repérés produisent du fameux service vert (groupe 2). Le hameau de la Razza apparaît cependant en dehors du mouvement général. Il est probable que la plupart des ateliers ne se mettent en place qu'à cette époque, comme à Mas Guy, Mas Girard et Mas Groboz, où les céramiques du groupe 1 paraissent très marginales. Les prospections précisent donc l'impression qui ressort des textes post-médiévaux: une expansion et une dispersion rapide des activités potières sur Treffort au détriment des Tupinières.

Lors de la dernière période d'activité des ateliers, c'est le hameau de la Razza qui semble prendre la première place dans la fabrication des poteries utilitaires traditionnelles (groupe 3). Les ateliers de Mas Girard et Mas Groboz fonctionnent encore aux XVIIIe et XIXe s., ceux de Mas Guy également, mais dans une moindre mesure. En revanche, les artisans délaissent probablement le hameau des Tupinières. Rappelons qu'un atelier s'installe au bourg même de Meillonnas, dans les locaux de la faïencerie, au milieu du XIXe s.

Il n'y a donc pas à proprement parler déplacement de pôles de production sur le territoire des communes de Meillonnas et de Treffort ; c'est plutôt le volume d'activité des hameaux qui semble varier selon les périodes, évoquant une éventuelle concurrence. Mais l'image que restituent les ramassages de surface est à considérer avec prudence : les conditions de collecte n'ont pas été strictement identiques partout, les produits les plus anciens (groupe 1) ont pu ne pas être accessibles partout, des confusions ont été possibles entre rejets d'ateliers et rejets domestiques, etc. 
Cependant, on retiendra l'hypothèse que la géographie de l'artisanat a été mouvante au fil des siècles dans les limites du terroir des deux communautés villageoises.

Sur des distances aussi réduites (les hameaux sont espacés en moyenne de 1,5 km), il est clair que la plus ou moins grande réussite des ateliers n'est pas fonction de la facilité d'accès aux matières premières : toutes les argiles souhaitées, selon la qualité de produits recherchée, sont également répandues dans le secteur. Il faut sans doute rechercher dans l'organisation même des ateliers, l'origine de la main-d'œuvre, dans la transmission du savoir-faire et de l'outil de travail, le moteur de l'évolution des ateliers.

B. M.-P. et E. F-B.

\section{La diffusion du service vert}

\section{Caractérisation de la production en laboratoire}

206 L'importance et le nombre des ensembles de service vert répertoriés dans le nord de la région Rhône-Alpes, ainsi que les caractéristiques morphologiques et techniques propres à cette vaisselle assuraient quelque chance de succès à la détermination de l'aire de diffusion des ateliers de Meillonnas-Treffort. Aux comparaisons typologiques qui avaient guidé les premières cartes de répartition devaient s'adjoindre les arguments incontestables du laboratoire.

207 L'hypothèse d'autres ateliers régionaux produisant du service vert, mais encore inconnus, ne pouvait être écartée. Par ailleurs, hors de la région, les ateliers du Jura, notamment ceux d'Étrepigney (Doubs) très actifs à l'époque moderne et réputés pour leurs poteries vertes en terre blanche, avaient pu rechercher des débouchés relativement éloignés vers le sud (Garneret 1958). Distants d'une centaine de kilomètres, les centres de Meillonnas et d'Étrepigney sont tous deux installés dans des secteurs où les ressources en argiles blanches d'âge pliocène sont importantes. Enfin les ateliers implantés près des kaolins de la moyenne et basse vallée du Rhône avaient eux aussi la possibilité de fabriquer des produits comparables. Il s'agissait donc de distinguer ce qui revenait effectivement aux potiers bressans.

A partir d'un matériel de référence et d'un échantillonnage large réalisé sur différents sites archéologiques de la région Rhône-Alpes, une étude des compositions chimiques a été entreprise. Son objectif était de définir les productions des ateliers de MeillonnasTreffort, afin de pouvoir les identifier sur les sites de consommation et aborder le problème de la diffusion de cette production. Le cas de l'atelier d'Étrepigney n'est traité que de façon secondaire.

\section{Échantillonnage}

Soixante-trois céramiques à glaçure verte collectées lors de ramassages de surface dans les environs de Meillonnas servent de références pour l'étude de cet atelier, ainsi que 4 échantillons d'argile blanche prélevés dans les niveaux de «blanc de Bresse » de la carrière de la Razza à Meillonnas. Pour l'atelier d'Étrepigney, seules 4 céramiques collectées lors de ramassages de surface ont été analysées. On trouve dans le tableau suivant (tableau 10) le détail de cet échantillonnage de référence. 
Tableau 10. Composition de l'échantillonnage de référence

\begin{tabular}{|l|r|}
\hline \multicolumn{1}{|c|}{ lieu de découverte } & numéro d'analyse \\
\hline $\begin{array}{l}\text { Meillonnas } \\
\text { Les Tupinières }\end{array}$ & MRL38 à MRL40 \\
\hline $\begin{array}{l}\text { Meillonnas } \\
\text { Les Tupinières, T1 (1) }\end{array}$ & $\begin{array}{c}\text { MRL76 à MRL90 } \\
\text { MRL141 à MRL155 }\end{array}$ \\
\hline Meillonnas & MRL236 à MRL248 \\
Les Tupinières & MRL251 à MRL252 \\
\hline Four Giroud & \\
\hline Treffort & \\
\hline $\begin{array}{l}\text { Mas Girard } \\
\text { T14 }\end{array}$ & MRL221 à MRL225 \\
T13 & MRL226 à MRL230 \\
T12 & MRL231à MRL235 \\
\hline Environs de Meillonnas & $\mathrm{n}=63$ \\
\hline "Blanc de Bresse" & MRL468 à MRL470 \\
\hline Meillonnas & MRL158 \\
Carrière de la Razza & $\mathrm{n}=4$ \\
\hline Étrepigney & MRL130 à MRL133 \\
\hline
\end{tabular}

210 A ces exemplaires collectés sur les sites d'atelier, on a comparé 89 céramiques à glaçure verte provenant de divers sites archéologiques dits de consommation par opposition aux sites d'atelier, (tableau 11). 
Tableau 11. Liste des ensembles analysés, provenant des sites de consommation

\begin{tabular}{|l|c|}
\hline \multicolumn{1}{|c|}{ lieu de découverte } & numéro d'analyse \\
\hline Anse (69) & MRL59 \\
\hline Besançon (25) & MRL314 et MRL315 \\
\hline Bressieux (38) & MRL253 \\
\hline Chalon-sur-Saône (71) & MRL44 à MRL54 \\
\hline Château-Gaillard (01) & MRL63 et MRL64 \\
\hline Genève (CH) & MRL316 à MRL320 \\
\hline Grenoble (38) & MRL312 \\
\hline La Chapelle-du-Châtelard (01) & MRL55 \\
\hline Lyon (69) & MRL1 à MRL5 \\
A. Max & MRL8 \\
Bellecour & MRL105 à MRL112 \\
St.-Vincent & MRL120 à MRL129 \\
A. Poncet & MRL102 \\
\hline Meillonnas château (01) & MRL60 à MRL62 \\
\hline Montagnieu (01) & MRL134 à MRL140 \\
\hline Nantua (01) & MRL65 à MRL74 \\
\hline Neuville-sur-Ain (01) & MRL255 et MRL256 \\
\hline St. Paul-Trois-Châteaux (26) & MRL75 \\
\hline Ternand (69) & MRL254 \\
\hline Valence (26) & MRL113 à MRL119 \\
\hline Vienne (38) & MRL56 à MRL58 \\
\hline Villefranche-sur-Saône (69) & MRL41 à MRL43 \\
\hline Viriat (01) & MRL101 \\
\hline Vulbens (74) & MRL6 et MRL7 \\
\hline Total échantillonnage & no \\
\hline
\end{tabular}

\section{Classification préliminaire}

211 Une première classification des données chimiques a été effectuée par analyse de grappe. Le résultat de ces calculs est exprimé sous la forme d'un dendrogramme (fig. 52). Sur ce type de diagramme on observe des regroupements en fonction des ressemblances de composition chimique ${ }^{31}$ des individus entre eux.

52- Dendrogramme de classification des céramiques analysées

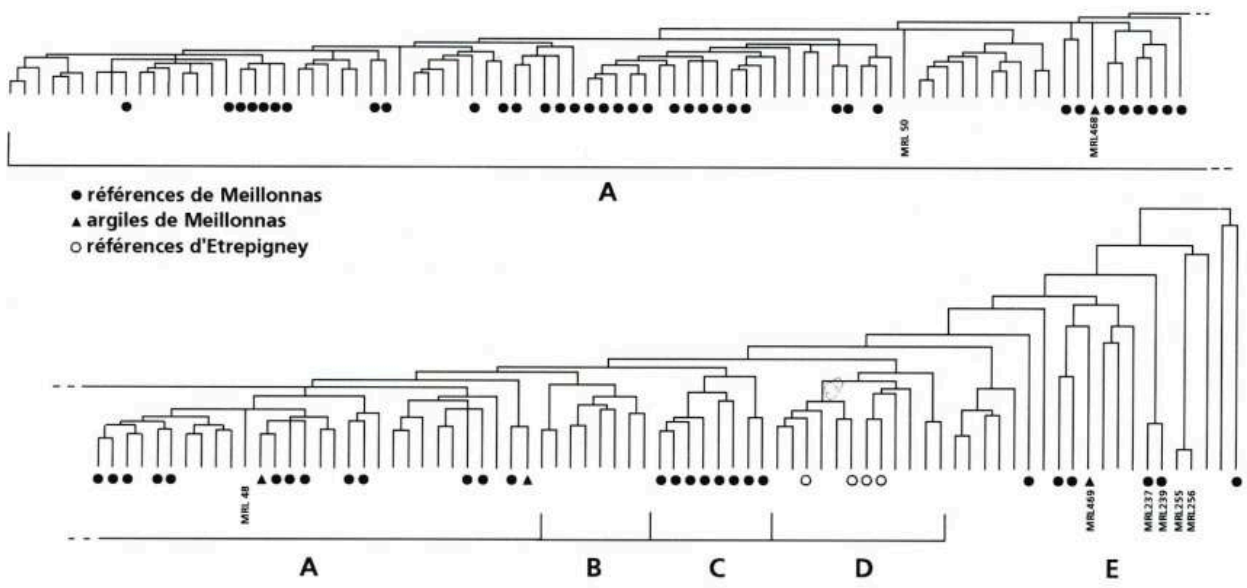

Mise en évidence de quatre groupes

212 Sur le graphique de la figure 52 les exemplaires provenant des ramassages de surface dans les environs de Meillonnas sont figurés par un point noir, les prélèvements de "Blanc de Bresse» 
par un triangle noir et les références d'Étrepigney par un rond blanc. Les exemplaires provenant de sites de consommation n'ont pas de symbole.

Ce diagramme met en évidence la présence de quatre groupes distincts notés A, B. C et D et matérialisés par des crochets.

- Dans le groupe A les hauteurs de jonction entre les différents individus sont faibles. Les exemplaires qui constituent ce groupe ont des caractéristiques chimiques communes: la probabilité pour qu'ils aient tous été fabriqués dans le même atelier est donc élevée. Cette probabilité est cependant plus faible pour les exemplaires qui se classent en position marginale entre les différents sous-groupes composant le groupe A, et que l'on désigne sous le nom de marginaux internes. La même restriction s'applique aux exemplaires qui se classent dans la partie droite du groupe et qui ont des hauteurs de fusion avec les autres exemplaires plus élevées. En effet, plus on s'éloigne des caractéristiques du groupe, plus on risque de se trouver dans le cas d'une ressemblance accidentelle.

- Les groupes B, C et D sont constitués de peu d'exemplaires et dans chacun d'eux les céramiques ont des caractéristiques chimiques communes : la probabilité pour qu'au sein de chaque groupe tous les exemplaires proviennent d'un même atelier est donc élevée. Toutefois, les effectifs de ces groupes étant faibles, on ne peut exclure qu'une céramique d'origine différente puisse se classer dans l'un d'eux simplement parce que sa composition chimique est un peu plus proche de certains exemplaires de ce groupe que des exemplaires appartenant aux autres groupes en présence.

Dans la partie droite du dendrogramme se rassemblent des exemplaires dont la hauteur de fusion avec les autres groupes est élevée, ils constituent l'ensemble E. Leurs compositions chimiques sont variées et très différentes de celles des groupes $\mathrm{A}, \mathrm{B}, \mathrm{C}$ et D.

215 Pour permettre la comparaison entre les compositions chimiques des différents groupes, les moyennes $(\mathrm{m})$ et écarts-types ${ }^{32}(\mathrm{~s})$ des groupes A, B, C et D sont présentés dans le tableau suivant (tableau 12). La moyenne de l'ensemble $\mathrm{E}$ ne figure pas dans ce tableau, car les exemplaires ont des compositions chimiques trop variées pour que le calcul des moyennes ait une signification.

216 Après cette description générale de la classification, on étudiera successivement le cas des différents groupes mis en évidence sur le diagramme. 
Tableau 12. Moyennes de chacun des groupes tels qu'ils sont définis dans la fig. $\mathbf{5 2}$

ELEMENTS MAJEURS EN POURCENTAGES D'OXYDES

\begin{tabular}{|c|c|c|c|c|c|c|c|c|c|c|}
\hline & $\mathrm{Na} 2 \mathrm{O}$ & K2O & MgO & $\mathrm{CaO}$ & $\mathrm{MnO}$ & $\mathrm{Al} 2 \mathrm{O3}$ & $\mathrm{Fe} 2 \mathrm{O3}$ & $\mathrm{SiO2}$ & TiO2 & P2O5 \\
\hline groupe $\mathrm{A} \mathbf{m}$ & 0,14 & 1,2 & 0,46 & 0,45 & 0,01 & 16,2 & 1,67 & 79,3 & 0,66 & 0,1 \\
\hline $\mathrm{n}=106 \quad \mathrm{~s}$ & 0,13 & 0,3 & 0,06 & 0,13 & 0,008 & 1,2 & 0,31 & 1,3 & 0,046 & 0,1 \\
\hline groupe B $\mathbf{m}$ & 0,24 & 1,1 & 0,48 & 1,12 & 0,011 & 16,5 & 1,6 & 77,9 & 0,626 & 0,3 \\
\hline $\mathrm{n}=8 \quad \mathrm{~s}$ & 0,13 & 0,3 & 0,06 & 0,3 & 0,008 & 1,3 & 0,31 & 1,2 & 0,025 & 0,2 \\
\hline groupe $\mathrm{C} \mathbf{m}$ & 0,07 & 0,7 & 0,42 & 0,41 & 0,012 & 17,8 & 3,26 & 76,4 & 0,693 & 0,1 \\
\hline $\mathrm{n}=8 \quad \mathrm{~s}$ & 0,07 & 0,2 & 0,07 & 0,06 & 0,008 & 1,1 & 0,57 & 0,8 & 0,042 & 0 \\
\hline groupe D $\mathbf{m}$ & 0,11 & 1,3 & 0,45 & 0,47 & 0,016 & 18,2 & 1,96 & 76,1 & 1,035 & 0,1 \\
\hline $\mathrm{n}=8 \quad \mathrm{~s}$ & 0,1 & 0,4 & 0,05 & 0,15 & 0,005 & 1,4 & 0,39 & 1,5 & 0,159 & 0 \\
\hline
\end{tabular}

\begin{tabular}{|c|c|c|c|c|c|c|c|c|c|c|}
\hline . & $\mathbf{R b}$ & $\mathrm{Sr}$ & $\mathrm{Ba}$ & $\mathrm{Ni}$ & Zn & $\mathrm{Cr}$ & $\mathbf{Z r}$ & La & $\mathrm{Ce}$ & V \\
\hline groupe A $\mathbf{m}$ & 56 & 48 & 181 & 32 & 24 & 69 & 389 & 37 & 73 & 81 \\
\hline $\mathrm{n}=106 \quad \mathrm{~s}$ & 15 & 7 & 40 & 6 & 14 & 9 & 57 & 14 & 10 & 9 \\
\hline groupe B $\mathbf{m}$ & 52 & 69 & 205 & 29 & 30 & 64 & 364 & 27 & 69 & 77 \\
\hline $\mathrm{n}=8 \quad \mathrm{~s}$ & 15 & 8 & 32 & 4 & 12 & 7 & 37 & 12 & 4 & 10 \\
\hline groupe $\mathrm{C} \mathbf{m}$ & 32 & 39 & 124 & 38 & 21 & 75 & 412 & 39 & 70 & 88 \\
\hline $\mathrm{n}=8 \quad \mathrm{~s}$ & 8 & 7 & 23 & 5 & 7 & 11 & 35 & 13 & 9 & 26 \\
\hline groupe D $\mathbf{m}$ & 62 & 60 & 274 & 31 & 52 & 62 & 421 & 56 & 78 & 99 \\
\hline $\mathrm{n}=8 \quad \mathrm{~s}$ & 15 & 4 & 64 & 6 & 17 & 8 & 60 & 27 & 10 & 14 \\
\hline
\end{tabular}

\section{Groupe A}

217 Ce groupe rassemble la majorité des références de Meillonnas, soit 40 céramiques collectées à Meillonnas au lieu-dit «Les Tupinières », 9 exemplaires recueillis dans la commune voisine de Treffort, et 3 échantillons de «blanc de Bresse». Soixante céramiques provenant de divers sites archéologiques régionaux se classent également dans ce groupe.

218 Le mélange des exemplaires provenant de sites de consommation avec les références semble satisfaisant. Pourtant, il a paru nécessaire de vérifier la cohérence du groupe A en calculant plus précisément la ressemblance entre les compositions chimiques des exemplaires de référence et celles des exemplaires provenant de sites d'habitat. Cette comparaison a été réalisée en calculant la distance de Mahalanobis (Picon 1984a) de chacun des exemplaires provenant de sites de consommation par rapport à un groupe ${ }^{33}$ constitué uniquement des références de la région de Meillonnas se classant dans le groupe A. Cette distance mesure le plus ou moins grand éloignement des compositions chimiques de chaque exemplaire par rapport aux caractéristiques du groupe. Pour simplifier la présentation de ces calculs, le résultat est exprimé sous forme d'histogrammes (fig. 53). L'histogramme présenté en haut de la figure 53 correspond au groupe constitué par les références, en dessous est présenté l'histogramme des exemplaires provenant de sites d'habitat. On voit que les modes ${ }^{34}$ des deux histogrammes sont très peu décalés. On peut donc considérer que le groupe $\mathrm{A}$ rassemble des exemplaires qui, dans leur grande majorité, ont été fabriqués dans les mêmes ateliers. 
53 - Histogrammes des distances du groupe A
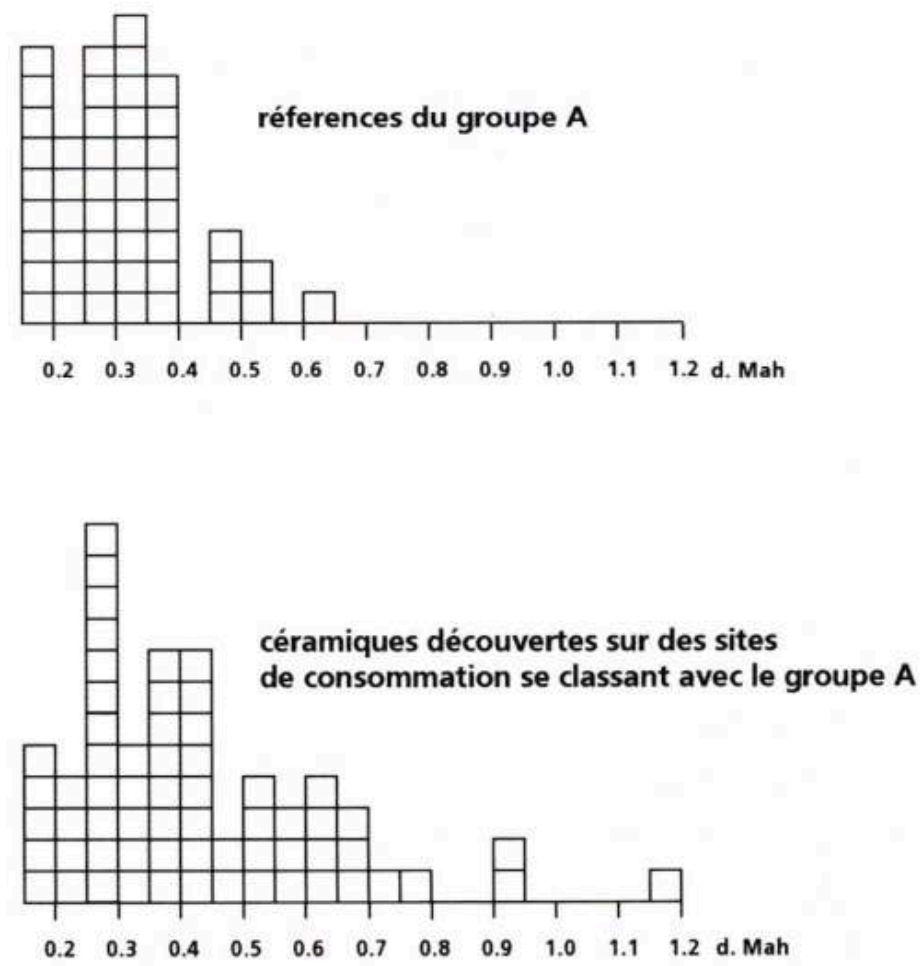

219 A l'issue de cette vérification, on peut avancer que tous les exemplaires provenant de sites de consommation et se classant dans le groupe A ont une forte probabilité d'être des productions de l'atelier de Meillonnas. On fera toutefois une réserve pour les céramiques MRL48 et MRL50 et l'argile MRL468 qui ont des positions assez marginales au sein du groupe (marginaux internes).

\section{Groupe B}

Ce groupe est composé uniquement d'exemplaires provenant de sites de consommation : trois exemplaires de Genève, deux exemplaires de Lyon Saint-Vincent, un exemplaire de Neuville, un exemplaire de Vienne et un exemplaire découvert dans les fouilles du château de Meillonnas.

Ces exemplaires ont comme caractéristique commune des taux de chaux plus élevés que dans tous les autres groupes $(\mathrm{CaO}=1,11 \%)$. C'est d'ailleurs principalement sur ce constituant que repose la distinction entre le groupe $\mathrm{B}$ et le groupe $\mathrm{A}$, les différences sur les autres constituants étant relativement faibles. On peut émettre deux hypothèses pour expliquer ceci :

- soit le groupe B correspond aux productions d'un atelier différent de Meillonnas, mais situé dans la région et employant un type d'argile voisin,

- soit il s'agit de productions réalisées à Meillonnas même, mais dans une pâte légèrement différente à la suite d'un changement de banc argileux dans l'exploitation de la carrière.

Cette dernière hypothèse semble peu probable, car le fait qu'aucune des références de Meillonnas ne se classe parmi le groupe B incite à la plus grande prudence. De plus, parmi les prélèvements d'argile effectués autour de Meillonnas, aucun ne présente ce 
type de composition chimique. L'hypothèse d'un atelier différent est donc la plus vraisemblable.

Il semble difficile, actuellement, d'en dire plus sur ce point. Il est certes possible que l'échantillonnage de référence tel qu'il a été réalisé ne soit pas représentatif de la totalité des productions du secteur de Meillonnas. De plus tous les ateliers constituant ce centre de production n'ont probablement pas été localisés. Ainsi à Saint-Etiennedes-Bois des installations sont mentionnées par les textes, mais n'ont pas été repérées lors des prospections.

\section{Groupe C}

Le groupe $C$ rassemble des exemplaires dont la caractéristique commune réside dans des taux d'oxyde de fer plus élevés que dans les groupes A, B et D ( $\mathrm{Fe} 2 \mathrm{O} 3=3,25 \%$ ). De plus, tous ces exemplaires ont été collectés lors des prospections à Meillonnas. Ceci conduit à formuler deux hypothèses quant à l'origine du groupe $C$ :

- soit le groupe $\mathrm{C}$ rassemble des exemplaires fabriqués à Meillonnas avec une pâte légèrement différente du fait d'un changement de banc argileux dans la carrière,

- soit le groupe C correspond aux productions d'un autre atelier dans la région dont la commercialisation se serait faite par l'intermédiaire de Meillonnas.

La première hypothèse semble la plus vraisemblable, car ce groupe contient uniquement des références. De plus, la principale différence de composition chimique entre le groupe $C$ et le groupe $A$ réside dans les taux d'oxyde de fer. Or, on a pu vérifier que la teneur en oxydes de fer est très variable selon les bancs dans les argiles pliocènes utilisées à Meillonnas (cf. supra). L'hypothèse d'un atelier à Meillonnas utilisant un banc d'argile légèrement différent est donc très probable.

\section{Groupe D}

Dans le groupe $\mathrm{D}$ se classent sept céramiques découvertes à Chalon-sur-Saône, un exemplaire de Besançon et quatre références de l'atelier d'Étrepigney (Jura).

Les différences de composition chimique entre les références d'Étrepigney et celles de Meillonnas sont assez faibles; ceci était prévisible du fait de la grande similitude des gisements argileux utilisés dans les deux ateliers. En effet, l'atelier d'Étrepigney est situé comme Meillonnas dans des formations argileuses pliocènes. Les «argiles d'Étrepigney » sont des argiles blanches avec des intercalations de niveaux noirs, assez similaires à celles de Meillonnas ${ }^{35}$. Les principales différences résident dans des taux de titane, baryum et zinc plus élevés à Étrepigney qu'à Meillonnas. Ces différences sont suffisantes pour que la distinction entre les deux ateliers ne pose pas de problème.

Les exemplaires de sites de consommation se classant dans le groupe D ne sont assurément pas des productions de l'atelier de Meillonnas. Sachant qu'Étrepigney est un autre atelier important (environ $120 \mathrm{~km}$ au nord de Meillonnas) et que les quatre références de cet atelier se classent dans le groupe D. il existe une bonne probabilité pour que les exemplaires de Chalon-sur-Saône et Besançon soient originaires d'Étrepigney. De plus, ce sont les deux sites les plus proches d'Étrepigney qui justement présentent ces caractéristiques. 


\section{Ensemble E}

Dans cet ensemble se classent toutes les céramiques qui ont des compositions chimiques très différentes des groupes $\mathrm{A}, \mathrm{B}, \mathrm{C}$ et $\mathrm{D}$. Les jonctions entre la plupart des exemplaires se font très haut ce qui indique des compositions chimiques hétérogènes et donc des origines variées. Les différences de compositions chimiques entre les exemplaires des autres groupes sont très importantes : aucun de ces exemplaires n'est attribuable à Meillonnas ou à Étrepigney.

On examinera cependant le cas particulier des céramiques MRL255 et MRL256 dont les compositions chimiques se ressemblent beaucoup (jonction très basse sur la grappe). Elles sont très différentes du groupe $A$ et du groupe $D$ et ne peuvent donc être originaires ni de Meillonnas ni d'Étrepigney. Ces deux exemplaires ont été découverts à Saint-Paul-Trois-Châteaux et présentent des affinités avec les compositions chimiques des argiles de l'Uzège (Gard) ou de Bollène (Vaucluse). Il faut vraisemblablement rechercher leur origine dans cette région.

Six exemplaires collectés lors des ramassages de surface dans la région de Meillonnas se classent dans cet ensemble. Parmi eux, deux exemplaires attirent l'attention : MRL237 et MRL239 dont les compositions chimiques diffèrent du groupe A surtout par leurs taux de phosphore et de baryum. Sachant que les teneurs élevées de ces constituants révèlent fréquemment la présence d'une altération de composition chimique au cours de l'enfouissement, il n'est pas impossible que ces exemplaires soient des productions de l'atelier de Meillonnas.

232 La méthode de classification par analyse de grappe employée ci-dessus est insuffisante pour quantifier les dissemblances réelles entre les groupes. On a donc utilisé le calcul des distances de Mahalanobis qui permet d'affiner la classification et donc de vérifier si les hypothèses formulées ci-dessus quant à l'origine des différents groupes sont fondées ou non. Un groupe de référence a été constitué en incluant tous les exemplaires se classant lors de l'analyse de grappe dans le groupe A sauf les marginaux internes MRL48, MRL50 et MRL468.

On a calculé la distance de chacun des exemplaires qui constituent ce groupe par rapport au centre du groupe. Le résultat de ce calcul est présenté sous forme d'un histogramme des distances de Mahalanobis (fig. 54). Trois exemplaires se placent en position marginale vers les valeurs élevées des distances de Mahalanobis; ils ont donc une probabilité moindre d'appartenir au groupe. 


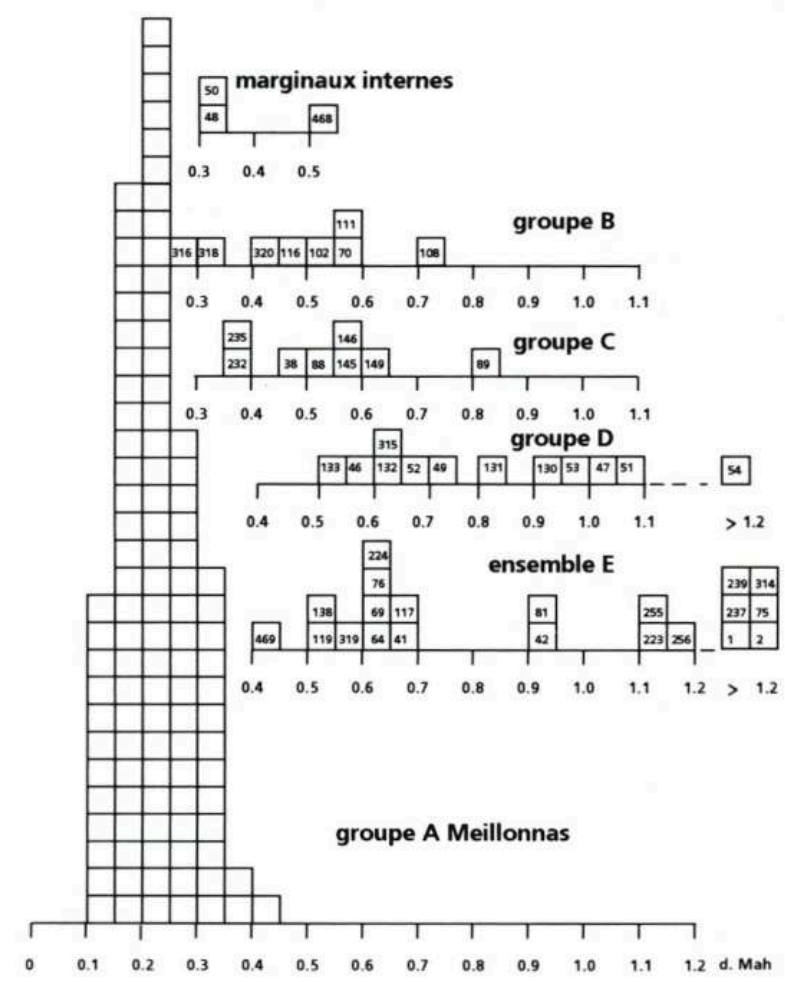

234 On a ensuite comparé les marginaux internes MRL48 et MRL50 à ce groupe de référence. Leurs distances sont inférieures aux distances maximales des exemplaires qui ont servi à constituer le groupe. Bien que situés parmi les distances de Mahalanobis les plus élevées, ces exemplaires ont une bonne probabilité d'être des productions de Meillonnas.

Le cas de l'argile MRL468 est différent. Elle se place sur la grappe en position marginale à l'intérieur du groupe A. Sa distance de Mahalanobis par rapport au groupe A est légèrement supérieure à la distance de Mahalanobis maximale des exemplaires du groupe. Ceci s'explique aisément: un prélèvement réduit d'argile a rarement une composition identique à la pâte céramique une fois travaillée et donc homogénéisée. C'est d'autant plus vrai dans le cas des argiles de Bresse dans lesquelles on sait qu'il existe des variations selon les bancs et à l'intérieur des bancs. On peut faire le même type d'observation pour MRL469 qui, elle, se classe dans l'ensemble E. Les différences de compositions chimiques qui lors de l'analyse de grappe l'éloignaient du groupe A s'inscrivent en fait dans les lois de variations internes du groupe : c'est pourquoi MRL469 se rapproche sur l'histogramme des distances de Mahalanobis. Sa distance reste cependant parmi les maximales du groupe.

Pour ce qui est des autres groupes, on observe sur la figure 54 un décalage régulier des histogrammes des distances de Mahalanobis par rapport au groupe de Meillonnas (groupe A).

237 - Les groupes B et C sont les plus proches du groupe A. Ceci n'est pas en désaccord avec l'hypothèse de l'existence d'un autre atelier proche de Meillonnas ou de l'utilisation d'un banc d'argile différent au sein d'une même formation géologique. 
238 - Le groupe D est plus éloigné. Ceci n'est pas en contradiction avec l'hypothèse d'un atelier plus éloigné tel Étrepigney.

Quant à l'ensemble E, tous les exemplaires (sauf l'argile MRL469) ont des distances de Mahalanobis très supérieures aux distances maximales du groupe. On ne peut donc pas les attribuer à Meillonnas.

Cette étude a permis de caractériser l'atelier de Meillonnas et d'aborder le problème de la diffusion de sa production. D'après les résultats des analyses et classifications on peut dire que l'on trouve des céramiques à glaçure verte assurément originaires de Meillonnas sur les sites suivants: Anse (69), Bressieux (38), Chalon-sur-Saône (71), Château-Gaillard (01), Genève (CH), Grenoble (38), La-Chapelle-du-Châtelard (01), Lyon (69), Meillonnas (01), Montagnieu (01), Nantua (01), Neuville-sur-Ain (01), Valence (26), Vienne (38), Villefranche-sur-Saône (69), Viriat (01), Vulbens (74).

241 Quant à l'atelier d'Étrepigney, les quelques analyses réalisées permettent de formuler l'hypothèse que ses productions ont été peu diffusées vers le sud puisque les seuls sites (parmi ceux qui ont été étudiés ici) où l'on a pu les reconnaître sont Chalon-sur-Saône (71) et Besançon (25).

242 Le dernier tableau (tableau 13) donne une synthèse des attributions d'origine réalisées à la suite de cette étude.

Tableau 13. Attribution d'origine des exemplaires provenant des sites de consommation

\begin{tabular}{|c|c|c|c|c|}
\hline \multicolumn{2}{|c|}{ lieu de découverte } & \multirow{2}{*}{$\begin{array}{c}\text { attributions } \\
\text { à Meillonnas } \\
\text { MRL59 } \\
\end{array}$} & \multirow{2}{*}{$\begin{array}{l}\text { attributions } \\
\text { à Êtrepigney }\end{array}$} & \multirow[t]{2}{*}{ inclassables } \\
\hline Anse (69) & MRL59 & & & \\
\hline Besançon (25) & MRL314 et MRL315 & & MRL315 & MRL314 (ens. E) \\
\hline Bressieux (38) & MRL253 & MRL253 & & \\
\hline Chalon-sur-Saône (71) & MRL44 à MRL54 & $\begin{array}{l}\text { MRL44 et MRLA5 } \\
\text { MRL48 et MRL50 }\end{array}$ & $\begin{array}{c}\text { MRL } 46 \text { et MRL } 47 \\
\text { MRL } 49 \\
\text { MRLSI a MRL } 54\end{array}$ & \\
\hline Château-Gaillard (01) & MRL63 et MRL64 & MRL63 et MRL 64 & & \\
\hline Genève (CH) & MRL_316 a MRL 320 & MRL317 & & $\begin{array}{l}\text { MRL.319 (ens. E) } \\
\text { MRL316 (gr. B) } \\
\text { MRL.318 (gr. B) } \\
\text { MRL } 320 \text { (gr. B) }\end{array}$ \\
\hline Grenoble (38) & MRL 312 & MRL312 & & \\
\hline La Chapelle-du-Châtelard (01) & MRL.55 & MRL.55 & & \\
\hline Lyon (69) & & & & \\
\hline A. Max & MRLI à MRL 5 & MRL3 à MRLS 5 & & $\begin{array}{l}\text { MRL1 (ens. E) } \\
\text { MRL2 (ens. E) }\end{array}$ \\
\hline Bellecour & MRL8 & MRL8 & & \\
\hline St.-Vincent & MRL105 a MRL112 & $\begin{array}{c}\text { MRL105 a MRLI07 } \\
\text { MRLL109 et MRLL110 } \\
\text { MRLII } 12 \\
\text { MRL120 a MRL129 }\end{array}$ & & $\begin{array}{l}\text { MRL108 (gr. B) } \\
\text { MRL111 (gr. B) }\end{array}$ \\
\hline Meillonnas château (01) & MRL102 & & & MRLI02 (gr. B) \\
\hline Montagnieu (01) & MRL60) a MRL62 & MRL60 à MRL62 & & \\
\hline Nantua (01) & MRLL134 à MRL.140 & $\begin{array}{l}\text { MRL.134 à MRL.137 } \\
\text { MRL.139 et MRL140 }\end{array}$ & & MRL138 (ens. E) \\
\hline Neuville-sur-Ain (01) & MRL65 a MRL 74 & $\begin{array}{l}\text { MRL65 a MRL68 } \\
\text { MRL71 a MRL.74 }\end{array}$ & & $\begin{array}{l}\text { MRL69 (ens. E) } \\
\text { MRL70 (gr. B) }\end{array}$ \\
\hline St. Paul-Trois-Châteaux (26) & MRL 255 et MRL 256 & & & $\begin{array}{l}\text { MRL255 (ens. E) } \\
\text { MRL256 (ens. E) }\end{array}$ \\
\hline Ternand (69) & MRL75 & & & MRL75 \\
\hline Valence (26) & MRL254 & MRL.254 & & \\
\hline Vienne (38) & MRL113 3 à MRL119 & $\begin{array}{l}\text { MRLI113 à MRLI1 } 15 \\
\text { MRL.118 }\end{array}$ & & $\begin{array}{l}\text { MRLL16 (gr. B) } \\
\text { MRRL117 (ens. E) } \\
\text { MRLI19 (ens. E) }\end{array}$ \\
\hline Villefranche-sur-Saâne (69) & MRL56 et MRL.58 & MRL56 et MRL.58 & & \\
\hline Viriat (01) & $\begin{array}{l}\text { MRL41 à MRL43 } \\
\text { MRL101 }\end{array}$ & $\begin{array}{l}\text { MRL43 } \\
\text { MRLI01 }\end{array}$ & & $\begin{array}{l}\text { MRL41 (ens. E) } \\
\text { MRL42 (ens. E) }\end{array}$ \\
\hline Vulbens (74) & MRL6 et MRL7 & MRL6 et MRL7 & & \\
\hline Total & & $\mathrm{n}=60$ & $\mathrm{n}=8$ & $\mathrm{n}=21$ \\
\hline
\end{tabular}

A. S. 


\section{Un commerce interrégional}

Rappelons que les recherches sur les ateliers de Meillonnas-Treffort en général, et sur le service vert en particulier, ont été envisagées lorsque l'on a pris conscience que nombre de fouilles régionales restituaient une quantité plus ou moins importante de cette vaisselle très caractéristique. Cette large diffusion attestait la vitalité commerciale des ateliers producteurs qui méritaient une attention particulière. Dès 1985 débutait une enquête auprès des archéologues et responsables d'opérations dans la région, afin de dresser une carte de diffusion du service vert aussi complète que possible ${ }^{36}$. Nous étions en cela aidés par la grande facilité qu'il y a à distinguer ce type de vaisselle, sans avoir nécessairement recours aux services d'un spécialiste. Les informations recueillies, croisées avec les résultats des analyses de laboratoire, donnent une bonne idée de la répartition des sites de consommation et confirment l'ampleur de la production des ateliers de Meillonnas-Treffort (fig. 55). Cependant cette carte ne saurait être exhaustive, puisque les découvertes se poursuivent à l'heure actuelle. Du moins, les limites de la diffusion commerciale des ateliers se dessinent, même si les analyses de pâte, confirmant l'attribution à Meillonnas, ne concernent que dix-sept sites sur les trente-sept répertoriés.

55 - Proposition de restitution de l'aire de diffusion du service vert depuis Meillonnas-Treffort

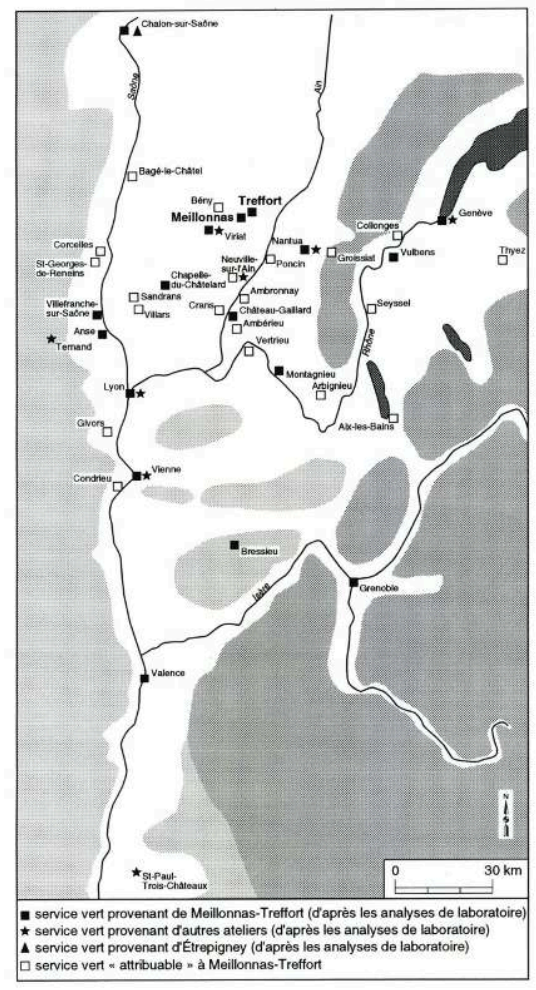

Sites ayant restitué du service vert attribué ou attribuable aux ateliers de Meillonnas-Treffort :

Ain :

Ambérieu-en-Bugey, Ambronay, Arbignieu, Bagé-le-Chatel, Bény, La Chapelle-duChâtelard, Château-Gaillard, Collonges, Crans, Groissiat-Nerciat, Montagnieu, Nantua, Neuville-sur-Ain, Poncins, Sandrans, Villars-les-Dombes, Viriat 
Drôme :

Valence

Isère :

Bressieux, Grenoble, Vertrieu, Vienne

Rhône:

Anse, Condrieu, Corcelles-en-Beaujolais, Givors, Lyon, Saint-Georges-de-Reneins,

Villefranche-sur-Saône

Savoie :

Aix-les-Bains

Haute-Savoie :

Annecy, Seyssel, Thonon-les-Bains, Thyez, Vulbens

Saône-et-Loire :

Chalon-sur-Saône

Suisse:

Genève

La répartition des lieux de découverte de poteries du service vert montre un rayonnement commercial relativement large des ateliers bressans. Tout à fait logiquement, la concentration des sites dans la plaine de l'Ain est très sensible. Les confins se signalent aussi assez clairement. Au nord (Chalon-sur-Saône et Besançon) les productions de Meillonnas-Treffort se heurtent à la concurrence des potiers d'Étrepigney (Jura).

D'autres séries d'analyses de composition des pâtes permettraient de mieux situer la limite entre les aires d'influence de ces deux centres de production : zones de répulsion ou au contraire d'interpénétration. Il est aussi probable qu'entre ces deux pôles, d'autres ateliers de moindre envergure, non encore répertoriés, aient proposé des produits comparables au service vert. Les résultats des analyses de certains échantillons provenant de sites de consommation, notamment le groupe B, laissent cette hypothèse ouverte (cf. supra).

$247 \mathrm{Au}$ sud de Valence, la rareté ou l'absence de service vert s'explique sans doute, par l'influence d'autres lieux de production à forte renommée comme les ateliers provençaux d'Uzège ou de la région de Bollène. Plus près de nous, au nord de Valence, les argiles kaoliniques de la moyenne vallée du Rhône ont favorisé l'éclosion de nombreux ateliers produisant également des poteries réfractaires (secteur de Larnage, par exemple) (cf. chapitre suivant).

248 La Saône, au nord de Lyon, et le Rhône au sud constituent une barrière occidentale que le service vert ne franchit pas, à l'exception de quelques sites particulièrement proches des cours d'eau (Anse, Villefranche, Corcelles, Saint-Georges-de-Reneins, ou Givors et Condrieu).

249 Cette vaisselle de qualité, culinaire et de table, n'a pas rencontré de concurrence marquée vers l'est puisqu'on la retrouve en Suisse, en Haute-Savoie et en Dauphiné. La barrière infranchissable semble avoir été la montagne. Jusqu'à présent nous n'avons aucun indice de sa présence en zone montagneuse. 


\section{Conclusion}

L'enquête de terrain sur les ateliers de la région de Meillonnas a, en grande mesure, confirmé les données d'archives et les a considérablement enrichies. Les communes de Meillonnas et de Treffort ont été largement explorées et prospectées (vingt-cinq hectares, près de 13000 tessons recueillis et étudiés). La grande quantité du mobilier en pâte blanche et glaçure verte, que les fouilles régionales mettent au jour de plus en plus souvent, prouve encore une fois que ces centres de production ont eu une importante activité, surtout aux XVIe et XVIIe s. L'étude typologique du matériel ramassé en surface, confrontée avec les points de prélèvement, reflète l'histoire de l'artisanat dans le secteur, et le déplacement des ateliers au fil du temps.

La présence d'une matière première argileuse abondante et facile d'accès est, à l'évidence, le moteur de l'implantation d'un artisanat de la terre cuite dans le secteur. Les diverses qualités de ces argiles ont favorisé la fabrication de produits variés; vaisselle culinaire réfractaire, vaisselle de table glaçurée, ustensiles domestiques, mais aussi creusets et carreaux de poêles. Parce qu'ils en avaient les moyens, les potiers ont su s'adapter à l'évolution du marché, garantissant ainsi la pérennité de leur activité.

3 Les ateliers les plus anciens (mentionnés également dans les textes dès 1416) se sont installés aux Tupinières (commune de Meillonnas). Quelques arguments, bien que rares, laissent penser à une origine fort ancienne comme la présence de becs pontés et pots à cuire sans col, à lèvres évasées ou en bandeau (XII-XIIIe s.). Mais la production connaît réellement quelque importance, semble-t-il, au XVe s. avec une spécialisation dans la poterie culinaire (marmites) et de larges formes ouvertes (bassins) en pâte grise ou brun clair sans revêtement. Dès la fin du XVe s. et durant les XVIe et XVIIe s., des ateliers fabriquant une vaisselle de qualité, culinaire mais surtout de table à la glaçure vert vif caractéristique, connaissent un réel succès économique. Ils s'étendent sur le territoire de Treffort, avec leur centre principal au Mas Girard, mais également au Mas Groboz et au Mas Guy. L'importance du rayonnement commercial de ces ateliers a été mise en évidence à partir d'environ cent cinquante analyses de pâte qui attestent la diffusion commerciale de grande ampleur atteinte par ces centres de production. Leurs céramiques sont largement diffusées dans la quasi totalité de la plaine de l'Ain et descendent dans la vallée du Rhône jusqu'à Valence. Rien d'étonnant à ce que les pays de l'Ain aient été largement approvisionnés, mais plus surprenant est de retrouver les produits de Meillonnas-Treffort en grande quantité à Lyon, Vienne et Valence, et de constater aussi la poussée commerciale vers l'est (Haute-Savoie, Suisse). La ville de Grenoble est également atteinte, bien que marginalement. Les ateliers, du service vert semblent avoir dû, en revanche, limiter leur diffusion vers le nord (pays de la Saône), où l'atelier concurrent d'Étrepigney (Jura) est bien implanté.

Enfin, à la fin du XVIIe s. et jusqu'au début du XXe s., les ateliers désormais rassemblés au hameau de la Razza, produisent des poteries relativement banales, à couverte monochrome jaune, orangée ou brune qui n'offrent pas d'originalité par rapport aux produits de Bourg-en-Bresse qui leur font, semble-t-il, une concurrence néfaste. Meillonnas reste cependant réputé grâce à l'installation de la faïencerie dans le château et à l'exploitation des carrières d'argiles qui, par leur qualité réfractaire, permettent la fabrication de moules et creusets pour l'industrie.

Aux XVIe et XVIIe s., la région semble donc avoir été sillonnée par un trafic de céramiques qui atteste, si besoin était, le rendement des ateliers de Meillonnas et de 
Treffort et leur capacité à fabriquer des produits de bonne qualité pouvant atteindre des marchés relativement éloignés. En cela les potiers ont pu profiter d'une viabilité relativement facile en raison des faibles reliefs et d'un réseau hydrographique dense.

La vitalité commerciale de ce centre potier apparaît dans les sources écrites explorées, mais cependant de façon peu significative. Rappelons que les potiers disposaient de «bancs » pour la vente, sous les halles de Treffort dès 1349. Le nombre de ces bancs n'a d'ailleurs cessé d'augmenter jusqu'au début du XVIe s. Malheureusement, au-delà, on ignore l'évolution de ce centre de distribution, faute de registre des redevances. En revanche, les informations directes sur les modalités du transport font défaut: les voituriers mentionnés en 1761 semblent ne transporter que de la terre. Mais la voie d'eau (l'Ain et le Rhône, mais aussi la Saône) est suggérée par la présence d'un revendeur grossiste de vaisselle de Meillonnas installé à Pont-de-Veyle en 1635.

Certes, la diffusion des ateliers de Meillonnas-Treffort garde un caractère régional. Mais le phénomène est frappant dans la mesure où il s'agit de vaisselle courante. Dans l'état actuel des connaissances, peu de centres de production en secteur rhônalpin se signalent par une telle ampleur et une telle durée dans la commercialisation de produits populaires. Exceptionnel ou exemplaire, le cas de Meillonnas-Treffort méritait qu'on lui prêtât une attention particulière.

\section{NOTES}

1. Responsable de la fouille F. Villedieu.

2. Responsable de la fouille F. Raynaud.

3. A.D. Ain : C. 112, mémoire sur la manufacture de faïence.

4. Le travail réalisé dans le cadre du Projet collectif de recherche H 19 a porté seulement sur la production des poteries traditionnelles. L'étude des faïences de Meillonnas (faïencerie du château) est menée depuis 1987 par J. Rosen et son équipe dans le cadre d'une fouille programmée et du programme de recherche national sur la faïence française. Ces fouilles ont montré que le château fut aussi le lieu de productions plus éphémères, comme les faïences brunes, les grès et aussi des poteries glaçurées des XVIIIe et XIXe s. Ce travail a servi de référence pour compléter les informations fournies par les ramassages de surface en ce qui concerne cette dernière catégorie de vaisselle (Rapport de fouilles programmées 1988-1991; Rosen 1993).

5. Cartes géologiques de Saint-Amour et de Bourg-en-Bresse au 1/50 000. BRGM.

6. D'après la coupe de la carrière de la Razza publiée par Paul Darnand (Darnand 1989).

7. D'après les recherches de J. Rosen sur la faïencerie du château de Meillonnas.

8. A.D. Côte d'Or : B 10158 à B 10280.

9. A.D. Côte d'Or : B 743, f $87 \mathrm{v}^{\circ}-89 \mathrm{v}^{\circ}$.

10. A.D. Côte d'Or : $B 747$ fo61-83.

11. A.D. Côte d'Or: B 10276, f०54: Recepit de et pro locagio quinque bancharum tuppinariorum in dicta ala de Trefforti vendetum et externum pro dictum castellanum locatorum qualibet bancha viginti denariis...(1525).

12. A.D. Côte d'Or : B 11595 et A.D. Ain : Mi 0331, fo 179-198, P 213vº. 
13. Ain : $4 \mathrm{~B}$,

14. A.D. Ain : $9 B$.

15. A.D. Ain : B 96, B 84, B 221, B 66. (XVIIe et XVIIIe s.).

16. A.D. Ain : $3 \mathrm{E} 12343$

17. A.D. Ain : 3E 5196-5203, 3E 5204, versement de Me Berger.

18. A.D. Ain : 3E 2190-2191; Pont-de-Veyle, cartons $n^{\circ} 7,20,22,55,57,65$.

19. -A.D. Ain : C 112, mémoire sur la manufacture de faïence rédigé par le seigneur de Meillonnas, H. de Marron, en 1761.

20. A.D. Ain : versement de Me Berger, $\mathrm{n}^{\circ} 5: 2$ nov. 1679 .

21. A.D. Ain : versement de Me Berger, $n^{\circ} 5: 10$ oct. 1683.

22. A.D. Ain : versement de Me Berger, $n^{\circ} 5: 3$ oct. 1677 .

23. A.D. Ain : registres des états des sections des communes de Treffort et Meillonnas.

24. A.D. Ain : C 112, 1761 (cf. note 19).

25. A.D. Ain : 3E 2190, fo $27 \mathrm{v}^{\circ}-28 \mathrm{v}^{\circ}, 26$ déc. 1635.

26. Ce four a été découvert fortuitement en 1974 dans la propriété de la famille Giroud qui a très largement ouvert l'accès au mobilier qui comblait le four. Que Mme Giroud et ses enfants soient ici remerciés. Notre gratitude va aussi à M. P. Darnand pour toutes les informations qu'il nous a fournies et son aide efficace sur le terrain.

27. A. D. Ain, 53M2. La vaste enquête des Préfets, menée à l'échelle du pays, à l'instigation du Ministère de l'Intérieur, devait dresser le tableau des ressources, des pratiques et capacités de l'artisanat céramique de façon à mieux répondre aux effets de la concurrence étrangère. Les réponses des maires des communes aux préfets sont une source irremplaçable de renseignements pour qui s'intéresse au sujet.

28. Nous remercions Me Berger, ancien notaire de Treffort, pour les renseignements fournis et l'accès à la collection des « carreaux émaillés » de Treffort.

29. Indications fournies par L. Moyret ( $\dagger$ ), (Rapport de fouille de sauvetage 1985).

30. Voir note 26.

31. La hauteur du segment reliant deux ou plusieurs individus est fonction du degré de dissimilarité de leurs compositions chimiques; plus le segment est court plus les individus se ressemblent, et, inversement, plus la jonction se fait haut plus les individus sont différents.

32. L'écart-type mesure la dispersion des valeurs par rapport à la moyenne.

33. Ici les calculs ont été réalisés en tenant compte uniquement des huit constituants majeurs : $\mathrm{K} 2 \mathrm{O}, \mathrm{MgO}, \mathrm{CaO}, \mathrm{MnO}, \mathrm{A} 12 \mathrm{O} 3, \mathrm{Fe} 2 \mathrm{O} 3, \mathrm{Si0} 2, \mathrm{TiO} 2$.

34. Un mode au sens statistique du terme correspond à la classe de distances la mieux représentée.

35. BRGM. Carte géologique de Dole au 1/50 000.

36. Nous tenons à remercier ici tous ceux qui ont aimablement participé à notre enquête en signalant les lieux de découverte et en mettant à notre disposition, pour étude et analyses, le mobilier dont ils disposaient. 


\title{
Chapitre 2. Dans la moyenne vallée du Rhône : le secteur d'Érôme et de Larnage, un exemple parmi d'autres
}

\author{
Élise Faure-Boucharlat, Bruna Maccari-Poisson, Sophie Savay-Guerraz et \\ Anne Schmitt
}

1 La recherche de l'origine des céramiques issues des principales fouilles de Lyon et de Vienne nous amena, dès les premières années de l'enquête, à travailler sur la vallée du Rhône, en aval de Lyon, où la présence de matériaux argileux d'accès aisé, tout comme les facilités de transport offertes par la voie d'eau, constituaient des critères d'implantation d'ateliers rarement réunis dans la région.

\section{Objectif des recherches}

2 La profonde transformation du couloir rhodanien depuis l'ère industrielle a gêné les investigations de terrain et les informations recueillies restent lacunaires. Des indices toponymiques très forts dans le secteur de Vienne (Isère), quartier des Tupinières, des indices géologiques et bibliographiques dans les environs de Givors (Rhône), à Loiresur-Rhône et à Bans guidèrent les premières recherches au fil du fleuve, dans la vallée proprement dite comme sur les reliefs qui la bordent, en rive droite (fig. 1 introduction). Mais l'absence de sources écrites antérieures à la Révolution, à mettre en relation avec les quelques témoins archéologiques repérés, limita les résultats de l'enquête à la simple localisation d'ateliers de poteries traditionnelles, probablement pas antérieurs au milieu du XVIe s. Quel crédit apporter en effet aux affirmations des érudits et folkloristes locaux d'après lesquels la fabrication de terres cuites architecturales à Loire-sur-Rhône remonterait à la plus haute antiquité ; l'extraction des argiles à poterie serait mentionnée dès le XVIe s., et enfin toujours à Loire-surRhône une première famille de potiers apparaîtrait à Bans au milieu du XVIe s. ?

3 En tout cas, les prospections et ramassages de surface réalisés sur ces communes offrent une première approche des fabrications locales. Il s'agit de types de produits 
largement connus par les fouilles de Lyon et de Vienne par exemple. Les deux catégories les mieux représentées sont les récipients à glaçure monochrome (vert, brun sombre et brillant, noir mat) et les quasi « universelles » vaisselles dites décorées aux engobes, avec leurs deux variantes : à fond clair et à fond sombre. Les formes pour la table (bols, écuelles à oreilles, jattes, assiettes, plats) sont les plus nombreuses. Les formes fermées sont avant tout des vases à liquide. Les décors sont la plupart du temps constitués d'un réseau de lignes parallèles ou entrecroisées. Des motifs curvilignes évoquent des motifs végétaux. La pâte est rouge, grossière et friable. Des détails, comme la forme lourde des tenons et des anses, l'exécution sommaire des décors, la médiocre qualité de la glaçure dénotent une production des plus communes. Encore au début du XIXe s., les poteries de Loire-sur-Rhône n'ont pas très bonne réputation : on les dit « de facture grossière et barbouillées de la façon la plus barbare... » (Cochard 1814-16, pp. K à Lv).

4 Bien que limitées, les informations recueillies à Vienne et à Loire-sur-Rhône sont évoquées ici, en raison de la similitude des conditions d'implantation et de production de ces ateliers avec ceux rencontrés en aval (Rapport d'activité du Projet collectif de recherche 1986 et 1987).

5 En effet, une enquête plus approfondie a été conduite dans la partie de la vallée du Rhône comprise entre Saint-Vallier et Crozes-Hermitage, sur la rive gauche du fleuve, dans le département de la Drôme, en amont du confluent avec l'Isère. Les recherches furent motivées par la découverte et la fouille, en 1986, d'un petit atelier de potier (datable des Xe-XIe s.) situé sur la commune de Bren (Drôme), canton de Saint-Donatsur-l'Herbasse, à une dizaine de kilomètre à l'est du Rhône. Cet atelier, éphémère et isolé, semble-t-il, bénéficiait néanmoins de conditions naturelles favorables à l'artisanat de la terre cuite, propres à ce secteur du Bas-Dauphiné (Rapport d'activité $\mathrm{du}$ Projet collectif de recherche 1986 et Faure-Boucharlat 1990). La diversité et l'abondance des affleurements argileux miocènes et pliocènes, ainsi que la richesse des témoignages toponymiques, incitèrent à élargir le champ des recherches de terrain et d'archives. Si l'atelier de Bren reste le seul vestige médiéval actuellement reconnu dans la zone des reliefs molassiques, en revanche des concentrations d'ateliers postmédiévaux et modernes furent rapidement localisées plus près du fleuve (fig. 56). 


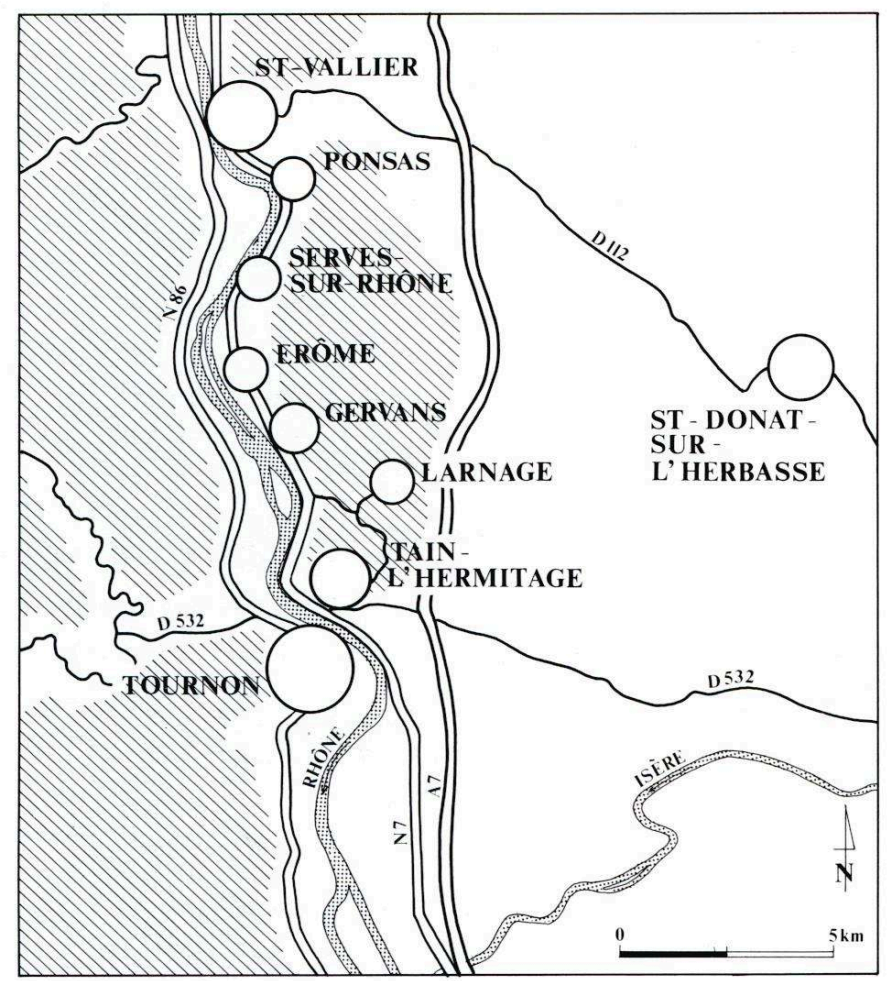

6 Les investigations ont porté sur les communes de Ponsas, Serves-sur-Rhône, Érôme, Gervans et Larnage. Plusieurs séries d'indices complémentaires invitaient à se pencher sur cette région en particulier. Il s'agissait de données d'ordre géologique, on le verra, mais aussi de données bibliographiques et enfin de mentions prodiguées par les statistiques industrielles contemporaines (XIXe s.) ou les enquêtes de l'Ancien Régime (XVIIIe s. surtout). En outre la spécificité des argiles kaoliniques de Larnage, terres blanches largement réputées, devait permettre de repérer assez facilement les productions et d'en rechercher la diffusion commerciale avec quelque chance de succès. Les communes drômoises paraissaient donc propices à une étude de type monographique, situation relativement exceptionnelle pour la région Rhône-Alpes où les concentrations d'ateliers sont rares. Dans ces conditions et parallèlement aux prospections de terrain, il a paru pertinent d'effectuer une enquête d'archives afin de mieux cerner l'ampleur de l'activité céramique d'Érôme et de sa région.

Si la plus ancienne mention d'artisanat potier à Larnage se place en 1552 (cf. tableau 2 Larnage), les indices de terrain réunis à ce jour sur cette commune ne sont pas antérieurs au milieu du XVIIe s. En revanche, sur les autres communes, une partie du mobilier recueilli, notamment la vaisselle aux décors d'engobes, pourrait illustrer la production dès le milieu du XVIe s.

Les nombreuses enquêtes statistiques établies au cours du XIXe s. révèlent l'importance de la production céramique dans ce secteur de la moyenne vallée du Rhône. Bien que parfois divergentes, les sources mentionnent plusieurs sites de fabrication: Érôme, Larnage et Ponsas bien sûr, mais aussi Tain-l'Hermitage, Saint-Vallier et Saint-Uze ${ }^{1}$. Les produits sont diversifiés par rapport aux périodes précédentes, puisque pipes, mais surtout poteries de grès se développent ou apparaissent à partir des années 1820 , au moins. Le caractère artisanal des fabriques semble s'effacer peu à peu au cours de cette 
période ; en effet les recensements d'ouvriers occupés par dizaines dans les poteries ou briqueteries d'Érôme ou Larnage sont courants, même si l'activité paraît toujours soumise à de fortes variations saisonnières.

9 Une petite usine d'objets utilitaires et décoratifs en grès à Ponsas, une fabrique d'éléments industriels et un magasin de vente à Érôme, perpétuent le souvenir des activités artisanales du passé. Des nombreuses poteries que comportaient ces agglomérations, il ne subsiste plus que des bâtiments ruinés ou tellement transformés qu'il est difficile de les identifier avec certitude.

\section{Environnement naturel et ressources en argiles}

11 La zone étudiée recouvre approximativement le « défilé » du Rhône, correspondant au passage du fleuve dans la fracture qui, en limite orientale du Massif Central, détache l'îlot granitique de Saint-Vallier du plateau vivarois. Le Rhône dans son cours actuel marque la limite entre le Massif Central, cristallin, et le Bas-Dauphiné, essentiellement sédimentaire.

Sur cette rive gauche du fleuve, les agglomérations prennent place au débouché des ruisseaux qui, depuis les hauteurs (Puy-de-Serves, les Planards, les Méjans) ont entaillé le versant ouest du massif granitique. A l'exception d'Érôme, qui s'étale plus largement dans la basse terrasse du Rhône s'élargissant quelque peu à cet endroit, les autres villages s'étirent au pied des reliefs, le long du fleuve et des cours d'eau affluents. A l'heure actuelle quelques exploitations agricoles subsistent dans les agglomérations, mais la fonction résidentielle tend à l'emporter progressivement, comme en témoigne le développement des lotissements sur les zones de relief. La voie ferrée et la route nationale 7 accentuent les contraintes de la topographie sur la disposition de l'habitat ; du moins pérennisent-elles le rôle de voie de communication majeure tenu par le défilé du Rhône.

13 Ces données géographiques ne sont probablement pas sans influence sur le processus de répartition de l'artisanat de la terre cuite dans le secteur. Bien évidemment ce paramètre se combine avec les possibilités du sous-sol qui offre des conditions favorables au développement de ce type d'activité. Le cas étudié ici présente sur bien des points les mêmes caractéristiques que celles réunies, plus en amont de la vallée du Rhône, autour de Vienne et de Loire-sur-Rhône où l'on retrouve les mêmes types de matériaux argileux (fig. 57). 


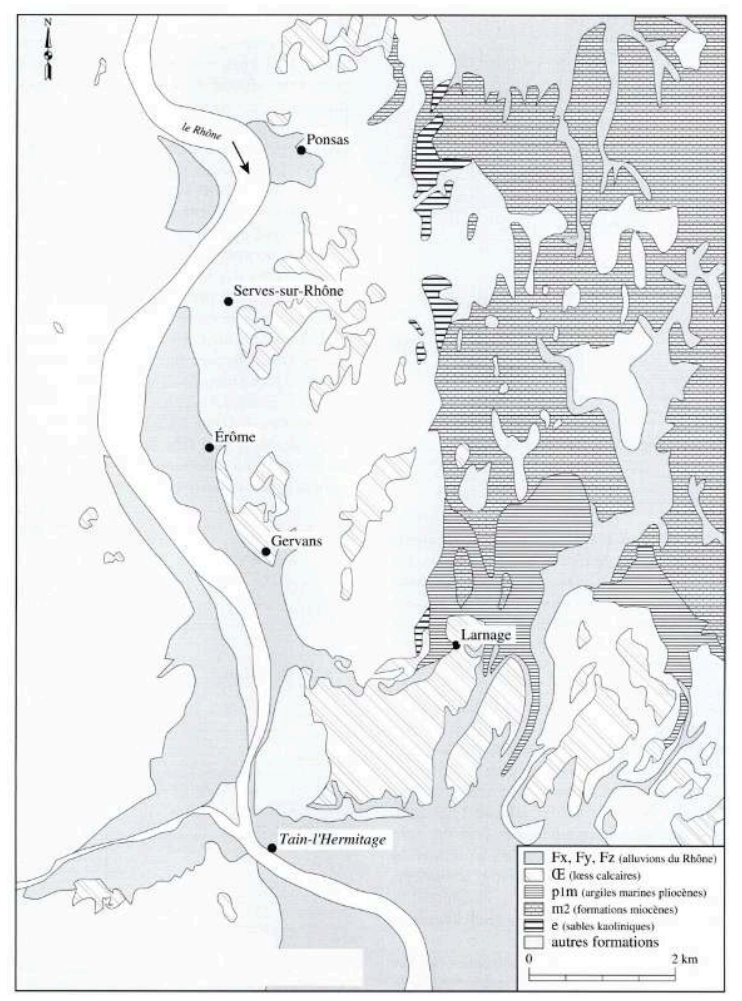

D'APRÈs LA CARTE gÉologiQue AU 1/50 000 SZ TOURNON BRGM transgressions marines importantes du Miocène (dépôts miocènes du Bas-Dauphiné) et la phase de surrection post-miocène qui a provoqué le surcreusement du lit du Rhône. Dans la ria étroite ainsi créée, la mer remontait jusqu'aux environs de Givors. Les dépôts marins de cette époque sont argileux (argiles pliocènes). Durant tout le Pliocène on assiste à un comblement progressif du bassin. Les formations d'argiles rougeâtres à galets de quartzite, que l'on retrouve sur les plateaux, correspondent à la fin du cycle de remblaiement (Villafranchien). Au quaternaire les glaciers du Rhône et de la BièvreIsère envahissent le domaine rhodanien apportant une grande masse d'alluvions. En périphérie des glaciers se développent des loess.

\section{hétérogène, assez impropre au tournage, mais utilisable pour la fabrication de tuiles et briques.}

17 Les colluvions : en surface des roches cristallines du Massif Central (dont les massifs isolés de Vienne et de Saint-Vallier constituent le prolongement) on peut observer diverses formations d'altérations. Il s'agit d'arènes plus ou moins grossières ou argileuses selon leur degré d'évolution. Ces gisements ont en général une extension très limitée et sont rarement représentés sur la carte géologique.

Le loess calcaire (OE) : il s'agit de dépôts d'origine éolienne limoneux et argileux qui se sont mis en place au quaternaire en périphérie des glaciers. Ce matériau est 
hétérogène, très sableux par endroits, argileux en d'autres. De plus, le taux de chaux est très variable, car en surface intervient souvent un phénomène de décalcification. Des affleurements de loess existent un peu partout dans la région et notamment à Vienne, Loire-sur-Rhône, Érôme.

19 Les formations glaciaires (p2b) : ces formations déposées par les glaciers sont constituées de galets roulés d'origine alpine inclus dans une matrice argileuse. C'est un matériau hétérogène, mais qui localement peut fournir un gisement d'argile exploitable. Cette formation est bien développée sur le plateau de Bonnevaux au Sud de Vienne et sur le plateau de Roussillon.

20 Les argiles marines pliocènes (p1m) : du fait de la topographie encaissée de la ria pliocène, ces argiles existent dans le fond de toutes les vallées. Le point le plus au nord où l'on rencontre ces argiles se situe aux environs de Givors. Ces argiles sont compactes, bleutées grises ou brunes selon les niveaux. Les taux de chaux mesurés sont en moyenne de $18 \%$. On observe par endroit des nodules calcaires et elles peuvent présenter des passées plus sableuses.

21 A Loire-sur-Rhône, la tuilerie Blache exploitait encore récemment une carrière ouverte dans les argiles pliocènes. A Roussillon, le potier établi au lieu-dit « Les Chals » utilise les niveaux superficiels de la formation; il considère que les niveaux bleus sont trop plastiques et difficiles à travailler. Dans le défilé du Rhône, les argiles pliocènes affleurent à Ponsas et à Erôme (entre autres). A Bren, on observe le passage entre le faciès marin et le faciès continental.

22 Les formations miocènes $(\mathbf{m} 2)$ : elles sont présentes sur une grande étendue à l'est du Rhône dans la plaine du Bas-Dauphiné. Il s'agit de façon générale d'une molasse sablogréseuse, mais elle peut présenter par endroits des intercalations argileuses. Des niveaux de ce type sont signalés aux environs de Bren.

23 Les sables kaoliniques (e) : A l'est du massif cristallin de Saint-Vallier, on trouve des sables kaoliniques datés de l'Éocène dits « sables de Douévas ». Il s'agit d'une alternance de bancs sableux blancs ou jaunâtres composés de quartz, feldspaths et galets de roches cristallophylliennes dans une matrice kaolinique. Des affleurements de cette formation sont visibles à Douévas, les Planards et Larnage.

Le tableau suivant (tableau 1) présente une synthèse des types d'argiles disponibles aux alentours de chacun des ateliers étudiés. Y sont intégrées également, à titre comparatif, les observations faites lors de prospections géologiques autour des ateliers de Bren, Vienne et Loire-sur-Rhône. 
Tableau 1. Les différentes argiles utilisées par les artisans au Moyen Age et à l'époque moderne

\begin{tabular}{|l|c|c|c|c|c|}
\hline Formation & Vienne & $\begin{array}{c}\text { Loire- } \\
\text { sur- } \\
\text { Rhône }\end{array}$ & $\begin{array}{c}\text { Erôme } \\
\text { Gervans } \\
\text { Ponsas }\end{array}$ & Larnage & Bren \\
\hline Alluvions du Rhône & $\mathrm{X}$ & $\mathrm{X}$ & $\mathrm{X}$ & & \\
\hline Loess & $\mathrm{X}$ & $\mathrm{X}$ & $\mathrm{X}$ & $\mathrm{X}$ & \\
\hline Formations glaciaires & $\mathrm{X}$ & $\mathrm{X}$ & & & \\
\hline $\begin{array}{l}\text { Argiles d'altération } \\
\text { de massifs cristallins }\end{array}$ & $\mathrm{X}$ & $\mathrm{X}$ & $\mathrm{X}$ & & \\
\hline Argiles pliocènes & & $\mathrm{X}$ & $\mathrm{X}$ & $\mathrm{X}$ & $\mathrm{X}$ \\
\hline Argiles miocènes & & & & & $\mathrm{X}$ \\
\hline $\begin{array}{l}\text { Sables kaoliniques } \\
\text { Éocènes }\end{array}$ & & & & $\mathrm{X}$ & \\
\hline
\end{tabular}

A Larnage, ce sont les argiles kaoliniques qui ont été utilisées pour la fabrication des céramiques à pâte blanche et glaçure jaune.

A Bren, l'atelier est installé directement sur un banc d'argiles pliocènes. Celles-ci n'ont pourtant été utilisées que pour la fabrication des fours. Les céramiques ont été réalisées avec des argiles non calcaires. Aucun prélèvement de ce type d'argile n'a pu être effectué aux alentours de Bren. Il faut vraisemblablement les rechercher dans les formations miocènes ou dans les colluvions.

Trop peu d'analyses de composition des pâtes concernant les produits de la vallée du Rhône ont été réalisées pour indiquer sans risque quels types d'argile ont utilisés les potiers. L'aspect des pâtes évoque des argiles non calcaires (Vienne, Loire-sur-Rhône, Érôme). Cependant un des tessons analysés révèle une composition à forte teneur en calcaire. La tradition rapporte que les potiers de Loire-sur-Rhône utilisaient, au début du XIXe s., un mélange d'argiles loessiques non calcaires et d'argiles pliocènes calcaires (Cochard 1814-1816, pp. K à Lv).

En tout cas, la présence sur les mêmes sites de ces matières premières de nature variée a favorisé la diversité des productions au cours des âges et l'adaptation des artisans à la demande de la clientèle, jusqu'à la généralisation de la faïence qui concerna particulièrement les officines proches des gisements de matériaux calcaires.

A.S. et E. F.-B.

\section{Une enquête historique fructueuse}

Dès 1899, dans son article consacré à la céramique du Dauphiné, Pilot de Thorey cite de nombreux noms d'artisans, recensés par les registres paroissiaux du XVIIIe s. à Ponsas, à Érôme et à Larnage (Pilot de Thorey 1899). Il signale, en outre, des inventaires après décès qui décrivent des poteries en terre d'Érôme parmi les biens meubles, tant de 
particuliers que de marchands faïenciers grenoblois (XVIIIe s.). Enfin, il ne manque pas de souligner l'emploi de terre kaolinique à Larnage, pour la confection de creusets destinés à l'Hôtel de la Monnaie de Lyon.

\section{Les sources utilisées}

\section{Les enquêtes et statistiques des XVIIIe et XIXe siècle}

Les procès-verbaux de Réformation des Eaux et Forêts du Dauphiné du XVIIIe s. n'évoquent que très marginalement l'artisanat de la terre cuite, dont l'incidence sur le couvert forestier paraît négligeable aux enquêteurs. Une exception cependant, lors de la visite de la communauté de Serves en 1701, l'officier des eaux et forêts déplore les dégradations commises par les potiers d'Érôme et de Ponsas sur les bois environnants².

Sur les cent quinze communautés recensées dans l'élection de Romans lors de cette Réformation, les mentions relatives à Érôme et Ponsas sont uniques ${ }^{3}$ Neuf autres communautés seulement comptent des ateliers, des tuileries exclusivement, dont la consommation en bois est sans conséquence sur le couvert forestier. Ainsi à Viriville (Isère) où les tuilleries quoyqu'au nombre de quatre (...) ne doivent faire aucune peine par rapport à la consommation du bois; leur activité est en effet discontinue et le bois utilisé est si peu de chose dans un territoire si remply d'arbres ${ }^{4}$.

Le dépouillement des procès-verbaux de Réformation des élections de Vienne et Grenoble, n'indique guère que quelques tuileries, mais aucun autre atelier de poteries, et surtout il n'est question que d'établissements isolés, jamais d'activité communautaire, comme à Ponsas et à Érôme ${ }^{5}$.

Citons ensuite plusieurs enquêtes sur l'industrie de l'Ancien Régime. Celle de l'intendant Fontanieu date de 1730. Elle enregistre deux cent trente-cinq ouvriers travaillant à la poterie de terre sur l'ensemble de la province, en spécifiant qu'à Larnage, on fabriquait des creusets de poterie blanche ; à Thein (Tain-l'Hermitage) des pipes grossières; à Chantemerle de la tenaille rouge; à Mercurol, de la tenaille blanche; à Serves des pots grossiers et de la ferraille fine couleur café de même qu'à Ponsas où, en outre, on commercialisait de la faïence blanche (Dubois 1932).

Ces communes sont les seules à être citées dans les élections de Romans et de Valence. Le centre de Dieulefit dépend de l'élection de Montélimar ; les élections de Grenoble et de Vienne ne comportent aucune mention d'atelier de poterie.

L'enquête industrielle de 1772 mentionne deux cent cinquante-huit ouvriers occupés à la fabrication de la poterie dans la province du Dauphiné. Outre Dieulefit (vingt-huit fabricants), les communautés citées dans le département de la Drôme sont Érôme (avec vingt-cinq fabricants) et Ponsas, où seul un fabricant de faïence fine est recensé (Pilot de Thorey 1899).

Le nombre de fabricants comptabilisés à Érôme et Dieulefit est à peu près équivalent ; néanmoins, le centre de Dieulefit emploie en outre deux cent vingt-quatre ouvriers potiers, celui d'Érôme aucun. Alors que chaque fabrique de Dieulefit réalise vingt fournées annuelles, celles d'Érôme n'en cuisent que cinq à huit. D'emblée, on peut remarquer qu'à la fin de l'Ancien Régime, les structures de production de ces deux centres ne sont guère comparables: à Dieulefit, les ateliers sont organisés selon un schéma semi-industriel, tandis qu'à Érôme fonctionnent des cellules artisanales, de type familial. 
affaires conclues devant notaires. Ces données sont sans doute très intéressantes au regard de l'histoire des fortunes et de l'économie rurale, mais il nous a semblé prématuré d'aborder de telles questions; par ailleurs, les relations interpersonnelles (familiales, mais aussi financières) sont omniprésentes, mais là encore il nous paraît préférable de réserver l'étude sociologique et de nous consacrer d'abord à celle de l'organisation professionnelle.

43 Des séries à caractère plus proprement économique, comme la série $C$ (administration régionale de l'Ancien Régime), ne possèdent malheureusement pas d'inventaires assez détaillés qui permettraient d'aborder de front la question de l'artisanat céramique dans le département de la Drôme.

La série E (sous-section Communes) répertorie essentiellement les registres paroissiaux et d'État Civil pour les communes de Larnage, Ponsas et Érôme. La commune de Larnage possède un fonds d'archives plus abondant, où figurent, entre autres, des parcellaires du XVIIe s. La sous-section Famille (dépôts des papiers de familles) de la série $\mathrm{E}$ a fourni un point de départ à l'étude ; parmi les actes concernant deux familles de potiers d'Érôme, des noms de notaires étaient mentionnés à plusieurs reprises. Ces études ont donc été examinées particulièrement. Des sondages ont néanmoins été 
pratiqués dans les registres d'autres fonds de notaires. Ont été ainsi sélectionnés les notaires résidant à Tain-l'Hermitage, Saint-Vallier, Marsas et Chantemerle-les-Blés. Bien que ce choix soit aléatoire, il reste la seule méthode possible eu égard au volume des registres notariaux. Ainsi, le fonds Jean Baptiste Baborier, notaire à Saint-Vallier de 1726 à 1762, est constitué de vingt-quatre registres de deux cent cinquante feuillets chacun (en moyenne).

Dans la série B (archives judiciaires), le dépouillement exhaustif des actes des judicatures d'Érôme, Gervans, Ponsas, Serves et Larnage a été entrepris. Seuls les XVIIe et XVIIIe s. sont représentés. L'intérêt majeur de ces dossiers, certains concernant des artisans céramistes, est de fournir, à l'occasion de procédures civiles ou criminelles (règlements de successions litigieuses, comptes-rendus d'audiences...), des inventaires de biens meubles et immeubles.

Le XIXe s. a été volontairement négligé (la bibliographie indique pourtant avec certitude que l'artisanat céramique y était florissant). La plupart des découvertes archéologiques faites à Lyon concernent des lots de céramiques datées des XVIe, XVIIe et XVIIIe s.; étant donné notre volonté de travailler en liaison avec les données de terrain, la période contemporaine n'a pas été étudiée en détail.

47 En dépit de ce choix, la consultation des documents cadastraux du XIXe s. reste indispensable, à moins d'ignorer une question essentielle: celle des localisations d'ateliers ou de carrières. Les rares précisions géographiques antérieures au cadastre napoléonien ne dépassent guère l'échelon du lieu-dit et les parcellaires de l'Ancien Régime (quand ils existent) ne sont pas toujours interprétables. On a considéré que la localisation des ateliers du début du XIXe s. pouvait guider la recherche des établissements plus anciens. Ces précisions topographiques sont essentielles pour orienter les prospections de terrain; elles livrent aussi des renseignements relatifs à l'implantation des ateliers, comme leur intégration éventuelle à l'habitat, leur constitution en quartier spécialisé, et la proximité des lieux d'extraction de l'argile...

\section{Réalité d'un artisanat}

On ignore actuellement si l'artisanat céramique s'exerçait déjà dans cette région à la période médiévale. Au cours des sondages dans les archives notariales, les registres de trois notaires établis à Saint-Vallier au XVe s., ont été dépouillés, mais sans résultat ${ }^{6}$ L'essentiel de la documentation présentée ici concerne les XVIe, XVIIe et XVIIIe s.

\section{Les matières premières}

\section{L'argile}

L'aspect technique ou géologique n'est bien entendu jamais évoqué directement, les mentions concernant plutôt les propriétés des terrains argileux ou la manière de les exploiter.

On dispose de cinq textes qui enregistrent la cession de terres propres à la fabrication de la céramique.

51 - Le premier, daté de 1623, est sans doute le plus riche ${ }^{7}$. Il conclut un accord entre deux beaux-frères, tous deux potiers à Gervans, pour l'exploitation des biens dotaux de leurs épouses respectives. L'accord stipule quil pourron prendre heux et leurs hoirs, héritiers, 
successeurs, a l'advenir quelconque de [la] terre d'argile pour servir a leur mestier pour faire la potterie de terre, sur le fonds l'un de l'autre au lieu-dit Le Blanc, sur le territoire de la commune de Gervans.

52 - En 1717, Félix Delosme cède à son fils Jacques, potier de terre à Larnage, à l'occasion de son mariage,

la propriété d'une terre (...) située audit Larnage, au terroir des Grenouillères (...) dans lequel fond est un terrier de mine blanche pour jouir duditfond du jour de nopces 8 .

53 La mention terrier de mine blanche indique avec certitude qu'au début du XVIIIe s. au moins, on exploitait le kaolin de Larnage. Jusqu'alors, les seules mentions de son emploi concernaient la fabrication des briques réfractaires au XIXe s. et des creusets au XVIIIe s.

54 - Le troisième document enregistre le mariage, en 1701, de Claude Nicolas, potier de terre à Ponsas ; il reçoit de sa mère Jeanne Sonier

une maison et ezance, terre et jardin avec l'usage du four à cuire vesselle et sa chape, quelle a scituée audit Ponsas; [elle] luy constitue le droit quelle a de se servir et prendre de terre propre à faire veysselle dans le fond dudit feu Sonier' 9

55 Ce dernier, père de Jeanne Sonier, lui avait remis en dot l'ensemble des biens et droits énumérés.

56 Outre l'affirmation du droit de prendre la terre et sa transmission directe ou par alliance, il apparaît au fil de ce contrat que la carrière d'argile et le four à poteries pouvaient être voisins, à condition que le fond mentionné ne fasse qu'un avec la maison, terre et jardin.

57 - Par une vente conclue le 24 avril 1782, Henri Sonier, potier de terre à Ponsas, cède à Fabien Robin, lui-même marchand potier à Ponsas

le droit et faculté exclusive de tirer de la terre de tuilerie et poterie dans une pièce de terre que jouit et possède ledit Henri Sonier au lieu de Ponsas. Ce droit est cédé à perpétuité, c'est-à-dire pour tout le tems ou il y aura dans le susdit fond de le terre propre à la tuillerie ou poterie ${ }^{10}$.

58 Les modalités d'exploitation du terrain sont ensuite détaillées. Fabien Robin est autorisé

à rouvrir quelques carrières qui auraient été abandonnées depuis plus de quatre ans [mais il est tenu de] payer les dommages qu'occasionneraient cette nouvelle recherche relativement aux arbres qui y avaient été plantés après ledit temps.

Enfin il est censé rendre le terrain dans l'état dans lequel il l'a trouvé

les trous de carrières devant après l'entière fouille [être] recomblés autant que faire ce pourra et le plus uniment possible.

60 Par ailleurs, le propriétaire, $\mathrm{H}$. Sonier, se réserve la sixième partie des terres de tuilerie et poterie pour son usage personnel, s'engageant à dédommager F. Robin pour les frais d'extraction. Enfin une dernière restriction intime à Robin de déblayer l'argile extraite dans un délai de deux ans faute de quoi il serait loisible audit Saunier de sen prévaloir.

61 L'argile extraite à Ponsas paraît avoir servi indistinctement à la fabrication des tuiles ou des poteries (à moins qu'il ne s'agisse d'envisager légalement les deux cas afin d'éviter toute controverse). 

consenti en 1629 par Jehan Rebatet potier de terre à Erôme (en tant que tuteur de Guillaume, fils de feu Jacques Rebatet potier de terre à Érôme) à un dénommé Sébastien, précise entre autres que Jacques Rebatet avait acquis

avec les autres pothiers de terre dudit lieu tous les droictz et pouvoir et faculté [d'extraire de l'argile] dans les terres out terroir que son propre a prendre de terre pour le service de leurdit mestier ${ }^{11}$.

63 La contrepartie de ce droit consiste en une rente dont le montant n'est pas précisé. Le droit dont disposait Jacques Rebatet, ou plutôt sa part, est loué à Sébastien pour une durée de neuf ans et pour le loyer de deux livres deux sous.

L'ensemble des textes cités permet de supposer que l'extraction d'argile se faisait dans chaque communauté (Ponsas, Érôme) dans plusieurs carrières plus ou moins temporaires, dans des terroirs connus pour leur sous-sol argileux, mais malheureusement non localisés. L'extraction était pratiquée directement par le potier, même s'il arrivait qu'il puisse acheter sa terre à un confrère. Des inventaires de biens d'artisans potiers énumèrent d'ailleurs quelques outils d'extraction. Louis Nicolas, potier de terre à Érôme, décédé vers 1758, laissait

n tour de bois pour tirer de la terre [et] deux cordes assez grosses servant pour sortir la terre des mines ${ }^{12}$.

Jean Carrier marchand faïencier à Ponsas mourut en 1768, laissant quatre bennes servant à voiturer de la terre ${ }^{13}$.

On conclura en abordant un arrentement passé, le 21 août 1769, par Claude François de Mure, seigneur de Larnage, à Jean Sauvajon, potier à Érôme et Claude Chabrerat, travailleur de Larnage ${ }^{14}$ Le seigneur de Larnage baille à ferme, pour une durée de quatre ans

les mines de terres blanches situées dans l'étendue de la terre et seigneurie de Larnage, c'est à dire les droits seigneuriaux que ledit seigneur a sur lesdites mines pour en jouir par lesdits fermiers ainsi qu'en ont jouits ou dus jouir les précédents fermiers suivant les titres et la possession dudit seigneur. [Il est] au surplus convenu que lesdits fermiers ne pourront faire de magazins de la terre blanche dudit lieu de Larnage (...) qui puissent causer des dommages interest audit seigneur ny à ses fermiers postérieurs, et dans le cas quils se trouveraient entre les mains au dela de ce quils pourroient débiter la dernière année de leur ferme, ils seront tenus de la laisser audit seigneur de Larnage ou aux fermiers qui leur succéderont, étant préalablement remboursés de la valleur, comme aussi lesdits fermiers s'obligent de veiller exactement à l'exploitation desdites mines, à la conservation des droits dudit seigneur sur icelles et de procurer le débit de la terre en provenant le plus qu'il leur sera possible, tant en terre qu'en creuzets. Ledit seigneur demeurant chargé d'inhiber et faire inhiber à tous les habitants du lieu de Larnage et ailleurs de prendre, vendre et débiter aucune partie de leur terre blanche sus-affermée sous quelque prétexte que ce soit, donnant pouvoir a cesdits fermiers de se pourvoir en son nom contre les contrevenants (...) bien entendu qu'il est prohibé à tout particulier de ladite terre et ailleurs, sauf lesdits fermiers de faire des creuzets suivants les titres dudit seigneur.

La teneur de cet acte est radicalement différente de celle des textes cités précédemment. La gestion des gisements de kaolin s'effectue dans le cadre seigneurial et leur propriété demeure l'exclusivité, semble-t-il, du seigneur de Larnage. Le montant de la ferme s'élève à cinq cent cinquante livres payables annuellement et il faut supposer que le produit de la vente des creusets et du kaolin couvre au moins ce loyer, auquel il faut ajouter les frais d'exploitation. Peut-on pour autant en déduire le coût de 
la matière première ? L'interdiction de stocker l'argile, l'exclusivité de son extraction et de sa vente indiquent néanmoins qu'il s'agit d'une denrée rentable, sinon rare. La qualité des fermiers est difficile à interpréter; l'un d'entre eux est potier, mais il n'en ressort pas pour autant qu'il utilise le kaolin pour son propre travail.

On a déjà vu que le kaolin de Larnage servait à la fabrication de creusets destinés à l'Hôtel de la Monnaie de Lyon. Or, en 1728, la ferme des mines de terre blanche était directement concédée aux maîtres affineurs de l'Hôtel de la Monnaie de Lyon. On peut se demander si les creusets mentionnés par l'acte de 1769 sont réservés au même usage, ou s'ils sont destinés à d'autres activités métallurgiques; les débouchés et la commercialisation s'en trouveraient alors modifiés...

\section{Le combustible}

70 Aux actes notariaux d'intérêt local, s'ajoutent les documents issus de l'administration forestière de la province, évoqués en introduction, et dont le point de vue plus général mérite d'être rappelé.

71 Le procès-verbal de réformation de 1701 mentionne l'exploitation, au lieu-dit Les Planards, de bois

composés en pueil de chênes, hêtres, noisettiers, chataigniers et mort bois qu'on coupe à deux ou trois ans au plus sans ordre reiglé ny mesure ny aucune réserve de balivaux, pour en faire des bourrées qu'on vend ensuite aux potiers et tuiliers qui sont establis aux environs dudit bois ; [ce qui provoque] une grande dégradation au moyen des fourneaux.

72 Les fourneaux incriminés sont ceux des potiers d'Érôme ${ }^{15}$.

73 Plus brièvement évoqué, le cas de Ponsas et des alentours de Saint-Barthélemy-de-Vals n'en amène pas moins le réformateur à critiquer les

abus que causent les faiseurs de briques et de thuiles. Quelques thuileries et quelques fours de pottiers de terre

sont en activité dans la communauté de Ponsas, mais le bois est acheté en dehors de son territoire propre, entre autres sur celui de Saint-Barthélémy-de-Vals (bois taillis de chêne, hêtre et meschans pin ${ }^{16}$.

La visite de réformation de 1727, précise, quant à elle, que l'on coupe

journellement 200 seterées de taillis pour la cuison (sic) de la vaisselle de terre que

l'on fabrique dans le pays ${ }^{17}$.

76 Il semblerait donc que les ateliers d'Érôme et de sa région provoquaient des dégradations préjudiciables aux forêts locales. Avant d'en déduire sûrement que l'artisanat céramique était gros consommateur de bois et, par voie de conséquence, que cette activité était intense, sinon florissante, il paraît indispensable de rappeler deux faits. D'une part, le couvert forestier des communautés d'Érôme et de Ponsas étaient peut-être plus fragile que ceux d'autres communautés de l'élection. D'autre part, il ne faut pas oublier que l'un des objectifs prioritaires des officiers commis à la réformation de 1701 était de déterminer les parcelles dont les bois convenaient à la construction navale. La proximité d'un cours d'eau était essentielle pour assurer le flottage des grumes. Or la communauté d'Érôme correspond parfaitement à ce schéma, puisqu'elle borde la rive gauche du Rhône. La sévérité du réformateur à l'égard des déprédations provoquées par les artisans potiers ou tuiliers s'en trouvait sans doute renforcée. 
77 Un acte notarié, de la même époque, contredit par ailleurs l'accusation portée par les officiers de Eaux et Forêts contre les potiers et les tuiliers d'exploiter les bois sans souci de gestion du couvert forestier. Il s'agit d'un contrat conclu par cinq potiers d'Érôme pour l'exploitation d'une coupe de bois. Située dans le territoire du mandement de Chantemerle, cette coupe est relativement éloignée des ateliers. Elle comprend l'exploitation de deux tènements de bois pour une durée de trois années consécutives ; le propriétaire de la coupe se réserve les chênes et les hêtres, abandonnant aux potiers les pins et les charmes sur pied, ainsi que le mort bois de chêne. La coupe est donc réglée, la conservation des essences est prévue par la réserve les grosses souches de chênes et de hêtres. Enfin, seules les essences de moindre qualité sont accessibles aux potiers, celles propres à faire du bois d'œuvre leur étant interdites. Bien entendu, cet acte unique ne suffit pas pour infirmer les dires des réformateurs des Eaux et Forêts, tout au plus peut-il les nuancer.

\section{L'atelier}

Aucun texte traitant de l'atelier du potier ou du tuilier n'est antérieur au XVIIIe s. Le fonds Habrard (notaire à Saint-Vallier) comprend pour les années 1621-1633 une centaine d'actes, pour la rédaction desquels ont comparu des artisans de la terre cuite. Aucun ne concerne l'atelier et ses dépendances, mais les raisons d'un tel laconisme sont peut-être fortuites.

A partir du XVIIIe s., trois catégories de renseignements apparaissent ; elles concernent l'atelier en tant que tel (localisation, structures bâties), son outillage et les modalités de son fonctionnement.

\section{Les bâtiments}

La composition des bâtiments est diversement décrite. En 1701, le contrat de mariage de Claude Nicolas, potier à Ponsas, fait état

d'une maison avec l'usage du four à cuire veysselle et sa chape et, en outre d'une boutique de poterie [avec] ses meubles ${ }^{18}$.

81 L'héritage de Jacques Delome, potier à Larnage, comporte

des bâtiments composés de plusieurs pièces d'écurie, cellier, cave, le tout joint ensemble avec une pièce servant pour la poterie, d'un petit magazin, d'un four à cuire le pain et un autre pour la vaisselle, d'un engare, plassage, cour et aisance ; un jardin, une aire de battage pour le blé et un parc à bestiaux complètent l'ensemble ${ }^{19}$.

Dans ces deux exemples, l'atelier n'est pas distinct des bâtiments de l'exploitation agricole (cas Delome) ou de la maison d'habitation (cas Nicolas); tout au plus, une ou plusieurs pièces sont-elles réservées à la fabrication de la céramique: atelier proprement dit, magazin et/ou boutique. A l'inverse, le four est soigneusement distingué : chacun des ateliers le possède en propre et il se trouve sans doute à proximité du corps de bâtiment principal.

84 A l'occasion du décès en 1768 de J. Carrier, marchand faïencier de Ponsas, l'huissier chargé de dresser l'inventaire de ses biens visite successivement la cuisine, la chambre, un cabinet, la lingerie, le magasin et la fabrique. Dans ce cas encore, la maison abrite l'atelier-ou l'inverse ! - et s'il n'est pas fait mention d'un four, c'est sans doute parce qu'il s'agit d'un inventaire des effets mobiliers ${ }^{20}$ 
85 L'inventaire des biens de L. Nicolas, potier décédé en 1758, n'est pas aussi disert; il signifie seulement que la maison du défunt est située dans le village d'Érôme, voisine

d'un plassage dans lequel il y a un four à cuire la veyselle de terre, presque détruit ${ }^{21}$. consultés témoignent plutôt en faveur d'une certaine disparité. Néanmoins, la faiblesse de l'échantillonnage et la diversité des activités (tuile, poterie, faïence) en sont peutêtre la cause.

\section{L'outillage et le mobilier}

91 Seuls les inventaires après décès et les contrats de location ont fourni quelques données sur ce sujet. Les testaments ne mentionnent jamais l'outil de travail et les contrats de mariage ne détaillent pas la composition des meubles de l'atelier. Trois actes traitent de la fabrication de la faïence, un seul de celle de la poterie.

92 Outre les outils (fig. 58) liés à la seule extraction de la terre (cf. supra), les outils de fabrication sont les suivants :

93 - des roues à faire vaisselle ou tours à fabriquer, la plupart du temps au nombre de deux ${ }^{24}$ ou trois ${ }^{25}$ en bois de sapin, ou de chêne et noyer ;

94 - des planches en bois de sapin (de douze à vingtquatre), pour entreposer la ferraille;

95 - un banc à battre la terre (parfois en bois de mûrier) avec ses petites barres de fer avec le même usage ou pals ;

96 - un ou deux moulins pour le vernis (alquifoux ou sulfure de plomb, pas de mention d'étain). Absent de l'inventaire du faïencier M. Sauvajon, un moulin est en revanche présent dans celui du potier L. Nicolas. On trouve en outre

un mortier en bois à piler le vernis et un marteau de fer avec son manche bois pour piquer la pierre du moulin

97

dans l'énoncé du contrat de location entre C. Sauvajon et J. Adam, faïencier ${ }^{26}$. L'inventaire de L. Nicolas, faïencier, signale 45 livres de verny moulu dans une urne, celui $\mathrm{du}$ faïencier J. Carrier 14 terrasses de terre pour l'entrepôt du verni lorsqu'il est moulu ${ }^{27}$;

98 - des tonneaux servan à tenir l'eau et la brouette pour les porter ${ }^{28}$. 


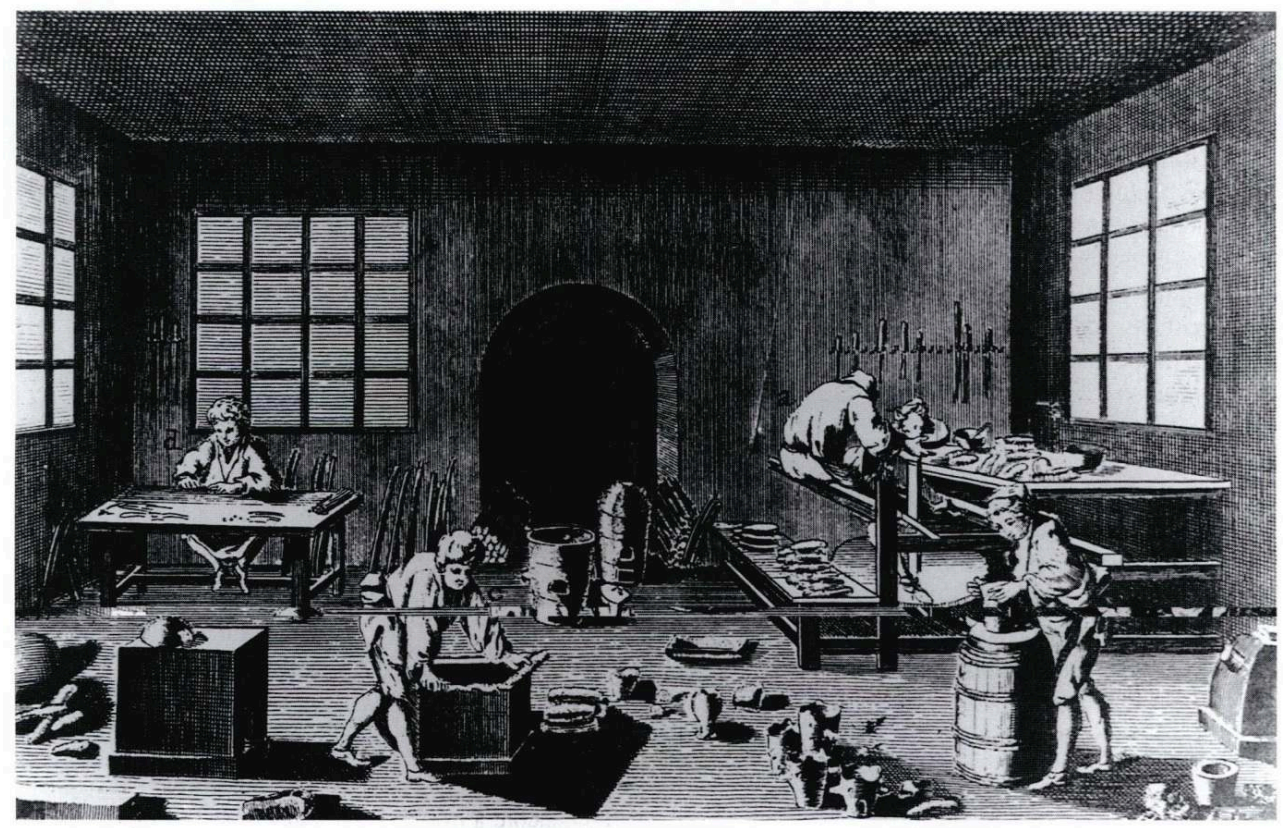

Extrait de l'Encyclopédie ; Diderot et d'Alembert, Arts de la céramique, (Inter-Livres, PI. I)

Seul J. Carrier, faïencier à Ponsas, fabriquait des céramiques moulées. Il possédait en effet un assez grand nombre de moules de plâtre pour les plats, les assiettes, les terrines, les saladiers, les plats à barbe, les salières, les cafetières...

Enfin, trois actes mentionnent des éléments de fours ou de mobilier de cuisson. Deux d'entre eux recensent une douzaine de planches ou soliveaux pour la couverture $d u$ four à cuire la vaisselle ${ }^{29}$ le troisième précise que parmi les biens loués avec la fabrique de faïence, J. Adam dispose des plaques et pilliers nécessaires pour les fournées de la fayence ${ }^{30}$.

\section{Les modalités d'exploitation : propriété et location}

La plupart des artisans possèdent leur atelier, parfois les terrains d'où ils extraient l'argile. Par ailleurs, leurs testaments indiquent qu'ils sont souvent propriétaires de parcelles de bois ou de broussailles. Les biens immobiliers échouant en déshérence ou en usufruit (à la veuve dans la plupart des cas) peuvent être loués ou vendus à des artisans sans atelier ou qui désirent effectuer un placement; ainsi un faïencier de Ponsas devient, en 1748, locataire d'une tuilerie située dans la même commune ${ }^{31}$.

Enfin, quelques textes témoignent que les fours peuvent être utilisés, sinon collectivement, du moins par les membres d'une même famille. Jeanne Sonier, par exemple, a droict de jouir par moytié avec les héritiers de feu Claude Sonnier, son père, du four à poterie sis à Ponsas dont elle dote en 1701 son fils Claude Nicolas.

C. Sauvajon, quant à elle, stipule dans le contrat de location de sa fabrique de faïence d'Érôme aux frères Marion, qu'elle se réserve de

faire cuire dans le four sus-affermé toute la vesselle qui pourra être fabriquée par sa famille, à la charge qu'elle remplacera à chaque fournées les plaques et les piliers qui se casseront ${ }^{32}$. 


\section{Les artisans}

Des « lignées » d'artisans potiers

Sans prétendre recenser exhaustivement l'ensemble des artisans de la terre cuite qui ont travaillé à Érôme et dans sa région, il était intéressant d'en présenter la population (tableaux 2 à 6). Les listes de potiers, tuiliers... qui suivent n'ont pas à proprement parler de valeur statistique. Tout au plus reflètent-elles bien la densité élevée de cette population qui laisse supposer un artisanat actif. La quarantaine de potiers recensés à Érôme/Gervans sur une période d'une douzaine d'années seulement (16211634) révèle bien cette vitalité.

La progression du nombre des artisans que l'on observe entre la fin du XVIe s. et le XVIIIe s. est plus délicate à interpréter. Il est indéniable, en effet, que même s'il est probable que l'artisanat ait connu une expansion réelle entre ces deux périodes, cette croissance est fortement accentuée par l'inflation de la documentation disponible. Les moyens de pondérer de manière sûre cette augmentation restent encore à trouver ; par ailleurs, il faut rappeler que les dépouillements des archives notariales ne sont pas exhaustifs, ce qui renforce le caractère aléatoire des données chiffrées.

Tableau 2. Les artisans « oulliers de terre » au XVle s. à Larnage et à Érôme

\begin{tabular}{|c|c|c|c|c|}
\hline date & nom & prénom & qualification & localisation \\
\hline 1552 & DELOME & Jehan & Potier & Larnage \\
\hline & & & & qualification \\
\hline date & nom & prénom & Potier & Érôme \\
\hline $1580-81$ & ALLEMAND & Jehan & Potier & Érôme \\
\hline 1581 & ALLEMAND & Pierre & Potier & Érôme \\
\hline 1581 & BEDON & Estienne & Potier & Érôme \\
\hline 1581 & BEDON & Laurens & Potier & Érôme \\
\hline 1581 & FAYOLLE & François & Potier & Érôme \\
\hline 1581 & SALLEVIN & Jehan & Potier & Érôme \\
\hline 1581 & SAUVAJON & Jehan & Potier & Érôme \\
\hline 1581 & SAYMIAN & Anthoine & Potier & \\
\hline
\end{tabular}

Source : registres de Geoffroy Charron, notaire à Tain-I'Hermitage

Source : Estienne Deloche, notaire à Tain-l'Hermitage ; A.D. Drôme 2 E 5727 (1578-1581)

A.D. Drôme 2E 5720 (1552-1553) 
Tableau 3. Les artisans céramistes au XVIle siècle

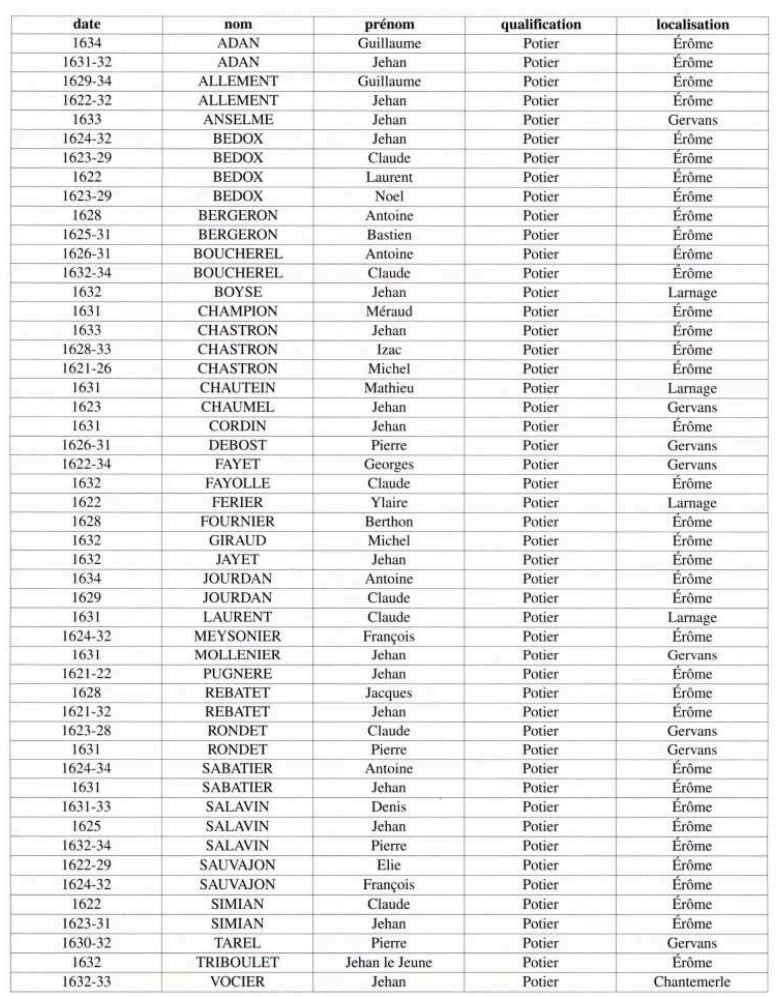

Source : Pierre 1er Habrard, notaire à Saint-Vallier

A.D. Drôme 2E 9460-9460 bis (1621-1633)

De même, on a opté pour une présentation par étude notariale de ces listes, afin de bien mettre en évidence les possibles variations de qualité qui pouvaient exister entre les différents registres. Par exemple, les registres des notaires Deloche (XVIe s.) et Habrard (début XVIIe s.) ne recensent aucun artisan exerçant à Ponsas (tableaux 2 et 3). Doiton pour autant en conclure que des potiers étaient installés à Érôme plus précocement qu'à Ponsas ? Rien n'est moins sûr, car il est fort possible que le notaire des artisans de Ponsas n'ait pas été retrouvé. La question mérite pourtant de rester posée.

107 A l'inverse, l'absence de tuiliers à Érôme paraît plus significative. Elle est d'ailleurs confirmée par les registres paroissiaux de cette commune et par les actes de procédure. Difficile d'envisager que cette absence ait affecté toutes les sources consultées sans qu'elle corresponde à une réalité historique. A une époque ou la diversification des activités de la terre cuite est plutôt la tendance, la relative résistance d'Érôme à ce courant est remarquable. En revanche, l'apparition des faïenciers au cours de la deuxième moitié du XVIIIIe s. coïncide avec la généralisation de la faïence à cette période (tableaux 4 à 6). La permanence de certains patronymes (les Delome à Larnage) ou leur fréquence (les Faure à Ponsas) révèle la spécialisation de plusieurs familles dans l'artisanat de la terre cuite. Il existe également de nombreux exemples d'alliances passées entres ces diverses familles, sans doute à la faveur d'intérêts professionnels communs. 
Tableau 4. Les artisans céramistes à la fin du XVIle siècle

\begin{tabular}{|c|c|c|c|c|}
\hline date & nom & prénom & qualification & localisation \\
\hline 1697 & FOURNIER & Antoine & Potier & Larnage \\
\hline 1696 & FOURNIER & Etienne & Potier & Marsas \\
\hline 1700 & GIRAUD & Michel & Potier & Érôme \\
\hline 1700 & HABRARD & Barthélémy & Potier & Larnage (?) \\
\hline $1697-1700$ & JOURDAN & Etienne & Tuilier & Larnage \\
\hline 1700 & MARMIGNON & Jean-Jullien & Potier & Larnage (?) \\
\hline 1697 & OLLIER & Claude & Potier & Larnage \\
\hline 1700 & RONDET & Jean & Potier & Érome \\
\hline 1700 & ROURE & Claude & Potier & Larnage (?) \\
\hline 1700 & SAUVAJON & Benoit & Potier & Larnage \\
\hline 1700 & SAUVAJON & François & Potier & Larnage \\
\hline 1697 & SAUVAJON & Jacques & Potier & Larnage \\
\hline 1700 & TRAVERSIER & Joseph & Potier & Larnage \\
\hline 1700 & TRAVERSIER & Jean & Potier & Larnage \\
\hline 1700 & TRIBOULET & Pierre & Potier & Érôme \\
\hline
\end{tabular}

Source : Pierre Richard, notaire à Chantemerle-les-Blés

A.D. Drôme 2E 7717-7718, (1697-1698, 1699-1700)

Tableau 5. Les artisans céramistes au XVIIIe siècle

\begin{tabular}{|c|c|c|c|c|}
\hline date & nom & prénom & qualification & localisation \\
\hline 1731 & CHOMEL & Antoine & Tuilier & Ponsas \\
\hline 1731 & CHOMEL & Christophe & Potier & Ponsas \\
\hline 1731 & CHOMEL & Jacques & Tuilier & Ponsas \\
\hline 1729 & DELOSME & Jean & Potier & Larnage \\
\hline 1731-32 & FAURE & Antoine & Tuilier & Ponsas \\
\hline 1729 & FOURNIER & Antoine & Potier & Ponsas \\
\hline 1730 & GAUSAND (?) & Jean & Potier & Érôme \\
\hline 1730 & GAUSAND (?) & Pierre & Potier & Érôme \\
\hline 1729 & GIRAUD & Jean & Potier & Érôme \\
\hline 1729 & GUIGONNET & Claude & Potier & Ponsas \\
\hline 1729 & GUIGONNET & Sébastien & Potier & Ponsas \\
\hline 1729 & MAIGRE & Jean & Tuilier & Ponsas \\
\hline 1729-31 & OLLIER & Claude & Potier & Ponsas \\
\hline 1732 & OLLIER & Henri & Potier & Ponsas \\
\hline 1729 & ORIOL & Denis & Potier & Érôme \\
\hline 1729 & PARADIS & Michel & Potier & Ponsas \\
\hline \multirow[t]{2}{*}{ 1729-31 } & PERRIER & Jacques & Potier (29) & Ponsas \\
\hline & & & Tuilier (31) & Ponsas \\
\hline 1732 & ROBIN & Imbert & Potier & Ponsas \\
\hline 1729 & SONIER & Antoine & Potier & Ponsas \\
\hline 1729 & TRIBOULET & Pierre & Potier & Érôme \\
\hline
\end{tabular}

Source : Jean-Baptiste Baborier, notaire à Saint-Vallier

A.D. Drôme 2E 9510-9511 (1726-1732) 
Tableau 6. Les artisans céramistes au XVIIIe siècle

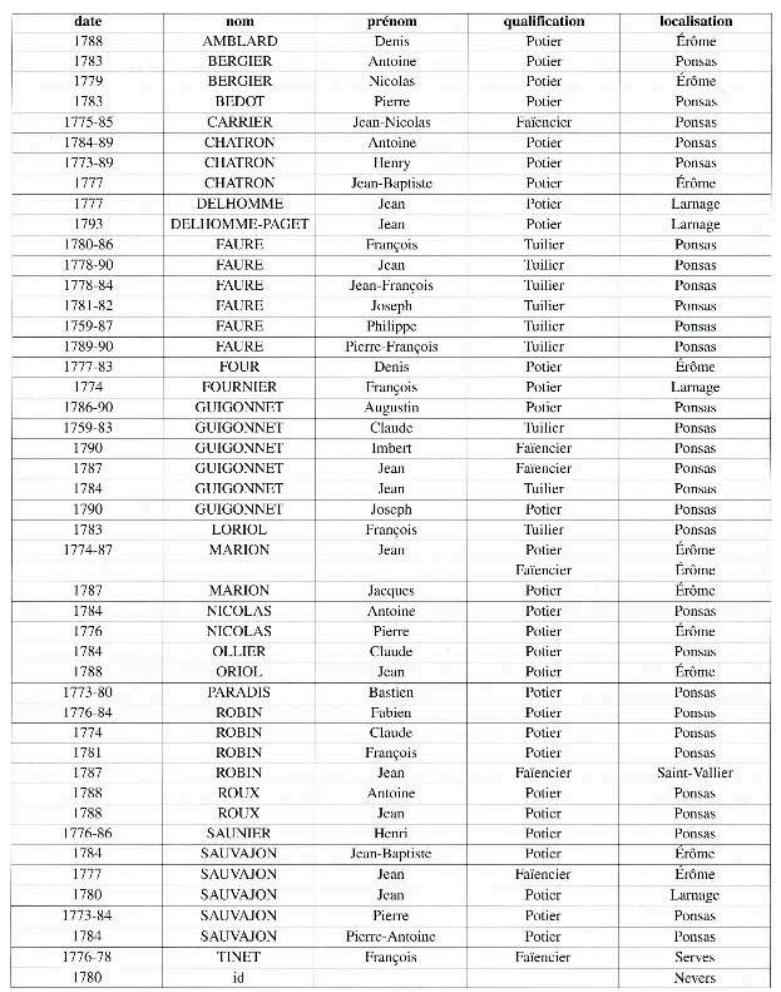

Source : Bureaux de l'enregistrement des actes notariés : Saint-Vallier

A.D. Drôme 2C 221,223-Tain-l'Hermitage

A.D. Drôme 2C 233,3Q (1799)

\section{L'apprentissage}

Le degré de qualification des divers artisans n'est guère évoqué ; l'appellation maître potier figure dans plusieurs actes notariés, mais on ignore si elle était employée au sens strict de la hiérarchie artisanale, faute d'autres indices relatifs à la maitrise.

Il arrive toutefois qu'un maitre potier forme un apprenti. Une quittance du 9 juin 1624 révèle que Claude Rondet, maître potier à Gervans (commune d'Érôme), reçoit en apprentissage Pierre Sylvestre (fils de laboureur) originaire du mandement de Vals (dont fait partie la commune de Ponsas); cet apprenti qui déclare se contante[r] fort bien de l'estât de potier de terre ${ }^{33}$.

110 Deux ans plus tôt, Jehan Champion confiait à Bastien Bergeron, maître potier à Érôme, son fils Méraud, pour apprendre le métier et l'art de potier de terre ${ }^{34}$. B. Bergeron s'engage pour un an, assurant l'entretien et la nourriture de son apprenti, en contrepartie de quoi, il recevra trentesix livres, son épouse une paiyre de manches de drap et Jehan Bedox $^{35}$ son serviteur une payre de bas. Il serait intéressant de savoir si ce J. Bedost est le même que celui mentionné en 1633 comme potier à Gervans, ou encore celui mentionné comme potier à Érôme dès 1629. Ce qui permettrait en effet de donner au terme de serviteur une acception professionnelle, synonyme d'ouvrier.

L'enseignement fut, semble-t-il, profitable à Méraud Champion que l'on retrouve établi potier à Érôme en 1631, lorsqu'il prend en apprentissage Imbert Despinnasses de Gervans. Le contrat est conclu pour une durée de deux ans, M. Champion assurant 
l'entretien et la nourriture en échange de quoi, I. Despinnasses est tenu de luy donner le service desdites deux années ${ }^{36}$.

112 Le contrat passé en 1632 entre Pierre Vinel et Jehan Bedox est plus exceptionnel. Il stipule que J. Bedox d'Érôme se louera à P. Vinel de Crussol (Vivarais) pour le servir de son art de potterie de terre ledit tempt [un an] pour le prix et somme de soyxante livres et une chemize de toylle ${ }^{37}$. S'agit-il d'un contrat entre ouvrier et patron, car il n'est pas question d'association entre les deux parties? Quant à Jehan Bedox, s'il était fait la preuve de son identité avec les homonymes déjà évoqués, il serait alors possible de lui reconstituer les étapes d'une carrière caractérisée par la mobilité.

\section{Activités complémentaires}

113 Qu'il se qualifie de potier (ou tuilier) n'empêche guère l'artisan de se livrer à d'autres activités, agricoles pour l'essentiel. Les actes de ventes ou d'échanges de tènements ou terres, vignes, prés, bois... passés entre des particuliers et des potiers (ou entre potiers) sont nombreux; les aires à battre le blé signalées par plusieurs textes, les pressoirs, tonneaux... mentionnés par d'autres en sont autant de confirmations.

114 A ce titre, on ne citera que deux documents. Le premier répertorie les biens de la succession J. Delome (potier à Larnage, décédé en 1737) ; outre une vingtaine de parcelles (terres arables, vignes, bois...) l'héritage comprend des meubles vinaires, attraits aratoires et cheptiaux de bestiaux ${ }^{38}$.

115 Le deuxième est constitué par un livre de comptes tenu par Sébastien Nicolas, potier à Ponsas en 1742, qui fait état, au chapitre des recettes, de la vente qu'il fit de pommes, poires, amandes et vendanges ${ }^{39}$. Il est incontestable qu'à Érôme et dans sa région, l'artisanat de la poterie s'exerçait dans le cadre de l'économie rurale.

\section{Des textes peu précis sur les productions}

116 Les productions des potiers d'Érôme ou de Larnage ne sont pas traitées dans la majorité des actes notariaux ou judiciaires étudiés. Les inventaires après décès de faïenciers ne mentionnent guère qu'un catalogue de formes, tellement courantes qu'il est de peu d'utilité pour notre propos.

117 C'est en fait sur les lieux de consommation que l'on trouve le plus (et c'est encore peu) de renseignements sur les productions du secteur d'Érôme. La céramique fabriquée à Lamage a pu être identifiée parmi les tessons mis au jour sur les chantiers de fouilles de la région Rhône-Alpes grâce aux analyses physico-chimiques de leur pâte. En revanche, il est impossible actuellement de reconnaître les productions d'Érôme ou de Ponsas. Quelques textes d'archives attestent cependant que des productions d'Érôme ont été commercialisées à Lyon, Grenoble et Vienne. Il s'agit dans tous les cas d'inventaires après décès de particuliers (Vienne $\mathrm{e}^{40}$ mais surtout de revendeurs (Lyon, Grenoble ${ }^{41}$ ). Les mentions les plus courantes énumèrent des assiettes, des écuelles, des cafetières ou des plats parfois de couleur grise ou brune. La plus ancienne allusion à ces «terres d'Érôme » figure dans un inventaire lyonnais daté de $1610^{42}$ (fig. 59). 
59 - Extrait d'un inventaire après décès de marchand chandelier lyonnais, daté de 1610

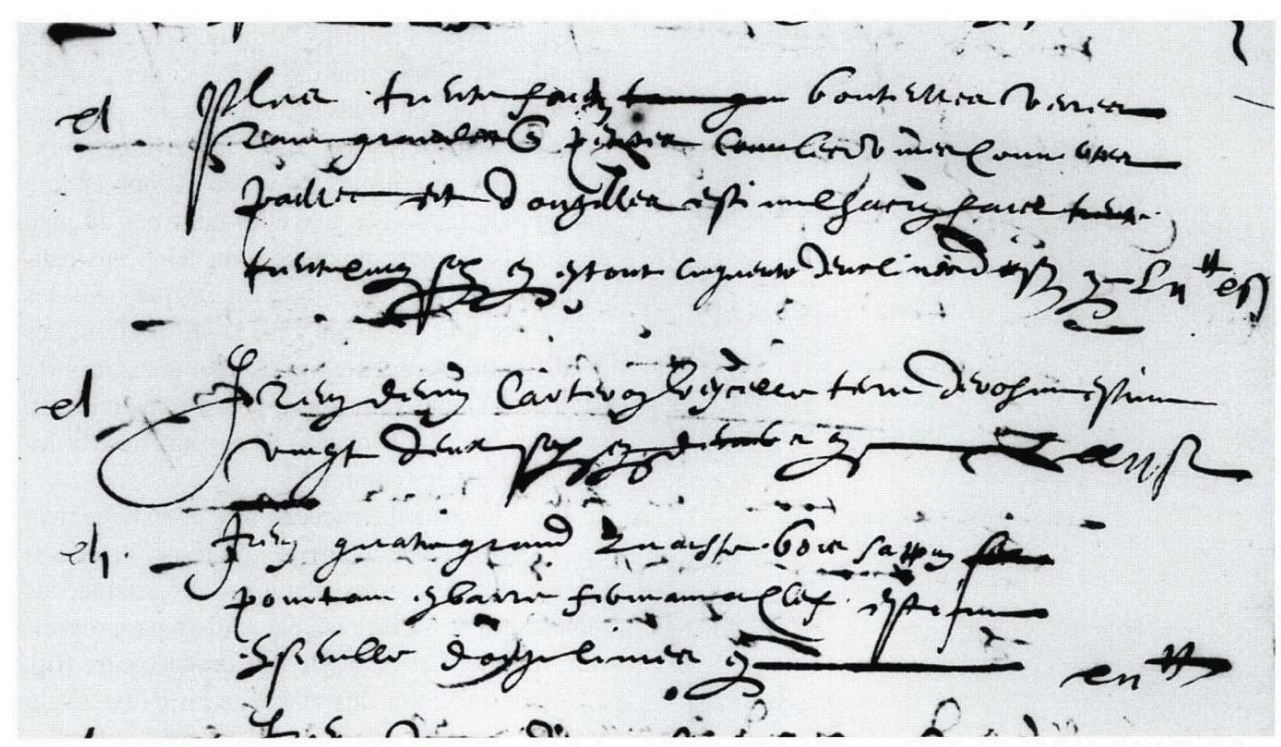

Transcription : « demy carteron veycelle terre d'Erosme »

A.D.Rhône. - BP 1887 ||

118 Si ces données assurent que les poteries d'Érôme atteignaient au moins les villes de Grenoble, de Lyon et de Vienne, la question de leur reconnaissance reste posée. Sur quel(s) critère(s) se basaient les experts chargés de les inventorier ? Quelle signification peut-on attribuer à l'expression "terre d'Érôme "? Les échantillons collectés lors des prospections, sur le lieu même de la fabrication, offrent sur ce point plusieurs possibilités, puisque plusieurs catégories de produits ont été déterminées (cf. infra).

119 S. S.-G.

\section{Les données archéologiques}

\section{Localisation des ateliers}

Les prospections ont pris en compte les lieux de production présumés et les lieux d'approvisionnement en matières premières. Des prélèvements ont été effectués dans les différents matériaux argileux mentionnés ci-dessus, afin d'en comparer la composition avec celle des poteries fabriquées dans le secteur. Les flancs des plateaux où s'étagent les talus limoneux et loessiques, les anfractuosités des ravins où affleurent les argiles pliocènes ont été explorés. Une carrière ancienne a été repérée sur la commune d'Érôme où, semble-t-il, ces deux catégories de matériaux ont été exploitées, la première en front de taille, la deuxième en puits (fig. 60). Il est bien sûr impossible de dater l'ouvrage, abandonné, semble-t-il, assez récemment et qui a pu alimenter les derniers ateliers d'artisanat d'art encore en activité dans le secteur. Du moins peut-on $\mathrm{y}$ voir l'ultime répondant archéologique aux informations fournies par les textes des XVIIe et XVIIIe s. : à Érôme, Ponsas et Gervans l'argile était extraite par les carriers eux-mêmes, en puits ou en fosses à ciel ouvert, dispersés sur les affleurements argileux à proximité des ateliers (cf. supra). En revanche l'exploitation des terres blanches ou kaolins de Lamage et de ses environs a considérablement marqué le paysage (fig. 61). De vastes carrières en front de taille sont encore en activité pour la fabrication de 
produits industriels. Les traces des exploitations anciennes ont disparu en raison de la mécanisation du travail. Les textes mentionnent toutefois l'utilisation du kaolin pour la fabrication de vaisselle de terre dès le début du XVIIIe s. (cf. supra).

60 - Dernières traces d'exploitation d'argile sur la commune d'Érôme : extraction en puits et en carrière

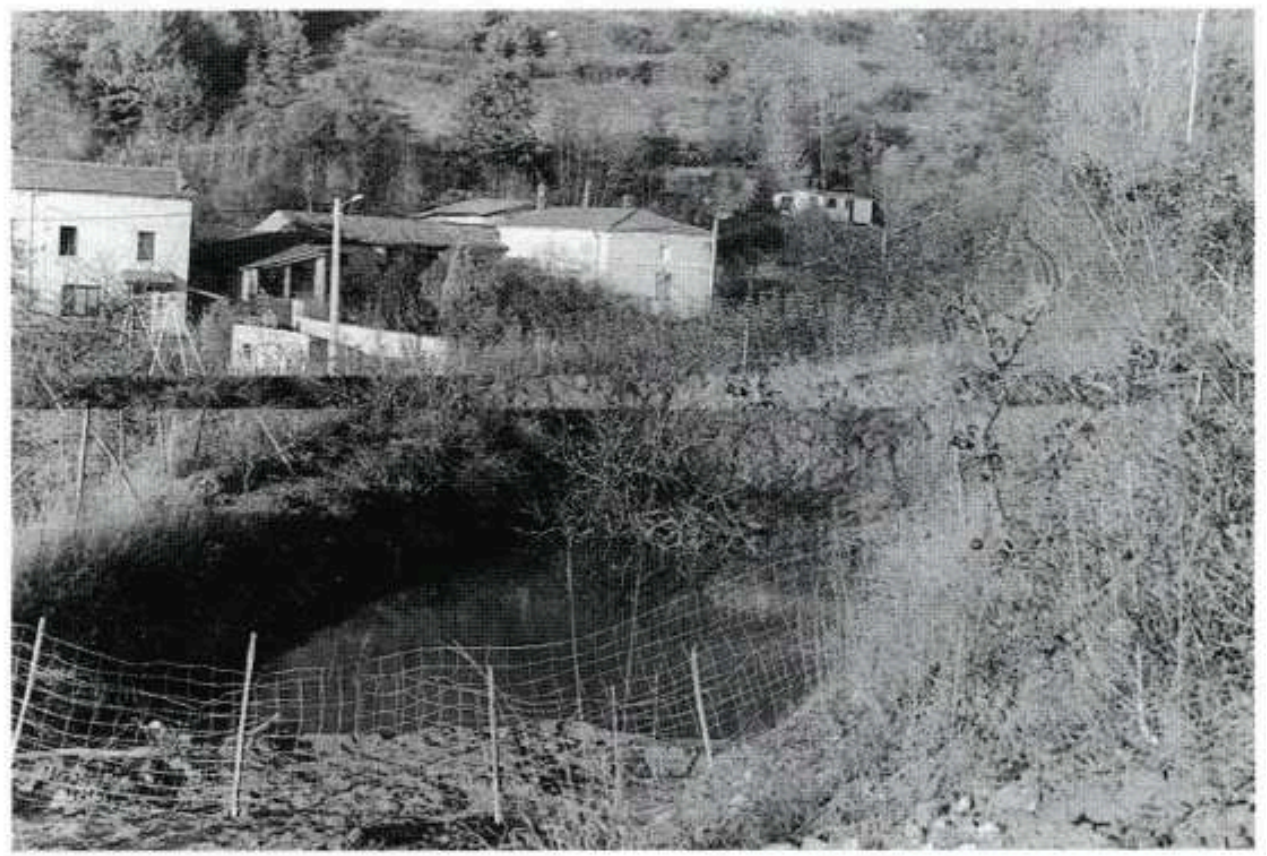

61 - Ancienne carrière de kaolin de Douévas, au nord de Larnage

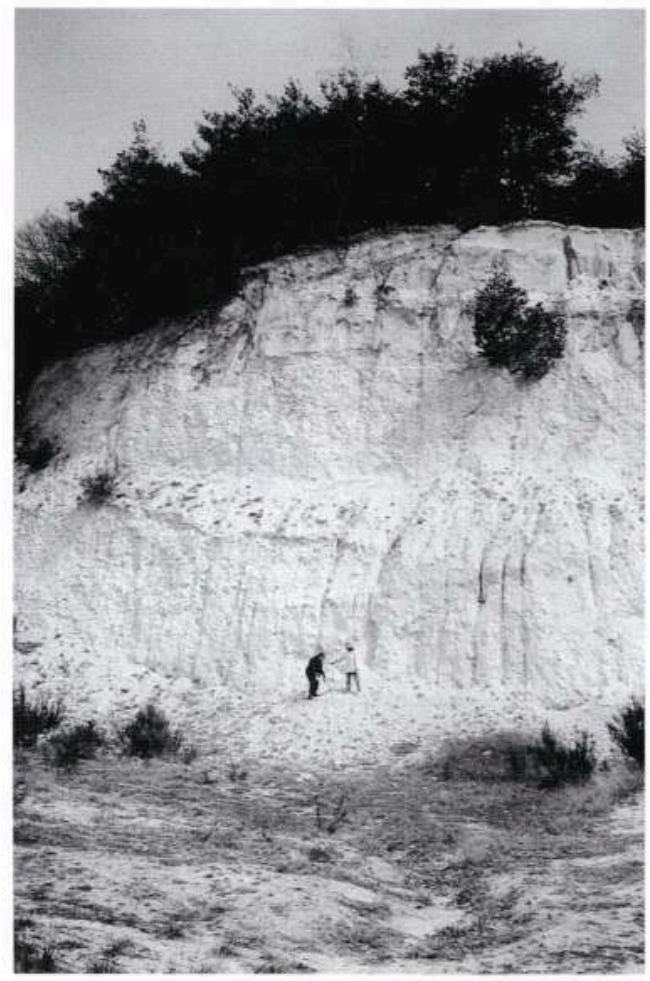



réalisés par progression régulière et parallèle des prospecteurs (fig. 62). Compte tenu des surfaces en cause et du caractère aléatoire de l'accessibilité des parcelles dans ces zones densément habitées, on ne pouvait prétendre effectuer des ramassages aussi exhaustifs et systématiques qu'en Bresse ou en Beaujolais. Seules les zones de concentration évidente de tessons ont été reportées sur les plans parcellaires. Les zones livrant des épandages de tessons plus diffus n'ont pas été retenues comme critères de localisation de rejets d'atelier. Néanmoins, les tessons recueillis ont été étudiés avec les autres communes illustrant a priori la production des ateliers locaux. Compte tenu de ces conditions de prospection, l'analyse de la répartition des zones de ramassage est indissociable de l'étude des plans cadastraux et des mentions textuelles, car les résultats assez lacunaires de l'enquête de terrain se trouvent heureusement compensés par les données d'archives. L'addition des informations autorisait une cartographie cumulative relativement fiable des officines.

\section{2- Paysage viticole des terrasses du Rhône}

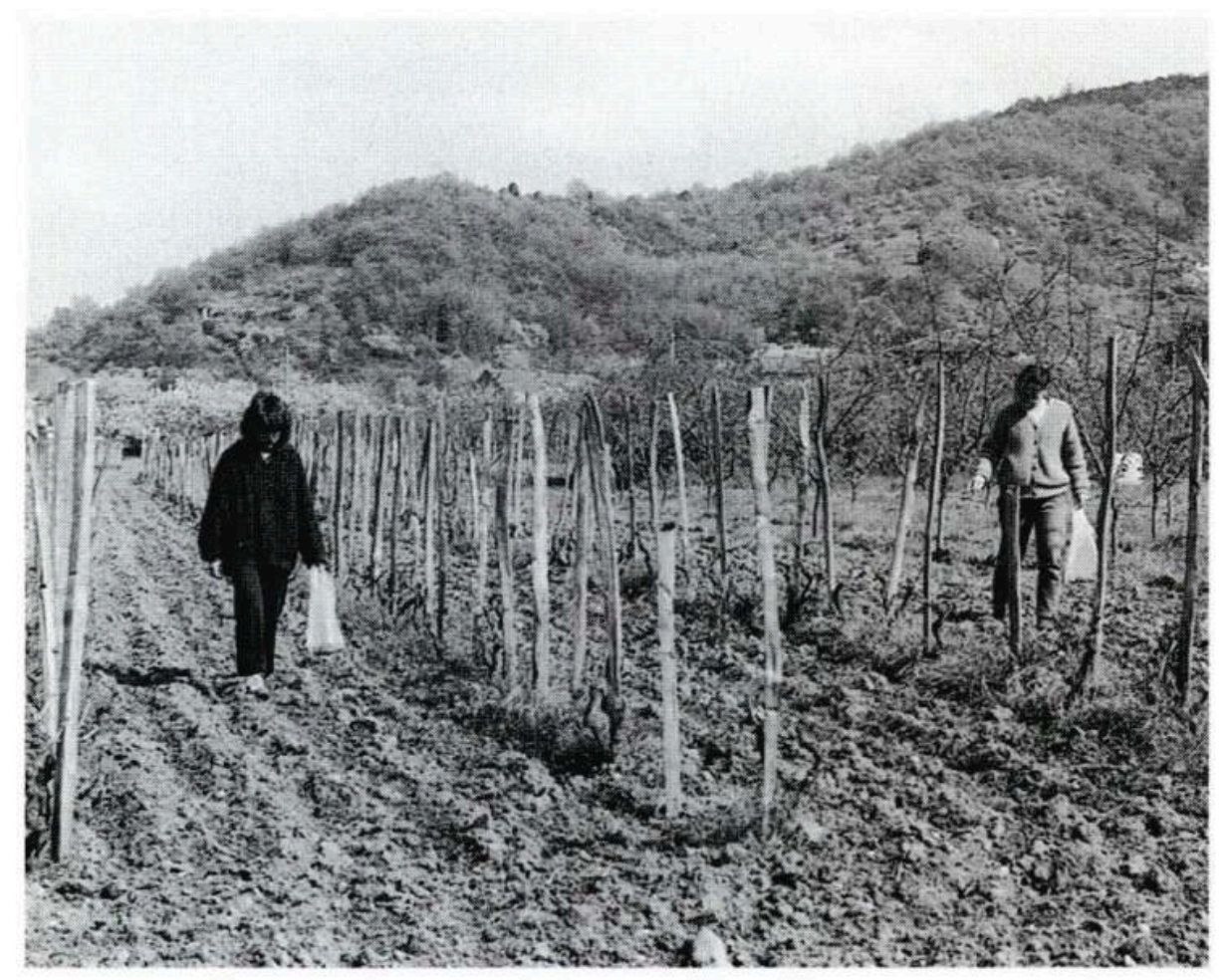

Secteur prospecté à Ponsas 
Les indications topographiques mentionnées dans les actes de l'Ancien Régime sont trop peu précises pour être reportées sur un plan. A quelques rares exceptions près concernant les communes de Larnage et d'Érôme, « l'adresse » des ateliers s'identifie au nom de l'une ou l'autre des communautés étudiées. L'intérêt des premiers plans cadastraux se trouve de ce fait encore accru. Outre la localisation précise des ateliers qui existaient dans la première moitié du XIXe s., ces plans offrent en effet une image de l'artisanat en partie héritée des époques antérieures. Plutôt que des reproductions des plans de 1830, on a choisi de replacer les ateliers recensés par les états des sections $\mathrm{du}$ XIXe s. sur les fonds cadastraux actuels, pour assurer une meilleure confrontation entre les données d'archives et celles des prospections de terrain. Signalons que l'organisation topographique des communes étudiées n'a guère évolué entre les deux cadastrations, excepté les destructions provoquées par le chemin de fer à Érôme et la construction de pavillons isolés ; la répartition des hameaux et le centre de chacun des villages ont peu varié entre l'établissement des deux cadastres.

A l'heure actuelle, quatorze zones de concentrations ont été repérées sur les communes d'Érôme, Ponsas, Gervans et Larnage, considérées comme des aires de rejets, et, par conséquent, susceptibles de signaler la proximité d'un atelier (tableau 7 et fig. 63 à 66). La commune de Serves, incomplètement prospectée il est vrai, n'a livré aucun indice de surface.

Tableau 7. Localisation des zones des ramassages de surface

\begin{tabular}{|c|c|c|c|}
\hline réf. carte & commune & lieu-dit & parcelle \\
\hline T1 & Érôme & Le Bourg (est) & E 140-141 \\
\hline T2 & Érôme & Les Verres & H 235 \\
\hline T3 & Érôme & Les Verres & H 460 \\
\hline T4 & Érôme & Le Bourg (est) & E 125 \\
\hline T5 & Érôme & Le Bourg (est) & E 146-147 \\
\hline T6 & Gervans & Sous les Blancs & C971 \\
\hline T7 & Érôme & Le Tout & C1182 \\
\hline T8 & Érôme & Le Bourg & E302 \\
\hline T9 & Érôme & Le Bourg (la Rionne) & H227 \\
\hline T10 & Ponsas & Les Romanets & B 152-153-154 \\
& & (ravin du Bouchard) & \\
\hline T11 & Ponsas & Le Bourg - Les Romanets & B 121-122 \\
\hline T12 & Larnage & Les Sautons & B2 730 a \\
\hline T13 & Larnage & Village & B3 977-978-979 \\
\hline T14 & Larnage & Hameau & B3 934-941 \\
\hline
\end{tabular}

Comme dans toutes les tentatives de localisation d'ateliers, la confusion entre rejets artisanaux et rejets domestiques ne peut être totalement écartée, en particulier, et c'est ici le cas, lorsque les prospections se déroulent près des zones d'habitats. Aussi les témoignages incontestables du travail des potiers ont-ils été relevés avec soin: agglomérats d'argile cuits ou surcuits, tessons de ratés de cuisson (à Érôme en T2, T3, 
$\mathrm{T} 4$, T5, et T9 et à Gervans en T6) ainsi que des pernettes et des cales en forme de boudins de terre (à Ponsas en T1 et T10).

Si les informations relatives aux tuileries fournies par les plans anciens sont reportées sur les cartes, notre enquête de terrain ne s'y est pas attardée. En effet, il paraît probable que les deux types d'activité, poteries et tuileries, étaient dissociés; et la fabrication des terres cuites architecturales sortait de nos centres d'intérêt.

63 - Carte de réparatition des ateliers, toutes sources confondues, sur la commune d'Érôme

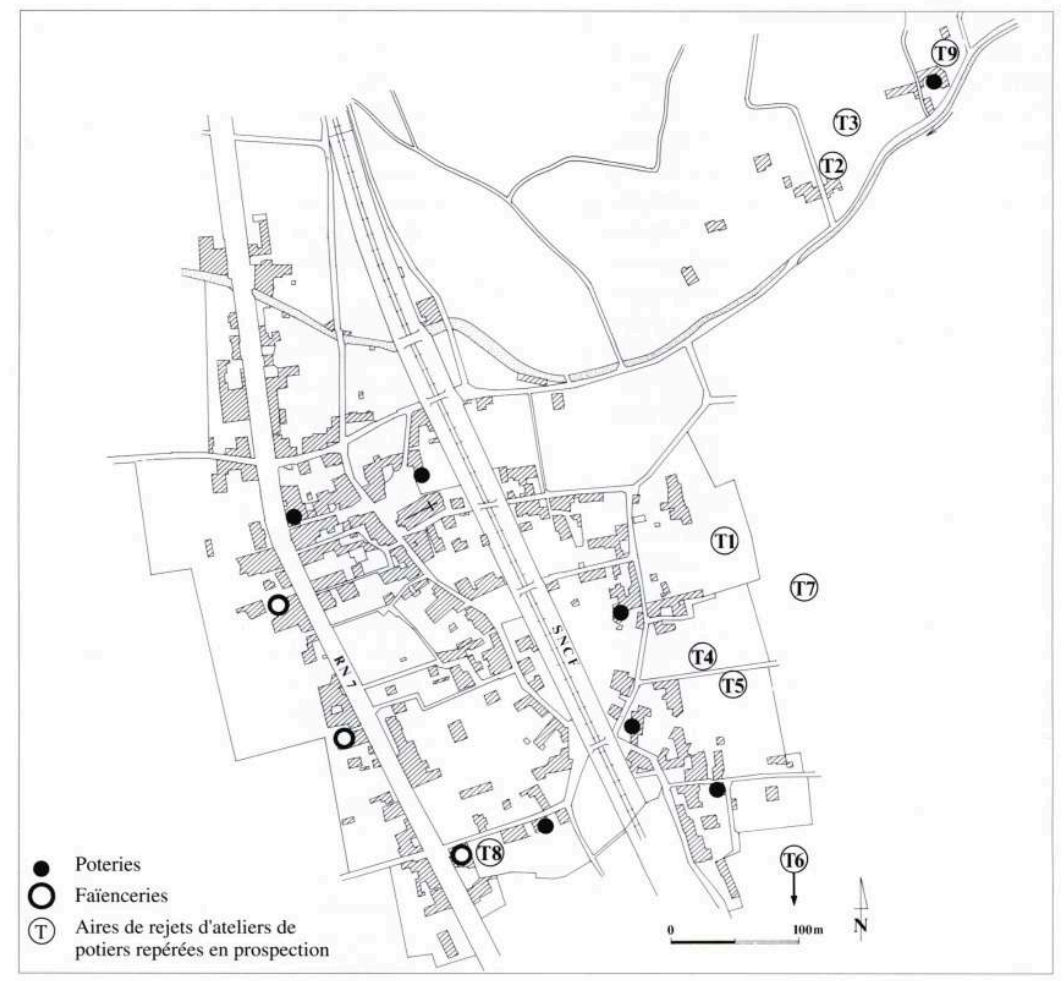

Les points de ramassage se concentrent donc dans les agglomérations, mais il n'y a pas toujours de relation nette entre ceux-ci et la localisation des ateliers à partir du cadastre napoléonien. Seuls T8, T9 à Érôme et T11 à Ponsas sont proches de poteries signalées dans le cadastre. Il n'est pas toujours aisé d'expliquer la répartition des points de ramassage. D'une part, les prospections ne sont pas exhaustives, d'autre part, le paysage a été considérablement modifié par les travaux de régulation du Rhône et la construction de la voie ferrée. Cependant, il est clair, et l'enquête historique le confirme, que les ateliers étaient installés dans les villages, dispersés parmi les exploitations agricoles. L'image de Ponsas est caractéristique de ce schéma, plusieurs ateliers de poterie constituant même l'embryon d'un quartier spécialisé. Le cas de Larnage est plus nuancé, puisque trois tuileries sont établies au nord-ouest du hameau des Bonassons, à l'écart des ateliers du « centre » villageois.

La relation topographique exacte entre les ateliers portés au cadastre ou mentionnés par les textes et les bâtiments anciens encore en élévation dans les villages n'a pu être établie. Elle réclamerait une enquête particulière, tout comme la recherche de vestiges d'installations (tours, fours, aires de chauffage et de stockage...) à l'intérieur de ce bâti fortement remanié. Quelques traces de l'artisanat céramique subsistent en remploi dans des constructions récentes: tubulures, éléments de parois de fours, cales 
d'enfournement... (fig. 67). L'image de l'artisanat restituée plus haut (bâtiments, outillage, fonctionnement) se fonde exclusivement sur les archives notariales à partir du XVIIIe s. (cf. supra).

\section{4 - Carte de répartition des ateliers, toutes sources confondues, sur la commune de Ponsas}

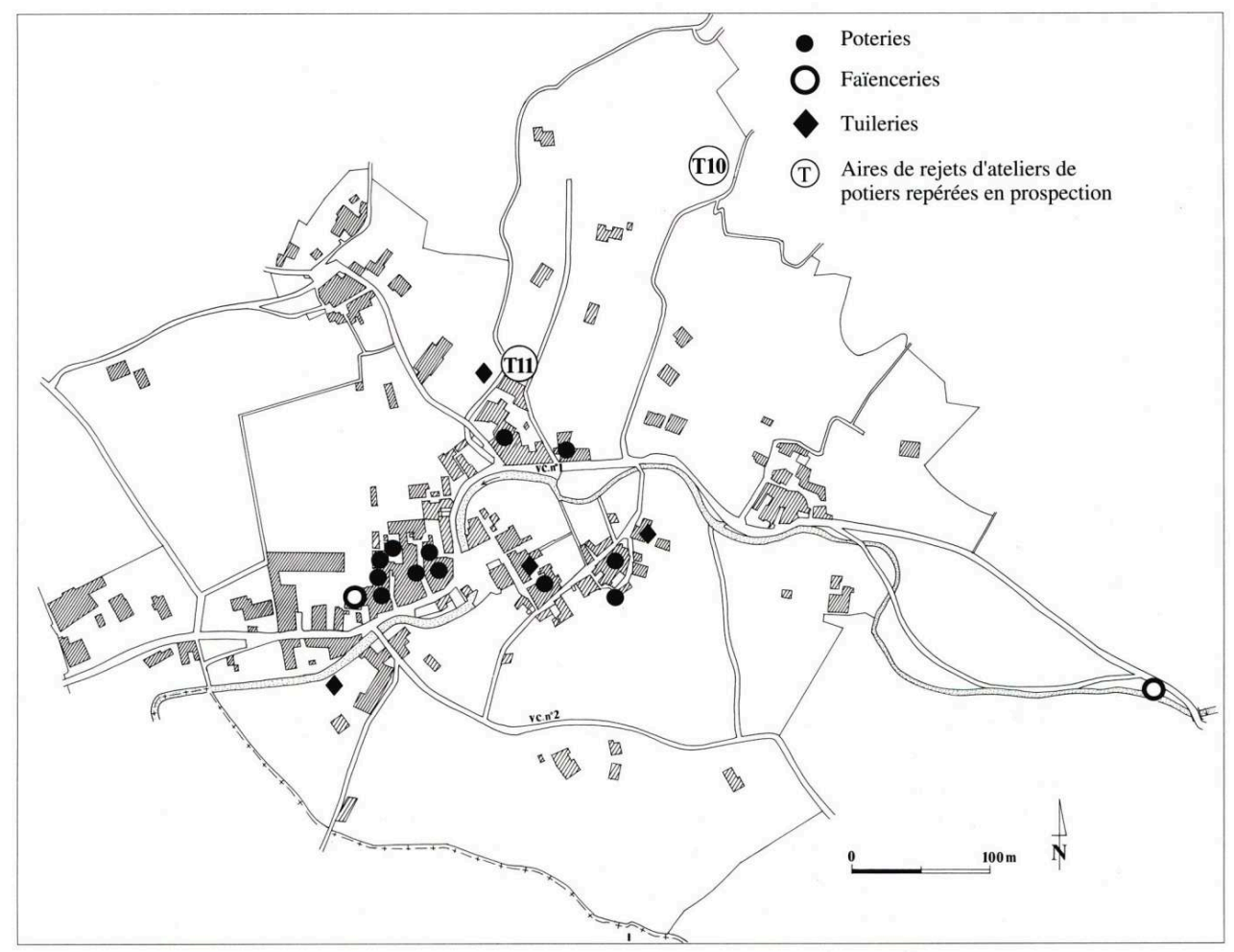

Les indices de terrain élargissent donc la répartition des ateliers telle qu'elle serait suggérée seulement par les données cadastrales. Il est vrai que les prospections ont rarement été fructueuses (si l'on excepte Larnage) dans les zones d'habitat dense. Mais T6 sur Gervans, T7 sur Érôme et T10 sur Ponsas pourraient signaler des ateliers relativement éloignés des bourgs. Il est à noter que $\mathrm{T} 6$ et $\mathrm{T} 7$ sont situés près de ravins propres à procurer des matériaux argileux.

Les cartes de répartition des ateliers (fig. 63 à 66) appellent quelques réserves : elles représentent vraisemblablement un état partiel d'une réalité plus foisonnante. Ces résultats doivent être mis en regard des listes d'artisans établies à partir des fonds notariés du XVIe au XVIIIe s. (cf. supra, tableaux 2 à 6); plusieurs dizaines d'artisans sont en effet recensés au cours des XVIIe et XVIIIe s. Ces listes suggèrent la place prépondérante d'Érôme dès le XVIe s., et tout au cours du XVIIe s. Au XVIIIe s., les mentions concernant Ponsas sont les plus nombreuses. Les communes de Gervans et de Serves semblent en revanche beaucoup moins propices à l'installation des ateliers, comme cela ressort également de l'enquête de terrain. Si la mention la plus ancienne concerne Larnage (milieu XVIe s.), ce n'est qu'à la fin du XVIIe s. que l'artisanat y semble bien implanté (cf. supra). 
65 - Carte de répartition des ateliers, toutes sources confondues, sur la commune de Larnage, vue générale

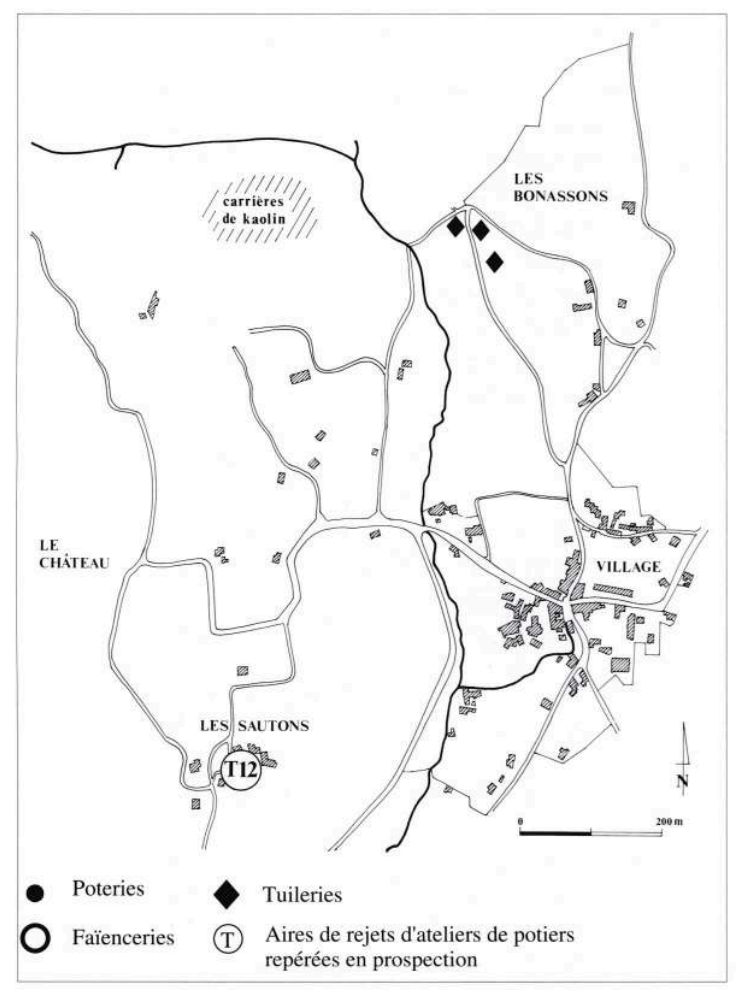

66 - Carte de répartition des ateliers, toutes sources confondues, sur la commune de Larnage, détail du bourg

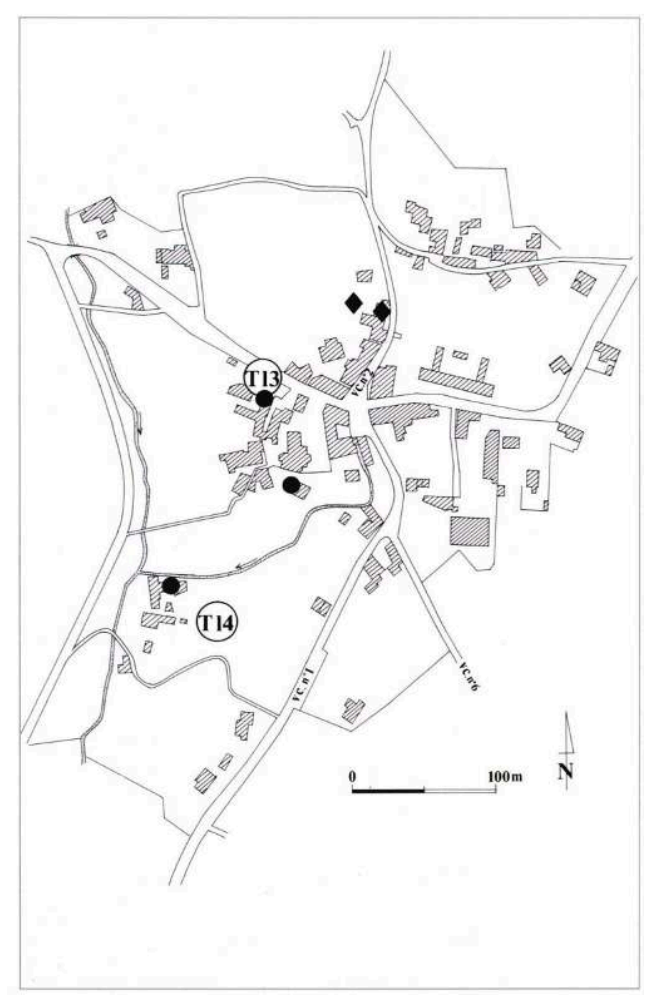




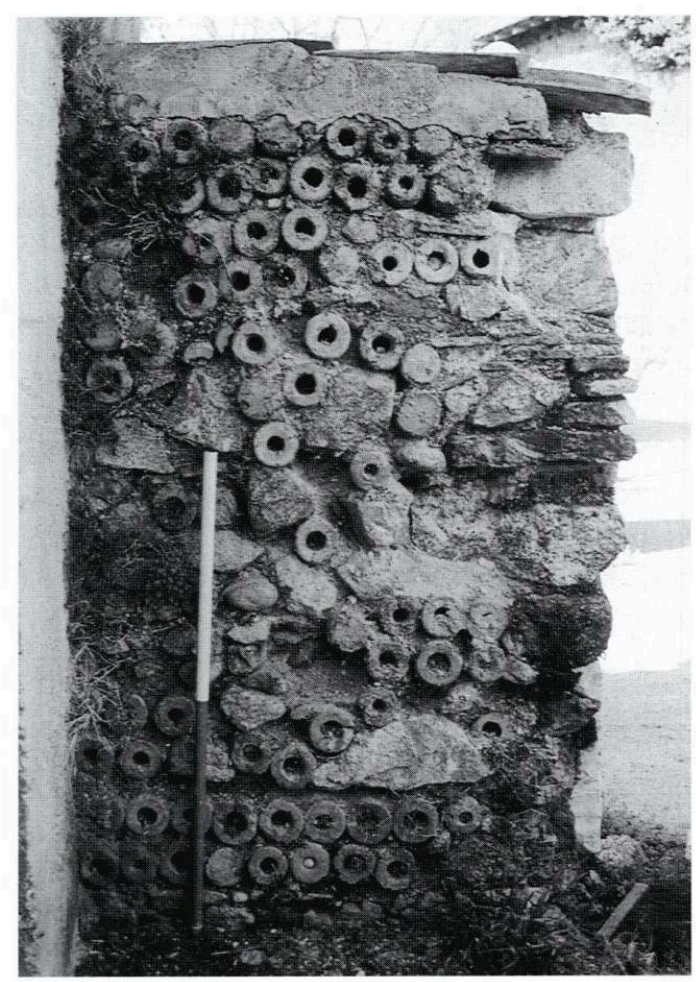

131 Peut-on en conclure que la localisation des ateliers a connu une évolution au fil des années dans l'ensemble du secteur étudié ? On ne saurait l'affirmer. En effet, cela ne se traduit pas dans les vestiges de leur production collectés lors des prospections. Si l'on excepte les poteries particulières fabriquées à Larnage en pâte blanche, les ensembles provenant d'Érôme, Ponsas et Gervans montrent une belle uniformité d'un site à l'autre.

\section{Production des ateliers}

133 La production des ateliers répartis sur les communes d'Érôme, Ponsas, Gervans et Larnage nous est connue par 1898 échantillons dont 1165 pour la seule commune d'Érôme, la plus prospectée. Les ramassages de surface ont été moins productifs qu'on ne l'escomptait au départ. Aux raisons exposées plus haut (topographie des ateliers par rapport aux habitats), pourrait s'ajouter la durée d'activité des ateliers sans doute relativement courte. Par conséquent, les traces archéologiques, à savoir essentiellement les zones de rejet s'en trouveraient réduites. C'est du moins l'impression retirée si l'on compare les prospections réalisées dans la vallée du Rhône aux expériences conduites parallèlement en Bresse ou en Beaujolais où les ramassages ont pu être plus étendus et où la chronologie des ateliers est plus large.

134 La présentation des différentes catégories de vaisselles issues des ramassages de surface se référe à la classification technologique présentée dans la seconde partie de cet ouvrage. On indiquera donc ci-dessous les renvois à la nomenclature adoptée dans la seconde partie de l'ouvrage. 
Les observations faites un peu plus haut à propos des produits originaires de Loire-surRhône et de Vienne peuvent être transposées ici et précisées grâce à un matériel plus abondant. La particularité de la production reste bien la vaisselle de table aux décors d'engobes (familles E2 et E5) appliqués sous glaçure transparente: décors tracés en clair sur fond d'engobe sombre (brun-rouge) ou, à l'inverse, tracés en sombre sur fond clair (crème, jaune paille). Dans cette catégorie, les petites formes ouvertes, écuelles, coupes, assiettes sont les plus nombreuses. Des plats à marli et des vases à liquides comportent également ce type de décor. Tous les exemplaires sont en pâte rouge.

La plupart des sites ont également livré des tessons aux décors polychromes (brun, beige, marron) rapidement exécutés : décors "jaspés » (famille E3), «mouchetés » ou tout simplement "tachés». Le répertoire des formes pour la table y est aussi bien représenté, mais on y remarque des éléments de grands récipients de forme fermée, pots ou cruches.

Parmi l'ensemble des tessons à glaçure monochrome s'individualisent trois séries relativement peu nombreuses, mais bien caractéristiques :

- les glaçures noires mates sur pâte rouge, (famille E8)

- les glaçures vert cru sur pâte rouge appliquées sur engobe, (famille El)

- les glaçures jaune paille sur pâte blanche (famille B2).

Cette dernière catégorie est fabriquée avec les argiles kaoliniques de Larnage. Les poteries en pâte blanche sont précisément de loin les plus nombreuses sur les parcelles prospectées à Larnage. Ces produits bien caractéristiques, dits "service jaune » par commodité, ont fait l'objet d'une étude complémentaire en laboratoire qui a montré, d'une part, la relation entre la matière première locale et les céramiques collectées en prospection à Larnage même et, d'autre part, la diffusion commerciale des ateliers à l'échelle régionale (cf. infra).

139 La fragmentation des pièces recueillies sur les sites d'atelier, leur mauvais état de conservation ne permettent pas de dresser une typologie fiable des formes et des décors. Fort heureusement l'étude peut être complétée en prenant en compte le mobilier issu de plusieurs fouilles urbaines récentes menées dans la région. En effet, les ressemblances mises en lumière entre ces différents ensembles nous conduisent à formuler l'hypothèse de la commercialisation des produits de la vallée du Rhône jusqu'à Lyon.

\section{Le groupe d'érôme et ponsas : prédominance de la vaisselle aux décors d'engobe}

140 Un premier ensemble de céramiques provient des prospections effectuées dans les secteurs d'Érôme, Gervans et Ponsas. Une dizaine de lieux de ramassage ont restitué 1440 tessons qui ont été divisés en quatre groupes principaux (tableau 8). 


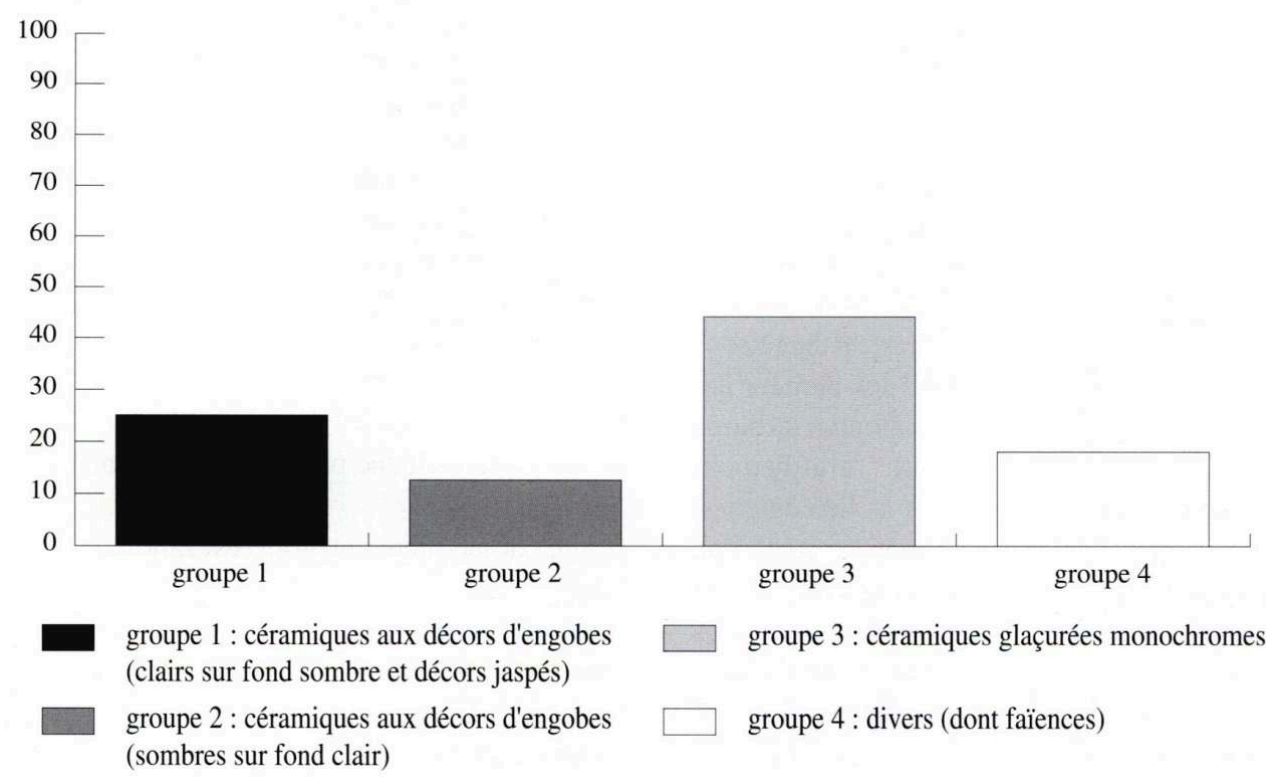

Cumul pour les communes d'Érôme, de Gervans et Ponsas

141 Groupe 1 : il réunit toutes les céramiques ornées de motifs clairs sur un fond d'engobe sombre (rouge ou brun). Le décor est en général effectué à la barbotine blanche et utilise des motifs linéaires ou géométriques : cercles, quadrillages, festons et, dans un cas, un motif floral (fig. 68). Les fragments identifiables restent rares, parce que les tessons sont très altérés. Plus rarement, le décor est obtenu par l'utilisation d'un engobe brun plus sombre. Dans ce cas, on utilise plutôt de larges taches irrégulières qui donnent à la surface ornée un aspect marbré ou tacheté. Ce groupe représente en moyenne plus de $25 \%$ de l'ensemble de tessons ramassés. 
68 - Fragments de vaisselle décorée aux engobes (écuelles et plats à marli), collectés en prospection : décor clair sur fond sombre (groupe 1)

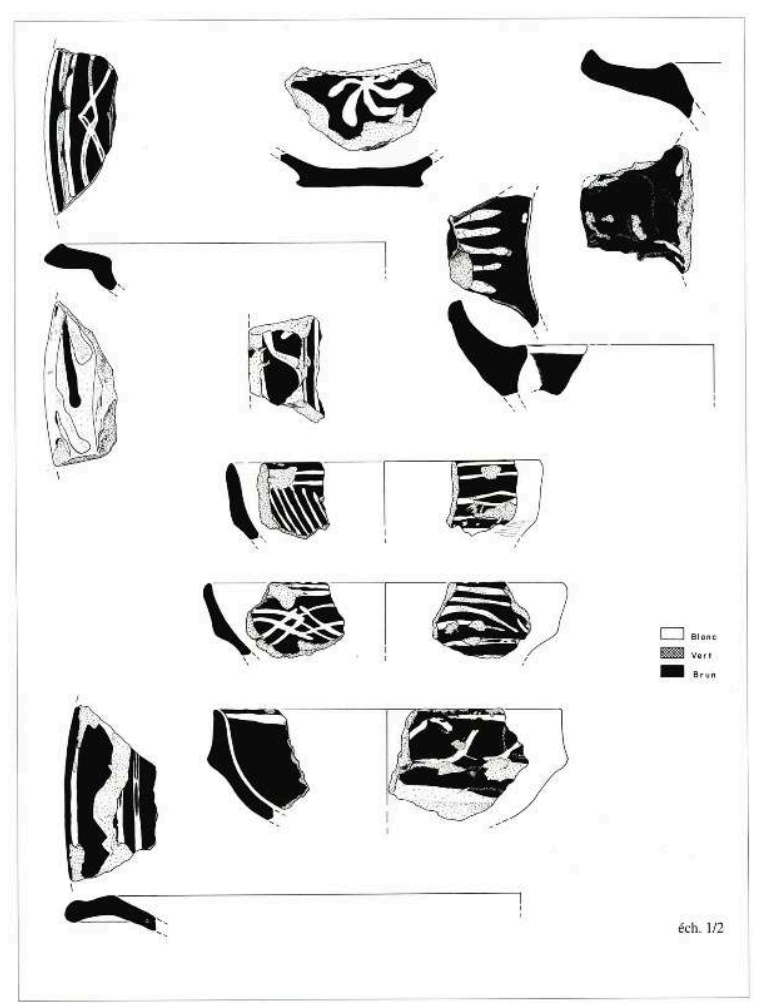

Groupe 2: on a réuni dans ce groupe tous les tessons qui sont ou semblent avoir été ornés de motifs sombres sur un fond d'engobe clair. Le décor a souvent disparu et apparaît en négatif. La couleur utilisée est surtout le brun, mais parfois il est accompagné de taches vertes (fig. 69). Dans quatre exemplaires on a pu observer, de plus, des incisions qui soulignent le motif décoratif. Dans l'ensemble des lieux de ramassage, ce groupe est moins bien représenté que le groupe précédent; il atteint un maximum de $18,6 \%$ en T2, par exemple, mais seulement 12,6 \% en moyenne générale. 
69 - Fragments de vaisselle décorée aux engobes (écuelles), collectés en prospection : décor sombre sur fond clair (groupe 2)

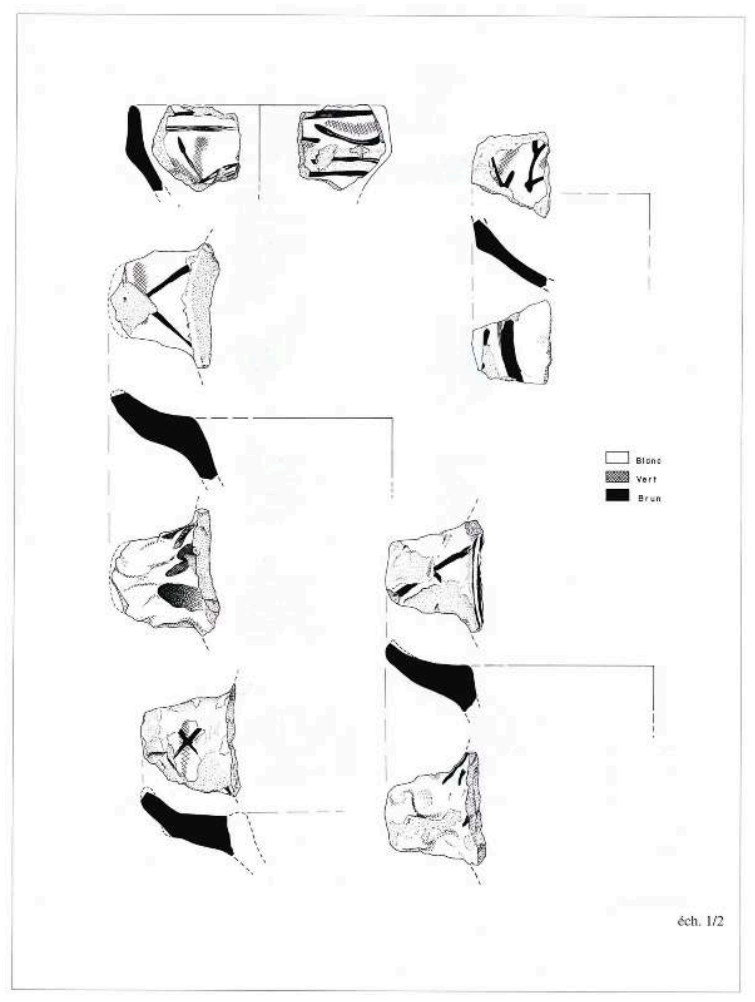

Groupe 3 : il réunit les céramiques recouvertes de glaçure monochrome : vert, jaune, brun, marron, marron très foncé presque noir, avec ou sans engobe préalable. Dans ce groupe sont réunis également les rarissimes tessons à glaçure jaune sur pâte blanche qui sont au contraire très représentés sur le secteur de Larnage. Ici, dans les zones d'Érôme et Ponsas, ils constituent une exception (8 tessons en tout!). Les autres glaçures monochromes sont largement représentées partout avec un pourcentage global de $44,2 \%$ (61,7 \% sur T6).

Groupe 4 : ce dernier groupe inclut diverses productions : en majorité des céramiques sans revêtement ou non identifiables, ainsi que les rares exemplaires de grès ou de faïences. Le cas de T10 à Ponsas est à souligner.

Les différents lieux de ramassage ont restitué un nombre de tessons très variable: important en T1, T2, T4/T5 et T10, en revanche plus limité en T7 et T11. Cependant, les quatre groupes de céramiques sont présents en proportion presque constante d'une aire de ramassage à l'autre. Le groupe le mieux représenté est celui des céramiques à glaçures monochromes (groupe 3) qui atteint une moyenne de $44,2 \%$. En raison de son hétérogénéité, les chiffres du groupe 4 n'ont pas grande signification ; les pourcentages restent en général au-dessous de $20 \%$, sauf le cas unique de T10. A cet endroit, en effet, on a retrouvé beaucoup de faïences et de tessons identifiables comme des biscuits de dégourdi. Il s'agit d'une trouvaille exceptionnelle et que les textes permettent d'expliquer.

On soulignera surtout la présence des groupes 1 et 2 dont la production, à coup sûr locale, est tout à fait caractéristique de ce groupe des ateliers de la vallée du Rhône. Le groupe 1 est toujours bien représenté $(25,1 \%$ en moyenne). On ne saurait oublier, cependant, que ce comptage n'a pu tenir compte que des tessons où le décor est 
présent. Les formes, fermées ou ouvertes, ne sont jamais entièrement décorées; il se peut donc que quelques tessons attribués au groupe 3 (avec glaçure monochrome sur fond d'engobe sombre) appartiennent à ce groupe.

Le groupe 2 (céramiques décorées en sombre sur fond clair) est représenté sur tous les points de ramassage, mais toujours en plus faible quantité (12,6\% en moyenne). Il pourrait s'agir d'une production relativement marginale, pour nos ateliers. Un décalage chronologique entre la production du groupe 1 et celle du groupe 2 n'est pas à exclure. En effet, d'après les fouilles régionales, les céramiques à fond clair semblent apparaître quelques décennies avant les céramiques à fond sombre et connaître une vogue de moins longue durée (pas au-delà du XVIIIe s.).

Il est difficile de restituer le catalogue des ateliers du secteur d'Érôme à partir de tessons collectés, en raison de leur faible taille et de leur mauvais état de conservation. Les éléments les plus caractéristiques appartiennent aux poteries aux décors d'engobes (groupes 1 et 2). On note une nette majorité de formes pour la table : assiettes et plats à marli, écuelles à oreilles. Le répertoire décoratif de ces "faïences du pauvre" est simple et répétitif, faisant majoritairement appel à des jeux de lignes parallèles ou entrecroisées (fig. 68 et 69).

149 Complétant ces informations, le portrait de ces catégories de récipients, (familles E2 et E5), présenté dans la seconde partie de l'ouvrage peut s'appliquer dans une certaine mesure aux produits des ateliers du secteur d'Érôme. Mais ceux-ci se laissent difficilement individualiser par rapport aux céramiques d'autres origines, en raison du caractère quasi "universel" de la vaisselle aux motifs apposés sur engobes, durant les XVIIe et XVIIIe s.

Globalement, les tessons collectés à Érôme, Ponsas, Gervans, indiquent que le travail des artisans potiers s'inscrivait dans un mouvement très général de fabrication de vaisselles populaires, sans souci d'originalité. Il faudrait sans doute, et encore sans garantie de résultat, une analyse comparative détaillée des céramiques ornées de la région pour détecter des séries de motifs ou de savoir-faire propres à tel ou tel groupe d'ateliers. Au moins peut-on espérer distinguer prochainement sur le marché lyonnais, par exemple, les arrivages du nord, depuis le Val de Saône (Poteries tradionnelles du Val de Saône 1984, pp. 26-29), de ceux du sud, depuis la Vallée du Rhône.

\section{Le secteur de Larnage consacré au service jaune}

151 Les céramiques décorées aux engobes (groupes 1 et 2) sont, en revanche, pratiquement absentes dans tous les points de ramassage à Larnage ( $0,1 \%$ en moyenne). Mais le site était surtout connu pour avoir produit une céramique à pâte blanche, recouverte directement de glaçure jaune épaisse.

Pour présenter le matériel recueilli (tableau 9), on a divisé le groupe 3 (glaçures monochromes) en deux sous-groupes ( $3 a$ et $3 b$ ), afin de mieux mettre en évidence la présence massive de cette production locale. En T12 le service jaune est largement majoritaire (90\%). Il est moins abondant, mais toujours bien représenté en moyenne générale $(87,5 \%)$. 
Tableau 9. Représentation des groupes de produits d'après les ramassages de surface

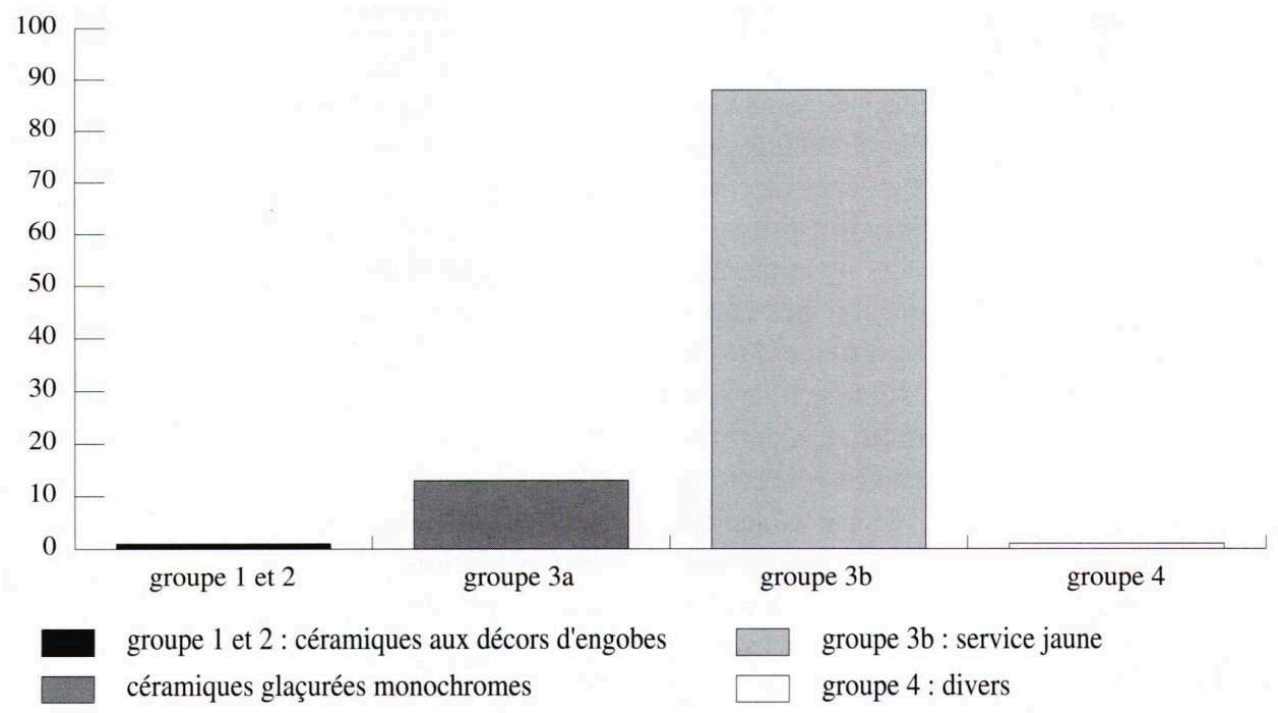

Cumul pour la commune de Larnage

Les poteries du type service jaune sont très fragiles et s'émiettent facilement en se cassant. La petitesse des fragments recueillis sur place rend très difficile l'identification des formes. La présence de formes ouvertes pour la table, munies d'un large marli, ainsi que celle de formes culinaires dotées d'un manche creux est cependant assurée. Les informations complémentaires recueillies sur les sites d'utilisation, notamment Lyon et Condrieu dans le Rhône et Vienne dans l'Isère, confirment l'image d'un catalogue de formes limité et d'une production stéréotypée (fig. 70).

70 - Pièces du service jaune de Larnage (glaçure monochrome jaune sur terre blanche), provenant de diverses fouilles lyonnaises

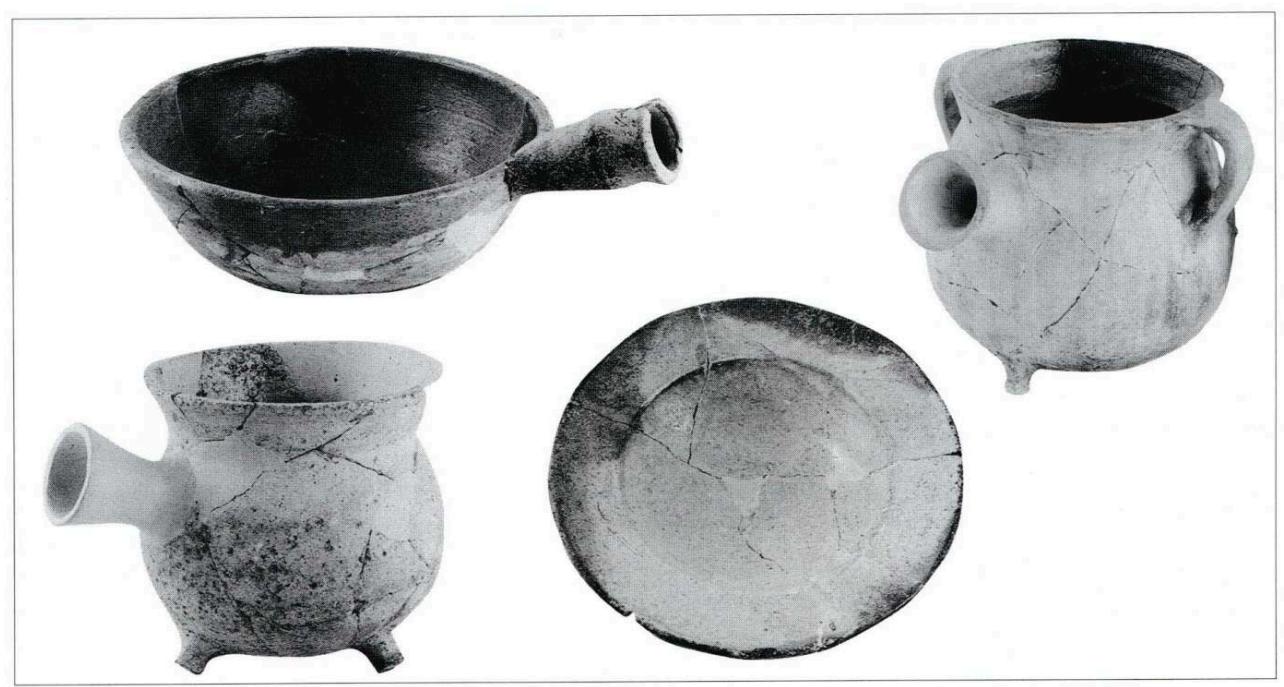

Les assiettes (type 3311), de loin la forme la plus répandue, ont un diamètre d'ouverture qui se situe entre 26 et $28 \mathrm{~cm}$ (fig. 71). Les formes plus grandes, qui atteignent un diamètre d'ouverture de $36 \mathrm{~cm}$, sont rares (fig. $71 \mathbf{~ n}^{\circ}$ 4). Les profils très bas, toujours avec un large marli, sont également moins courants (fig. $71 \mathbf{n}^{\circ} 5$ à 7 ) 
(types 3611 et 3612). Enfin, la forme d'écuelle à larges oreilles festonnées est presque unique (fig. $71 \mathrm{n}^{\circ}$ 8).

71 - Pièces du service jaune de Larnage, provenant des fouilles de Condrieu (Rhône)
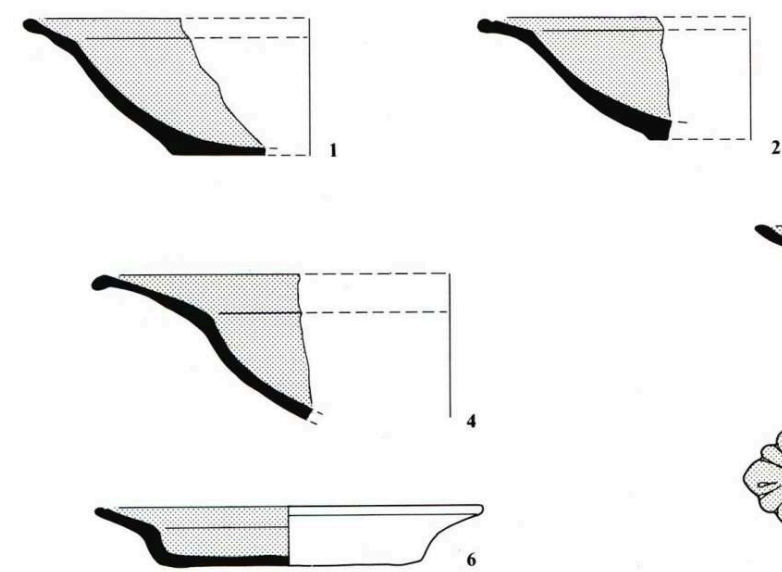
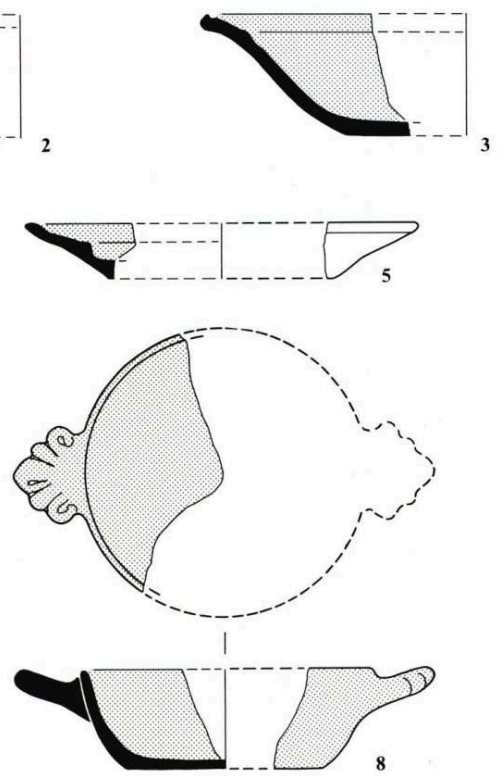

Parmi les formes hautes dominent les pots tripodes munis ou non de deux anses et toujours d'un manche creux (fig. $72 \mathbf{n}^{\circ} 1$ à 3 ) (type 1341).

Les poêlons (type 3831) sont nombreux (formes basses avec un manche creux), les couvercles également; ils appartiennent tous au même type : plats avec un bouton de préhension en leur milieu (fig. $72 \mathbf{n}^{\circ}$ 4).

72 - Pièces du service jaune de Larnage, provenant des fouilles de Condrieu (Rhône)
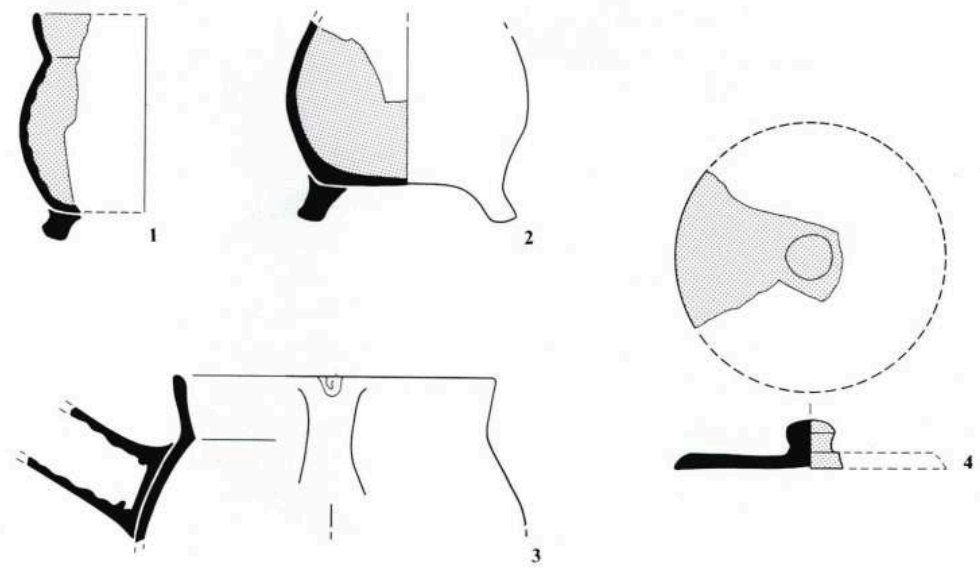


\section{Période d'activité des ateliers d'après le matériel recueilli} XVIIle s. Il serait vraisemblablement possible d'établir une chronologie plus précise des ateliers les uns par rapport aux autres, par une étude plus poussée des formes et des décors; mais le matériel recueilli sur place est trop dégradé pour apporter des 
arguments fiables et encore trop peu nombreux pour offrir des statistiques significatives reposant par exemple sur la proportion relative des récipients de table ou de stockage, ou sur le vocabulaire ornemental des décors aux engobes.

163 La faible quantité de faïence recueillie en prospection n'offre guère d'informations chronologiques. La faïence n'est guère populaire, dans la région, avant le milieu du XVIIIe s., avec le développement de fabrications locales de vaisselle blanche. Les archives, en l'occurrence, compensent les informations du terrain: les potiers traditionnels voient leur communauté s'élargir aux faïenciers dans le courant du XVIIIe s. (cf. supra) (tableau 6). Le mouvement est irréversible à la fin de ce siècle.

Le cas des ateliers du groupe de Larnage est plus simple à traiter en raison de l'homogénéité et de la spécificité de leurs produits. Le service jaune est fort bien répertorié et daté désormais dans la région : il apparaît dans le dernier quart du XVIIe s. et connaît un succès grandissant durant le siècle suivant. Sa disparition assez brutale des dépotoirs urbains laisse envisager l'arrêt de la production de ce type de vaisselle à la fin du XVIIIe s.

E. F.-B.

\section{La diffusion du service jaune de Larnage}

Les recherches effectuées en laboratoire concernent l'origine des céramiques à pâte blanche et glaçure monochrome jaune que l'on trouve sur différents sites archéologiques de la Drôme, de l'Isère, du Rhône, de la Saône-et-Loire et du Doubs. Des données archéologiques et historiques convergentes signalent la région de Larnage dans la Drôme comme un lieu de production possible pour de telles céramiques.

167 Les analyses chimiques du matériel recueilli ont permis de constituer un groupe de référence représentatif des productions de cet atelier. Les céramiques à pâte blanche et glaçure monochrome jaune trouvées sur les sites d'habitat ont été comparées à ce groupe et une étude sur la diffusion de l'atelier de Larnage a pu être entreprise.

\section{Échantillonnage}

Un échantillonnage de 57 céramiques a été constitué de la façon suivante :

- 25 exemplaires ont été recueillis lors des ramassages de surface sur le territoire de Larnage ; MRL185 à MRL199 (T14) et MRL200 à MRL209 (T12) ${ }^{43}$

- 32 exemplaires proviennent de différents sites d'habitat (tableau 10). 
Tableau 10. Exemplaires de sites de consommation

\begin{tabular}{|l|c|c|}
\hline lieu de découverte & nb d'ex. & $\mathbf{n}^{\circ}$ d'analyse \\
\hline Besançon (25) & 2 & $\begin{array}{l}\text { MRL313 } \\
\text { MRL385 }\end{array}$ \\
\hline $\begin{array}{l}\text { Brussieu (69) } \\
\text { mines de Pampailly }\end{array}$ & 2 & MRL310 à MRL311 \\
\hline $\begin{array}{l}\text { Chalon-sur-Saône (71) } \\
\text { Musée Denon }\end{array}$ & 1 & MRL184 \\
\hline Grenoble (38) & 4 & MRL306 à MRL309 \\
\hline $\begin{array}{l}\text { Lyon (69) } \\
\text { Rue des Farges }\end{array}$ & 1 & MRL177 \\
Ilot Vieille Monnaie & 10 & MRL165 à MRL171 \\
& & MRL175 à MRL176 \\
Place Antonin Poncet & 2 & MRL173 à MRL174 \\
Saint-Vincent & 2 & MLR172 \\
& 4 & MRL178 à MRL181 \\
\hline Valence (26) & 32 & MRL257 à MRL260 \\
\hline Vienne (38) & & \\
\hline TOTAL & 482 \\
\hline
\end{tabular}

\section{La composition et les propriétés des pâtes de larnage} compositions. Il s'agit de gisements de feldspaths kaolinisés très résistants d'âge Éocène, appelés localement "sables de Larnage ", identiques à ceux que l'on trouve à Douévas, une commune au nord de Larnage où les carrières sont exploitées actuellement pour leurs feldspaths ${ }^{44}$. Ces kaolins possèdent des propriétés réfractaires ; ils ont servi notamment à la fabrication de creusets pour l'hôtel de la Monnaie à Lyon au XVIIIe s. et de briques au XIXe s. L'utilisation de ces argiles kaolinitiques pour la fabrication de la poterie donne des céramiques à faible coefficient de dilatation, ce qui permet de les utiliser comme céramiques culinaires. Le pourcentage de fer peu élevé donne des pâtes claires homogènes sur lesquelles l'application d'une glaçure transparente donnera des tons uniformes.

\section{Classification préliminaire}

Une classification de l'ensemble du matériel analysé a été faite par analyse de grappes. Cette méthode de classification consiste à calculer le degré de ressemblance des céramiques entre elles et à les regrouper par affinité de composition. Les résultats de ce 
calcul sont exprimés sous forme de dendrogramme permettant de bien visualiser les regroupements (fig. 73).

73 - Dendrogramme de classification des céramiques analysées

- références de Larnage

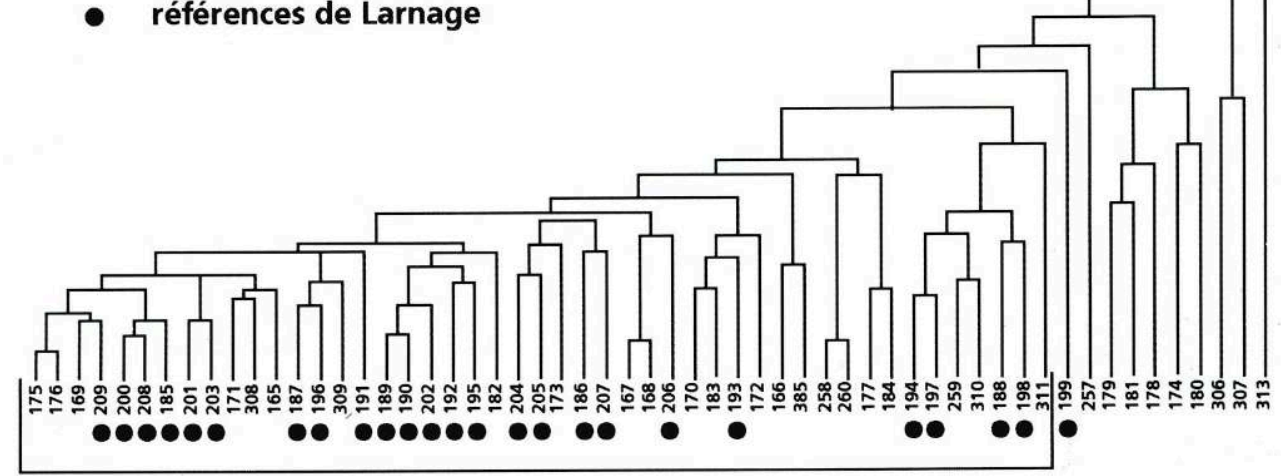

A

B

Mise en évidence de deux groupes

Sur le diagramme, on peut voir un ensemble homogène (groupe A) où se rassemblent des exemplaires ayant des compositions chimiques similaires ; à la droite de ce groupe, se classent des exemplaires ayant des compositions très hétérogènes que l'on désignera sous le terme d'ensemble B.

\section{Étude du groupe $\mathrm{A}$}

L'étude du groupe A montre que 23 céramiques d'habitat se classent assez bien avec 24 des 25 références de Larnage (repérées par un point noir). On peut donc dire que les exemplaires des sites d'habitat entrant dans ce groupe ont une forte probabilité d'être des productions de l'atelier de Larnage. Les moyennes (m), écarts-types (s) et écartstypes réduits ( $\mathrm{s} \%$ ) des constituants chimiques de ce groupe sont présentés dans le tableau suivant (tableau 11). On remarquera toutefois que l'exemplaire MRL311 (découvert à Brussieu) fusionne à une hauteur élevée. Il conviendra de vérifier sa position dans le groupe et éventuellement celle de quelques autres exemplaires marginaux par une autre méthode (cf. infra).

Tableau 11. Composition chimique moyenne du groupe de référence de Larnage (groupe A)

\begin{tabular}{|c|c|c|c|c|c|c|c|c|c|c|c|}
\hline \multicolumn{10}{|c|}{ ELEMENTS MAJEURS EN POURCENTAGES D'OXYDES } \\
\hline & Na2O & K2O & MgO & CaO & MnO & Al2O3 & Fe2O3 & SiO2 & TiO2 & P2O5 \\
\hline $\mathbf{m}$ & 0,45 & 4,3 & 0,42 & 0,64 & 0,010 & 27,7 & 1,20 & 64,0 & 0,941 & 0,3 \\
\hline $\mathbf{s}$ & 0,30 & 0,4 & 0,14 & 0,37 & 0,003 & 1,9 & 0,35 & 1,7 & 0,069 & 0,1 \\
\hline $\mathbf{s \%}$ & 68 & 9 & 34 & 58 & 27 & 5 & 29 & 3 & 7 & 40 \\
\hline \multicolumn{8}{|c|}{ ELEMENTS TRACES EN PPM } \\
\hline $\mathbf{9}$ & $\mathbf{R b}$ & $\mathbf{S r}$ & $\mathbf{B a}$ & $\mathbf{N i}$ & $\mathbf{Z n}$ & $\mathbf{C r}$ & $\mathbf{Z r}$ & $\mathbf{L a}$ & $\mathbf{C e}$ & $\mathbf{V}$ \\
\hline $\mathbf{m}$ & 243 & 289 & 502 & 22 & 40 & 71 & 328 & 102 & 167 & 94 \\
\hline $\mathbf{s}$ & 31 & 116 & 124 & 10 & 18 & 8 & 25 & 17 & 19 & 12 \\
\hline $\mathbf{s \%}$ & 13 & 40 & 25 & 46 & 45 & 11 & 8 & 17 & 12 & 12 \\
\hline
\end{tabular}




\section{Étude de l'ensemble B}

174 L'ensemble B est composé de dix exemplaires ayant des compositions chimiques très hétérogènes. On constate que MRL199, bien que recueilli sur le site de Lamage, présente des compositions très différentes des autres références de Larnage, notamment pour le strontium et le chrome. Il est possible que cet exemplaire soit étranger à l'atelier.

Les exemplaires MRL257, MRL306. MRL307 et MRL313 ont également des compositions différentes de celles de Larnage et sont différentes entre elles. On peut noter cependant que les deux exemplaires MRL306 et MRL307 qui proviennent de Grenoble ont en commun des pourcentages élevés d'oxyde de manganèse qui pourraient être l'indice d'une production différente, peut-être régionale.

Plus intéressant est le groupe constitué des cinq céramiques MRL179, MRL18L MRL178, MRL174 et MRL180 dont quatre proviennent de Valence et une de Lyon (MRL174). Ces exemplaires se caractérisent par des pourcentages de potassium de l'ordre de $1 \%$ au lieu de $4 \%$ dans le groupe A. Ceci suffit pour affirmer que ces céramiques ne sont pas des productions de Larnage.

177 Pour les exemplaires de l'ensemble B non attribuables à Larnage, d'autres origines ont été envisagées. On a donc effectué des comparaisons avec d'autres céramiques à pâte kaolinitique de la région de l'Uzège (Gard), Bollène (Vaucluse) et Dieulefit (Drôme). Dans un souci de concision, les différents diagrammes de classification ne sont pas présentés ici. Aucun exemplaire ne présente d'affinité de compositions chimiques avec l'Uzège et Bollène. Seuls les échantillons de Valence ont des similitudes avec les références de l'atelier de Dieulefit, très grand centre céramique situé à une soixantaine de kilomètres au sud-est de Valence. L'hypothèse de Dieulefit semble fort probable en raison de l'importance de cet atelier. Il faudrait cependant un échantillonnage plus grand de références de Dieulefit pour effectuer des comparaisons plus précises. Il serait également nécessaire, à titre de précaution supplémentaire, d'étudier les différentes argiles blanches qui peuvent exister dans la région valentinoise.

On notera que l'exemplaire MRL174, trouvé place Antonin Poncet à Lyon, présente un taux anormalement élevé de phosphore. Il s'agit d'une altération au cours de l'enfouissement, mais, avec ce type d'argile, ces altérations ont peu de répercussions sur les autres constituants.

\section{Calcul des distances}

179 Pour mieux mettre en évidence les différences de composition qui existent entre les exemplaires du groupe A, on a utilisé le calcul des distances de Mahalanobis (Picon 1984a) qui permet de connaître la distance de chacun des exemplaires par rapport au centre du groupe. Puis ce même calcul a été utilisé pour connaître la distance entre chaque exemplaire de l'ensemble B et le groupe A.

180 Un groupe de référence a donc été constitué avec tous les exemplaires du groupe A tel qu'il est défini sur le dendrogramme (fig. 73). A cause du faible nombre d'exemplaires de ce groupe A $(n=47)$ seuls ont été utilisés les dix constituants chimiques suivants : $\mathrm{K} 2 \mathrm{O}, \mathrm{Rb}, \mathrm{MgO}, \mathrm{CaO}, \mathrm{MnO}, \mathrm{A} 12 \mathrm{O} 3, \mathrm{Cr}, \mathrm{Fe} 2 \mathrm{O} 3, \mathrm{SiO} 2, \mathrm{TiO} 2$.

181 Les exemplaires de l'ensemble $\mathrm{B}$ ont été comparés à ce groupe pour vérifier leur non appartenance à Larnage. Le diagramme (fig. 74) présente l'histogramme des distances du groupe A avec, pour comparaison, l'histogramme des distances des exemplaires de 
l'ensemble B par rapport au groupe A. Plus la distance est grande, moins la céramique ressemble au groupe et donc moins elle a de chance d'appartenir au groupe.

74 - Comparaison des histogrammes des distances du groupe A et de l'ensemble B
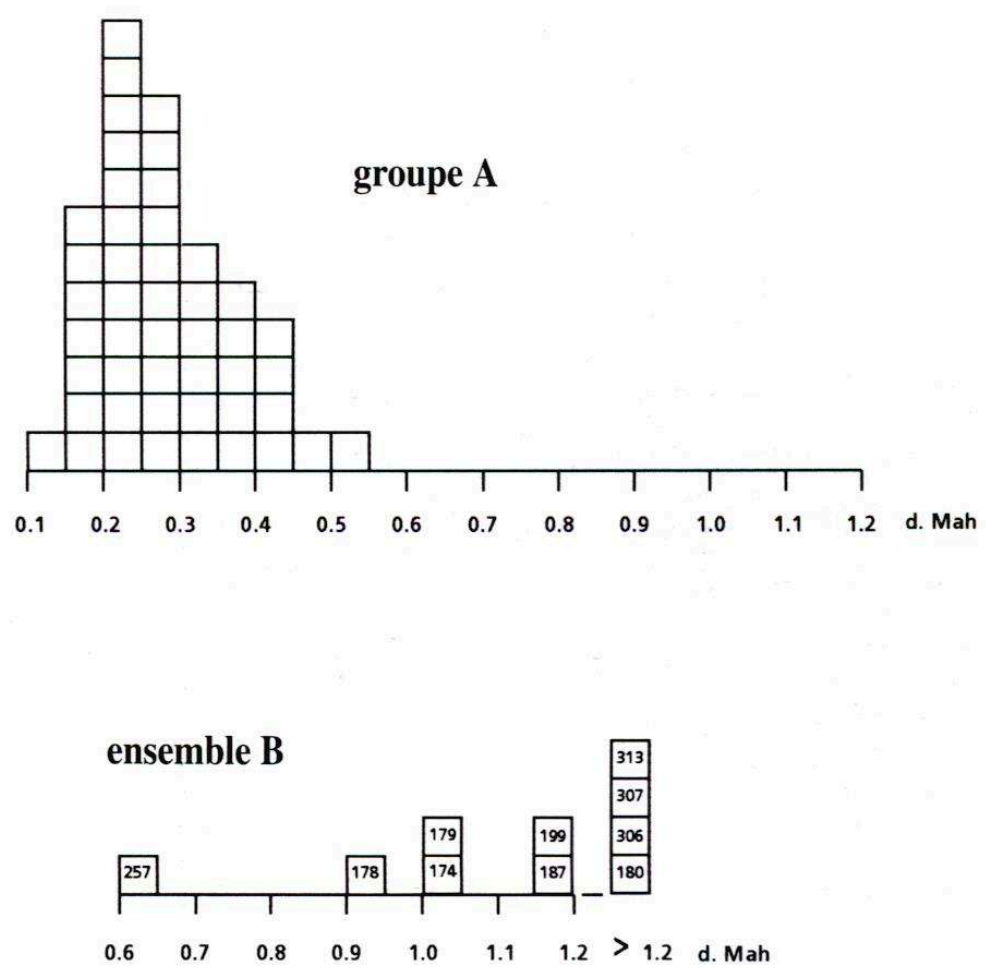

On remarquera sur l'histogramme du groupe A une légère dispersion vers les valeurs élevées : trois céramiques provenant des sites d'habitat ont des distances supérieures à 0,4. Si la probabilité d'appartenance à Larnage est très grande pour la plupart des exemplaires, on peut émettre un doute pour ces céramiques marginales. Pour exprimer la position de chacune de ces céramiques au sein du groupe, on a utilisé le coefficient $\mathrm{R}^{45}$ : celui-ci prend la valeur 100 lorsque la distance de la céramique au groupe est égale à la limite inférieure des distances du groupe (partie gauche de l'histogramme) et la valeur 0 lorsque cette distance est égale à la limite supérieure du groupe (partie droite de l'histogramme). Ainsi, plus R est faible, plus l'exemplaire se trouve dans la partie droite de l'histogramme, plus sa probabilité d'appartenance au groupe est faible.

Quant aux céramiques de l'ensemble B, on voit qu'elles ont toutes des distances supérieures à la plus élevée du groupe. L'hypothèse, déjà formulée plus haut, d'une origine différente de Larnage se trouve ainsi confirmée.

\section{Attributions d'origine}

Les résultats des attributions d'origine ont été rassemblés dans le tableau précèdent (tableau 12). Pour chaque site, ont été reportés les numéros d'analyse et les attributions lorsqu'elles étaient possibles, ainsi que la valeur du coefficient $\mathrm{R}$ dans le cas de l'attribution à Larnage. On rappelle que plus le coefficient $R$ est faible, plus grand est le risque de non appartenance au groupe (Picon 1984b). L'attribution au groupe de Larnage des exemplaires dont le coefficient $\mathrm{R}$ est faible devra donc être utilisée avec la 
plus extrême prudence. Néanmoins la cartographie de l'aire de diffusion commerciale des ateliers de Larnage peut être tentée (fig. 75).

Tableau 12. Exemplaires provenant de sites de consommation, attributions d'origine

\begin{tabular}{|c|c|c|c|c|}
\hline lieu de découverte & $\begin{array}{c}\text { attributions } \\
\text { à Larnage }\end{array}$ & $\operatorname{coef} \cdot \mathbf{R}$ & $\begin{array}{l}\text { attributions à Dieulefit } \\
\text { (hypothèse) }\end{array}$ & inclassables \\
\hline $\begin{array}{l}\text { Besançon (25) } \\
\text { MLR313 et MRL385 }\end{array}$ & MRL_385 & 17 & & MRL 313 \\
\hline $\begin{array}{l}\text { Brussieu (69) } \\
\text { MRL310 à MRL_311 }\end{array}$ & $\begin{array}{l}\text { MRL } 310 \\
\text { MRL } 311\end{array}$ & $\begin{array}{c}23 \\
2\end{array}$ & & \\
\hline $\begin{array}{l}\text { Chalon-sur-Saône (71) } \\
\text { MRL184 }\end{array}$ & MRL184 & 9 & & \\
\hline $\begin{array}{l}\text { Grenoble (38) } \\
\text { MRL } 306 \text { a MRL309 }\end{array}$ & $\begin{array}{l}\text { MRL308 } \\
\text { MRL309 }\end{array}$ & $\begin{array}{l}51 \\
49\end{array}$ & & $\begin{array}{l}\text { MRL306 } \\
\text { MRL307 }\end{array}$ \\
\hline $\begin{array}{l}\text { Lyon (69) } \\
\text { Farges } \\
\text { Vieille Monnaic }\end{array}$ & MRL177 & 26 & & \\
\hline MRLI65 à MRL.171 & $\begin{array}{l}\text { MRL165 } \\
\text { MRL166 } \\
\text { MRL167 } \\
\text { MRL168 } \\
\text { MRL169 } \\
\text { MRL170 } \\
\text { MRL171 }\end{array}$ & $\begin{array}{l}72 \\
55 \\
68 \\
43 \\
89 \\
77 \\
57\end{array}$ & & \\
\hline MRL175 à MRL176 & $\begin{array}{l}\text { MRL175 } \\
\text { MRL176 }\end{array}$ & & & \\
\hline $\begin{array}{l}\text { MRL183 } \\
\text { Antonin Poncet }\end{array}$ & MRL.183 & 45 & & \\
\hline $\begin{array}{l}\text { MRL173 à MRL174 } \\
\text { Saint-Vincent }\end{array}$ & MRL173 & 32 & & MRL174 \\
\hline $\begin{array}{l}\text { MRL172 } \\
\text { MRL182 }\end{array}$ & $\begin{array}{l}\text { MRL172 } \\
\text { MRL182 }\end{array}$ & $\begin{array}{l}11 \\
98\end{array}$ & & \\
\hline $\begin{array}{l}\text { Valence (26) } \\
\text { MRL178 a } \mathrm{aRL} 181\end{array}$ & & & MRLI78 à MRL18I & \\
\hline $\begin{array}{l}\text { Vienne (38) } \\
\text { MRL257 à MRL.260 }\end{array}$ & $\begin{array}{l}\text { MRL258 } \\
\text { MRL259 } \\
\text { MRL260 }\end{array}$ & $\begin{array}{l}19 \\
60 \\
15\end{array}$ & & MRL257 \\
\hline
\end{tabular}

75 - Lieux de commercialisation du service jaune de Larnage

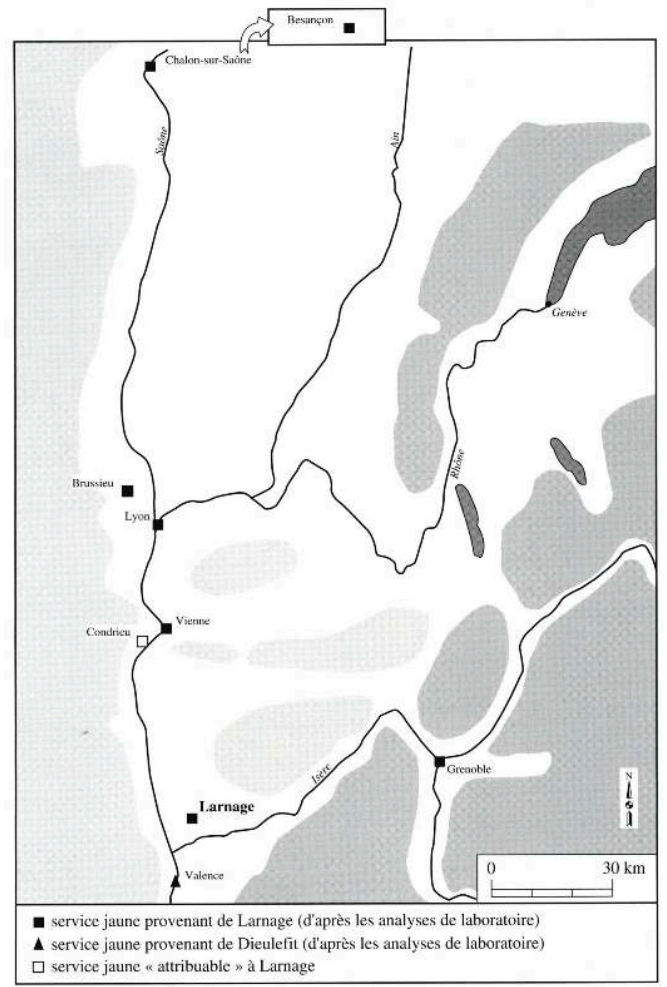


En conclusion, on peut dire que les analyses physico-chimiques ont permis de caractériser les productions de l'atelier de Larnage et de les identifier sur les sites de consommation de Lyon, de Grenoble et de Vienne qui sont les plus proches de la zone productrice.

La diffusion de cet atelier au nord de Lyon ne semble pas évidente. On constate en effet que les échantillons de Brussieu, Besançon et Chalon-sur-Saône sont ceux qui ont les plus faibles valeurs du coefficient $\mathrm{R}$, donc la plus faible probabilité d'appartenance aux productions de l'atelier de Larnage. Cependant quelques arguments plaident en faveur de l'appartenance des exemplaires de Besançon et de Chalon-sur-Saône aux ateliers de Larnage. Il s'agit de vases typologiquement complets, en l'occurrence quelques assiettes et surtout des pots à cuire tripodes, en tout point comparables aux récipients lyonnais assurément attribués à Larnage $\left(20000^{\mathrm{m} 3}\right.$ d'histoire 1992 p. 302 et Les Saintes Maries 1993 pp. 99, 105, 125, 164). Ces trouvailles excentrées et encore isolées ne traduisent certes pas un courant de commercialisation développé. Mais le transport par la voie d'eau (Rhône, Saône, Doubs) paraît logique. Précisons qu'un des vases de Chalon-sur-Saône provient des dragages de la Saône ${ }^{46}$. Les autres proviennent de dépotoirs urbains et sont associés à des récipients du service vert de Meillonnas.

A. $\mathbf{s .}$

\section{Conclusion}

38 Les ateliers de la moyenne vallée du Rhône offrent, pour la période post-médiévale, une image assez complète de la diversité des productions populaires régionales et du constant souci d'adaptation des artisans aux goûts des consommateurs; la qualité des matières premières utilisables étant la seule limite à ces contingences commerciales. Dans ce secteur de la vallée du Rhône, on a la chance de pouvoir observer les destinées parallèles de productions différentes et complémentaires : à partir des terres propres à la fabrication de la vaisselle commune, des terres kaoliniques propres à celle des récipients culinaires et autres objets réfractaires ou bien des terres calcaires propres à la fabrication des faïences.

Certes les résultats des ramassages de surface n'offrent pas la possibilité de retracer l'évolution de la topographie artisanale à l'intérieur des territoires villageois entre le XVIe et le XVIIIe s., comme cela a pu ressortir des prospections réalisées sur les ateliers bressans. En revanche, les sources écrites et les plans anciens compensent largement l'état fragmentaire des données archéologiques. La localisation des ateliers, la nature de leur production et leur période d'activité se trouvent précisées. Mais surtout les archives restituent l'histoire d'une communauté d'artisans spécialisés et l'image d'une forte concentration d'ateliers dans un secteur favorisé par les richesses du sol en argiles de diverses qualités.

La commercialisation des produits par le Rhône, si elle n'a pu être prouvée, constituait fort probablement un atout supplémentaire justifiant une telle concentration. Le compte péager de Serves, à quelques kilomètres en amont d'Érôme, mentionne bien en 1592 et 1593 deux embarcations chargées de vaisselle de terre, mais hélas! ni la provenance, ni la destination des marchandises ne sont précisées ${ }^{47}$. Plus marginal, mais cependant assuré, est le transport par colportage, ainsi que le dénote un texte de 1748 (le jeune colporteur approvisionnait le marché de Romans dans la Drôme) ${ }^{48}$ (fig. 76). 
76 - Extrait du procès-verbal d'interpellation d'un jeune colporteur qui avait acheté de la « terraille » à Érôme, pour la vendre à Romans en 1748

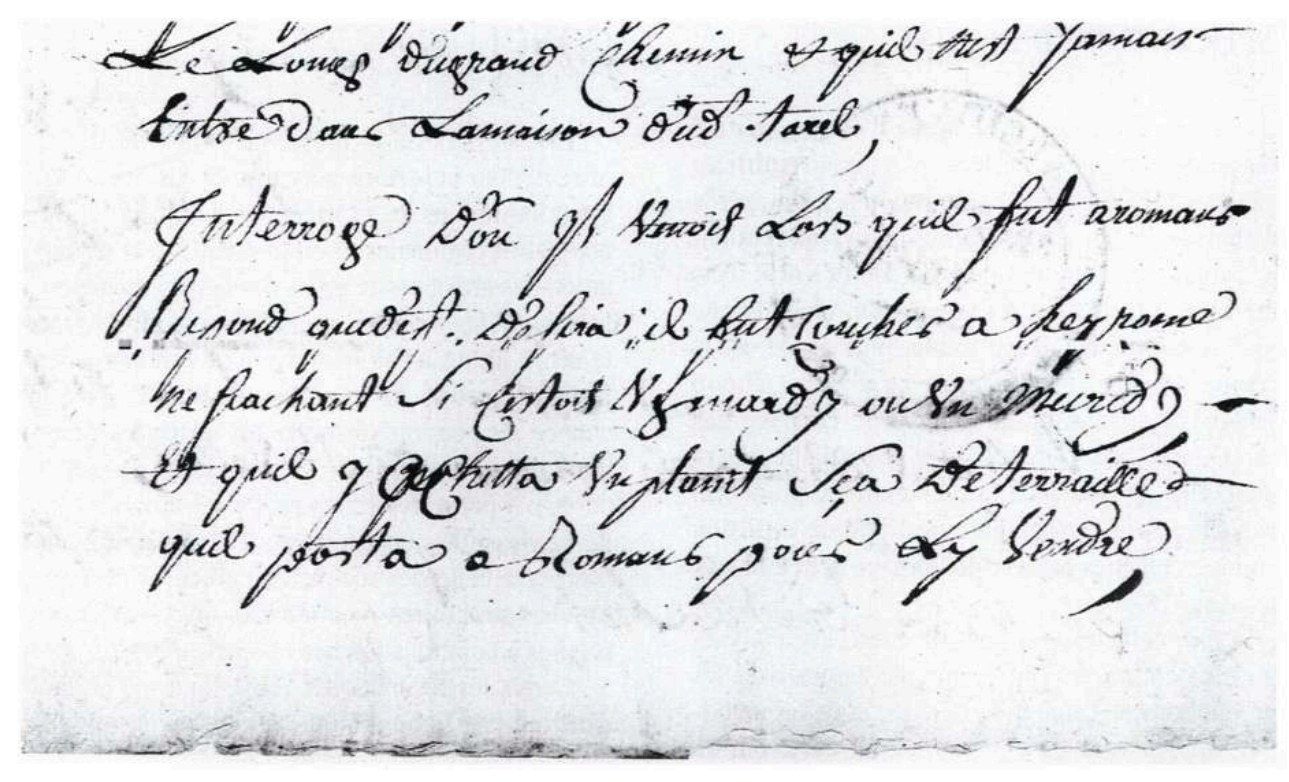

A.D.Drôme. - B 1505

L'aire de diffusion des ateliers de Larnage se dessine en partie grâce à ce service jaune si caractéristique. La question est désormais posée de la limite méridionale de leur aire d'influence par rapport aux produits concurrents des ateliers de Dieulefit, de l'Uzège et du Bas-Rhône implantés beaucoup plus anciennement près d'affleurements kaoliniques de première qualité. Rappelons que les analyses de pâte effectuées sur quelques tessons provenant de Valence ont permis de les attribuer aux ateliers de Dieulefit (cf. supra). La vitalité économique de ceux-ci, à l'époque moderne en tout cas, où ils approvisionnent tout le sud de la France, exerça une forte concurrence que les artisans de Larnage n'étaient probablement pas en mesure de contrer (Potiers et poteries du pays de Dieulefit 1986, p. 25).

Il reste beaucoup à faire pour retracer la destination des vaisselles en pâte rouge depuis leurs officines de la moyenne vallée du Rhône. On l'a vu plus haut, quelques points de repères apparaissent au fil des textes : Lyon, Grenoble et Vienne (cf. supra et notes 40 à 42). Mais reconnaitre les produits en question dans les rejets d'ateliers et les dépotoirs urbains n'est pas chose faite. Du moins, certaines interprétations hâtives peuvent être remises en cause : elles concernent en particulier les très populaires poteries aux décors d'engobe. Traditionnellement attribuées, dans notre région, au seul Val de Saône, il convient désormais de compter avec l'apport des ateliers de la vallée du Rhône, comme l'illustre, tardivement il est vrai, mais sans ambiguïté, un vase à vinaigre fabriqué à Loire-sur-Rhône (fig. 77). Les recherches ultérieures s'attacheront à départir ce qui revient à l'une ou à l'autre de ces régions productrices. 


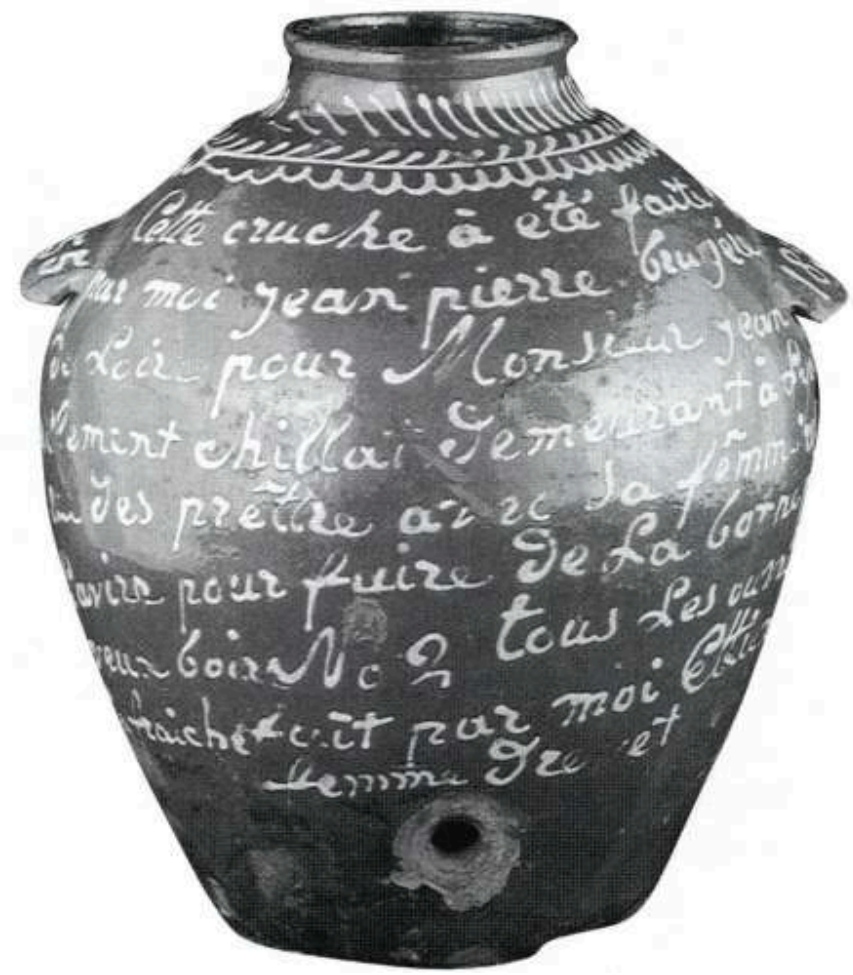

Collection musée Gadagne - Lyon

En 1730, l'inventaire établi par l'intendant Fontanieu retient la fabrication à Serves/ Érome de "pots grossiers et ferrailles fines couleur café, ainsi que faïences blanches». Quelle réalité recouvrent, par ailleurs, les formules utilisées dans certains inventaires, en particulier ces fameuses, mais énigmatiques «terre d'Erôme ", signalées dès 1610 (cf. note 42). Logiquement, celles-ci devraient désigner une vaisselle caractéristique, susceptible d'être distinguée parmi les lots disponibles chez les revendeurs. A l'évidence, il faut alors exclure les récipients aux décors d'engobe (groupe 1 et 2, cf. supra) dont la fabrication était largement répandue dans de nombreux autres centres potiers.

194 Il ne peut davantage s'agir du service jaune, non pas parce qu'il est originaire de Larnage - les poteries de Larnage pouvaient être commercialisées à partir d'Érôme et l'appellation recouvrirait un sens global - mais parce que la mention en question est du tout début du XVIIe s. : or, toutes les données recueillies sur les sites d'utilisation de la région concourent à indiquer que la fabrication de vaisselle avec les kaolins de Larnage ne débute pas avant le milieu de ce siècle.

Par élimination, on pourrait déduire que la réputation des ateliers du secteur d'Érôme a peut-être tenu à une autre catégorie de vaisselle à glaçure monochrome rencontrée dans les ramassages (groupe 3, cf. supra). La vaisselle à glaçure verte unie sur pâte rouge engobée s'avère très répandue dans la région (Lyon, Vienne, Grenoble) dès le milieu du XVIe s. où elle représente parfois $16 \%$ des ensembles archéologiques répertoriés. Ces taux sont comparables à ceux établis pour le service vert de Meillonnas, à la même période, ou le service jaune de Larnage à la fin du XVIIe s. (cf. seconde partie). 
Cependant, cette céramique verte est fort mal représentée dans les ramassages effectués.

196 Autre possibilité : les « terres d'Erôme " évoqueraient les produits à glaçure couvrante sombre (marron à noir) qui s'individualisent bien parmi les lots ramassés; pourtant cette catégorie est relativement marginale d'après les indices de surface. Elle l'est aussi dans les dépotoirs urbains étudiés, à Lyon notamment. Les premières apparitions sont datées du milieu du XVIe s. (cf. seconde partie). Faut-il voir dans les «terrailles fines couleurs café" s signalées par l'Intendant Fontanieu en 1730 (qui paradoxalement ignore les productions de Larnage !) la poursuite d'une production locale déjà commercialisée en 1610 ? Il est certain, par ailleurs, que le grand plat décoratif (fig. 78) fait en 1727 pour le Sieur de Saint-Vallier n'est pas représentatif des produits de grande consommation distribués dans cette partie de la vallée du Rhône.

78 - Grand plat décoratif fabriqué par Guigonnet à Ponsas en 1727 aux armes de Monsieur de Saint-Vallier

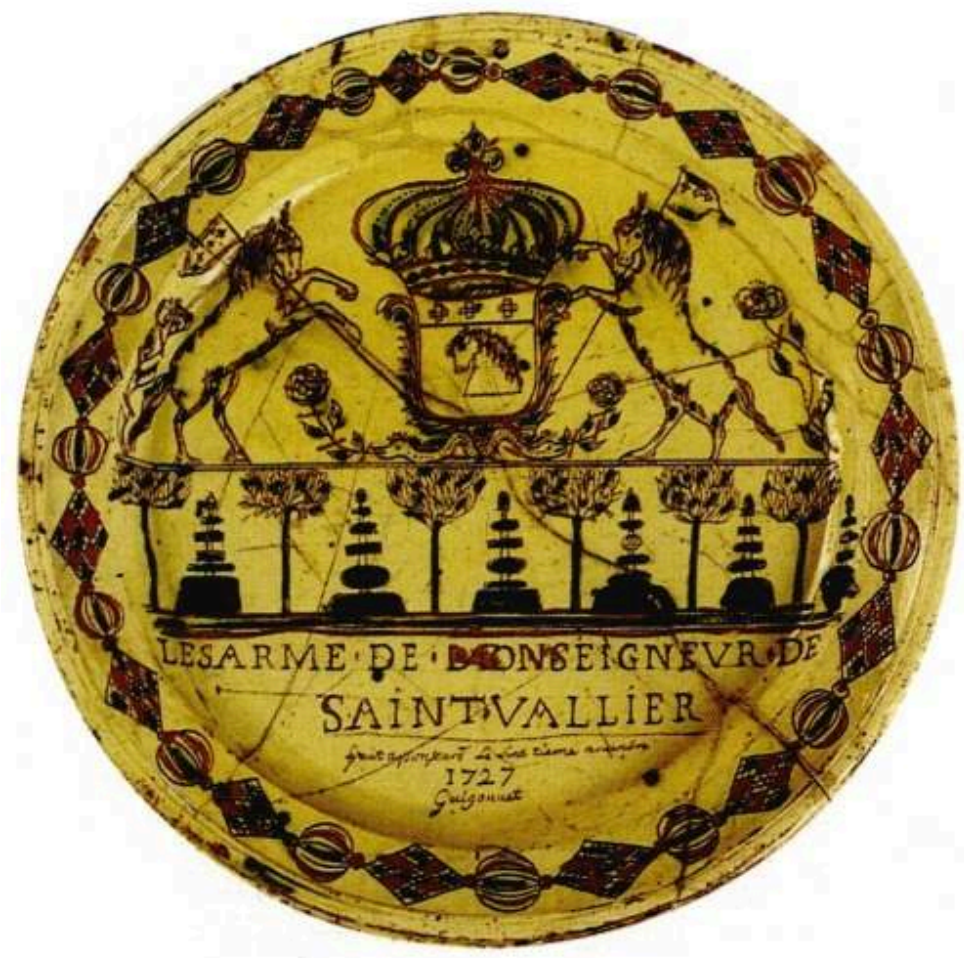

Diam. $43 \mathrm{~cm}$.

Collection musée Dauphinois, cliché musée Dauphinois - Grenoble

197 L'ensemble de ces considérations montre combien la définition de l'aire de diffusion des ateliers céramiques est chose délicate. Les indications d'ordre typologique ou stylistique restent sujettes à caution. C'est l'utilisation par les potiers d'une matière première remarquable qui est souvent le seul critère fiable de distinction. Ainsi en est-il du service jaune de Larnage dont les pâtes réfractaires bien caractéristiques ont permis de suivre la diffusion dans toute la région. En revanche la commercialisation des récipients plus courants, fabriqués à partir d'argiles banales par les ateliers de Ponsas, Serves, Gervans et surtout Erôme est encore fort mal connue. 
198 La chronologie proposée pour les ateliers drômois garde une marge d'incertitude. Les mentions textuelles ne peuvent prétendre à l'exhaustivité et on a vu plus haut les limites des informations livrées par les terrains prospectés. La phase d'activité la plus dense se place sans conteste aux XVIIe et XVIIIe s. Mais une grande partie des rejets examinés s'apparente à des catégories de vaisselles connues, par ailleurs, sur les sites d'utilisation dès le milieu du XVIe s. Compte tenu de l'ampleur du phénomène artisanal dans le secteur, l'hypothèse d'ateliers actifs dès cette époque est à retenir. En revanche, il faut reconnaître l'absence de témoignages d'une tradition plus ancienne, en l'état actuel de la recherche.

Si l'étude présentée ici ne s'étend pas au-delà du XVIIIe s., l'histoire des ateliers regroupés autour d'Érôme et de Larnage ne s'arrête pas pour autant. Ceux-ci rentrent dans «l'ère industrielle» et connaissent alors des fortunes diverses. Tandis que l'exploitation des kaolins de Larnage permet l'évolution des officines vers la fabrication industrielle de produits réfractaires, creusets, briques, sanitaires, les potiers d'Érôme, de Ponsas et de Serves subissent, à la fin du XIXe s., comme tous les ateliers traditionnels, la baisse progressive des débouchés commerciaux (importations de produits étrangers, concurrence des autres matériaux...). La reconversion de certains artisans dans la production de grès à Ponsas, ou de pipes à Érôme constitue probablement un sursis (fig. 79). Pourtant, le savoir-faire des artisans céramistes, même au-delà de la première guerre mondiale, reste profondément ancré dans cette région de la moyenne vallée du Rhône. Dans cette lignée rentrent alors les ateliers proches de Saint-Uze (fig. 80), de Saint-Barthélemy-de-Vals et de Saint-Vallier constituant un vaste ensemble, qui, en écho aux centres de la région de Dieulefit, font du département de la Drôme un terrain propice à la tradition potière. 
79 - Plan joint au dossier de remplacement d'une fabrique de faïence par un four à cuire la poterie en grès, à Pensas en 1824

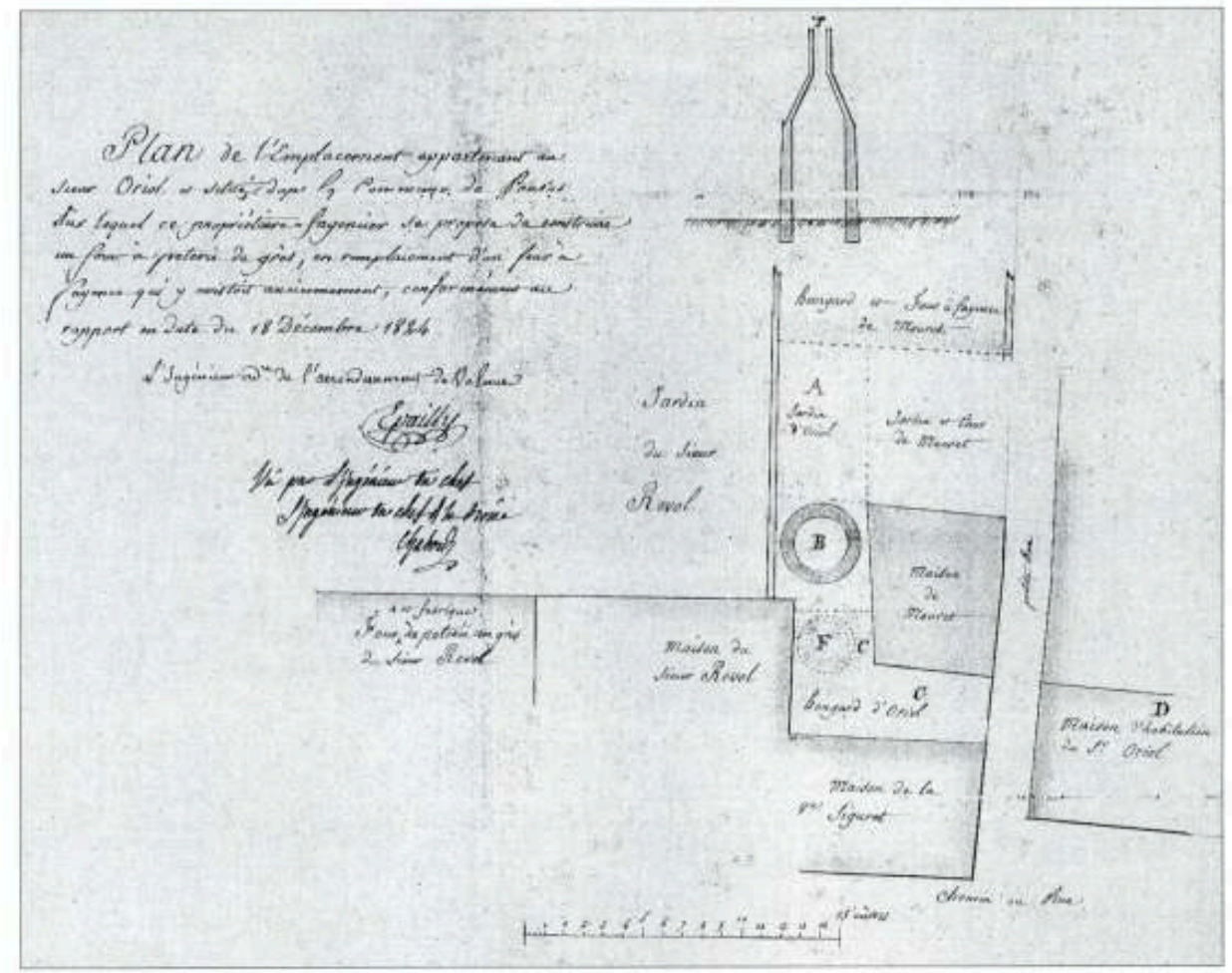

A.D.Drôme. - M 2106

80 - Bouteilles en grès provenant de la fabrique Revol à Saint-Uze, XIXe siècle

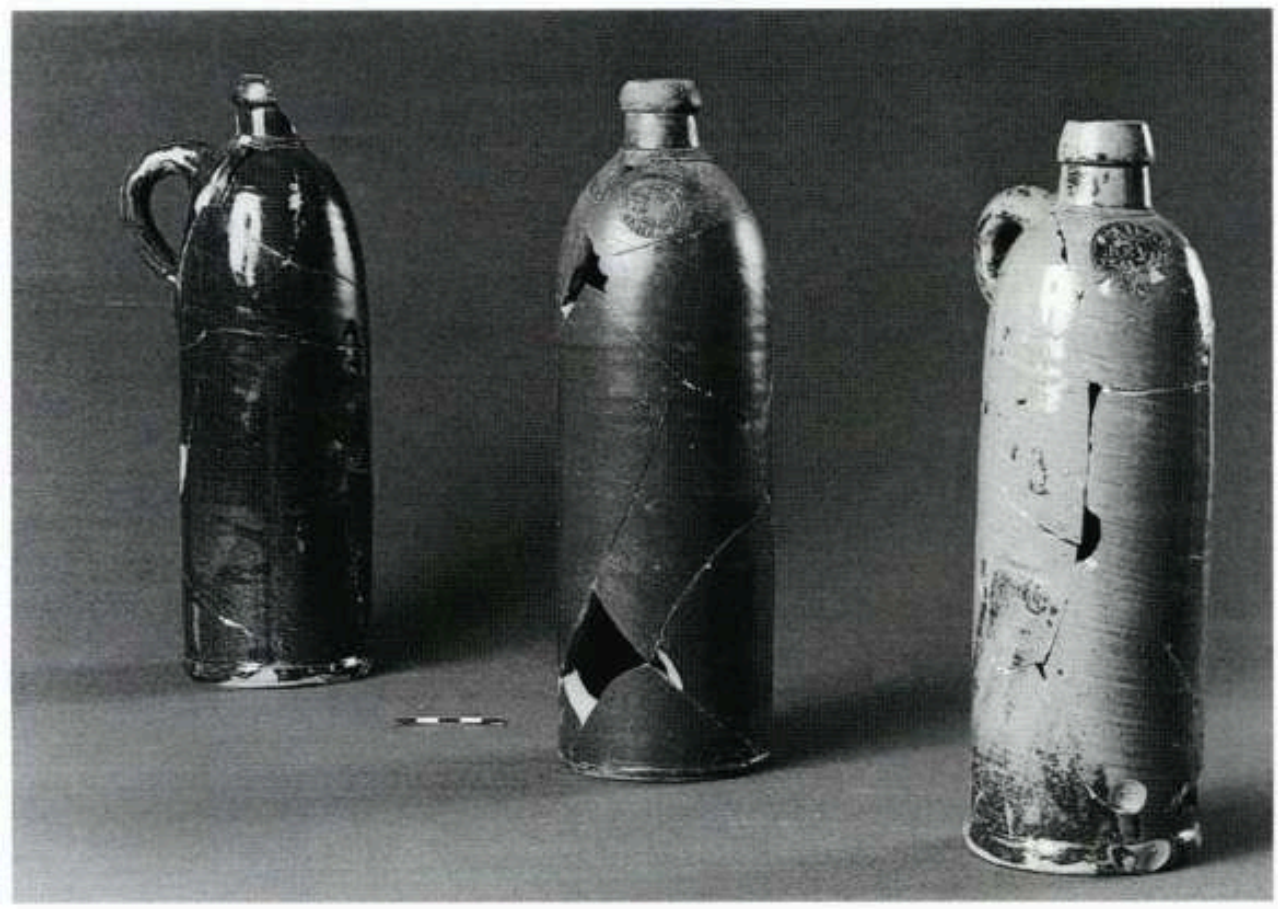

Fouilles quartier Saint-Jean à Lyon

Collection M C G R - Lyon 


\section{NOTES}

1. AD Drôme - 43 M 5 à 7, 48 M 11 à 13, 48 M 16 et 17, M 2100 à 2111 (par ordre alphabétique des communes)

2. A.D. Isère.- IIC 929, élection de Romans, fol. 178 vo et 192 vo.

3. Le territoire de l'élection de Romans comportait des communautés situées aujourd'hui dans les départements de la Drôme et de l'Isère. La communauté de Serves désigne l'actuelle commune d'Érôme.

4. A.D. Isère.- IIC 929, élection de Romans, fol. 297.

5. A.D. Isère.- IIC 927, 930-931.

6. A.D. Drôme.- 2E 2456, étude Tozel, 1467-1478 - 2E 2455, étude Des Rosiers 1449-1450 - 2E 2457 2459, étude Chabannes, 1503, 1520-1525.

7. A.D. Drôme.- 2E 9460.

8. A.D. Drôme.- B 1635 (judicature de Larnage), succession F. Delosme.

9. A.D. Drôme.- B 2262 (judicature de Serves), papiers de la famille Nicolas.

10. A.D. Drôme.- 2E 9591.

11. A.D. Drôme.- 2E 9460.

12. A.D. Drôme.- B 1514 (judicature d'Érôme), succession Nicolas.

13. A.D. Drôme.- B 1520 (judicature d'Érôme), succession Carrier.

14. Drôme.- 2E 7825.

15. A.D. Isère.- IIC 929, élection de Romans, fol. 178 vo.

16. Idem, fol. 192 vo.

17. A.D. Isère.- IIC 961-962, élection de Romans, fol. 504.

18. A.D. Drôme.- B 2262.

19. A.D. Drôme.- B 1635.

20. A.D. Drôme.- B 1520.

21. A.D. Drôme.- B 1514.

22. A.D. Drôme.- 2E 4905.

23. A.D. Drôme.- $2 \mathrm{E} 7846$

24. A.D. Drôme.- B 1514, succession Sauvajon (faïence), ibid, succession Nicolas (poterie), 2E 1846, Sauvajon/Marion (faïence).

25. A.D. Drôme.- B 1520 Carrier J. (faïence).

26. A.D. Drôme.- 2E 7847.

27. A.D. Drôme.- B 1520.

28. A.D. Drôme.- B 1514 Nicolas (poterie).

29. A.D. Drôme.- B 1514, Sauvajon (faïence) et Nicolas (poterie).

30. A.D. Drôme.- $2 \mathrm{E} 7847$.

31. A.D. Drôme.- 2E 4905, Paradis/Carrier.

32. A.D. Drôme.- 2E 7846.

33. A.D. Drôme.- 2E 9460.

34. Idem.

35. Orthographié Bedox ou Bedost. 
36. A.D. Drôme.- 2E 9460.

37. Idem.

38. A.D. Drôme.- B 1635.

39. A.D. Drôme.- B 2262.

40. A.D. Isère.- $3 \mathrm{E} 5213,10$ septembre 1760 , document communiqué par R. Bony.

41. A.D. Rhône.- BP 1882, BP 2131, BP 2242. A.D. Isère.-13B 63510 juin et 9 décembre 1782.

42. A.D. Rhône.- BP 1187.

43. Pour la signification des termes $\mathrm{T} 12$ et $\mathrm{T}$ 14, voir l'exposé sur les prospections ainsi que les cartes de localisation des prélèvements.

44. BRGM, carte géologique au 1/50 000 de Tournon.

45. $R=100 \mathrm{n} / \mathrm{N}$ où $\mathrm{n}$ est le nombre de céramiques du groupe qui ont une distance de Mahalanobis supérieure à celle de la céramique étudiée, $\mathrm{N}$ est le nombre total de céramiques du groupe.

46. Collection du musée Denon. Exemplaire signalé par L. Bonnamour que nous remercions vivement.

47. A.D. Isère.- B 2895.

48. A.D. Drôme.- B 1505. 


\title{
Chapitre 3. Les ateliers du Beaujolais : la tradition du Val de Saône
}

\author{
Élise Faure-Boucharlat, Georges Ducomet, Bruna Maccari-Poisson et Anne \\ Schmitt
}

1 Dès les premières années d'existence du projet collectif de recherche sur les ateliers médiévaux et modernes céramiques de la région, s'imposa l'idée de pousser les investigations en direction de la vallée de la Saône, au nord de Lyon. Plusieurs interrogations ou hypothèses semblaient en effet devoir trouver réponse ou justification dans ce secteur :

\section{Origine des recherches}

Certaines catégories de poteries communes, en pâte grise, trouvées en abondance sur les sites lyonnais de la fin du Moyen Âge (comme les marmites à "anses coudées" ou les réchauds de table), avaient été rapprochées des productions de la région chalonnaise (Saône-et-Loire) sur des critères exclusivement typologiques. On pensait bien évidemment aux fameux ateliers du secteur de Sevrey (Renimel 1974). L'approvisionnement des marchés lyonnais, en vaisselle culinaire, depuis le nord, reposait-il sur ces seuls ateliers ou existait il, plus près de Lyon en aval de Chalon-surSaône d'autres centres de production?

Dans le même ordre d'idée, la recherche de l'origine des vaisselles de table ou de stockage, aux décors d'engobes polychromes, omniprésentes dans les dépotoirs régionaux à partir du XVIIe s., amena à s'intéresser également au Val de Saône, traditionnellement admis comme spécialisé dans ce type de fabrications (Jeanton et Dard 1943, Armand - Caillat 1946 et Les Poteries traditionnelles du Val de Saône, 1984). Tournugeois et Mâconnais (Saône-et-Loire), avaient-ils eu l'exclusivité de la diffusion des poteries décorées aux engobes? Quelle situation offraient, par exemple, sur le 
cours inférieur de la Saône, les secteurs de Belleville-sur-Saône et de Villefranche-surSaône (Rhône) ?

Enfin, les informations archéologiques recueillies en amont et en aval de Chalon-surSaône, grâce aux prospections subaquatiques et aux surveillances de dragages effectuées par L. Bonnamour ${ }^{1}$ montrent le rôle joué par cette voie d'eau dans la commercialisation des terres cuites tout au cours du Moyen Âge et à l'époque moderne (Bonnamour 1985, 1986, 1987). En aval de Mâcon, les informations sont beaucoup moins nombreuses; toutefois, les quelques pièces réunies au musée de Saint-Georges-deReneins (Rhône) pourraient constituer de précieux témoins du transport des poteries par la Saône à une quarantaine de kilomètres au nord de Lyon².

5 En réalité, diverses circonstances ont accéléré notre démarche et les découvertes de terrain ont, en l'occurrence, précédé l'enquête historique. En effet, dans le cadre de la réalisation de la carte archéologique régionale, les prospections menées dans le secteur de Belleville-sur-Saône par N. Girard et R. Convert, ont révélé, en divers points de la commune de Corcelles-en-Beaujolais, une impressionnante concentration de tessons médiévaux en pâte grise ${ }^{3}$. En quelques mois, avec la collaboration des "inventeurs" et des habitants, était estimé le potentiel "céramologique" de la commune et les prospections s'étendaient en direction du sud-ouest à Pizay, à Saint-ÉtiennedesOullières ${ }^{4}$ à Blacé et à Saint-Georges-de-Reneins. Enfin, des visites ponctuelles, non suivies de ramassages systématiques, ont montré que le phénomène touchait également les communes de Chénas, Dracé et Le Pérréon ${ }^{5}$. L'ensemble de ces communes se situe dans le département du Rhône, en rive droite de la Saône, au cœur du Beaujolais viticole (fig. 81). En outre, d'autres sites au nord de la zone étudiée, en Saône-et-Loire, comme Charnay-les-Mâcon, Crèches-sur-Saône, Romanèche-Thorins, étaient connus depuis longtemps pour leur production de terres cuites vernissées traditionnelles. 


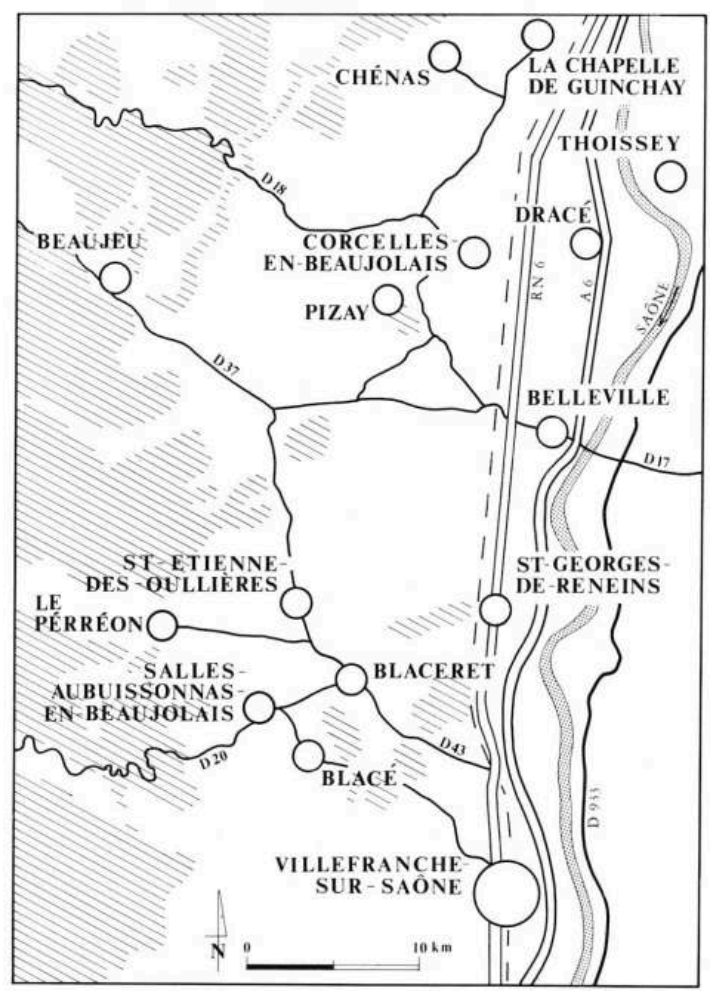

6 L'enquête conduite par J.-F. Garmier sur les ateliers du Mâconnais et du Tournugeois ne prend en compte que la période post-révolutionnaire (Les poteries traditionnelles $\mathrm{du}$ Val de Saône, 1984). Mais rien n'interdit de penser à une vocation plus ancienne, comme le suggère la toponymie (un hameau de Crèches-sur-Saône est dénommé Dracé-lesOllières).

7 Les vestiges de l'activité potière présentés ici affectent donc un terroir considérable : 20 $\mathrm{km}$ séparent le point le plus septentrionnal (Chénas) du plus méridional (Blacé). Si l'enquête archéologique détaillée a porté sur quatre communes, les résultats montrent une répartition en deux ensembles topographiques: un secteur nord autour de Corcelles-en-Beaujolais et un secteur sud autour de Saint-Étienne-des-Oullières.

8 Malgré l'importance des surfaces prospectées, on ne saurait prétendre à une cartographie exhaustive des indices de l'artisanat ; mais d'ores et déjà apparaissent les traces d'une intense activité : une vingtaine de sites, plus ou moins étendus, retiennent l'attention. Et les ramassages de surface ont livré un mobilier considérable qui offre de nombreux indices chronologiques. La longévité de la tradition artisanale semble assurée depuis le haut Moyen Âge jusqu'à l'époque moderne.

L'étude conduite dans le Beaujolais s'inscrit donc dans le très vaste courant des productions céramiques de la Vallée de la Saône, courant relativement bien connu pour le tronçon compris entre Chalon-sur-Saône et Mâcon, mais dont on ignorait jusque-là le prolongement vers le sud en direction de Lyon.

E. F.-B. 


\section{Environnement et ressources en argiles}

11 Les ateliers, ou plutôt les groupes d'ateliers, identifiés dans la région de Corcelles-enBeaujolais et de Saint-Étienne-des-Oullières, connaissent un environnement topographique et géologique commun. Ils se répartissent dans le bas versant oriental des monts du Beaujolais (culminant à $895 \mathrm{~m}$ ), à leur limite avec la plaine de la Saône, en rive droite, à une altitude moyenne de $300 \mathrm{~m}$. Seul le Mont Brouilly $(483 \mathrm{~m})$ se détache à quelque distance de l'ensemble montagneux.

12 Un abondant réseau de ruisseaux et rivières parcourt les faibles reliefs, avant de se jeter dans la Saône; le Douby, l'Ardière, la Vauxonne sont les plus importants. Sur les arènes granitiques vallonnées s'étagent des vignobles aux noms fameux (Fleurie, Morgon, Brouilly). Le contraste de la végétation est frappant entre les paysages riants de la côte viticole et les crêtes sombres d'une montagne relativement austère, dont la forêt primitive a cédé en partie la place aux vignobles de la façade orientale.

13 La région est densément occupée. Les communes, étendues, comptent, outre les villages groupés autour de l'église paroissiale, de nombreux hameaux qui témoignent d'une mise en valeur ancienne du terroir: une ou deux grosses exploitations agricoles d'architecture traditionnelle auxquelles se sont agrégées des habitations plus récentes. Citons par exemple les hameaux du Vieux Bourg et de Chassagne à Corcelles-enBeaujolais, celui de Botheland à Saint-Etienne-des-Oullières, celui de Blaceret à Blacé et celui de Marsangues à Saint-Georges-de-Reneins. Tous ces pôles d'habitat sont reliés par un enchevêtrement de chemins et de routes secondaires, globalement ouest-est, dont le calme et le pittoresque tranchent avec la saignée que constituent les grandes voies de communication nord-sud regroupées en cette rive droite de la Saône : chemin de fer Paris-Marseille, route nationale 6, autoroute A6.

14 A une distance moyenne de 4 à $6 \mathrm{~km}$ du cours de la Saône, les sites étudiés trouvent place sur les moyennes et basses terrasses de la rivière. Constitué en majeure partie des formations fluviatiles, le sous-sol offre de larges possibilités d'approvisionnement en matière première ${ }^{6}$ (fig. 82). 


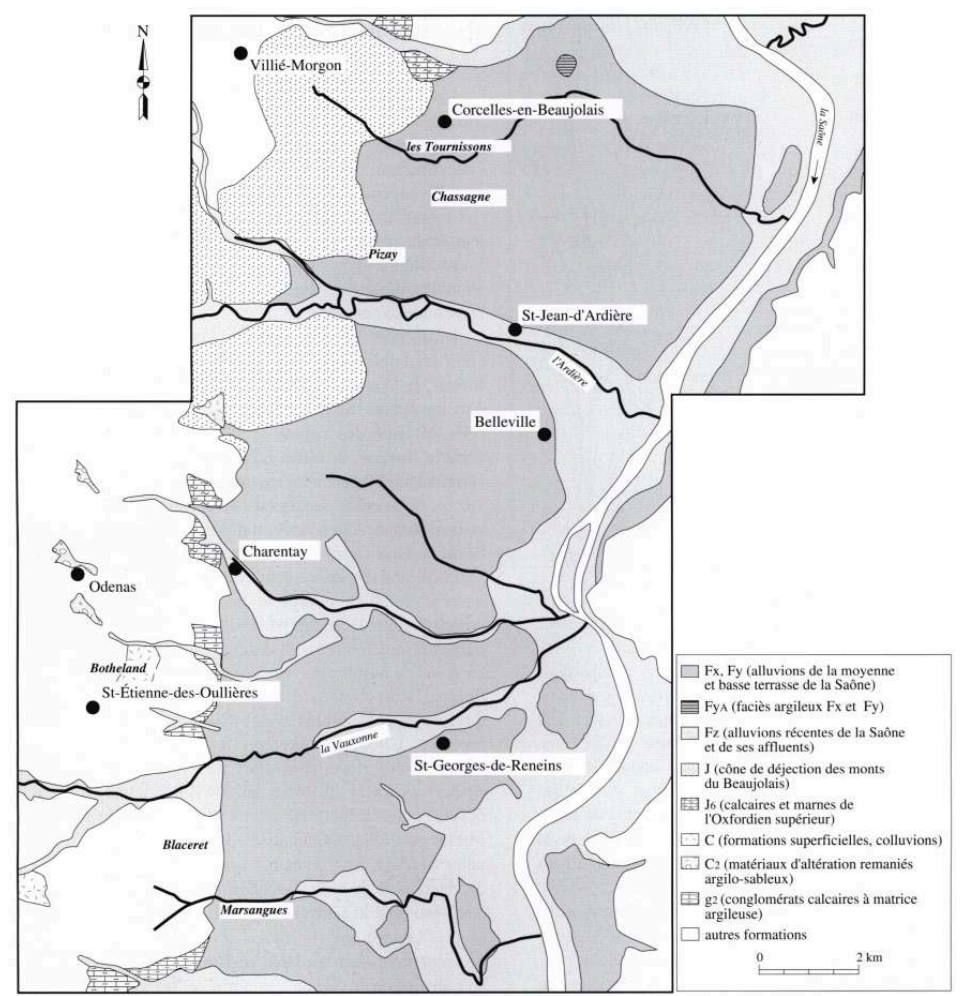

D'après les cartes géologiques de la France au 1/50 000, Paris, BRGM : Beaujeu (649), Belleville (650), Amplepuis (673), Villefranche-sur-Saône (674)

Les larges épandages des alluvions de la moyenne et de la basse terrasse de la Saône (Fx et Fy) constituent l'essentiel du sous-sol du secteur qui nous préoccupe: il s'agit surtout de matériaux sableux et gravillonneux. Cependant, des faciès argileux et limoneux (FxA et FyA) apparaissent en plusieurs points, en particulier au hameau des fournissons à Corcelles-en-Beaujolais. En revanche, ils sont absents de la partie sud du territoire étudié. Plus au nord, à la Chapelle-de-Guinchay et à Dracé, ces matériaux auraient été exploités dans le passé, pour la fabrication des poteries. Les alluvions récentes de la Saône et de ses affluents (Fz) ont alimenté les tuileries de Saint-Romaindes-Iles (à $6 \mathrm{~km}$ au nord-est de Corcelles) jusqu'à tout récemment. La partie ouest du secteur est occupée par les cônes de déjection des monts du Beaujolais (J): les cailloutis, de nature variée, sont inclus dans une matrice sablograveleuse souvent riche en argile. Les affleurements limités et dispersés sont difficiles à localiser.

Les formations limoneuses (OE 1 et $\mathrm{OE} 2$ ) recouvrent la plus grande partie de la rive gauche de la Saône. Mais sur la rive droite, elles ne sont pas directement accessibles.

Les calcaires et marnes de l'Oxfordien (J 6) apparaissent aux confins nord-ouest de la commune de Corcelles-en-Beaujolais et au nord de Saint-Étienne-des-Oullières, à SaintLager. Plusieurs carrières exploitées pour des fours à chaux livrent d'importantes intercalations argileuses plus ou moins ferrugineuses. Cependant, leur haute teneur en calcaire s'accorde mal avec la fabrication de poteries culinaires. 

trouve en abondance l'eau et le bois et surtout la terre. Toutefois, celle-ci n'offre pas de qualités exceptionnelles ou particulières qui auraient permis aux artisans de produire une vaisselle susceptible de se démarquer sur le marché. Les ramassages de surface ne laissent aucun doute à ce sujet. On peut penser que l'abondance de la matière première ne justifie pas à elle seule la pérennité des installations artisanales. C'est plutôt la conjonction de ces facteurs naturels avec la proximité d'une grande voie d'eau navigable, facilitant la commercialisation des produits, qui explique le regroupement des officines et leur longue durée d'activité. Des observations analogues ont été faites à propos de l'implantation des ateliers médiévaux de Sevrey-en-Chalonnais (Renimel 1974, pp. 17-20).

Certaines formations quaternaires superficielles comportent des niveaux de colluvions de type limoneux plus ou moins sableux (c), produit d'altération du socle. Ils sont visibles à Saint-Étienne-des-Oullières, au lieu-dit Botheland.

Des matériaux d'altération remaniés, argilo-sableux, ou limoneux (C2) comblent certains fonds de vallons aux formes adoucies. Ces colluvions sont accessibles au nord de Saint-Étienne-des-Oullières à Odenas et de Saint-Lager.

moins argileuse (g2) pouvant donner lieu à des affleurements d'argiles carbonatées. Cette formation est visible en particulier dans la partie est de Saint-Etienne-desOullières.

affleurements argileux ont été visités et prélevés, aucune trace d'extraction ancienne n'a été repérée avec certitude. Il est probable que les potiers tiraient la terre aussi près que possible de leurs ateliers, depuis de multiples petites carrières qui ont peu marqué le paysage et qui sont aujourd'hui comblées ou remodelées. Il est donc difficile de faire un lien étroit entre la matière première et les produits finis. A l'heure actuelle, quelques observations de portée générale ont pu être faites grâce au concours du Laboratoire de céramologie de Lyon (CNRS, UPR 7524). diverses d'origine beaujolaise. Le pourcentage d'inclusions est important et assez variable selon les exemplaires; la granulométrie est continue et la fraction grossière abondante. Ces caractéristiques correspondent assez bien aux argiles alluviales qui ont été prélevées lors des prospections géologiques dans la région.

composition des argiles et de l'abondance de grains détritiques dans les gisements. Ceci rend très difficile l'interprétation des analyses chimiques des céramiques et, par conséquent, la recherche de la diffusion des ateliers de cette région. Les études en cours permettent d'entrevoir quelques pistes de recherche qui seront explorées ultérieurement.

Globalement, la région apparaît donc propice à la fabrication de céramiques. On y A. S. et E. E-B. 


\section{Cartographie des vestiges d'ateliers}

\section{Objectifs et méthodes}

27 L'enquête réalisée sur les ateliers du Beaujolais se distingue à plus d'un titre de celles présentées dans les chapitres précédents. En effet, elle n'a pas été accompagnée de recherches historiques. Compte tenu du temps et des moyens disponibles, mais surtout de la période d'activité des ateliers considérés (Moyen Âge) et de la nature de leurs productions (vaisselle culinaire commune), les chances de trouver des informations dans les archives semblaient très minces. Depuis, ces premières impressions ont été nuancées au fur et à mesure des découvertes.

Dans ces conditions, il paraissait nécessaire de renforcer les recherches de terrain. Les prospections au sol et les ramassages de surface ont bien sûr dû s'adapter aux dimensions du territoire étudié. Les prospections ont couvert près de $15 \mathrm{~km}^{2}$ dans le secteur nord (Corcelles-en-Beaujolais) et environ $23 \mathrm{~km}^{2}$ dans le secteur sud (SaintÉtienne-des-Oullières). Les zones qui ont livré des indices de surface, plus ou moins denses et plus ou moins fiables, représentent $316500 \mathrm{~m}^{2}$. Par chance, le travail était facilité par le couvert végétal très homogène dans cette région : rangées de vignes à perte de vue, découpant "naturellement" le terrain. Lors d'une première reconnaissance, les parcelles ont été systématiquement parcourues selon un maillage régulier mais lâche (passages espacés de 4 à $5 \mathrm{~m}$, soit de trois à quatre rangées de vigne). Dans le cas où des zones de concentration de tessons étaient repérées, un ramassage était alors effectué. Il s'agissait de recueillir un échantillonnage le plus représentatif possible du mobilier répandu au sol. Une petite équipe de prospecteurs, de composition constante, selon des allées et venues régulières (espacées de 1,50 m environ, soit toutes les rangées de vigne) a donc prélevé le plus de tessons possible lors de chaque passage, sans sélection ni de couleur, ni de taille, ni de forme. Certes, les circonstances des ramassages n'ont pas été constantes au cours des nombreuses séances de prospection : les conditions climatiques (sol sec ou humide) et la lisibilité du terrain (présence de feuilles, de pierrailles...) ont en effet été variables et certaines parcelles ont dû être revisitées. Cependant, on peut estimer que le caractère aléatoire de ce type de ramassages extensifs fait partie de la démarche et qu'il est pondéré par l'ampleur des surfaces en cause (Hesse 1980). Au cours des prospections, d'autres indices archéologiques étaient notés, comme la présence de tâches cendreuses, de terre cuite autre que poteries, de matériaux de construction, etc.

La restitution des résultats des ramassages effectués en Beaujolais a eu recours aux mêmes méthodes que celles mises en œuvre lors des deux autres expériences régionales. En l'absence de quadrillage prédéterminé, le décompte des tessons collectés a été fait par unité prospectée, très généralement la parcelle cadastrale. Aussi la cartographie, sur fond cadastral, restitue-t-elle la localisation des découvertes ainsi que la densité relative du mobilier découvert, permettant de hiérarchiser l'intérêt des secteurs prospectés et de départir, autant que faire se peut, les zones de rejets d'ateliers des zones d'épandage d'autre origine ${ }^{7}$. En particulier, les ramassages conduits à proximité des habitations sont sujets à caution et ne sont pas exempts de risques de "pollution" dus aux façons culturales (recharges en terre, notamment). En outre, l'appréhension de certaines zones n'a pu être que partielle en raison du couvert végétal (passage de la vigne à la prairie) ou d'aménagements divers (voirie, constructions, etc.) 
limitant artificiellement la prospection. Il fallait également compter avec la topographie: le déplacement des indices vers les bas de pente a pu fausser certains résultats.

Les tessons n'ont pas été recueillis pour leur seul intérêt quantitatif. Ils ont également fait l'objet d'une classification morphologique et technique de façon à dégager les grandes phases chronologiques des productions locales. Le volume du mobilier à traiter (51930 tessons) nous a conduit à établir un système d'inventaire volontairement simplifié qui ne retient que les critères les plus discriminants (cf. infra). En effet, la dispersion et la diversité des résultats n'autorisait pas, à cette étape de la recherche, à dresser le catalogue précis des vaisselles fabriquées par les ateliers du Beaujolais.

Par ces méthodes de large reconnaissance, à l'échelle de plusieurs communes, il s'agissait donc de tendre à une vision d'ensemble des vestiges d'artisanat, tant topographique que chronologique, sans privilégier a priori telle ou telle zone jugée plus attractive en raison de la nature, de la qualité des indices ou de la période concernée. Ces ratissages systématiques offraient en outre l'occasion d'observations sur des cas suffisamment nombreux pour tirer des enseignements de portée générale, comme la position des ateliers présumés par rapport aux habitats, aux ressources naturelles et aux voies de communication. C'était aussi la possibilité de juger de leur continuité dans le temps sur un même lieu ou, au contraire, de leur déplacement à l'intérieur du territoire étudié. Pour reprendre l'expression utilisée lors de travaux comparables menés sur les ateliers de Sevrey (Saône-et-Loire), "le schéma d'évolution horizontale des sites" était l'objectif poursuivi (Renimel 1974, pp. 29-31).

Mais en l'absence des preuves convergentes qu'auraient fourni les mentions textuelles, les données de l'archéologie ont été confortées par les techniques géophysiques mises en œuvre dans plusieurs zones où la concentration des indices de surface était particulièrement nette. Ainsi, des prospections électromagnétiques ont été réalisées en quatre secteurs sur la commune de Corcelles-en-Beaujolais et neuf autres secteurs ont été ainsi prospectés à la limite des communes de Blacé (Blaceret) et de Saint-Georgesde-Reneins (Marsangues). La prospection a été réalisée avec l'appareil électromagnétique EM15 (mesure de la susceptibilité magnétique) selon une grille de 5 $\mathrm{m} \times 5 \mathrm{~m}$ ou de $3 \mathrm{~m} \times 3 \mathrm{~m}$. L'objectif principal était de mettre en évidence des zones bien circonscrites de forte susceptibilité magnétique compatibles avec la présence d'aires de production de céramique; sur le plan méthodologique, la démarche était des plus classiques, puisqu'il s'agissait, pour la prospection géophysique, de franchir une étape dans la connaissance de sites simplement identifiés par la présence de matériel céramique en surface (concentrations et/ou épandages plus ou moins vastes et riches) ${ }^{8}$.

\section{E. F.-B.}

\section{Les ramassages de surface}

Les premiers indices archéologiques signalés au lieu-dit les Serves, à Corcelles-enBeaujolais, se situaient à l'écart du bourg et des hameaux (T6'). Aussi l'organisation des ramassages effectués en Beaujolais se distingue-t-elle de celle retenue dans le secteur bressan et dans la vallée du Rhône, où les zones d'habitats anciens ont polarisé les prospections, comme y invitaient les mentions textuelles. Ici, les zones intercalaires ont été systématiquement visitées, sans pour autant négliger la périphérie des habitats. 
Les informations orales recueillies auprès des habitants ou des exploitants ont été très fructueuses. Nul n'ignore, en effet, les principaux secteurs où le sol des vignes est jonché de "vieux pots cassés"9. En revanche, le souvenir d'une tradition artisanale semble évanoui, si l'on excepte l'indication d'une tuilerie "datant de la Révolution" (sic) au lieu-dit les Bruyères à Saint-Étienne-des-Oullières.

A Corcelles-en-Beaujolais (fig. 83) dix-huit zones, largement réparties sur la commune, ont livré des tessons de céramique ( $\mathrm{T}^{\prime}$ à $\left.\mathrm{T} 18^{\prime}\right)$. Il faut également signaler les observations ponctuelles faites en deux points de la commune voisine de Pisay ${ }^{10}$. L'ensemble des communes de Saint-Étienne-des-Oullières, Blacé et Saint-Georges-deReneins (fig. 84) (tableau 1) regroupe une trentaine de points de ramassage (T1 à T31). Partout les tessons recueillis montraient des caractéristiques communes qui étayaient l'hypothèse d'artisanat potier : céramique grossière, à forte majorité en pâte grise, et un répertoire de formes limité évoquant globalement le Moyen Âge. On verra plus loin comment ce tableau a pu être complété.

83 - Localisation des zones ayant livré du mobilier lors des ramassages de surface

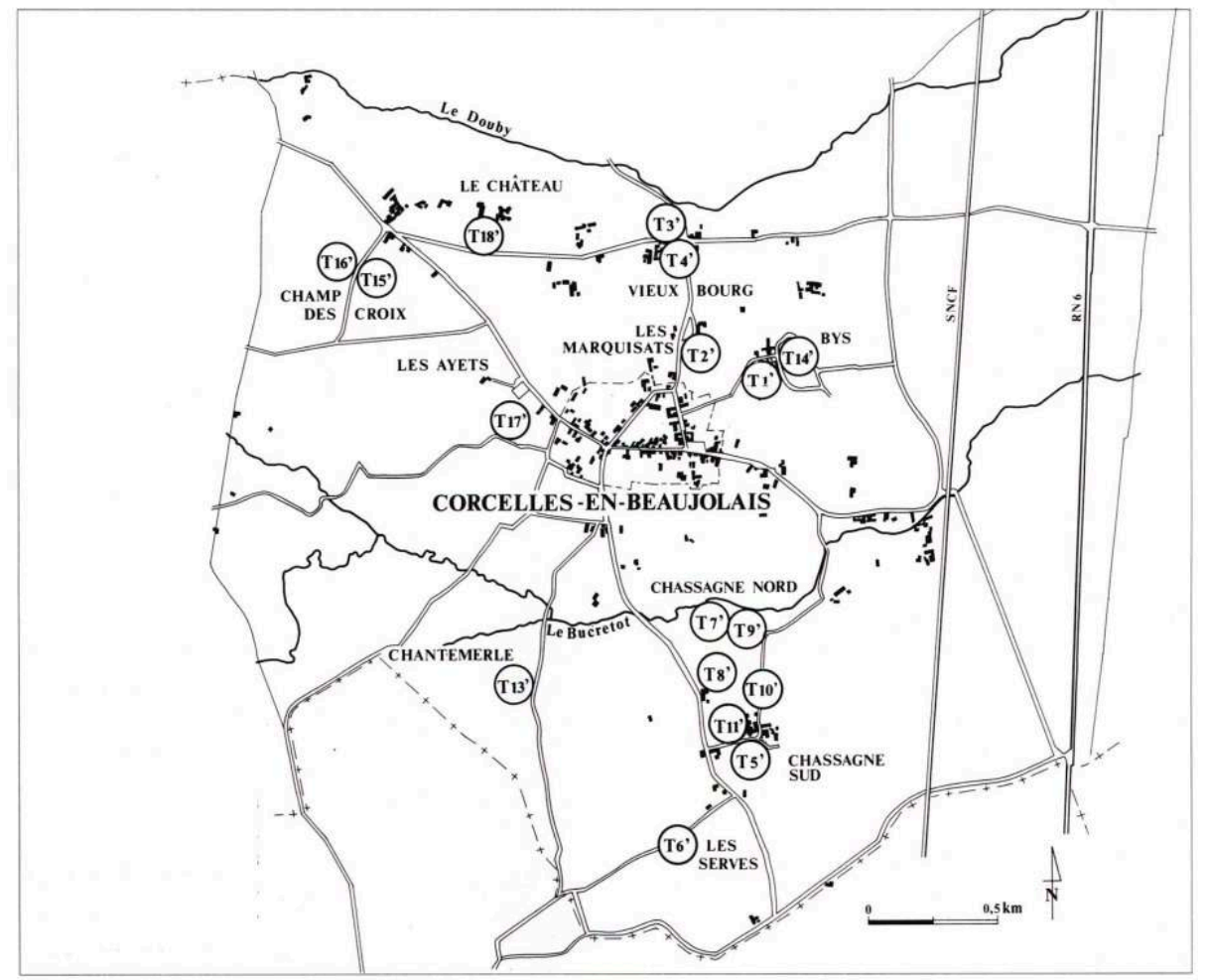

Commune de Courcelles-en-Beaujolais 
84 - Localisation des zones ayant livré du mobilier lors des ramassages de surface

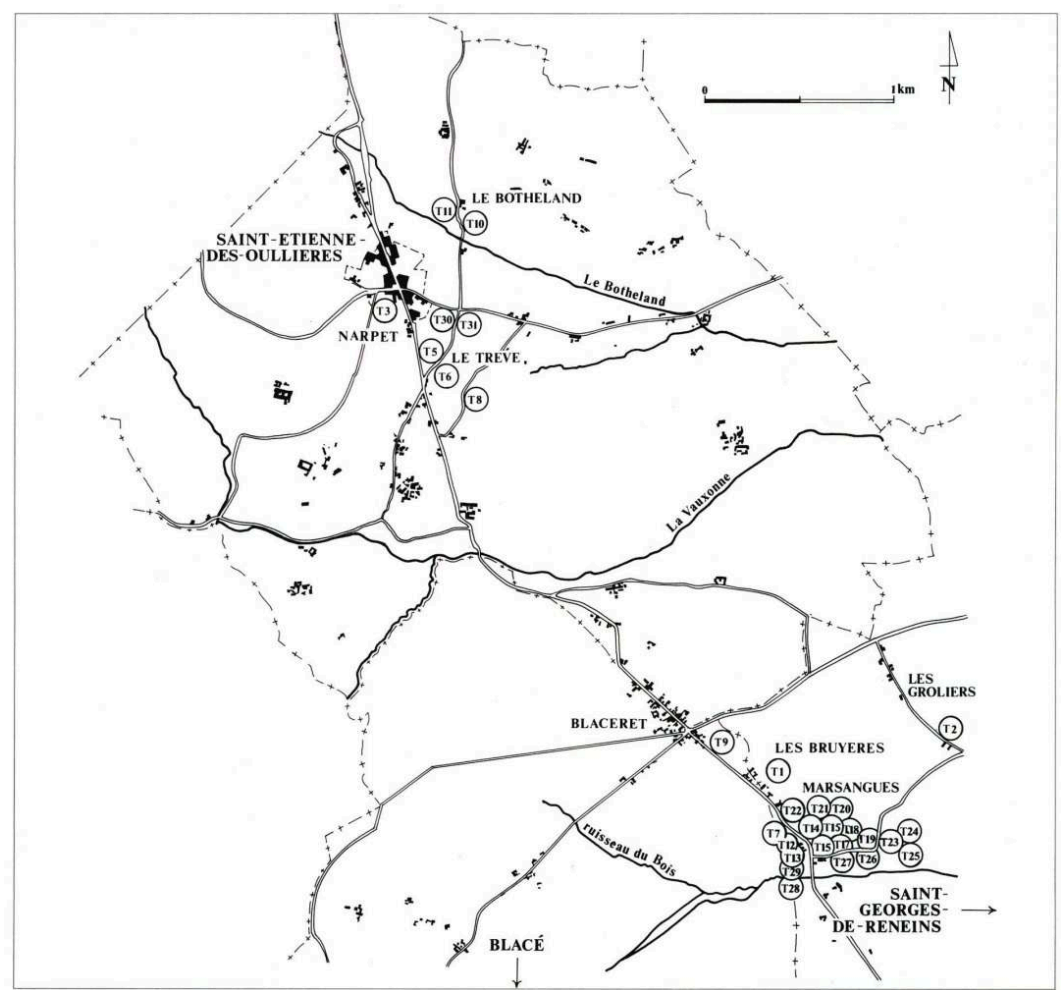

Communes de Saint-Étienne-des-Ouillières, Blacé et Saint-Georges-de-Reneins

37 La restitution graphique des résultats des prospections de surface n'est en aucun cas une image fidèle de la répartition des ateliers sur le territoire étudié. Il s'agit plutôt d'une "carte archéologique", aussi objective que possible, des indices de surface. L'interprétation de ces indices n'est pas toujours aisée et nombre de questions, à cette étape, restent en suspens. Si les prospections géophysiques ont complété, en certains points, les observations de terrain (cf. infra), seuls des sondages archéologiques, ultime étape, pourraient lever tous les doutes. La cartographie tient donc compte de ces incertitudes ${ }^{11}$. La compartimentation des découvertes en deux groupes est dictée uniquement par la géographie : au nord le groupe dit de Corcelles-en-Beaujolais, au sud celui dit de Saint-Étienne-des-Oullières. 
Tableau 1. Localisation des zones de ramassages de surface effectués sur les communes de Corcelles-en-Beaujolais, Saint-Etienne-des-Oullières, Blacé et Saint-Georges-de-Reneins

\begin{tabular}{|c|c|c|c|}
\hline $\begin{array}{c}\text { POINT DE } \\
\text { RAMASSAGE }\end{array}$ & COMMUNE & LIEU-DIT & PARCELLES \\
\hline $\mathrm{Tl}^{\circ}$ & Corcelles-en-Beaujolais & le Bys & AK $173-174$ (est) \\
\hline $\mathrm{T}^{\prime}$ & Corcelles-en-Beaujolais & les Marquisats & AK $110-109$ \\
\hline$T 3^{\prime}-T^{\prime}$ & Corcelles-en-Beaujolais & Vieux Bourg & $\mathrm{AB} 110-111$ \\
\hline T5' & Corcelles-en-Beaujolais & Chassagne & AE 33 et 42 à 46 \\
\hline T6 & Corcelles-en-Beaujolais & les Serves & $\mathrm{AB} 139$ à $141,173,175,176$ \\
\hline$T 7$ & Corcelles-en-Beaujolais & Chassagne nord & A $19-20$ \\
\hline T8' & Corcelles-en-Beaujolais & Chassagne nord & AE 29 (est) \\
\hline T9' & Corcelles-en-Beaujolais & Chassagne nord & AE 23-24 \\
\hline T10 & Corcelles-en-Beaujolais & Chassagne nord & AE 25 à 27 \\
\hline T11' & Corcelles-en-Beaujolais & Chassagne & A 349 (sud) \\
\hline${\mathrm{T} 13^{\prime}}^{\prime}$ & Corcelles-en-Beaujolais & Chantemerle & AD 237 (sud) \\
\hline T14' & Corcelles-en-Beaujolais & le Bys & AK $183,287-288$ \\
\hline $\mathrm{T}^{\prime} 5^{\prime}-\mathrm{T}^{\prime} 6^{\prime}$ & Corcelles-en-Beaujolais & Champ des Croix & $A B 230$ a $232,268,271$ \\
\hline T17 & Corcelles-en-Beaujolais & les Aycts & AC 82 et 358 (sud) \\
\hline T18: & Corcelles-en-Beaujolais & le Château & $\mathrm{AB} 60 \mathrm{a}, 60 \mathrm{~b}, 61$ \\
\hline T1 & Saint-Georges-de-Reneins & les Bruyères & N 381 \\
\hline $\mathrm{T} 2$ & Saint-Georges-de-Reneins & les Grolieres & N 179b \\
\hline T3 & Saint-Etienne-des-Oullières & Narpet & E1 651 (est) \\
\hline T5 & Saint-Etienne-des-Oullières & le Treve & A 67 a $69 \mathrm{a}, 521$ \\
\hline $\mathrm{T} 7$ & Blacé / Saint-Georges-de-Reneins & Marsangues & $\mathrm{Al}, 505,1141$ \\
\hline T8 & Saint-Etienne-des-Oullières & le Trève & A 57 a 59 \\
\hline T9 & Blacé & Blaceret & Al 353 \\
\hline T10 & Saint-Etienne-des-Oullières & le Botheland & D 44 a 48 \\
\hline $\mathrm{T} 11$ & Saint-Etienne-des-Oullières & le Botheland & E1 529a et b \\
\hline $\mathrm{T} 12$ & Blacé/Saint-Georges-de-Reneins & Marsangues & Al $487-488,490 \mathrm{~N} 366-367$ \\
\hline $\mathrm{T} 13$ & Blacé / Saint-Georges-de-Reneins & Marsangues & Al 496 a 498, N 358 \\
\hline T14 & Saint-Georges-de-Reneins & Marsangues & N $334-335$ (ouest) \\
\hline T15 & Saint-Georges-de-Reneins & Marsangues & N $338-339$ \\
\hline T16 & Saint-Georges-de-Reneins & Marsangues & N 334 - 335 (est), 315 (sud) \\
\hline T17 & Saint-Georges-de-Reneins & Marsangues & N 336 - 337, 332 (sud) \\
\hline T18 & Saint-Georges-de-Reneins & Marsangues & N 332 (nord) - 333 \\
\hline T19 & Saint-Georges-de-Reneins & Marsangues & $\mathrm{N} 326,328$ \\
\hline $\mathrm{T} 20$ & Saint-Georges-de-Reneins & Marsangues & $\mathrm{N} 317 \mathrm{a}$ \\
\hline $\mathrm{T} 21-\mathrm{T} 22$ & Saint-Georges-de-Reneins & Marsangues & N 315 (sud), 425 \\
\hline $\mathrm{T} 23$ & Saint-Georges-de-Reneins & Marsangues & 083 a 86 \\
\hline $\mathrm{T} 24$ & Saint-Georges-de-Reneins & Marsangues & O 80 a 82 \\
\hline T25 & Saint-Georges-de-Reneins & Marsangues & 075 \\
\hline $\mathrm{T} 26$ & Saint-Georges-de-Reneins & Marsangues & 058 \\
\hline T27 & Saint-Georges-de-Reneins & Marsangues & $053,56,57$ \\
\hline $\mathrm{T} 28$ & Blacé / Saint-Georges-de-Reneins & Marsangues & Al $347,500, N$ 344a \\
\hline $\mathrm{T} 29$ & Blacé / Saint-Georges-de-Reneins & Marsangues & A1 499, N $356-357$ \\
\hline $\mathrm{T} 30$ & Saint-Etienne-des-Oullières & les Grandes Bruyères & E1 $287-288$ \\
\hline T31 & Saint-Etienne-des-Oullières & les Grandes Bruyères & A 71 a 73 \\
\hline
\end{tabular}

\section{Le groupe des ateliers de Corcelles-en-Beaujolais}

D'après les informations recueillies, on peut classer les sites en trois catégories (fig. 85 à 90).

1 - Les sites qui réunissent plusieurs types d'indices associés à une forte concentration de tessons en surface. Il s'agit du centre de T2' (les Marquisats), de T6' (les Serves) de T7' (Chassagne nord) et de T13' (Chantemerle) (fig. 85 à 87 et tableau 2). 
85 - Corcelles-en-Beaujolais : résultats des ramassages de surface aux lieux-dits les Marquisats (T2') et le Bys ( $\mathrm{T} 1$ ' et $\mathrm{T} 14^{\prime}$ )

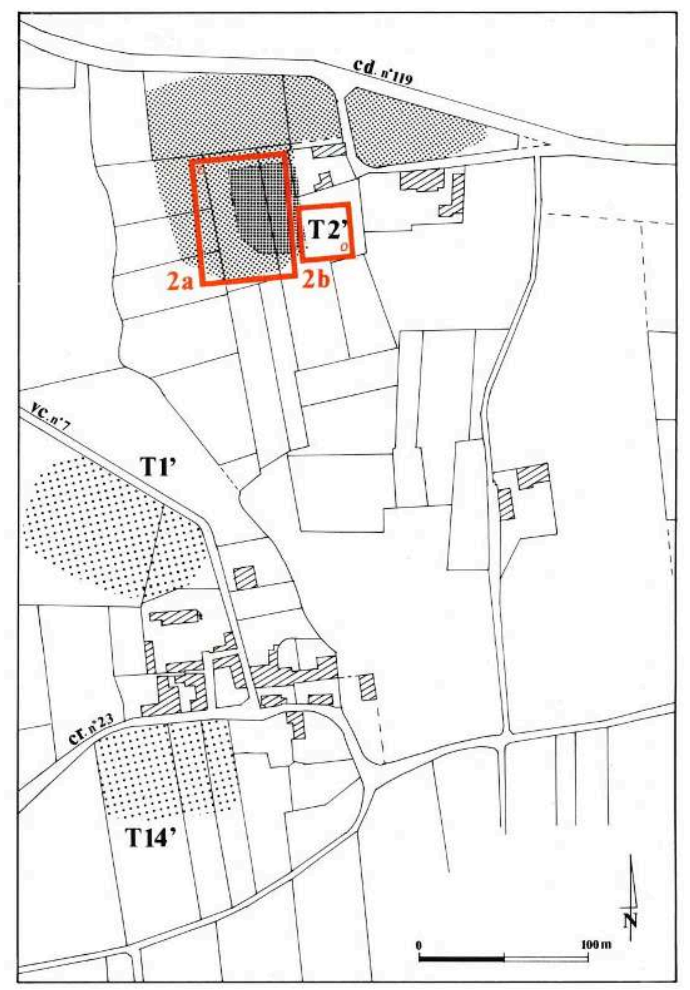

Les zones où ont été effectuées des prospections géo physiques sont encadrées en rouge (cf. légende fig. 86) 
Tableau 2. Quantification des résultats des ramassages de surface

\begin{tabular}{|c|c|c|c|}
\hline $\begin{array}{c}\text { Zone de } \\
\text { ramassage }\end{array}$ & $\begin{array}{c}\text { Surface } \\
\qquad\left(\mathbf{m}^{2}\right)\end{array}$ & $\begin{array}{l}\text { Nb de tessons } \\
\text { collectés }\end{array}$ & $\begin{array}{l}\text { Taux de } \\
\text { répartition }\end{array}$ \\
\hline T1' & 2500 & 271 & 1 \\
\hline T2' & 4500 & 1393 & 3 \\
\hline T3' - T4' & 3000 & 106 & 0.3 \\
\hline T5' & 12000 & 740 & 0.6 \\
\hline T6' & 1000 & 430 & 4.3 \\
\hline T7' & 5500 & 3028 & 5.5 \\
\hline T8' & 5000 & 839 & 1.6 \\
\hline T9' & 3000 & 138 & 0.4 \\
\hline T10' & 10000 & 239 & 0.2 \\
\hline T11' & 5000 & 140 & 0.2 \\
\hline T13' & 2000 & 1072 & 5.3 \\
\hline T14' & 9000 & 69 & 0.1 \\
\hline T15' - T16' & 5000 & 860 & 1.7 \\
\hline T17' & 1000 & 181 & 1.8 \\
\hline T18' & 10000 & 259 & 0.2 \\
\hline
\end{tabular}

Groupe des ateliers de Corcelles-en-Beaujolais cendreuses, dont l'une très nette et très circonscrite (cercle de $3 \mathrm{~m}$ de diamètre environ) aux Marquisats. Le site T13', bien délimité, associe à des tessons de vaisselle de nombreux fragments de tuiles à rebord, très calcinées, tout comme T7'. Celui-ci restitue une grande quantité d'éclats de tuiles plates à rebord, surcuites, déformées, voire vitrifiées par la chaleur. Ce dernier site produisait-il concurremment vaisselle et céramique architecturale ou bien s'agit-il des matériaux de construction des fours ? La deuxième hypothèse semble plus probable: tous les tessons de tuiles observés sont surcuits et leur proportion (50 échantillons collectés) par rapport aux tessons de vaisselle reste faible. Il faut également souligner, pour l'ensemble de ces sites, l'absence d'autres catégories de mobilier, habituellement mises en relation avec des activités domestiques (faune, métal...).

Ces quatre sites retiennent donc en priorité l'attention: il y a de fortes probabilités pour qu'ils correspondent à la localisation d'ateliers de potiers. 
86 - Corcelles-en-Beaujolais : résultats des ramassages de surface aux lieux-dits les Serves (T6'), Chassagne nord (T7', T8' et $\left.\mathrm{T} 10^{\prime}\right)$ et Chassagne sud ( $\mathrm{T} 5^{\prime}$ et $\left.\mathrm{t} 1 \mathrm{1}^{\prime}\right)$
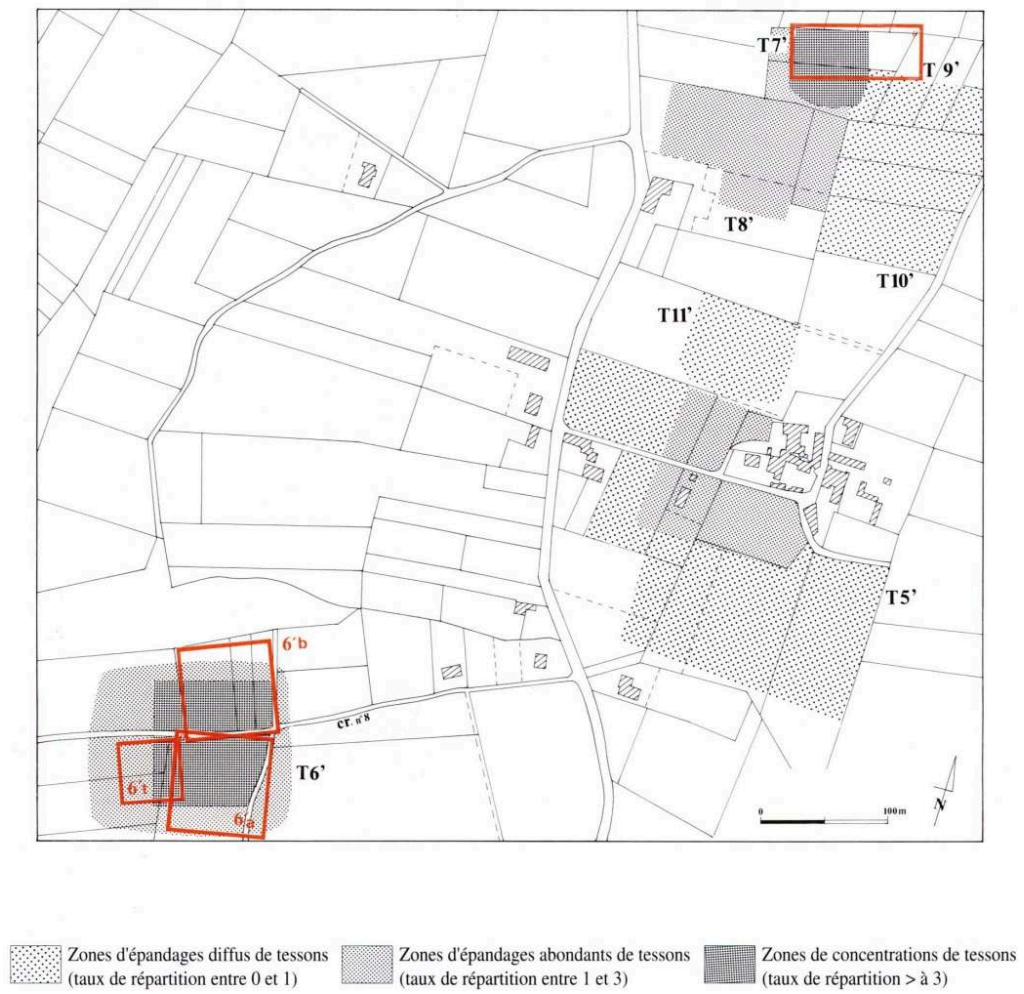

Les zones où ont été effectuées des prospections géophysiques sont encadrées en rouge

2 - Les sites qui présentent des épandages de tessons moins denses que précédemment, mais plus étendus et souvent difficiles à délimiter. On peut ranger dans cette catégorie T8' (Chassagne nord), T5' (Chassagne sud), la périphérie de T2' (les Marquisats), T15' et T16' pour partie (Champ des Croix) et T17' (les Ayets) (fig. 85, 86 et 89).

S'il semble assez évident que la périphérie de T2' et de T8' peuvent être mis en relation avec les ateliers voisins (déplacement des tessons en surface par l'érosion ou les labours), les autres sites offrent d'autres cas de figure. Le site du Champ des Croix (T15' - T16') présente des similitudes avec celui de T13' décrit plus haut : il est isolé du bourg et des hameaux actuels; la céramique recueillie, particulièrement grossière, est associée à des fragments de briques et tuiles plates dont la majorité est surcuite. En revanche, les limites du site sont plus difficiles à cerner et la densité des tessons y est plus faible. Le pendage du terrain peut en partie expliquer la diffusion plus lâche des vestiges de surface. Mais les zones T15' - T16', où les indices sont exclusivement céramiques et de facture homogène, pourraient bien signaler une ou des officines, dont on verra plus loin qu'elles sont parmi les plus anciennes de la contrée. 


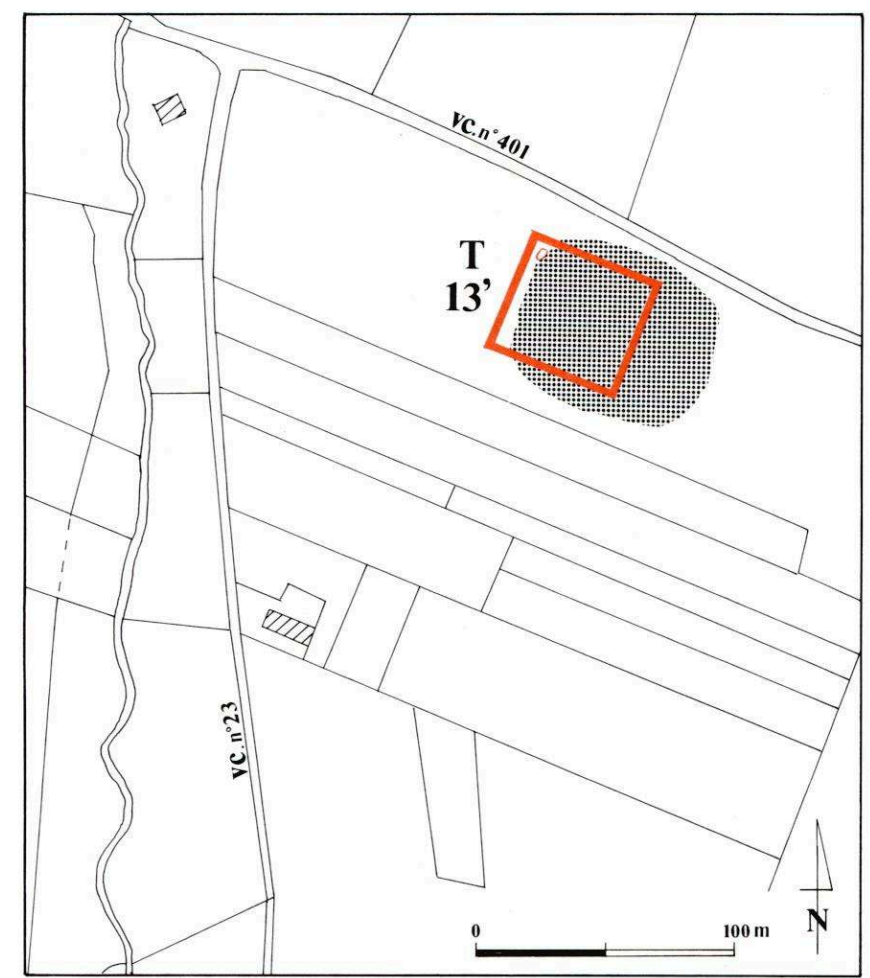

Les zones où ont été effectuées des prospections géophysiques sont encadrées en rouge (cf. légende fig. 86)

En revanche, T17' et T5' restent plus énigmatiques. La proximité des habitats accuse les risques de remaniement (en particulier recharges en terre et rejets domestiques). D'ailleurs, ces sites montrent des apports de mobilier moderne (tuiles mécaniques, vaisselle vernissée et faïence). Pourtant, à Chassagne, l'extension des indices et leur forte densité à proximité immédiate du hameau, leur parenté morphologique avec les produits des ramassages voisins, plaident pour des vestiges d'artisanat.

3 - Enfin ont été cartographies pour mémoire les zones d'épandage qui ne présentent pas de critères suffisants pour être retenues comme indices d'ateliers. Il s'agit de T3' et T4' (Vieux Bourg) (fig. 90), T1' et T14' (le Bys) (fig. 85), T18' (près du Château) (fig. 88). Ces sites se caractérisent par des limites floues, une faible densité de tessons de poteries auxquels se mêlent quelques vestiges d'autre nature (éléments de constructions, déchets métalliques, faune). Il faut noter que tous ces sites sont proches d'habitations. Par ailleurs, T10' et T11' (fig. 86) ainsi que les franges de T15' - T16' (fig. 88) peuvent être interprétés comme le déplacement en surface des vestiges observés plus clairement dans les parcelles voisines. 
88 - Corcelles-en-Beaujolais : résultats des ramassages de surface au lieu-dit Champ des Croix (T15', T16') et au Château (T18')

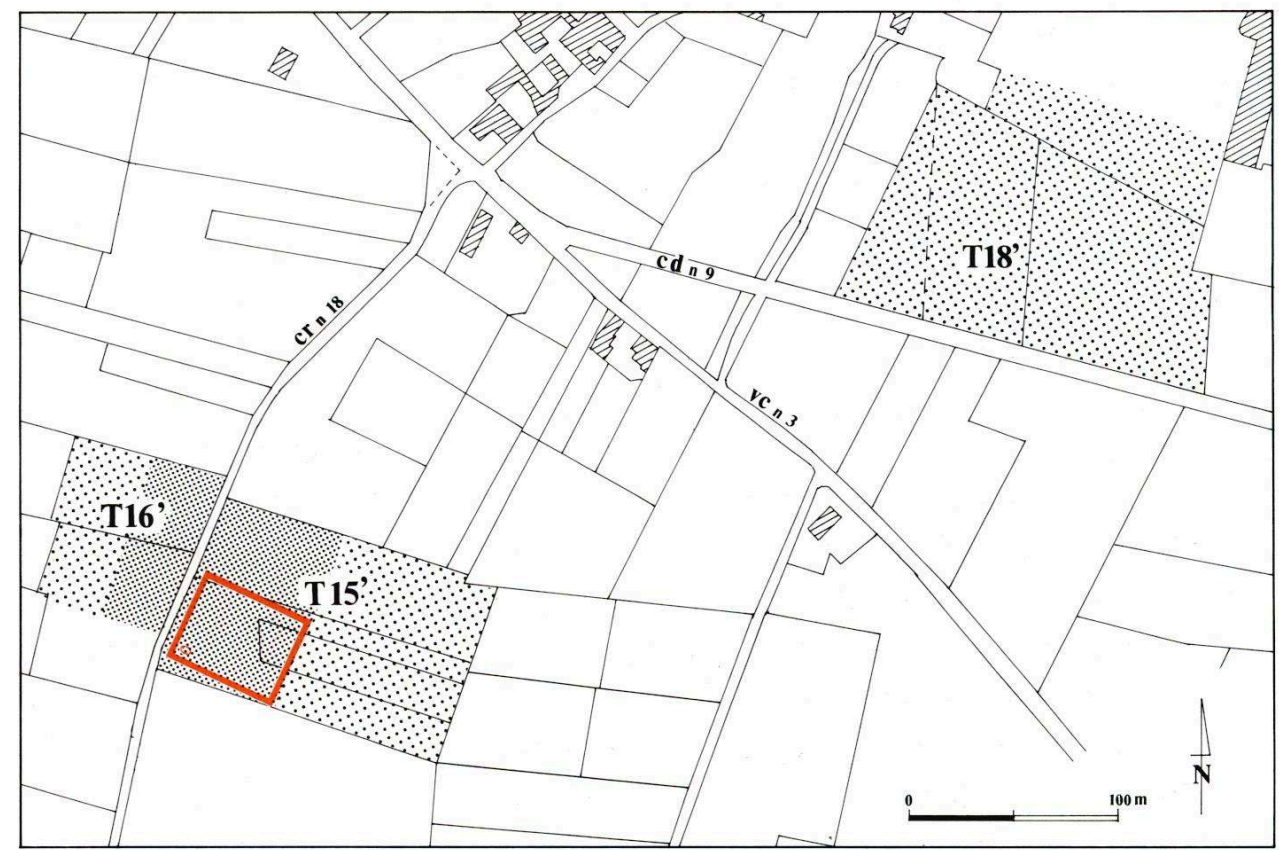

Les zones où ont été effectuées des prospections géophysiques sont encadrées en rouge (cf. légende fig. 86)

89 - Corcelles-en-Beaujolais : résultats des ramassages de surface au lieu-dit les Ayets (T17')

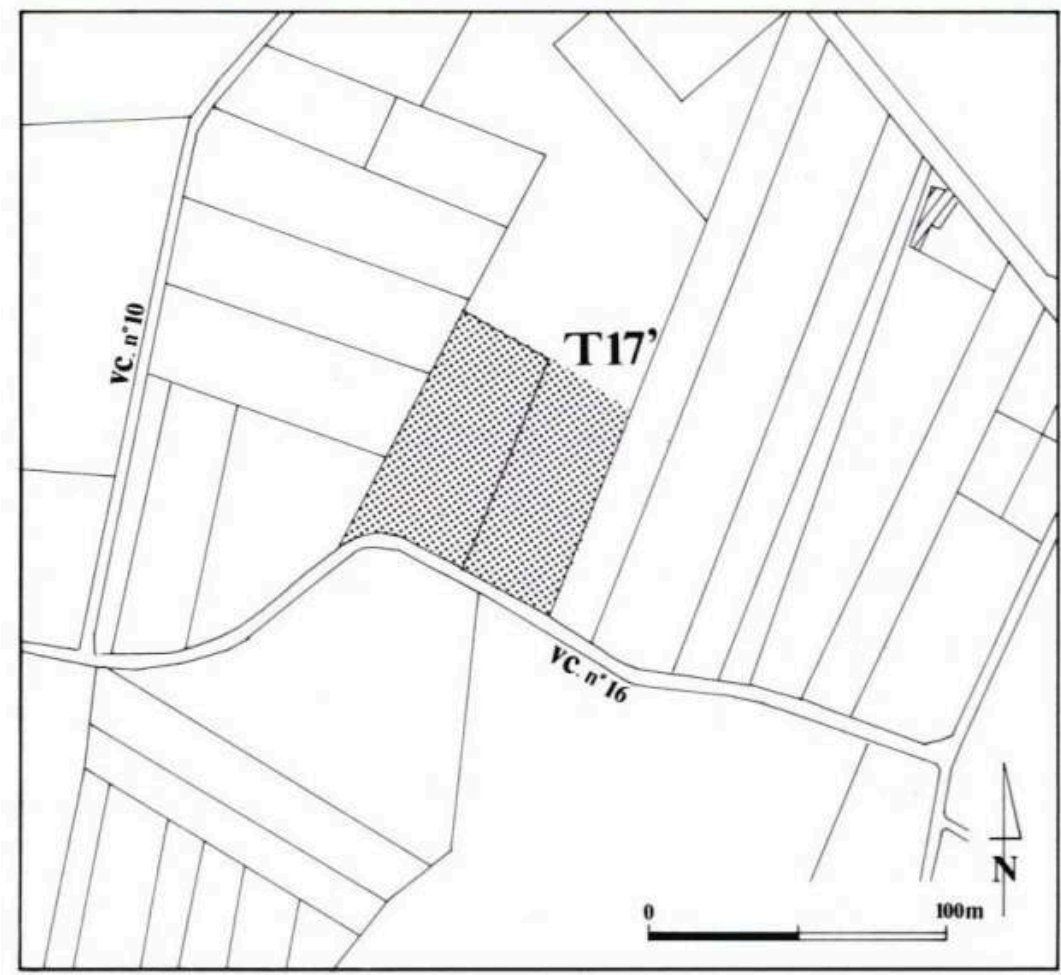


90 - Corcelles-en-Beaujolais : résultats des ramassages au lieu-dit le Vieux-Bourg (T3' et T4')

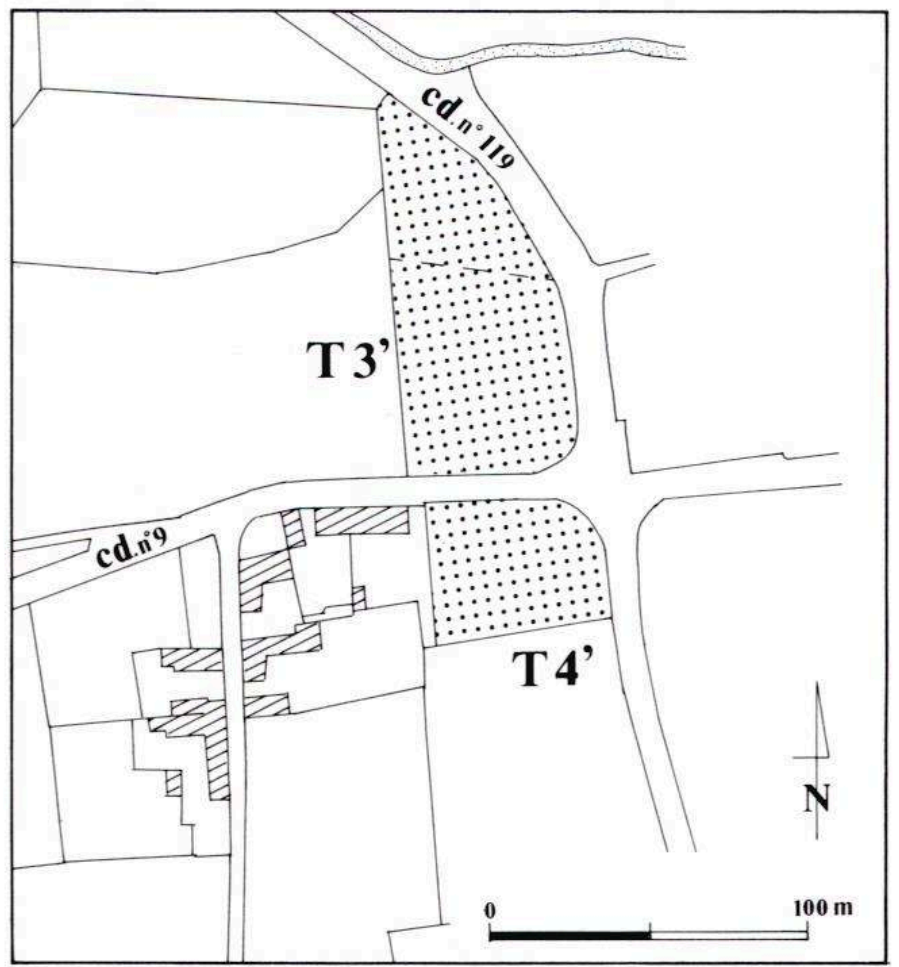

cf. légende fig. 86

Le groupe des ateliers de Saint-Étienne-des-Oullières

Dans ce secteur, les données archéologiques livrent une image plus contrastée que dans le cas précédent (fig. 91 à 96) et (tableau 3). 
91 - Blacé et Saint-Georges-de-Reneins : résultats des ramassages de surface aux lieux-dits les Bruyères ( $\mathrm{T} 1$ ) et Marsangues ( $T 7$ et $\mathrm{T} 12$ à $\mathrm{T} 29$ )

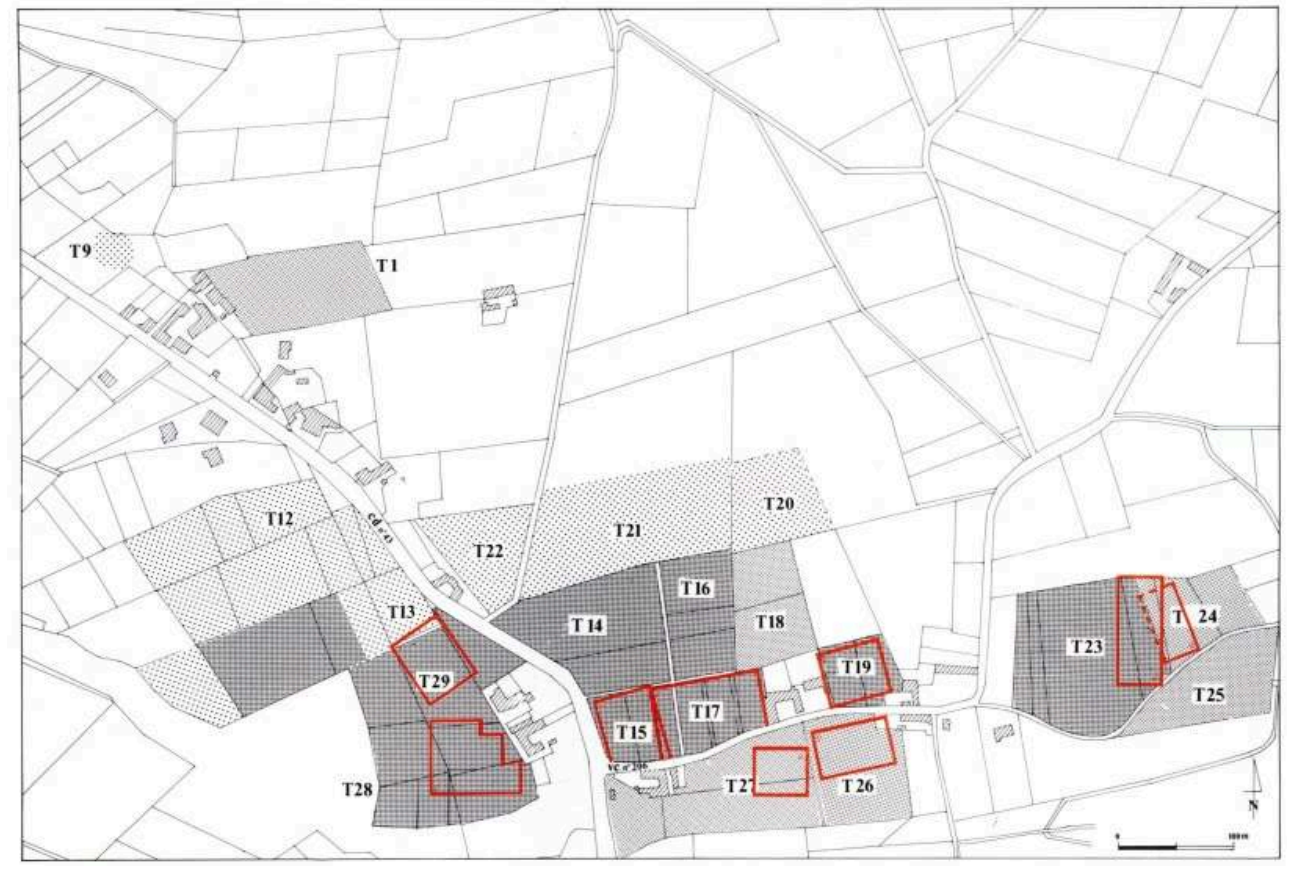

Les zones où ont été effectuées des prospections géophysiques sont encadrées en rouge (cf. légende fig. 86)

Tableau 3. Quantification des résultats des ramassages de surface

\begin{tabular}{|c|c|c|c|}
\hline $\begin{array}{c}\text { Zone de } \\
\text { ramassage }\end{array}$ & $\begin{array}{c}\text { Surface } \\
\left(\mathbf{m}^{2}\right)\end{array}$ & $\begin{array}{c}\text { Nb de tessons } \\
\text { collectés }\end{array}$ & $\begin{array}{c}\text { Taux de } \\
\text { répartition }\end{array}$ \\
\hline $\mathrm{T} 1$ & 4500 & 1014 & 2.2 \\
\hline $\mathrm{T} 2$ & 4000 & 162 & 0.4 \\
\hline $\mathrm{T} 3$ & 3000 & 502 & 1.6 \\
\hline $\mathrm{T} 5$ & 5000 & 85 & 0.2 \\
\hline $\mathrm{T} 6$ & 10000 & 154 & 0.1 \\
\hline $\mathrm{T} 7$ & 9000 & 1595 & 1.7 \\
\hline $\mathrm{T} 8$ & 4500 & 405 & 1.0 \\
\hline $\mathrm{T} 9$ & 2000 & 78 & 0.3 \\
\hline $\mathrm{T} 10$ & 10000 & 1441 & 1.4 \\
\hline $\mathrm{T} 11$ & 2000 & 441 & 2.2 \\
\hline $\mathrm{T} 12$ & 8000 & 248 & 0.3 \\
\hline $\mathrm{T} 13$ & 12000 & 1050 & 0.8 \\
\hline $\mathrm{T} 14$ & 10000 & 3776 & 3.7 \\
\hline $\mathrm{T} 15$ & 4000 & 1445 & 3.6 \\
\hline $\mathrm{T} 16$ & 6000 & 2883 & 4.8 \\
\hline $\mathrm{T} 17$ & 4500 & 4339 & 9.6 \\
\hline $\mathrm{T} 18$ & 5500 & 1372 & 2.4 \\
\hline $\mathrm{T} 19$ & 3000 & 1821 & 6 \\
\hline $\mathrm{T} 20$ & 5000 & 298 & 0.5 \\
\hline $\mathrm{T} 21-\mathrm{T} 22$ & 20000 & 692 & 0.3 \\
\hline $\mathrm{T} 23$ & 10000 & 3823 & 3.8 \\
\hline $\mathrm{T} 24$ & 7500 & 1870 & 2.4 \\
\hline $\mathrm{T} 25$ & 6500 & 1556 & 2.4 \\
\hline $\mathrm{T} 26$ & 8500 & 2536 & 2.9 \\
\hline $\mathrm{T} 27$ & 10000 & 2889 & 2.8 \\
\hline $\mathrm{T} 28$ & 5000 & 2201 & 4.4 \\
\hline $\mathrm{T} 29$ & 6000 & 2894 & 5.7 \\
\hline $\mathrm{T} 30$ & 5000 & 150 & 0.3 \\
\hline $\mathrm{T} 31$ & 10000 & 434 & 0.4 \\
\hline & & & \\
\hline
\end{tabular}

Groupe des ateliers de Saint-Étienne-des-Oullières 
Tout d'abord, la localisation des zones d'épandage est plus irrégulière puisque deux ensembles se dessinent assez nettement, l'un autour du bourg de Saint-Etienne, l'autre autour du hameau de Marsangues (réparti entre les communes de Blacé et de SaintGeorges-de-Reneins). Par ailleurs, la répartition des tessons est très variable d'un ensemble à l'autre. Ceci nécessite de pondérer quelque peu la cartographie restituée à partir du seul critère quantitatif. Là aussi, on rencontre les trois catégories de sites établies plus haut.

92 - Concentration de tessons au sol dans une vigne de Saint-Georges-de-Reneins au lieu-dit Marsangues (T19)

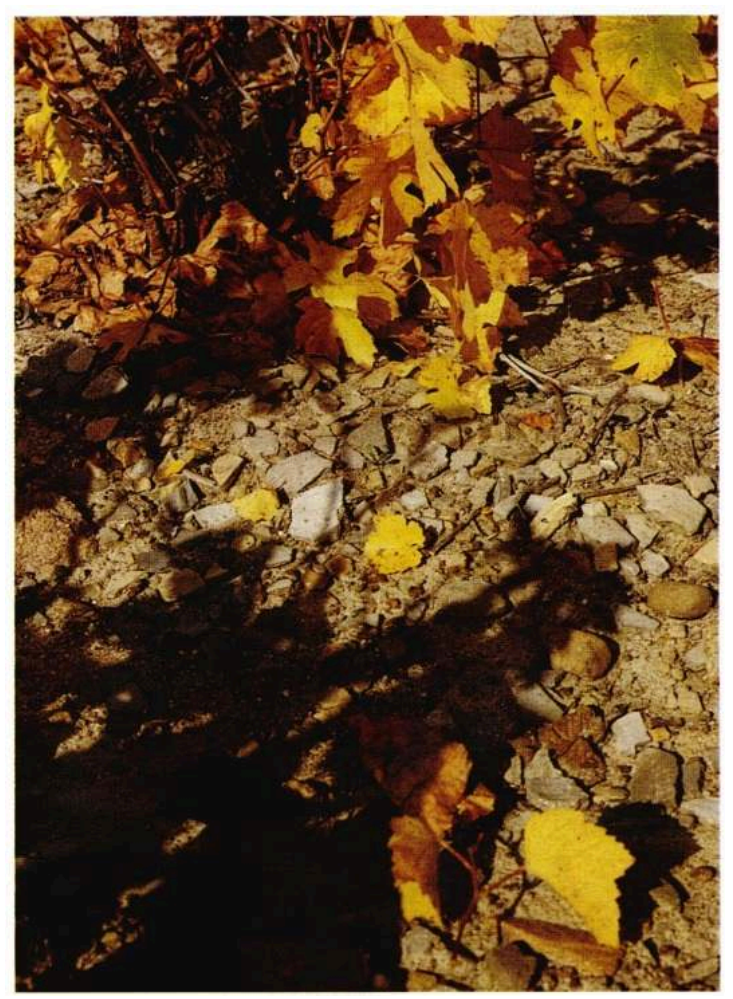

1 - Sans conteste, les plus fortes concentrations de rejets d'ateliers se regroupent au hameau de Marsangues où elles occupent une surface considérable (T14 à T29) (fig. 91, 92). Il convient de souligner les très fortes valeurs atteintes par les ramassages en T16, T17, T19, T28, T29. Outre des tessons de poteries en abondance, on relève dans ces parcelles des témoignages irréfutables de l'activité potière :

- $\circ$ des sortes de boudins d'argile pouvant avoir servi de cales d'enfournement en T23 et T25,

- des blocs de terre cuite irréguliers évoquant des éléments de parois ou de soles de fours en T25, T26, T28, T29,

- un poinçon (rosace) pour le décor ou le marquage des poteries (fig. $114 \mathbf{n}^{\circ} \mathbf{3 2}$ ).

- enfin, des briques calcinées en T18 et T29 rappellent des découvertes faites à Corcelles et évoquent des éléments de fours.

$\mathrm{Au}$ nord de cette zone, les indices de surface s'étalent de façon plus diffuse dans les parcelles voisines (T7, T12, T13, T20, T21, T22). Ces épandages sont très probablement le résultat du transport du mobilier en surface par les différents agents (labours, ruissellement). La limite nette au sud est artificielle : en effet, les vignes cèdent la place à des prairies et à des vergers, nous privant des informations. 
2 - En regard de telles évidences archéologiques, les autres sites paraissent fort discrets. Néanmoins, cinq autres points de ramassage offrent des indices intéressants. Parmi eux $\mathrm{T} 1$, au lieu-dit les Bruyères (fig. 91) présente, en plus d'une remarquable concentration de tessons, dont quelques ratés de cuisson, des fragments de briques surcuites. D'ailleurs, les maçonneries d'une maison voisine, à Blaceret, comportent en remploi une grande quantité de briques calcinées et vitrifiées, ainsi qu'un gros fond de récipient (fig. 93).

93 - Briques calcinées et fond de poterie en remploi dans le mur d'une construction à Blaceret (commune de Blacé), à proximité de $\mathrm{T} 1$

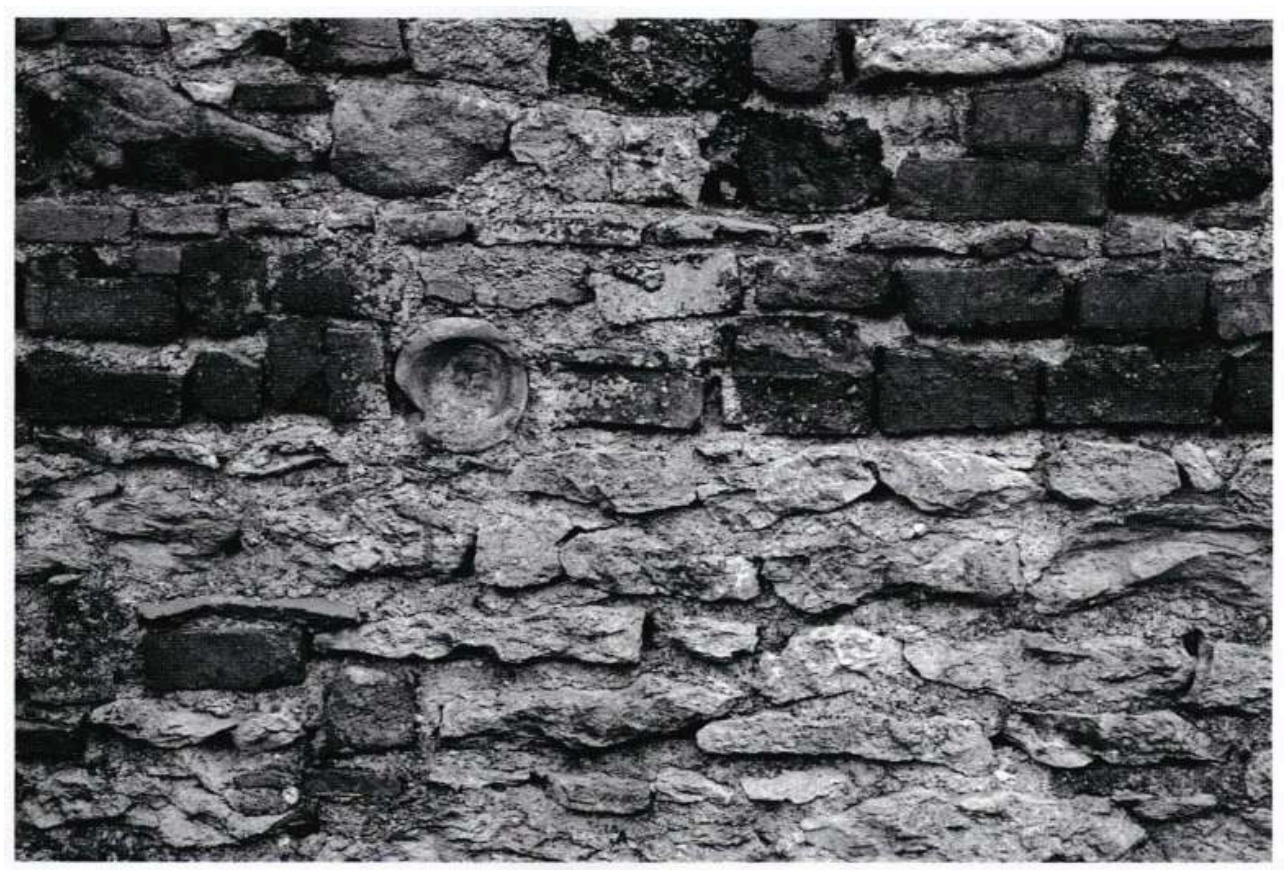

Le site de T3, dans le bourg même de Saint-Etienne, et celui de T8, un peu à l'écart, au lieu-dit le Trève sont, quant à eux, bien circonscrits (fig. 94) et probablement à mettre en relation avec l'activité potière, bien qu'il n'y ait pas d'autres indices qu'une relative concentration de tessons. L'homogénéité du mobilier recueilli, en dépit de la proximité des habitations, plaide en faveur de cette hypothèse. En outre, entre ces deux points, les prospections ont révélé de larges zones d'épandages diffus mais livrant également un mobilier homogène ( $\mathrm{T} 5, \mathrm{~T} 6, \mathrm{~T} 30$ et $\mathrm{T} 31)$. Il s'agit de terrains en pente où le déplacement des indices est accentué et ôte toute chance d'une localisation plus précise d'éventuels vestiges d'ateliers. 
94 - Saint-Étienne-des-Oullières : résultats des ramassages de surface aux lieux-dits Marpet (T3), le Trève ( $T 5, T 6$ et $T 8)$ et les Grandes Bruyères (T30 et $T 31)$

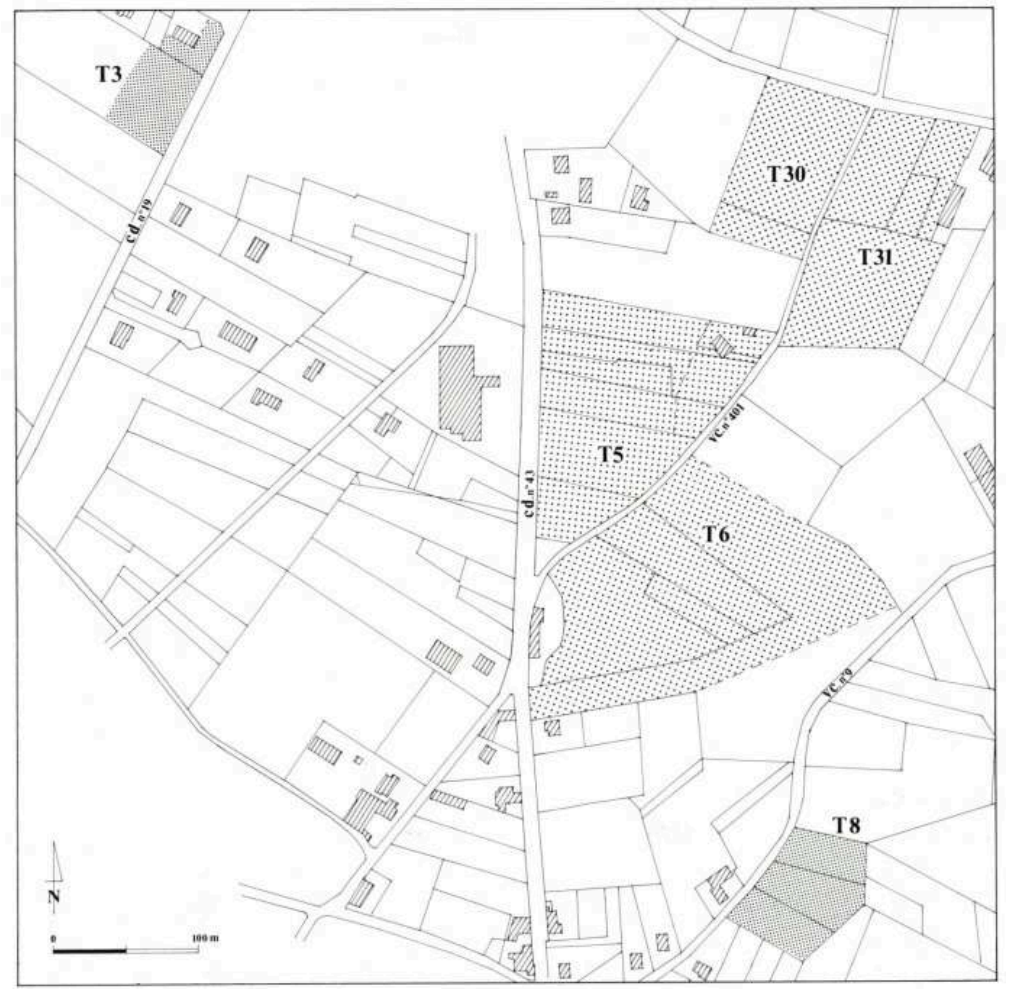

52 Au nord-est du bourg, au lieu-dit le Botheland, deux derniers points de ramassage retiennent l'attention: T10 et T11 (fig. 95). Quoique limités dans l'espace en raison de la topographie (ruisseau et route encaissés, proximité de bâtiments, pente accusée), les ramassages ont livré un mobilier qui se distingue des autres productions : poteries très grossières à grosses inclusions, tessons si épais qu'on hésite à les attribuer à des récipients ainsi que des fragments de briques. Certes, le mobilier n'est pas exempt de "pollution" (quelques tessons modernes, des scories) liée à la proximité d'une ferme ; mais, par sa masse et son uniformité morphologique et technologique, il semble être redevable à un site de production. 
95 - Saint-Étienne-des-Oullières : résultats des ramassages de surface au lieu-dit le Botheland (T10 $-\mathrm{T} 11)$

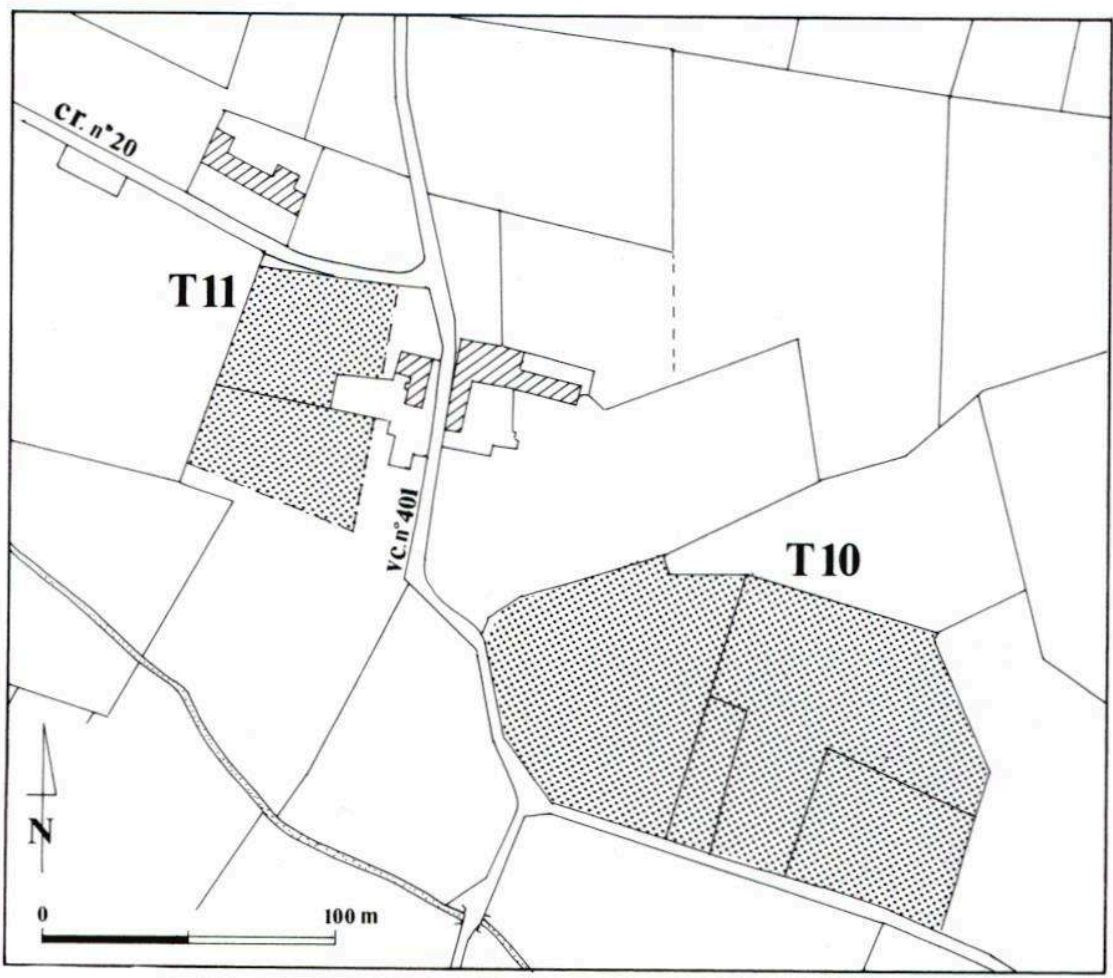

533 - Parmi les zones d'épandages diffus dont l'interprétation archéologique reste en suspens, ont déjà été évoquées celles qui se situent au Trève (T5, T6, T30, T31), ainsi que celles qui encadrent les ateliers de Marsangues (T12, T13, T20 à 22). Pour être complet, il faut encore mentionner $\mathrm{T} 2$, situé près d'une grosse et ancienne exploitation qui pourrait prendre la suite d'une maison forte (fig. 96). A Blaceret, la petite surface concernée par T9 reste encore inexpliquée (fig. 91). Dans les deux cas une petite proportion de mobilier moderne est mêlée aux tessons médiévaux. 


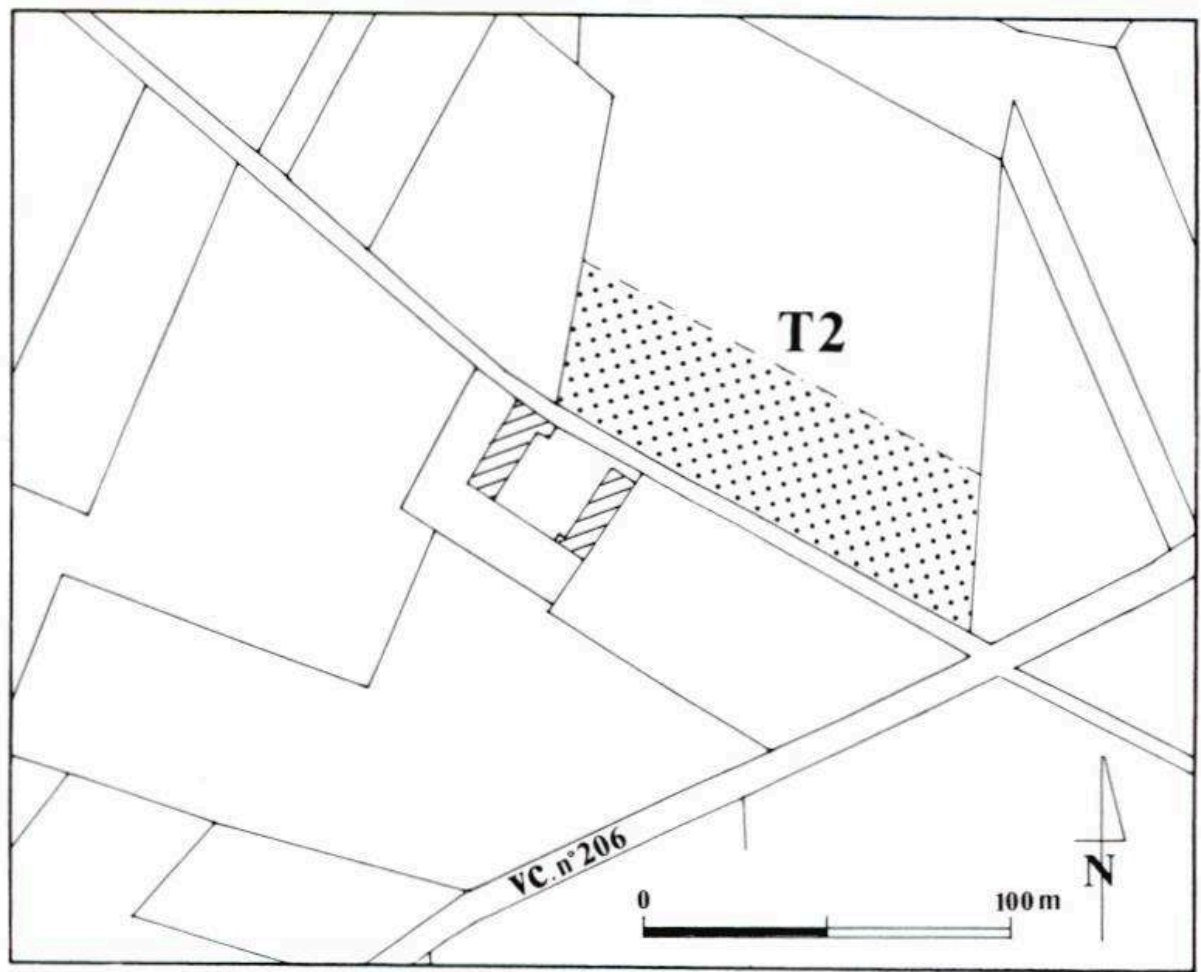

Les prospections de surface, accompagnées de ramassages systématiques, offrent donc un bilan très positif pour l'ensemble du territoire étudié. Les vestiges repérés en surface et cartographiés permettent une première approche des structures artisanales enfouies. La quantité de mobilier collecté, l'ampleur des surfaces concernées par les épandages laissent présumer que l'on a affaire à un phénomène de longue durée. L'analyse typologique des échantillons apporte de bons repères chronologiques (cf. infra).

Dès cette étape, plusieurs sites ou groupes de sites se détachent et paraissent particulièrement probants: $\mathrm{T} 2{ }^{\prime}, \mathrm{T} 6^{\prime}, \mathrm{T} 7^{\prime}$ et $\mathrm{T} 13^{\prime}$ à Corcelles-en-Beaujolais, le vaste ensemble de Marsangues à la frontière de Blacé et de Saint-Georges-de-Reneins (T14 à T29), ainsi que T3, T10 et T11 à Saint-Étienne-des-Oullières. Mais d'autres zones, apparemment moins riches, pourraient également correspondre à des lieux de production, telles $\mathrm{T}^{\prime}$ et $\mathrm{T} 15^{\prime}-\mathrm{T} 16^{\prime}$ et $\mathrm{T} 17^{\prime}$ à Corcelles-en-Beaujolais, ou bien T1 et T8 à Saint-Etienne-des-Oullières.

Les prospections géophysiques avaient pour but de fournir des critères d'interprétation complémentaires. On jugera ci-dessous à quel point les résultats des deux méthodes de prospection n'ont de sens qu'étroitement confrontés les uns aux autres. 


\section{Les prospections géophysiques}

Le choix d'implantation des prospections géophysiques répondait à plusieurs préoccupations, outre bien sûr celle d'explorer les zones les plus riches en vestiges de surface :

- recueillir des informations dans les deux secteurs étudiés (groupe de Corcelles-en-Beaujolais et groupe de Saint-Étienne-des-Oullières),

- privilégier les occasions de travail extensif afin de mieux délimiter les sites,

- sélectionner divers cas de figure (sites isolés ou proches d'habitats, sites étendus ou circonscrits, sites appartenant a priori à différentes phases chronologiques de l'activité artisanale, sites débordant manifestement sur des zones non prospectables à vue).

Pour le groupe de Corcelles, ont été retenus les points de ramassage suivants: T2' (subdivisé en T2' a et T2' b), T6', (subdivisé en T6' a, T6' b et T6' t), T13' et T15'. Pour celui de Saint-Etienne, ont été retenus : T15, T17, T19, T23, T24, T26, T27, T28 et T29. Au total près de $50000 \mathrm{~m}^{2}$ ont ainsi été prospectés, soit environ $15 \%$ des surfaces livrant des indices de surface (fig. 83, 84).

Sur la base des informations archéologiques, la prospection géophysique pouvait s'implanter au mieux, sans risque de dispersion, avec pour objectif premier la délimitation précise de chacune des zones d'épandages. Celles-ci sont interprétées comme l'extension maximum de chaque atelier supposé. Au vu des résultats, il est permis dans un second temps, lorsque les contrastes sont suffisants, de tenter une interprétation des points forts ; ces derniers pouvant, dans le meilleur des cas, traduire la présence de structures liées à la production de céramique, et d'une manière générale, des secteurs de plus forte accumulation de terres cuites et chauffées dans le sous-sol proche.

61 Toutes les parcelles prospectées, sans exception, sont plantées en vigne; toutes sauf T15' à Corcelles, sont tendues de fils de fer. De ce fait toutes les méthodes, en principe adaptées à la reconnaissance de structures de combustion, deviennent inopérantes parce que perturbées. Une seule formule permet de s'affranchir - en partie seulement de cette contrainte: l'utilisation d'un appareillage électromagnétique peu sensible (EM15) ; cela n'est pas, bien sûr, sans impact sur la pertinence de l'exploration. En effet, la profondeur d'investigation du EM15 est d'environ $45 \mathrm{~cm}$. La mesure qu'il détermine est celle de la susceptibilité magnétique du sol, plus que celle des structures ellesmêmes. Son application à la prospection des ateliers de terre cuite se fonde sur les principes suivants : les terres et sols proches des fours ont été affectés par l'activité de chauffe et ont donc subi une augmentation de leur susceptibilité magnétique naturelle ; l'aire de travail était probablement encombrée de déchets de céramique et parsemée de structures annexes (dépotoirs notamment); enfin les destructions répétées (travaux agricoles surtout) ont remonté et mêlé une partie de ces matériaux dans les couches superficielles. Compte tenu de toutes ces caractéristiques, il est, dans une grande majorité des cas, inutile de procéder avec un échantillonnage fin ; la maille de $5 \mathrm{~m}$ est la plus compatible avec les possibilités de l'appareil ; c'est en effet l'instrument de zonage par excellence (fig. 97). 
97 - Prospections électromagnétiques à Corcelles-en-Beaujolais, lieu-dit les Marquisats (T2') : manipulation de l'appareil de mesures EM15

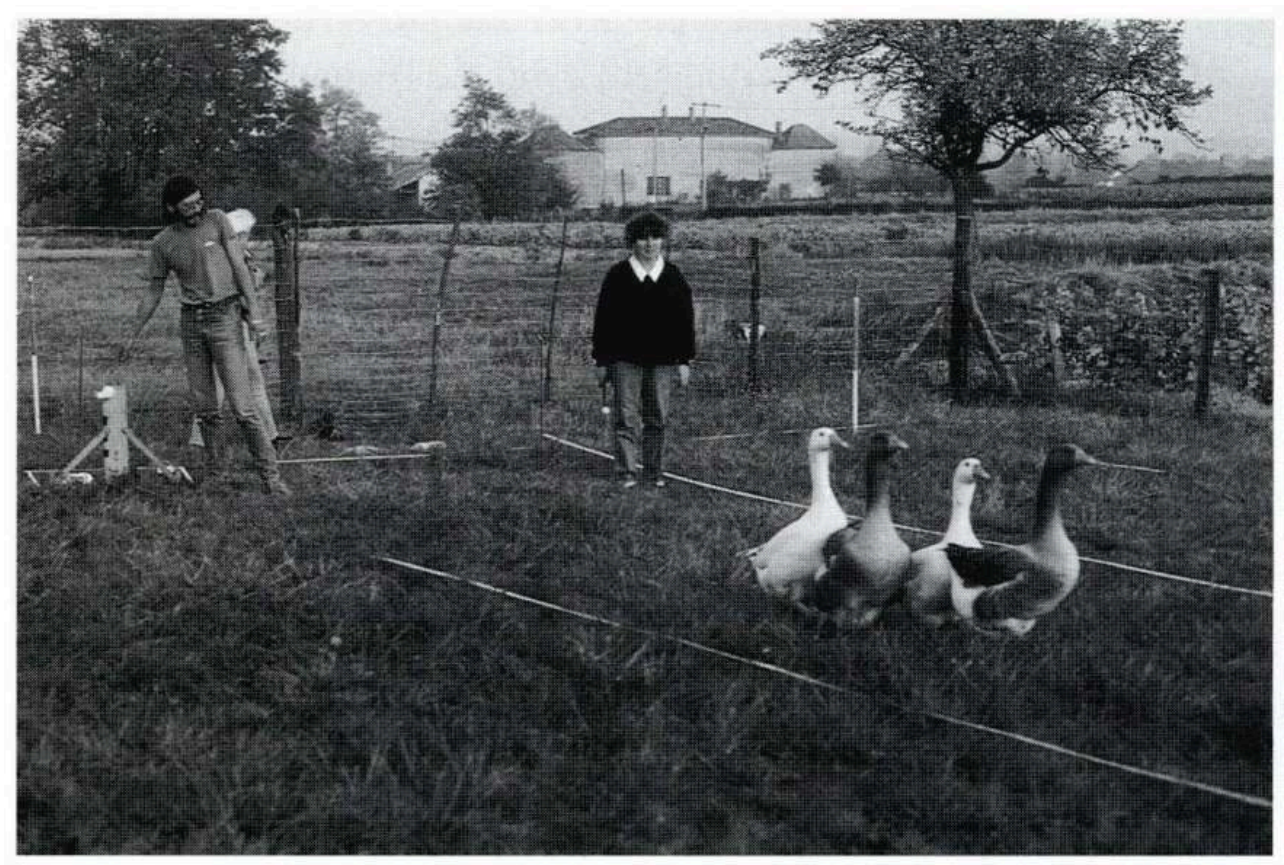

Or, dans les cas qui nous occupent, la forte proportion de sable dans le sol constitue un nouvel obstacle qui, pour être surmonté, à l'inverse du précédent (fils de fer), réclame des instruments de mesure de grande sensibilité. Le sable, en effet, a naturellement une susceptibilité magnétique nulle ou très faible qui, par conséquent, n'augmente pratiquement pas lorsque les matériaux sont chauffés. Seule la part d'argile composant ces sols et l'argile dont sont constituées la céramique et les structures elles-mêmes possèdent une susceptibilité magnétique accrue et mesurable; pour le EM15, la masse de matériaux dotés de cette propriété physique est alors insuffisante. On peut donc considérer que les couches superficielles et celles englobant les structures sont en quelque sorte, presque "transparentes" pour les mesures.

Pourtant, l'existence de certains indices matériels au sol laisse peu de doute sur le fait qu'il y a eu activité de production de céramique. Le peu de réponses obtenues en prospection électromagnétique pourrait être interprété comme la preuve d'un arasement important des structures des sites; ou de leur petite taille et de leur précarité. Quel que soit le degré de restriction, ceci limite les masses de matériaux mesurables ${ }^{12}$.

Enfin, il faut insister sur le fait que, dans une situation comme celle-ci, la profondeur d'investigation est strictement limitée à $45 \mathrm{~cm}$; il est exclu qu'une structure plus profonde puisse être repérée. A chaque fois que sera évoquée l'éventualité d'une détection de structure ce sera dans ce contexte là; ce qui signifie que, si le recouvrement est en réalité plus important, l'interprétation sera faussée. Il faut en permanence garder cette éventualité présente à l'esprit.

Sur de nombreuses cartes, la dynamique des mesures est donc très faible. Ne pouvant $a$ priori la négliger, les cartes la décrivent dans toute la gamme des valeurs; il faut donc se référer à l'échelle des valeurs pour relativiser l'importance des maxima ${ }^{13}$. De toute évidence, certaines variations de faible amplitude, sans forme ni organisation, doivent correspondre à l'hétérogénéité de la susceptibilité magnétique superficielle. 

lieu à une carte probante par sa cohérence et non suspecte d'influences parasites (métalliques : fils de fer, déchets superficiels etc.). Il se trouve qu'elle se distingue par sa situation topographique et la nature de son sol ; actuellement cette caractéristique est le seul argument solide qui nous autorise à transgresser la simple évidence des résultats géophysiques et à ne pas considérer comme rédhibitoire l'apparente contradiction entre indices de surface et mesures de susceptibilité du sous-sol proche.

\section{Corcelles-en-Beaujolais}

\section{T6' : les Serves (fig. 86 et 98)}

Par commodité, la zone a été subdivisée en trois parties :

T6' a : Parcelles : AB 173 (vigne et chemin) surface : $75 \mathrm{~m} \mathrm{x} 95 \mathrm{~m}$, grille : $5 \mathrm{~m} \mathrm{x} 5 \mathrm{~m}$

T6' b : Parcelles AB 140 à 142 (vigne) surface : $75 \mathrm{~m} \mathrm{x} 75 \mathrm{~m}$, grille : $5 \mathrm{~m} \mathrm{x} 5 \mathrm{~m}$

T6' t : Parcelles : AB 175 - 176 surface : $50 \mathrm{~m} \times 50 \mathrm{~m}$, grille : $5 \mathrm{~m} \times 5 \mathrm{~m}$

Il faut insister sur le fait que la zone prospectée se trouve sur le sommet d'une butte et que la parcelle $\mathrm{T} 6 \mathrm{~b}$, au nord, se situe dans la pente. La parcelle obtenue est tout à fait remarquable tant au niveau de l'information générale (limites du site) que de la description de détail. Seule incertitude : la carte est incomplète au sud-ouest; le site de toute évidence se poursuit au-delà des limites de la zone prospectée. Ce secteur mérite donc une description détaillée.

98 - Corcelles-en-Beaujolais, les Serves : carte en densité de gris de la susceptibilité magnétique de l'ensemble T6'

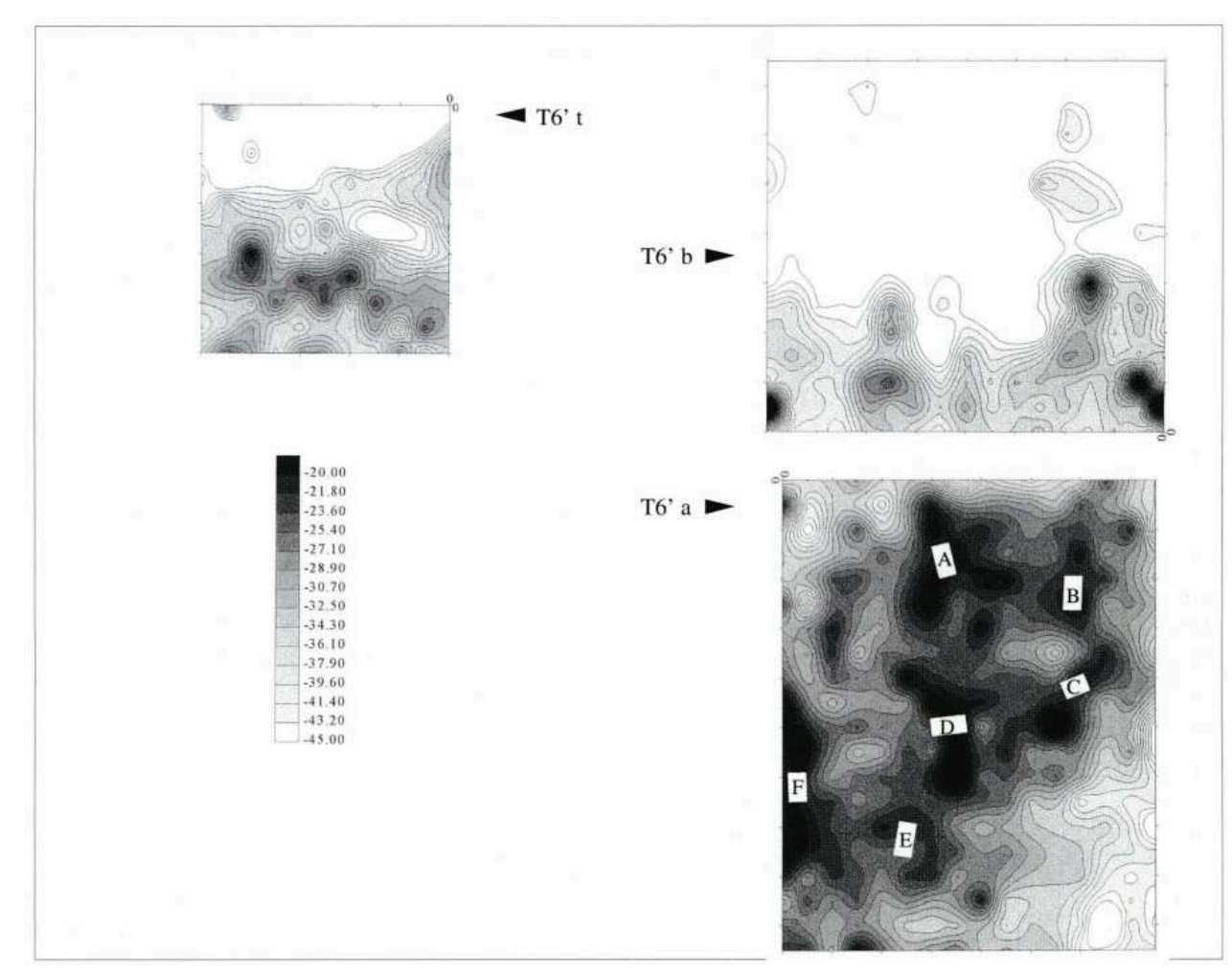


L'information principale est donnée par les niveaux moyens (gris) qui dessinent une vaste anomalie située pour l'essentiel dans la parcelle T6 a. Les niveaux gris pâle et blancs montrent à l'ouest et au nord, ponctuée encore de quelques hausses très isolées, très "effilochées", la limite extrême de la zone sensible.

70 La caractéristique première de ces niveaux intermédiaires, au nord surtout, est une nette tendance à l'orthogonalité que l'on retrouvera au niveau supérieur. Dans la partie méridionale de la carte, l'ensemble se désaxe vers l'ouest. Cependant, l'intérêt présenté par cette organisation orthogonale et son orientation doit être relativisé ; on peut, en effet, suspecter ce qu'il est convenu d'appeler l'effet de profil (tendance qu'ont les anomalies à s'organiser dans le sens des profils et perpendiculairement à eux) accentué par la maille large employée. Cet effet parasite ne peut pourtant à lui tout seul être à l'origine d'un tel agencement. Cette nappe de valeurs moyennes traduit vraisemblablement une présence importante de matériaux liés à l'activité de cuisson, répandus dans le sous-sol proche.

71 Le niveau $-28,90$, lui-même organisé en nappe de forte tendance quadrangulaire, au nord surtout, donne à la zone sensible sa configuration la plus précise. Là encore, il ne peut s'agir que de la réponse due à une masse toujours plus importante de terres chauffées et de terres cuites, peut-être à la proximité de structures de chauffe ou annexes. La forme précise du dessin de ce niveau de susceptibilité magnétique ne peut cependant être fortuite; témoigne-t-elle directement de la manière dont s'organise l'atelier? L'ordonnance des principaux points forts ne contredit en rien cette impression.

72 Pour faciliter la lecture de détail, les principales anomalies de très forte susceptibilité magnétique sont baptisées d'une lettre. A ce stade de l'interprétation, et du fait de la méthode employée, on en est réduit aux hypothèses; cependant la présomption peut être plus ou moins grande. Rappelons que le EM15, ne révèle que des masses de matériaux dont la susceptibilité magnétique peut être très forte, comme dans le cas de A, B, C, D et F, mais ne permet en aucun cas de distinguer entre une simple accumulation et une structure; les suppositions reposent donc sur certains particularismes : formes, organisation, etc. .

73 C'est dans cet esprit qu'il faut noter l'absence de dispersion, le caractère particulièrement ordonné de la répartition de ces anomalies de très fortes valeurs qui sont par ailleurs, pour la plupart, reliées entre elles par un niveau de très fortes valeurs (niveau -25,40 en lecture). Ce système de liaison a toute son importance; l'aspect linéaire, étroit de l'anomalie qu'il compose n'est peut-être pas sans rapport avec un type d'organisation. Signalons enfin, à propos de ce niveau, qu'il opère une sélection entre les points forts de la carte, créant ainsi, au moins, deux entités principales : l'une regroupant A, B, C, D et E, l'autre malheureusement incomplète, occupée par F.

74 Le groupe constitué de A, B, C et D est remarquablement structuré ; il forme, articulé autour d'un noyau de plus faibles valeurs, un quadrilatère dont chaque angle est marqué par une anomalie de très forte susceptibilité magnétique. Ce dernier est encore prolongé par l'anomalie E qui se distingue cependant par une valeur un peu moins forte. En revanche, au sud-est, la susceptibilité magnétique décroît et toute la zone sensible se désaxe vers le sud-ouest. 
75 Nous noterons la présence périphérique de l'anomalie G; sa susceptibilité magnétique moindre et sa position quelque peu marginale suggèrent peut-être une activité annexe, un statut particulier.

L'anomalie $\mathrm{F}$ inaugure une seconde zone de très forte susceptibilité magnétique; la surface occupée par les très fortes valeurs est particulièrement importante et homogène ce qui n'était pas le cas précédemment. Il y a pourtant lieu d'émettre quelques réserves: toute la bordure de la carte correspond à la limite de la vigne constituée par un fossé ; cette zone était particulièrement sale (déchets métalliques, fils de fer...). Il est possible que certains aient échappé à l'attention; à l'appui de ces craintes, on constate la non-concordance des informations entre T6 a et T6 t. Ceci ne semble pas, cependant, remettre en cause totalement la crédibilité de F ; sa partie sud/ sud-est notamment est, a priori, tout à fait fiable.

L'ouest de la carte, correspondant à la parcelle $\mathrm{T} 6 \mathrm{t}$, ne montre plus qu'une susceptibilité magnétique atténuée, un morcellement d'anomalies de petites dimensions inscrit dans une traînée (est-ouest) de valeurs très moyennes (niveaux gris clair). Cet effritement de la susceptibilité magnétique, l'apparition d'anomalies quasi résiduelles indiquent que nous sommes vraisemblablement sortis de ce qui pourrait être la zone de production. Au nord, la limite est franche (niveaux blancs) et, malgré le hiatus entre les deux cartes, se retrouve sans ambiguïté en T6 b.

\section{T7' : Chassagne nord (fig. 86 et 99)}

Parcelles : AE 19-20

surface : $35 \mathrm{~m} \times 35 \mathrm{~m}$, grille : $3 \mathrm{~m} \times 3 \mathrm{~m}$

Ces parcelles de vigne sont caractérisées, en zone médiane, par de très fortes concentrations de matériel céramique; ces concentrations disparaissent assez rapidement à l'ouest et au sud. Au nord, la parcelle est bordée par un bosquet improspectable, à l'est par une zone de friches.

80 D'une manière générale, surtout si on se réfère aux réponses obtenues sur le site précédent, la susceptibilité magnétique mesurée en $\mathrm{T} 7$ ' est particulièrement faible. Il serait utile, à ce propos, de pouvoir déterminer la proportion de matériaux sableux présents dans le sous-sol proche, sachant qu'une faible teneur en argile peut être défavorable à la prospection électromagnétique (cf. supra).

99 - Corcelles-en-Beaujolais, Chassagne nord : carte en densité de gris de la susceptibilité magnétique de T7', 1/1000e

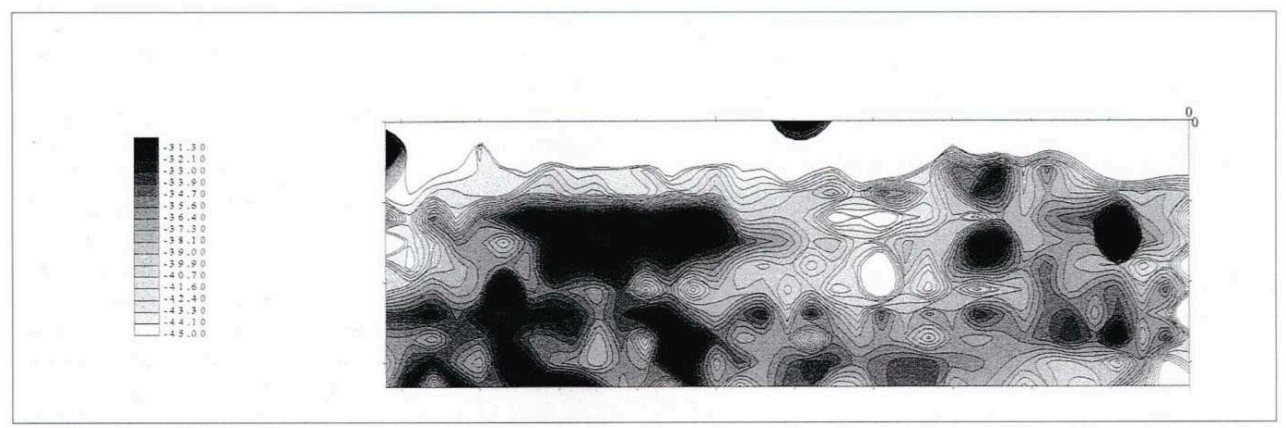

81 Dans le cas qui nous occupe, la tendance est en effet la suivante: susceptibilité magnétique très atténuée (extrêmement peu de très fortes et fortes valeurs). Beaucoup d'anomalies très localisées (anomalies "pastilles"), d'ordinaire identifiées comme des 
réponses dues à la présence de déchets métalliques; des zones (nappes) de valeurs moyennes très maigres et disloquées. Plusieurs explications sont possibles : proportion trop importante de matériaux sableux (la réponse de l'appareil ne se produit qu'à l'aplomb des secteurs de plus grande accumulation de matériaux, voire de structures). Dans ce cas toute hausse de la susceptibilité magnétique, si légère soit-elle, doit retenir l'attention. Autres hypothèses: l'atelier est un petit centre de production; il est détruit ; il est trop profondément enfoui. Ces raisons peuvent bien sûr se cumuler, c'est même le plus probable.

L'analyse de la carte montre l'existence de deux secteurs sensibles :

83 - au nord-est de la parcelle, cinq anomalies "pastilles" (elles n'ont, chacune, à leur origine pas plus de deux ou trois mesures); quatre d'entre elles ne sont constituées que de très moyennes et moyennes valeurs de susceptibilité magnétique. On ne peut exclure qu'elles ne soient que la réponse due au matériel existant en surface. Si cela était le cas, nous pouvons être certains qu'elles ne pourraient masquer par leur présence (beaucoup trop ténue) la réponse due à une éventuelle structure souterraine. Nous restons en présence de deux solutions (il y a toujours le risque de "parasitage métallique") : la mesure est celle du matériel, visible au sol; la mesure est celle, très atténuée, d'une structure enfouie (vraisemblablement d'importance moyenne, type dépotoir, etc.). Une seule de ces cinq anomalies montre une forte susceptibilité magnétique (noir). Succède à ce secteur, une zone de très faible susceptibilité magnétique bien circonscrite et de tendance nettement orthogonale; cette tendance doit être pour une bonne part due à l'effet de profil. Il se peut qu'elle ait néanmoins une certaine réalité, ce qui, ajouté à l'incontestable absence de susceptibilité, à cet effet de "trou" et au fait que ce dernier s'interpose entre deux zones sensibles, suggère que cette anomalie pourrait traduire, dans le cas d'un atelier, un aspect de l'utilisation de l'espace, du fonctionnement et de l'organisation du site.

84 - au sud-ouest, la seconde zone sensible est fort différente de la précédente pour deux raisons : d'une part, elle correspond à un secteur de fortes concentrations de matériel en surface, d'autre part elle se compose d'anomalies en nappe, donc occupe un espace plus important. Elle a cependant en commun avec le secteur oriental, une susceptibilité magnétique presque essentiellement moyenne. Cet aspect plus étale (même si les dimensions sont très modestes) pris par ces anomalies, l'absence, au sein de celles-ci, de noyaux de fortes valeurs, plaident en faveur de l'existence de simples épandages; rien, en effet, ne permet d'aller plus loin dans l'interprétation.

Enfin, toute la bordure nord de la carte est barrée par une zone de très faibles (blanches) valeurs (dont la forme est certainement affectée en partie par l'effet de profil). Cette limite du site est également nette à l'est. L'incertitude demeure quant aux limites ouest/sud-ouest.

86 Une constatation s'impose : il y a peu de correspondance entre la réalité visible en surface (T7' offre un des taux de concentration du mobilier parmi les plus élevés rencontrés) et l'information géophysique. A certains égards, les résultats sont paradoxaux, mais non dépourvus d'intérêt. Si globalement la susceptibilité magnétique est faible, les anomalies les plus marquées à l'est de la parcelle ne correspondent pas au secteur où les épandages de surface sont les plus riches (à l'ouest de la parcelle). On pourrait alors supposer que les concentrations des vestiges de surface sont susceptibles d'indiquer les zones où les structures archéologiques enfouies sont les plus remaniées. A cette étape, seuls des sondages archéologiques permettraient d'établir un lien réel 
entre les deux méthodes de prospection. En tout état de cause, l'interprétation du site de Chassagne nord comme officine de potier ne fait guère de doute.

T2' : les Marquisats (fig. 85 et 100)

La zone a été subdivisée en deux parties :

- T2' a : Parcelle : AK 110 (vigne) surface : $50 \mathrm{~m} \times 75 \mathrm{~m}$, grille : $5 \mathrm{~m} \times 5 \mathrm{~m}$

- T2' b : Parcelles : AK 109 (prairie) surface : $30 \mathrm{~m} \times 30 \mathrm{~m}$, grille : $3 \mathrm{~m} \times 3 \mathrm{~m}$

La carte présente sensiblement les mêmes caractéristiques que la précédente ; le même raisonnement peut lui être appliqué.

100 - Corcelles-en-Beaujolais, les Marquisats : carte en densité de gris de la susceptibilité magnétique de l'ensemble T2' (T2' a, T2' b), 1/1000e

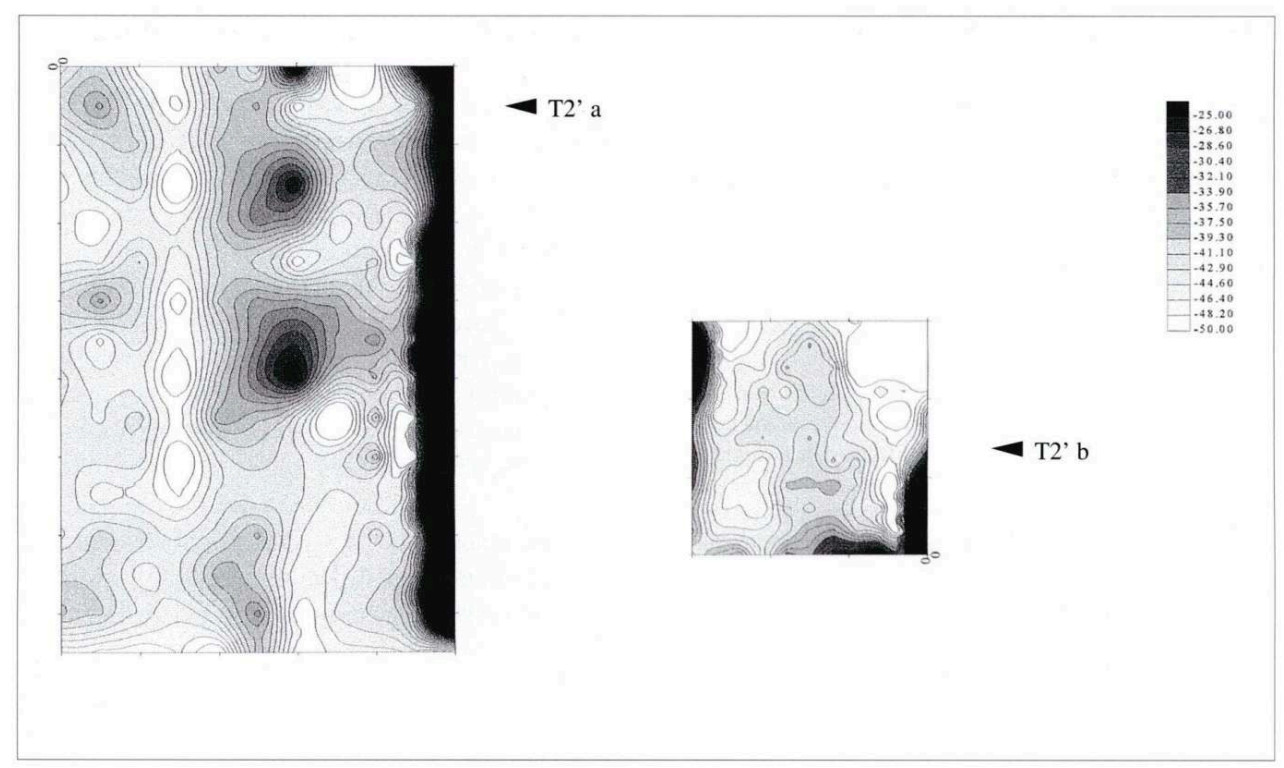

On distingue deux anomalies, au centre et centre-ouest de la parcelle T2' $\mathrm{a}$ : très localisées, essentiellement composées de valeurs moyennes, elles ne correspondent pas à des zones de forte concentration de matériel. Ce qui paradoxalement (cf. supra) renforce leur crédibilité. Notons qu'elles s'inscrivent chacune dans une nappe de valeurs considérées ici comme faibles (gris clair et blanc), que la nappe centrale met en relation son noyau de susceptibilité magnétique avec l'anomalie de fortes valeurs située en bordure nord de la carte. Cette anomalie peut être associée à la tache cendreuse visible au sol (anomalie largement amplifiée, comme sur tout le bord nord de la carte, par la présence de la clôture). Si, pour les raisons déjà exposées plus haut, on reçoit l'idée que la susceptibilité magnétique est globalement atténuée, ces nappes de niveaux gris pourraient, sans incohérence, jouer le rôle des niveaux de susceptibilité moyenne observés en T6'. Elles sont bien circonscrites et leurs dimensions sont incompatibles avec celles d'épandages; les deux anomalies qu'elles révèlent acquièrent, dans ce cas, une consistance plus conforme aux vestiges recherchés.

La moitié nord-ouest de la bordure nord de la parcelle T2' a est occupée par des anomalies de forte et très forte susceptibilité magnétique. Ce phénomène n'étant pas constant jusqu'à l'est, on ne peut incriminer complètement l'effet de la clôture, bien que celui-ci ait une incidence certaine sur la hausse des valeurs. Il ne faut donc pas négliger ce secteur. Dans ce contexte perturbé, l'interprétation est impuissante ; seul un sondage pourra vérifier l'authenticité de l'information. 
91 La difficulté est la même pour la parcelle T2' b, puisque les rares anomalies de forte susceptibilité magnétique se trouvent en bordure de clôture. Il convient toutefois de noter que l'anomalie (rouge) située en limite sud-ouest de cette parcelle prolonge l'anomalie apparue de l'autre côté, à proximité de la tache cendreuse.

Les résultats obtenus aux Marquisats sont donc intéressants et corroborent en partie ceux des prospections de surface. Ils concourent à désigner ce site comme un lieu de production.

\section{T13' : Chantemerle (fig. 87 et 101)}

Parcelles : AD 237 (vigne)

surface : $45 \mathrm{~m} \times 50 \mathrm{~m}$, grille : $5 \mathrm{~m} \times 5 \mathrm{~m}$

101 - Corcelles-en-Beaujolais, Chantemerle : carte en densité de gris de la susceptibilité magnétique de $\mathrm{T} 13$ ', 1/1000e

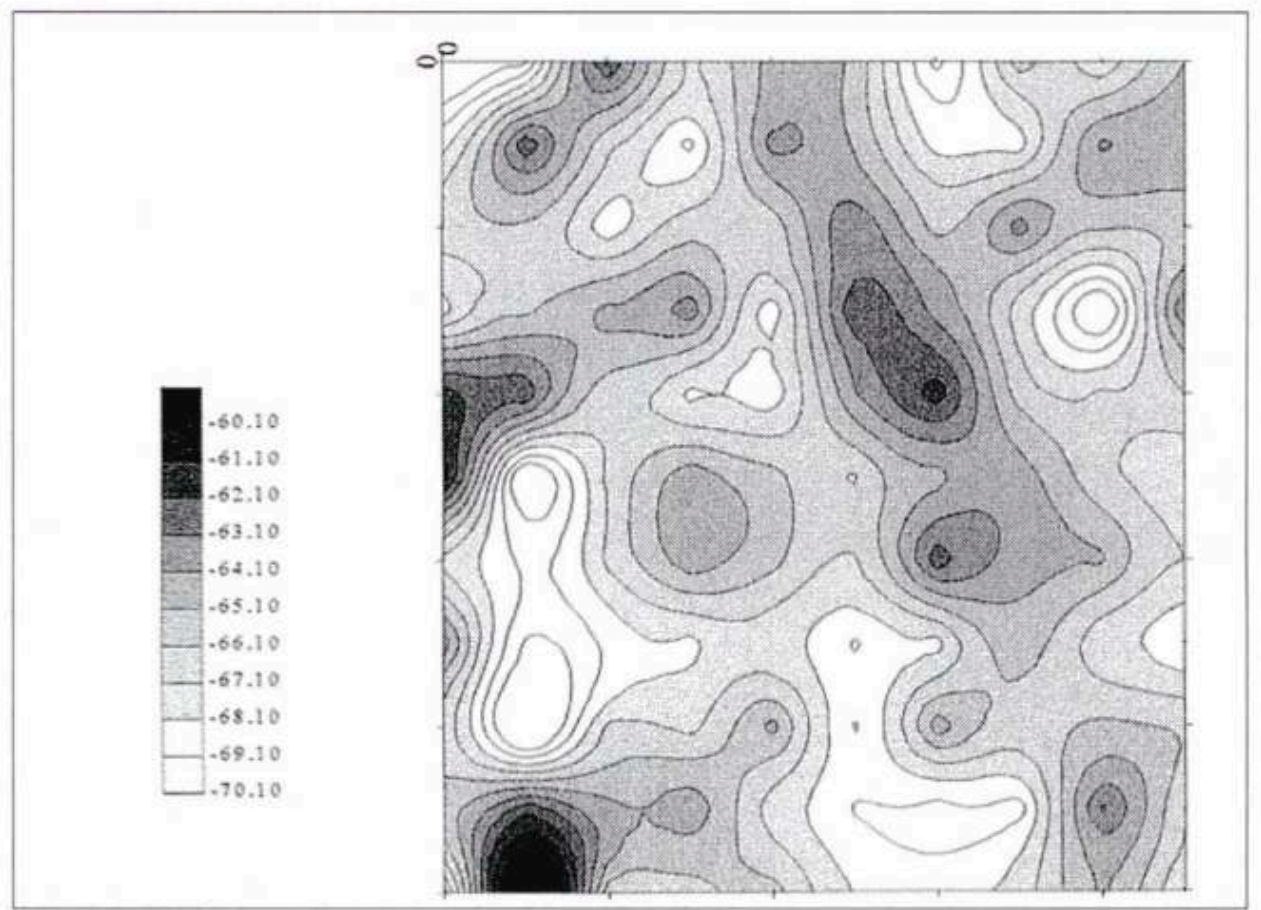

94 La susceptibilité magnétique est globalement faible et les valeurs en lecture ne progressent que de -70 à -60 .

Toutefois, le niveau - 67,1 (troisième gris) développe un système d'anomalies linéaires orientées à $45^{\circ}$ par rapport aux bords de la carte (on ne peut donc les suspecter d'être affectées par l'effet parasite de profil). Si l'on fait provisoirement abstraction de la très faible susceptibilité magnétique, cette organisation (sorte de maillage nettement orthogonal) peut susciter l'intérêt. Le niveau - 62,9 dessine quelques anomalies (une notamment sur les profils 25/30) de taille déjà conséquente (3 à 4 mesures).

T15' : Champ des Croix (fig. 88 et 102)

Parcelles : $A B 230$ à 232 (vigne)

surface : $40 \mathrm{~m} \times 50 \mathrm{~m}$, grille : $5 \mathrm{~m}$ x $5 \mathrm{~m}$

97 Ce site s'apparente au précédent : même faiblesse de la progression des valeurs. Le fait que cette vigne ne soit pas tendue de fils de fer ne semble pas avoir d'incidence. On 
peut noter l'existence de trois anomalies lisibles à partir du troisième niveau de gris (67,1 en lecture).

102 - Corcelles-en-Beaujolais, Champ des Croix : carte en densité de gris de la susceptibilité magnétique de $\mathrm{T} 15$ ', 1/1000e

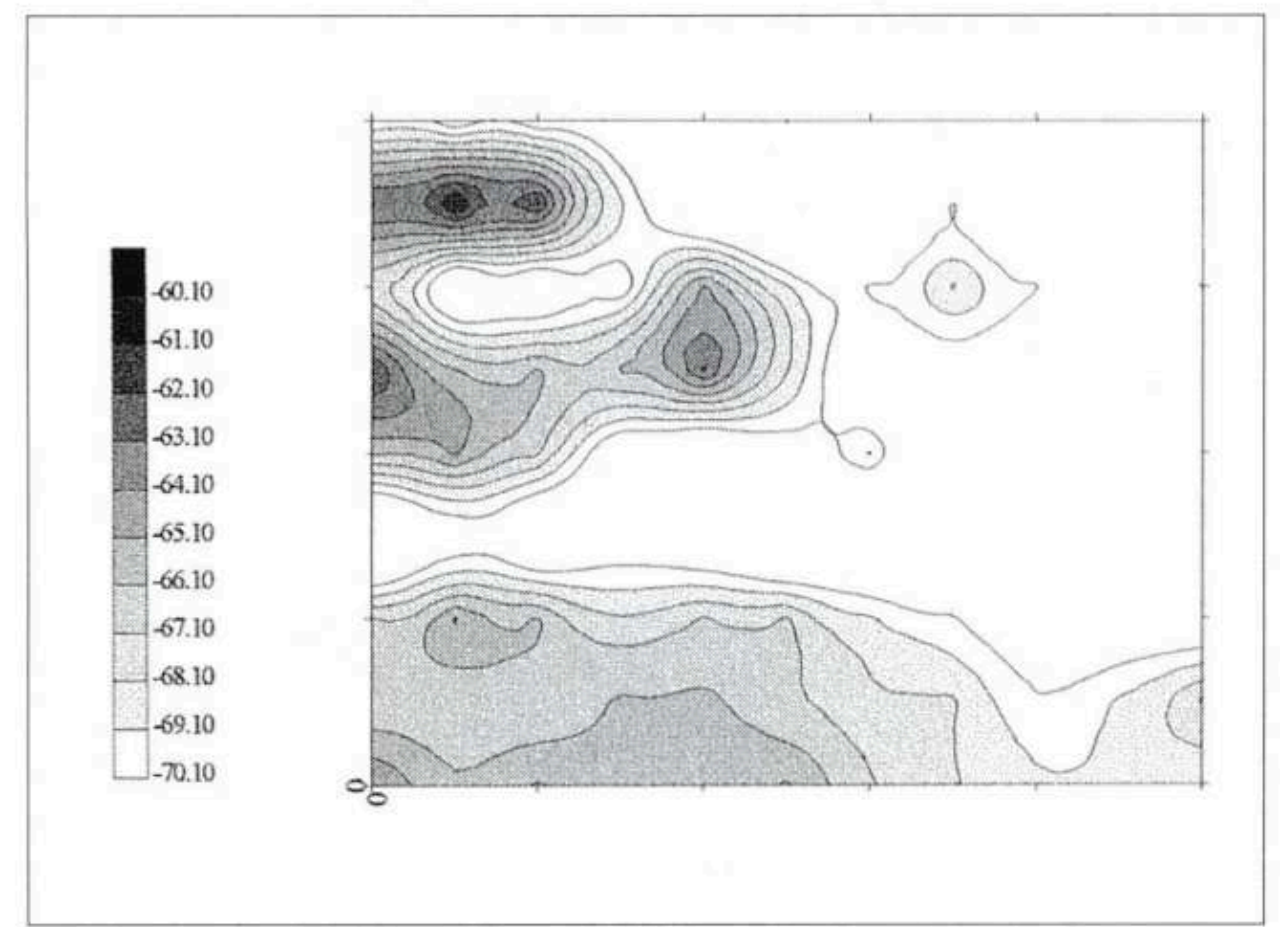

\section{Blacé et Saint-Georges-de-Reneins} ième niveau de gris - 60,7) assez homogène dans la partie centrale, ayant tendance à se désagréger à l'ouest (T15'), mais surtout nettement délimitée à l'est par de plus faibles valeurs. Cette frontière pose problème dans la mesure où elle s'organise dans l'axe des profils et qu'elle semble correspondre à une limite entre deux vignes, celle de l'est (vieille vigne) n'étant plus tendue de fils de fer. L'espace intérieur est marqué par quelques anomalies de plus forte valeur (niveau - 54,3), malheureusement affectées par l'effet de profil. Nous n'accorderons que peu de crédit aux fortes valeurs constituant la bordure ouest de la carte (probable effet de bord). 
103 - Saint-Georges-de-Reneins, Marsangues : carte en densité de gris de la susceptibilité magnétique de l'ensemble T15 - T17,1/1500e

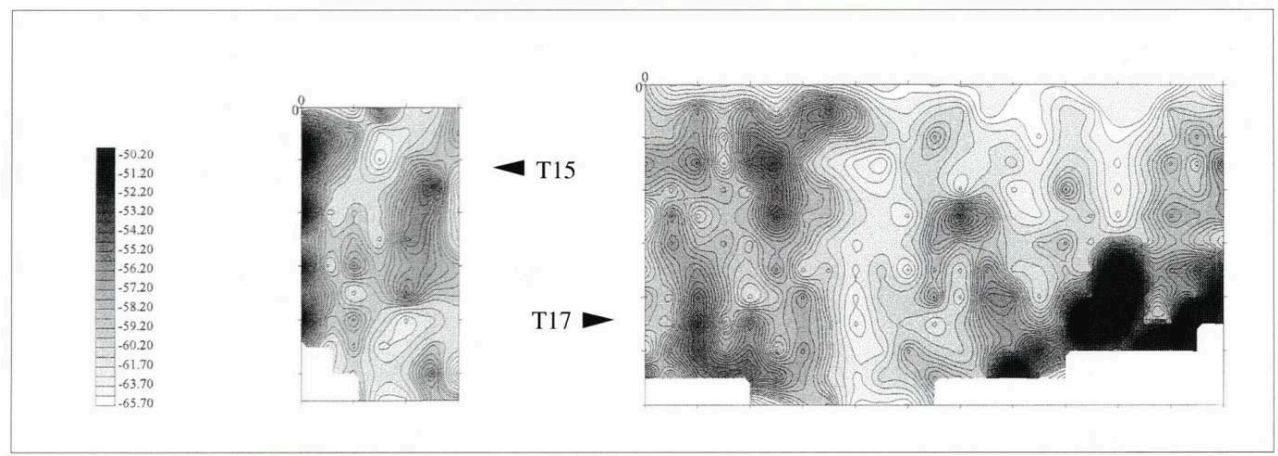

L'analyse de cet ensemble est assez typique des incertitudes qui paralysent l'interprétation. Quoi qu'il en soit, on ne peut négliger ces quelques relatifs points forts et l'éventualité qu'ils puissent signaler la présence de structures ou de zones liées à l'atelier de production de céramique est à retenir.

\section{T26 - T27 : Marsangues (fig. 91 et 104)}

Parcelles : 056 à 58

surface : $45 \mathrm{~m}$ x $67 \mathrm{~m}$ (T26) - $35 \mathrm{~m} \mathrm{x} 45 \mathrm{~m}$ (T27)

grille : $5 \mathrm{~m} \times 5 \mathrm{~m}$

104 - Saint-Georges-de-Reneins, Marsangues : carte en densité de gris de la susceptibilité magnétique de l'ensemble T26 - T27, 1/1000e

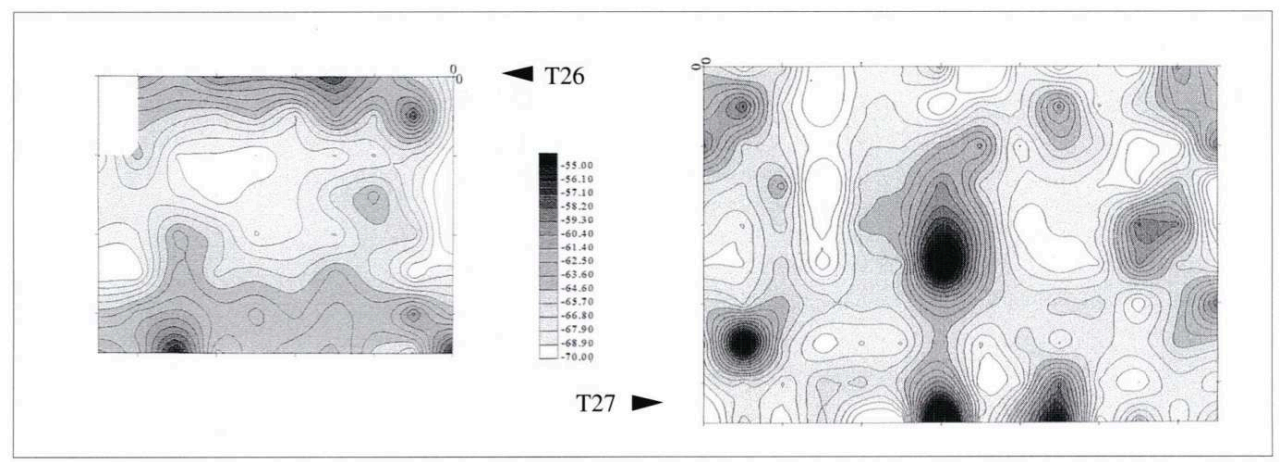

En T27 les valeurs en lecture se situent entre - 70 et - 55. Dans leur grande majorité, les mesures sont inférieures à - 65,7. Le troisième niveau de gris (autour de -62,5) dessine des anomalies linéaires, très étroites, "effilochées", dont les extrémités sont souvent marquées par une anomalie de plus forte susceptibilité magnétique, très localisée (une seule mesure). Hétérogénéité ou accidents de surface? L'hypothèse, décrite ci-dessus, qui veut qu'en l'absence d'une réponse significative du sol les mesures n'extraient qu'un "squelette" du site tel qu'il est conservé, peut s'appliquer à cette image.

La parcelle T26 ne se différencie de la précédente que par un aspect plus "empâté" des formes prises par le troisième niveau de gris.

Le plus gênant dans le cas de ces deux cartes, c'est l'absence de limites. On a l'impression que ces anomalies peuvent se répéter à l'infini bien au-delà des frontières de la carte, alors que la zone d'épandage de matériel semble, au contraire, bien circonscrite. 
Parcelles : N 326, 328

surface : $75 \mathrm{~m} \times 80 \mathrm{~m}$, grille : $5 \mathrm{~m} \times 5 \mathrm{~m}$

105 - Saint-Georges-de-Reneins, Marsangues : carte en densité de gris de la susceptibilité magnétique de l'ensemble T19 1/1000

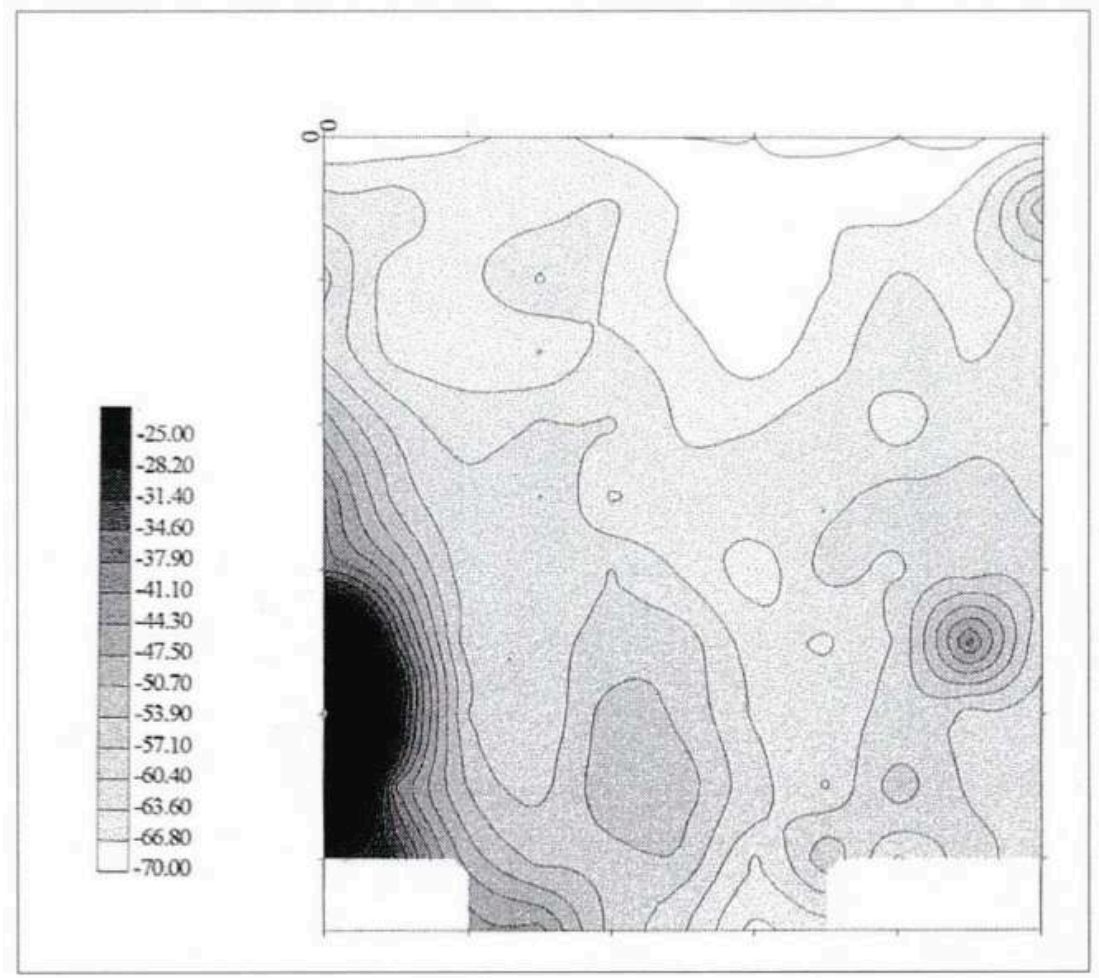

De très fortes valeurs (valeurs positives) ont été rencontrées dans ces parcelles. Elles se concentrent en bordure sud-ouest de la zone prospectée. Notons l'existence d'une extension en "coude" soulignée par le troisième niveau de gris $(-57,1)$, et de trois petites anomalies isolées, au sud-est.

On ne peut malheureusement accorder qu'un crédit limité à cette anomalie de très fortes valeurs: sa situation à l'angle de la vigne, en bordure à la fois de route, de chemin et d'habitation (avec présence d'un poteau) permet d'imaginer toutes sortes de perturbations possibles. Quelques sondages à la tarière seraient peut-être le moyen, simple et suffisant, de contrôler la réalité de cette anomalie.

T23 - T24 : Marsangues (fig. 91 et 106)

Parcelles : 081 à 84 (vigne et chemin)

surface : $30 \mathrm{~m}$ x $95 \mathrm{~m}$ (T23) - $30 \mathrm{~m} \times 70 \mathrm{~m}$ (T24), grille : $5 \mathrm{~m} \times 5 \mathrm{~m}$ 
106 - Saint-Georges-de-Reneins, Marsangues : carte en densité de gris de la susceptibilité magnétique de l'ensemble T23 - T24, 1/1000e

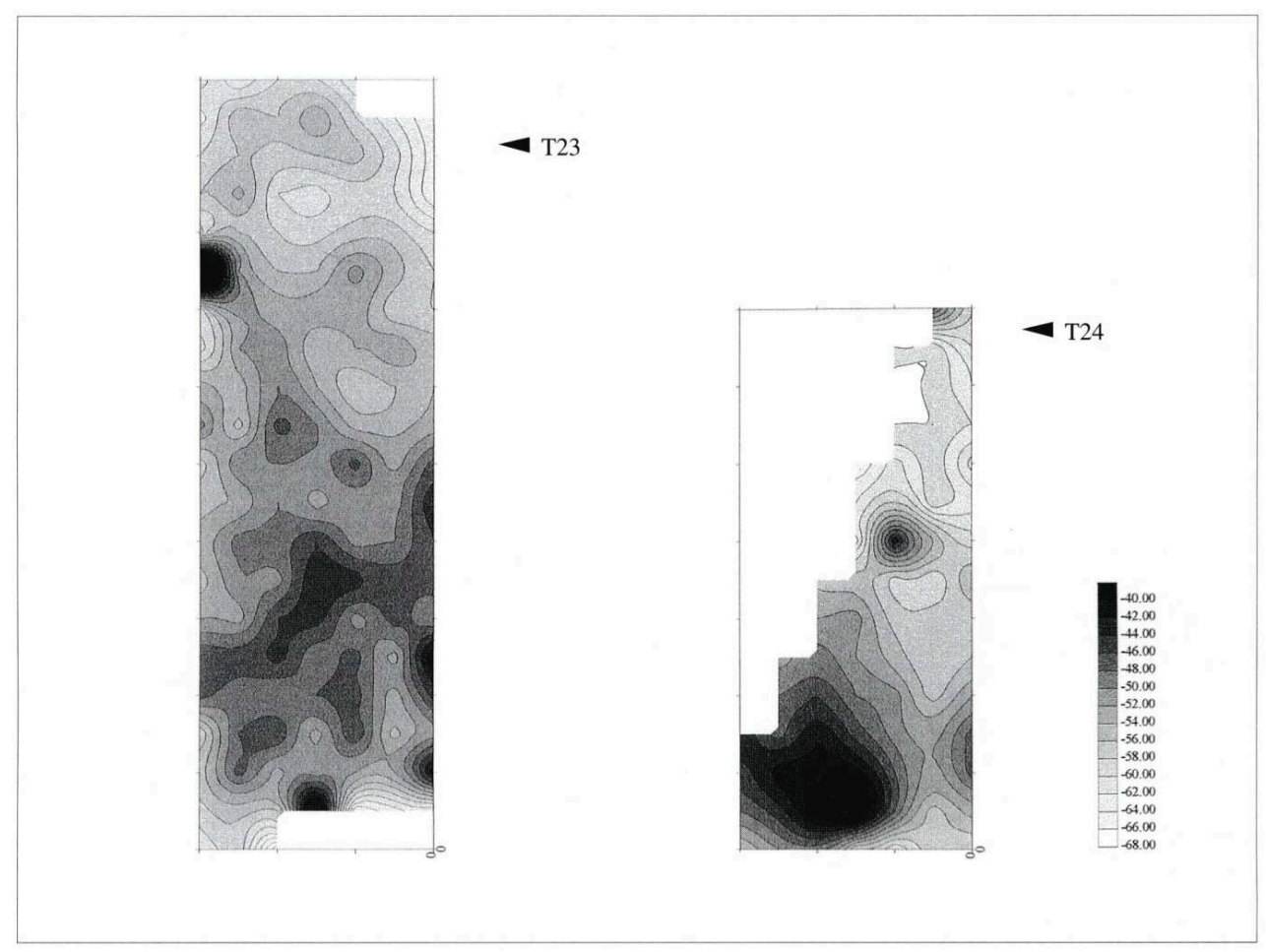

111 C'est l'une des cartes les plus intéressantes. Dans ces parcelles, la mesure progresse de 70 à - 40 (niveaux blancs : - 70 à - 68). En effet, la réponse du sol est en moyenne plus forte : les trois derniers niveaux de gris correspondent à des valeurs $(-48$ à - 40) que les précédentes cartes ne connaissent pas. Elle permet la mise en valeur de nappes, assez homogènes, dont la susceptibilité magnétique décroît régulièrement du sud au nord ; la nature du sol ne semble pas différente de celle des autres parcelles. Si cela se confirmait, nous pourrions conclure à la présence dans le sol de masses particulièrement importantes de matériaux liés à l'activité de la cuisson.

112 La zone sensible se situe au sud et semble se développer nord-est/sud-ouest avec une extension linéaire vers le nord-ouest. Le cinquième niveau de gris (environ - 50) qui la souligne, voit sa continuité rompue par la frontière (chemin) entre les deux cartes; l'orientation des deux vignes, donc des profils, n'étant pas la même, l'interpolation des mesures, lors du traitement, s'avérait impossible.

La parcelle T23 se caractérise par un étalement des fortes valeurs (épandage ?) alors que la parcelle T24 les concentre autour d'un point fort (structure?).

114 T29 : Blaceret (fig. 91 et 107)

Parcelles : N 356 (vigne)

surface : $55 \mathrm{~m} \mathrm{x} 65 \mathrm{~m}$, grille : $5 \mathrm{~m} \times 5 \mathrm{~m}$ 


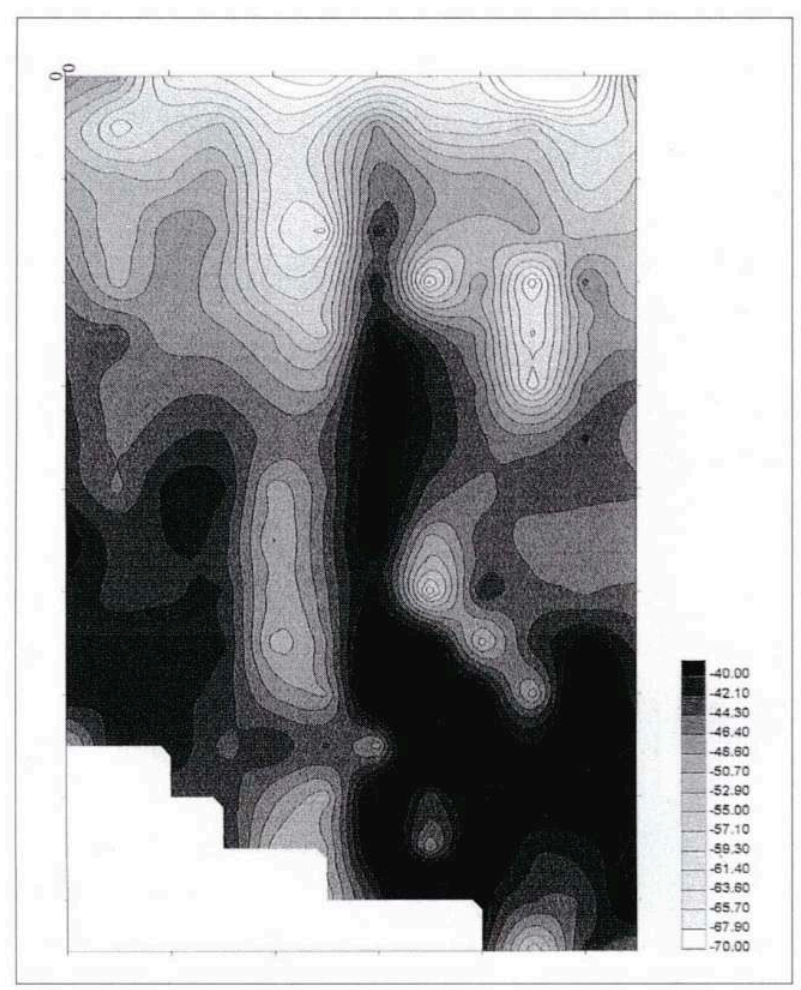

115 C'est certainement la carte qui présente le plus d'intérêt pour le secteur de Blaceret. Les valeurs s'échelonnent entre - 70 et - 40 (niveau blanc - 70). La susceptibilité magnétique augmente progressivement par nappes successives du nord au sud (exactement au sud-est). Les limites ne sont réellement atteintes ni à l'ouest ni à l'est (chemin). A l'intérieur de la nappe de susceptibilité magnétique décrite par le sixième niveau de gris $(-48,6)$ il faut distinguer une large anomalie (noire) de plus fortes valeurs (- 40 et plus), véritable épicentre, et, se développant à partir de celui-ci, un niveau de forte susceptibilité (environ - 45. septième niveau de gris) sous forme d'anomalies découpées (extensions en "écharpe" vers le nord, le nord-ouest, le sud), puis en nappes homogènes (au sud-ouest). Notons enfin l'existence de deux anomalies de forte valeur (noir), très localisées (1 mesure chacune), mais qui, dans ce contexte, doivent retenir l'attention.

116 T28 : Blaceret (fig. 91 et 108)

Parcelles : N 347-347 a (vigne et chemin)

surface : $75 \mathrm{~m} \times 80 \mathrm{~m}$, grille : $5 \mathrm{~m}$ x $5 \mathrm{~m}$ 


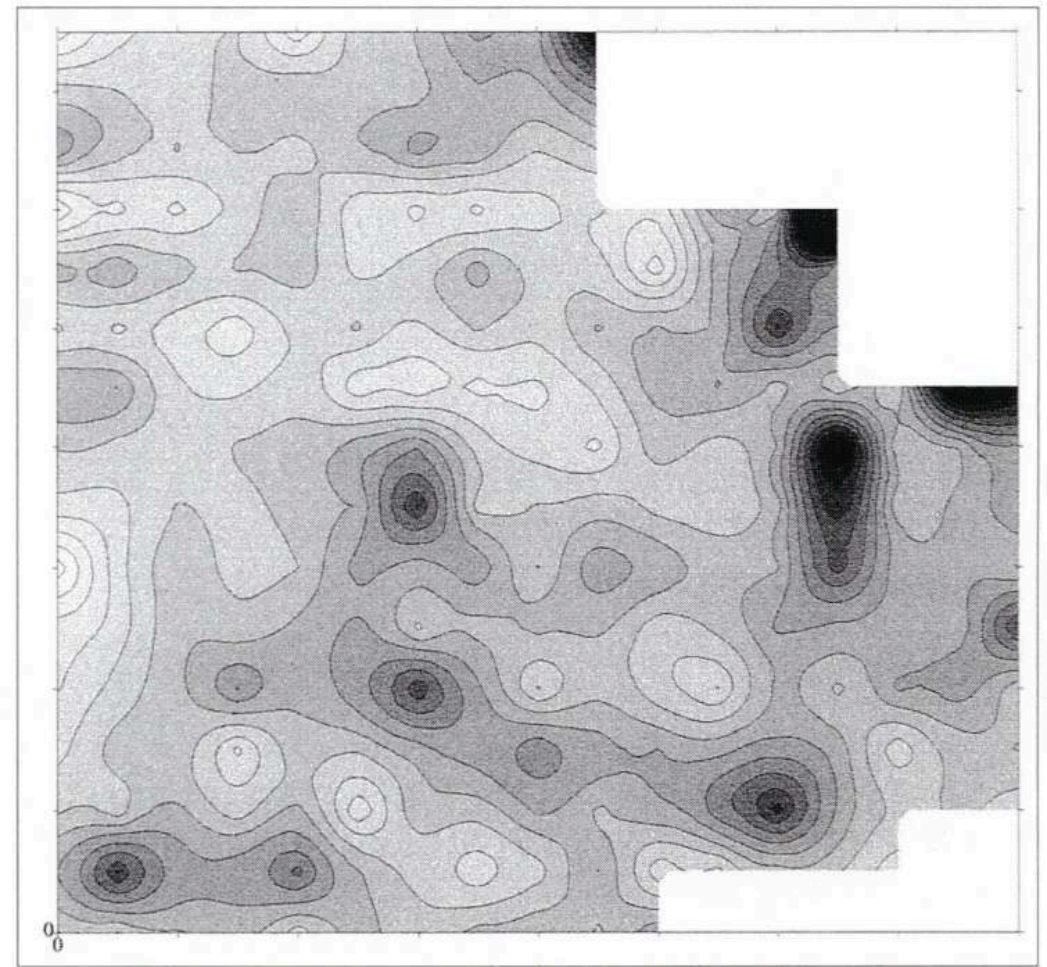

117 Cette parcelle est contiguë, au sud, à la précédente et semble indiquer la fin de la zone de fortes valeurs : on ne retrouve en effet rien de semblable à ce qui existe en T29.

Le fond de la carte est constitué d'une nappe très hétérogène de valeurs moyennes (guère plus de - 55). Les fortes valeurs se concentrent sur la bordure (échancrée) au nord-est. Dans la logique de l'ensemble T29/T28, elles paraissent décrire l'extrémité sud de ce que nous pourrions interpréter comme étant, soit le site de production luimême, soit un secteur particulier de ce dernier (une zone de dépotoir ou de concentration de structures), soit simplement la partie la mieux conservée de l'atelier. Ces fortes valeurs peuvent aussi n'être que l'image des perturbations de surface des abords de la ferme.

119 Notons l'existence, plus au sud d'une anomalie linéaire (cinquième niveau de gris), en forme de «L» inversé, ponctuée de trois petites anomalies d'un peu plus forte susceptibilité, à l'est d'une zone de fortes valeurs, perpendiculaire aux profils : ce sont là les seuls points remarquables de la carte.

Il y a de fortes probabilités pour que la nette différence existant entre ces deux zones traduise une réalité archéologique ; mais il peut, avant tout, s'agir d'une image de ce qui est conservé de l'atelier, plutôt que d'une description de son organisation véritable. En ce sens la parcelle T28, malgré l'aspect peu cohérent de sa carte de susceptibilité magnétique, ne doit pas être négligée.

G. D.

\section{Un riche patrimoine artisanal}

L'ensemble des investigations de terrain conduites en Beaujolais autorise une première approche de la répartition des lieux de production sur quelques communes. On possède 
désormais une cartographie raisonnée, aussi exhaustive que possible, base indispensable à une enquête de terrain plus poussée.

Le tableau, page suivante, (tableau 4), concentre les informations recueillies sur les sites concernés par l'artisanat céramique : vestiges de surface et données géophysiques. Tous les sites qui n'ont livré d'autres indices que des épandages de tessons plus ou moins diffus n'ont pas été retenus à cette étape de la recherche.

Tableau 4. Confrontation des données archéologiques et géophysiques recueillies sur les principaux sites de production céramique

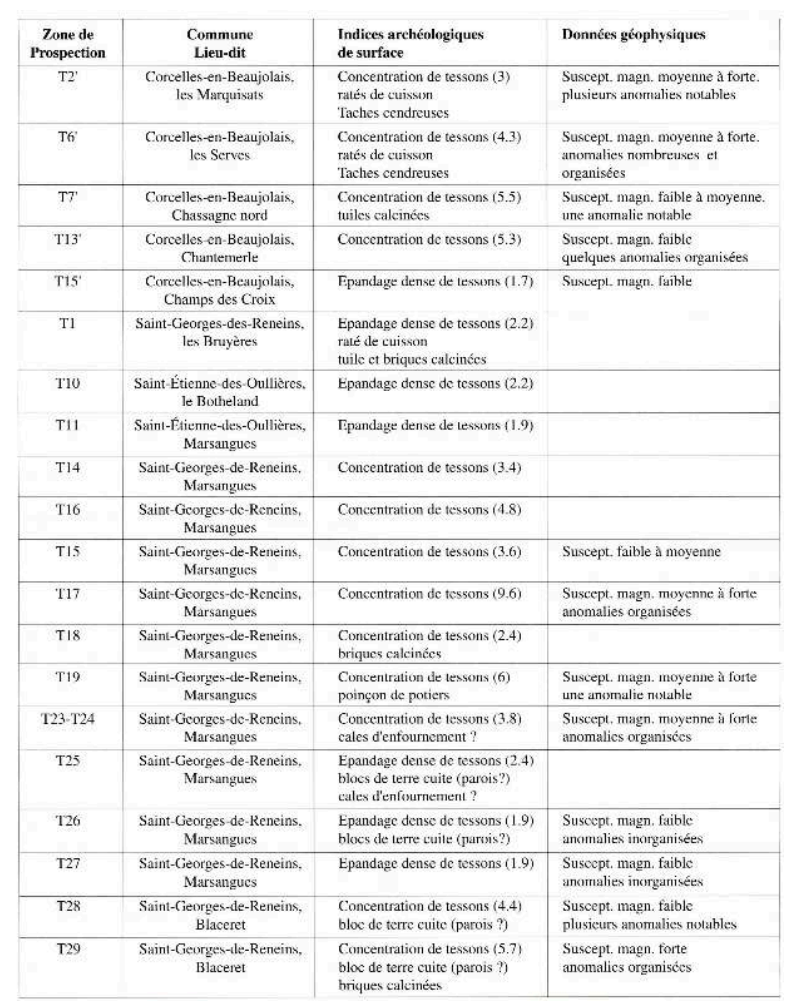

Les chiffres entre parenthèses renvoient au taux de densité des tessons au sol : tableaux 2 et 3

Dans plusieurs cas, le croisement des informations confirme les convictions acquises lors des prospections terrestres. Il s'agit des sites de T6' (les Serves) à Corcelles-enBeaujolais, ainsi que de T19, T23 - T24, et T29 au hameau de Marsangues. Les parcelles correspondantes recèlent très probablement les vestiges des ateliers et plus précisément des fours eux-mêmes. Parfois le croisement des informations n'est pas possible, faute de prospections géophysiques, mais de forts indices de surface conduisent à établir le lien avec l'artisanat de la terre cuite. Il en est ainsi de T1 et T10 T11 à Saint-Étienne-des-Oullières d'une part, et de T14, T16, T18 et T25 au hameau de Marsangues (Saint-Georges-de-Reneins), d'autre part.

Enfin, plusieurs cas montrent une relative contradiction entre les résultats des deux types de prospection. On a vu plus haut que bien des causes, internes ou externes, pouvaient être évoquées et qu'aucun cas n'était véritablement rédhibitoire. Les sites T13' et T15' - 16' à Corcelles-en-Beaujolais, exemplaires à cet égard, sont cependant retenus à titre d'hypothèse parmi la liste des lieux de production. Seuls des sondages pourraient lever les incertitudes. Quant à T2' et T7', toujours à Corcelles-en-Beaujolais, 
l'accumulation des traces archéologiques et des données géophysiques, certes mitigées, plaident en faveur de zones de production.

Le raisonnement est différent à propos de plusieurs parcelles sises à Marsangues que l'on a tout lieu de considérer comme un regroupement d'officines. Si l'ensemble du secteur présente des vestiges de surface particulièrement éloquents, les valeurs géophysiques sont plus irrégulières comme en T15, T17, T26 et T27. Mais peut-être fournissent-elles, par la négative, des informations sur la topographie des ateliers, départissant les aires de cuisson, par exemple, des autres zones de travail comportant des vestiges de moindre susceptibilité magnétique. La démonstration de cette hypothèse est quasi évidente dans les résultats obtenus en T28 et T29, zones aussi riches l'une que l'autre en vestiges de surface. Prise isolément, la parcelle T28 n'aurait pas retenu l'attention du géophysicien. Mais associée à T29, au contraire très marquante, probable épicentre de la zone de production, elle apparaît comme le prolongement logique de l'organisation du ou des ateliers.

On pourrait envisager d'étendre les prospections géophysiques à toutes les parcelles concernées par des ramassages de surface fructueux, pour vérifier la validité du raisonnement. En attendant, on tient pour le secteur de Marsangues une série de résultats particulièrement positifs. Pour les autres secteurs, les informations sont plus circonscrites et témoignent d'ateliers plus dispersés ou de moindre envergure, mais non moins avérés. Des quarante-trois zones de ramassage prises en compte au début de cette enquête, vingt-et-une offrent des critères suffisants pour étayer l'hypothèse d'une concentration d'ateliers de poterie dans ce secteur du Val de Saône durant le Moyen Âge.

E. F.-B.

\section{Production et chronologie des ateliers}

L'appréhension générale de la localisation des ateliers beaujolais ne peut être tentée sans aborder la question délicate de leur datation à partir du mobilier collecté.

Un atout : l'échantillon disponible est important (près de 52000 tessons) et autorise des observations d'ordre statistique, encore qu'il faille bien relativiser les choses; moins du quart est identifiable, c'est-à-dire qu'il peut être rapporté à une forme ou partie de forme de récipient.

Une difficulté : le manque de collections de référence, mieux conservées, auxquelles raccorder la typologie élaborée ${ }^{14}$. Celle-ci garde donc une grande part d'hypothèse jusqu'à découvertes complémentaires, plus lisibles. Toutefois, en l'absence de critères de datation absolue (textes, archéométrie, par exemple), les propositions chronologiques s'appuient sur les comparaisons établies dans deux directions : d'une part avec le mobilier des sites "utilisateurs" fouillés ces dernières années dans la région, d'autre part avec les séries des sites "producteurs" de la région chalonnaise, en particulier Sevrey (Saône-et-Loire).

132 L'intégralité du produit des ramassages de surface a été comptabilisée et étudiée. Mais l'analyse typologique s'appesantit, bien évidemment, sur les lots provenant des sites les plus probants. L'objectif est double: déterminer la date et la durée de l'activité des ateliers localisés, mais aussi établir leur chronologie relative et retracer, autant que 
faire se peut, l'évolution géographique des installations à l'intérieur des terroirs concernés.

\section{Portrait de produits ordinaires}

Mais avant d'explorer les voies de la typo-chronologie, quelques remarques d'ordre général s'imposent. Les céramiques beaujolaises offrent en effet des caractéristiques communes qui, même considérées sur la longue durée, en font une production assez homogène. Il s'agit très généralement de poteries à pâte grossière, voire très grossière, criblée d'inclusions jusqu'à la surface des parois particulièrement rugueuses. Quelques cas exceptionnels de pâte fine, sonore, concernent de petites formes fermées. Une telle proportion d'inclusions rend les pâtes friables, à quoi il faut ajouter des conditions de cuisson apparemment assez irrégulières. Les pâtes grises prédominent dans l'ensemble. Quant aux pâtes claires, elles présentent une gamme variée de beiges, de brans et de rouges. La distinction entre les modes de cuisson, en atmosphère oxydante ou réductrice, n'est pas toujours aisée, ce qui suggère une certaine part de hasard et une maitrise toute relative du degré et de l'atmosphère de cuisson. En témoignent également les pâtes dites "sandwich" (rouges à cœur, sombres en surface ou vice-versa) et les nuances de couleurs sur un même récipient.

Le répertoire des formes est limité : vaisselle commune de cuisine, en particulier pots à cuire et marmites. Certains sites offrent également des formes basses et ouvertes qui fournissent quelques repères chronologiques (mortiers, jattes ou bassins). La facture laisse peu de place aux finitions et à la fantaisie : les "décors" sont rares et sommaires (grosses bandes rapportées digitées, bourrelets pincés, grosses cannelures verticales obtenues par lissage aux doigts ou cannelures horizontales obtenues au tournage). Les revêtements glaçurés sont exceptionnels et semblent réservés, très parcimonieusement (taches, coulures) à la partie supérieure des récipients. A noter que la glaçure concerne principalement des pâtes claires.

La vaisselle des ateliers beaujolais ne brille donc ni par son aspect, ni par sa facture. On retire l'impression d'un travail hâtif, à partir de matériaux tout-venant. Il faut bien le reconnaitre, les productions en question sont des plus ordinaires ce qui semble toutefois n'avoir nui ni à l'expansion commerciale des ateliers, ni à leur longévité. 


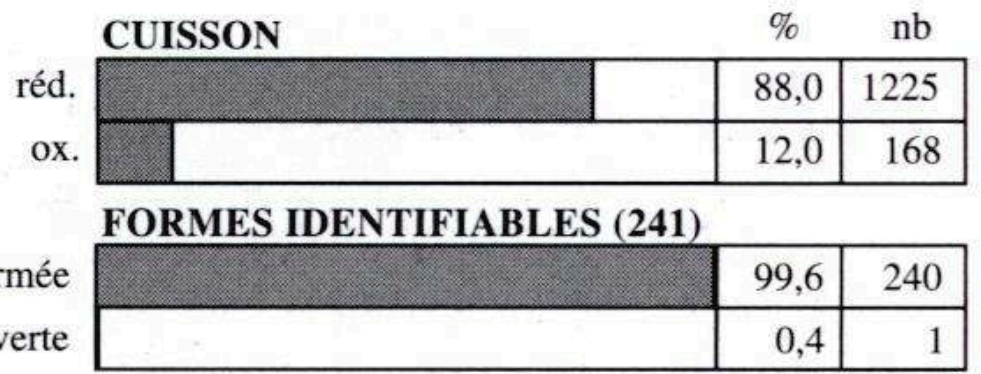

LEVRES FORMES FERMEES (240)

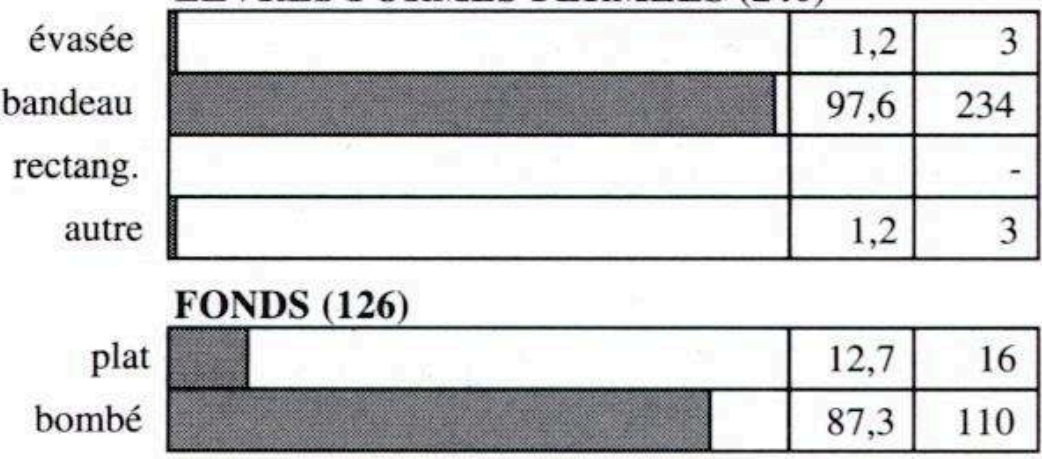

TOTAL 1393 tessons

Tableau 6. Corcelles-en-Beaujolais, Les Serves. T6'

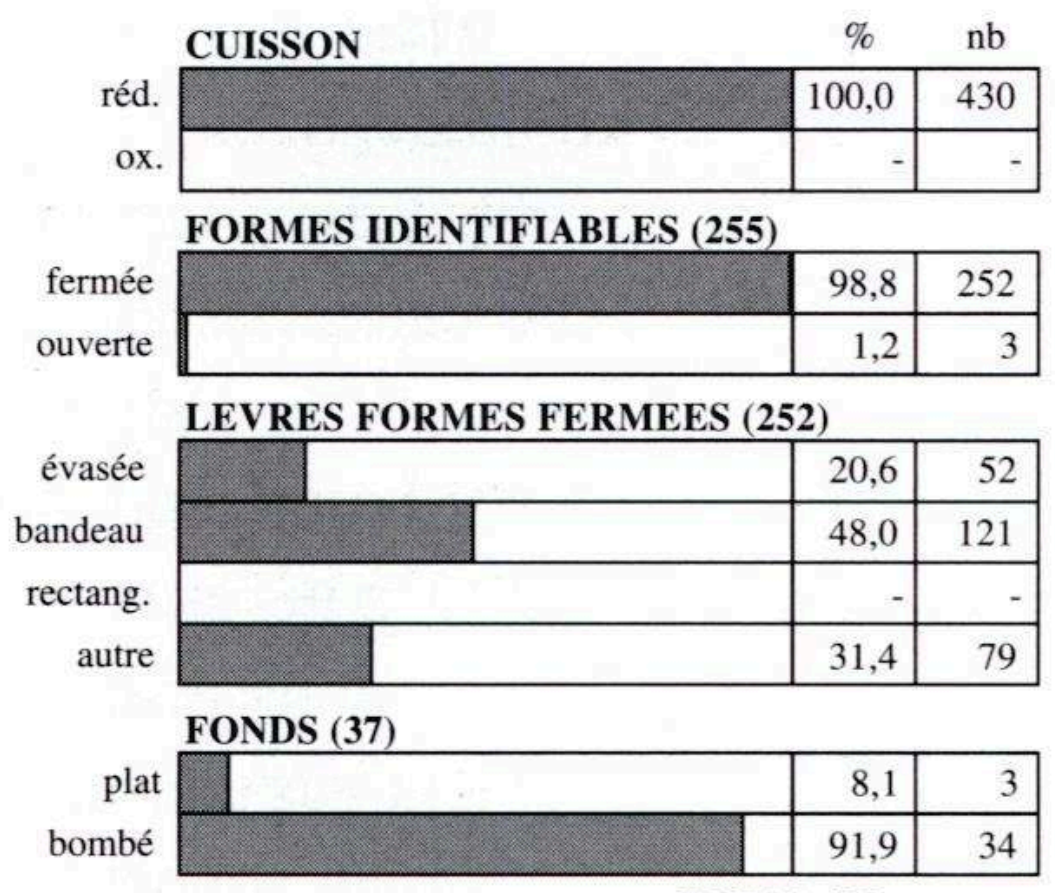

TOTAL 430 tessons 
Tableau 7. Corcelles-en-Beaujolais, Chassagne nord. T7

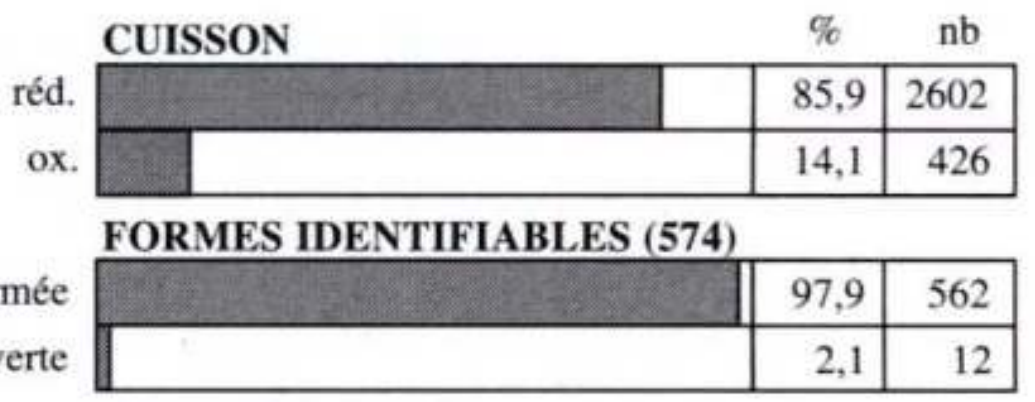

\section{LEVRES FORMES FERMEES (562)}

évasée
bandeau
rectang.
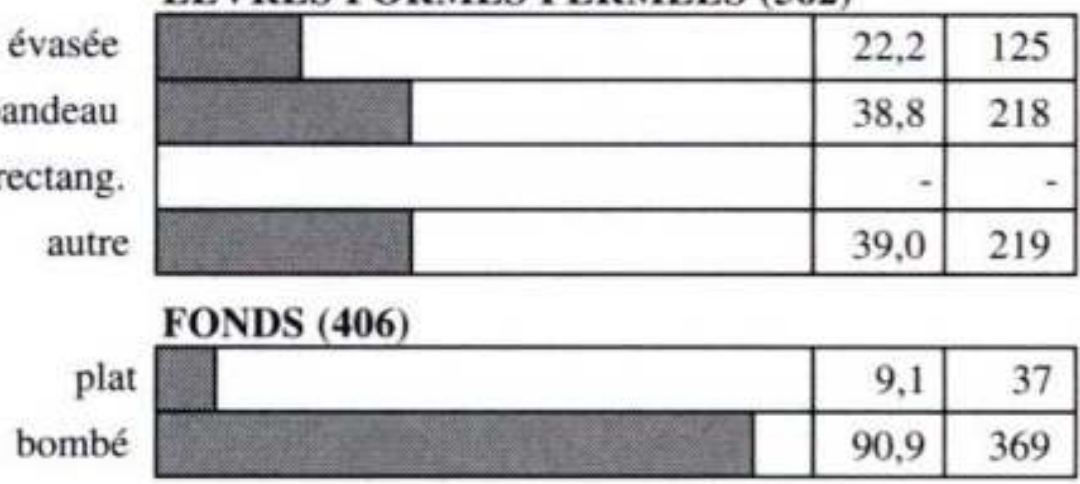

TOTAL 3028 tessons

Tableau 8. Corcelles-en-Beaujolais, Chassagne nord. T8'

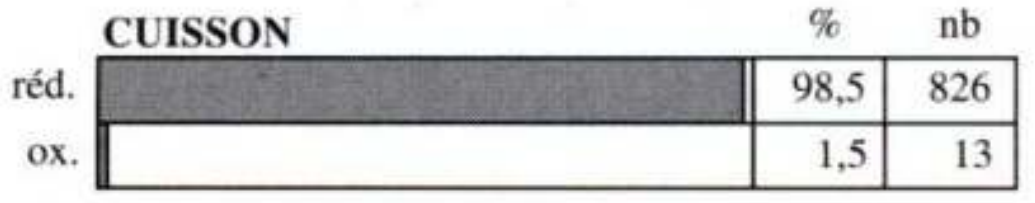

FORMES IDENTIFIABLES (97)

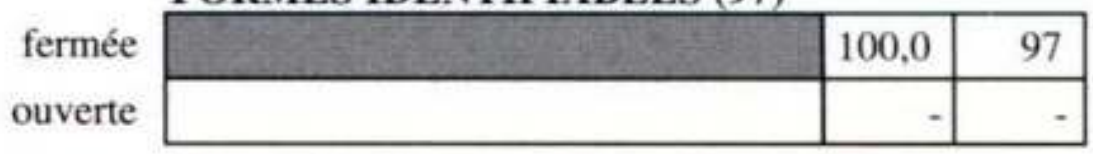

LEVRES FORMES FERMEES (97)

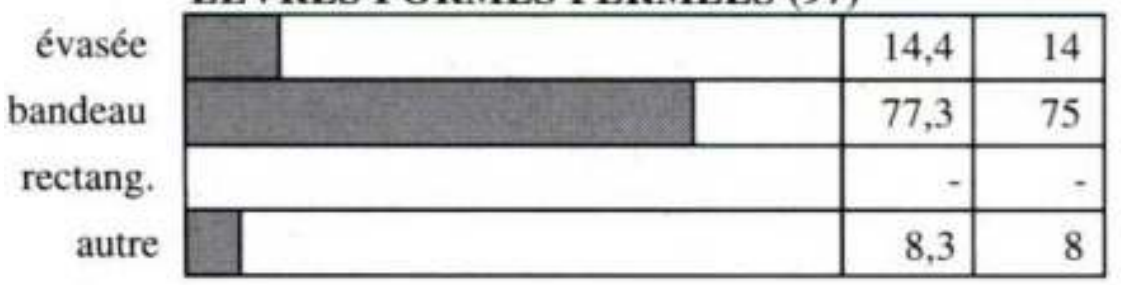

FONDS (41)

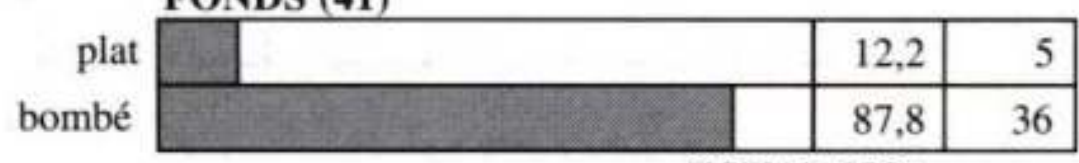

TOTAL 839 tessons 
Tableau 9. Corcelles-en-Beaujolais, Chassagne. T5'

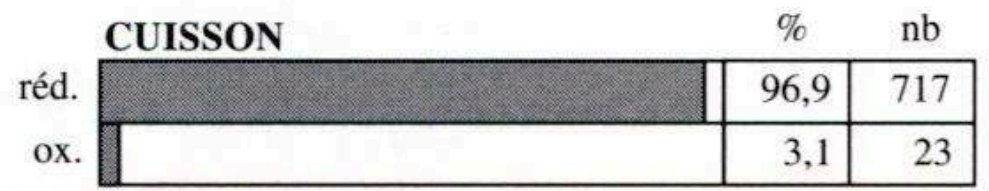

FORMES IDENTIFIABLES (94)

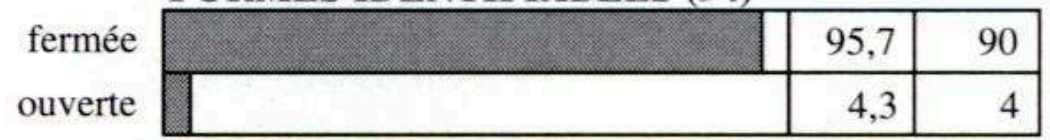

LEVRES FORMES FERMEES (90)

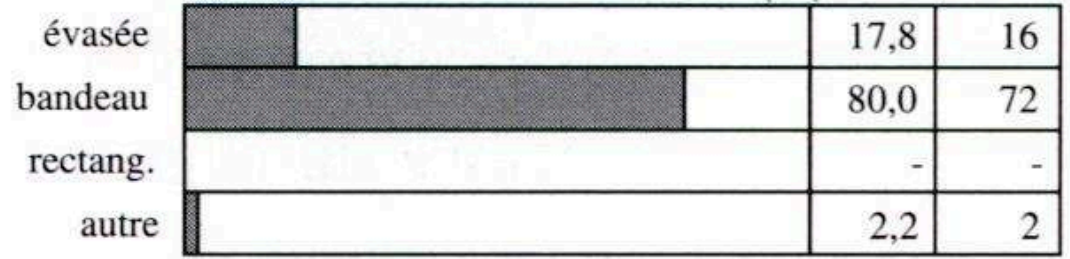

FONDS (54)

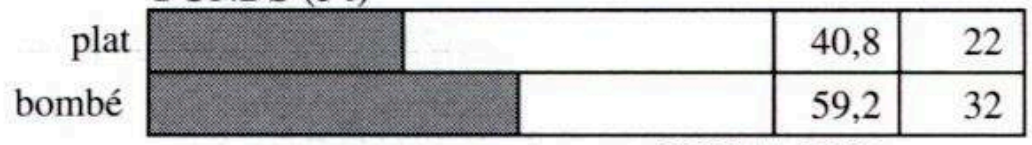

TOTAL 740 tessons

Tableau 10. Corcelles-en-Beaujolais, Chantemerle. T13'

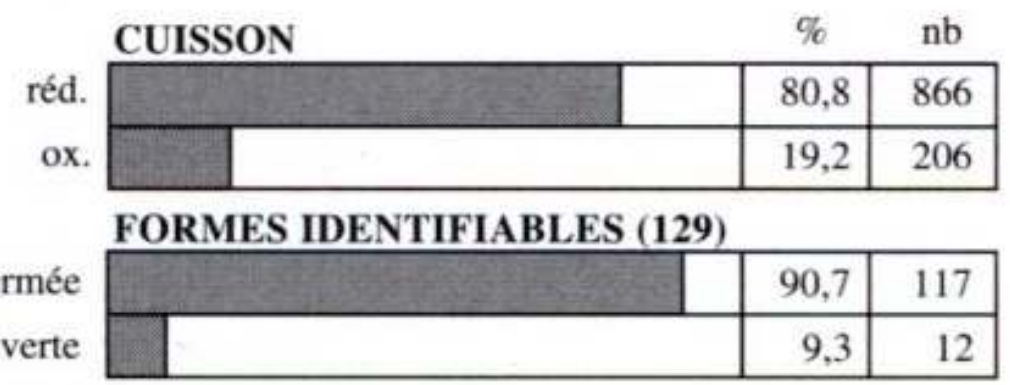

LEVRES FORMES FERMEES (117)

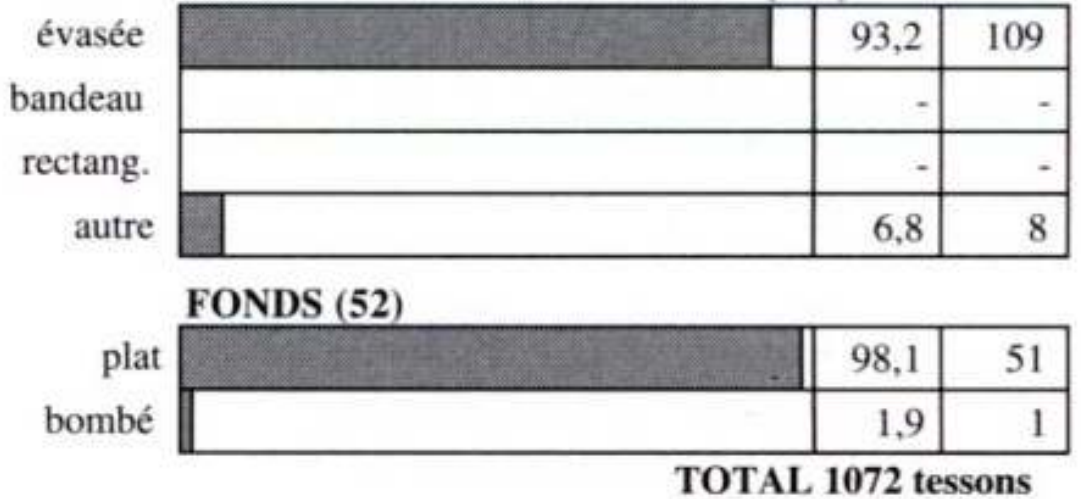

TOTAL 1072 tessons 

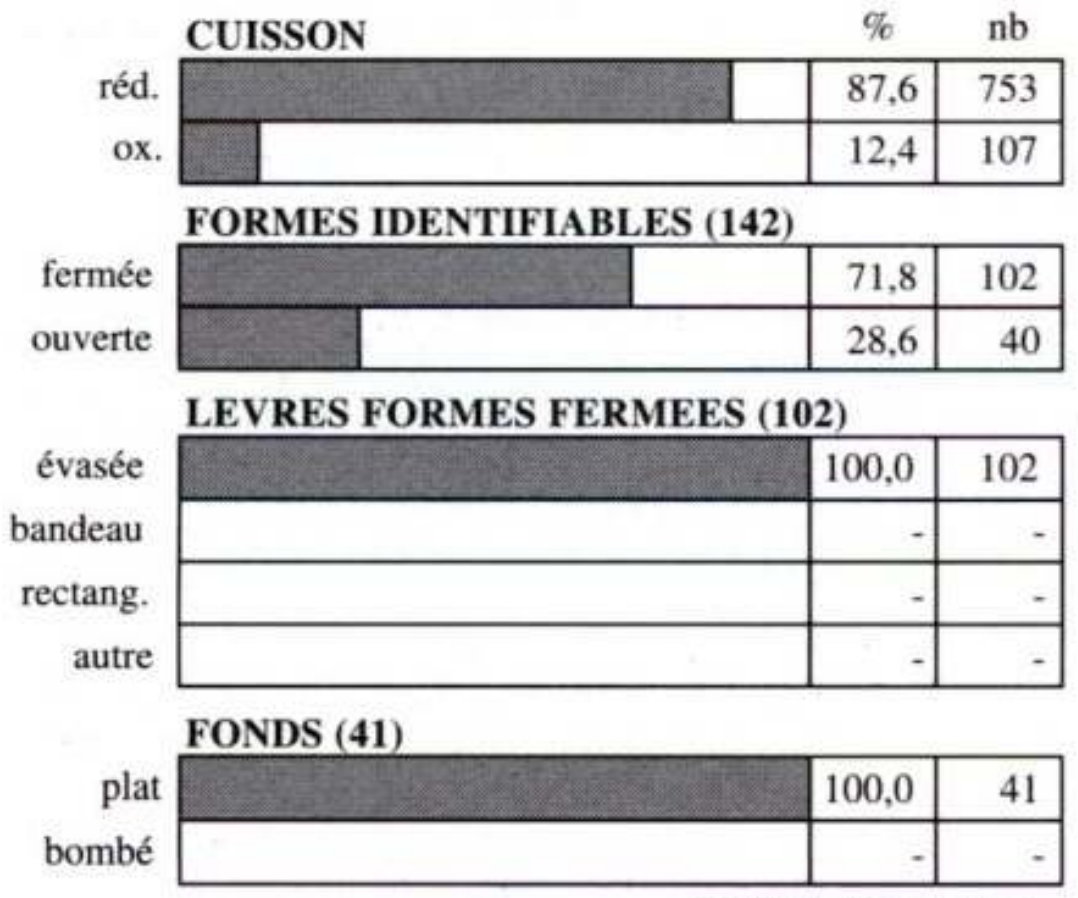

TOTAL 860 tessons

Tableau 12. Corcelles-en-Beaujolais, Les Ayets. T17'

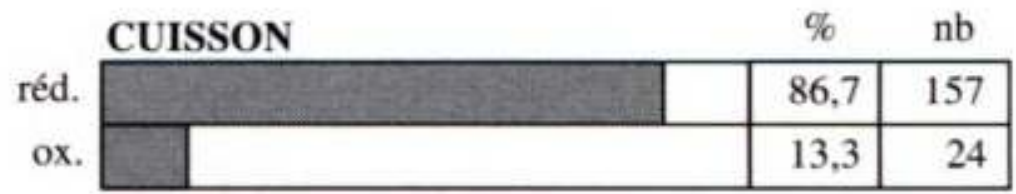

FORMES IDENTIFIABLES (16)

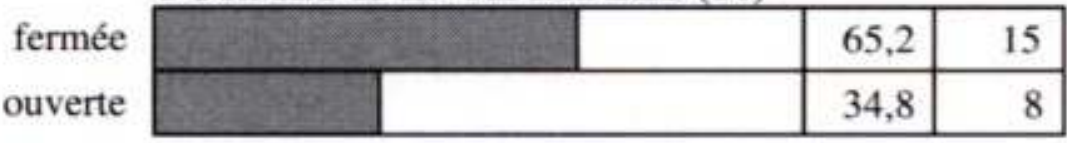

\section{LEVRES FORMES FERMEES (11)}

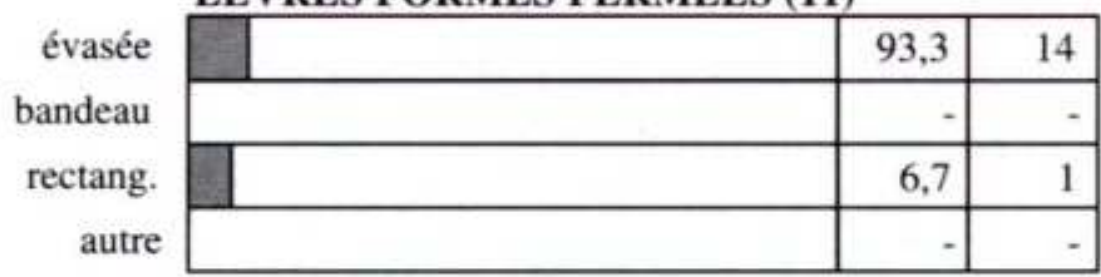

FONDS (25)

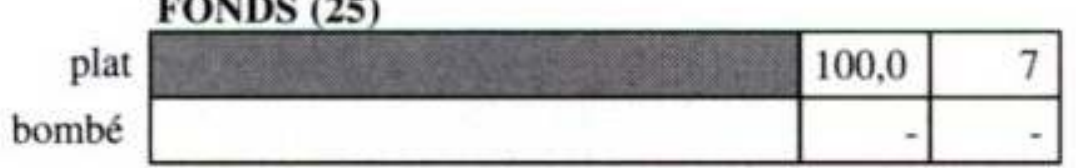

TOTAL 181 tessons 
Tableau 13. St-Etienne-les-Oullières, Botheland. T10

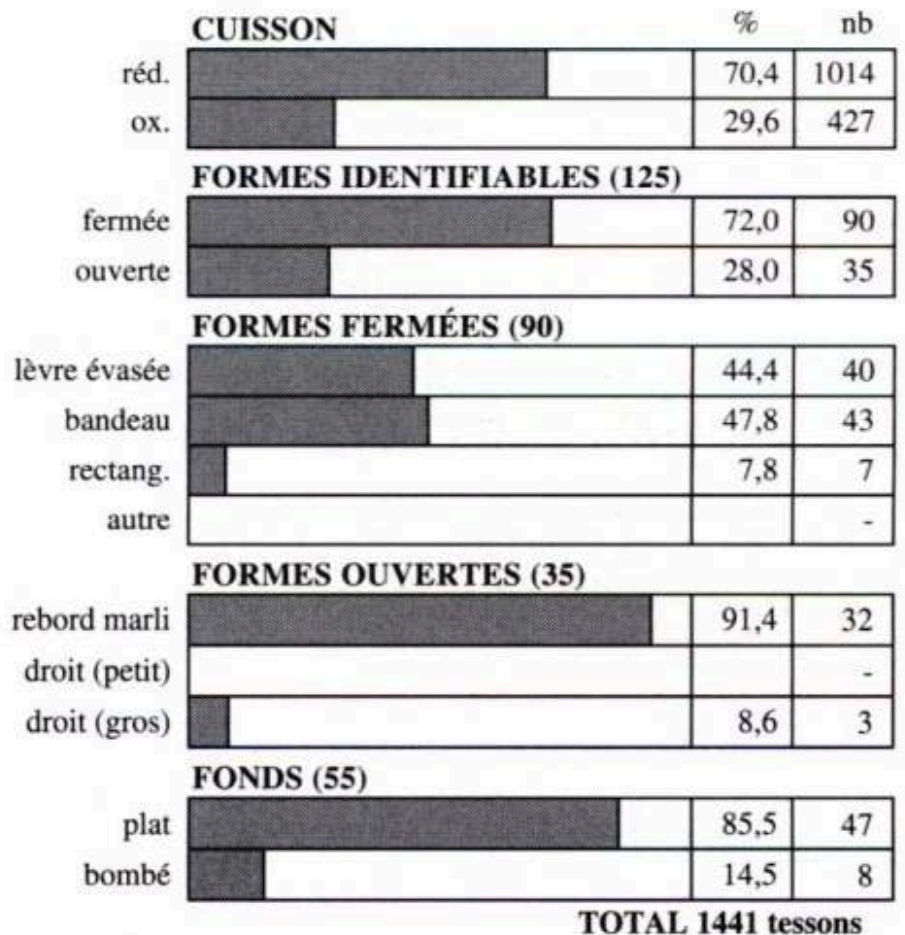

Tableau 14. St-Etienne-les-Oullières, Botheland. T11

\begin{tabular}{|c|c|c|c|}
\hline & CUISSON & \multicolumn{2}{|r|}{$\mathrm{nb}$} \\
\hline \multirow[t]{2}{*}{ réd. } & & 69,4 & 306 \\
\hline & & 30,6 & 135 \\
\hline & \multicolumn{3}{|c|}{ FORMES IDENTIFIABLES (44) } \\
\hline fermée & & 65,9 & 29 \\
\hline \multirow[t]{2}{*}{ ouverte } & & 34,1 & 15 \\
\hline & \multicolumn{3}{|c|}{ FORMES FERMÉES (29) } \\
\hline lèvre évasée & & 51,7 & 15 \\
\hline bandeau & & 31,0 & 9 \\
\hline \multirow{3}{*}{$\begin{array}{r}\text { rectang. } \\
\text { autre }\end{array}$} & & 17,3 & 5 \\
\hline & & & - \\
\hline & \multicolumn{3}{|c|}{ FORMES OUVERTES (15) } \\
\hline rebord marli & & 60,0 & 9 \\
\hline droit (petit) & & 20,0 & 3 \\
\hline \multirow[t]{2}{*}{ droit (gros) } & & 20,0 & 3 \\
\hline & \multicolumn{3}{|c|}{ FONDS (20) } \\
\hline plat & & 60,0 & 12 \\
\hline bombé & & 40,0 & 8 \\
\hline
\end{tabular}

TOTAL 441 tessons 
Tableau 15. St-Etienne-des-Oullières. T1

\begin{tabular}{|c|c|c|}
\hline CUISSON & $\%$ & $\mathrm{nb}$ \\
\hline réd. & 73,6 & 746 \\
\hline ox. & 26,4 & 268 \\
\hline
\end{tabular}

FORMES IDENTIFIABLES (128)

\begin{tabular}{|c|c|c|}
\hline fermée & 59,4 & 76 \\
\hline ouverte & 40,6 & 52 \\
\hline
\end{tabular}

FORMES FERMÉES (76)

lèvre évasée

bandeau

rectang.

autre

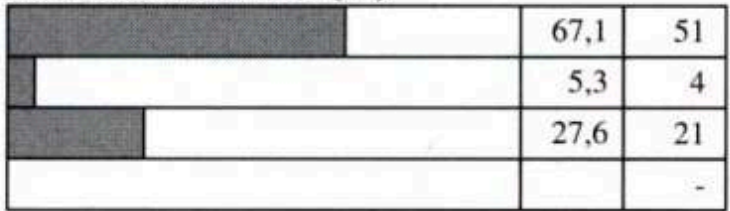

FORMES OUVERTES (52)

\begin{tabular}{c|c|r|r|r|}
\cline { 2 - 5 } rebord marli & & 84,6 & 44 \\
\cline { 2 - 5 } $\begin{array}{c}\text { droit (petit) } \\
\text { droit (gros) }\end{array}$ & & & 11,5 & 6 \\
\cline { 2 - 5 } nyyyyy & & &
\end{tabular}

FONDS (24)

plat

bombé

\begin{tabular}{|l|l|l|r|r|}
\hline \multicolumn{2}{|l|}{} & & 58,3 & 14 \\
\hline & & 41,7 & 10 \\
\hline
\end{tabular}

TOTAL 1014 tessons

Tableau 16. St-Georges-de-Reneins, Marsangues. T7

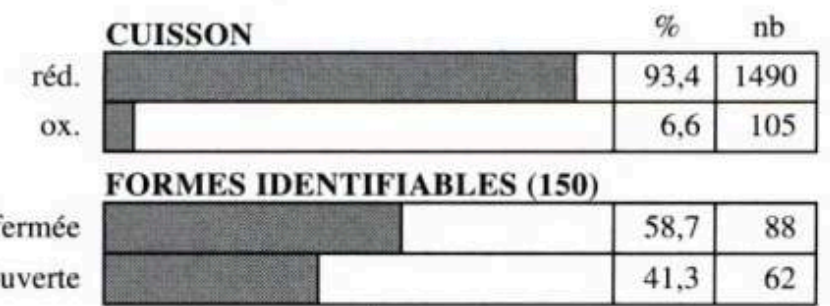

FORMES FERMÉES (88)

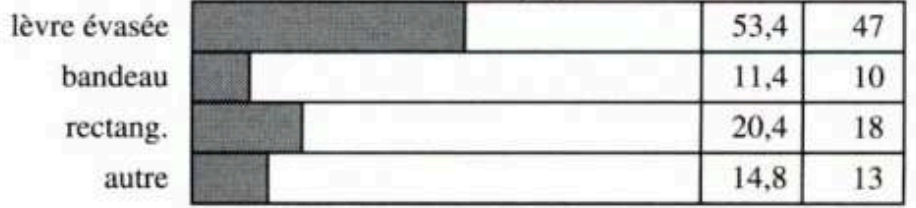

FORMES OUVERTES (62)

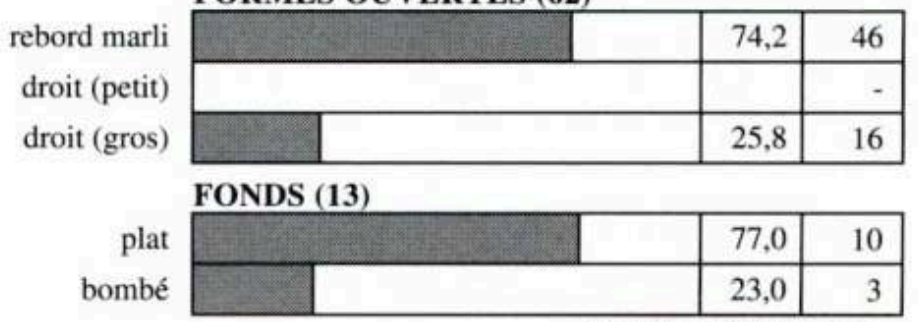

TOTAL 1595 tessons 
Tableau 17. Blacé, Blaceret. T13

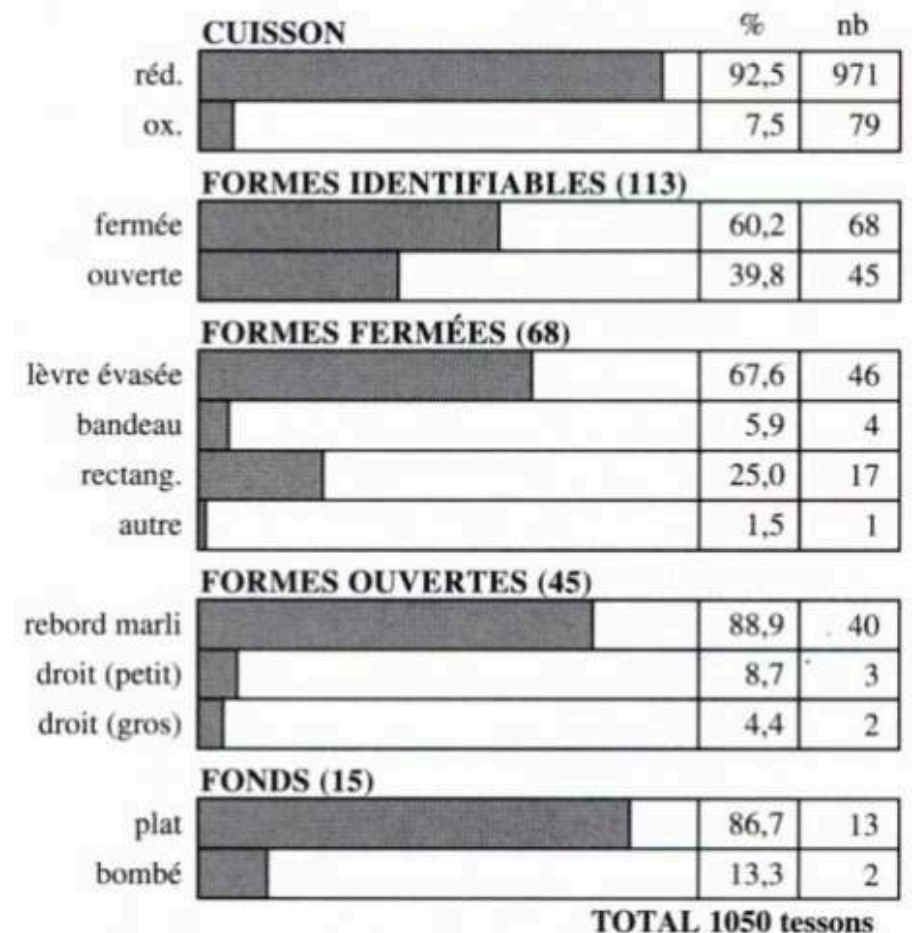

Tableau 18. St-Georges-de-Reneins, Marsangues. T14

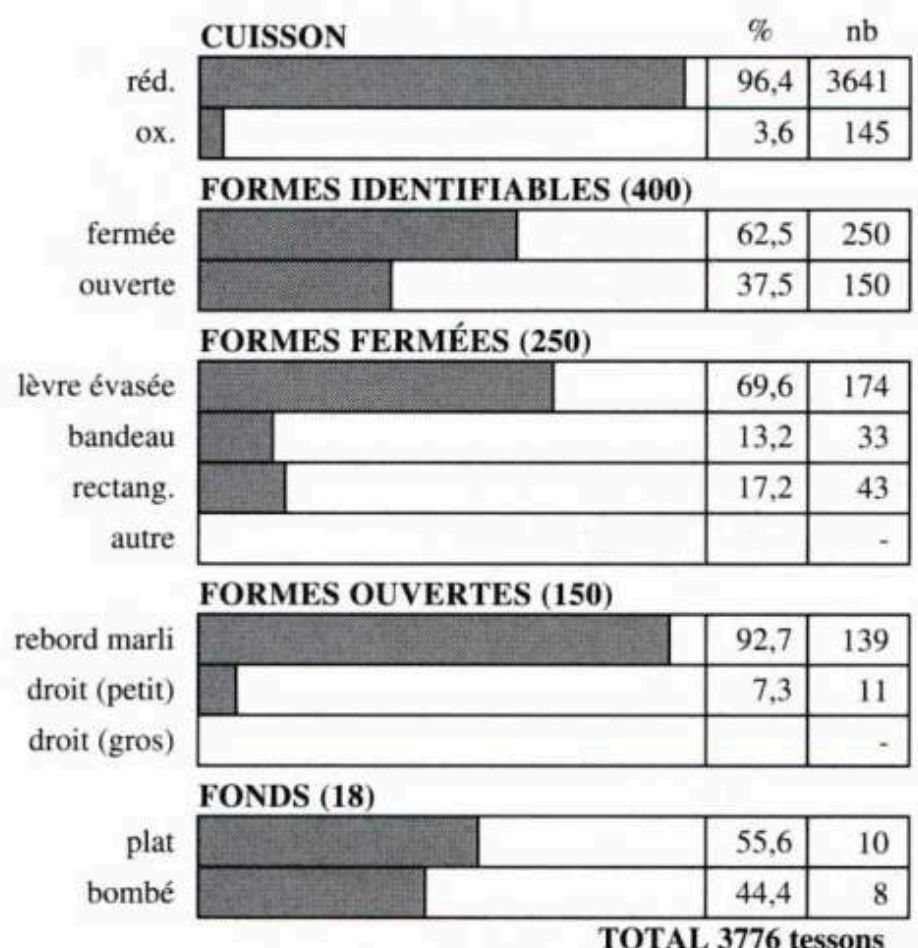

TOTAL 3776 tessons 
Tableau 19. St-Georges-de-Reneins, Marsangues. T15

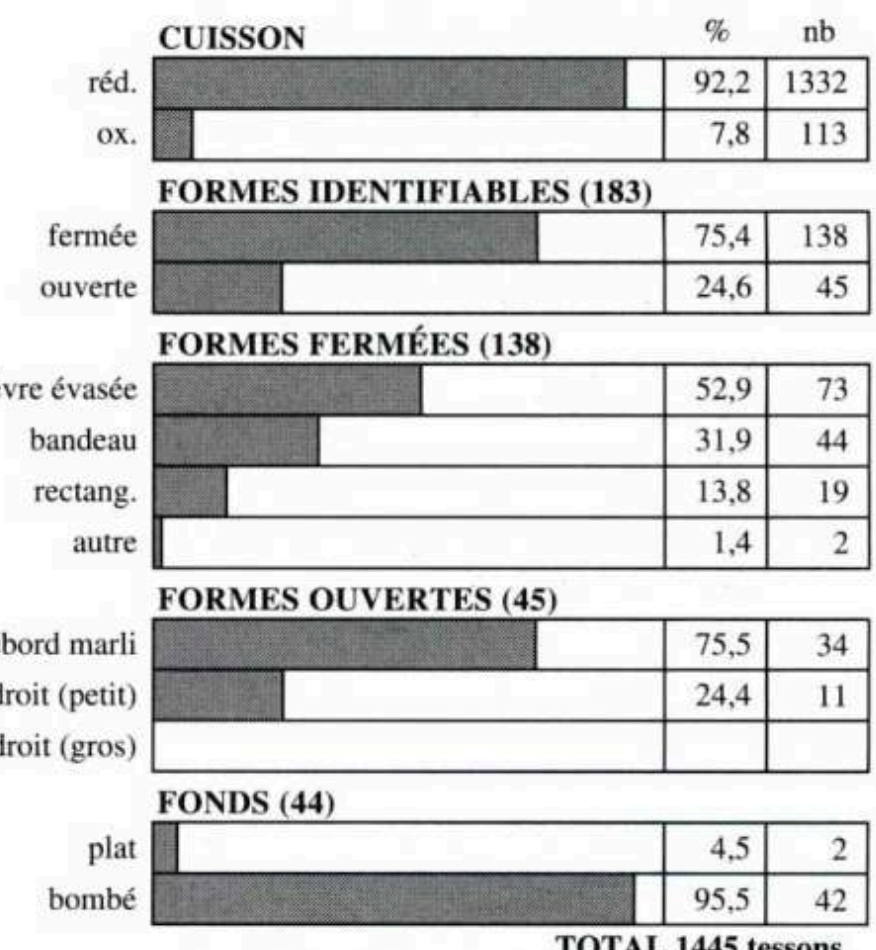

Tableau 20. St-Georges-de-Reneins, Marsangues. T16

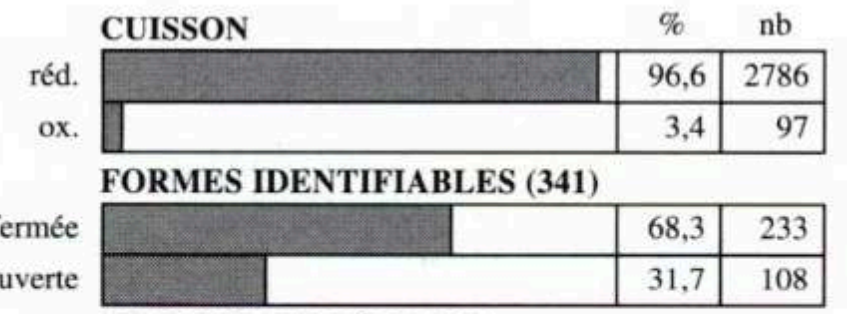

FORMES FERMÉES (233)

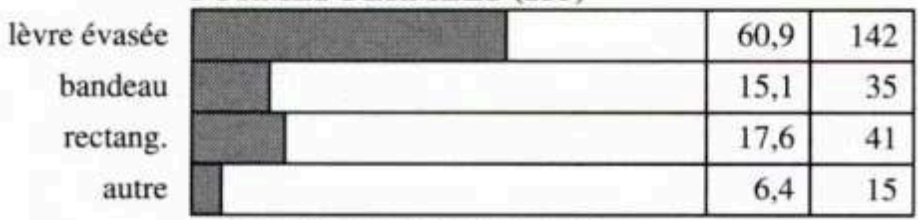

FORMES OUVERTES (108)

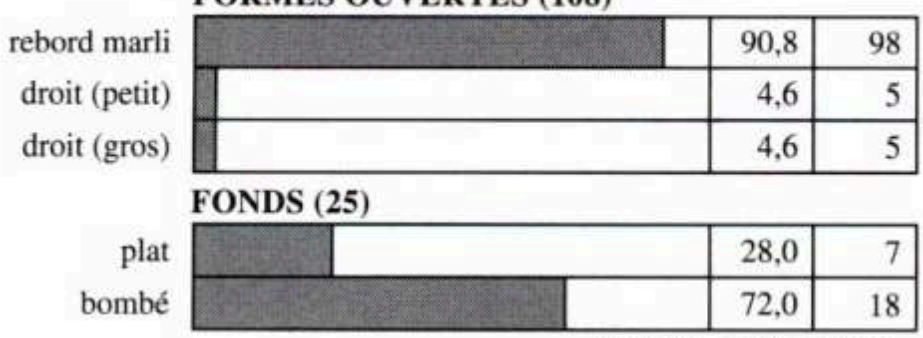

TOTAL 2883 tessons 
Tableau 21. St-Georges-de-Reneins, Marsangues. T17

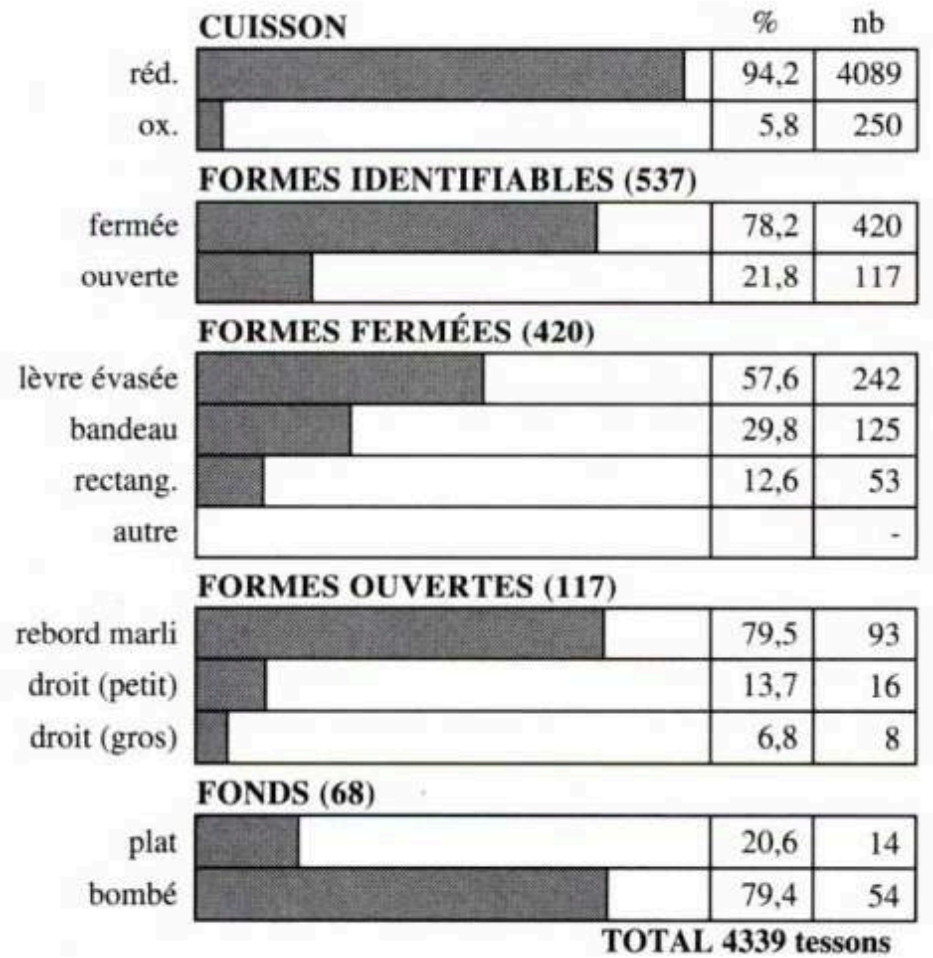

Tableau 22. St-Georges-de-Reneins, Marsangues. T18

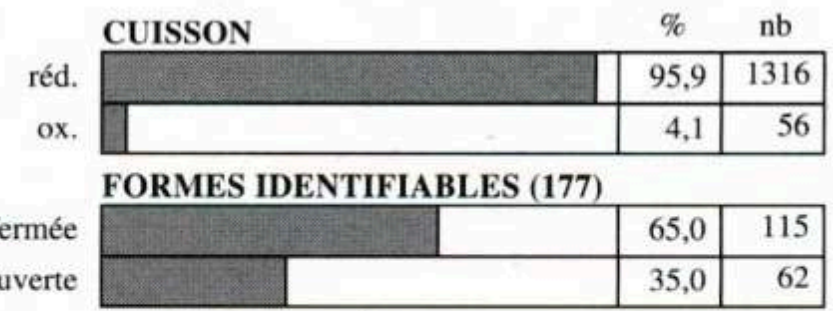

FORMES FERMÉES (115)

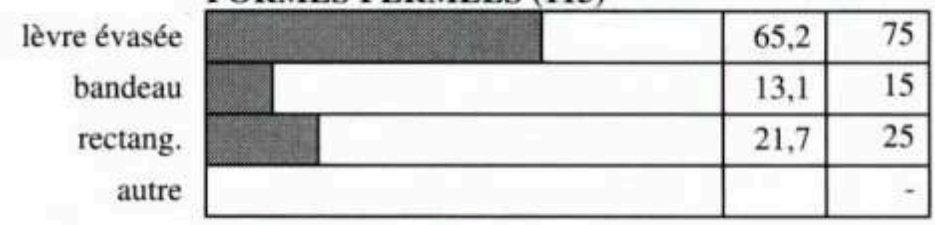

FORMES OUVERTES (62)

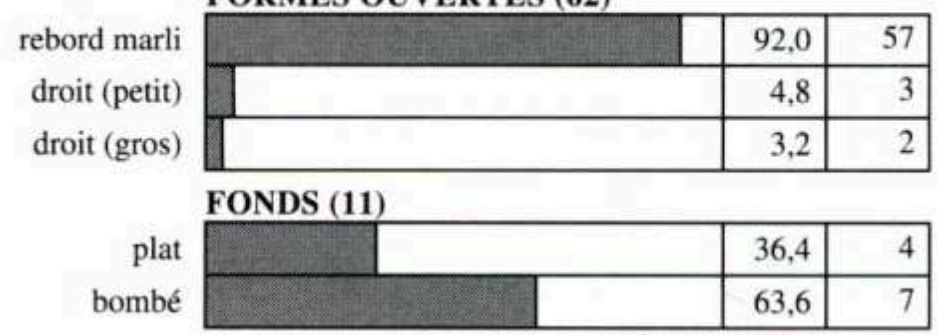

TOTAL 1372 tessons 


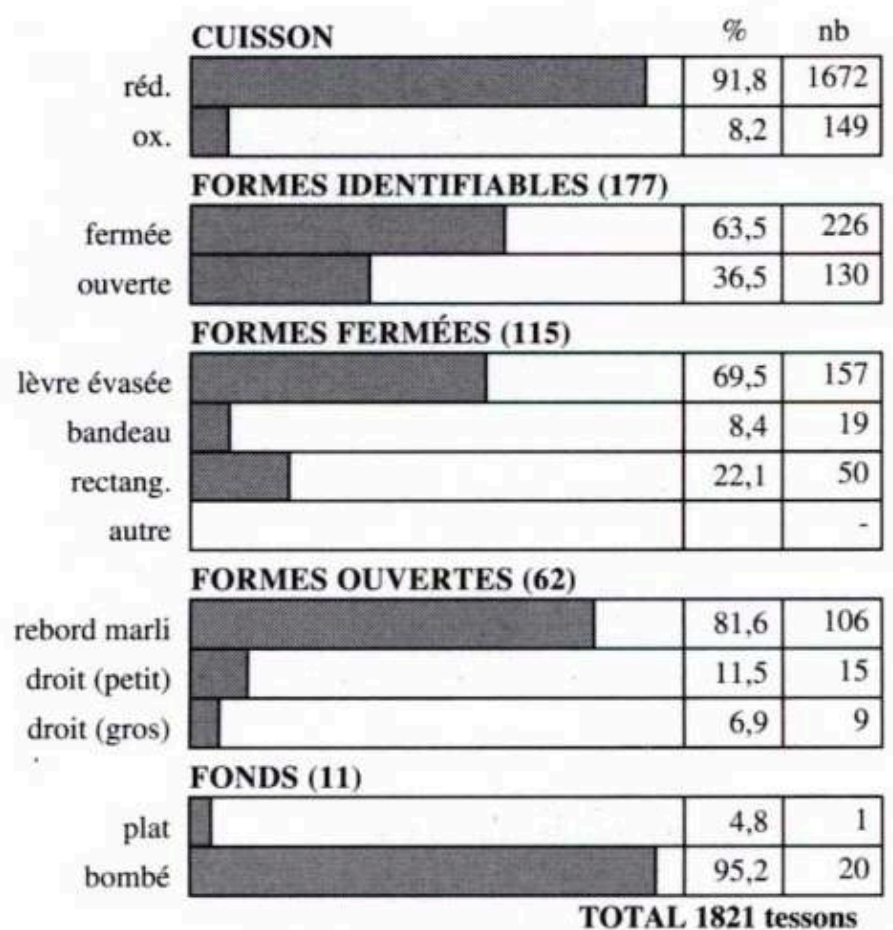

Tableau 24. St-Georges-de-Reneins, Marsangues. T21.22

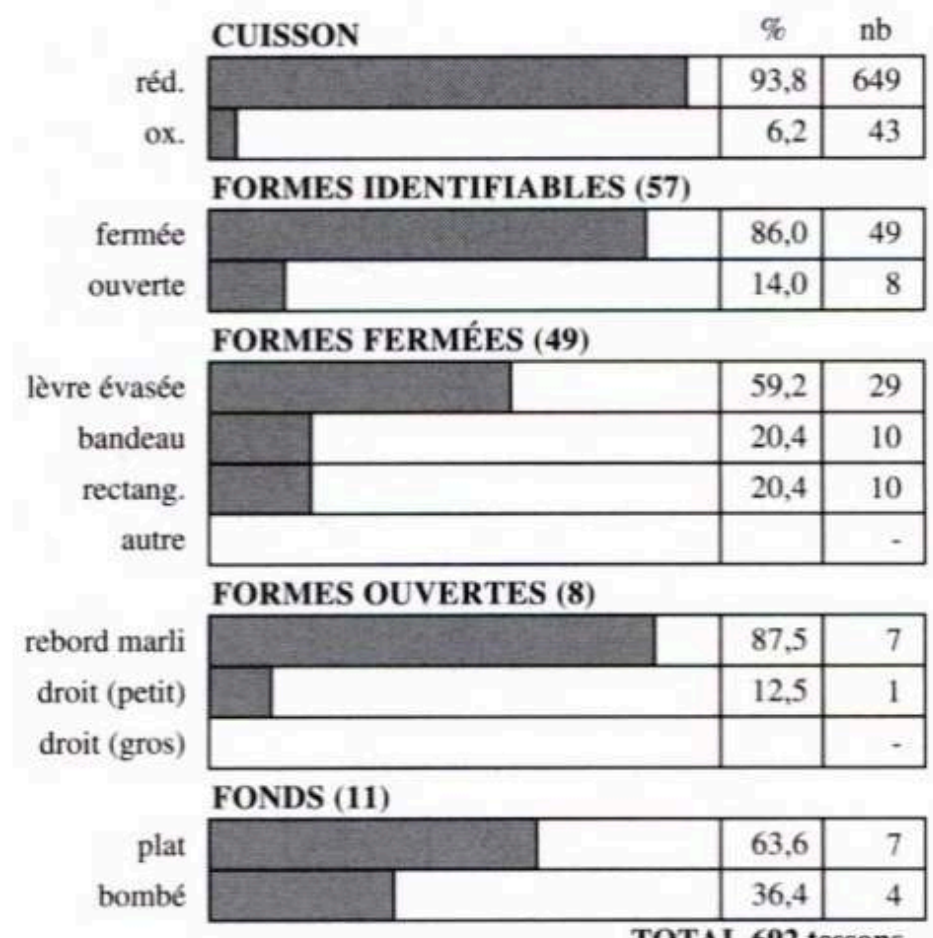

TOTAL 692 tessons 
Tableau 25. St-Georges-de-Reneins, Marsangues. T23

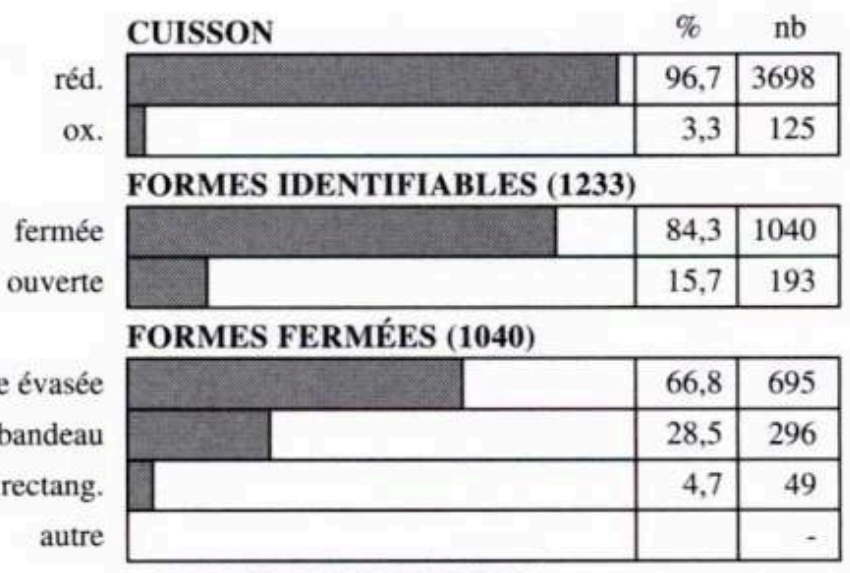

FORMES OUVERTES (193)

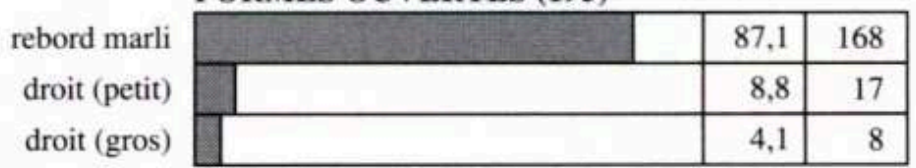

FONDS (257)

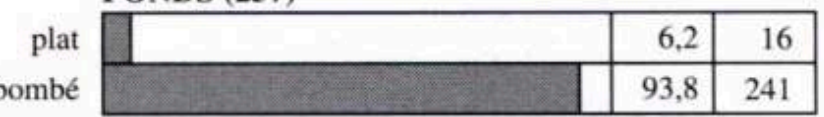

TOTAL 3823 tessons

Tableau 26. St-Georges-de-Reneins, Marsangues. T24

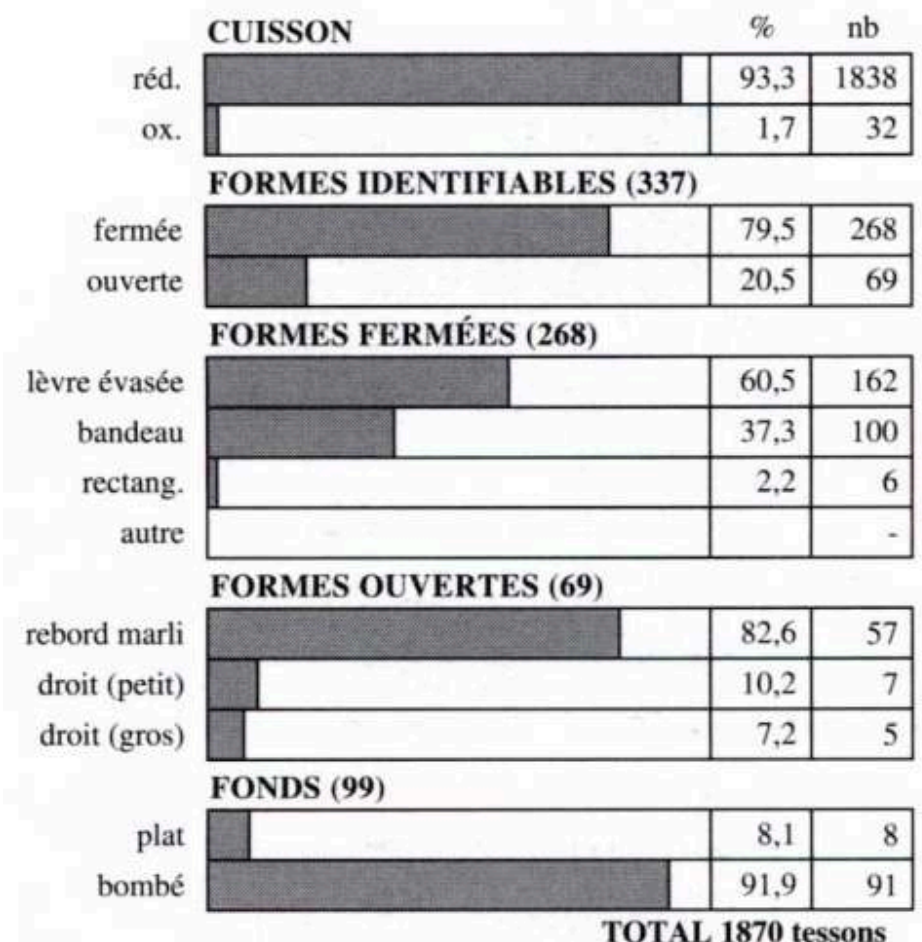

TOTAL 1870 tessons 
Tableau 27. St-Georges-de-Reneins, Marsangues. T25

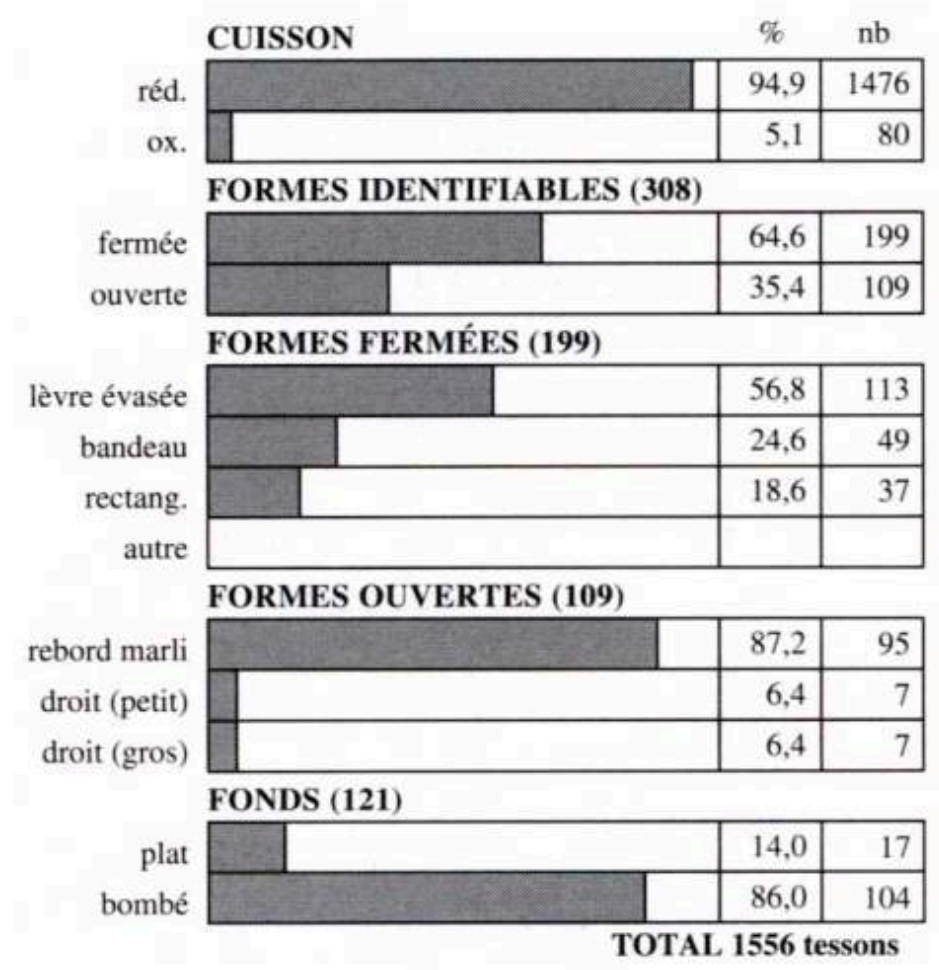

Tableau 28. St-Georges-de-Reneins, Marsangues. T26

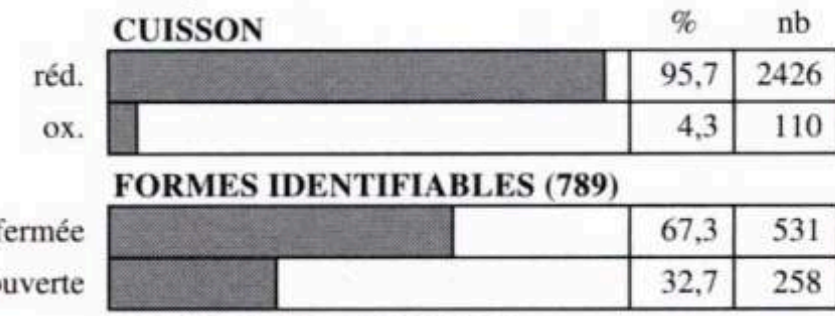

FORMES FERMÉES (531)

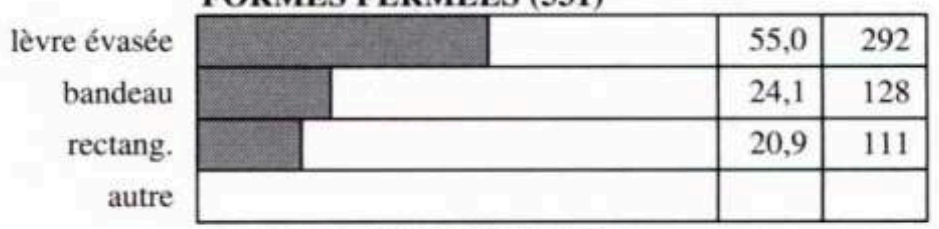

FORMES OUVERTES (258)

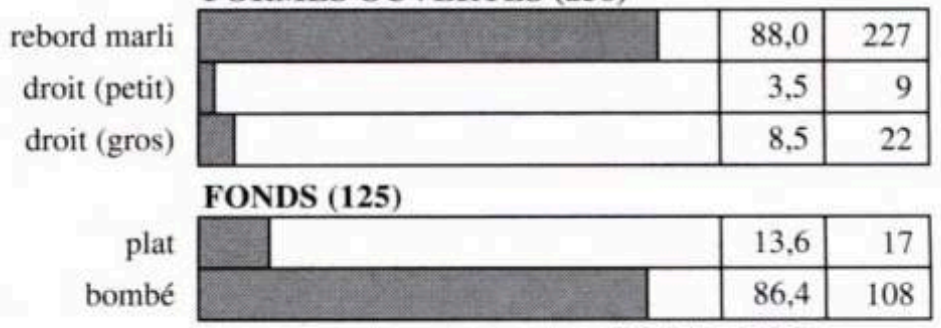

TOTAL 2536 tessons 


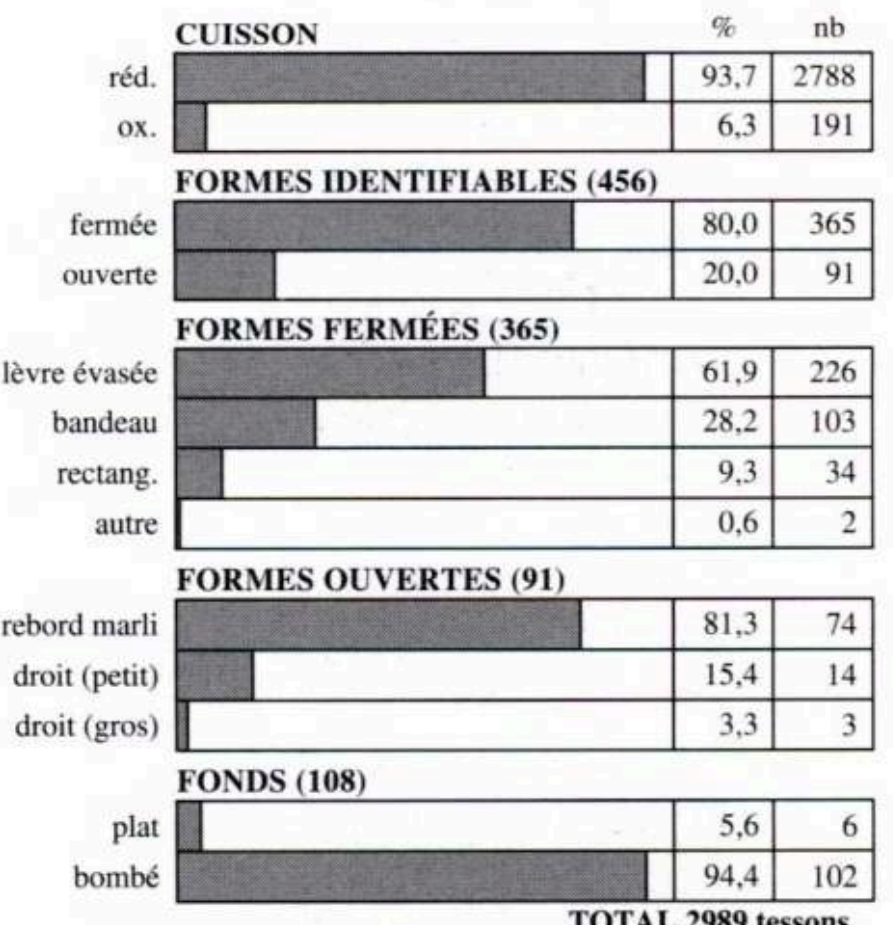

Tableau 30. St-Georges-de-Reneins, Marsangues. T28

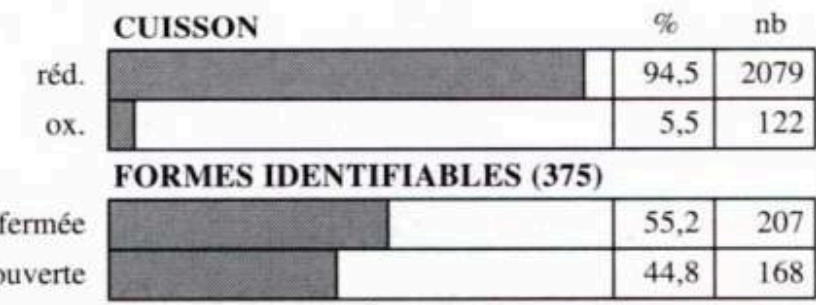

FORMES FERMÉES (207)

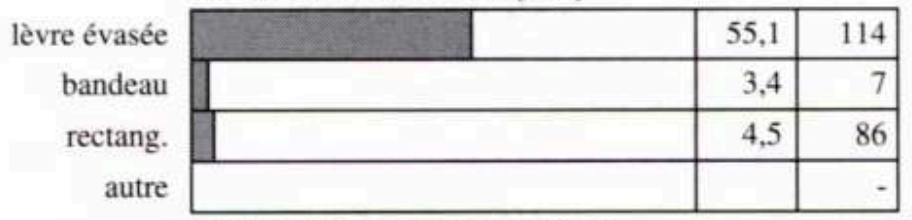

FORMES OUVERTES (168)

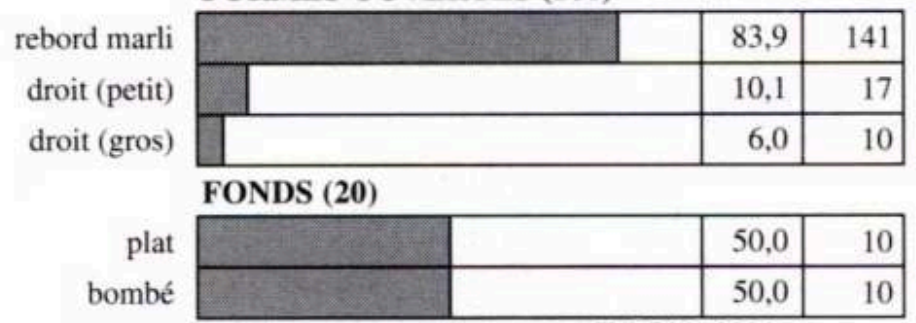

TOTAL 2201 tessons 


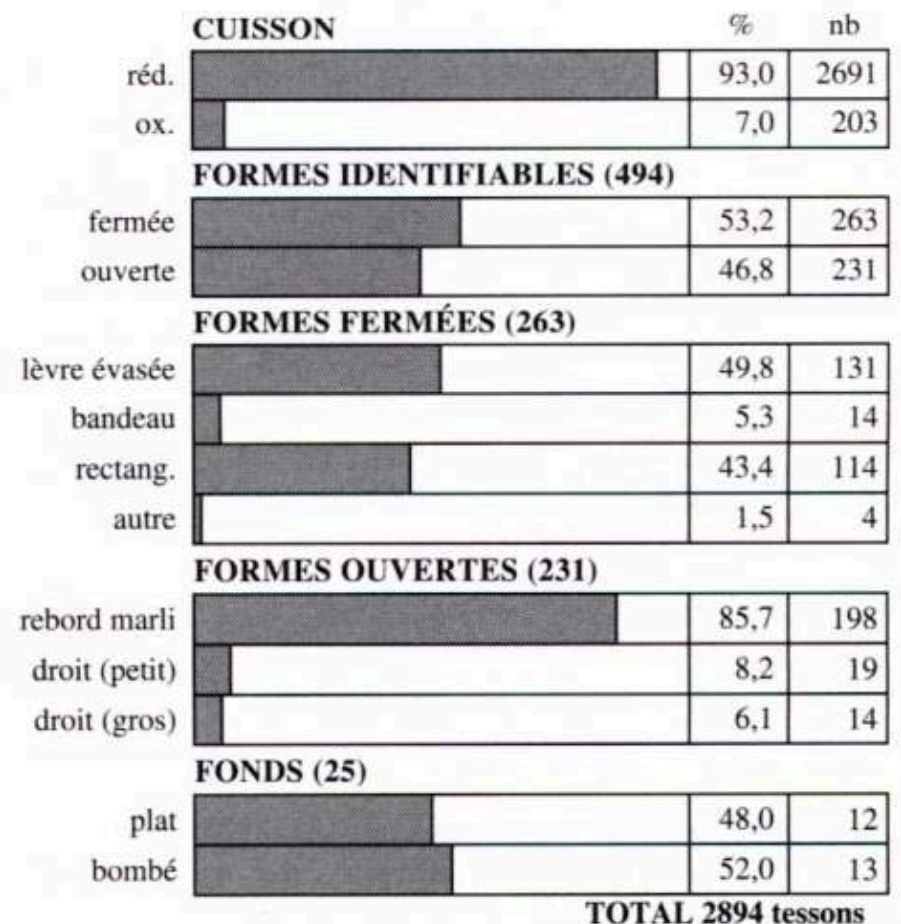

Compte tenu du volume de matériel à traiter, on a retenu essentiellement les caractères susceptibles de fournir des indices de datation (tableaux 5 à 31) :

- mode de cuisson (oxydante ou réductrice). Le décompte est fait sur l'ensemble des tessons d'un lot,

- proportion relative des formes fermées et des formes ouvertes; le décompte est fait sur l'ensemble des formes de rebords identifiables.

- parmi les rebords de formes fermées, deux types majeurs sont retenus : lèvre à évasement externe (avec ou sans gorge interne), lèvre en bandeau (tous types confondus), lèvre à profil rectangulaire (extrémité horizontale).

- parmi les rebords de formes ouvertes, deux types sont retenus : rebord en marli ou rebord vertical subdivisé en gros (diamètre $>25 \mathrm{~cm}$ ) ou petit gabarit (diamètre $<25 \mathrm{~cm}$ ).

- proportion relative des fonds plats et des fonds bombés; il faut préciser que cette rubrique ne comporte que des chiffres minima, car l'estimation de la forme du fond à partir d'un tesson est particulièrement difficile pour ces céramiques grossières.

137 S'ils n'apparaissent pas dans les graphiques, d'autres traits typologiques ont été consignés qui concourent à la définition des productions beaujolaises: ils seront indiqués au fil du texte (formes de lèvre particulières, présence d'éléments verseurs, de préhension, etc.).

Enfin, les graphiques sont réservés aux lots les plus significatifs : ceux qui proviennent quasi-assurément de tessonniers d'ateliers. On a également présenté, à titre indicatif, quelques ensembles qui, s'ils ne localisent pas des ateliers, pourraient provenir des sites producteurs voisins. 


\section{Les ateliers de Corcelles-en-Beaujolais} en bandeau (fig. $109 \mathrm{n}^{\circ} 19$ à 28). Ce type de lèvre est partout majoritaire, tandis que les lèvres à évasement externe (avec face interne plus ou moins concave) atteignent $20 \%$ maximum sur deux des sites (T6' et $\left.\mathrm{T}^{\prime}\right)$ (fig. $110 \mathbf{n}^{\circ} \mathbf{1}$ à $\left.\mathbf{5}\right)$; elles sont quasi absentes en T2'. Un troisième type de lèvre est répertorié et est caractéristique de ce premier groupe d'ateliers : il s'agit des lèvres en amande (largement évasées vers l'extérieur en courbe continue). Ce type est particulièrement bien représenté en T6' et T7', alors qu'il l'est à peine en T2' (fig. $109 \mathbf{n}^{\circ} 32$ à 34). Pour les formes fermées, les diamètres d'ouverture connus se répartissent entre 13 et $16 \mathrm{~cm}$, ce qui place les productions beaujolaises dans la bonne moyenne des gabarits des poteries culinaires. Les fonds bombés (lenticulaires) prédominent partout, entre 87 et $92 \%$, sauf en T5 où ils avoisinent $60 \%$ seulement.

146 La présence dans ces lots de fragments d'anses rubanées (fig. $109 \mathbf{n}^{\circ} 14$ à 17, fig. 110 $\mathbf{n}^{\circ} 21$ à 27) et de becs signale la fabrication de cruches. Celles-ci viennent loin en nombre derrière les pots à cuire, à en croire la faiblesse de l'échantillon d'anses et de becs collectés : on dénombre 143 fragments d'anses, 2 fragments de becs pontés, et 6 de becs pincés sur la totalité de ce groupe d'ateliers. 
109 - Sélection des productions de Corcelles-en-Beaujolais

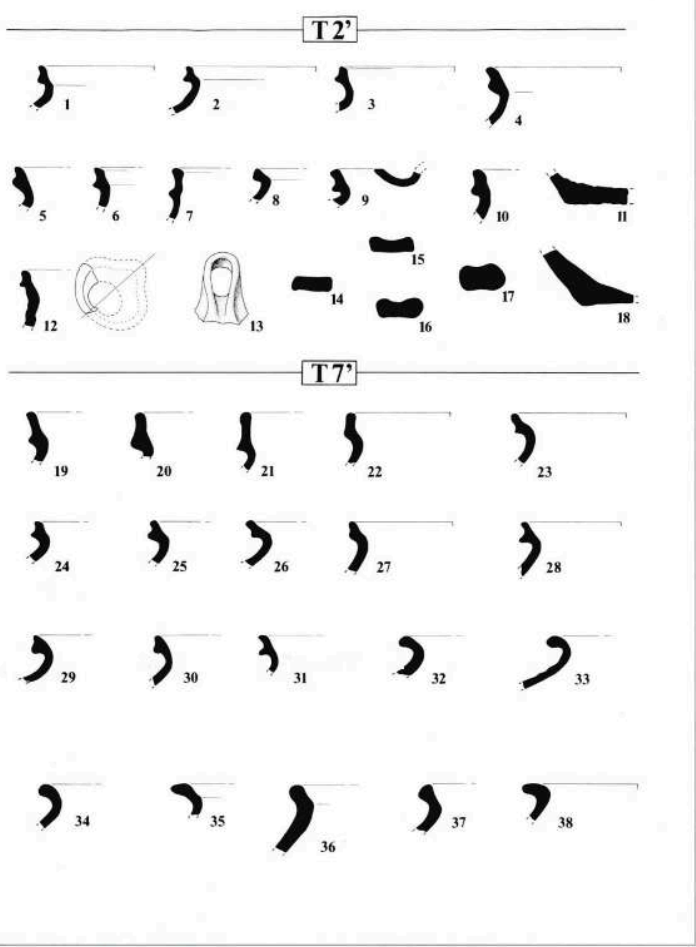

Les Marquisats et Chassagne nord

$147 \mathrm{Au}$ hasard des ramassages, on relève quelques formes rares : quelques exemplaires de couvercles et un petit contingent de larges récipients bas, sortes de bassins à rebord droit plus ou moins évasé, dont l'extrémité présente un épaississement interne ou externe (fig. $110 \mathbf{n}^{\circ} 7$ à 11). Dans un seul cas, la lèvre est nettement évasée (fig. $110 \mathbf{n}^{\circ}$ 14 et 30). Lorsque le diamètre de l'ouverture est connu, il dépasse les $30 \mathrm{~cm}$. 


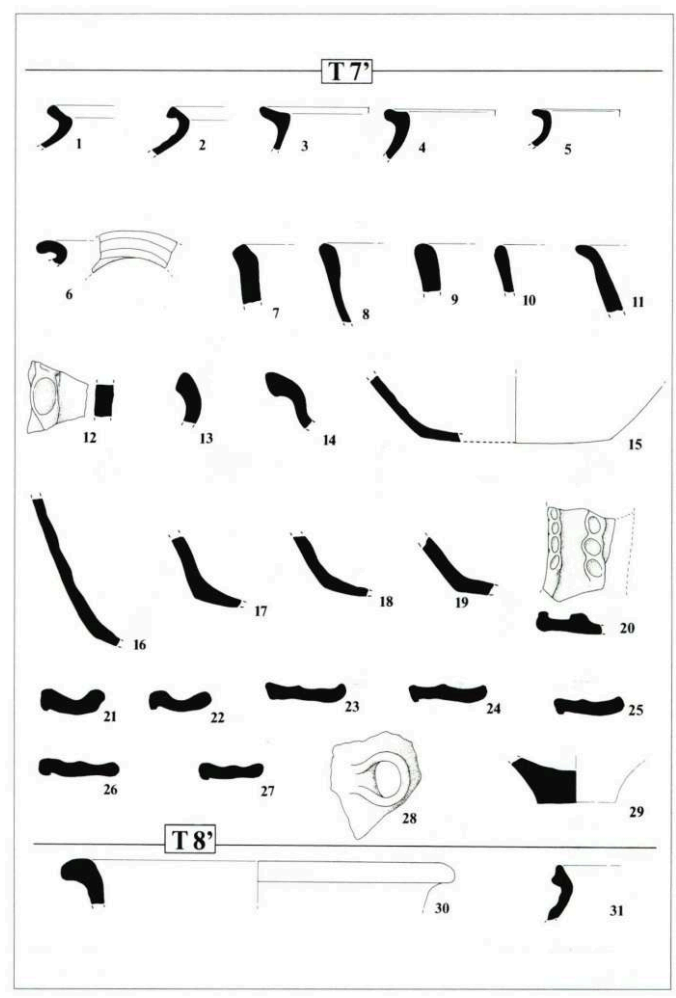

Chassagne nord

Le décor le plus fréquent (peut-on parler de décor?) consiste en cannelures horizontales sur la partie haute des pots ou cruches ( 270 cas répertoriés en tout) ; Les autres décors sont rarissimes (quelques exemples de bandes appliquées digitées et une dizaine de motifs imprimés à la molette). Rapportée au nombre total de tessons de panses identifiables provenant des lots examinés (3950), la pratique du décor paraît fort peu répandue. On ne saurait passer sous silence l'unique tesson recouvert d'une glaçure au plomb, transparente, non couvrante et appliquée sur pâte grise.

Le portrait ainsi dressé évoque les poteries en usage dans la région durant les siècles qui encadrent l'An Mil. Pour compléter et nuancer leur étude, des rapprochements peuvent être établis avec une série de trois ensembles de céramiques géographiquement proches, numériquement importants, bien datés, étudiés récemment selon des méthodes communes et qui jalonnent la période dont il est question : Décines-Charpieu (Rhône), Charavines et Chirens (Isère). On a pu déterminer, grâce à des critères de datation absolue (monnaies, dendrochronologie) et par des comparaisons minutieuses entre les lots, que ceux-ci se placent respectivement à la fin du Xe s., au début du XIe s. et à la deuxième moitié du XIe s. Toutes les caractéristiques des vaisseliers de ces trois sites se retrouvent dans les productions de Corcelles-enBeaujolais : uniformité des pots à cuire et cruches globulaires à fond lenticulaire et lèvre en bandeau ou évasée, décor sommaire et rare, glaçure balbutiante, etc. (Collardelle et Verdel 1993, pp. 189-203; Bouvier et alii 1993, pp. 251-257).

Toutes les caractéristiques certes, mais pas exclusivement celles-ci ; le tableau mérite d'être nuancé pour Corcelles-en-Beaujolais. Les poteries des Marquisats (T2'), qui rentrent tout à fait dans les normes rencontrées à Décines par exemple (formes fermées quasi exclusives, très nette prédominance des rebords en bandeau), pourraient 
indiquer que le ou les ateliers de ce secteur ont fonctionné dès la fin du Xe s. et au XIe s. Mais, l'installation des autres ateliers du premier groupe de Corcelles-en-Beaujolais, aux Serves $\left(\mathrm{T}^{\prime}\right)$ et à Chassagne $\left(\mathrm{T}^{\prime}, \mathrm{T} 8^{\prime}, \mathrm{T} 5^{\prime}\right)$, pourrait être plus précoce. Certains "archaïsmes" plaident en faveur de cette hypothèse: persistance d'une proportion notable de fonds plats (fig. $110 \mathbf{n}^{\circ}$ 29), présence de lèvres en amande en nombre non négligeable, mais aussi de quelques formes ouvertes notamment en $\mathrm{T} 7$ '. Il est difficile d'avancer une date précise, mais on retiendra que ces traits morphologiques évoquent des vaisselles du haut Moyen Âge. A titre de comparaison rappelons que des fonds plats équipent tous les pots ovoïdes (devenus "urnes funéraires") de la nécropole de SaintLaurent-de-Choulans à Lyon datés des VIe - VIIIe s. (Faure-Boucharlat et Reynaud 1986), que les lèvres en amande sont considérées comme héritières des formes de l'Antiquité tardive sur plusieurs sites de la vallée du Rhône (Faure-Boucharlat et alii 1980, p. 436). A contrario, on considère que c'est la disparition des formes ouvertes en terre cuite qui caractérise le vaisselier en usage au cours du Xe s. ${ }^{15}$.

151 C'est en observant les rejets des ateliers du deuxième groupe de Corcelles-en-Beaujolais (T13', T15' - 16' et $\left.\mathrm{T} 17^{\prime}\right)$ que des arguments de chronologie relative se dégagent et permettent éventuellement de caler la production des différentes zones les unes par rapport aux autres. Il faut cependant bien garder à l'esprit la différence quantitative des échantillons observés.

152 - Le deuxième ensemble des poteries produites à Corcelles-en-Beaujolais se distingue en effet assez clairement du précédent (tableaux 10 à 12 et fig. 111), sauf en ce qui concerne les techniques de fabrication: on retrouve partout le même type de pâtes sableuses et friables, la même irrégularité des teintes après cuisson, sans que se dégagent franchement des groupes technologiques. Tout au plus observe-t-on que le taux des poteries, cuites assurément en atmosphère réductrice, est assez constant d'un site à l'autre et globalement inférieur aux cas examinés précédemment (entre 80,8\% et $86,7 \%)$. 


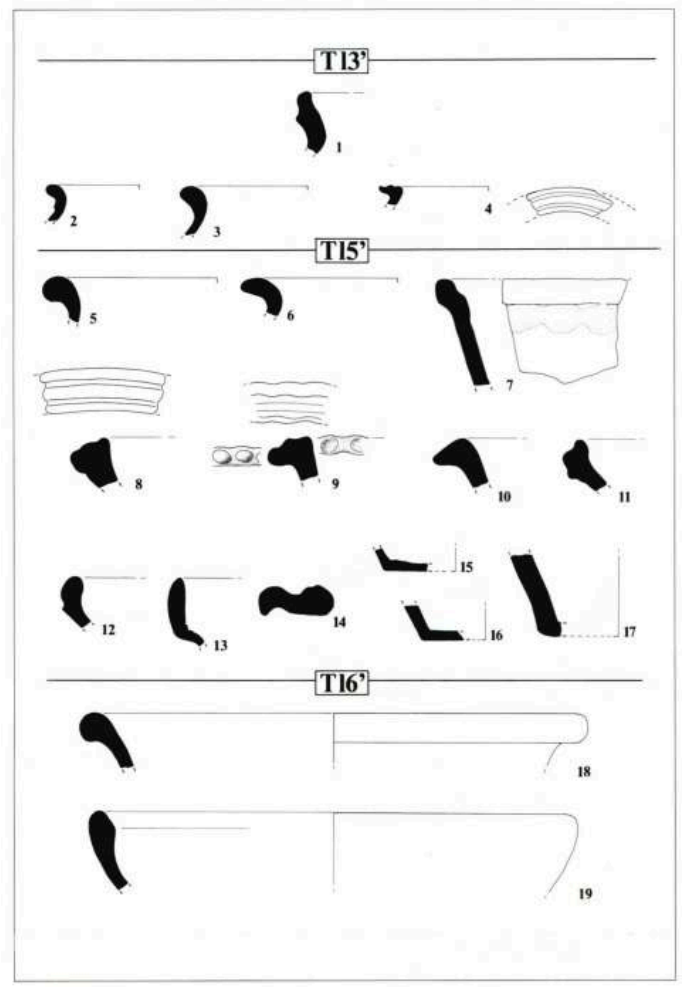

Chantemerle et Champ des Croix

153 Mais les constats les plus marquants sont surtout une forte proportion de formes ouvertes (atteignant 34,8\% en T17', par exemple), l'absence totale de rebords en bandeau sur les trois sites et la très nette prédominance, pour ne pas dire l'exclusivité des fonds plats. Certains exemplaires montrent des traces nettes de décollement à la ficelle (fig. $111 \mathbf{n}^{\circ} 15$ à 17).

Le catalogue des formes peut être en partie reconstitué : pots à fond plat et lèvre évasée (fig. $111 \mathbf{n}^{\circ} 2$ à 6) (diamètre d'ouverture variant entre 11 et $20 \mathrm{~cm}$ ); bols ou jattes à bords rentrant, caréné ou évasé (fig. $\left.111 \mathrm{n}^{\circ} 12,13,18,19\right)$; récipients à rebord en bourrelet épais, plus ou moins travaillé, évoquant des mortiers (fig. $111 \mathbf{n}^{\circ} 8$ à 11); tous ces récipients de formes basses sont dotés d'un fond plat et sont de taille très variable (diamètre connu entre 19 et $30 \mathrm{~cm}$ ).

Un tel répertoire, associé à certaines factures caractéristiques (lèvres en amande, bourrelets surépaissis des probables mortiers, épaisseur des fonds), évoque les céramiques en usage au début du Moyen Âge. Si l'on fait abstraction de la qualité très ordinaire des récipients fabriqués à Corcelles-en-Beaujolais, ceux-ci peuvent être comparés à des ensembles mobiliers relativement bien datés, en milieu rural, comme en milieu urbain. Les références concernent aussi bien la Bourgogne et l'aire alpine que le sud-est de la France, avec des nuances régionales bien sûr (Bourgogne médiévale 1987, pp. 131-137, 220-223 ; CATHMA 1986, pp. 42-49 ; Cattedu 1992 ; Haldimann 1994).

Malgré tout, la datation des premières productions beaujolaises est bien périlleuse en raison de l'état fragmentaire de l'échantillon et surtout des lacunes qui subsistent dans l'appréciation du vaisselier des premiers siècles du Moyen Âge. 
157 Il ne semble pas que l'on puisse tirer argument des techniques de cuisson utilisées par les potiers : les pâtes claires restent majoritaires dans les régions jurassienne et alpine tout au cours du VIIe s., tandis que la proportion semble inversée en Provence à même époque. En revanche, le rapport des formes ouvertes et des formes fermées, reflet approximatif de la répartition entre vaisselle de table et poteries de cuisine, est un critère plus fiable: les formes basses, jattes carénées ou tronconiques, mortiers, assurent la continuité avec le répertoire antique et poursuivent leur carrière du Ve au VIIe s. ; la concurrence probable du bois se fait sentir à partir du VIIIe s., expliquant le hiatus céramologique constaté aux VIIIe et IXe s.

A cet égard, l'ensemble beaujolais pourrait prendre place avant le VIIIe s. en cohérence avec les données recueillies dans les régions limitrophes.

159 Mais le rapprochement s'arrête là, car, paradoxalement, les potiers de Corcelles ne semblent pas avoir fabriqué le pot à cuire par excellence qui se répand à partir du VIe s. en Bourgogne, Lyonnais, Genevois, Jura et vallée du Rhône, héritier lui aussi des ollae de l'Antiquité. Dans les régions citées ces pots ovoïdes se caractérisent par leur lèvre en bourrelet anguleux (rebord en poulie), ancêtre du célèbre et omniprésent rebord en bandeau. A Corcelles, les pots à cuire sont équipés de simples lèvres évasées au profil arrondi. On serait tenté d'y voir un certain archaïsme ou une pratique tout à fait locale, sans écarter les effets du hasard des découvertes; cette observation ne vient pas en contradiction avec la proposition de datation formulée plus haut. En tout cas, l'absence de tout rebord en bandeau confirmerait que les premiers ateliers de Corcelles n'ont pas travaillé au-delà de la fin du VIIe s., ou début du VIIIe s.

\section{Les ateliers de Saint-Étienne-des-Oullières, Blacé et Saint-Georges-de-Reneins}

160 Avec les ateliers de la partie sud de la région étudiée, on découvre une production au répertoire plus varié. Les sites ont en effet livré des lots plus hétérogènes reflétant probablement la permanence des installations sur les mêmes lieux.

161 - On a indiqué plus haut que les ateliers de Saint-Étienne-des-Oullières ne sont pas parmi les plus archéologiquement évidents. Cependant, le cas de T10 et T11, au Botheland, retient l'attention (fig. 112 et tableaux 13 et 14). 
112 - Sélection des productions de Saint-Étienne-des-Oullières (le Botheland) et Saint-Georges-deReneins (les Bruyères)

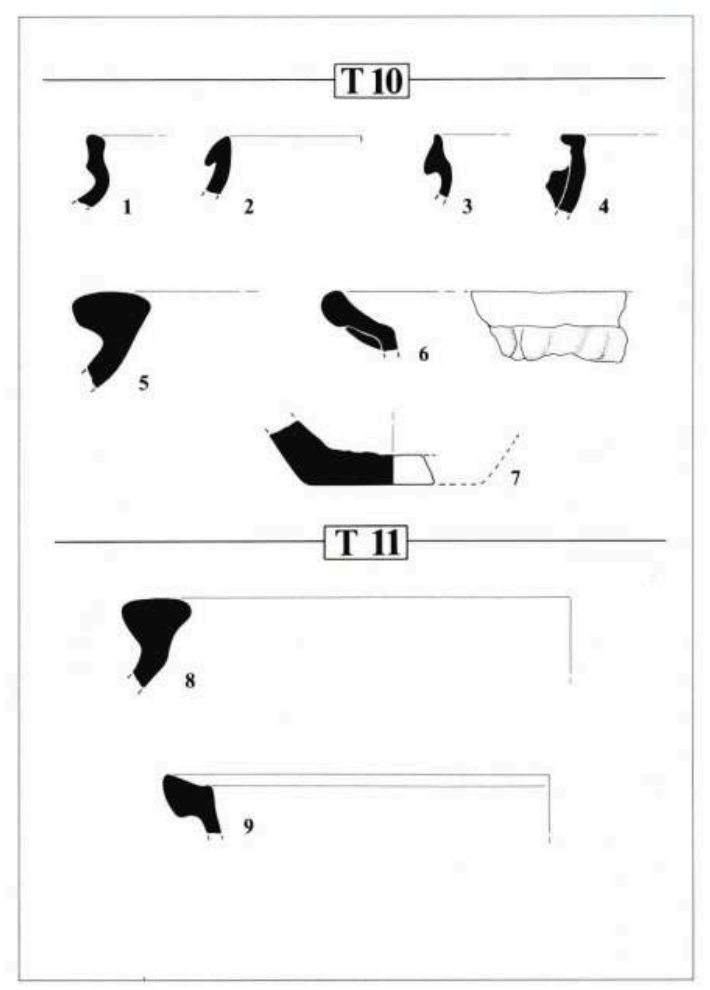

162 Par la prépondérance des pâtes sombres, des formes fermées, du tandem lèvre évasée/ rebord en bandeau, les ateliers du Botheland évoquent le plein Moyen Âge. Mais le pourcentage élevé de fonds plats, associé à l'apparition de formes encore inédites pour les ateliers beaujolais, à savoir la marmite à col haut et anses symétriques (fig. $112 \mathbf{n}^{\circ}$ 4) et le plat ou assiette à rebord en marli (fig. $112 \mathbf{n}^{\circ}$ 9), évoque la fin du Moyen Âge. A ces formes les plus caractéristiques il faut ajouter les gros récipients à rebord en bourrelet, à ouverture large, sortes de bassins ou cuveaux (fig. $112 n^{\circ} 5,6$ et 9). Des décors de bandes rapportées digitées affectent souvent la partie supérieure de leurs parois.

Les exemples sont légion de ces types de récipients dans le répertoire présenté dans la seconde partie de l'ouvrage et sont datés, en sites d'habitats, des XVe - XVIe s. Ces premières descriptions donnent le ton: les autres ateliers confirment que l'artisanat connaît, dans ce secteur, son plein épanouissement à la fin du Moyen Âge.

165 Avant de rejoindre les ateliers regroupés aux hameaux de Blaceret et Marsangues, plus au sud, une rapide observation des tessons recueillis près du bourg de Saint-Étiennedes-Oullières apporte quelques informations complémentaires. Certes, il ne s'agit que d'épandages trop peu significatifs pour fournir des localisations d'ateliers. Néanmoins les relatives concentrations de $\mathrm{T} 3$ et $\mathrm{T} 8$ suggèrent des rejets d'ateliers voisins, non repérables actuellement.

Pour les lots provenant de ces deux zones, deux faits sont à souligner : les pâtes cuites en atmosphère oxydante l'emportent (ce qui ne se produit nulle part ailleurs) et les fonds plats sont très fortement majoritaires. Ces ensembles, qui se distinguent ainsi des autres productions, sont à considérer avec prudence, car non exempts de "pollution" 
au contact des habitats. Toutefois l'hypothèse d'une phase chronologique distincte, peut-être postérieure à celle des ateliers du Botheland, n'est pas à exclure.

167 - Le groupe des ateliers de Blaceret/Marsangues a livré à lui seul presque la moitié des tessons collectés en Beaujolais. C'est dire que l'échantillonnage recueilli offre toutes les garanties d'une réelle représentativité. Il est constitué par le fruit des ramassages opérés en T1, T7, T12 à T29 (fig. 113 à 116 et tableaux 15 à 31).

113 - Sélection des productions de Saint-Georges-de-Reneins (Marsangues)

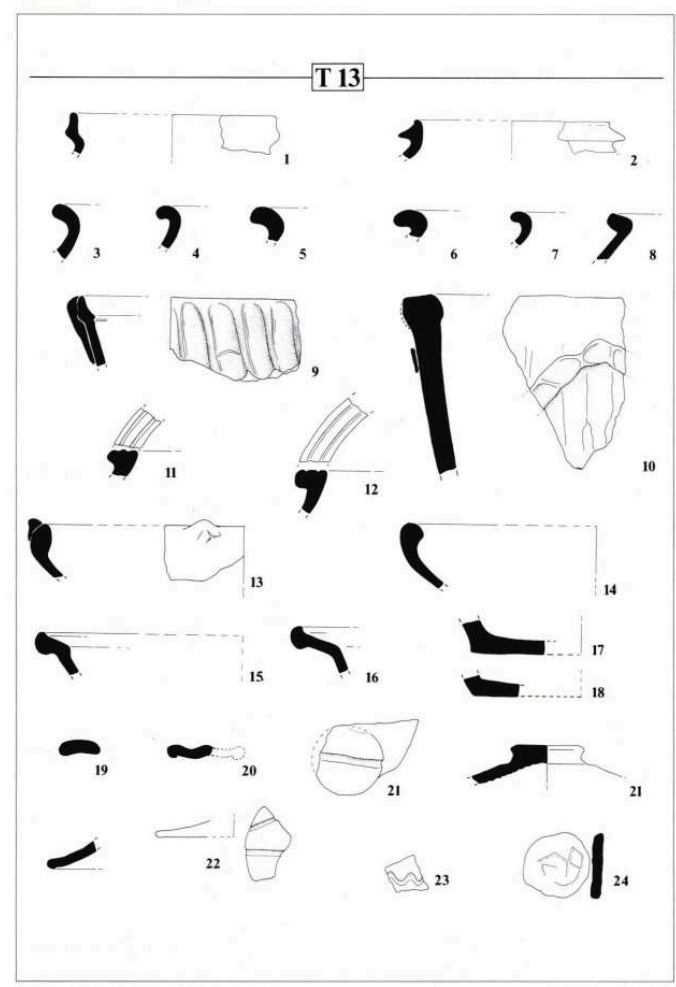

Premier fait marquant : la très nette majorité des pâtes grises, partout supérieure à $92 \%$, si l'on excepte T1 où on n'en dénombre que $73,6 \%$. A noter aussi la prédominance générale des formes fermées, avec cependant des nuances d'un point à l'autre $(84,3 \%$ pour le taux le plus élevé en T23 et seulement 53,2 \% en T29).

L'observation des fonds offre des résultats plus hétérogènes : la proportion relative des deux types, plat et bombé, est très variable d'un point à l'autre et reste un sujet d'étonnement. Cependant, la représentativité des fragments de fonds comptabilisés est contestable. On remarque en effet que, pour le groupe des ateliers de Marsangues, ceux-ci sont étonnamment peu nombreux par rapport au nombre de fragments collectés ( $3 \%$ du total des tessons). Ce taux est inférieur aux décomptes faits pour les sites de Corcelles-en-Beaujolais (par comparaison, les lèvres représentent $18 \%$ du total des tessons). Il faut donc admettre une sous-représentation des fonds qui s'explique par une difficile, voire impossible identification. Par la négative, ceci est une information typologique : on sait par ailleurs que certaines marmites de la fin du Moyen Âge sont équipées de fonds complètement globulaires (aussi dits hémisphériques), dont les fragments ne sont pas discernables de ceux des panses. Or, les rebords et cols de marmites à lèvre rectangulaire sont bien représentés dans ces mêmes lots (jusqu'à $43,4 \%$ des formes fermées en T29). 
Parmi les ouvertures des formes fermées, la lèvre évasée vient partout en tête (entre 70 et $50 \%$ ). Désormais, cette appellation recouvre une réalité assez variée qui comprend la lèvre "classique" avec gorge interne plus ou moins prononcée (fig. $113 \mathrm{n}^{\circ}$ 8, fig. $114 \mathrm{n}^{\circ}$ 3 et 10, fig. $115 \mathrm{n}^{\circ} 7$ et 8), la lèvre rabattue vers le haut de la panse (fig. $114 \mathrm{n}^{\circ} 19$, fig. $116 \mathrm{n}^{\circ} 8$ et 24), la lèvre à double inflexion externe et quelques types hybrides. Ensuite, le rebord en bandeau (fig. $114 n^{\circ} 1$, fig. $115 n^{\circ} 5,6,25$ à 27) et la lèvre à profil rectangulaire associée à un col cylindrique (fig. $\left.115 \mathbf{n}^{\circ} \mathbf{9}, \mathbf{1 0}, \mathbf{1 6}, 28,29\right)$ se disputent la deuxième place avec des scores irréguliers selon les cas.

114 - Sélection des productions de Saint-Georges-de-Reneins (Marsangues)

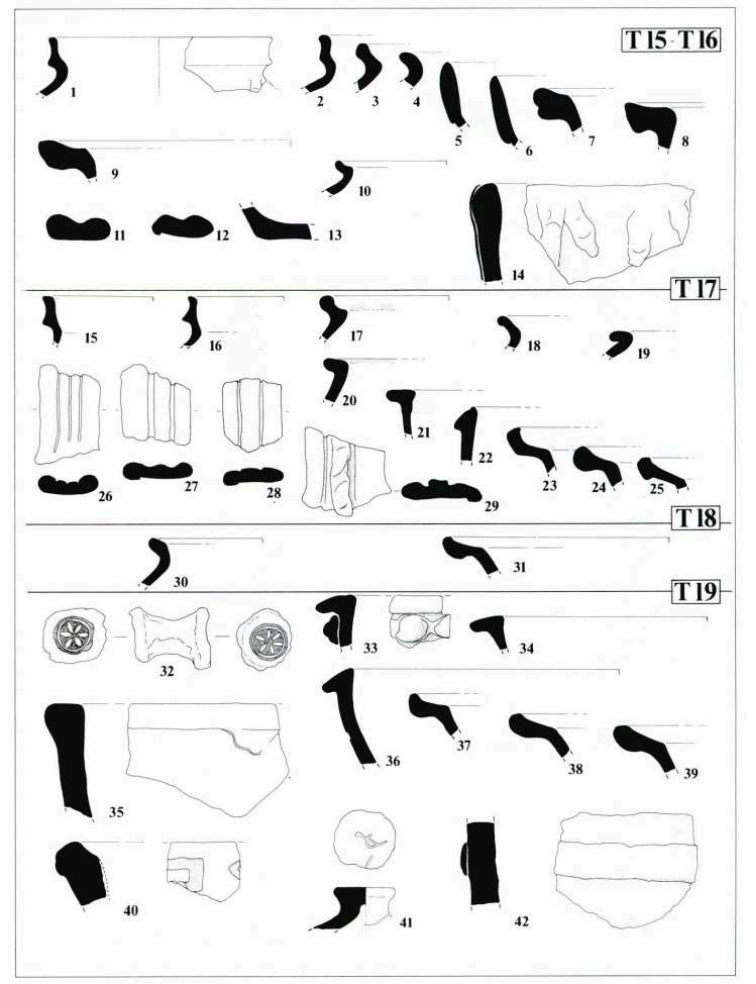

Parmi les rebords de formes ouvertes, le marli est nettement le plus fréquent sur tous les sites (de $92,7 \%$ en T14 à 74,2\% en T7) et les exemplaires collectés montrent une assez grande régularité de taille tandis que le profil est diversifié (inclinaison, traitement de la lèvre en bourrelet ou non...) (fig. $113 \mathrm{n}^{\circ} 15$ et 16, fig. $114 \mathrm{n}^{\circ} 37$ à 39, fig. $114 \mathrm{n}^{\circ} 37$ à 39, fig. $116 \mathrm{n}^{\circ}$ 31, 32). En revanche, les récipients à rebord droit sont plus difficiles à cerner. Quant au gabarit, il semble que, globalement les "petites" tailles (diamètre inférieur ou égal à $25 \mathrm{~cm}$ ) prédominent : les lèvres sont simples, à extrémité biseautée (fig. $114 \mathrm{n}^{\circ} 5$ et 6) ou arrondies dotées d'un bourrelet interne ou externe (fig. $113 \mathrm{n}^{\circ} 13$ et 14 , fig. $114 \mathrm{n}^{\circ} 34$ et 36 ). Mais on observe des cas particuliers comme le rebord aplati horizontal (fig. $113 \mathrm{n}^{\circ} \mathbf{1 1}, \mathbf{1 2}$, fig. $115 \mathrm{n}^{\circ} \mathbf{1 1 , 1 2 )}$ ).

Les rebords des "grands" récipients (diamètre supérieur à $30 \mathrm{~cm}$ ) offrent des profils variés dont la typologie reste floue eu égard à la grossièreté de la facture. Verticaux ou obliques ils sont souvent soulignés par des applications ornées au doigt (bandes digitées classiques ou grosses cannelures verticales) (fig. $113 \mathrm{n}^{\circ} 9$ et 10, fig. $115 \mathrm{n}^{\circ} 14,15,20$, 36 et fig. $116 n^{\circ} 41,42$ ). 
En complément de ces formes de base, les ramassages ont également livré des becs verseurs, essentiellement des becs pontés associés à des lèvres évasées; $13 \%$ des fragments de lèvres sont ainsi équipés de becs. Les éléments de préhension sont avant tout des anses plates classées en quatre catégories : les anses en simple ruban (fig. 113 $n^{\circ}$ 19), les anses larges à cannelures verticales (fig. $114 n^{\circ} 26$ à 29), les anses étroites et épaisses constituées de deux parties accolées, dites bifides. (fig. $\left.116 \mathbf{n}^{\circ} \mathbf{4 3}, \mathbf{4 4}\right)$ et enfin les anses à section cylindrique et profil coudé. Les anses larges sont souvent ornées d'une bande médiane repoussée au doigt. Les fragments d'anses représentent $8 \%$ de l'ensemble de l'échantillon, ce qui est considérable. A titre comparatif, à Corcelles-en-Beaujolais, les anses atteignent à peine $2 \%$.

On dispose aussi, mais en faible nombre (quelques dizaines), de tenons horizontaux (fig. $115 \mathrm{n}^{\circ}$ 35) ou verticaux et d'oreilles. Des manches creux (quelques dizaines également) complètent la panoplie (fig. $115 \mathrm{n}^{\circ} 38$ et fig. $116 \mathrm{n}^{\circ}$ 49). Encore plus rares sont les fragments d'anses à section ronde, dites "en panier" (fig. $115 \mathrm{n}^{\circ} 4$ et fig. 116 $\mathbf{n}^{\circ} 46$ à 48).

Malgré la marge d'incertitude qui résulte de la fragmentation des pièces, le répertoire des ateliers de Marsangues se laisse assez bien reconstituer pour peu que l'on ait recours aux récipients comparables provenant de sites d'utilisation, notamment de Lyon (on se référera donc fréquemment à la typologie présentée dans la seconde partie de l'ouvrage). Une évidence s'impose: les formes répertoriées ne sont pas toutes contemporaines.

115 - Sélection des productions de Saint-Georges-de-Reneins (Marsangues)

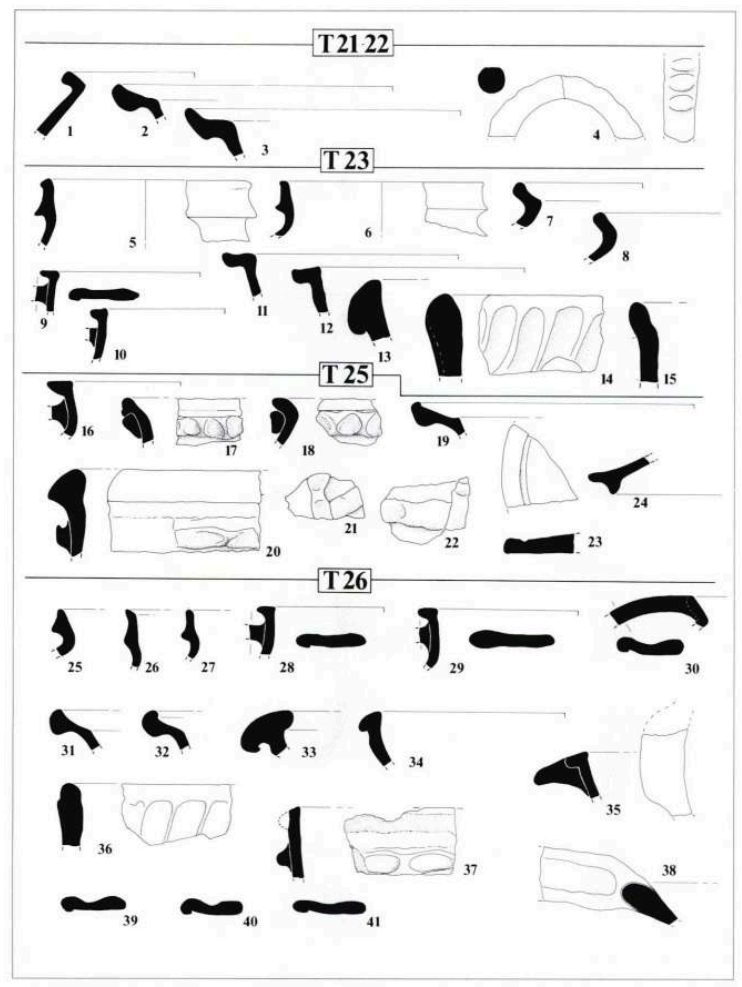

Les productions les plus anciennes sont constituées par :

- les pots ou oules à rebord en bandeau (type 1371)

- les pots ou oules à lèvres évasées 
- les cruches à bec ponté (type 11051)

- les pots de transports, oules à lèvres en bandeau munie d'une anse de panier (type 10112).

Ces vases d'usage polyvalent, très probablement munis de fonds bombés (lenticulaires), sont encore empreints d'une forte tradition médiévale. Mais des observations récentes sur plusieurs sites lyonnais ont montré que ces quatre formes sont encore présentes parmi les vaisselles communes de la fin du XIIe et de la première moitié du XIIIe s. D'ailleurs, elles coexistent toujours. Au milieu du XIIIe s., on note la disparition des cruches à bec ponté ; celle des rebords en bandeau semble définitive à la fin du XIIIe s. et les pots à cuire globulaires sont tout aussi définitivement supplantés par les marmites à la même période (cf. infra, 2ème partie, synthèse).

Aussi, la fabrication de marmites, bien attestée à Marsangues, pourrait correspondre à l'activité des ateliers à la fin du XIIIe s. et au-delà, jusqu'au XVe s. En effet, les premières marmites apparaissent à Anse comme à Lyon dans la deuxième moitié du XIIIe s. On peut leur comparer quelques exemplaires de Marsangues (fig. $115 \mathbf{n}^{\circ} \mathbf{3 0}$ ) : forme globulaire, ouverture évasée sans col distinct, anses symétriques plates rattachées sur la lèvre (Maccari-Poisson 1994, pp. 106-107). Dans les classifications présentées dans les tableaux, les lèvres de ces marmites sont réunies dans la même rubrique que celles des simples pots à cuire mentionnés ci-dessus. Ce qui expliquerait la sur-représentation des lèvres évasées. Mais les ateliers de Marsangues ont produit en très grande quantité, et de façon stéréotypée, des marmites d'un type bien différent, tenues dans la région pour appartenir à la fin du Moyen Âge (type 1441).

Dans les ramassages, elles apparaissent sous la forme des lèvres dites rectangulaires. Mais ces récipients sont suffisamment connus pour qu'on puisse restituer leur profil : récipient globulaire, à col haut, plus ou moins évasé, muni de deux anses en ruban dont l'attache supérieure est placée sur le col (fig. $115 \mathbf{n}^{\circ}$ 29). On a noté plus haut la forte représentation des fragments d'anses rubanées. Elle trouve son explication ici. On sait que ces marmites sont très répandues dans la région au XVe, voire au XVIe s. Il est difficile de dire quand le type achevé se met en place. Des exemplaires lyonnais du XIVe s. s'en rapprochent beaucoup (Maccari-Poisson 1994, pp. 106-107).

La fabrication de marmites à anses coudées, adaptation du type précédent, est aussi attestée à Marsangues par quelques fragments de ces anses très caractéristiques (type 1311). Certes, cette production paraitt marginale par rapport aux marmites classiques, mais elle a l'avantage d'être bien datée. Dans les dépotoirs lyonnais, les marmites à anses coudées, à fond plat ou lenticulaire, constituent l'essentiel de la vaisselle culinaire à la fin du XVe et au XVIe s. C'est probablement au décor de leurs anses qu'était destiné le poinçon à rosace découvert en T19 (fig. $114 \mathbf{n}^{\circ}$ 32). On a relevé dans la région plusieurs exemples d'estampilles de cette sorte (Maccari-Poisson 1994, p. 116 et fig. 98).

181 La grande quantité de formes ouvertes fabriquées à Marsangues renforce l'hypothèse d'une longue période d'activité. Trois catégories se distinguent, comprenant chacune de nombreuses variantes.

182 - La production de plats ou assiettes creuses sans couverte semble une spécialité locale. On trouve peu d'éléments de comparaison en sites d'habitat où les assiettes sont généralement glaçurées. A Marsangues, elles ne sont qu'exceptionnellement en pâte rouge et un seul exemplaire glaçuré a été retrouvé. Les assiettes à marli (type 3311) 
n'apparaissent avant la fin du XVe s. sur les tables régionales et ne semblent vraiment populaires qu'au XVIe s.

183 - Les jattes de Marsangues offrent des formes variées. Les plus classiques, comparables à celles trouvées en habitat, sont munies d'un rebord plat presque horizontal couronnant des parois peu évasées, droites ou concaves (type 3221). Elles peuvent recevoir des anses ou des tenons de préhension. Leur fond est plat. Les petites jattes à profil courbe et lèvre arrondie rentrante munies ou non de tenons (fig. $\left.113 \mathrm{n}^{\circ} \mathbf{1 3}, \mathbf{1 4}\right)$ font penser à des écuelles. Des exemplaires de Marsangues (fig. $115 \mathbf{n}^{\circ} \mathbf{1 1 , 1 2}$ ) se rapprochent des écuelles en pâte grise provenant d'un dépotoir lyonnais du XVe s., (Maccari-Poisson 1988, fig. 10) : profil tronconique, fond plat, rebord étiré en collerette.

184 - Les bassins avec leurs parois épaisses, leurs rebords grossiers, renforcés de bandes de terre modelées évoquent des récipients à usage non culinaire (hygiène, lessive). C'est à ces gros récipients que semble convenir le fort contingent de grosses anses cannelées collecté dans le secteur de Marsangues. Les fouilles d'habitat n'ont pas, jusque-là, livré de tels exemplaires. On manque donc d'éléments de comparaison.

185 D'une manière générale, ces jattes et bassins n'équipent régulièrement les cuisines régionales qu'à partir du XVe s., si l'on excepte quelques cas isolés au cours des siècles précédents.

186 Les artisans potiers de Marsangues ont également eu le souci d'attirer l'intérêt des consommateurs par quelques formes rares ou par des effets techniques et décoratifs :

187 - des chauffe-plats à tenons de calage verticaux, piédouche et manche creux. Ceux-ci se rapprochent du type 7111, mais qui, lui, est muni d'anses. Cet accessoire de la table en pâte grise est assez précisément daté de la fin du XVIe s. (Becker et alii 1989, fig. 29 n 33).

188 - des couvercles rainurés, probablement pour caler une ficelle de fixation (fig. $113 \mathbf{n}^{\circ}$ 21,22, fig. $\left.115 n^{\circ} 23,24\right)$.

189 - des récipients à fond muni de petits pieds (marmites probablement) imitant, comme les anses coudées, les formes des chaudrons métalliques.

190 - des passoires ou pots à châtaignes (fig. $116 \mathbf{n}^{\circ}$ 9).

191 - quelques pièces agrémentées de taches de glaçure. Il se trouve que la plupart des lèvres concernées sont des lèvres évasées de petit gabarit. Un peu moins d'une centaine de tessons ont été dénombrés. Le revêtement plombifère est appliqué très irrégulièrement sur pâte grise, beige ou rouge (fig. $114 \mathrm{n}^{\circ} 17$ et 20, fig. $116 \mathrm{n}^{\circ} 5$ et 13).

192 - quelques plats ou assiettes en pâte rouge à surface lissée, rares cas où les productions beaujolaises se départissent d'un genre strictement ordinaire. 


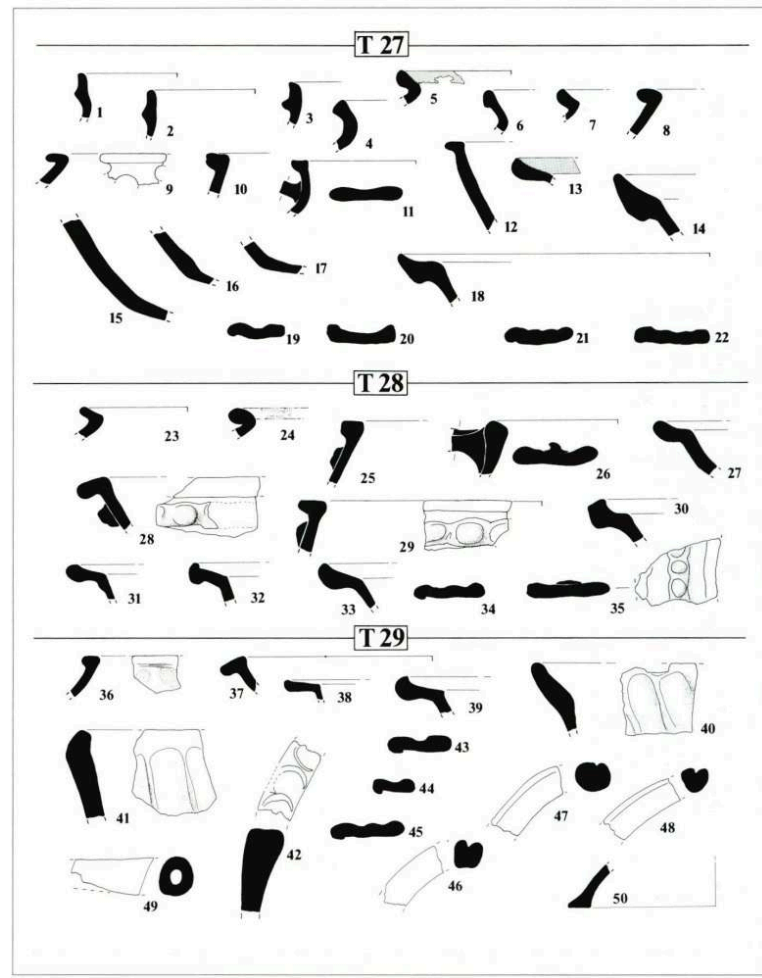

193 Nul doute que les potiers installés dans les hameaux de Marsangues, de Blaceret et de Botheland se livraient, à la fin du Moyen Âge, à une production de masse des vaisselles culinaires et de table les plus populaires. Le parallèle assez précis qui existe entre ces fabrications beaujolaise et celles de Meillonnas-Treffort (cf. supra) en est une confirmation. On retrouve de part et d'autre les mêmes formes caractéristiques en pâte grise (marmites à col haut, à anses rubanées ou coudées, assiettes et plats à marli, jattes, écuelles). A Meillonnas, il s'agit des dernières productions communes avant le lancement du service vert, fin XVe, début XVIe s.

Grâce aux nombreuses comparaisons régionales, on dispose donc d'arguments relativement solides pour dater les ateliers du groupe de Saint-Etienne-des-Oullières et en particulier ceux du hameau de Marsangues. Ceux-ci pourraient avoir été le cœur de l'artisanat local, depuis la fin du XIIe s., au moins, jusqu'au milieu du XVIe s. On ne peut exclure totalement que leur mise en place ait été un peu plus précoce et que leur déclin soit intervenu au début du XVIIe s.

La continuité de l'activité des ateliers durant toute cette période n'est pas totalement démontrée, mais reste probable. On manque en effet d'informations chronologiques pour le XIVe s. et le début du XVe s., car bizarrement la céramique de cette époque reste assez mal connue dans la région. En outre, sur ces sites de production de poteries communes, on est privé des points de repère que seraient les vaisselles de table plus luxueuses, plus élaborées et donc mieux datées. 


\section{Les phases d'activité des ateliers du Beaujolais}

197 À partir de l'inventaire précis des rejets d'ateliers se dégage une connaissance assez précise des terres cuites fabriquées en Beaujolais. On retire la certitude d'une longue tradition artisanale depuis les premiers siècles du Moyen Âge jusqu'à l'aube des temps modernes. Tout au long de ce millénaire, la localisation des ateliers varie; on peut désormais tenter de dessiner les grands traits du paysage artisanal (fig. 117).

\section{7 - Les phases d'activité des ateliers du Beaujolais}

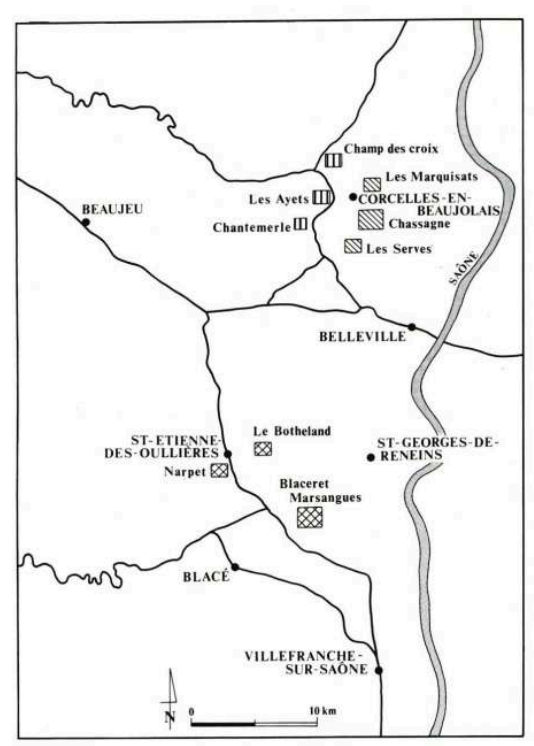

Dater avec exactitude l'arrivée des premiers potiers est chose délicate. L'extrême lenteur de l'évolution des vaisselles en usage durant tout le haut Moyen Âge invite à la plus grande prudence et les propositions formulées ici gagneraient évidemment à être vérifiées à l'occasion d'une enquête archéologique plus poussée. En tout cas, les ateliers les plus précoces s'installent à Corcelles-en-Beaujolais, à Chantemerle (T13'), au Champ des Croix (T15' - T16') et aux Ayets (T17'). Ils pourraient avoir fonctionné dès les VIe VIIe s. Il est encore plus difficile de déterminer leur durée d'activité à partir des échantillons collectés. L'absence de formes caractéristiques du vaisselier médiéval (fond bombé, lèvre en bandeau) invite à ne pas dépasser le VIIIe $s$.

Les premiers ateliers sont distants les uns des autres et isolés des zones d'habitats traditionnels. Les vestiges de surface sont assez circonscrits et moins denses que partout ailleurs; en outre, les indices géophysiques, relativement discrets, confortent l'image d'officines de petite taille, probablement précaires et actuellement très érodées.

En revanche, les ateliers qui leur succèdent, en d'autres lieux, laissent une toute autre impression et semblent témoigner d'un deuxième souffle de l'artisanat céramique. Aux Marquisats (T2'), aux Serves (T6') et à Chassagne (T7', $\left.\mathrm{T} 8^{\prime}, \mathrm{T} 5^{\prime}\right)$, on pourrait avoir affaire 
à des regroupements d'ateliers fort actifs. Les données archéologiques et géophysiques sont significatives, notamment aux Serves. Sans grand risque d'erreur, on peut placer aux Xe et XIe s. la phase la plus florissante de leur travail. Tous ces sites ne sont peutêtre pas exactement contemporains. On a vu plus haut des nuances typologiques notables dans les rejets examinés. La grande homogénéité reconnue dans les productions de T2' pourrait indiquer que les ateliers des Marquisats ont eu un destin relativement bref (fin Xe - début XIe s.). A l'inverse le ou les ateliers situés au nord de Chassagne (T7') auraient fonctionné plus longtemps, en débutant plus tôt, peut-être fin IXe - début Xe s. Il en va de même pour T6' aux Serves. Par ailleurs, aucun argument typologique solide n'autorise à exclure que le secteur de Chassagne ait encore abrité des officines au début du XIIe s.

201 Les ateliers de cette deuxième phase de l'histoire de l'artisanat se rapprochent de la Saône et, semble-t-il, des zones habitées. Les causes de ce déplacement ne sont actuellement pas connues. Plusieurs facteurs ont pu y contribuer : l'accès plus aisé aux matières premières tirées de la terrasse alluviale, ainsi qu'à la voie d'eau pour la commercialisation des produits. Dire s'il y a rupture ou continuité de la production entre les deux phases décrites ci-dessus serait bien imprudent dans l'état actuel des connaissances. Objectivement, le maillon manquant, à savoir la période carolingienne, est difficile à cerner dans les tessons collectés, mais aussi plus généralement à travers la céramique régionale.

Sans aucun doute, après le déclin des ateliers de Corcelles-en-Beaujolais, la relève est assurée par les artisans installés à Saint-Étienne-des-Oullières, à Blacé et à SaintGeorges-de-Reneins, dans des conditions assez proches de celles de leurs aînés. L'implantation est durable, particulièrement aux hameaux de Blaceret et de Marsangues qui montrent les traces d'une forte concentration d'officines. Depuis le milieu du XIIe s. probablement, à coup sûr à la fin de ce siècle, les artisans poursuivent les fabrications traditionnelles de vaisselle commune en adaptant, avec les matériaux grossiers dont ils disposent, l'offre à la demande de plus en plus diversifiée des consommateurs. Cette troisième et ultime phase des ateliers beaujolais, actuellement connus, est encore florissante au XVe s. et sans doute au XVIe s. On dispose de quelques indices typologiques pour envisager qu'elle se prolonge au début du XVIIe s.

E. F.-B.

\section{Conclusion}

Avec ces trois temps forts, se dessine la réalité mouvante de l'artisanat potier dans la petite région étudiée ici.

Les phénomènes observés en Beaujolais ne sont pas isolés et s'inscrivent dans une forte tradition propre au Val de Saône, dont les témoignages contemporains ou plus récents sont nombreux. On peut imaginer que le déclin des ateliers, dont l'histoire vient d'être retracée, est lié à la concurrence d'autres ateliers, mieux placés par rapport à la Saône, disposant aussi d'argiles de meilleure qualité et ainsi mieux armés pour s'adapter à l'évolution du marché, et en particulier, à la nécessité de produire des récipients à couverte glaçurée. A ce titre, les ateliers tout proches du Méconnais se sont fait, au cours du XVIIe s., au plus tard, une spécialité des belles vaisselles de table aux décors 
d'engobes. Sont-ce là, les concurrents que la communauté potière de Marsangues avait à redouter, enlisée qu'elle était dans des techniques de production d'un autre âge ?

L'aspect le plus intéressant des découvertes faites en Beaujolais est d'offrir un pendant "méridional" aux célèbres ateliers de Sevrey en Chalonnais, reconnus et étudiés depuis longtemps; ainsi se font jour d'autres possibilités quant à l'approvisionnement des marchés de la vallée de la Saône, y compris jusqu'à Lyon. En outre, les résultats présentés ici ne sont que provisoires, puisque d'autres secteurs "névralgiques" sont signalés aux abords de la zone étudiée.

Quoi qu'il en soit, les productions de Sevrey et celles du Beaujolais présentent de grandes similitudes et les installations semblent avoir connu des destinées très proches (Renimel 1974), constatation qui renforce la notion d'une tradition régionale. Il est donc tout à fait indiqué de conclure le travail présenté ici par un parallèle appuyé entre ces deux concentrations d'ateliers distantes d'une cinquantaine de kilomètres.

La chronologie des ateliers de Sevrey repose davantage sur l'examen des collections trouvées hors contexte artisanal (dragages de la Saône) que sur l'analyse systématique d'un important échantillonnage de rejets d'ateliers. Elle est donc à considérer dans ses grandes lignes; mais elle offre l'avantage inestimable d'offrir un catalogue de formes complètes, auxquelles raccrocher les découvertes fragmentaires. Les connaissances reposent également sur une série de textes qui émaillent la vie d'une communauté artisanale particulièrement féconde. Ces atouts, dont on pourrait rêver pour le Beaujolais, peuvent être exploités pour compléter l'image encore trop partielle à laquelle on est parvenu.

Les premières manifestations du travail de la poterie à Sevrey sont datées du IXe s. Les produits de cette époque (groupe I) ne trouvent pas de correspondants en Beaujolais. Ils présentent des particularités locales (carènes, décors de molette élaborés, gobelets), empreinte encore sensible de la tradition burgonde (Renimel 1984, fig. 13 à 16 et 18). Il est vrai que des indices nets pour l'époque carolingienne font encore défaut en zone beaujolaise. En revanche, les productions, datées à Sevrey des Xe et XIe s. (groupe II) peuvent être rapprochées de celles des ateliers beaujolais de la deuxième phase (Renimel 1974, fig. 21 à 26). Mais c'est avec les récipients des groupes III et IV de Sevrey (XIIIe - XVe s.) que les analogies sont les plus fortes (Renimel 1974, fig. 27 à 34). On retrouve de part et d'autre les formes caractéristiques de marmites à anses coudées, de gros bassins aux décors digités, de chauffe-plats ou réchauds à manche. Les poêlons signalés à Sevrey sont apparemment absents en secteur beaujolais où l'on n'a pas non plus la preuve de la fabrication de cruches de table à lèvre en bandeau pincé, très nombreuses dans le groupe IV de Sevrey. A l'inverse, les artisans de Sevrey semblent ignorer l'ouïe de transport à anse de panier comme la marmite à col haut et anses plates. Et surtout, les plats et assiettes à marli restent une spécialité beaujolaise.

210 Autre nuance à signaler entre les deux régions, cette fois-ci en matière de méthode de fabrication: l'évolution technologique sensible à Sevrey entre le IXe et le XVe s. n'est absolument pas remarquée en Beaujolais. On a vu plus haut que l'on a bien du mal parfois à distinguer les modes de cuisson et que toutes les couleurs de pâtes sont présentes tout le temps. On ne relève pas non plus les signes d'une augmentation du souci de qualité de la part des potiers. Les argiles restent désespérément grossières, même lorsqu'il s'agit de fabriquer plats et assiettes.

Les données textuelles font revivre les artisans de Sevrey. On peut imaginer que leurs confrères beaujolais connaissaient une situation comparable à la leur, et l'on se 
permettra d'extrapoler en attendant qu'une enquête d'archives, si elle est fructueuse, vienne fournir les informations qui font actuellement défaut. Des faits relatés par les auteurs (Armand-Caillat 1946; Renimel 1974), il faut retenir l'expansion économique des XIIIe et XIVe s. et le déclin amorcé au XVIe s. Des 40 à 50 ateliers recensés pour les XVe - XVIe s., il n'en reste que cinq à la fin du XVIIIIe s.

212 Amorcé plus tôt dans le Moyen Âge, mais achevé aussi plus tôt, semble-t-il, le phénomène artisanal révélé en Beaujolais n'en reste pas moins une réplique du cas chalonnais. Le rapprochement entre les deux secteurs ouvre des pistes de recherche intéressantes: confronter de plus près les répertoires et les chronologies établis, déterminer leur aire de diffusion respective, par exemple.

213 Le travail présenté ici est une première étape d'une recherche à poursuivre. Il démontre combien des prospections systématiques peuvent apporter de renseignements en pareilles circonstances. L'exploitation tout aussi systématique des résultats des ramassages de surface contribue à dessiner le paysage artisanal avec une relative précision. Certes, les questions en suspens ne sauraient faire l'économie d'une enquête de terrain plus poussée: préciser, voire réviser, les localisations et les datations proposées, compléter le répertoire des fabrications, observer l'évolution des structures de cuisson sur une longue durée, retrouver l'organisation interne des ateliers, rechercher le point d'embarquement des produits sur la Saône... Parallèlement, l'enquête d'archives pourrait vérifier si une communauté de potiers aussi active n'a laissé aucun souvenir dans les sources écrites.

E. F.-B.

\section{NOTES}

1. Nous remercions ici Louis Bonnamour pour les informations qu'il nous a fournies et son accueil au musée Denon de Chalon-sur-Saône.

2. Quelques pièces médiévales complètes sont conservées à Saint-Georges-de-Reneins. Leur origine exacte n'est malheureusement pas mentionnée. Plusieurs pièces sont intentionnellement perforées sur la panse. Ces perforations pourraient correspondre à la sélection opérée au moment du chargement des poteries sur la Saône. Cette pratique a été relevée par L. Bonnamour lors des fouilles subaquatiques du Port-Guillot à Lux (Saône-et-Loire), point d'embarquement présumé des produits fabriqués à Sevrey (Bonnamour 1985-86, pp. 55-56).

3. Nous tenons à remercier très sincèrement Roland Convert et Nathalie Girard pour leurs précieuses informations et leur aide efficace et désintéressée lors du lancement du programme de travail en Beaujolais.

4. Contrairement à ce que nous pensions au départ, le toponyme "Oullières", associé à SaintÉtienne, ne serait pas révélateur d'une tradition artisanale, mais plutôt des techniques de mise en culture : forme de labours profonds.

5. Informations fournies par J.-O. Guilhot que nous remercions bien sincèrement.

6. Présentation succincte établie à partir des notices des cartes géologiques de la France au 1/50 000, BRGM, Paris : Beaujeu (649), Belleville (650), Amplepuis (673) et Villefranche-sur-Saône (674). 
7. La cartographie utilise des trames de différente densité (trois valeurs de gris) qui restituent la proportion de l'échantillon collecté par rapport à la surface prospectée. Ici, par commodité les rapports ont été multipliés par 10. La plus faible tranche de valeur se situe entre 0 et 1 (épandages diffus); la tranche moyenne entre 1 et 3 (épandage dense); la tranche la plus forte, au-dessus de 3 (fortes concentrations de tessons).

8. Les mesures électromagnétiques ont été réalisées lors de deux campagnes de deux jours par G. Ducomet (section de prospections archéologiques, Centre de recherches géophysiques de Garchy, CNRS).

9. Toutes les personnes interrogées ont facilité et autorisé les prospections, même lorsque cellesci se déroulaient dans les parcelles attenantes aux habitations. Que tous trouvent ici l'expression de notre reconnaissance.

10. Les découvertes faites à Pizay n'ont pas pu être exploitées en raison du trop grand remaniement du terrain à cet endroit. On a pu cependant noter le remploi en grand nombre, dans les murs d'une maison fortifiée, de grosses briques portant les traces d'un feu intense (surface calcinée ou vitrifiée).

11. Pour l'échelle de valeur des trames symbolisant les zonages, voir note 7.

12. Des mesures faites sur des échantillons de terre de surface prélevés sur certaines parcelles prospectées confirment la faible susceptibilité magnétique des sols. Les mêmes échantillons ont été exposés à la chaleur d'un foyer, ce qui a permis de constater que la susceptibilité n'augmentait que très faiblement. Cette dernière expérience n'a bien sûr aucune valeur scientifique; elle appelle cependant une remarque d'ordre comparatif: après chauffage des échantillons, leur susceptibilité magnétique est encore inférieure à la susceptibilité magnétique naturelle d'une terre de surface prise dans un champ labouré à Garchy (Nièvre). Le rôle passif des couches superficielles amène à considérer que l'appareil ne répondra qu'à l'aplomb d'une structure, d'une poche de matériaux chauffés ou cuits. Les anomalies correspondantes seront nécessairement très localisées; de l'importance, de l'état de conservation des vestiges, dépendra une susceptibilité magnétique plus ou moins forte.

13. Principe de lecture des cartes en densité de gris : ces cartes ne sont qu'une variante de représentation graphique. Les minima de susceptibilité magnétique apparaissent en blanc, les maxima en noir. Se reporter à l'échelle des gris qui accompagne chaque carte. Dans tous les cas, le zéro a été calé à - 70. La valeur - 70 (niveau blanc) qui apparaît sur l'échelle des gris correspond donc à une susceptibilité nulle. Les contraintes techniques du système d'impression font que l'échelle est approximative et diffère légèrement dans les deux sens du plan.

14. En effet, la chrono-typologie établie pour les ateliers de Sevrey repose en grande partie sur l'étude des collections issues des dragages de la Saône sur laquelle les produits étaient transportés : le matériel recueilli en prospection peut ainsi être sans difficulté rapporté à des formes complètes.

15. On ne peut que regretter que le secteur beaujolais se situe en dehors de l'aire de diffusion des fameux vases à fond marqué, précieux indices chronologiques pour le Lyonnais et le Dauphiné et qui font, hélas, défaut ici. 


\section{Synthèse}

\section{Élise Faure-Boucharlat et Sophie Savay-Guerraz}

$1 \quad$ Les recherches sur les lieux de production de terre cuite ne sont pas nouvelles dans la région Rhône-Alpes. Les premières enquêtes sur ce sujet abordaient de larges secteurs en s'appuyant, d'une part, sur la toponymie et, d'autre part sur les sources écrites postrévolutionnaires, en particulier les enquêtes de commodo et incomodo (série $\mathrm{M}$ des archives). Cette approche, par force assez globale, s'intéressa surtout aux départements du Rhône et de l'Isère (Chemorin 1984; Faure-Boucharlat 1980). Quelques traits généraux pouvaient être dégagés quant à la répartition des ateliers. Néanmoins, ce survol régional ne révélait guère de concentrations d'ateliers céramiques, susceptibles de se distinguer par la pérennité des installations.

2 Ces premiers résultats se devaient d'être approfondis en concentrant les efforts sur des aires géographiques plus limitées en vue d'enquêtes micro-régionales. Le choix des zones étudiées répond à des stimulations d'ordre divers dont le hasard n'est pas absent. Mais c'est toujours la recherche de l'origine de produits rencontrés en grand nombre, dans les sites où ils furent utilisés, qui est le point de départ de la démarche dans les trois cas présentés dans ce volume. En effet, les débouchés commerciaux offerts par les villes (Lyon, Vienne, Grenoble...) apparaissent le point de convergence de vaisselles bien caractéristique comme les désormais célèbres service vert et service jaune.

3 Si la découverte d'une concentration d'ateliers médiévaux dans le Beaujolais a été aidée par des trouvailles fortuites, l'étude de ce secteur entrait cependant dans la logique d'ensemble : l'approvisionnement de Lyon en vaisselle commune depuis les ateliers du Val de Saône.

Guidés, en outre, par l'évidence des paramètres essentiels qui avaient favorisé l'installation des ateliers (affleurements argileux abondants et parfois de qualité, facilité d'acheminement de produits), l'équipe se lança dans l'approche monographique de trois secteurs bien distincts dans les départements de l'Ain, de la Drôme et du Rhône. 


\section{Les méthodes d'investigation}

5 Evidemment chacun de ces secteurs présentait des particularités qui ont conduit à adapter les méthodes d'investigation, mais un schéma général de travail a été appliqué. Pour localiser les ateliers, la part belle a été faite aux prospections de terrain, grâce auxquelles se dessine, avec plus ou moins de bonheur, le «paysage artisanal ». Dans le Beaujolais, les résultats ont été confortés par des prospections géophysiques. Le recours aux ramassages systématiques a livré dans tous les cas un échantillonnage significatif à partir duquel le catalogue des produits fabriqués est reconstitué. La détermination de la période d'activité des ateliers, de leur permanence en un même lieu, ou au contraire de leur déplacement d'une époque à l'autre, s'est révélée délicate. Quelques heureux repères sont fournis par les textes pour le secteur bressan et la moyenne vallée du Rhône. Rien de tel en Beaujolais où l'enquête d'archives reste à faire. Aussi, en l'absence de sondages et de fouilles, l'examen des rejets collectés reste la source essentielle de renseignements. Travail de bénédictin que le tri de ces milliers de tessons! Mais combien révélateur, pour peu qu'il soit complet et méthodique. Les propositions de datation avancées ici se fondent donc avant tout sur la comparaison de ces rejets avec le mobilier issu des fouilles régionales offrant des critères chronologiques fiables. La longue durée de l'activité potière à Meillonnas-Treffort et en Beaujolais est ainsi démontrée et une restitution de la topographie évolutive des ateliers est possible à partir des catégories céramiques reconnues.

6 Les prospections de terrain ont bien sur englobé la reconnaissance des gisements d'argile où s'approvisionnaient les artisans, reconnaissance facilitée, dans les cas bressan et rhodanien, par la présence d'argiles réfractaires, pas exclusivement utilisées, d'ailleurs. Mais en Beaujolais, la banalité des matériaux et leur dispersion ne livrent pas de pistes précises à l'heure actuelle.

7 Une fois déterminées les productions des ateliers au fil des siècles, la question de leur commercialisation a été abordée. Repérés dans les collections régionales, le service vert de Meillonnas et le service jaune de Larnage ont fait l'objet d'une étude approfondie à l'issue de laquelle apparaît l'aire de diffusion de ces centres. Les cartes présentées illustrent seulement une étape de la recherche susceptible d'être complétée et précisée à tout moment. Du moins se fondent-elles sur des arguments solides fournis par les analyses de laboratoire: prélèvements d'argiles locales, fragments de terres cuites collectées sur les ateliers eux-mêmes et sur de nombreux sites de consommation, constituent les échantillons dont la composition chimique a été comparée. Tout reste à faire en revanche pour les poteries communes, telles les vaisselles aux décors d'engobes à pâte calcaire de la moyenne vallée du Rhône où les grossiers récipients du Beaujolais.

8 Les témoins écrits de la diffusion commerciale des céramiques sont peu nombreux : ils proviennent tous de textes rattachés aux lieux de consommation. Ainsi, c'est au fil d'inventaires après décès dressés à Lyon, Vienne ou Grenoble que sont mentionnées les poteries produites à Érôme. Les archives « locales » n'évoquent leur commercialisation que de manière anecdotique ou accidentelle. Pour l'instant aucun indice relatif aux ventes depuis Meillonnas ou Larnage, dont les vaisselles ont pourtant inondé le marché lyonnais, comme en témoigne l'archéologie, n'a été relevé.

9 L'étude des archives artisanales a été menée à bien pour les secteurs bressan (Meillonnas-Treffort) et drômois (Érôme, Ponsas, Larnage). Elle s'est révélée inégalement féconde. La même démarche a pourtant été mise en œuvre. La période 
contemporaine n'était certes pas le but de nos recherches, mais il était impossible d'ignorer plusieurs documents de cette période, qui constituent une base de départ irremplaçable: les multiples statistiques industrielles, les enquêtes économiques et surtout les plans et les registres du cadastre dit napoléonien. Les premiers offrent une vue d'ensemble de la fabrication de la céramique dans un département, les seconds prodiguent une localisation cartographique précise des ateliers qui fonctionnaient au début du XIXe s. Ce dernier plan cadastral présente l'avantage d'avoir été établi avant la révolution industrielle et, dans le cas de nos recherches, il formait la totalité de notre documentation cartographique ancienne! Mais ce sont surtout les archives de l'Ancien Régime et médiévales, périodes que nous avions choisi de documenter plus particulièrement, qui se sont révélées d'un apport inégal, selon qu'elles traitaient de la région d'Érôme ou de celle de Meillonnas. Les actes notariés concernant la Drôme ont en effet livré une masse de renseignements - et le potentiel est encore grand - que ceux de l'Ain sont bien loin d'avoir fournie. La disparition de la plupart des registres des notaires de Meillonnas explique sans doute cette disparité, que la conservation de ceux des études de Treffort n'a pas réussi à compenser. A un degré moindre, les archives judiciaires des deux sites ont reproduit un schéma identique. A l'inverse, la lecture des registres des terriers de l'Ain, couplée à celles des comptabilités des châtellenies, a permis d'aborder l'histoire des ateliers médiévaux de Meillonnas, ce que, faute de documents appropriés, nous n'avons pas pu faire pour la Drôme.

Les données d'archives ont orienté les prospections de terrain, particulièrement à Meillonnas-Treffort où la convergence des deux sources d'informations a été particulièrement fructueuse pour localiser les ateliers. Dans la vallée du Rhône, le recours aux cadastres anciens a été au moins aussi « rentable» que les prospections. Avant tout, les textes ont fait revivre les communautés artisanales. Si en Bresse des séries de patronymes donnent une idée assez précise du nombre de potiers et de leurs liens familiaux, pour la vallée du Rhône, les modes de fonctionnement de la communauté peuvent être entrevus : liens familiaux et professionnels, apprentissages, héritages, accords d'exploitation, acquisition des matières premières, et mille autres choses encore pourraient être extraites des actes notariés. En revanche, dans les deux cas, fort peu de renseignements sur l'organisation même des ateliers, les locaux, l'équipement, l'outillage et encore moins sur les productions. Quoi qu'il en soit l'intérêt des données textuelles, lorsqu'elles existent, invite à tenter la démarche pour les officines beaujolaises, même si la quête est toujours longue et parfois aléatoire.

\section{Trois études de cas}

11 Menées de front dans des contextes géographiques et chronologiques variés, ces trois enquêtes régionales livrent différents cas de figures où transparaît la combinaison des facteurs qui ont présidé à l'implantation des ateliers.

\section{Les ressources naturelles}

- En 1449, les reconnaissances passées par les tupiniers de Meillonnas pour leurs ateliers sis aux Tupinières sont muets sur la question de l'argile (tout comme sur le combustible d'ailleurs). La documentation postérieure n'est guère plus diserte sur le sujet. Un acte notarié daté de 1683 rappelle néanmoins que les potiers de la Razza 
« exigent certain droict de terre propre à fabricquer des pots et plats "

dans une pièce de terre proche du "moullin Taboret $~^{1}$ De nos jours encore, des carrières d'argile sont creusées au lieu-dit Moulin-Tabouret au sein d'une formation plioquaternaire qui affleure largement sur les territoires des communes étudiées. Elle se distingue surtout par un faciès ponctuel constitué d'une succession de bancs d'argiles siliceuses, dont l'un de terre d'engobe dit «blanc de Bresse ».

Les propriétés réfractaires de ces terres ont été largement exploitées par les potiers de Meillonnas et Treffort qui fournirent en

« terre à feu le tiers du Royaume et même la Suisse et la Savoye $»^{2}$

ce que l'étude du matériel de plusieurs fouilles régionales confirme au moins pour le XVIe s. et une partie du XVIIe s. La composition des poteries communes produites du XIIe s. au XIV s. aux Tupinières, ainsi que celle des carreaux décorés à vernis plombifère mis en œuvre au château de Treffort au XIVe s. est distincte de celle des céramiques réfractaires des XVI-XVIIIe s. produites sur l'ensemble des hameaux recensés. Il serait intéressant de savoir si cette répartition répond à différentes qualités de résistance au feu, à l'ouverture de nouvelles carrières ou à l'évolution des critères esthétiques et techniques. Les premières productions sont cuites en atmosphère réductrice, les secondes en atmosphère oxydante. La pâte de ces dernières souvent très blanche est recouverte d'une glaçure au plomb de couleur verte. Les potiers ont pu dans ce cas sélectionner les terres afin d'obtenir la teinte la plus claire possible.

Les sites de fabrication de poteries coïncident avec la zone d'affleurement du faciès argileux et des carrières sont attestées non seulement au Moulin-Tabouret mais aussi à la Razza et aux Tupinières. Certaines se devinent encore aujourd'hui sous la forme de dépressions envahies de taillis. Il semble donc que le critère géologique ait fortement conditionné et favorisé la création puis le développement de l'activité céramique de cette région.

- Dans la vallée du Rhône, les ressources en argile d'Érôme et de Ponsas sont fournies par les alluvions du fleuve d'une part, et par des affleurements ponctuels d'argiles calcaires plus ou moins sableuses du Pliocène marin. Leur extraction nécessitait une découverte du terrain sur un mètre d'épaisseur environ. Le contexte géologique n'est donc pas particulièrement favorable. Le combustible (bois) était, quant à lui, acheminé sur parfois plusieurs kilomètres depuis Chantemerle ou les bois communaux alentours. Les activités de la tuile, de la poterie et de la faïence s'exercèrent conjointement à Ponsas à partir du XVIIIe s. La production de la terre cuite architecturale semble inconnue à Érôme, où seuls sont mentionnés les potiers de la fin du XVIe au milieu du XIXe s., les faïenciers apparaissant au cours du XVIIIe s.

Le cas de Larnage est sensiblement différent puisque des gisements de kaolin affleurent sur le territoire de cette commune, où ils sont encore exploités en une vaste carrière à ciel ouvert. De telles argiles sont quasiment uniques dans la région Rhône-Alpes, si l'on excepte celles beaucoup plus méridionales de Dieulefit. Elles furent mises en œuvre pour la fabrication de céramiques à usage culinaire (marmites, poëlons) bien que la typologie établie à ce jour comporte également des exemplaires de formes ouvertes, telles qu'assiettes et plats. Les prospections de terrain n'ont pas fourni d'indices de productions traditionnelles, bien que les argiles du Pliocène marin soient aussi largement répandues sur le territoire de Larnage. Excepté un tuilier qui exerçait vers 1700, Larnage s'est consacré à la fabrication de poteries réfractaires depuis le milieu du XVIe s. jusqu'au XIXe s., époque à laquelle apparaissent les briquetiers spécialisés dans les produits réfractaires. En revanche, celle des creusets y est plus ancienne (XVIIIe s. au moins), qu'ils soient fabriqués sur place par les 
fermiers des «mines de terre blanche $»^{3}$ ou que, en 1728 par exemple, celles-ci soient directement affermées aux maîtres affineurs de l'Hôtel de la Monnaie de Lyon.

- Ce n'est probablement pas la qualité des argiles qui est la raison première du développement durable de l'artisanat céramique en secteur beaujolais. La nature des productions est là pour en témoigner. Faute de données textuelles on ne sait rien sur ces questions d'approvisionnement, sauf ce qu'enseigne la logique. On peut supposer que le combustible ne manquait pas avant la mise en place du vignoble dans la région. Le contexte géologique n'est pas original : dans toute la vallée, les alluvions des terrasses de la Saône offrent de nombreuses passées argileuses auxquelles s'ajoutent ponctuellement des argiles calcaires (marnes de l'Oxfordien) et des argiles issues de l'altération des roches cristallines des monts du Beaujolais. Il est difficile de dicerner une logique d'implantation des ateliers eu égard à la diversité et à l'éparpillement des gisements potentiels.

\section{La diffusion des produits}

- Les analyses de laboratoire ont permis d'attester la diffusion des céramiques culinaires (service vert) produites à Meillonnas à partir du XVIe s. au moins. La distribution est large : département de l'Ain, Val de Saône jusqu'à Mâcon, vallée du Rhône (Lyon et Vienne) et Haute-Savoie ; l'hypothèse de débouchés plus méridionaux (Valence) est envisagée ainsi que d'autres vers le canton de Genève. Malgré cette diversité, deux réseaux commerciaux s'affirment : axe Saône-Rhône et vallée de l'Ain. Ils requièrent l'un et l'autre des transports à moyenne, voire longue distance. La diffusion commerciale des ateliers de MeillonnasTreffort se voit imposer des limites au nord par la concurrence des ateliers jurassiens d'Etrepigney qui offraient des produits analogues (terre blanche réfractaire, revêtement glaçuré de belle qualité).

- Les vaisselles réfractaires fabriquées à Larnage aux XVIIe et XVIIIe s. étaient très prisées des consommateurs lyonnais, ce que confirment les pourcentages établis pour les dépotoirs urbains où le service jaune remplace progressivement le service vert. Les analyses de laboratoire ont en outre démontré sa commercialisation vers Vienne, mais aussi Grenoble. Les exemplaires trouvés plus au nord, à Chalon-sur-Saône et à Besançon, laissent entrevoir un marché assez large. En revanche, les ateliers de Dieulefit, dotés eux aussi d'argiles kaoliniques, font probablement une rude concurrence pour la diffusion vers le sud. Il serait intéressant de pouvoir comparer les aires d'influence de ces deux groupes d'ateliers.

Les productions des autres ateliers drômois (Érôme, Ponsas, Serves, Gervans) qui se rattachent à la grande famille des céramiques vernissées (à décors engobés notamment) suivaient-elles les mêmes circuits? La question reste ouverte. L'immédiate proximité de la vallée du Rhône est à l'évidence l'atout majeur de ces ateliers, mais un atout partagé par nombre d'autres officines, localisées ou à découvrir, installées sur les rives du fleuve entre Vienne et Valence. C'est dire que l'enquête risque d'être longue et difficile !

- C'est encore la présence d'une voie d'eau navigable, qui est à l'origine de la remarquable concentration d'ateliers médiévaux découverte dans le Val de Saône beaujolais. Les débouchés commerciaux de cette production de masse de poteries communes ne sont actuellement pas repérés. Par leur situation, les ateliers se trouvent tout désignés pour alimenter les villes toutes proches de Beaujeu, de Belleville et de Villefranche, dont l'expansion semble coïncider avec leur phase de plein épanouissement. On peut supposer que Lyon était aussi atteint par la Saône. Le parallèle frappant que l'on peut établir avec les ateliers de Sevrey, près de Chalon-sur-Saône (périodes d'activité, catalogue des productions) invite à poursuivre la comparaison et à considérer que la diffusion des ateliers du Val de 
Saône, de Chalon-sur-Saône à Belleville, est une question globale et une piste de recherche pour les années à venir.

\section{La répartition des ateliers}

17 Sans prétendre à l'exhaustivité, on a tenté d'établir le plus objectivement possible la cartographie des ateliers des trois zones étudiées. Combinées avec les informations chronologiques, les cartes font apparaître une réalité mouvante, reflet de l'interaction des divers pôles d'attraction : carrières, agglomérations, voies de communication.

- Les ateliers médiévaux et modernes du secteur de Meillonnas se répartissent en hameaux spécialisés sur la frange occidentale des communes. A une exception près, la production de chaque groupe d'ateliers semble être exclusive: poteries domestiques et terres cuites architecturales ne se confondent pas géographiquement. La spécialisation professionnelle des artisans est d'ailleurs tout aussi stricte : les actes notariaux ne mentionnent jamais de double activité (potier/tuilier) ni de familles « métissant » potiers et tuiliers.

En 1761, le sieur De Marron, seigneur de Meillonnas, établit une manufacture de faïences dans les dépendances de son château, au cœur même du village de Meillonnas. Cette installation en « centre ville » est néanmoins sans conséquence sur l'artisanat de la poterie qui demeure dans les quartiers précités. On constate l'absence d'ateliers de céramiques traditionnelles dans les bourgs et leur éparpillement au sein des hameaux environnants, mais il est difficile d'en déduire un schéma constitutif. Les officines ont-elles été rejetées hors des centres villageois en application de décisions communautaires (ou autres) leur interdisant un périmètre "mis en défens »? Aucun texte de cette teneur (ou s'y référant) n'est parvenu jusqu'à nous.

Les hameaux ont pu se créer autour des artisans : outre celui des Tupinières au toponyme significatif, des lieux-dits tels que Mas Tabouret, Mas Girard, sont des formations anthroponymiques constituées à partir de noms de familles comptant de nombreux potiers. Dans cette hypothèse, les artisans auraient eu tout intérêt à s'installer le plus près possible des gisements d'argile, la spécialisation constatée pour la majorité des hameaux trouverait là son explication, de même, en ce qui concerne l'absence de l'artisanat dans les bourgs proprement dits.

- Pour le groupe des ateliers de la moyenne vallée du Rhône, on ne possède pas de localisation précise avant les plans cadastraux de 1830. Ceux-ci figurent plusieurs ateliers de potiers ou tuiliers à Érôme, Ponsas et Lamage. Aussi a-t-on choisi cette localisation par défaut considérant qu'elle était probablement le reflet des situations antérieures. Les premières mentions textuelles se placent au milieu du XVIe s. Les informations archéologiques n'ont pas livré d'indices plus anciens.

Que ce soit à Érôme ou à Ponsas, l'essentiel des ateliers se concentrait dans les villages, s'intégrant aux habitations et Ton peut raisonnablement admettre que la géographie de l'artisanat s'est adaptée à la configuration topographique locale. L'image de Ponsas est même caractéristique de ce fait: plusieurs poteries y constituent l'embryon d'un quartier spécialisé. Le cas de Larnage est plus nuancé ; les ateliers de poterie sont implantés dans le village proprement dit, mais aussi à l'écart. Des ramassages de surface attestent la présence d'ateliers dans un hameau de Larnage au lieu-dit les Sautons.

- La localisation des ateliers du Beaujolais repose uniquement sur des indices archéologiques. Leur organiation spatiale offre un schéma complexe en raison de la longue période considérée et de l'étendue du territoire concerné. Il semble que les ateliers les plus anciens (haut Moyen Age) sont dispersés et répartis le long de la haute terrasse de la Saône. Leur 
relation avec les habitats contemporains nous échappe en l'état actuel de la recherche. Le phénomène de pôles artisanaux apparaît plus tard, alors que les ateliers se rapprochent du cours de la Saône, tout en restant probablement en retrait des zones inondables. Un groupe se forme au hameau de Chassagne (X-XIIe s.) sur la commune de Corcelles-en-Beaujolais. Le hameau de Marsangues (commune de Saint-Georges-de-Reneins) pourrait être né du regroupement des officines à partir des XII-XIIIe s. Faut-il voir, dans cette nouvelle implantation, à une dizaine de kilomètres au sud, la nécessité de se rapprocher d'un point d'embarquement sur la Saône, situé au niveau de Saint-Georges-de-Reneins?

\section{Une enquête à poursuivre} aboutis selon les circonstances du travail, les moyens consacrés, mais aussi la nature des découvertes effectuées. Dans tous les cas, elles démontrent l'intérêt qu'il y a à aborder les centres de production céramique de façon extensive. Cette « archéologie du paysage artisanal » n'est pas une fin en soit ; c'est un mode d'approche, parmi d'autres, d'un vaste potentiel archéologique. Ses résultats sont d'autant plus riches qu'ils sont confrontés à d'autres méthodes d'investigation, quand cela est possible, en particulier les données des textes. L'appui du laboratoire spécialisé est indispensable dès lors qu'on aborde la question de la diffusion des produits et de l'origine des matières premières. On jugera, pour chacune de ces études de cas, comment l'enquête pourrait se poursuivre. - Les ateliers bressans pourraient donner lieu à des prospections géophysiques. Il conviendrait de confirmer la datation des ateliers les plus anciens (XIXIIe s. ?). La détermination de l'aire de diffusion, à travers le service vert, reste bien sûr une question ouverte.

- Le groupe d'Érôme-Larnage trouve place dans le réseau dense des ateliers de la vallée du Rhône, où les activités de l'aire industrielle oblitèrent souvent les traces plus anciennes : l'absence d'indices archéologiques antérieurs au XVIe s. serait à confirmer. Les relations des ateliers étudiés avec d'autres ateliers de la vallée du Rhône, en rive droite comme en rive gauche, seraient à mettre en lumière (échanges de personnels, de savoir-faire, complémentarité ou concurrence commerciale...). Notamment la comparaison détaillée des vaisselles en argile kaolinique, produites par Larnage, Dieulefit et les ateliers de l'Uzège, serait fort utile.

- Les ateliers du Beaujolais s'inscrivent, quant à eux, dans une région qui s'avère concentrer un énorme potentiel pour l'artisanat céramique, tout au long du Moyen Age. Les prospections de terrain seraient à étendre vers le nord comme vers le sud en suivant les terrasses de la Saône. L'expérience acquise dans la partie bourguignonne du val de Saône, invite à mieux prendre en compte les découvertes subaquatiques. Les textes qui, dès le XIVe s., ont gardé le souvenir des fabricants de poterie commune installés près de Chalon-surSaône, seraient-ils muets sur leurs congénères installés à la latitude de Belleville ?

Il est évident que, partout, le travail réalisé pourrait déboucher sur un programme de sondages ou de fouilles archéologiques, dont la stratégie serait solidement étayée par ces enquêtes préliminaires. Il subsiste cependant une inquiétude de taille : l'état de conservation de structures par nature fragiles, soumises aux labours répétés (en particulier culture de la vigne). Et pourtant, nombre de thèmes abordés ici se verraient révisés et enrichis, et surtout, se révèleraient enfin concrètement l'agencement des 
ateliers et les techniques mises en œuvre par les artisans potiers que les pages qui précèdent ont contribué à faire revivre.

20 E. F-B. et S. S-G.

\section{NOTES}

1. A.D. Ain : versement Maître Berger, $n^{\circ} 5$, Doisy Notaire

2. A.D. Ain : mémoire De Marron, C 112

3. A.D. Drôme : 3 E 7825, Etude Pascal (1769) 
Seconde partie. Répertoire illustré des céramiques domestiques en lyonnais (XII ${ }^{\mathrm{e}} \mathrm{XVIII}{ }^{\mathrm{e}}$ siècle) 


\section{Avant-propos}

1 Le père du mort s'occupe d'archéologie... Une marotte inoffensive. Il a découvert un jour une poterie, peut-être de valeur, et, depuis, il creuse, il fouille, il ramène au jour des débris de vases abandonnés par les caraques ou de vieilles bouteilles lancées du train de Sète par des voyageurs imprudents; il range ses saletés comme de vieux échantillons; il est heureux... Il écrit là-dessus, je me demande quoi.

Enfin, ça ne fait de mal à personne.

2 Léo Malet: Les enquêtes de Nestor Burma et les nouveaux mystères de Paris. Tome I

3 Coll. Bouquins. Robert Laffont.

4 «Solution au cimetière » p. 251 


\section{Introduction}

118 - Les sites lyonnais

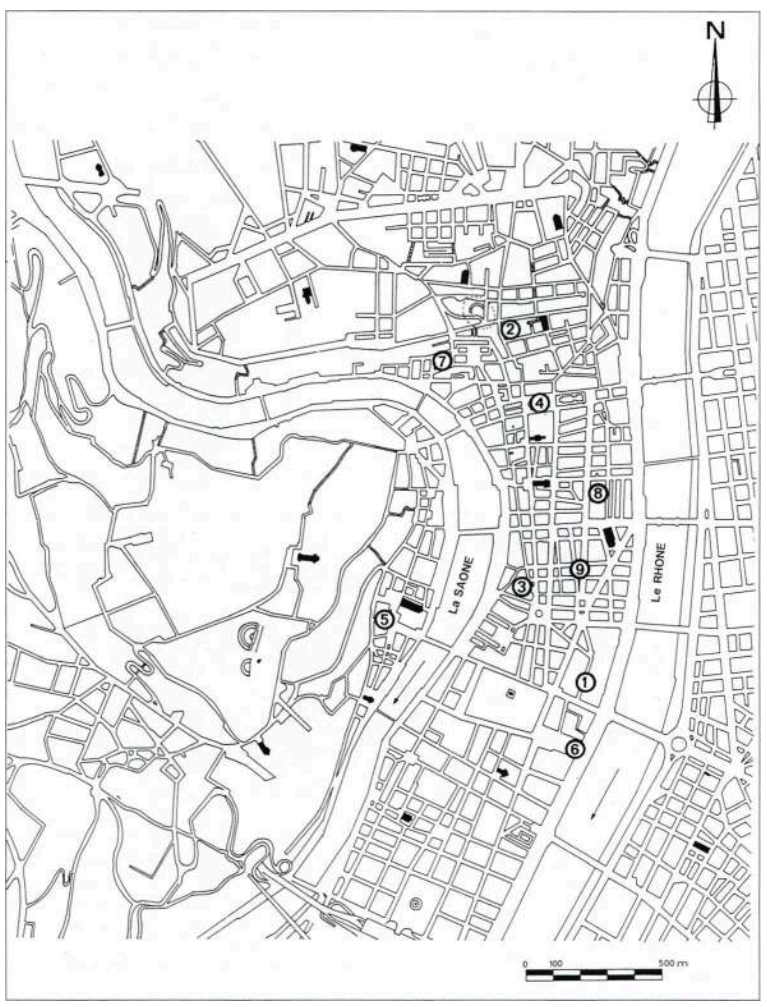

1 : rue Bellecordière, Hôtel-Dieu, 2 : rue René Leynaud (Vieille Monnaie), 3 : rue de la Monnaie (îlot 24), 4 : place des Terreaux, 5 : rue Tramassac, Saint-Jean, 6 : place Antonin Poncet, 7 : quartier SaintVincent, 8 : place de la Bourse, 9 : rue Palais-Grillet

1 Depuis plusieurs années, les nombreuses interventions archéologiques réalisées à Lyon permettent de mieux comprendre le passé médiéval et moderne de la ville, mais en même temps révèlent la faiblesse de la chronologie des documents matériels.

2 En ce qui concerne la céramique, ce fait est évident à partir du XIIIe s. et ce, jusqu'au XVIIIe s. En effet, si une thèse explore les Xe, XIe et XIIe s. (Boucharlat 1980), les époques postérieures ne sont connues que par le biais d'études ponctuelles: un 
mémoire de maîtrise pour le XIIIe s. (Vicard 1984) et quelques articles pour les XVIe et XVIIe s. (Maccari-Poisson 1988 ; Vicard 1989).

3 Pour appréhender la céramique à sa juste valeur, pour la replacer dans son contexte aussi bien historique que sociologique ou tout simplement typologique, il devient indispensable de créer une typochronologie de référence couvrant toute la période comprise entre le XIIe et le XVIIIe s.

4 Ce travail est volontairement limité à la ville de Lyon, zone d'utilisation, où le matériel issu des fouilles de ces dernières années ne manque pas (fig. 118).

5 Six sites sont mis à contribution: la rue du Palais-Grillet; la place de la Bourse; le quartier Saint-Vincent, qui contient lui-même trois secteurs distincts (1 rue de la Vieille, 1 rue Bouteille et le secteur de la rue Touret); la rue de la Monnaie, connue également sous le nom d'îlot 24 ; la rue René Leynaud, ou îlot Vieille Monnaie (I.V.M) et enfin, la rue Bellecordière, citée aussi sous le nom d'Hôtel-Dieu ${ }^{1}$. Il faut pourtant faire une légère entorse au contexte géographique pour intégrer les résultats de la fouille du château d'Anse, dans le Rhône, au nord de Lyon, afin de bénéficier d'une typologie concernant le XIIIe s. ${ }^{2}$. D'autre part, en appoint, nous utiliserons parfois le mobilier issu des fouilles de la rue Tramassac, de la place de la Bourse, de la place Antonin Poncet et de la place des Terreaux ${ }^{3}$.

6 Le corpus s'élève donc à 7006 fragments pour l'époque médiévale, 3694 pour le XVe s., 68879 pour le XVIe s., 11108 pour le XVIIe s., 5490 pour la période charnière entre le XVIIe et le XVIIIe s. et 1122 pour le XVIIIe s., soit un total de 97299 tessons $^{4}$ dont le point commun réside dans le fait qu'ils proviennent, dans leur majorité, d'ensembles clos, dépotoirs, fosses et fosses septiques.

7 Pour gérer un tel potentiel et établir les comparaisons qui s'imposent, il est nécessaire que la grille de lecture soit homogène, c'est pourquoi, le chapitre 1 concerne la classification des vases. Dans le chapitre 2, le contexte archéologique, l'étude céramologique et les indices de datation sont pris en compte, pour chaque lot, en respectant l'ordre chronologique. Enfin, le chapitre 3 présente une synthèse des informations obtenues selon les trois axes de recherche.

8 L'étude de ce mobilier permet de faire la jonction avec les époques antérieures, d'intégrer les lots déjà publiés et de présenter une évolution chronologique, qui, même si elle montre certaines incertitudes, n'en permet pas moins de disposer d'une base solide pour la poursuite des recherches.

9 T. V.

\section{NOTES}

1. Les fouilles du Palais-Grillet ont été dirigées par Grégoire Ayala, celles de la place de la Bourse, par Catherine Arlaud, celles de Saint-Vincent, par Jean-Paul Lascoux, celles de la rue René Leynaud et de la rue Bellecordière, par Luc Jaquin. 
2. La fouille du château d'Anse a été effectuée par Muriel Soubeyran, sous la direction de JeanFrançois Reynaud.

3. Les fouilles de la rue Tramassac ont été dirigées par Joëlle Burnouf, celles de la place Antonin Poncet, par Christine Becker, celles de la place des Terreaux, par Catherine Arlaud. L'étude de la céramique des deux premiers chantiers a déjà été publiée (B. Maccari-Poisson 1994 et T. Vicard 1989), celle des Terreaux est en cours de publication.

4. Il s'agit du nombre de fragments avant collage. 


\title{
Chapitre 1. Pour une typologie des récipients
}

\author{
Tommy Vicard
}

1 La première étape dans l'étude de cette céramique post-médiévale et moderne consiste à élaborer une méthode de classification destinée à organiser la description de l'ensemble du mobilier rassemblé, en tenant compte de plusieurs critères, afin de cerner au mieux la personnalité de chaque vase et de lui établir une véritable «carte d'identité ». Cette classification peut s'articuler en trois parties, chacune correspondant à une vision différente de l'objet, mais néanmoins complémentaire: dans un premier temps, nous nous intéresserons au côté fonctionnel, ensuite à la morphologie, puis aux techniques de fabrication du récipient.

\section{Fonction}

Chaque vase a une fonction bien précise, laquelle détermine la morphologie de l'objet, qu'il soit de luxe ou d'utilité courante et ce, en dehors de tout contexte chronologique ou technique: l'utilisation est en relation directe avec la forme. C'est pourquoi nous plaçons la notion de fonction en amont de la classification. Mais depuis toujours, si le fabricant propose, l'acheteur, lui, dispose et l'examen de nombreuses céramiques témoigne d'un usage multi-fonctionnel : ainsi, les traces très nettes de brûlé que l'on trouve sur certains fonds d'assiettes suggèrent l'emploi de réchauds pour tenir les aliments à bonne température; de même, des traces semblables sur quelques cruches montrent que ces dernières ont parfois servi de marmites ou de coquemars. Dans notre classification, c'est la fonction originelle supposée qui est indiquée, déduite d'une part de l'observation visuelle des caractéristiques de chaque récipient, d'autre part de la consultation de dictionnaires et de glossaires spécifiques ${ }^{1}$ qui permettent de reconnaître des formes et leur destination et de les suivre ainsi siècle par siècle. 


\section{Récipients pour la préparation des aliments}

3 Bassin : récipient à usage multifonctionnel qui peut être utilisé aussi bien pour la préparation que pour le service, voire même pour la lessive ou la toilette : grand vase circulaire, à paroi rectiligne, avec parfois un bec et deux anses ; souvent non glaçuré.

4 Jatte : usage multifonctionnel : récipient à paroi rectiligne peu évasée, haute, muni d'anses ou de tenons et parfois d'un bec pincé et toujours glaçuré.

\section{Récipients pour la cuisson des aliments}

5 Coquemar : récipient que l'on pose directement sur l'âtre, au coin du foyer et qui sert à faire mijoter les aliments. Muni d'une seule anse ou d'un manche, il montre très souvent dans la partie opposée des zones rubéfiées très prononcées, où se sont produites des modifications dans la coloration de la pâte.

6 Lèchefrite : récipient que l'on place sous le gril ou sous la broche pour recueillir le jus des aliments qui rôtissent : rectangulaire ou circulaire, plat, à paroi droite, glaçuré ou non, pourvu d'anses ou de manches et d'un bec pincé.

7 Marmite : récipient que l'on pose sur les braises, sur un trépied ou directement sur le potager. Il est muni de deux anses et/ou d'un manche et parfois de pieds; la panse est généralement globulaire et le fond hémisphérique ou bombé. La paroi externe porte souvent de fortes traçes d'utilisation au feu.

8 Pot à cuire : même fonction que la marmite, mais morphologie différente; il s'agit d'un récipient à fond plat et à paroi rectiligne, avec système de préhension.

Oule: même fonction et même morphologie que la marmite, mais le récipient est dépourvu de système de préhension.

10 Poêlon : petite poêle à fond plat, pourvue d'un manche, dans laquelle on fait cuire les aliments.

\section{Récipients pour le service et la consommation des aliments}

11 Assiette creuse : récipient individuel, généralement circulaire possédant un marli court évasé ou presque horizontal, une paroi évasée courbe et un fond plat.

Plat : récipient de morphologie identique à l'assiette creuse, mais servant à présenter les aliments. La distinction entre fonction collective ou individuelle se fait en principe par les dimensions.

13 Assiette plate : récipient individuel à fond plat et large marli.

14 Écuelle : récipient servant à consommer des aliments ou des boissons, pourvu d'un rebord droit sur lequel se greffent deux tenons horizontaux (oreilles), d'une paroi hémisphérique parfois carénée et d'un fond plat. Précisons ici que le bol est pratiquement identique à l'écuelle, si ce n'est l'absence de système de préhension, mais que ce mot d'origine anglaise n'apparaît qu'à la fin du XVIIIe s. (Vocabulaire Typologique des Objets Civils Domestiques p. 180) 


\section{Récipients pour le service des boissons}

Cruche de table : récipient caractérisé par un élément verseur, bec ponté, pincé ou tubulaire, situé en face d'une anse verticale.

Pichet : récipient possédant une anse verticale, mais sans élément verseur.

\section{Récipients pour la consommation des boissons}

Biberon : petit récipient de forme globulaire, muni d'un mince bec tubulaire parfois perpendiculaire à une anse verticale.

Tasse : petit récipient individuel pour boire des liquides chauds, de morphologie identique à l'écuelle, mais de dimensions réduites et pourvu d'une anse verticale.

Gobelet : récipient à paroi haute et rectiligne, sans élément de préhension, muni d'un pied.

\section{Accessoires de service}

Chauffe-plat : ustensile dont le rebord, équipé de trois tenons, permet de poser un récipient qu'on veut maintenir au chaud.

Réchaud : ustensile haut et cylindrique à fond plat, qui possède un ressaut interne à mi-hauteur servant de support à une grille sur laquelle on peut disposer des braises. Une ouverture est perçée dans le bas de la paroi pour retirer les cendres.

\section{Récipients pour la conservation et le transport des aliments}

Cruche : grand récipient pour transporter ou conserver un liquide, à une ou plusieurs anses verticales ou en panier et souvent muni d'un bec tubulaire.

Cruche de stockage : le seul exemplaire est incomplet: fond plat, panse surbaissée avec deux anses dans la partie supérieure. Sans doute dépourvu d'élément verseur.

24 Pot de stockage : récipient bas, qui montre une panse évasée, mais dont le col convergent réduit le diamètre d'ouverture et facilite la pose d'un système de fermeture. Il est dépourvu d'élément verseur, mais possède soit des anses, soit des tenons de préhension.

Oule de transport : récipient morphologiquement identique à l'oule, mais muni d'une anse en panier facilitant sa préhension.

\section{Accessoires d'hygiène corporelle}

Pot de chambre : récipient haut et évasé, pourvu d'une anse verticale, mais sans élément verseur. 


\section{Objets divers}

Couvercle: élément s'adaptant à l'ouverture d'un récipient pour la fermer complètement ou non; plat ou creux avec, au centre, un tenon de préhension ou une anse.

Sifflet : il s'agit d'un récipient creux que l'on remplit d'eau, muni d'un pied et d'un bec tubulaire. La partie supérieure de l'objet est souvent décorée d'une tête d'animal.

29 Tirelire : récipient entièrement fermé, percé seulement d'une fente dans la partie supérieure de la panse, dans laquelle on introduit de la monnaie.

Jouets culinaires ou « dînette » : reproduction, en modèle réduit, de vases utilitaires.

\section{Morphologie}

31 La seconde partie de la classification du mobilier céramique concerne la description morphologique des récipients. L'objectif principal est de prendre en compte le nombre maximum de vases et en particulier les formes incomplètes.

\section{Mode de classement}

Il s'agit, en premier lieu, de décrire de manière compréhensible les différents segments d'un vase : lèvre, col, panse, pied, fond, anse, système verseur. Pourtant, décider qu'audelà de tel degré d'inclinaison un changement se produit dans le profil d'une lèvre, ou préciser par une convention mathématique stricte la différence entre panse globulaire et ovoïde relèvent souvent du domaine de l'arbitraire : il suffit de superposer, par exemple, les dessins du profil d'une marmite à anses coudées pris à différents endroits du même vase pour en être convaincu. Cependant, en typologie, il semble qu'on ne peut se passer de conventions, même parfois non satisfaisantes. C'est pourquoi on a tenté de simplifier la description des segments de chaque vase, tout en utilisant les conventions couramment admises en céramologie.

L'étape suivante consiste à ordonner ces descriptions. À ce niveau, deux voies s'offrent à nous. La première consiste à attribuer, à chaque vase, un code, numérique ou alphabétique, qui renvoie à une description globale de tous les segments composant ledit vase; c'est une méthode simple, mais qui comporte deux défauts : d'une part, l'archéologue effectue, en amont, un tri sans exposer sa démarche au lecteur, qui se contente de la description brute des vases, type 1, 2 et 3...etc.; d'autre part, des récipients très proches morphologiquement finissent souvent par engendrer des " sous-groupes » tels que, par exemple: "vase $1 \mathrm{a}, 1 \mathrm{~b}$ ou $15 \mathrm{c}$ ». A ce stade, la démarche d'identification est assez complexe pour ne plus se contenter de greffer un numéro par vase. Nous sommes alors proche d'une deuxième façon d'appréhender la céramique, qui consiste à effectuer un classement hiérarchique et relationnel des descriptions de segments, en utilisant un système à plusieurs niveaux permettant de passer d'une vision globale de l'objet à l'examen de détails révélateurs. Dans cette optique, les différences morphologiques des segments, combinées entre elles, génèrent les types de vases. Ce mode de classement a été utilisé pour l'étude de la céramique indigène gauloise de Feurs (Vaginay 1988) et peut être repris pour des périodes très différentes quand les caractéristiques (ensembles clos, foisonnement des formes) et les objectifs (mise en place d'une méthode descriptive et d'une terminologie précise) restent 
identiques. De ce travail, sont conservées les définitions des niveaux : classe, groupe, forme, type, ainsi que la numérotation linéaire qui permet, à chaque étape, d'intégrer de nouveaux numéros dans le classement en respectant les caractéristiques des vases; chaque céramique est donc codifiée par un nombre de quatre chiffres: le premier définit la classe, le second, le groupe, le troisième, la forme et le dernier, le type. Le numéro 3421 sera, par exemple, le type 1 de la forme 2 du groupe 4 de la classe 3. Par contre, les critères de distinction changent, puisqu'ils sont adaptés au mobilier présenté (cf. annexe).

\section{Les classes}

Pour les céramiques "usuelles ", les classes sont déterminées par deux rapports ; l'un tient compte de la hauteur totale du récipient et de son diamètre d'ouverture; le second considère le diamètre du col et le diamètre maximum de la panse ou de la paroi. Cette combinaison de critères donne cinq classes : 1 , les vases hauts fermés ; 2 , les vases bas fermés; 3, les vases bas ouverts; 4, les vases plats ouverts; 5 , les vases hauts ouverts, auxquelles nous pouvons en rajouter deux autres : 6 , les couvercles et 7 , les formes spéciales (sifflet, tirelire, réchaud).

\section{Les groupes}

A ce niveau, pour la classe 1 , les trois critères retenus concernent la morphologie de la panse, la morphologie du fond et la présence ou l'absence d'un élément verseur. La combinaison de ces trois critères permet la distinction de dix groupes.

Dans la classe 2, qui propose un groupe, les même critères sont pris en compte.

A partir de la classe 3, on entre dans le domaine des formes ouvertes, et les termes «panse » et «lèvre » sont délaissés au profit de "paroi » et « rebord». La classe 3 intègre plusieurs critères : la morphologie de la paroi combinée avec son profil; la présence ou l'absence d'un marli ; la morphologie du fond; parfois la présence ou l'absence d'élément verseur ou aussi la présence ou l'absence d'un pied et d'un col. Cette classe donne huit groupes. trois groupes. La classe 5 ajoute la morphologie du pied et donne deux groupes.

La classe 6 se divise en deux groupes : couvercles plats ou creux.

La classe 7, qui fournit également deux groupes, se compose de récipients extrêmement diversifiés et utilise donc tous les critères disponibles.

Pour l'ensemble des classes, on totalise 28 groupes.

\section{Les formes}

En classe 1, quatre critères sont utilisés : la présence ou l'absence du col ainsi que sa morphologie; la description de l'élément verseur; la description de l'élément de préhension ; la présence ou l'absence du pied et sa morphologie. La combinaison de ces différents critères donne vingt-neuf formes.

En classe 2, les critères restent identiques, mais il n'y a qu'une seule forme. 


\section{Les types}

En classe 3, la distinction se fait surtout par les systèmes de préhension grâce à de nouveaux éléments, mais aussi par la morphologie du pied, la présence ou l'absence de l'élément verseur et aboutit à vingt et une formes.

En classe 4, l'accent est mis sur la morphologie et le profil du marli, de même que sur la morphologie du fond et du pied. L'ensemble donne six formes.

La classe 5 se distingue par la présence ou l'absence des éléments de préhension ou de l'élément verseur et par la morphologie du fond, et donne cinq formes.

La classe 6 regroupe trois formes définies, uniquement par le système de préhension.

La classe 7 fournit également trois formes.

Pour l'ensemble des classes, nous avons donc soixante-sept formes.

5 Pour la totalité des formes, les types sont caractérisés par le profil de la lèvre ou du rebord; par la présence ou non d'une ou plusieurs inflexions avec leur orientation et leur degré d'inclinaison, et la description des faces et de l'extrémité. Ces caractéristiques combinées fournissent cent-huit types différents.

\section{Typologie}

\section{Classe 1. vases hauts fermés}

Groupe 11 : Panse ovoïde, fond plat, élément verseur

Forme 111 ; col moyen cylindrique ou légèrement évasé, bec pincé opposé à une anse plate verticale sur col et milieu panse, base étalée ou droite.

Type 1111 : CRUCHE; une inflexion externe oblique vers le haut, faces parallèles, face interne concave, extrémité plate.

Type 1112 : CRUCHE; lèvre sans inflexion, faces parallèles, extrémité convexe ou plate, parfois ressaut ou épaississement externe.

Type 1113 : CRUCHE; une inflexion interne oblique vers le haut, faces parallèles, extrémité convexe.

Type 1114 : CRUCHE; une inflexion externe oblique vers le haut, faces convergentes, face interne concave, extrémité convexe.

Forme 1122 : col court droit ou absence de col, bec tubulaire parfois ponté, opposé à une anse plate verticale sur lèvre et milieu panse, anse plate en panier dans le même axe, base étalée.

Type 1121 : CRUCHE; lèvre sans inflexion, faces divergentes, extrémité concave.

Type 1122 : CRUCHE; une inflexion externe oblique vers le haut, face interne concave, extrémité convexe. 

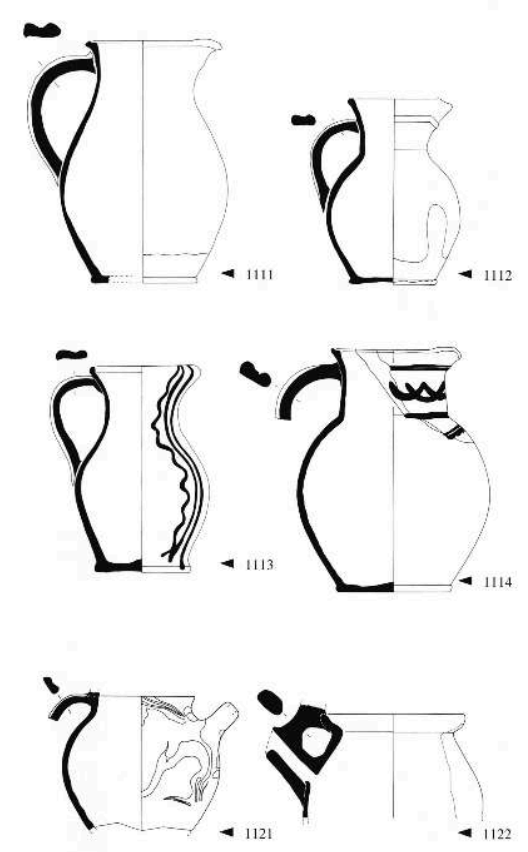

54 Forme 113 : col court cylindrique, bec tubulaire perpendiculaire à deux anses plates verticales opposées sur lèvre et haut panse, absence de pied.

Type 1131 : CRUCHE; une inflexion externe oblique vers le haut, faces parallèles, extrémité plate ou une inflexion externe horizontale, faces parallèles, extrémité convexe.

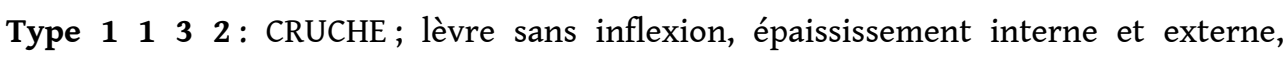
extrémité convexe.

Forme 114 : col court évasé, parfois avec gorge interne, bec tubulaire opposé à une anse plate verticale sur lèvre et milieu panse, pied court droit.

Type 1141 : CRUCHE; lèvre sans inflexion, faces parallèles, extrémité convexe.

Type 1142 : CRUCHE; lèvre sans inflexion, faces divergentes, extrémité concave.

Forme 115 : col haut cylindrique, bec pincé opposé à une anse ovale verticale sur col et milieu panse, pied tronconique court.

Type 151 : CRUCHE; lèvre sans inflexion, faces parallèles, extrémité convexe.

Forme 116 : col haut cylindrique, bec tubulaire opposé à une anse ovale verticale sur col et milieu panse, pied tronconique court. 
Type 1161 : CHOCOLATIÈRE; une inflexion interne oblique vers le haut, faces

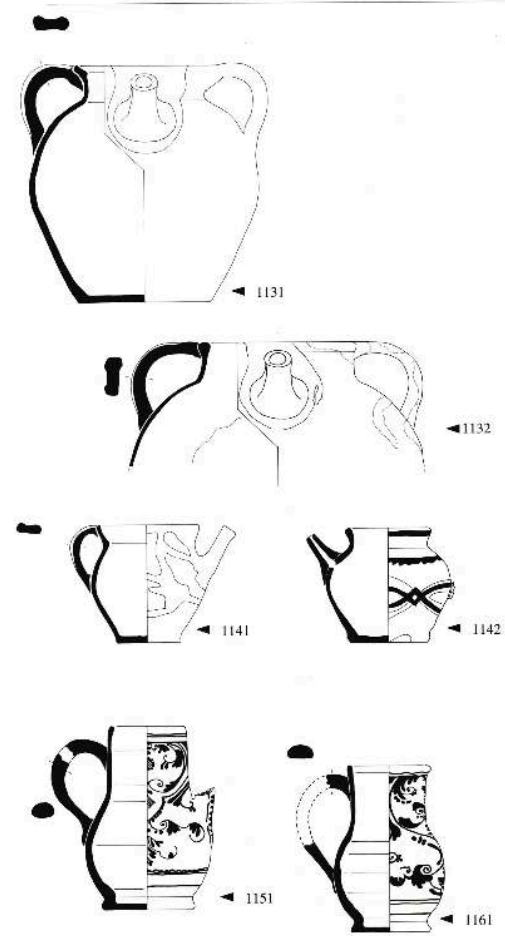

parallèles, extrémité convexe.

Groupe 12 : Panse ovoïde, fond plat, absence d'élément verseur

57 Forme 121 : col court évasé, deux anses plates verticales accolées ou opposées ou une anse plate verticale sur lèvre et milieu panse, tripode.

Type 1211 : MARMITE; lèvre sans inflexion, faces parallèles, face interne concave, extrémité convexe.

Forme 122 : col court évasé, une anse plate verticale ou deux anses plates verticales opposées sur lèvre et haut panse, absence de pied.

Type 1221 : MARMITE; lèvre sans inflexion, faces parallèles ou face interne concave, extrémité plate ou convexe ou épaississement externe, extrémité convexe.

Forme 123 : col court cylindrique ou évasé, une anse plate verticale sur lèvre ou col et milieu panse avec poucier, base étalée.

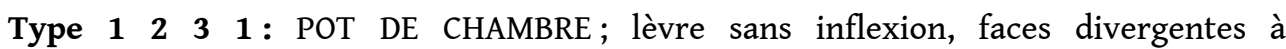
épaississement interne et externe ou faces parallèles, extrémité plate.

Forme 124 : col court évasé, une anse plate verticale attache sup. inconnue et attache inf. sur milieu panse, pied droit court.

Type 1241 : PICHET ?; lèvre sans inflexion, faces parallèles, extrémité plate. 

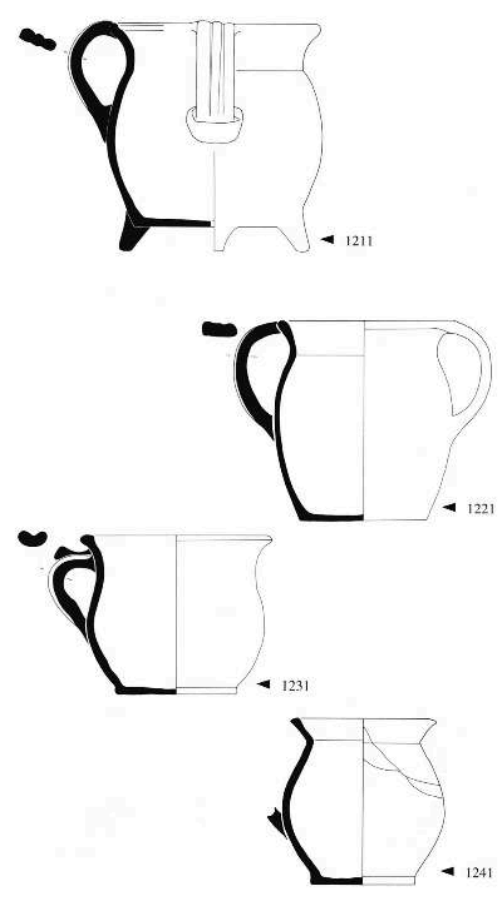

Groupe 13 : Panse ovoïde ou globulaire, fond bombé, absence d'élément verseur

61 Forme 131 : col moyen évasé, deux anses verticales de section circulaire coudées et opposées sur lèvre et haut panse.

Type 1311 : MARMITE; lèvre sans inflexion, faces parallèles, extrémité plate ou convexe ; ou épaississement externe, extrémité plate ou convexe ou faces divergentes, extrémité plate ou convexe.

Forme 132 : col évasé, court ou moyen, deux anses plates verticales opposées sur lèvre et haut panse.

Type 1321 : MARMITE; lèvre sans inflexion, épaississement externe, extrémité convexe.

63 Forme 133 : col court évasé, deux anses plates verticales opposées sur haut et milieu panse.

Type 1331 : MARMITE; lèvre sans inflexion, épaississement externe, extrémité plate oblique vers le bas côté externe.

64 Forme 134 : col court (ou moyen) évasé, deux anses plates verticales opposées sur lèvre et haut panse parfois perpendiculaires à un manche creux sur haut panse, tripode.

Type 134 1: MARMITE; lèvre sans inflexion, faces divergentes, épaississement interne, extrémité plate. 


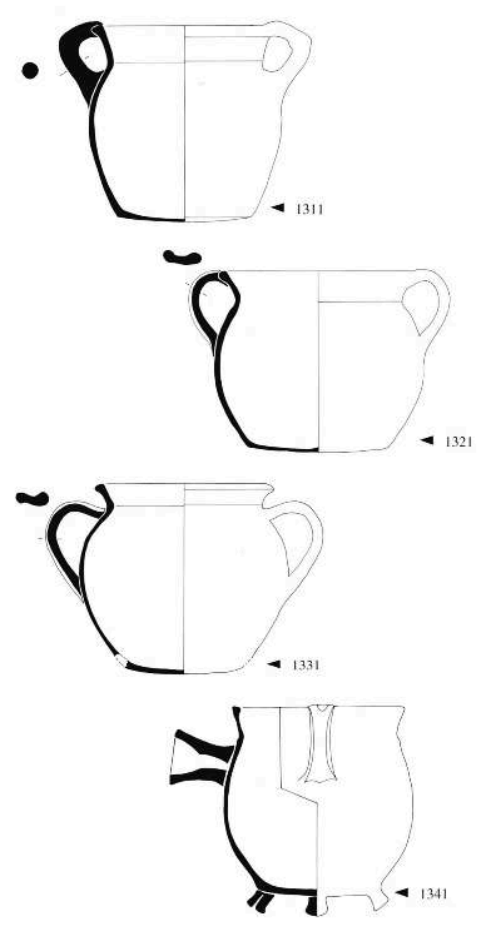

Forme 135 : absence de col, deux anses plates verticales opposées sur lèvre et milieu panse.

Type 1351 : MARMITE; une inflexion externe oblique vers le haut, faces parallèles, face interne concave, extrémité convexe.

Type 1352 : MARMITE; double inflexion externe, faces parallèles, extrémité plate.

Forme 136 : absence de col, une anse plate verticale sur lèvre et milieu panse.

Type 1361 : COQUEMAR; une inflexion externe oblique vers le haut, faces interne et externe concaves, extrémité plate.

67 Forme 137 : absence de col, absence d'élément de préhension.

Type 1371 : OULE; lèvre dite « en bandeau » à une inflexion externe oblique vers le haut, face interne concave, ressaut sur face externe.

68 Forme 138 : absence de col, deux anses plates verticales opposées sur lèvre et haut panse.

Type 1381 : MARMITE; une inflexion externe légèrement oblique vers le haut, faces interne et externe concaves, extrémité convexe. 


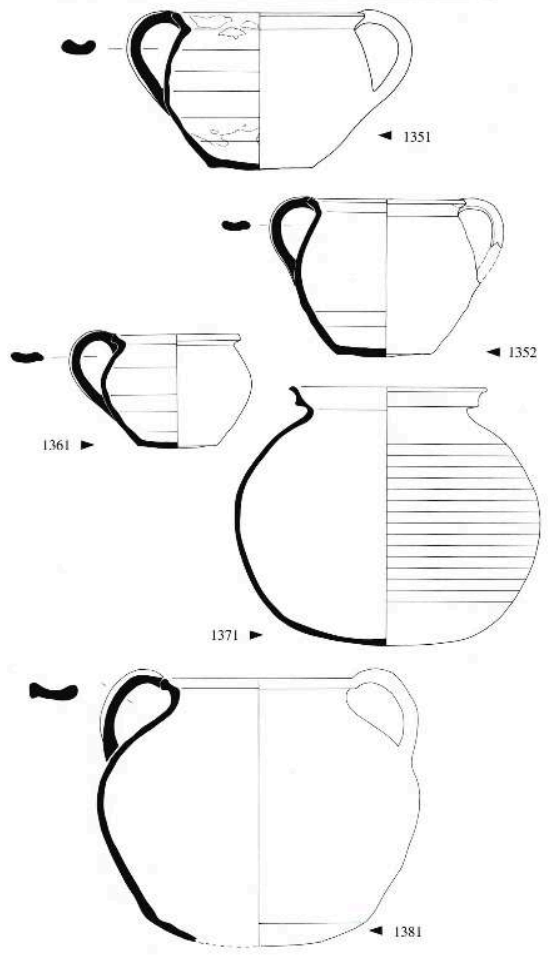

69 Forme 139 : col moyen très évasé, deux anses verticales de section circulaire opposées sur col et milieu panse.

Type 139 1: MARMITE; lèvre sans inflexion, épaississement externe, faces convergentes, extrémité convexe.

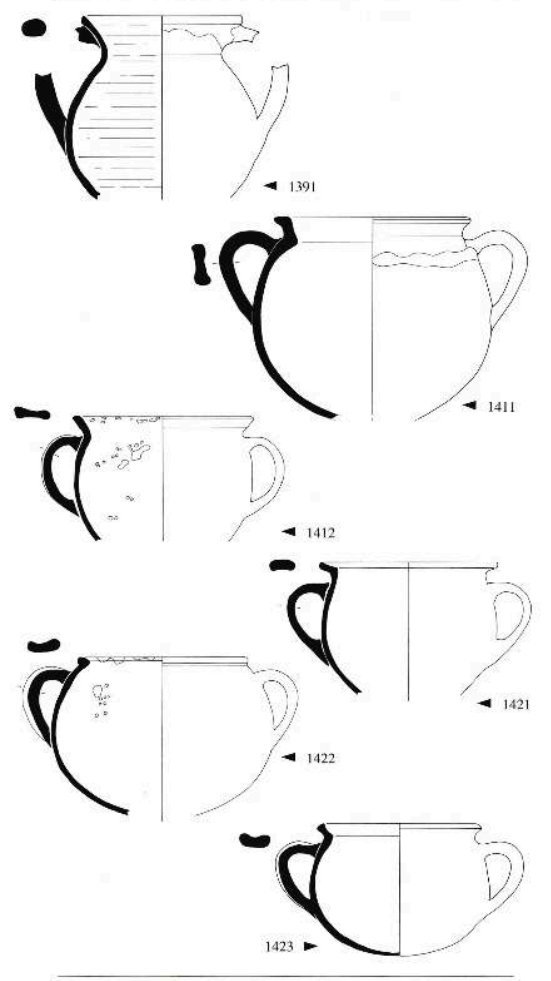




\section{Groupe 14 : Panse globulaire, fond hémisphérique, absence d'élément verseur}

\section{milieu panse.}

Type 1411 : MARMITE; lèvre sans inflexion, épaississement externe, extrémité plate, oblique vers le bas côté externe ou horizontale.

Type 1412 : MARMITE; lèvre sans inflexion, faces parallèles, extrémité plate ou épaississement externe, extrémité convexe.

Forme 142 : absence de col, deux anses plates verticales opposées sur haut et milieu panse.

Type 1421 : MARMITE; une inflexion externe oblique vers le haut, faces parallèles, face interne concave, extrémité plate ou épaississement externe, extrémité convexe.

Type 1422 : MARMITE; absence de lèvre, épaississement externe, extrémité convexe. Type 1423 : MARMITE; une inflexion externe légèrement oblique vers le haut, faces parallèles, face interne concave, extrémité plate.

Forme 143 : col court évasé, deux anses plates verticales opposées sur lèvre et haut panse. Type 1431 : MARMITE; lèvre sans inflexion, faces divergentes, extrémité plate.

73 Forme 144 : col court droit ou convergent, deux anses plates verticales opposées sur col et milieu panse.

Type 1441 : MARMITE; une inflexion externe horizontale ou légèrement oblique vers le haut, faces interne et externe concaves, extrémité plate biseautée ou convexe.

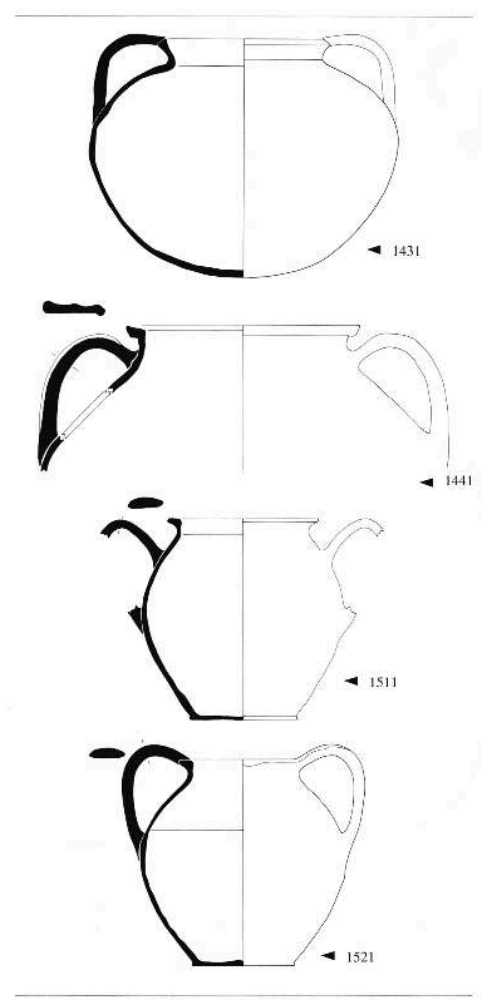

\section{Groupe 15 : Panse ovoïde haute, fond plat, absence d'élément verseur}

Forme 151 : absence de col, deux anses à section ovales verticales opposées sur haut et milieu panse, base étalée. 
Type 1511 : POT À CUIRE; une inflexion externe horizontale, faces convergentes, extrémité plate.

Forme 152 : absence de col, deux anses verticales à section ovale opposées sur lèvre et milieu panse, base étalée.

Type 1521 : POT À CUIRE; une inflexion externe horizontale, faces convergentes, extrémité plate.

Forme 153 : col court convergent, deux anses ovales verticales opposées sur haut et milieu panse, tripode.

Type 1531 : POT À CUIRE; une inflexion externe horizontale, faces parallèles, face interne concave, extrémité convexe.

77 Forme 154 : absence de col, une anse verticale de section ronde sur lèvre et milieu panse, pied droit court.

Type 1541 : COQUEMAR; une inflexion externe oblique vers le haut, faces parallèles, extrémité convexe.

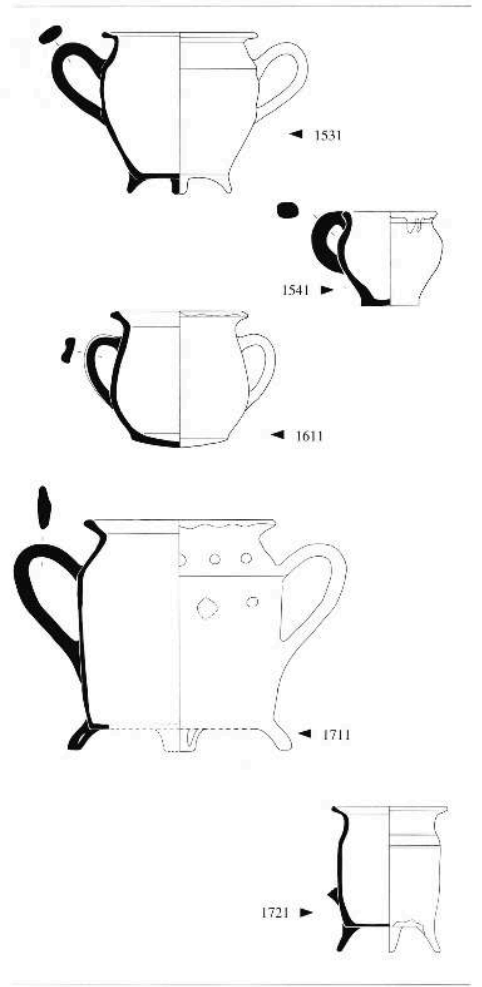

Groupe 16 : Panse surbaissée, fond bombé, absence d'élément verseur

Forme 161 : col court évasé, deux anses plates verticales opposées sur haut et bas panse.

Type 1611 : MARMITE; une inflexion externe oblique vers le bas, faces convergentes, extrémité plate.

Groupe 17 : Panse droite, fond plat, absence d'élément verseur

Forme 171 : col court convergent, liaison col/panse anguleuse, deux anses ovales verticales opposées sur haut et milieu panse, tripode. 
Type 1711 : POT À CUIRE; une inflexion externe oblique vers le haut, faces parallèles, face interne concave, extrémité convexe.

Forme 172 : col court cylindrique, liaison col/panse anguleuse, une anse ovale verticale attache sup. inconnue, attache inf. sur bas de panse, tripode.

Type 1721 : POT À CUIRE; une inflexion externe oblique vers le haut, faces parallèles, face interne concave, extrémité plate.

81 Forme 173 : col court convergent avec apex, deux anses plates verticales opposées sur haut panse, absence de pied.

Type 173 1: POT DE STOCKAGE; lèvre sans inflexion, épaississement externe, extrémité convexe.

Forme 174 : absence de col, une anse plate verticale sur lèvre et milieu panse, absence de pied.

Type 1741 : COQUEMAR; lèvre sans inflexion, légèrement oblique vers le haut, faces parallèles, extrémité convexe.

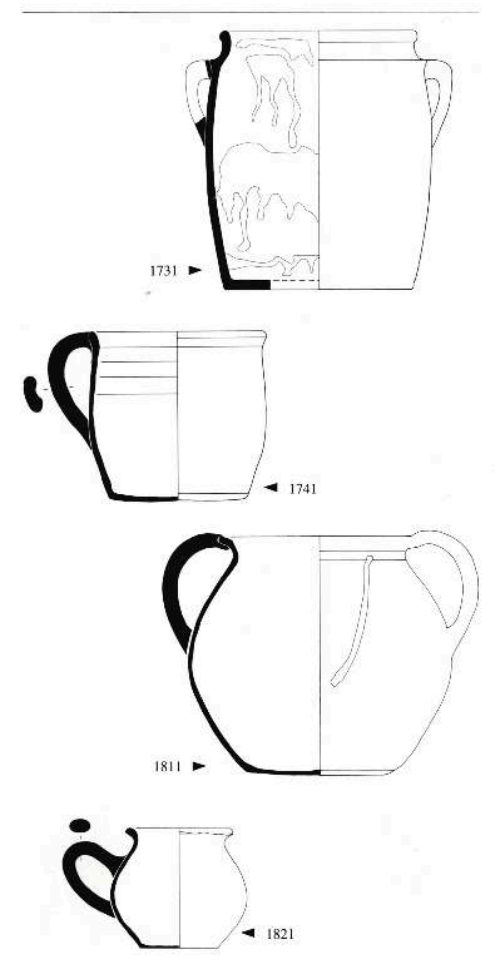

Groupe 18 : Panse globulaire ou ovale, fond plat, absence d'élément verseur

Forme 181 : col court évasé, deux anses ovales verticales opposées sur lèvre et milieu panse, absence de pied.

Type 1811 : MARMITE; une inflexion externe oblique vers le haut, faces parallèles, extrémité convexe.

Forme 182 : absence de col, une anse ovale verticale sur haut et bas panse, absence de pied.

Type 1821 : COQUEMAR; une inflexion externe oblique vers le haut, épaississement externe, extrémité plate ou convexe. 
Forme 183 : col court évasé, deux anses plates verticales opposées sur lèvre et milieu panse, absence de pied.

Type 1831 : MARMITE; lèvre sans inflexion, faces parallèles, extrémité convexe.

Type 1832 : MARMITE; une inflexion externe horizontale, faces convergentes, face interne concave, extrémité plate.

Forme 184 : col court évasé, une anse plate verticale sur col et bas panse, absence de pied.

Type 1841 : COQUEMAR; lèvre sans inflexion, faces parallèles, extrémité convexe.

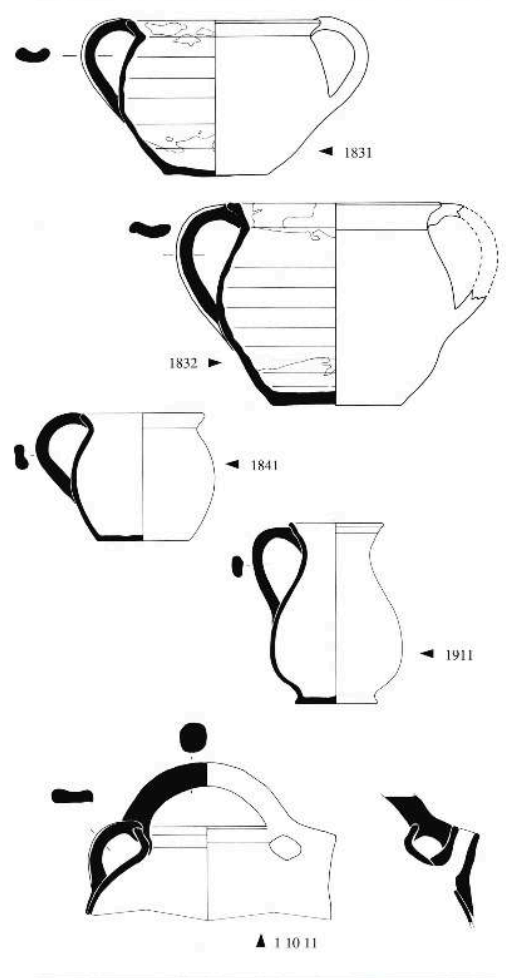

\section{Groupe 19 : Panse surbaissée, fond plat, élément verseur}

Forme 191 : col moyen, cylindrique puis évasé, une anse ovale verticale sur col et milieu panse opposée à un bec pincé, base étalée.

Type 1911 : CRUCHE; lèvre sans inflexion, faces parallèles, extrémité convexe.

\section{Groupe 110 : Panse globulaire, élément verseur}

Forme 1101 : absence de col, une anse plate verticale sur lèvre et haut panse opposée à un bec tubulaire ponté, une anse ronde en panier dans le même axe, fond non connu.

Type 11011 : CRUCHE; une inflexion externe oblique vers le haut, face interne concave, extrémité plate.

Forme 1102 : col court évasé, bec tubulaire perpendiculaire à une anse plate verticale sur lèvre et milieu panse, fond non connu.

Type 11021 : BIBERON; lèvre sans inflexion, faces parallèles, extrémité plate.

Forme 1103 : absence de col, un bec tubulaire perpendiculaire à une anse plate verticale sur lèvre et milieu panse, absence de pied, fond plat.

Type 11031 : BIBERON; absence de lèvre, épaississement externe. 
91 Forme 1104 : col court évasé, une anse plate verticale, attache sup. non connue et attache inf. sur bas de panse opposée à un bec tubulaire, pied court droit, fond plat.

Type 11041 : BIBERON; lèvre sans inflexion, épaississement externe, extrémité convexe.

Forme 1105 : absence de col, une anse plate verticale sur lèvre et haut panse opposée à un bec ponté, fond bombé.

Type 11051 : CRUCHE A BEC PONTE; une inflexion externe vers le haut, faces parallèles, face interne concave, extrémité plate ou faces convergentes, extrémité convexe.

93 Forme 1106 : col haut droit ou légèrement évasé, une anse plate verticale sur col et milieu ou bas panse opposée à un bec pincé, fond plat, absence de pied ou pied court droit.

Type 11061 : CRUCHE; lèvre sans inflexion, faces convergentes, face interne très oblique vers le bas ou faces divergentes, extrémité plate ou faces parallèles, extrémité convexe ou une inflexion externe oblique vers le haut, faces parallèles, extrémité convexe.
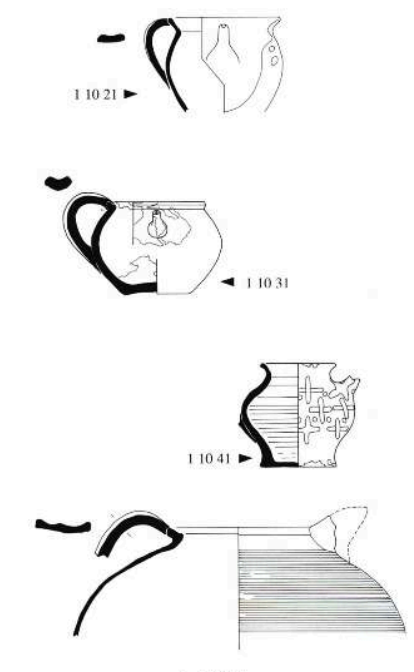

$\triangle 11051$

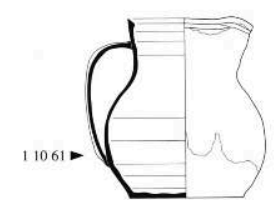

Groupe 111 : panse fuselée, fond plat ou concave, absence d'élément verseur

Forme 1111: col court évasé, une anse plate verticale sur col et milieu panse, base étalée.

Type 11111 : PICHET; lèvre sans inflexion, faces parallèles, face interne plate oblique coté interne.

Forme 1112: col haut droit ou légèrement évasé, une anse plate verticale sur col et milieu panse, pied haut ou parfois court tronconique, ou base étalée. 
Type 11121 : PICHET; une inflexion externe oblique vers le haut, faces convergentes ou parallèles, parfois face interne concave, extrémité convexe.

\section{Groupe 112 : panse surbaissée, fond plat, absence d'élément verseur}

Forme 1121 : col haut droit, une anse plate verticale sur col et bas panse, absence de pied.

Type 11211 : PICHET; une inflexion externe oblique vers le haut, faces convergentes. Type 11212 : PICHET; lèvre sans inflexion, faces parallèles, extrémité convexe ou face interne oblique vers le bas.

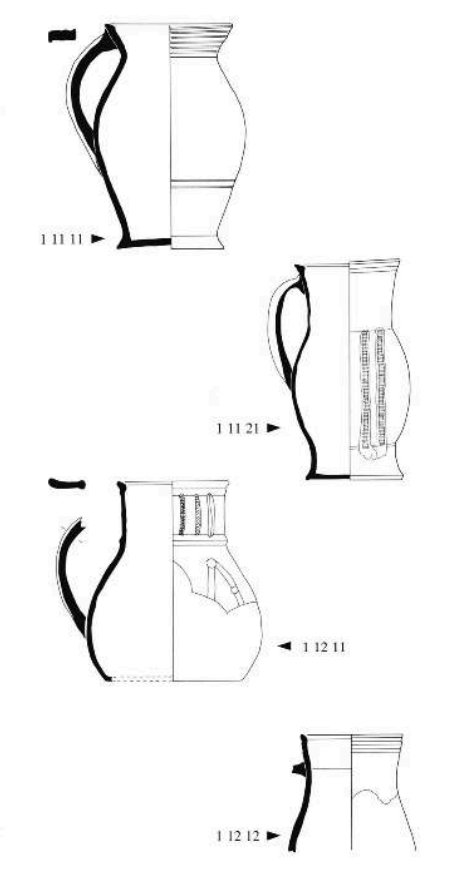

\section{Classe 2 vases bas fermés}

\section{Groupe 21 : panse évasée, rectiligne, fond plat, absence d'élément verseur}

Forme 211 : col moyen convergent, liaison col/panse anguleuse, deux tenons plats opposés sur haut panse, pied moyen évasé.

Type 2111 : POT DE STOCKAGE; une inflexion externe oblique vers le haut, faces parallèles, extrémité convexe.

\section{Groupe 22 : panse évasée courbe, fond bombé, absence d'élément verseur}

Forme 221 : col moyen convergent, liaison col panse anguleuse, deux anses plates verticales opposées sur haut et milieu panse.

Type 2211 : POT DE STOCKAGE; lèvres sans inflexion, faces divergentes, extrémité convexe. 
Groupe 23 : panse évasée courbe, fond plat, absence d'élément verseur

Forme 23 1: col court convergent, liaison col panse anguleuse, deux anses plates verticales opposées sur haut et milieu panse, absence de pied.

Type 2311 : POT DE STOCKAGE; lèvre sans inflexion, faces divergentes, extrémité plate.
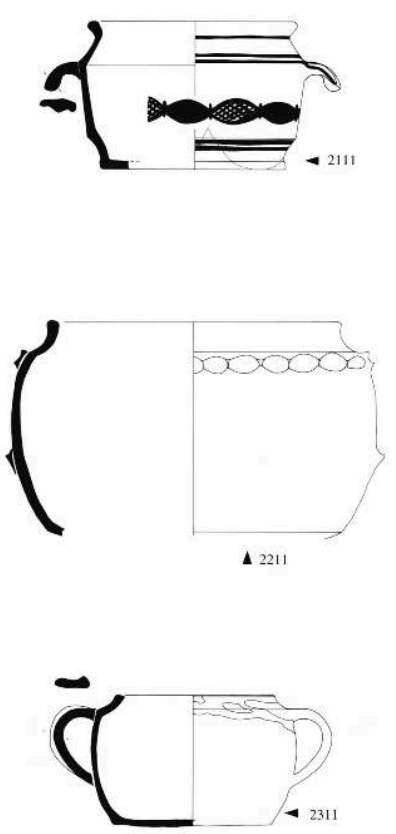

\section{Classe 3 vases bas ouverts}

Groupe 31 : Paroi cylindrique, absence de marli, fond plat, absence de pied, parfois bec pincé

Forme 311 : une ou deux anses plates verticales opposées sur rebord et bas paroi.

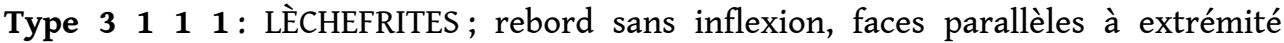
convexe, horizontale ou oblique vers le bas côté interne, parfois léger épaississement interne ou externe.

Groupe 32 : Paroi évasée rectiligne, absence de marli, fond plat, absence de pied

Forme 321 : deux tenons horizontaux opposés sur rebord ou parfois deux anses plates verticales opposées sur rebord et milieu paroi, absence d'élément verseur.

Type 3211 : BASSIN; une inflexion externe oblique vers le haut ou horizontale, faces parallèle; face interne plate ou convexe, face externe concave ou convexe ou à épaississement ; extrémité convexe.

Forme 322 : deux anses plates verticales opposées sur rebord et milieu paroi, absence d'élément verseur.

Type 3221 : JATTE ; une inflexion externe horizontale, faces convergentes, extrémité convexe pointue, ou faces parallèles, extrémité convexe. 
Type 3222 : JATTE; rebord sans inflexion, épaississement externe, extrémité plate, oblique vers le bas côté externe.
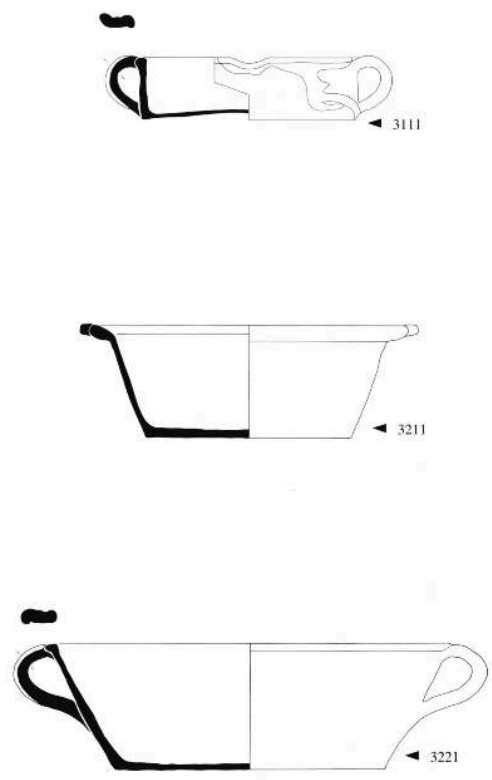

Forme 323 : deux anses plates verticales opposées sur haut et bas paroi, absence d'élément verseur.

Type 3231 : JATTE; rebord sans inflexion, faces divergentes, extrémité concave.

Forme 324 : deux tenons horizontaux opposés sur rebord perpendiculaire à un bec pincé.

Type 3241 : JATTE; une inflexion externe horizontale, faces convergentes, extrémité convexe.

Forme 325 : absence d'élément de préhension, absence d'élément verseur.

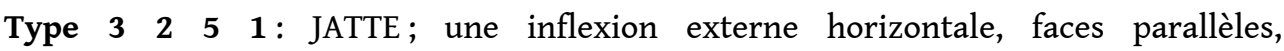
épaississement externe et interne ou interne, extrémité convexe.

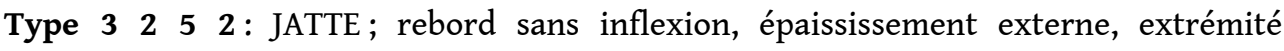
convexe.

Type 325 3: JATTE; une inflexion externe horizontale, face interne concave, extrémité plate mais oblique vers l'extérieur.

Type 3254 : JATTE; une inflexion externe très oblique vers le bas, faces convergentes, extrémité convexe. 


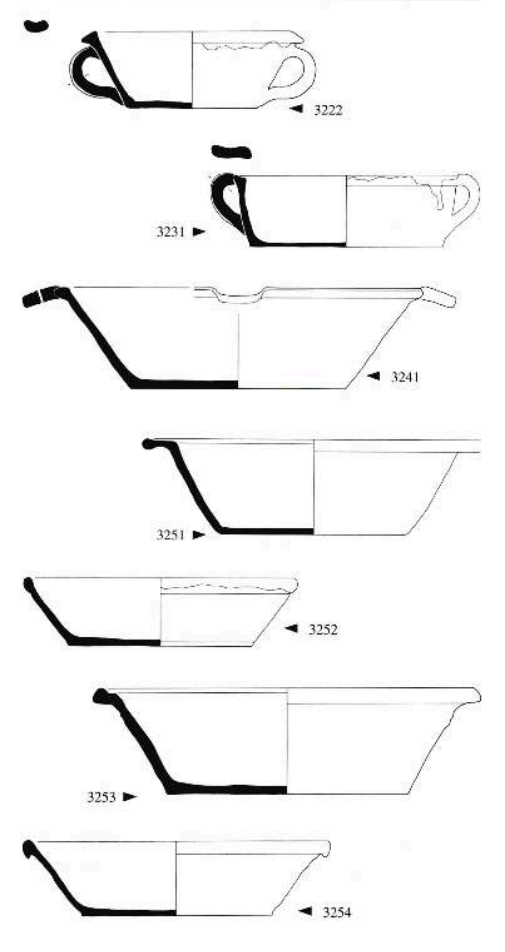

106 Forme 326 : une anse plate verticale sur rebord et bas paroi, absence d'élément verseur.

Type 3261 : TASSE; rebord sans inflexion, faces légèrement divergentes, extrémité plate.

Groupe 33 : Paroi évasée rectiligne ou légèrement courbe, marli, fond plat

107 Forme 331 : parfois pied droit court ou base étalée, absence d'élément verseur et de préhension.

Type $\begin{array}{llll}3 & 3 & 1 & 1\end{array}$ : ASSIETTE/PLAT CREUX; rebord sans inflexion, faces parallèles, extrémité convexe ou plate, ou à épaississement interne et externe ou à épaississement interne, marli petit ou moyen, évasé ou horizontal. 

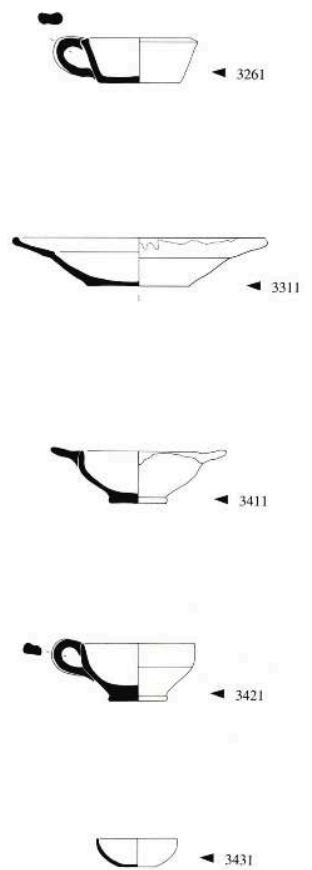

Groupe 34 : Paroi hémisphérique avec/sans carène externe, absence d'élément verseur, fond plat

108 Forme 341 : petit pied droit, deux oreilles horizontales opposées sur rebord. Type 3411 : ÉCUELLE; rebord sans inflexion, faces convergentes, extrémité pointue.

109 Forme 342 : petit pied, une anse verticale sur rebord et milieu paroi. Type 3421 : TASSE ; rebord sans inflexion, faces convergentes, extrémité pointue.

110 Forme 343 : absence d'élément de préhension, absence de pied Type 3431 : COUPELLE; rebord sans inflexion, faces convergentes, extrémité pointue.

111 Forme 344 : une oreille horizontale sur rebord avec au-dessous un anneau de préhension, petit pied annulaire.

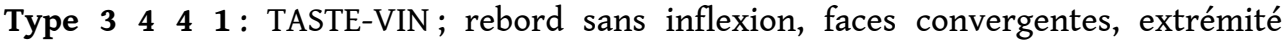
pointue. 


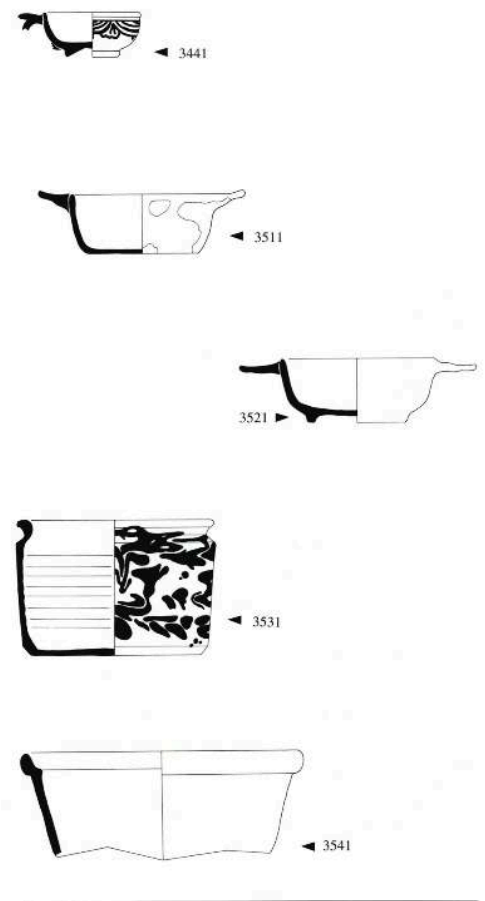

Groupe 35 : Paroi rectiligne légèrement évasée, absence de marli, fond plat, absence d'élément verseur

112 Forme 351 : deux oreilles horizontales opposées sur rebord, absence de pied.

Type 3511 : ÉCUELLE; rebord sans inflexion, faces convergentes, extrémité pointue.

113 Forme 352 : deux oreilles horizontales opposées sur rebord, petit pied cylindrique. Type 3521 : ÉCUELLE; rebord sans inflexion, faces convergentes, extrémité pointue.

114 Forme 353 : absence d'élément de préhension, liaison rebord/paroi anguleuse, absence de pied.

Type 3531 : POT À CONSERVE; rebord sans inflexion à gorge puis épaississement externe, extrémité convexe.

115 Forme 354 : absence d'élément de préhension, pied inconnu; liaison rebord/paroi avec ressaut interne.

Type 3541 : POT DE FLEURS; une inflexion externe oblique vers le haut, face interne concave, épaississement externe, extrémité convexe.

Groupe 36 : Paroi légèrement évasée courbe, marli, fond plat

116 Forme 361 : absence d'élément verseur, de préhension, de pied.

Type 3611 : ASSIETTE CREUSE; rebord sans inflexion, épaississement interne.

Type $\begin{array}{lllll}3 & 6 & 1 & 2\end{array}$ : ASSIETTE CREUSE; une inflexion externe horizontale, léger épaississement externe et interne, extrémité convexe. 

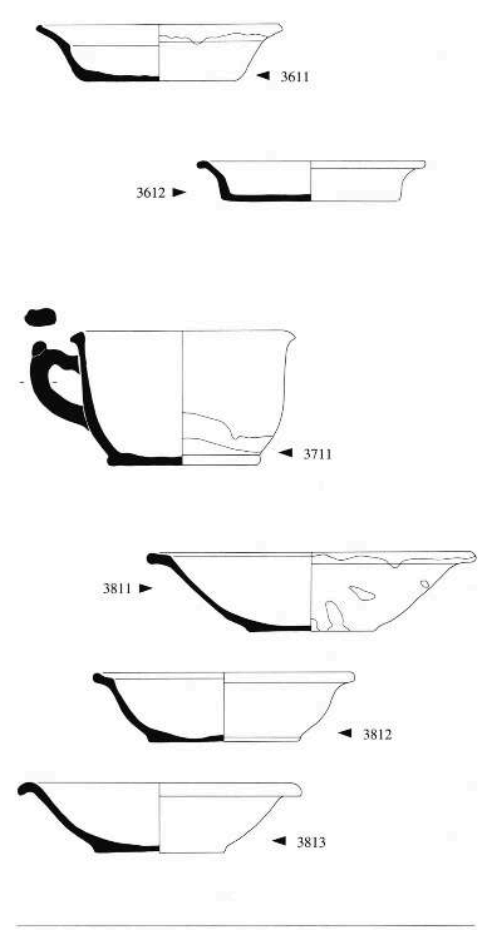

Groupe 37 : Paroi haute, légèrement évasée, absence de marli, fond plat

117 Forme 371 : base étalée, absence d'élément verseur, une anse verticale avec ou sans poucier, sur haut et bas paroi.

Type 3711 : POT DE CHAMBRE; une inflexion externe oblique vers le bas, faces convergentes ou à épaississement externe, extrémité convexe.

Groupe 38 : Paroi évasée courbe, absence de marli, fond plat

118 Forme 381 : absence d'élément de préhension et d'élément verseur.

Type 3811 : PLAT CREUX; une inflexion externe horizontale, faces parallèles, extrémité convexe.

Type 3812 : PLAT CREUX ; une inflexion externe oblique vers le haut, faces parallèles, extrémité convexe.

Type 3813 : PLAT CREUX; une inflexion externe oblique vers le bas, faces parallèles, extrémité convexe.

Type 3814 : PLAT CREUX ; une inflexion externe horizontale, épaississement interne/ externe, extrémité convexe.

119 Forme 382 : deux tenons sur milieu paroi, absence d'élément verseur.

Type 3821 : JATTE; une inflexion externe oblique vers le haut, face interne concave, extrémité convexe.

120 Forme 383 : un manche creux sur rebord, absence d'élément verseur.

Type 3831 : POÊLON; rebord sans inflexion, faces parallèles, extrémité convexe.

Type 3832 : POÊLON; une inflexion externe horizontale, faces parallèles, extrémité convexe. 
121 Forme 384 : bec pincé, liaison rebord/paroi anguleuse, deux anses plates horizontales opposées sur haut paroi.

Type 3841 : JATTE; une inflexion externe oblique vers le haut, faces parallèles, extrémité convexe.

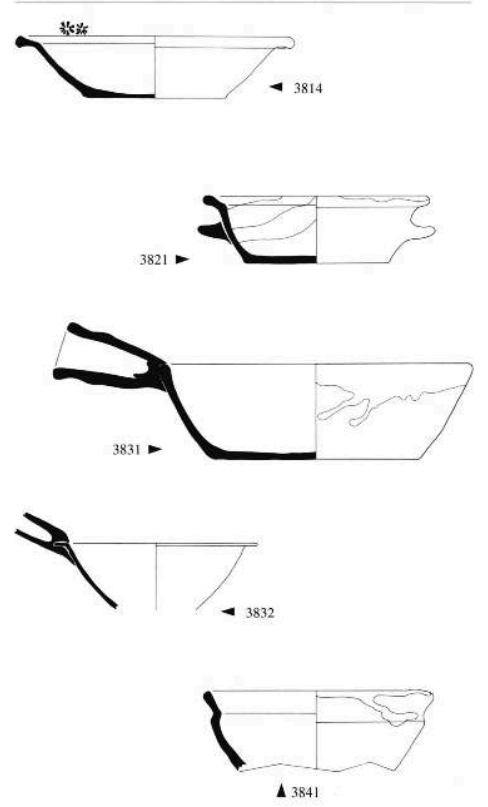

\section{Classe 4 vases plats ouverts}

\section{Groupe 41 : Absence de paroi, marli, fond plat}

Forme 411 : marli rectiligne très évasé, absence de pied, d'élément verseur, d'élément de préhension.

Type 4111 : ASSIETTE PLATE; rebord sans inflexion, faces parallèles, extrémité plate ou épaississement interne/externe, extrémité convexe.

Forme 412 : marli évasé à face interne convexe, absence de pied, d'élément verseur, d'élément de préhension.

Type $4 \begin{array}{lll} & 2 & 1\end{array}$ : ASSIETTE CREUSE; rebord sans inflexion, épaississement interne, extrémité convexe.

Groupe 42 : Paroi évasée courbe, marli peu évasé, fond plat

124 Forme 42 1: marli à face interne concave, absence de pied, d'élément verseur, d'élément de préhension.

Type 4211 : ASSIETTE PLATE; rebord sans inflexion, faces parallèles, extrémité convexe. 
Groupe 43 : Paroi évasée courbe, marli évasé, fond plat

Type 4321 : SOUCOUPE; rebord sans inflexion, épaississement interne, extrémité plate oblique côté externe.
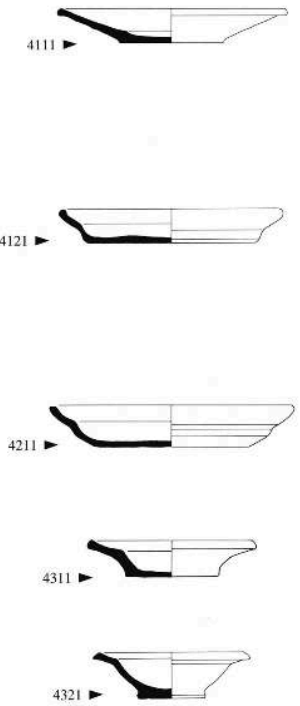

\section{Classe 5 vases hauts ouverts}

Groupe 51 : Paroi rectiligne légèrement évasée, absence de marli, fond plat ou concave

Forme 511 : absence d'élément de préhension et d'élément verseur, pied court tronconique.

Type 5111 : GOBELET; rebord sans inflexion, extrémité plate, petit épaississement interne.

Groupe 52 : Paroi haute, évasée courbe, absence de marli, fond percé

Forme 521 : absence d'élément de préhension et d'élément verseur, pied annulaire.

Type 5211 : POT DE FLEURS; épaississement externe, gorge externe, extrémité convexe. 

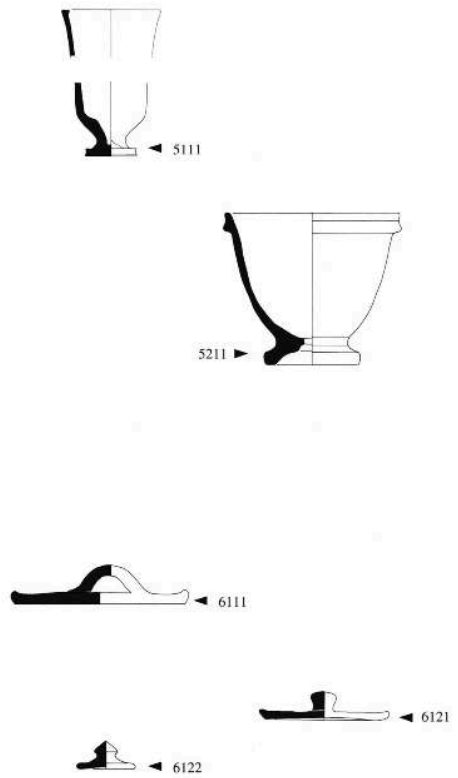

\section{Classe 6 couvercles}

\section{Groupe 61 : couvercle plat}

129 Forme 611 : une anse centrale horizontale ronde.

Type 6111 : rebord biseauté côté interne, épaississement externe.

130 Forme 612 : un tenon vertical de section ronde Type 6121 : rebord biseauté côté interne, épaississement externe Type 6122 : rebord plat, extrémité convexe. 

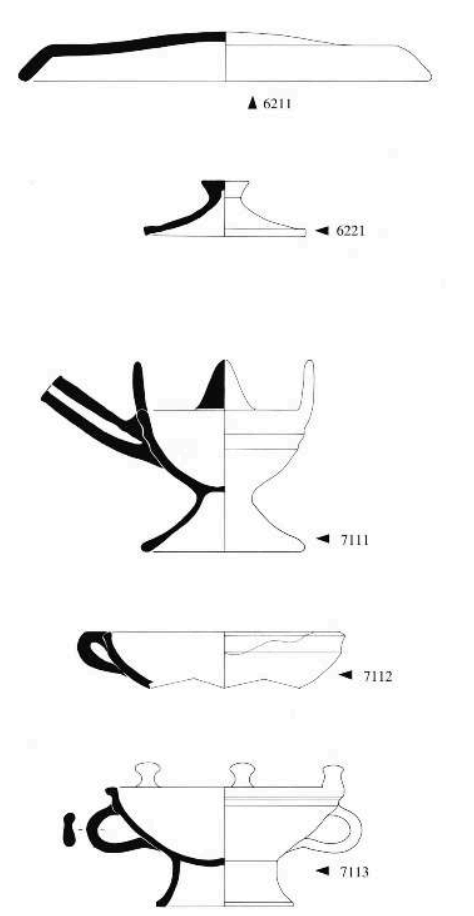

\section{Groupe 62 : couvercle creux}

Forme 621 : une anse horizontale centrale.

Type 6211 : rebord évasé, extrémité convexe.

Forme 622 : un tenon de préhension vertical.

Type 6221 : rebord sans inflexion, faces divergentes, extrémité plate ou biseautée.

\section{Classe 7 récipients divers}

Groupe 71 : Paroi évasée courbe, absence de marli, grand pied douche

Forme 711 : absence d'élément verseur, deux anses plates verticales opposées sur rebord et haut paroi ou sous le rebord et bas paroi ou un manche creux sur haut paroi, trois supports verticaux disposés en triangle sur le rebord.

Type 7111 : CHAUFFE-PLATS; rebord sans inflexion, faces parallèles, extrémité convexe.

Type 71112 : CHAUFFE-PLATS; rebord à gorge externe, épaississement interne, extrémité plate oblique.

Type 7113 : CHAUFFE-PLATS; rebord à une inflexion externe horizontale, extrémité convexe.

Groupe 72 : Paroi rectiligne, ressaut interne, absence de marli, ouverture dans bas paroi, fond plat

Forme 721 : absence de pied, absence d'élément de préhension.

Type 7211 : RÉCHAUD ; rebord sans inflexion, faces parallèles, extrémité plate. 
Groupe 73 : panse globulaire, fond plat, absence d'élément verseur et d'élément de préhension

Forme 731 : TIRELIRE; base étalée, ouverture dans partie supérieure de la panse.

\section{Groupe 74 : panse globulaire, élément verseur}

Forme 741 : GOURDE; un goulot court droit relié à la panse par un anneau.
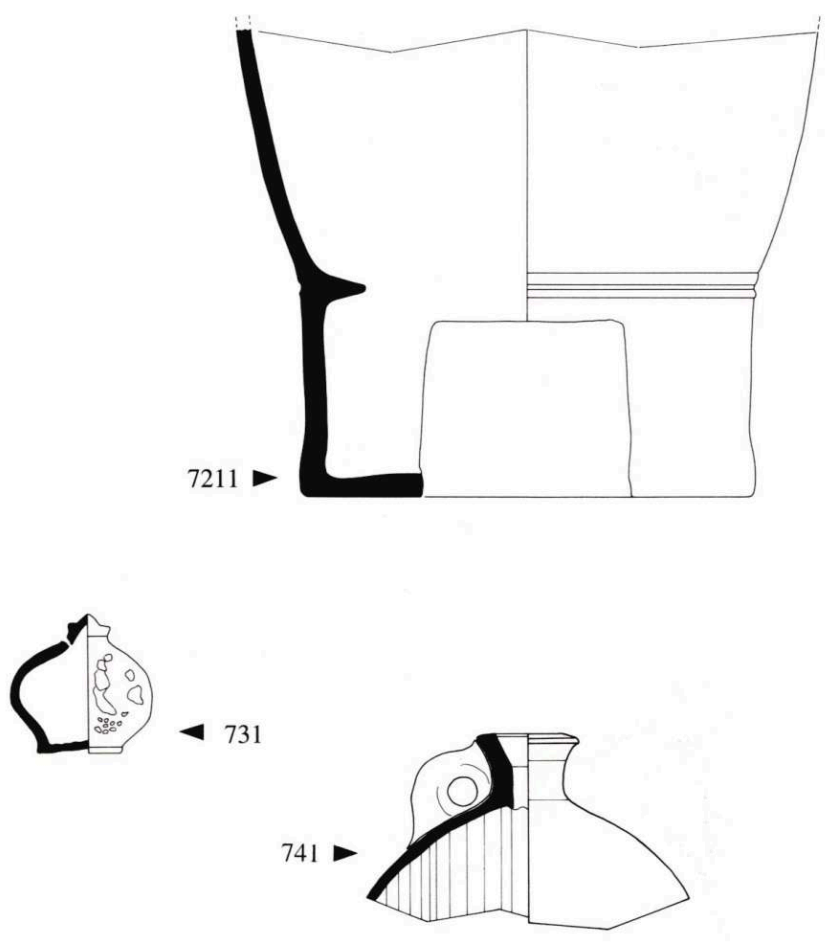

\section{Formes incomplètes}

Ce classement relationnel montre ses limites lorsqu'il s'agit de traiter les vases incomplets, du moins certains d'entre eux. Paradoxalement, si l'on ne rencontre guère de complications dans le cas d'un vase sans rebord, le problème devient plus ardu, lorsqu'on ne dispose que de la lèvre. En effet, la détermination d'un type tient compte essentiellement de ce segment, tout en étant dépendant des autres, puisqu'il s'agit d'un classement hiérarchique et relationnel. Le dernier chiffre, celui qui renseigne sur le type, ne peut pas être précédé de deux zéros (qui renvoient à la forme et au groupe), par manque d'information.

Par conséquent, les récipients incomplets sont traités de manière séparée, tout en respectant la méthode utilisée jusqu'alors. Simplement, à partir de l'identification de la classe, qui ne pose généralement aucun problème, nous rajoutons d'office un zéro, qui devient donc le signe distinctif des vases incomplets. Le classement se poursuit sur les 3 niveaux restants, les critères restent inchangés, bien que l'on fasse beaucoup plus référence à des absences d'identification. Cette méthode présente comme avantages, d'une part de ne pas interférer dans la typologie précédente, et d'autre part, de rayer sans problème de la liste tout vase que l'on aura, par la suite, réussi à reconstituer dans 
son intégralité ; celui-ci ira s'intégrer dans la typologie définitive. Ces vases incomplets ne concernent que les classes 1 et 3 et donnent 10 groupes, 28 formes et 33 types. La typologie complète est donc constituée de 7 classes, 44 groupes, 114 formes et 141 types.

\section{Vases incomplets}

\section{Classe 1 vases hauts fermés}

Groupe 101 : panse globulaire, fond hémisphérique ou bombé, absence d'élément verseur

Forme 1011 : absence de col, une anse pleine en panier sur lèvre.

Type 10111 : VASE DE TRANSPORT; lèvre sans inflexion, faces parallèles, extrémité plate, oblique côté interne.

Type 10112 : VASE DE TRANSPORT; lèvre dite "en bandeau", à une inflexion externe oblique vers le haut, face interne concave, ressaut sur face externe, extrémité convexe.

Forme 1012 : absence de col, deux anses plates verticales opposées sur lèvre et haut panse.

Type 10121 : MARMITE; une inflexion externe oblique vers le haut, face interne concave, faces convergentes.

Type 10122 : MARMITE ; lèvre sans inflexion, faces parallèles, extrémité convexe.

Forme 1013 : absence de col, une anse plate verticale sur lèvre et haut panse.

Type 10131 : COQUEMAR; une inflexion externe oblique vers le haut, faces parallèles, extrémité convexe.

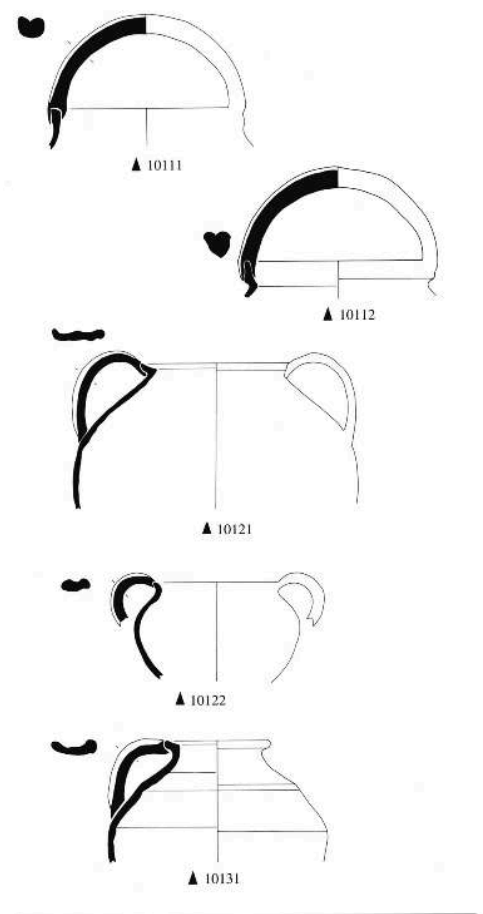


142 Forme 1014 : col court légèrement évasé, deux anses plates verticales opposées sur col et haut panse.

Type 10141 : MARMITE ; lèvre sans inflexion, faces divergentes, extrémité plate.

Forme 1015 : col court évasé, présence ou absence d'élément de préhension non connue.

Type 10151 : MARMITE?; lèvre sans inflexion, épaississement interne, extrémité convexe.

144 Forme 1016 : col moyen droit, une ou deux anses plates verticales (opposées?) sur jonction col/panse.

Type 10161 : MARMITE ?; une inflexion externe très oblique vers le bas, faces parallèles, extrémité convexe.

145 Forme 1017 : col court évasé, une ou deux anses plates verticales (opposées) sur lèvre et milieu panse.

Type 1017 1: MARMITE ?; lèvre sans inflexion, face interne concave, extrémité convexe.

Type 10172 : MARMITE ?; lèvre sans inflexion, faces parallèles, extrémité convexe.

Forme 1018 : col court évasé, une anse plate verticale sur col et milieu panse.

Type 10181 : MARMITE? PICHET ?; une inflexion externe oblique vers le haut, face interne concave, extrémité convexe.

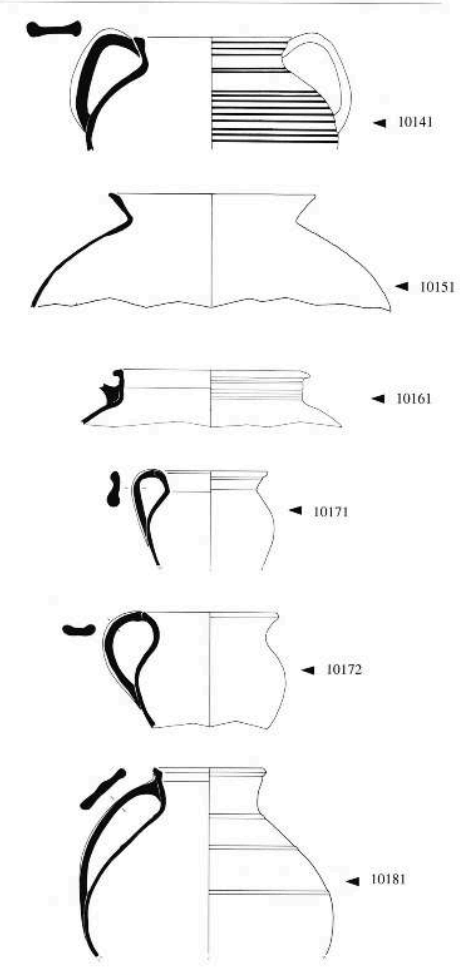

147 Forme 1019 : col court évasé avec ressaut interne, une ou deux anses plates verticales sur lèvre.

Type 10191 : MARMITE ?; lèvre sans inflexion, faces parallèles, extrémité convexe.

Forme 10110 : col court très évasé, deux anses plates verticales opposées sur lèvre et sans doute milieu panse.

Type 101101 : MARMITE; lèvre sans inflexion, faces parallèles, extrémité convexe. 


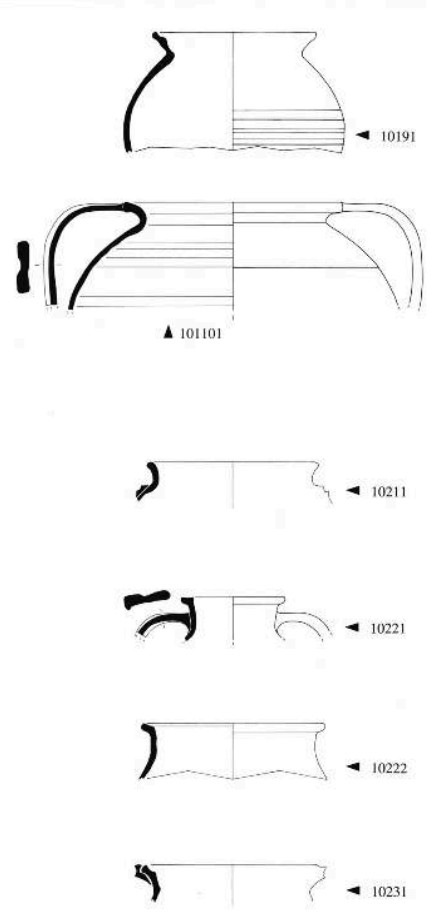

Groupe 102 : panse et fond inconnus, absence d'élément verseur

Forme 1021 : col court très légèrement évasé, deux anses plates verticales opposées sur haut panse ; attache inférieure inconnue.

Type 10211 : MARMITE ?; lèvre sans inflexion, faces parallèles, extrémité convexe.

Forme 1022 : col court (?) droit, une ou deux anses plates verticales (opposées) sur col ; attache inférieure inconnue.

Type 10221 : MARMITE ?; une inflexion externe horizontale, faces parallèles, extrémité convexe.

Type 10222 : MARMITE ?; une inflexion externe oblique vers le haut, face interne concave, parfois épaississement externe, extrémité convexe.

151 Forme 1023 : col court évasé, deux anses plates verticales opposées sur lèvre ; attache inférieure inconnue.

Type 10231 : MARMITE?; une inflexion externe oblique vers le haut, face interne concave, extrémité plate.

Groupe 103 : panse et fond inconnus, présence d'élément verseur ou de préhension non certifiée

Forme 1031 : sans doute col court très évasé.

Type 1031 1: MARMITE? lèvre sans inflexion, épaississement externe, faces convergentes.

Forme 1032 : col évasé, face interne concave.

Type 10321 : une inflexion externe oblique vers le haut, faces parallèles, extrémité plate. 
Type 10322 : MARMITE ?; lèvre sans inflexion, épaississement externe et interne, extrémité plate.

Forme 1033 : col court (?) légèrement évasé.

Type 10331 : MARMITE ?; lèvre sans inflexion, faces divergentes, extrémité plate.

Forme 1034 : absence de col, une anse en panier de section ovale digitée sur lèvre.

Type 10341 : POT DE TRANSPORT; absence de lèvre, ressaut plat côté externe.

Forme 1035 : col haut cylindrique, une anse plate sur lèvre et haut panse.

Type 10351 : PICHET ?; lèvre sans inflexion, faces parallèles, extrémité plate.

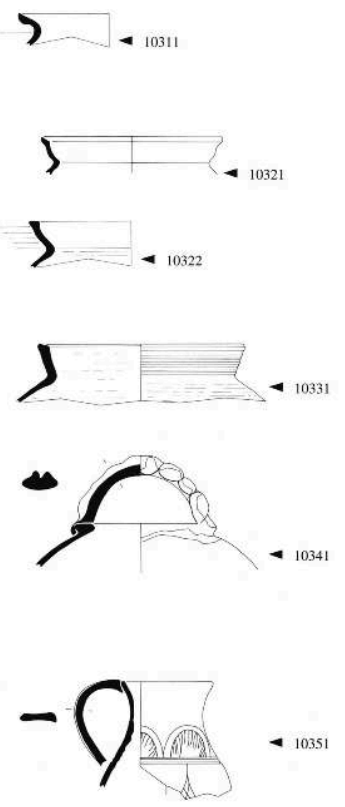

Groupe 104 : panse globulaire, fond hémisphérique, présence d'élément verseur non certifiée

157 Forme 1041 : col court droit, présence ou absence d'élément de préhension non connue.

Type 1041 1: MARMITE?; une inflexion externe oblique vers le haut, faces convergentes, extrémité convexe.

Groupe 105 : panse ovoïde, fond sans doute plat, présence d'élément verseur non certifiée

Forme 1051 : col moyen évasé, présence ou absence d'élément de préhension et de pied non connue.

Type 10511 : POT DE CHAMBRE ?; lèvre à une inflexion externe légèrement oblique vers le haut, faces convergentes, face interne plate. 
Groupe 106 : panse ovoïde, fond bombé ou plat, absence d'élément verseur connue.

Type 10611 : POT ?; une inflexion externe oblique vers le haut, faces parallèles, extrémité plate.

Groupe 107 : Panse surbaissée, fond plat, présence d'élément verseur non certifiée

Forme 1071 : col court évasé ?, deux anses plates opposées sur haut panse, absence de pied.

Type 10711 : CRUCHE DE STOCKAGE; lèvre inconnue.
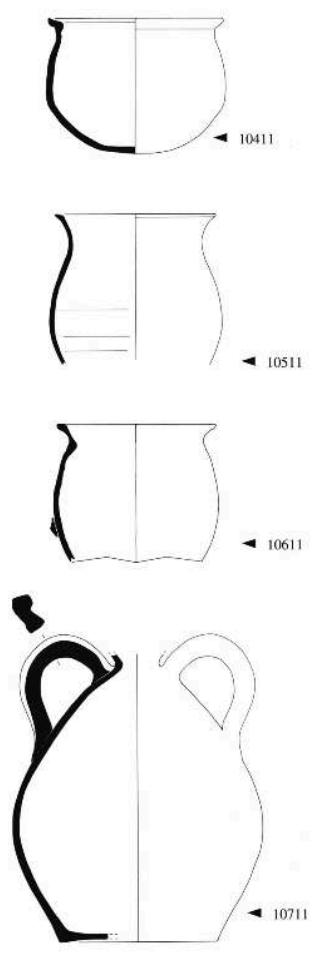

\section{Classe 3 vases bas ouverts}

Groupe 301 : paroi évasée courbe, absence de marli, fond sans doute plat

Forme 3011 : absence ou présence d'élément de préhension, d'élément verseur ou de pied non connue.

Type 30111 : JATTE; une inflexion externe horizontale, face interne plate, face externe convexe, extrémité convexe.

Groupe 302 : paroi évasée rectiligne, absence de marli, fond plat, absence de pied

Forme 3021 : absence ou présence d'élément de préhension, d'élément verseur non connue.

Type 30211 : TASSE ? rebord sans inflexion, faces divergentes, extrémité plate. 
Forme 3022 : une ou deux anses plates sur bas paroi perpendiculaires à un bec pincé et attache sup. non connue.

Type 30221 : JATTE; une inflexion externe horizontale, faces convergentes, face interne concave.

Groupe 303 : Paroi cylindrique, absence de marli, fond plat, absence de pied, parfois bec pincé

Forme 3031 : absence ou présence d'un élément de préhension non connue.

Type 30311 : JATTE; rebord à gorge externe puis à une inflexion externe oblique vers le haut, faces convergentes, extrémité convexe.
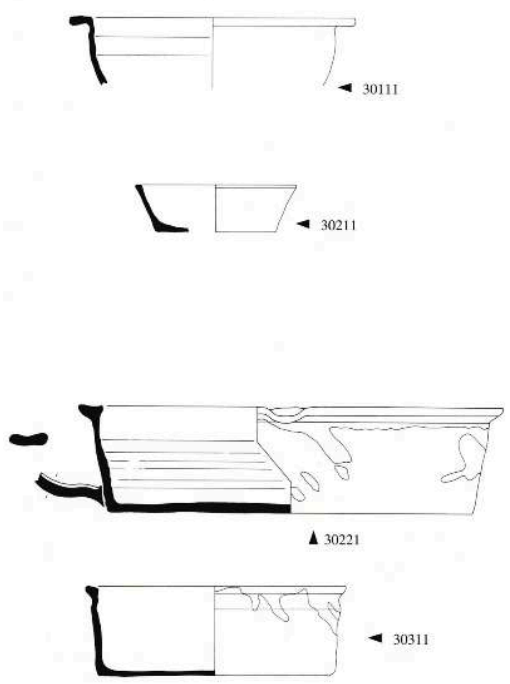

\section{Technologie}

165 Il est important d'intégrer dans la classification des éléments d'ordre technologique; dans ce but a été introduite la notion de «famille » caractérisée par un certain nombre de critères, isolés ou combinés selon les cas : mode de cuisson, présence ou non de glaçure, d'engobe, de décors. Nous ne faisons pas intervenir les caractéristiques des argiles; en effet, une simple description de la pâte n'apporte rien d'intéressant et multiplie les groupes. De plus un programme d'analyses en laboratoire est en cours sur ce sujet et les résultats arrivent régulièrement : ainsi, les échantillons issus des fouilles lyonnaises et concernant les familles B1 et B2 proviennent respectivement des régions de Meillonnas-Treffort et de Larnage.

166 Chaque famille est définie par une lettre de l'alphabet qui se rapproche le plus de la description fournie : $G$ pour grise, B pour blanche, E pour les céramiques engobées, etc. 


\section{Code et definition}

décor; les pâtes sont en général de couleur claire :

E1 : Cette famille tire son appellation du revêtement d'engobe blanc passé sur ses récipients avant la pose d'une glaçure de couleur verte.

E2 : Sur le vase tourné et séché, on passe une couche couvrante d'engobe (argile très finement tamisée et délayée à l'eau) de couleur rouge, parfois lie-de-vin. Dans un deuxième temps, après séchage de cette engobe, on procède au décor avec un instrument rempli d'argile semi-liquide de couleur blanche-la barbotine-et muni d'un bec assez fin pour en contrôler la sortie. La glaçure transparente peut alors être posée, après un nouveau temps de séchage ; sur le fond sombre, elle ressort de couleur rouge (les variations notées dans la couleur de la glaçure sont en fait imputables à celles de l'engobe) et sur la barbotine, d'une couleur tirant sur le jaune. Parfois la barbotine ou la glaçure sont chargées d'oxyde de cuivre, ce qui donne une couleur verte aux récipients. E3 : Cette technique de décoration dérive de la précédente: le récipient, tourné et séché, est recouvert d'un engobe rouge ou blanc; sur cette base, encore fraîche et liquide, on verse une deuxième couche, de couleur différente, qui est ensuite mélangée par rotation du récipient ou alors «travaillée » au moyen d'une plume promenée sur la surface. Après séchage, on applique une glaçure transparente.

E4 : Pâte claire, engobe blanc, glaçure jaune.

E5 : Le trait commun à ces deux familles réside dans le fond d'engobe blanc. Alors que pour la famille $\mathrm{E} 4$, la glaçure jaune est appliquée uniformément sur la surface, la famille E5 ajoute un décor de barbotine rouge, très souvent agrémenté de taches vertes obtenues à partir d'oxyde de cuivre.

E6: Pâte beige, engobe lie-de-vin et parfois décor à la barbotine blanche, glaçure transparente ; le tout localisé autour de l'élément verseur.

E7 : Sgraffito : sur le récipient recouvert d'un engobe blanc, on pratique des incisions à la pointe sèche avant l'application de barbotine rouge et d'oxyde de cuivre. Une glaçure jaune recouvre le tout.

E8: Divers: cette catégorie regroupe toutes les céramiques présentes à peu d'exemplaires et qui ne rentrent pas dans les familles décrites ci-dessus, telles que les glaçures transparentes sur engobe rouge ou les glaçures noires. 
GR : Cette famille concerne les grès.

173

P : Porcelaine.

Ces deux dernières familles ne se retrouvent pas dans le matériel étudié ici ; mais la présence de grès et de porcelaine du XVIe $s$. lors de fouilles récentes nous conduit à les intégrer dans cette liste.

174 Maintenant une carte d'identité complète peut être fournie pour chaque vase; par exemple : marmite, 1311, famille $\mathrm{G}$.

\section{NOTES}

1. Après consultation de ces ouvrages, il a paru plus simple d'utiliser le classement proposé par le Vocabulaire Typologique des Objets Civils Domestiques où une répartition des objets par fonction est déjà mise en place. 


\section{Chapitre 2. Les critères de datation à partir des données archéologiques}

1 De nombreuses contraintes président à la rédaction de ce chapitre et divisent l'étude en deux parties: l'une traite d'une période allant de la fin du XIIe s. au XIVe s., l'autre, d'une période allant du XVIe s. au XVIIIe s.

2 Pourquoi une telle coupure ? Principalement parce que le mobilier fait défaut pour le XIVe et une grande partie du XVe s. Ce n'est qu'à la fin de ce siècle que l'on recommence à collecter des informations à partir de trois sites, non inclus dans cette étude: un dépotoir me Tramassac, un second place de la Bourse et des couches d'occupation place des Terreaux: ces trois ensembles sont publiés ou en cours de publication. Ils sont évoqués ici pour comparaison, car riches d'informations chronologiques.

$\mathrm{Du}$ XIIe au XIVe s., chaque site est traité suivant l'ordre chronologique. L'étude se fait de manière identique : contexte archéologique, étude céramologique et proposition de datation.

4 Pour le XVe s., le mobilier des trois ensembles évoqués plus haut fait l'objet d'une brève synthèse.

5 A partir du XVIe s., le nombre de structures mises au jour et étudiées-plus de trente-la quantité et la variété du matériel recueilli en fouille à Lyon, et la présence de nombreux critères de datation ont conduit à adopter une démarche légèrement différente : dans un premier temps, sont présentés les contextes archéologiques de chaque site; puis sont abordées, de manière chronologique, l'étude céramologique et la datation, structure par structure, tous chantiers confondus, en analysant d'abord celles qui présentent des indices de datation absolue et en terminant par celles qui ne fournissent aucun élément chronologique, hormis la comparaison typologique. Enfin, un récapitulatif de l'ensemble des types se trouve en chapitre 3 dans la synthèse chronologique, sous forme de tableaux, pour chaque époque. 


\section{Du XIle au XIVe siècle}

\section{Fin XIle s., Lyon, rue Palais-Grillet}

\section{Contexte archéologique}

\section{Les fosses et la rue médiévale}

6 Le projet d'extension des magasins «Le Printemps", situés dans le deuxième arrondissement, nécessitait le décaissement de la portion sud de la rue du PalaisGrillet, en plein cœur de la presqu'île. L'intervention archéologique a mis au jour plusieurs niveaux d'occupation, aussi bien gallo-romains que modernes (Ayala 1992, pp. 293-305). De l'époque médiévale, nous avons retenu le matériel de 4 fosses, période VIII, ainsi que celui de la rue, pour leur chronologie relative et absolue.

7 Les fosses, de forme ovale, larges et profondes, remplies d'une terre noire et grasse et souvent installées à la croisée de structures antiques, sont interprétées comme fosses de récupération de matériaux (fig. 119). Elles témoignent de la reprise d'une activité dans ce secteur après une interruption de plus de huit siècles.

119 - Lyon, rue Palais-Grillet, emplacement des fosses médiévales

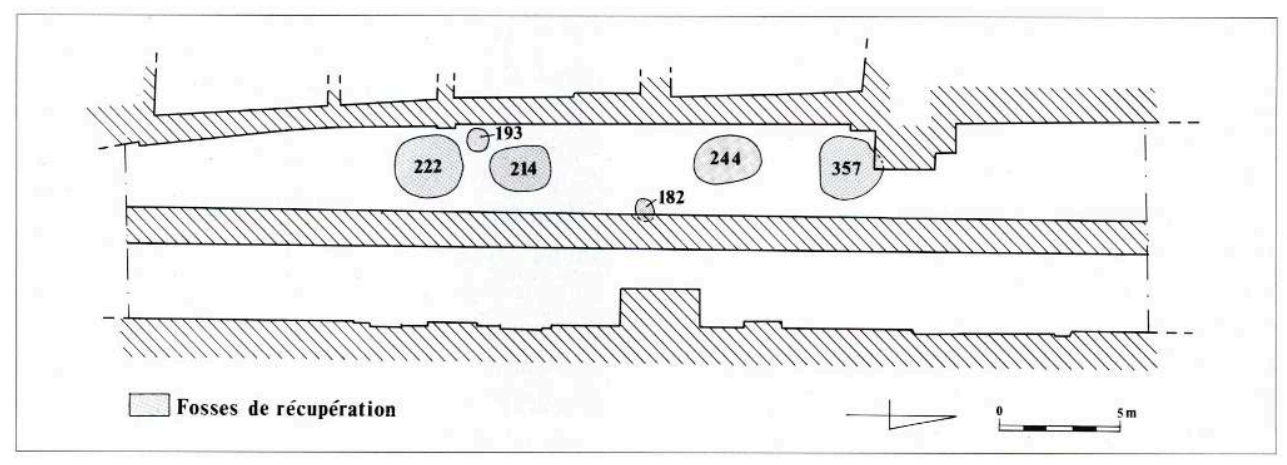

Par la suite, un apport de terre (US 89) est directement posé sur le remplissage de ces fosses : il s'agit d'une mise à niveau pour la construction d'une rue. A celle-ci succède de nouveau une couche de préparation (US 77), puis une nouvelle rue. Pour rehausser cette dernière, une série de niveaux de préparation est mise en place. La rue acquiert alors une meilleure structuration, basée sur l'emploi de gros galets en granite et de fragments de schiste (US 62).

\section{Étude céramologique}

Le matériel recueilli lors de la fouille des fosses est de quantité inégale : 335 tessons pour la fosse 222,278 pour la fosse 274,42 pour la fosse 357 et 17 pour la fosse 182 , qui fournissent un ensemble de 42 vases.

10 Avant d'étudier le matériel, il faut déterminer les relations de ces fosses entre elles. Bien qu'aucun recollage inter-fosses ne le prouve, nous savons par l'étude archéologique que ces fosses appartiennent à la même période chronologique. (Ayala 1992). Les oules et les cruches à bec ponté sont présentes dans les cinq fosses, alors que les ouïes à anse en panier et le pichet ne se retrouvent respectivement que dans une 
fosse. D'autres découvertes montrent pourtant que ces cinq types coexistent (château d'Anse ; place de la Bourse). Ils sont donc contemporains.

11 La céramique commune sombre est sans conteste la catégorie majoritaire avec un ensemble de 660 fragments, qui donnent 34 vases, dont des oules à lèvre en bandeau type 1371, des cruches à bec ponté type $\mathbf{1 1 0 5 1}$ et des oules à anse en panier, types 10111 et 10112. Ces derniers sont une nouveauté : une sorte de pot de transport dérivé de l'oule, avec une anse en panier accrochée sur la lèvre ; celle-ci présente deux profils : la traditionnelle lèvre en bandeau et une autre, sans inflexion, à extrémité plate. Les 4 types recensés en céramique glaçurée à pâte rouge font figure de parents pauvres : cruches à bec ponté, identiques aux modèles en pâte grise et pichet type 11121 .

12 En ce qui concerne les couches issues de la fouille de la rue, le recollage met en évidence un lien entre les US 77 et 62, qui sont donc contemporaines tout en étant chronologiquement séparées par deux niveaux de rues et un remblai d'apprêt. La plupart des types présents dans l'US 89 se trouvent également dans l'US 62 (excepté le type 10111), laquelle recolle avec 77. Cette cohésion morphologique permet de considérer le total de 307 fragments comme un tout: la céramique commune grise, toujours majoritaire avec 278 fragments, fournit un total de 14 vases, dont les profils ne présentent aucune surprise : oules à lèvre en bandeau, cruches à bec ponté, oules à anse en panier. En famille R1, les pichets ne sont présents qu'en nombre limité - 24 fragments - bien que légèrement supérieur au contenu des fosses citées plus haut.

\section{Datation}

D'après le rapport de fouille, la céramique recueillie dans le remplissage des fosses « ne permet pas de situer la formation de ces couches avant le XIIe s. Si l'on tient compte de la plausible hypothèse de A. Croze qui préconise de placer la création de la rue du PuitsPelu dans les années qui suivirent celle de l'Hôpital du Rhône, la formation de ces fosses, précédant l'installation de la rue, a dû s'opérer dans le troisième quart du XIIe s. Le denier anonyme des Archevêques de Lyon trouvé dans la fosse 219 (une fosse contemporaine mais dépourvue de matériel) confirme cette proposition chronologique.»

Proposition qui nous convient parfaitement, puisque les cruches à bec ponté en pâte rouge glaçurée sont attestées au XIIe s. (Faure-Boucharlat 1986) mais absentes au début XIIIe s. d'après le matériel trouvé à Anse. D'autre part, la chronologie établie pour Anse ne nous renseigne en rien sur la date d'apparition des pichets. Il semble, mais avec certaines réserves, que cette lacune puisse être comblée ici.

Quant aux niveaux de rue, "les arguments de datation de ces différentes phases sont tirés des rapports stratigraphiques entre les premiers niveaux de rue et les fosses de la période précédente; la datation de celles-ci fournissant un terminus ante quem précis. Ceci nous porte à placer la formation des rues (...) dans le dernier quart du XIIe s. Deux monnaies, trouvées dans la couche 62 sont datées du XIIe s.: cet argument chronologique pourrait situer le réaménagement de la rue à la fin de ce siècle. »

L'étude de la céramique ne permet pas, typologiquement et chronologiquement, de différencier le matériel des fosses de celui des rues; l'augmentation du nombre des pichets n'est pas un indice suffisant, bien qu'il mérite d'être noté. La proposition de datation fournie par le rapport de fouille confirme nos connaissances de la céramique du XIIe s. qui s'enrichissent d'une nouvelle donnée avec la présence d'oules à anse en 
panier. A ce sujet, rappelons que plusieurs vases semblables aux types 10111 et 10112 ont déjà été trouvés lors de fouilles anciennes (Faure-Boucharlat et Tardieu 1986), mais les éléments de datation ne permettaient pas alors une fourchette chronologique précise : XIIIe, XIVe s. ou même XVe s. parfois. Ces vases, issus des comblements des reins d'une voûte, place du Pilori, étaient contemporains de cruches à bec ponté, d'oules à lèvre en bandeau, de pichets décorés, mais aussi de marmites présentant des caractéristiques typologiques plus récentes, d'où, à l'époque, une proposition de datation prudente allant du XIIIe au XVe s.

\section{Début deuxième moitié du XIIle s., Anse (Rhône), Château des Tours}

17 Bien que situé à l'extérieur de Lyon, ce site a une importance primordiale pour la connaissance du mobilier médiéval; en effet, de nombreux types trouvés à Anse sont présents dans les fouilles lyonnaises.

\section{Contexte architectural et archéologique}

18 Le bâtiment se trouve à la limite du bourg d'Anse, à une trentaine de kilomètres au nord de Lyon, au centre d'une parcelle circulaire qui conserve le toponyme de «bassecour »; c'est une imposante bâtisse longitudinale flanquée à ses extrémités par deux tours: un donjon circulaire au sud, une tour semi-circulaire au nord. Plusieurs campagnes de fouilles (Feuillet 1985), une étude architecturale et une série de datations dendrochronologiques ont permis de montrer que l'aspect actuel du château est le fruit d'une longue évolution dans laquelle nous pouvons distinguer trois états (fig. 120) :

19 - L'état 1 concerne la construction de l'édifice en trois Campagnes au XIIIe s. :

20 Phase I : donjon circulaire de trois étages desservis par un escalier à vis.

21 Phase II : on rajoute la tour nord semi-circulaire reliée au donjon par deux courtines délimitant une cour centrale.

22 Phase III : un bâtiment s'implante dans la cour centrale, ne laissant subsister que deux petites cours au nord et au sud.

23 - L'état 2 renvoie à des remaniements aux XVe et XVIe s., donnant au château un caractère plus résidentiel: Claude Gaste (1466-1486) fait construire plusieurs ouvertures ainsi qu'un escalier à vis dans la cour nord, et Guy Bourgeois (1486-1511) en fait édifier un deuxième dans la cour sud, plaqué contre le donjon.

24 - L'état 3 englobe divers travaux d'entretien et des modifications mineures du XVIIe au XIXe s.

25 C'est dans la cour sud que se trouvent les deux structures qui font l'objet de cette étude : $\mathrm{S} 16$ et $\mathrm{F} 35$. 


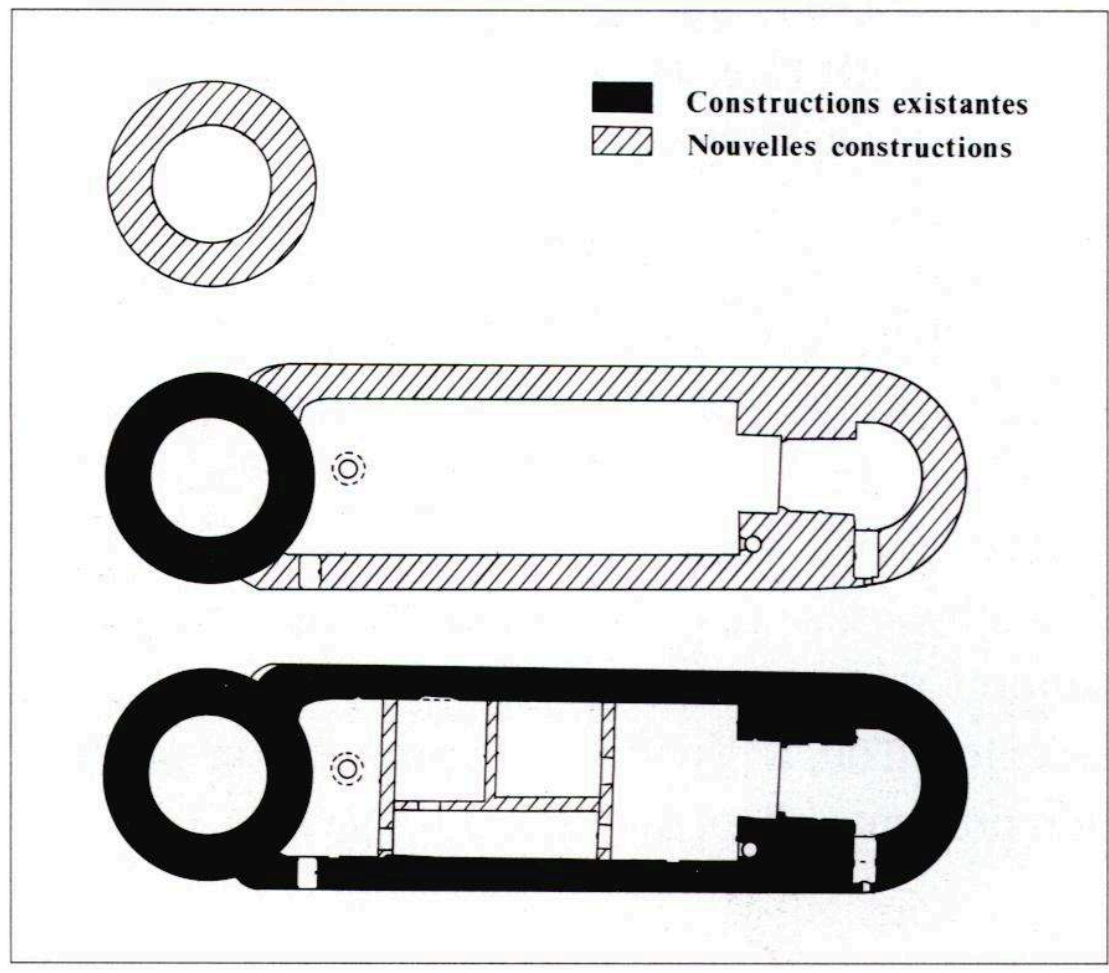

\section{La structure 16}

Il s'agit d'une structure enterrée, construite en pierres lutées à l'argile, de forme tronconique, d'une profondeur de $3,70 \mathrm{~m}$ pour un diamètre de $2 \mathrm{~m}$ et possédant une ouverture circulaire d'environ $30 \mathrm{~cm}$ de diamètre (fig. 121). La fouille ne nous renseigne pas sur la fonction d'origine; le fond est constitué d'une couche d'argile très grasse, stérile, posée sur le terrain naturel. L'hypothèse du puits est à rejeter du fait de la profondeur de la nappe phréatique et de la forme tronconique inhabituelle. Il ne s'agit pas non plus d'une citerne, car le parement interne ne présente aucune trace d'enduit, ni d'un silo, puisqu'on n'a retrouvé nulle trace de grain dans les joints d'argile, bien que l'utilisation de récipients tressés et éloignés des parois puisse infirmer cette interprétation; il faut cependant noter de fortes infiltrations d'eau. Un rôle de glacière est envisageable : la forme conique servirait alors à limiter les échanges caloriques. On ne connaît pas non plus l'aspect extérieur primitif: margelle ou ouverture au ras du sol? Lors de la découverte, un dallage tenait compte de l'ouverture grâce à des pierres taillées en demi-cercle, et les trois premières assises étaient liées par un mortier granuleux et friable, mais il semble cependant qu'il s'agisse d'un réaménagement. 


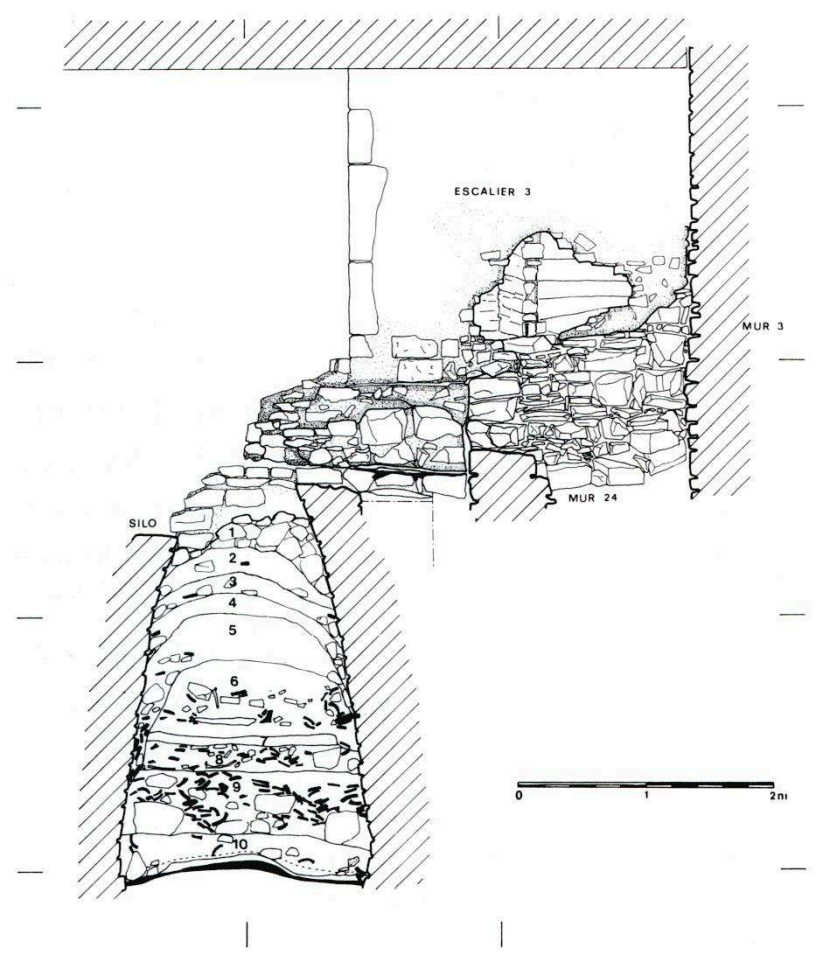

Dans un deuxième temps, S 16 a été réemployée comme dépotoir domestique et comblée jusqu'à l'ouverture en plusieurs étapes bien distinctes, composées de 19 couches archéologiques numérotées de 7.1 à 7.19. Les trois premières sont antérieures au comblement, puisqu'il s'agit de lœss vierge, de lœss rubéfié et d'argile grasse. Le remplissage proprement dit va donc de 7.16 à 7.1 et montre deux aspects : d'une part des pierres et des tuiles, d'autre part des cendres et du sable, sans doute des décharges de foyers qui livrent aussi de nombreux déchets alimentaires : os d'animaux en grande quantité, tels que porcs, moutons, bovins, volatiles, rongeurs ; des coquilles d'œufs, de noix ainsi que des noyaux, des écailles, des arêtes de poissons, des grains, beaucoup d'objets métalliques et, outre la céramique, une grande quantité de verres sur lesquels nous reviendrons ultérieurement. Il faut remarquer que les couches 12, 13, 14 constituées de cendres et de sable ne contiennent aucun déchet et très peu de céramique : 27 tessons pour 7.12, 61 pour 7.13, aucun pour 7.14 ; il s'agit peut être d'une étape d'assainissement.

Avant d'entreprendre l'étude, il est essentiel de comprendre le mode de remplissage. Une première approche met déjà en évidence trois périodes chronologiques : la plus récente, les couches 7.1 et 7.2, contient du matériel typique des XVIIe et XVIIIe s.; la deuxième inclut les couches 7.3 à 7.5, dont le matériel date de la fin du XVe, début du XVIe s. : ce mobilier, peu abondant, n'est pas analysé ici ; enfin, la première période concerne les couches restantes et nécessite une étude plus approfondie :

Le remontage des céramiques met en évidence des phénomènes d'interférences entre les couches : ainsi de nombreux tessons de 7.16 recollent avec 7.15. Même constatation pour 7.10 et $7.9 ; 7.9$ et $7.8 ; 7.9$ et $7.7 ; 7.8$ et $7.6 ; 7.7$ et 7.6 . Deux ensembles se dégagent : 7.16 et 7.15, puis 7.10 à 7.6. Il n'existe pas de collage entre ces deux ensembles, séparés, rappelons-le, par trois couches de sable et de cendres. 
en deux ensembles n'est cependant pas satisfaisante, puisqu'elle ne tient pas compte des types de céramique ; c'est pourquoi il est nécessaire d'employer en appoint une technique d'ordination débouchant sur une représentation graphique : la matrice ordonnable (Bertin 1977) (tableau 1). Sur un tableau de présence-absence plaçant en ordonnée les couches de remplissage et en abscisse les codes typologiques des vases, nous permutons ces derniers par rapprochement des lignes semblables : le tableau sort alors sans difficulté. Précisons toutefois que les types présents dans une seule couche ne sont pas inclus dans le tableau en vue d'une meilleure lisibilité, mais que l'on en tient compte bien évidemment dans le résultat final (il s'agit de 10222, 11212, 10331, 10151), et que le type 6221, un couvercle, est également laissé de côté : présent dans pratiquement toutes les couches, il n'apporte pourtant aucun renseignement.

Tableau 1. Anse, château des Tours : répartition des types dans les trois phases de remplissage du dépotoir S16

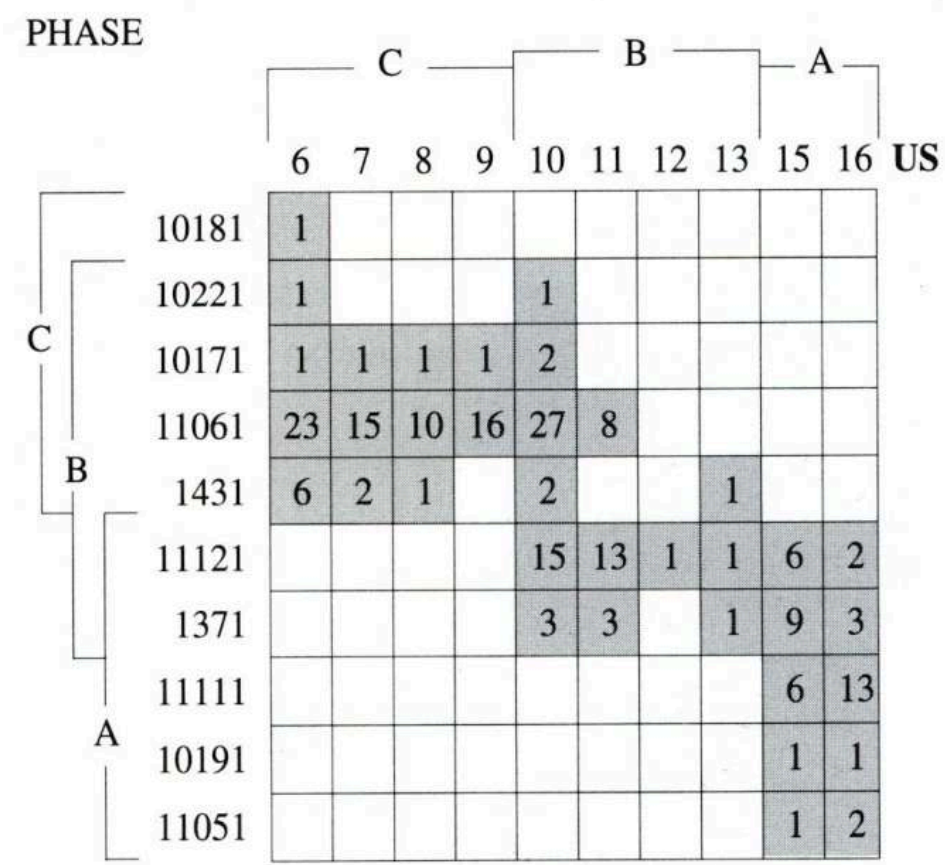

Type

Nous aboutissons ainsi à trois ensembles distincts :

- Phase A : elle regroupe les couches 15 et 16 et englobe les pichets types 11111, 11121, l'oule 1371, les marmites 10191 et 10151, la cruche à bec ponté 11051.

- Phase B : elle concerne les couches 13 à 10 et regroupe les marmites types 10222, 1431, 10171, 10221, 10331, les pichets 11212, 11121, l'oule 1371 et la cruche 11061.

- Phase $C$, qui regroupe les couches 6 à 9 et englobe les marmites types 10181, 10221, 1431, 10171 et la cruche 11061.

Nous n'avons pas permuté les couches de remplissage, restant ainsi fidèle au principe qui veut que «les couches archéologiques résultent de l'activité d'un groupe humain donné, alors que les couches superposées l'une au-dessus de l'autre déterminent la direction de l'écoulement du temps » (E. Pleszczynska 1978). Un simple coup d'œil au 
tableau montre qu'à l'intérieur des séquences $\mathrm{A}$ et $\mathrm{C}$, une permutation donnerait les mêmes résultats. Enfin, nous admettons aussi que, si l'on trouve la même forme en couches 10 et 6 , il est logique de penser qu'elle puisse être présente dans les couches 7 , 8 et 9.

Cette première période de remplissage de la structure $S 16$ est donc divisée en deux phases distinctes $\mathrm{A}$ et $\mathrm{C}$; la phase $\mathrm{B}$ est un élément charnière, une phase de transition comme le montrent les différents types qui appartiennent successivement à $\mathrm{A}$ ou à $\mathrm{C}$.

\section{La fosse 35}

Cette fosse, située dans l'angle formé par les murs 1 et 4 dans la cour sud, n'a pas eu d'utilisation primitive comme $\mathrm{F} 16$; c'est un dépotoir domestique, creusé à cet effet sur une profondeur d'environ 1 mètre, en pente raide vers le mur 4 sous lequel elle passe partiellement. Son comblement, constitué de 6 couches, est assez hétérogène: abondance de tuiles, de mortier, de briques, nombreux déchets alimentaires, objets métalliques, céramiques et verres (fig. 125).

Une erreur de gestion d'une partie du mobilier céramique ne nous permet plus de replacer celui-ci dans son contexte d'origine et nous oblige à le traiter en bloc; ce défaut est pourtant tempéré par les nombreux recollages entre couches qui prouvent bien que cette fosse forme un tout et qu'elle peut être étudiée dans sa globalité.

Il faut d'ores et déjà comprendre la relation entre $\mathrm{F} 35$ et $\mathrm{S} 16$, d'un point de vue typologique. Nous savons qu'une partie d'un vase de type 1431 provenant de la couche 13 de S 16 recolle avec d'autres morceaux de F 35. D'autre part, certains types sont communs aux deux fosses : c'est le cas des marmites 10221, 10331, 1431, du pichet 11212 et de la cruche 11061, en F 35, qui correspondent aux phases $C$ et $B$ de $S 16$, de l'oule 1371, de la cruche à bec ponté 11051, plutôt contemporains de la phase $\mathrm{A}$ et du couvercle 6221. Il faut également mentionner plusieurs types de marmites, particuliers à $\mathrm{F} 35$ : 10322, 10311, 10161, 101101, 1391 ainsi qu'une gourde, 741. En tenant compte de ces observations, nous pensons que le remplissage de $\mathrm{F} 35$ est contemporain de S 16 et peut-être plus proche des phases $B$ et $C$, comme le montre l'examen des types, que de la phase $\mathrm{A}$ : n'oublions pas la faible proportion des cruches à bec ponté $\mathbf{1 1 0 5 1}$ et des oules 1371 et l'absence du pichet 11121.

\section{Étude céramologique}

\section{Le silo S16}

\section{- Phase A}

On dénombre un total de 1301 tessons, pour 58 vases, répartis en deux familles : la commune grise G, avec 858 fragments (66\%) et la commune rouge glaçurée RI, avec 443 fragments (34\%). Dans la première famille, le récipient majoritaire est, sans conteste, l'oule à lèvre en bandeau, de type 1371 : c'est une céramique sans anse ni col, à panse globulaire et à fond bombé. Trois autres récipients culinaires sont présents dans cette phase A, mais en très peu d'exemplaires : type 10191 en 7.16 et en 7.15 avec l'amorce d'un léger col évasé et d'au moins une anse rubannée attachée à la lèvre; il faut noter, en toute impartialité, qu'il peut s'agir aussi bien d'un coquemar que d'une marmite ou même d'une cruche à bec ponté. Le type 10151, lui, n'est présent qu'en 7.15 : il s'agit, soit d'une oule, soit d'une marmite, l'état incomplet du vase ne permetant pas de 
trancher; toutefois on remarque un col court évasé. Il faut s'intéresser aussi à un récipient de taille respectable qu'il n'a pas été possible d'identifier : lèvre évasée et départ d'au moins une anse rubannée sur la lèvre; la panse est cerclée de bandes rapportées et digitées pour assurer la solidité de l'ensemble. La forme générale n'est pas reconstituable et il peut s'agir aussi bien d'un récipient de stockage que d'une grosse marmite. Enfin, mentionnons la présence de cruches à bec ponté de type 11051, en 7.16 et en 7.15, autre forme bien typique des XIe et XIIe s. s, à lèvre évasée, sans col et avec une anse rubannée opposée au bec ponté.

En ce qui concerne la céramique à pâte rouge glaçurée, la différence avec le matériel des époques antérieures est immédiatement perceptible: changement du mode de cuisson et pose d'une glaçure plombifère sans engobe. Cette glaçure est saupoudrée sur le vase avant cuisson, ce qui lui donne cet aspect « peau d'orange » bien caractéristique. Dans la phase A coexistent essentiellement deux types de pichet.

Le premier, 11111, concerne plusieurs exemplaires en 7.16 et en 7.15 ; il s'agit de récipients assez hauts (17 cm environ), à fond plat et base étalée, surmontée d'une panse fuselée. Cette impression d'allongement est encore accentuée par les dimensions restreintes du col et de la base; nous avons ici un vase bien adapté à sa fonction. La lèvre, réduite à sa plus simple expression, ne change pas d'un exemplaire à l'autre; l'anse présente la particularité d'être toujours cannelée, à trois ressauts et de se rattacher sous la lèvre et au milieu de la panse. De même, le col montre un décor de stries, tandis que le reste du récipient est exempt de motifs décoratifs. La glaçure, de qualité inégale, présente une teinte orangée parfois agrémentée de vert ou, plus rarement, de jaune.

Le deuxième type, 11121, présent en 7.16 et en 7.15 , possède une allure encore plus élancée grâce à un pied haut tronconique et à un col relativement important et peu évasé, le tout équilibré par une panse fuselée dont le diamètre maximal n'est jamais supérieur à celui de l'ouverture ni à celui de la base. La lèvre reste simple, mais on note quelquefois la présence d'un apex à la jonction lèvre-col. La couleur de la glaçure varie de l'orangé au vert, en passant par le jaune et le marron ; elle est, dans l'ensemble, de très bonne qualité. Outre son profil, la différence essentielle de ce vase par rapport au précédent tient dans l'abondance, la variété et la qualité des motifs décoratifs qui ornent ces pichets: bandes d'argile rapportées et moletées, pastilles poinçonnées, écailles obtenues par étirement de la pâte et enfin traces de molettes sur pâte de différentes sorte. Mis à part le décor d'écaillés qui couvre la totalité du vase, les autres motifs s'emploient parfois seuls, parfois en de multiples combinaisons; ainsi les pastilles voisinent avec les bandes moletées, ces dernières peuvent être employées seules, verticalement ou disposées en chevrons; le décor peut se limiter à la panse ou intégrer le col et le pied, de même les motifs décoratifs présentent parfois une couleur différente de celle du vase, ce qui contribue à leur mise en valeur (fig. 122). 


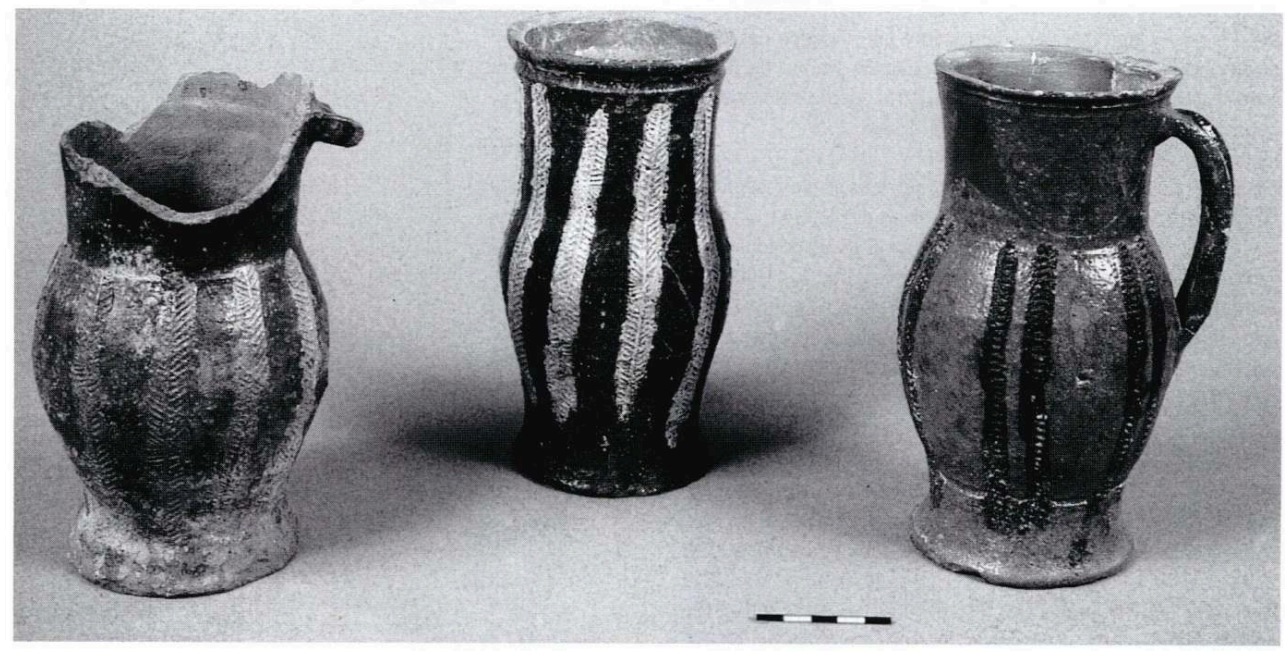

Ainsi, parallèlement à une production en commune grise traditionnelle, comme fossilisée dans la répétition d'anciennes formes, se développe une production originale, d'une technologie plus élaborée et qui manifeste une réelle recherche de diversité tant dans la forme que dans le décor. Ces pichets décorés posent beaucoup de questions, pour l'instant sans réponse, concernant leur date d'apparition, et surtout leur origine : importation ou production locale?

\section{- Phase B}

Cette phase, constituée des couches 7.10 à 7.13 et composée de 1161 fragments pour 96 vases, est considérée comme une période de transition ; un simple regard sur le tableau matriciel montre une césure dans l'évolution typologique. En effet, mis à part deux types propres à la couche $10(\mathbf{1 0 2 2 2}, \mathbf{1 1 2 1 2})$, le reste se partage en deux types issus de la phase A (11121 et 1371) et quatre types que l'on retrouve en phase C (10221, 1431, 10171, 11061). De plus, la commune rouge glaçurée R1 passe au premier plan avec 678 fragments $(58,5 \%)$ pour $482(41,5 \%)$ en commune grise $\mathrm{G}$, sans oublier un unique tesson en commune grise glaçurée $\mathrm{G} 1$.

En céramique commune grise, les six exemplaires d'oule à lèvre en bandeau, de type 1371 présents dans les couches 7.10 et 7.11, montrent une nette détérioration de ce profil : la concavité de la face interne nettement moins marquée et le ressaut extérieur moins proéminent suggèrent une certaine dégénérescence de la lèvre, comme si le modèle était peu à peu oublié. Par contre, on remarque deux exemplaires de type 143, marmite qui apparaît dans la couche 7.13. L'intérêt de cette phase réside dans la présence d'un exemplaire de type 10221, une marmite possédant un col droit, une lèvre horizontale et surtout une anse qui se raccorde au col: ce détail typologique d'une grande nouveauté nous éloigne fortement des communes grises de la phase A. Le type 10222 est de la même veine avec un col droit; le caractère incomplet du vase ne permet pas de préciser où se situe le départ des anses. Problème presque identique avec le type 10171, dont l'état ne permet pas de trancher entre marmite ou coquemar; notons toutefois la présence du col et de l'anse sur la lèvre. Même chose pour les 4 exemplaires de 10331 dans l'US 7.11, qui pourraient peut-être faire partie du même récipient malgré l'absence de collage: cette fragmentation ne permet pas de choisir 
entre oule et marmite, mais la présence d'un petit col évasé est indéniable. Il faut signaler, dans cette phase, la disparition de la cruche à bec ponté, de type 11051 .

C'est dans la famille R1, à pâte rouge glaçurée sans engobe, que l'on distingue bien l'aspect transitoire de la phase $\mathrm{B}$, puisque l'on retrouve à la fois des exemplaires de pichets 11121 et de cruches 11061, lesquelles avaient fait leur apparition dès la couche 7.11 : il s'agit d'un profil qui va perdurer sur plusieurs siècles, mais qui tranche, pour l'instant, avec la morphologie des pichets de la phase A. Bien plus qu'une simple différence typologique, c'est la conception même de cette cruche qui marque la nouveauté : le fond plat et surtout l'absence de pied permettent à la panse de prendre une forme plus globulaire, d'abaisser son centre de gravité. Cette panse est surmontée d'un col droit ou légèrement évasé, sur lequel vient se greffer le départ de l'anse, opposée à un petit bec pincé. Ce récipient est glaçuré sans engobe, et la plupart du temps dépourvu de décor, si ce n'est quelques exemplaires de poinçons ou d'incisions ; on reste pourtant bien loin de la décoration foisonnante et systématique des pichets. Nous sommes ici plutôt en présence d'un objet avant tout fonctionnel, de conception simple, donc de grande diffusion (fig. 123).

123 - Anse, château des Tours : cruche (type 11061)

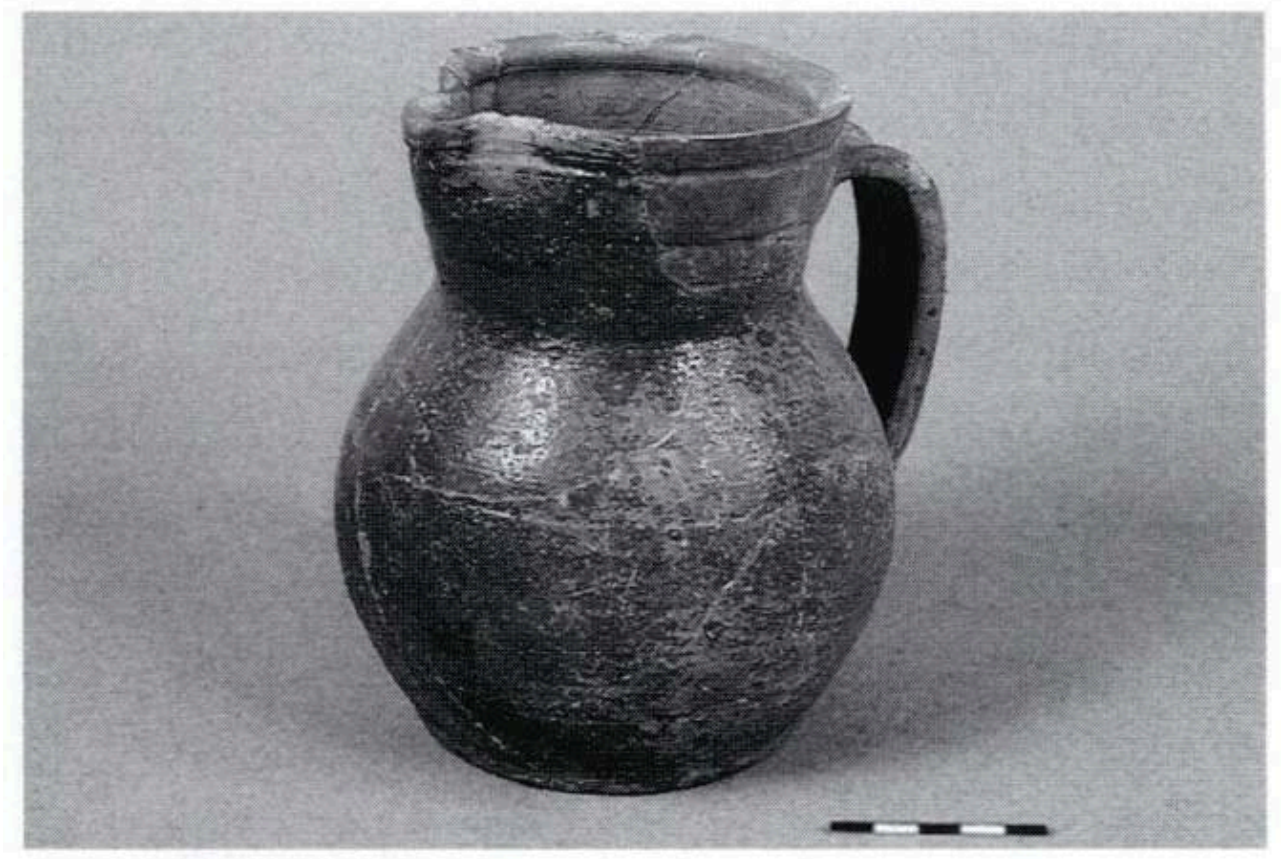

Il ne faut pas oublier le seul exemplaire de type 11212, présenté comme une variante de 11061 : il s'agit toujours d'une cruche, mais cette fois avec une panse surbaissée et sans élément verseur.

\section{- Phase C}

Cette phase, constituée des couches de 9 à 6 , fournit 1814 tessons pour 126 vases, qui se répartissent en quatre familles : 806 fragments pour la commune grise $G$, soit $44,5 \%$; 793 pour la commune rouge glaçurée R1, soit $44 \%$; 24 pour la commune grise glaçurée G1, soit $1,3 \%$ et 191 pour la commune rouge $R$, soit $10,5 \%$. Ces deux dernières familles ne 
livrent que peu de types identifiables, tout en étant absentes des phases précédentes : couvercle, cruche et poêlon pour la famille R et absolument rien pour G1.

On ne note pas l'apparition de nouveaux types en commune grise; nous retrouvons le type 10171 dans chaque couche, la marmite 1431 en 7.6 , en 7.7 et en 7.8 , la marmite 10221 en 7.6. Par contre, il faut mentionner la disparition des oules à lèvre en bandeau.

Dans la famille à pâte rouge glaçurée, R1, seules subsistent les cruches 11061, lesquelles montrent certaines variantes dans les profils des lèvres. Nous ne considérons pas ces différences comme significatives: l'aspect global du récipient reste inchangé. Par contre, la phase $\mathrm{C}$ amène un nouveau vase en tout point remarquable : il s'agit du type 10181, dont le fond manque. Cette céramique est composée du haut d'une cruche (petit col évasé, profil de la lèvre, attache de l'anse) et de la panse d'une marmite avec une forme globulaire très développée; cuite en mode oxydant, recouverte d'une glaçure d'excellente qualité, elle possède un décor inhabituel qui mérite attention : il s'agit de motifs à la barbotine blanche disposés sur l'ensemble du vase en quatre registres superposés : étoiles, doubles traits parallèles, chevrons ; l'anse est également décorée de chevrons superposés. C'est la première apparition de la barbotine comme élément décoratif (fig. 124). A observer cette céramique, on se demande si le décor a été fait en fonction du vase, ou si c'est l'inverse. Cette dernière hypothèse est plus intéressante, car elle explique le bas du vase, conçu comme une marmite, plus propice par sa surface à un décor important ; de plus, l'extrême minceur de la paroi ne semble pas prédisposer ce vase à un usage intensif. Nous sommes là en présence d'un objet purement décoratif, qui fait un peu contrepoids à la banalisation des cruches. C'est également de cette phase $C$ que provient un manche de poêlon cuit en mode oxydant. Nous ne pouvons certifier son appartenance à une forme ouverte, mais l'angle de cassure suggère un poêlon ou même une jatte ${ }^{1}$. 


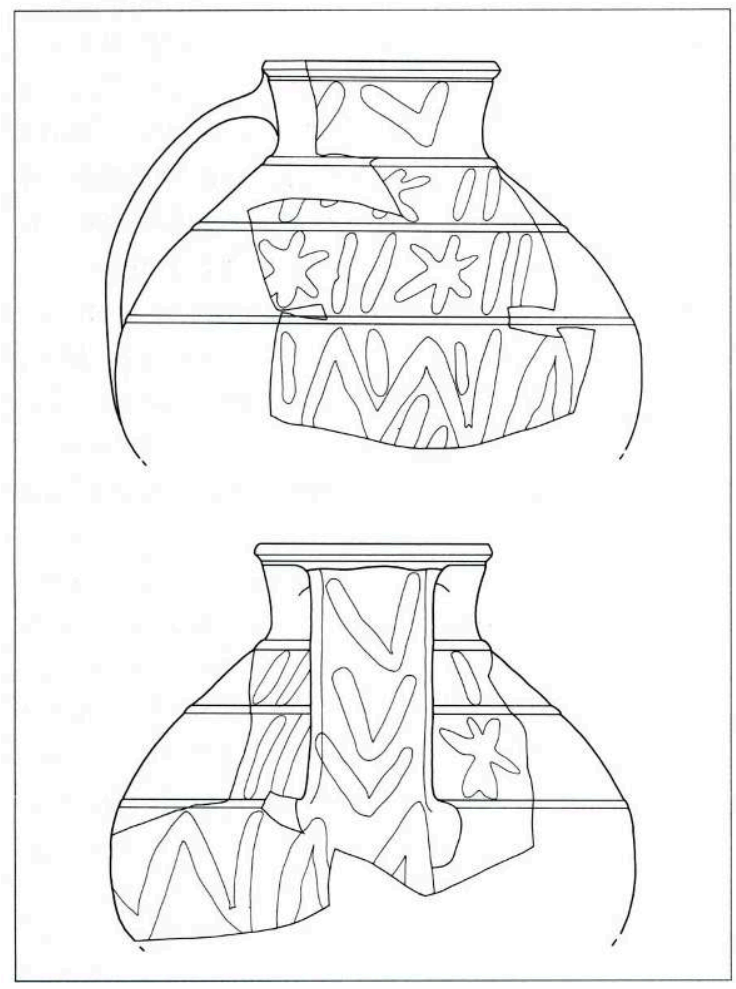

\section{La fosse 35}

Nous savons maintenant que cette fosse est contemporaine de la phase $\mathrm{C}$ de $\mathrm{S} 16$, puisqu'elle possède des types identiques qui ne se retrouvent pas dans la phase A. Mais F 35 montre aussi un éventail de nouveautés plus que surprenant. Le remplissage atteint 800 fragments pour 44 vases, ce qui est peu par rapport aux 4276 tessons de $\mathrm{S}$ 16 ; la répartition entre deux familles $\mathrm{G}$ et $\mathrm{R} 1$ révèle un déséquilibre certain : 81 tessons en commune rouge glaçurée R1 pour 719 en commune grise $\mathrm{G}$ !

Outre la marmite de type 1431, déjà rencontrée dans le silo $S 16$ et présente ici en plusieurs exemplaires, le seul vase qui ne soit pas unique en commune grise est une marmite, type 101101, de morphologie plutôt archaïque avec une amorce de col très évasé, des anses qui se greffent sur la lèvre et sans doute au milieu de la panse; le fond manque et rien ne permet de choisir entre fond bombé et hémisphérique, bien que, dans les comptages, les dix fonds recensés soient tous bombés. Nous avons ensuite deux autres types : 10322 et 10311, présents à un seul exemplaire, dont l'état fragmentaire ne laisse pas beaucoup de possibilités d'interprétation : il s'agit sans doute de marmites, pourvues toutes deux d'un col évasé plus ou moins haut. Le type 10161 est plus intéressant: une marmite à col droit haut, à lèvre très oblique côté externe et possédant une anse attachée à la jonction du col et de la panse: ces détails typologiques, plus que novateurs, suppriment à eux seuls la possibilité à la fosse $\mathrm{F} 35$ d'être contemporaine de la phase $\mathrm{A}$ de $\mathrm{S} 16$ : nous pouvons considérer dès lors les types 1371 et 11051 comme résiduels dans ce contexte. Dernier récipient issu de cette fosse, une gourde, 741, incomplète qui n'apporte pas d'élément nouveau; cet objet est trop rare pour qu'on puisse suivre une quelconque évolution. 
51 Malgré la faible quantité de fragments appartenant à la famille R1, nous identifions pourtant deux fragments de cruches 11061 et un de type 11212. L'originalité vient du récipient 1391 : une marmite cuite en mode oxydant possédant une glaçure interne d'excellente qualité, pourvue d'un haut col évasé sur lequel viennent se greffer deux anses de section ronde. Le profil complet de ces anses manque, mais on pense aussitôt aux marmites à anses coudées des époques postérieures (fin XVe, XVIe s.). Avant de voir dans ce type 1391 un prototype des ces fameuses marmites, il convient d'examiner les critères de datation de façon détaillée.

\section{Datation}

52 Il faut signaler que la fouille du château d'Anse remonte à plus de dix ans, ce qui explique certaines difficultés rencontrées lors de la lecture des fiches d'enregistrement. Notre but n'est pas de reprendre entièrement l'étude du contexte archéologique, cette opération ayant été faite dans deux mémoires de maîtrise (Feuillet 1983, Vicard 1984), mais d'examiner les éléments qui contribuent à la datation des structures et donc des céramiques qu'elles contiennent.

Le château d'Anse a fait l'objet d'une série de datations dendrochronologiques qui donnent les résultats suivants :

donjon (salle d'apparat) : automne-hiver 1213-1214 tour nord (tous niveaux) : automnehiver 1216-1217 bâtiment central (rez-de-chaussée) : automne-hiver 1217-1218.

La période de séchage avant utilisation du bois ne devant pas excéder une année, le château est donc le bâtiment attribué à l'archevêque Renaud de Forez (1193-1226).

\section{La structure 16}

Nous avons défini précédemment trois périodes d'utilisation de cette structure: la dernière, qui regroupe les couches 1 et 2, datable des XVIIe et XVIIIe s. ; la seconde, les couches 3 à 5 , datable de la fin XVe au début du XVIe s.; la première, qui concerne les couches 6 à 16 et que l'on peut diviser en trois phases de remplissage :

Phase A : couches 15 et 16

Phase $\mathrm{B}$ : couches 13 à 10

Phase $\mathrm{C}$ : couches 9 à 6 .

A l'intérieur de ces trois phases, plusieurs monnaies permettent de préciser la datation: de la couche 11 à la couche 8 , une série de deniers et d'oboles anonymes datent du XIIe s.; dans la couche 6, une monnaie d'Amédée TV, 1232-1252, fournit un terminus ante quem pour la phase C (Feuillet 1985, p. 178). Nous savons aussi que les couches qui scellent cette phase, c'est-à-dire 3,4 et 5, appartiennent à la deuxième période d'utilisation du dépotoir et datent du XVIe s. Faut-il conclure que la phase $C$ perdure du milieu XIIIe jusqu'au XVIe s.? Assurément non! Certes, la céramique montre une évolution typologique qui s'éloigne du XIIe s., mais il y a une trop grande disparité entre le matériel des couches 3,4 et 5 et celui de la phase $C$ pour accréditer l'hypothèse d'un remplissage régulier pendant trois siècles. De plus, les multiples recollages des fragments à l'intérieur de la phase $C$ suggèrent un remplissage rapide. C'est pourquoi nous concluons que la phase $C$ du remplissage de S 16 date de la deuxième moitié du XIIIe s. Mais qu'en est-il des phases A et B ? Dans un travail précédent (Vicard 1984), nous avons montré que la structure S 16 ne pouvait être que 
contemporaine du donjon : en conséquence, les phases A et B du remplissage se situent au début du XIIIe s., entre 1213 -date donnée par la dendrochronologie-et 1232/1252, date de la monnaie trouvée en couche 6 ; la présence d'oules à lèvre en bandeau et de cruches à bec ponté renforce cette hypothèse. Signalons enfin que l'étude des verres recueillis dans S 16 n'apporte aucun élément nouveau pour la datation de cette structure ${ }^{2}$.

En guise de conclusion, il faut revenir un peu sur la durée de S 16 en tant que dépotoir : de la couche 16 à la couche 1 , nous avons une durée de remplissage d'environ 400 ans. Il est évident que ce dépotoir n'a pas pu rester ouvert pendant quatre siècles : la cour sud, dans laquelle il est situé, a subi plusieurs remaniements à différentes époques. En fait, au XIIIe s., le remplissage des séquences $\mathrm{A}, \mathrm{B}$ et $\mathrm{C}$ se fait en continu, comme le montrent l'évolution du matériel céramique, la présence systématique de déchets alimentaires et de cendres; ensuite, il faut imaginer un arrêt, que l'on peut placer vers la fin du XIIIe s. : l'ouverture est sans doute scellée, puis oubliée. Aux XVe-XVIe s., l'utilisation reprend, avec les couches 3,4 et 5 , peut-être à mettre en relation avec les remaniements architecturaux effectués alors : beaucoup de pierres, tuiles et briques et quelques déchets alimentaires uniquement dans la couche 5 . Enfin, après un nouvel arrêt, le comblement reprend au XVIIe s. avec les couches 1 et 2 qui ne contiennent que des pierres de gros module, des briques et des tuiles ; on note aussi, à cette époque, des travaux dans le château.

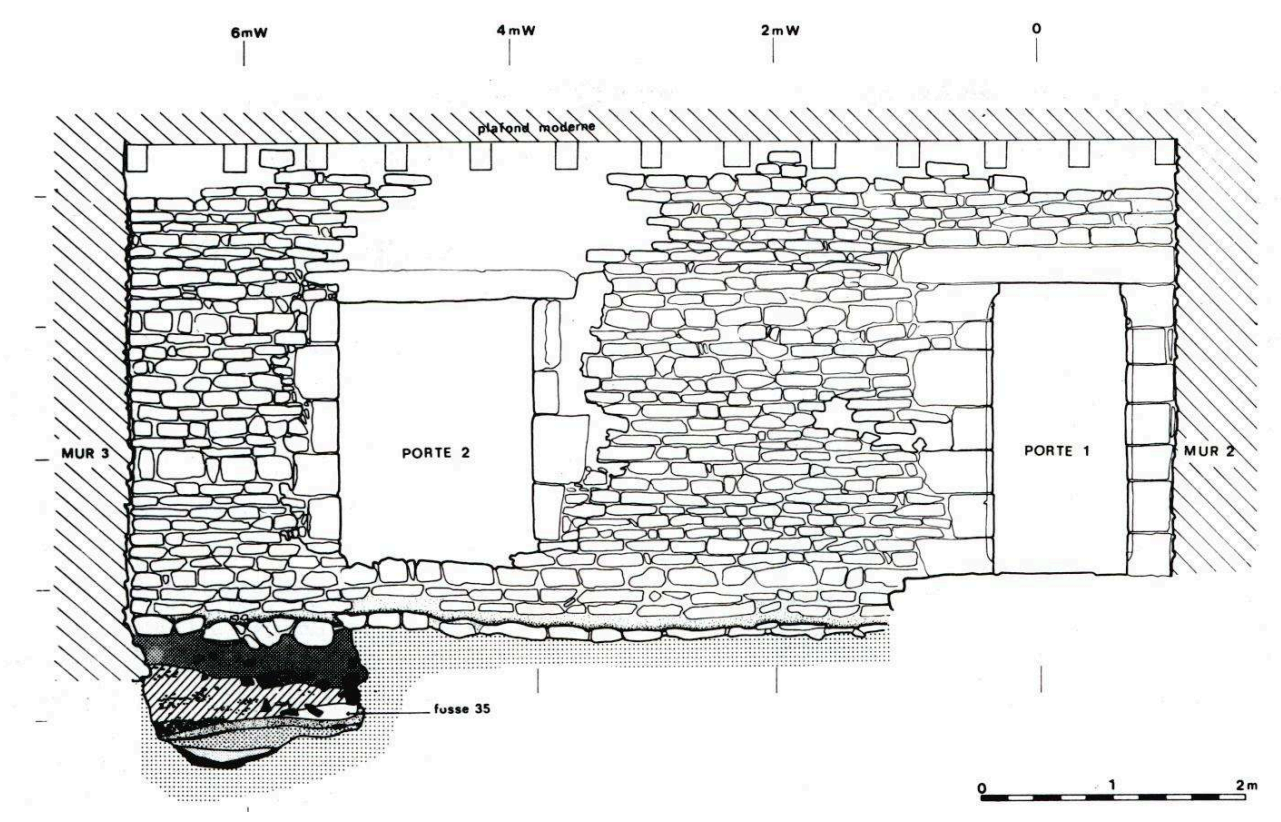

\section{La fosse 35}

Nous avons vu, d'après l'étude des céramiques, que $\mathrm{F} 35$ est contemporaine de la phase C de S 16: archéologiquement, nous n'avons aucune relation entre les deux dépotoirs. On sait que F 35 est scellée par une couche contemporaine d'un muret détruit par un escalier construit au XVe s. A l'ouest, elle est postérieure au mur 1, construit entre 1213 et 1217, qui relie la tour nord au donjon. Au nord, elle passe en partie sous le mur 4, 
appartenant au bâtiment central. Tout le problème réside dans le fait de savoir si F 35 est antérieure ou non à la construction de ce bâtiment en 12 171218, date de la poutre qui sert de linteau à la porte 2 (fig. 125). Sans remettre en cause la datation dendrochronologique, qui, depuis, a de nombreuses fois servi de référence avec succès dans la région, on peut se pencher sur l'hypothèse qui considère cette poutre comme étant en place : en effet, le relevé de cette partie du mur montre une reprise autour de la porte qui suggère que celle-ci n'est pas contemporaine du mur 4 , mais bien percée postérieurement. Une seule chose est sûre, c'est que F 35 n'est pas contemporaine de l'utilisation de cette porte, puisque la fosse déborde largement devant le seuil. Comme les éléments archéologiques ne permettent pas de trancher, nous nous en remettons à l'observation typologique de son remplissage pour la chronologie de cette fosse, c'est-àdire contemporain de la phase $\mathrm{C}$ de $\mathrm{S} 16$, datée de la deuxième moitié du XIIIe s., tout en émettant les réserves d'usage, liées à l'état actuel des connaissances. Le déséquilibre constaté entre commune rouge glaçurée et commune grise est à mettre probablement sur le compte des hasards du remplissage ${ }^{3}$. L'étude des verres recueillis dans $\mathrm{F} 35$ n'apporte également aucun élément nouveau pour la datation ${ }^{4}$.

\section{Début-milieu XIIle s., Lyon, Place de la Bourse}

\section{Contexte archéologique}

63 La construction d'un parc de stationnement souterrain, place de la Bourse, au cœur de la presqu'île, a donné lieu à une fouille archéologique qui a permis de mettre au jour des niveaux gallo-romains, médiévaux et modernes. La céramique de ce site, retenue pour l'étude, est intéressante dans la mesure où elle appartient au XIIIe s., une époque considérée ici comme "la première implantation humaine depuis dix siècles" (Rapport de fouilles, C. Arlaud, 1990). Le but est donc de vérifier cette datation et de voir quels éléments nouveaux ce matériel peut apporter.

On s'intéressera à la période 9 qui correspond à l'origine du parcellaire médiéval de la rue Buisson, dont ont été retenues les couches 1452, 1061, ainsi que la couche 770, remplissage de la fosse 769, et à la période 10 qui renvoie au développement du bâti dans ce même parcellaire avec un niveau d'occupation, 966 et le remplissage 934 de la fosse 935 (fig. 126). 


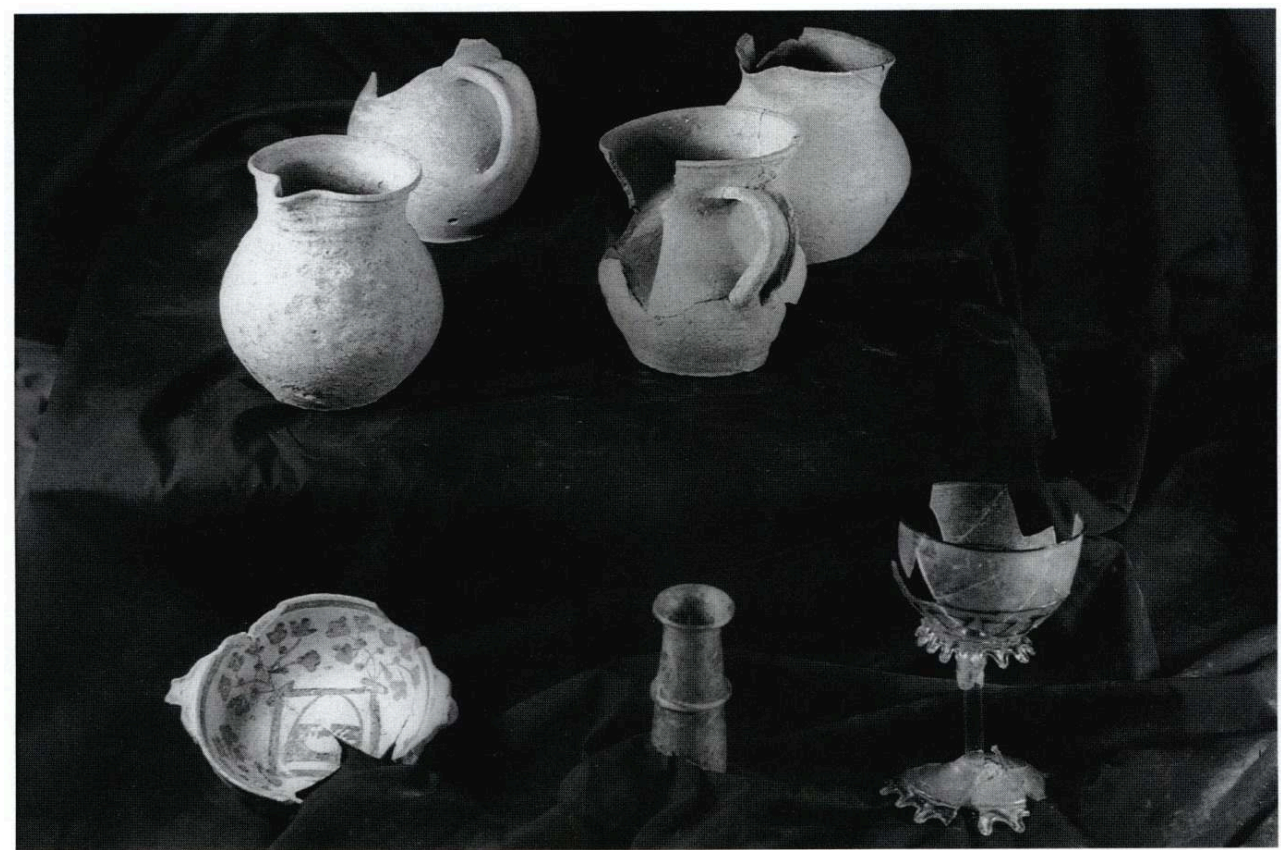

\section{Étude céramologique}

\section{Période 9}

En commune grise G, les couche 1061 et 1452 ne fournissent que 203 tessons pour 31 vases. Nous retrouvons les types déjà vus à Anse : l'oule à lèvre en bandeau, 1371 et la cruche à bec ponté, 11051. La couche 1452 montre deux exemplaires d'un type 10321 proche de 10322 d'Anse: il s'agit d'un vase non identifiable (oule ou marmite), possédant un col évasé avec une face interne concave, mais pourvu ici d'une lèvre à une inflexion externe oblique vers le haut. Dans les deux couches, l'oule à anse en panier attachée à la lèvre est également présente avec un profil en bandeau, type 10112, ou un profil sans inflexion, à faces parallèles, type 10111. L'élément de préhension, qui ressemble à une anse rubannée repliée sur elle-même, forme ainsi une sorte de boudin compact, bien adapté à sa fonction: celle d'un récipient servant au transport. En céramique glaçurée à pâte rouge R1, le matériel n'est guère abondant : 45 tessons pour les deux couches. On identifie des éléments de pichets 11121 ou 11212 et de cruches 11061. La couche 1061 fournit aussi un bec tubulaire, surmonté sans doute d'un anneau et décoré d'une bande moletée; malheureusement, le reste du récipient demeure inconnu.

La couche 770, d'un total de 96 tessons, donne 9 vases. En céramique commune grise G, nous recensons 88 fragments. On reconnaît des exemplaires de cruches à bec ponté, type 11051, associés cette fois à un nouveau type de marmite, 1441: il s'agit d'un récipient à col court convergent, avec une lèvre à une inflexion externe légèrement oblique vers le haut, parfois même horizontale; l'extrémité est souvent biseautée. D'autres exemplaires montrent que deux anses plates verticales s'attachent sur le col et au milieu de la panse. Il s'agit d'un type important qu'on aperçoit sur de nombreux sites étudiés par la suite (Lyon : rue de la Monnaie, Hôtel-Dieu). En céramique glaçurée 
à pâte rouge R1, un exemplaire de pichet de type $\mathbf{1 1 1 2 1}$ voisine avec une cruche de type 11061.

Période 10

67 La couche 966 fournit 137 tessons pour 12 vases ; 106 en commune grise G : oules de type 1371 et cruches à bec ponté de type $\mathbf{1 1 0 5 1}$ et $\mathbf{3 1}$ en commune rouge glaçurée R1 : trois exemplaires s'apparentent aux types 11212 et 11121, mais trois pichets $\mathbf{1 1 1 2 1}$ sont identifiés.

La fosse 934, forte de 140 tessons pour 13 vases, se compose, pour la famille G, de 128 fragments et de 12 pour la famille R1. Cette couche contient trois tessons de plus que 966, mais apporte pourtant beaucoup plus d'informations. En céramique commune grise, mis à part l'exemplaire de cruche à bec ponté 11051 et le vase type 10321, apparaissent deux nouveaux types de marmites: 10121, sans col, avec deux anses verticales attachées sur la lèvre et le haut de la panse et 10141, à col court légèrement évasé et à deux anses verticales attachées au col et au haut de la panse. La première possède une lèvre à une inflexion externe oblique vers le haut et la deuxième une lèvre sans inflexion ; les anses, rubannées ou cannelées, sont assez larges et montent bien audessus de l'ouverture. Ces deux marmites s'inscrivent assez bien dans la lignée de celles du XIIIe s. : les éléments de préhension sur le haut de la panse et sur la lèvre, de même que le col court évasé, se retrouvent à Anse.

69 En céramique glaçurée à pâte rouge, un pichet type $\mathbf{1 1 1 1 1}$ a été identifié ainsi que deux éléments que l'on ne peut attribuer à une cruche ou à un pichet.

\section{Datation}

La présence simultanée, dans la phase 9, de pichets, d'oules, de cruches à bec ponté associés à des cruches à pâte rouge glaçurée renvoie aux phases $\mathrm{A}$ et $\mathrm{B}$ du remplissage de S 16 au château d'Anse et autorise une datation comprise entre le début et le milieu du XIIIe s. La nouveauté du type 1441 dans la couche 770 n'apporte pas de changement chronologique. Quant à la période 10 , une datation située vers le milieu du XIIIe s. semble correcte. L'ensemble des fosses et des occupations du chantier de la Bourse, attribuées aux périodes 9 et 10, sont sans doute contemporaines les unes des autres, mais la faible quantité de fragments ne permet pas une grande précision, d'où la nécessité d'une datation globale et prudente réunissant les périodes 9 et 10 en un tout. Si le matériel médiéval recueilli place de la Bourse n'est pas important par sa quantité, il l'est assurément par la coexistence des divers types énoncés ci-dessus 5 .

\section{Milieu XIIle s., Lyon, quartier Saint-Vincent}

\section{Contexte archéologique}

71 Il s'agit d'une fosse dépotoir composée de deux couches, 4221 et 4042 qui recollent ensemble et dont le remplissage peut être considéré comme un tout ; les 496 fragments donnent 15 vases. Le manque de données ne permet pas d'approfondir le contexte archéologique. 


\section{Étude céramologique} très fragmentaire des céramiques de la famille $G$ ne permet malheureusement d'identifier qu'un seul type, $\mathbf{1 3 8 1}$ : il s'agit d'une marmite à deux anses opposées qui s'accrochent sur la lèvre et le haut de la panse; celle-ci, globulaire, se termine par un fond bombé. On remarque l'absence de col ainsi que la lèvre évasée, d'une grande simplicité. Mis à part son fond bombé, cette céramique se rapproche assez bien du type 1431, en particulier par les anses ${ }^{6}$. Le caractère incomplet d'un deuxième vase, de type 10411 ne permet pas une identification certaine; il présente un profil relativement inhabituel : en effet, le haut de la panse, peu resserré et surmonté d'un col droit, donne une allure de forme ouverte. Le profil de la lèvre est pourtant à rapprocher des cruches à bec ponté 11051 .

Le lot étudié fournit également neuf récipients pour la famille R1, dont plusieurs correspondent à des pichets type $\mathbf{1 1 1 2 1}$ rencontrés dans les fouilles du château d'Anse avec, pour l'exemplaire entier, une décoration classique de bandes rapportées. Par contre, un autre fond avec panse correspond sans nul doute à une cruche de type 11061. La nouveauté réside dans l'apparition du type 11211, qui réunit des caractères intéressants: fond plat, absence de pied, panse surbaissée et haut col droit. On a l'impression jusqu'ici d'une cruche un peu ventrue, mais l'absence de bec pincé indique bien qu'il s'agit là d'un pichet. La panse est décorée de bandes rapportées intercalées de pastilles d'argile; sur le col, des bandes rapportées et décorées à la molette encadrent la représentation grossière d'un visage, formé à partir de pastilles d'argile ; un ressaut sur la bande d'argile horizontale qui sépare le col de la panse suggère le menton du personnage (fig. 127). Ce type de récipient, ainsi que son décor, a déjà été trouvé sur le chantier de la rue Tramassac (A la Fortune du Pot, 1990) ainsi qu'à Clément V (Rapport de fouilles, V. Monnoyeur, 1992) : visage stylisé sur le col avec bandes rapportées croisées sur la paroi ou superposition de bandes rapportées horizontales sur la panse, imitant les tonnelets ${ }^{7}$. 


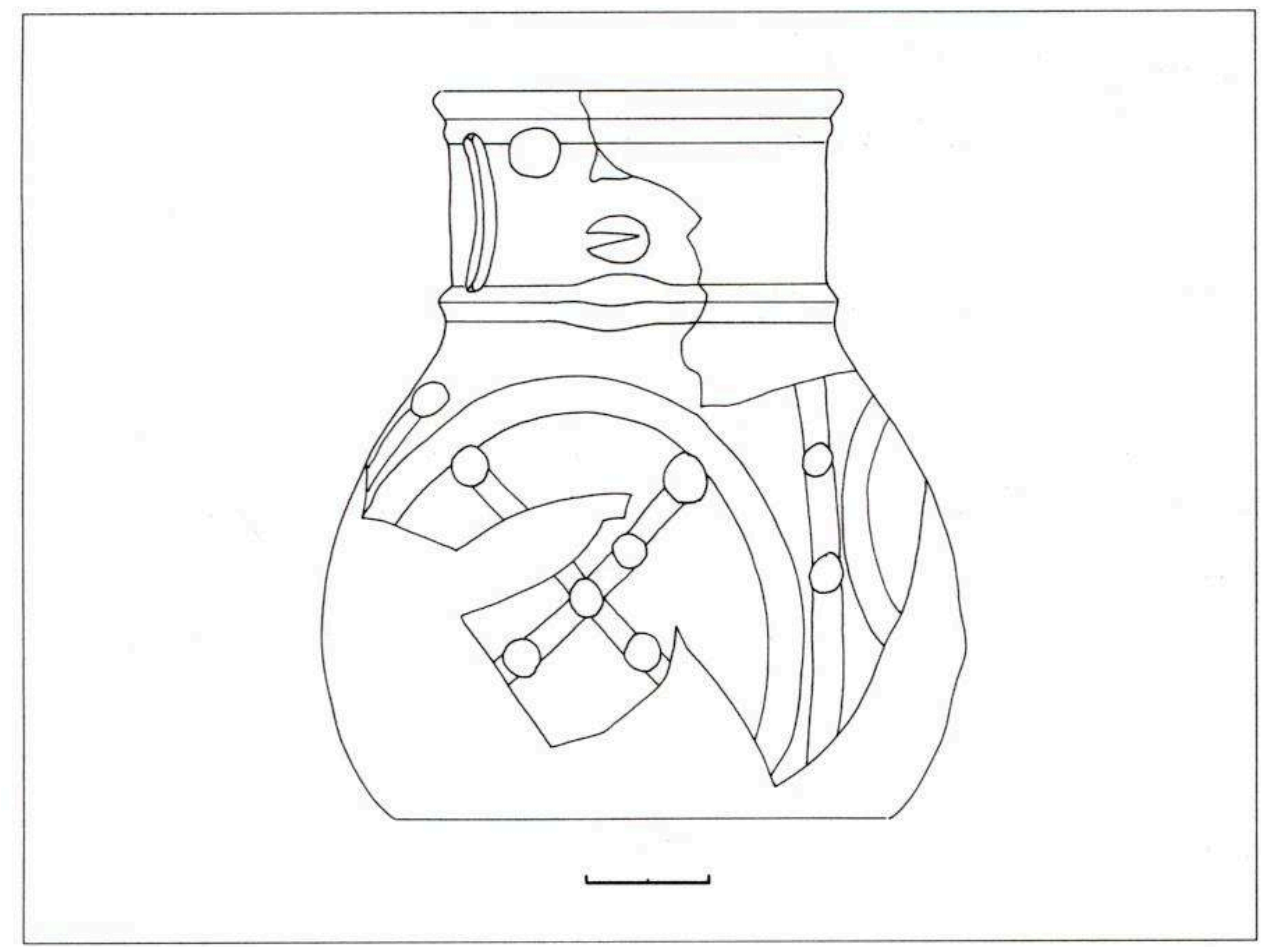

\section{Datation}

74 Typologiquement, le matériel se rapproche de la phase B du remplissage du silo S 16, au château d'Anse : présence simultanée des pichets et des cruches, absence d'oule et de cruche à bec ponté, mais présence de marmites; la datation reste délicate à formuler : elle se rapproche du milieu du XIIIe s.

\section{Milieu XIIle-XIVe s., Lyon, rue de la Monnaie}

\section{Contexte archéologique}

La construction d'un parking souterrain, à proximité de la place des Jacobins, est à l'origine de cette fouille. Des structures de toutes les époques se sont succédé à cet endroit. L'îlot médiéval et moderne s'étendait à l'origine d'un seul tenant entre la rue Mercière, la me de la Monnaie et celle du port du Temple. Au XIVe s., la majeure partie de la surface est occupée par des vignes, des jardins et des constructions sur les parcelles en bordure de la me Mercière. Au XVe s., des étables et des granges sont mentionnées sur la rue de la Monnaie avec des terrains attenants réservés à la culture. C'est à partir de la fin du XVIIe s. que le secteur connaît de nombreuses constructions, qui, malheureusement, détruisent les structures antérieures; c'est donc au centre de l'îlot que l'essentiel du contexte médiéval et moderne subsiste: le bâtiment le plus ancien, et le plus mal connu, est daté du XIIIe s., ainsi que quelques fosses dépotoirs.

On a retenu, pour la période médiévale, une fosse qui manque d'indices chronologiques absolus, mais qui n'en est pas moins extrêmement importante par le matériel fourni. Il s'agit de la fosse 1612, zone 37, remplie successivement par les couches 1688, 1669, 1606. Cette fosse entaille les niveaux gallo-romains; elle est coupée par un mur 
moderne de direction est-ouest. Au sud de ce mur, la fouille a permis de dégager la suite de la fosse, numérotée 1596. Les trois couches de remplissage, respectivement $1689,1644,1595$, correspondent donc à celles fouillées coté nord : ainsi $1606=1595$, $1669=1644$ et $1688=1689$. Précisons tout de suite qu'aucun matériel ne fut trouvé dans les couches 1644 et 1689 .

La première étape consiste bien naturellement à vérifier l'homogénéité du remplissage. Nous savons par les collages que 1688 est liée à 1669 ; nous pouvons donc les considérer comme un tout. Aucun des types présents dans ces 2 couches ne se retrouve en 1606 et 1595, pourtant archéologiquement immédiatement supérieures. Nous sommes en présence de deux phases de remplissage d'époques différentes. En effet, les couches 1606 et 1595 sont datables du XVIe s. et seront donc traitées dans la deuxième période de cette étude.

\section{Étude céramologique}

marmite 1441 à la Bourse (fin XIIe s.) ou à l'Hôtel-Dieu; la marmite 1381 à SaintVincent (milieu XIIIe s.); la cruche 11061, la marmite 10222, le pichet 11212 au château d'Anse (milieu XIIIe s.) ; le pichet 11211 à Tramassac (entre le XIIIe et le XIVe s.), Saint-Vincent (milieu XIIIe s.) et Clément V.

unt, un nouvel élément intervient dans ce site: les marmites à pâte rouge glaçurée. La première apparition d'une marmite en famille R1 provient de la fosse F 35 du château d'Anse, datée de la deuxième moitié du XIIIe s. On en signale aux XIIIe-XIVe s., à Lyon, rue Tramassac, associées à un matériel identique à celui étudié ici. Plus récemment, un dépotoir de la rue Tramassac, daté du XVe s. montre des marmites en 
famille R1, mais d'un profil entièrement différent (Maccari-Poisson 1994, pp. 93-116). Les types 1381 et 1441, ainsi que la céramique des couches 1669 et 1688, se situent donc, dans l'état actuel des connaissances, entre le milieu XIIIe et le XIVe s.

\section{Au XVe siècle}

Les informations concernant cette période sont plus que succinctes, puisqu'elles prennent leurs sources dans trois sites lyonnais seulement, non intégrés dans cette étude : rue Tramassac (Maccari-Poisson 1988), place de la Bourse (Rapport de fouilles, C. Arlaud, 1990), place des Terreaux (Rapport de fouilles, C. Arlaud, 1991-1994). Pour cette raison, la plupart des céramiques citées ne font pas l'objet d'un enregistrement dans notre typologie.

\section{Lyon, place des Terreaux}

Le matériel céramique provenant de niveaux d'occupation ou de comblement de fosses dépotoirs, recueilli, pour la fin du Moyen Age, dans le zone IX, ne brille pas par sa quantité. En contrepartie, il offre l'avantage d'être compris dans une fourchette chronologique sûre, établie d'après des critères de datation absolue : entre le début du XVe s. (monnaie de 1417/1422, couche 3640) et la fin de ce même siècle (destruction des maisons en 1480 et monnaie de 1467/1476, couche 3708).

On retiendra, pour l'étude, six couches $(3702,3706,3752,3755,3763$ et 3809) qui donnent un total de 1401 fragments, répartis en sept familles : 1128 en commune grise famille G, 57 en commune grise glaçurée famille G1, 15 en commune rouge famille R, 138 en commune rouge glaçurée famille R1, 55 en service vert de Meillonnas famille B1, 7 en faïence famille $F$ et 1 grès famille Gr.

Tableau 2. Place des Terreaux, zone IX : répartition des différentes familles pour la fin du XVe siècle

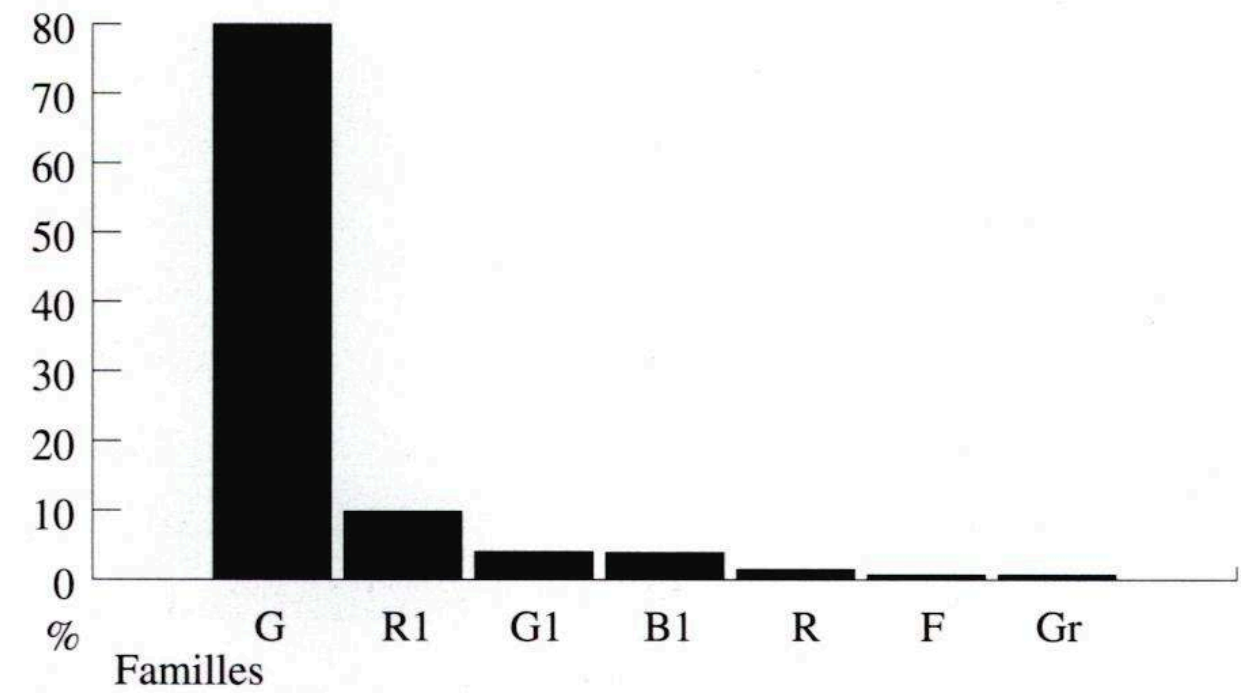

Le tableau (tableau 2) montre en ordre décroissant la place de chaque famille. Cette répartition s'inscrit bien dans la connaissance du mobilier de cette époque: 
prépondérance de la commune grise, suivie par la commune rouge glaçurée; la première famille assure la vaisselle de cuisine et la seconde, la vaisselle de table.

Ce schéma prend sa source à la fin du XIIe s., époque de la séparation entre ces deux types de vaisselle. Il faut noter ici la faible quantité de mobilier en famille R1, généralement de l'ordre de $30 \%$ entre le XIIe et le XVIe s. Cette différence est à mettre à l'ordre du contexte archéologique, essentiellement des couches d'occupation, moins fournies en mobilier que les dépotoirs. La commune grise glaçurée vient en troisième position avec $4 \%$ du total. Cette famille pose toujours un certain nombre de problèmes du fait qu'aucune forme n'est reconstituable. A défaut d'observation, on suppose qu'il ne s'agit pas de vases particuliers, mais d'exemplaires produits en commune grise et simplement recouverts d'une glaçure interne.

Plus surprenante est la présence du service vert de Meillonnas, qui ne totalise que 3,5\% de l'ensemble. Jusqu'à présent, on pensait que cette famille apparaissait au XVIe s. Les fouilles de la zone IX montrent qu'avant 1480, date de la destruction des maisons, cette production était déjà importée de la Bresse. Malheureusement, l'état fragmentaire des tessons n'autorise aucun collage et nous prive de la typologie.

91 Au sujet de la commune rouge non glaçurée, famille $R$, on ne peut que reposer les données du problème, à savoir que les vases produits en R1 ne sont pas glaçurés entièrement et, jusqu'à présent, aucune preuve de l'existence d'une production non glaçurée n'a été mise en évidence.

La faïence ne concerne que $0,5 \%$ du mobilier; il s'agit uniquement de vases d'importation, identiques à ceux trouvés au dépotoir de la place de la Bourse. Nous identifions des fonds appartenant à de grandes formes ouvertes, les mêmes que l'on retrouve au XVIe s., dans d'autres productions.

Quant à l'unique fragment de grès, nos connaissances sont trop succinctes dans ce domaine pour en tirer des conclusions.

En ce qui concerne les types, l'étude permet d'observer certains détails :

Marmites : en commune grise, les fonds sont bombés ou hémisphériques, jamais plats ; les panses restent globulaires dans la majorité des cas; le col, quasi systématique et généralement de petite taille, montre un profil évasé. On note une volonté évidente de simplifier les lèvres, généralement évasées avec parfois un épaississement externe ou bien horizontales. L'attache supérieure des anses se fait aussi bien au niveau de la lèvre que sur le col et même sur le haut de la panse : cette dernière caractéristique annonce les formes 141 et 142 du XVIe s., en commune rouge glaçurée qui possèdent le même emplacement de fixation des éléments de préhension. Les marmites en commune grise $\mathrm{du}$ XVe s. restent bien dans la tradition de celles du Moyen Age : le fond et la panse ne changent pas ; l'emplacement des anses ne doit pas être considéré comme un critère de datation; les lèvres se simplifient. En commune rouge glaçurée famille R1, aucune forme n'a pu être reconstituée; certains fragments de lèvre attestent pourtant leur présence, en R1, au XVe s.

96 Cruches: le fait le plus remarquable pour cette période concerne la présence de cruches à bec ponté en céramique commune grise, de type 11051. Ce genre de vase, typique des Xe-XIIe s., disparaît au début du XIIIe s. Diverses découvertes montrent que ce profil réapparaît dans des contextes fin XVe, début XVIe s. Les risques de confusion entre les deux époques restent minimes : les becs pontés du XVe s., sont de dimensions nettement supérieures à leurs homologues du Moyen Age. Si on s'interroge sur la 
résurgence d'une forme aussi ancienne à une époque où d'autres types de cruches sont produits en commune rouge glaçurée, on peut émettre deux hypothèses : la première envisage la pérennité de la cruche à bec ponté du XIIIe au XVe s., de manière si minoritaire que le fait n'est pas perceptible par les données archéologiques ; le manque de mobilier provenant de structures du XIVe s. donne un poids supplémentaire à cette idée. La deuxième hypothèse tient dans le surdimensionnement du bec verseur nécessitant la présence d'un renfort par dessus, d'où la création de becs pontés : une contrainte technique qui aboutit à la même forme à deux siècles d'intervalle. En commune rouge glaçurée, quelques fragments attestent la présence de cruches à bec pincé, identiques à celles de Tramassac, sans doute de type 11061. Aucune forme n'a pu être reconstituée.

Formes ouvertes : la mise au jour, dans la zone IX, d'un bassin en commune grise, de type 3211 et d'une assiette creuse en commune rouge glaçurée, de type 3311, montrent que ces deux céramiques, que l'on pensait propres au XVIe s., étaient déjà en service à la fin du XVe s. De plus, les faïences d'importation de la zone IX permettent d'identifier des fonds de plats creux 3311 et d'écuelles de type $\mathbf{3 4 1 1}$.

\section{Lyon, rue Tramassac} fond bombé, panse globulaire, petit col évasé avec des anses accrochées sur la lèvre et le milieu de la panse, dans la tradition des types 1381, 1431 ou 101101 ;'autre, à fond hémisphérique et panse globulaire, possède un col court évasé avec deux anses opposées attachées à la lèvre et au milieu de la panse et s'apparente au type 10321. Le dépotoir a également fourni un coquemar en pâte grise, à fond plat, panse globulaire, col court peu évasé et lèvre horizontale ; l'anse est rattachée à la lèvre et au milieu de la panse. Plus surprenante est la série de jattes de grande taille, en pâte grise, sans revêtement: le fond est hémisphérique, avec une panse globulaire aplatie, qui montre pourtant un étranglement du profil au niveau de la jonction avec un petit col évasé ; le système de préhension est constitué d'anses partant de la lèvre évasée ou de tenons (Maccari-Poisson 1988, p. 234, fig. 11).

101 Cette phase du dépotoir peut être datée du XVe s. Précisons qu'aucun indice de datation absolue ne vient renforcer cette hypothèse qui découle de la chronologie interne de ce remplissage (la phase antérieure étant du XIIIe s. et la phase postérieure du XVIe s.), et de l'observation du matériel: absence de types et de productions 
spécifiques au XVIe s., tels que les marmites à anses coudées en commune grise, les marmites à deux anses en commune rouge glaçurée, les écuelles et assiettes creuses, la faïence lyonnaise, la céramique à glaçure verte sur engobe blanc, etc.

\section{Lyon, place de la Bourse}

102 Les recherches archéologiques ont permis la découverte de nombreux dépotoirs ou fosses d'aisance, dont l'un, le dépotoir D1, appartenant à la période 11, peut être daté de la fin XVe s. Le matériel n'est pas encore publié et a fait seulement l'objet d'un compterendu dans le rapport de fouille : les observations restent donc partielles.

On recense 1657 fragments qui se répartissent en quatre productions : la commune grise $G$ avec 1054 tessons, la commune rouge glaçurée $R 1$ avec 588, la faïence $F$ avec 9 et les sgraffito E7 avec 6 tessons. La première famille comprend de nombreuses marmites à anses coudées, type $\mathbf{1 3 1 1}$ ainsi que d'autres, semblables à celles de la zone IX, de la fouille place des Terreaux. On trouve également un exemplaire au moins de cruche à bec ponté et sans doute un petit coquemar. La commune rouge glaçurée fournit des marmites à panse globulaire, fond bombé et deux anses plates opposées, de formes 141 et 142, des coquemars et des poêlons à bord droit, paroi évasée et dont le manche est opposé à un bec pincé. On trouve aussi de très nombreuses cruches de type 11061 et des pichets à grand col évasé, identiques à celui du dépotoir de Tramassac. En faïence d'importation, on identifie des cruches et une écuelle, tandis que la famille E7 fournit un plat creux.

La datation de ce comblement reste délicate. Il semble, en tout cas, que la présence des faïences et des sgraffito, ainsi que celle des marmites à anses coudées placent ce dépotoir à une époque plus récente que ceux de Tramassac et de la zone IX des Terreaux ; d'autre part, certains indices ne permettent pas de dépasser la fin du XVe ou le tout début du XVIe s. : en effet, on note l'absence de production à glaçure verte sur engobe blanc famille $\mathrm{El}$, ainsi que celle de la faïence lyonnaise, compensée par la présence de proto majolique italienne et faïence hispanique. De même, la grande quantité de marmites à anses coudées est équilibrée par la présence de nombreuses marmites à anses rubannées, phénomène que l'on ne retrouve pas au XVIe s. où la production des marmites imitant les récipients en métal est tellement forte qu'elle occulte pratiquement toutes les autres formes en commune grise. Plus problématique reste l'absence du service vert de Meillonnas : comme nous savons que cette famille est présente dès 1480 , à une époque où les marmites à anses coudées n'existaient pas, on peut suggérer que son absence sur ce site est due aux hasards des remplissages.

Toutes ces observations conduisent à placer le comblement de ce dépotoir entre l'extrême fin du XVe et le tout début du XVIe s., sans doute postérieurement au mobilier de la zone IX et de Tramassac, mais antérieurement à celui de l'Hôtel-Dieu.

En conclusion, l'image que renvoient ces découvertes de la céramique du XVe s est loin d'être complète, mais procure quand même un certain nombre de surprises. D'un point de vue général, le mobilier reste fortement imprégné de tradition médiévale. Pourtant, certains aspects annoncent les bouleversements du XVIe s.: les quelques formes ouvertes ou l'apparition, avec le service vert de Meillonnas famille B1 et des sgraffito famille E7, de deux nouvelles productions.

107 Cette fin du XVe s. est assurément une période de transition. 


\section{Les XVle, XVIle et XVIIle siècles}

Pour ces trois siècles, nous allons donc présenter les contextes archéologiques de chaque site avant d'aborder, de manière chronologique, l'étude céramologique et la datation.

Il convient, dès maintenant, pour éviter de laborieuses répétitions, de fixer les critères de datation à notre disposition, préalablement aux études monographiques :

les critères absolus : ils sont généralement extrinsèques à la céramique puisqu'ils proviennent des monnaies, textes, archives et données archéologiques. Toutefois, de rares récipients montrent des inscriptions et dates gravées sur leur surface,

les critères relatifs : ils consistent essentiellement en comparaisons typologiques des lots non datés avec du matériel bien calé chronologiquement.

A ce titre, certaines productions ou types de céramiques servent de référence :

- La faïence : les documents d'archives mentionnent la venue, à Lyon, de faïenciers originaires d'Italie et plus particulièrement de Toscane, dès le tout début du XVIe s. Les fouilles archéologiques montrent que la faïence lyonnaise est absente dans les couches de la fin du XVe s., puisque le dépotoir D1 de la Bourse, sur un total de 1657 tessons, n'en possède que 9 fragments, tous d'importation (Rapport de fouille, C. Arlaud 1990, pp. 81-84). Par contre, au début du XVIe s., le dépotoir D2, du même site, fournit 45 fragments pour un total de 6983 tessons: là encore, on compte beaucoup d'importations, mais également les premières faïences d'origine lyonnaise (Rapport de fouille, C. Arlaud, 1990, pp. 73-78). Enfin, depuis la fouille de la place des Terreaux, on sait que cette production occupe une place non négligeable au milieu de ce même siècle (Rapport de fouille, C. Arlaud, 1991-94).

- La production attribuée à Meillonnas-Treffort ou « service vert B1 » : son apparition se situe avant 1480 (cf. Terreaux zone IX) mais c'est à partir du milieu du XVIe s. que les potiers de ces villages inondent le marché lyonnais de cette céramique à glaçure verte et ce, jusqu'au milieu du XVIIIe s.

- La production attribuée à Larnage, ou « service jaune B2 » : autre céramique bien typée, à glaçure jaune sur pâte blanche sans engobe, issue d'un village de la moyenne vallée du Rhône; elle apparaît dans la deuxième moitié du XVIIe s. puisqu'on la trouve dans le dépotoir de la place Antonin Poncet (Becker et alii 1989), mais pas dans le puits de SaintVincent, daté du milieu de ce siècle.

- La marmite à anses coudées, de type 1311 (fig. 128): fond bombé, panse ovoïde ou globulaire, col moyen évasé ; la lèvre est sans inflexion et se cantonne à trois types : à faces parallèles ou à épaississement externe ou encore à faces divergentes; les anses, de section ronde, verticales et opposées sont ancrées sur la lèvre et le haut de la panse et présentent la particularité d'être coudées, imitant en cela les récipients de métal, ce qui en fait un très bon repère dans les ensembles de céramiques culinaires. On trouve le type $\mathbf{1 3 1 1}$ dès l'extrême fin du XVe, voire au début du XVIe s., dans le dépotoir D1 de la Bourse. Elle prend une place extrêmement importante au XVIe et assure en quelque sorte l'ossature de la production commune grise. Ce type disparaît sans doute au début du XVIIe s. Il faut noter qu'actuellement, on ne connait pas sa date d'apparition par rapport au service vert B1: les deux productions arrivent sans doute simultanément sur le marché. 


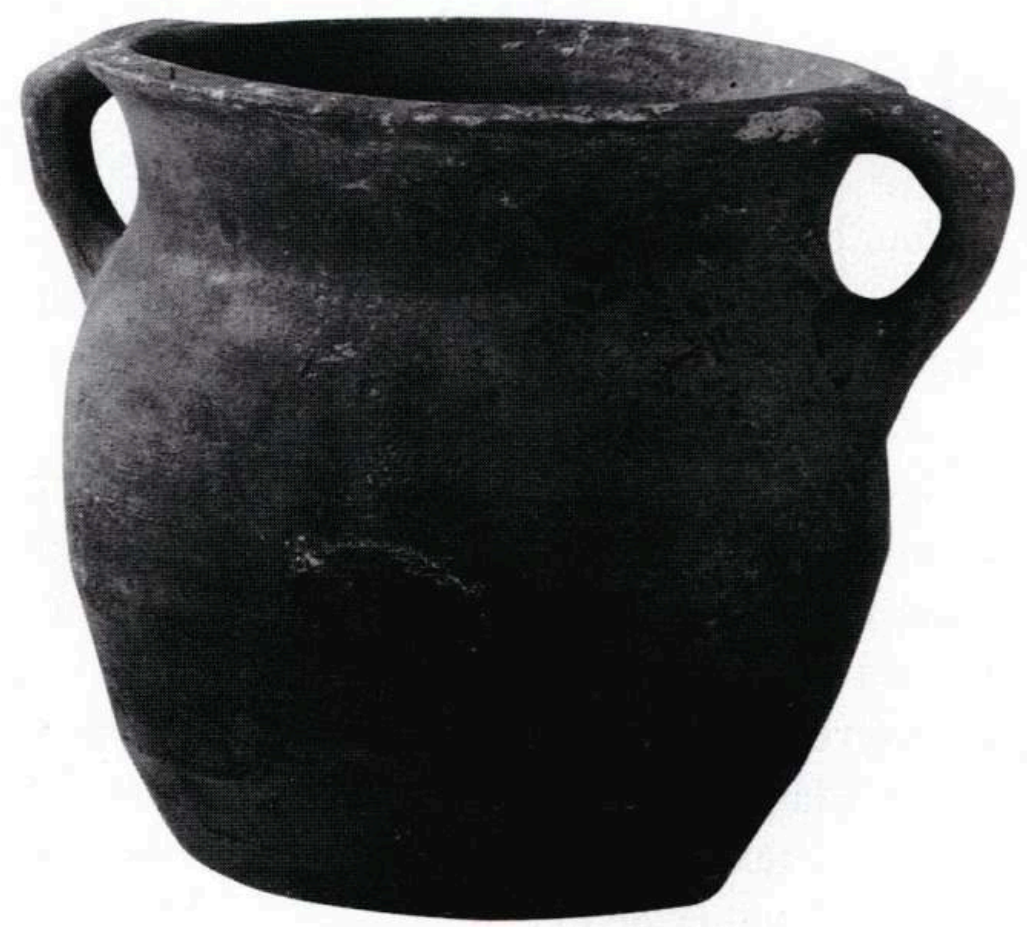

\section{Contexte archéologique}

113 Le dénominateur commun aux sites étudiés ici réside dans le fait qu'il s'agit de structures domestiques en lieu clos, parfois stratifiées: dépotoirs, fosses d'aisance, comblement de puits ; toutes sont issues de fouilles urbaines récentes.

\section{Lyon, rue de la Monnaie, îlot 24}

Le contexte archéologique est décrit dans la période précédente (cf. supra); pour le XVIe s., nous avons retenu trois ensembles sur ce chantier: la fosse 1612 et son comblement : les couches 1606 et 1595, zone 37 ; la fosse 1686 et son comblement : la couche 1687 , zone 37 et la fosse 1434 et son comblement : la couche 1435 , zone 32 . La totalité de ces remplissages fournit 365 fragments pour 60 vases après collage. Aucune donnée archéologique écrite n'est disponible sur ces structures.

\section{Lyon, rue René Leynaud, îlot Vieille Monnaie}

115 Situé au nord de la presqu'île, sur les pentes de la Croix-Rousse, ce secteur de la ville apparaît sur le plan scénographique du XVIe comme un îlot de verdure, où seules quelques maisons bordent les rues principales. Le quartier perd cet aspect campagnard à partir du XVIIIe s., consécutivement au développement de l'industrie de la soie. De rares fosses dépotoirs ou d'aisance, 153, 438 et 433, témoignent de l'occupation humaine à l'époque moderne : elles fournissent 1367 fragments qui donnent 165 vases. 


\section{Lyon, rue Bellecordière, Hôtel-Dieu}

Dans le cadre du programme de réhabilitation de l'Hôtel-Dieu, la construction, en soussol, d'une station de chauffage, a permis la fouille préventive d'un secteur, en limite de la rue Bellecordière, dans l'angle sud-ouest de l'aile sud de l'hôpital. Les fondations de quatre maisons détruites en 1832, ainsi que sept fosses dépotoirs ou fosses d'aisance remplies de matériel céramique ont été dégagées : elles fournissent 4481 fragments qui donnent 342 vases (fig.129).

129 - Lyon, rue Bellecordière, Hôtel-Dieu : emplacement des fosses dépotoirs

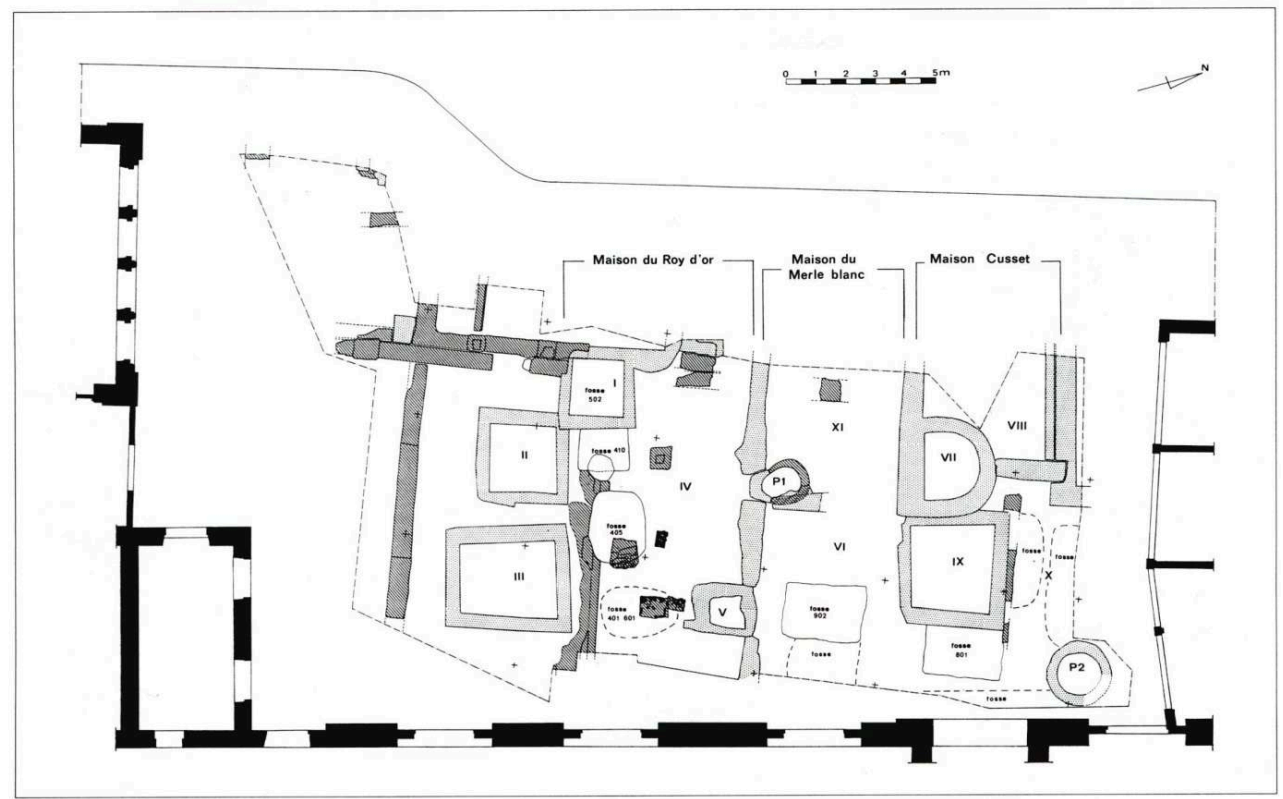

117 Du nord au sud, nous avons successivement :

- la maison Cusset, avec, à l'extrémité est, la fosse 801. La maison est composée des murs 6, 7, de la tour d'escalier M9 et d'une pièce formée des murs $10,35,36$ et 37 . Cette pièce est postérieure à l'escalier 9 et coupe la fosse 801, qui sont donc les structures les plus anciennes de l'ensemble. Cette maison est une rente de l'archevêché, mentionnée plusieurs fois par les archives entre 1446 et 1734. Le remplissage de la fosse 801 est composé de tuiles, briques, sable, mortier, cendres, charbon de bois, verre, métal et ardoises.

- la maison du Merle Blanc, avec, à l'extrémité est, les fosses 901 et 902 . Cette maison est constituée, au sud, des murs 14 et 11 et au nord, des murs 35 et 9 et du mur 16 qui est la limite ouest de la cour où ont été dégagées les fosses dépotoirs. La maison Cusset et celle du Merle Blanc forment une seule maison en deux corps de logis, séparés par une allée estouest joignant la rue Bellecordière au Rhône ; c'est une rente de l'Abbaye d'Ainay et de l'archevêché, également mentionnée entre 1446 et 1735. La fouille montre que la fosse 902 coupe la 901.

- la maison du Roy d'Or, avec d'ouest en est, les fosses 502, 410, 405 et 401/601. Cette maison est délimitée au nord par les murs 14 et 11 et au sud, par les murs 26 et 29 . Au sud-ouest, une petite pièce, en fait le dépotoir 502, est formé des murs 31, 32, 33 et 12 ; d'après le rapport de fouille, elle semble condamnée à partir de 1629. Cette maison, une rente de l'Abbaye d'Ainay et de l'archevêché, est mentionnée entre 1493 et 1735. La fouille montre que la fosse 410 est coupée par 502, que le remplissage de la fosse 405, formée d'un cuvelage en bois, est riche en os, charbons de bois et en cendres et que le dépotoir 502 est sans doute une fosse d'aisance. 
118 Paradoxalement, toutes ces informations ne nous sont guère d'utilité pour la datation des dépotoirs, ni pour les relations de ceux-ci avec le bâti. Force est de se rabattre sur les comparaisons typologiques. Malgré ce handicap, nous avons gardé les sept fosses pour l'étude, en raison de la diversité du matériel, qui fournit un bon jalon pour l'époque.

\section{Lyon, quartier Saint-Vincent}

\section{1 rue Bouteille}

La fouille de cette zone a permis de mettre au jour une dizaine de fosses dépotoirs : huit ont été retenues avec un total de 2968 tessons avant collage, ce qui nous donne ensuite 357 vases identifiés. D’autre part, la fouille quasi intégrale, sur 6 mètres de profondeur, du comblement d'un puits permet également de disposer de 10452 tessons. Ce matériel a été choisi pour étude en raison de contextes archéologiques bien stratifiés et de nombreux éléments de datation absolus tels que monnaies, archives et étude du parcellaire.

120 Secteur II, rue de la Vieille

Neuf structures utilisées en dépotoirs ont été mises au jour, dont cinq d'entres elles possèdent des éléments de datation absolue par les monnaies. Les différents remplissages fournissent 2639 fragments pour 352 vases après collage.

121 Secteur la, rue Touret

Nous retiendrons pour cette étude, le contenu de trois structures qui ont livré 836 fragments, lesquels donnent 105 vases.

\section{Le XVle siècle}

\section{Au début du siècle...}

La fouille des diverses structures trouvées à l'Hôtel-Dieu, rue Bellecordière, n'apporte aucun élément de datation absolue ; par contre, la coexistence de certains types donne à ce site une place importante pour la typologie ; le caractère homogène (fig. 130) de cet ensemble - en faisant abstraction de la fosse 401-601 - conduit à proposer une datation globale qui fait l'objet d'un paragraphe particulier. 


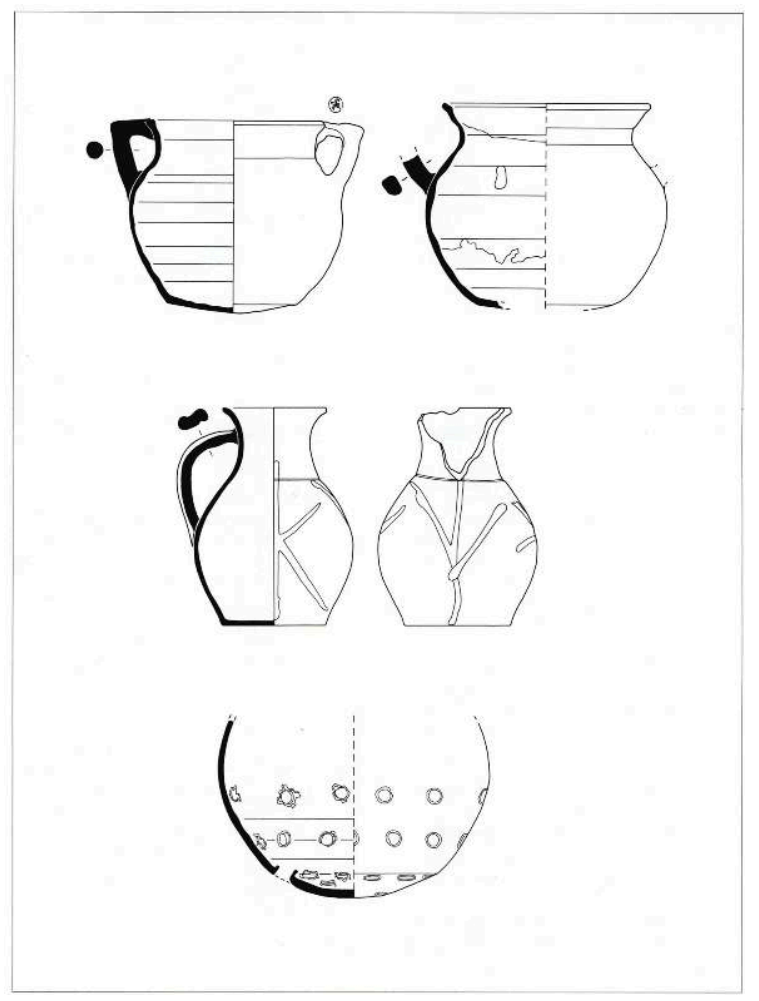

\section{La fosse 401-601}

Elle est située à l'Est, dans la maison du Roy d'Or, de même que les trois suivantes; le remplissage se compose de 248 tessons répartis en deux familles : 101 en commune grise et 147 en commune rouge glaçurée.

La composition du matériel est assez particulière : aucun des fragments de panse en céramique commune grise n'est en mesure de fournir un type identifiable; en famille $\mathrm{R} 1$, on recense plusieurs récipients de type 11212 ou 11061, ce qui pose un problème de datation, puisque ces vases se situent aussi bien au milieu du XIIIe qu'au début du XVIe s. ; et que peut-on dire de l'absence des familles B et F ? De même, l'examen des tessons de panse en R1, où l'on trouve six fragments décorés, soit de bandes de barbotine, soit de pastilles, et un motif zoomorphe apparenté à un oiseau, n'apporte aucun renseignement; on peut quand même noter que ce genre de décor est plus fréquent durant la période médiévale.

\section{La fosse 405}

Elle compte 834 fragments, répartis en 8 familles : 1 en faïence $F$ et en jaune sur engobe E4, 2 en verte sur engobe El, 13 en commune grise glaçurée G1, 27 attribués au service vert B1, 55 en commune rouge glaçurée RI, 53 en commune rouge $\mathrm{R}$ et 682 en commune grise $\mathrm{G}$.

Cette dernière se trouve représentée par des marmites à anses coudées, de type $\mathbf{1 3 1 1}$ qui forment un lot de 38 exemplaires. On trouve également des marmites de type 1441, déjà rencontrées à l'îlot 24 pour les périodes précédentes; il faut également mentionner une cruche à bec ponté en céramique grise glaçurée. 
En ce qui concerne la famille R1, on retrouve les mêmes produits avec les marmites de type 1441 et une cruche à bec ponté de type 11051 : il n'est pas rare de voir ces types présents aussi bien en G, G1 qu'en R1. Il existe aussi, dans cette fosse, un pichet de type 11212, ainsi que trois éléments non identifiables, mais dont deux peuvent être des marmites. En céramique commune rouge $R$, les 6 lèvres se divisent en deux récipients : un bassin de type 3211, à deux anses opposées qui s'accrochent sur la lèvre et le milieu de la paroi et une cruche éventuellement de type 1112. En ce qui concerne la famille B1, sur les 27 tessons présents, une cruche $\mathbf{1 1 1 2}$ a été identifiée ; il reste un fragment de lèvre non identifié, assez court, sans col, qui appartient peut-être à un coquemar. Un seul tesson de panse en faïence $F$ a été recueilli mais il n'apporte aucune information.

\section{La fosse 410}

Elle compte 665 fragments, répartis en 7 familles : 1 exemplaire pour les familles $\mathrm{F}$ et jaune décorée $\mathrm{E} 5,8$ en commune grise glaçurée $\mathrm{Gl}, 22$ attribués au service vert B1, 90 en commune rouge R, 94 en commune rouge glaçurée R1 et 449 en commune grise $\mathrm{G}$.

Cette dernière famille livre plusieurs marmites de types 1311 (parmi celles-ci, deux semblent gla-çurées) et 1441 ; il faut aussi en ajouter une de type 10161 et de type 1431, identiques à celles d'Anse, ainsi que deux cruches à bec ponté de type 11051 . Dans la famille R1, le matériel est plus abondant et diversifié : des bassins de type 3211, des cruches de type 11061 (certaines ne sont pas glaçurées, mais les tessons sont trop petits pour étendre cette observation à l'ensemble du vase), des marmites de type 1441, un lèchefrite de type 3111, à parois verticales, un poêlon, peut-être de type 3831 .

\section{La fosse 502}

Les 635 tessons trouvés dans la fosse 502 se répartissent en 8 familles : 1 en divers E8, 6 en jaune décorée E5, 8 en verte sur engobe $\mathrm{El}, 29$ attribués au service vert B1, 34 en commune grise glaçurée $\mathrm{G} 1,101$ en commune rouge $\mathrm{R}, 151$ en commune rouge glaçurée RI et 635 en commune grise G.

Un très grand nombre-trente exemplaires-de marmites à anses coudées de type 1311, appartenant à cette famille, provient de cette fosse, associé à des marmites de type 1441, un bassin de type 3211 et un fond globulaire, qui présente la particularité d'être percé de nombreux trous jusqu'à mi-hauteur: ceux-ci ont été faits avant cuisson, de manière peu soignée, en laissant de fréquents bourrelets d'argile sur les bords, ce qui permet en tout cas d'infirmer l'hypothèse d'une faisselle; il s'agit peut être d'un ustensile à cuire les châtaignes ou tout simplement d'une passoire ${ }^{8}$ Enfin, en famille $G$, a été identifié un nouveau type, un coquemar entier, 1361, avec une lèvre très simple, à une inflexion oblique vers le haut. Il faut noter que cette lèvre est en tout point identique à celle des cruches à bec ponté de type 11051, dont le reste du vase possède les mêmes caractéristiques: panse globulaire, fond bombé et absence de col.

Deux lèvres non identifiées et un biberon de type 11031, muni d'une anse verticale perpendiculaire à un petit bec tubulaire composent la totalité d'une famille peu fréquente : la commune grise glaçurée G1. Un autre biberon, en divers E8, de type 11041, provient également de cette fosse : l'anse est à l'opposé du bec tubulaire; il est revêtu sur ses faces interne et externe d'une glaçure sur engobe foncé avec, sur la face 
externe, un décor à la barbotine blanche de croix et de points disposés sur trois registres.

En céramique commune à pâte rouge, famille $R$, seules quelques cruches de type 1112 sont présentes, ainsi qu'un nouveau type de marmite, 1352, à fond bombé, sans col et à deux anses plates verticales opposées. La famille R1 fournit une cruche de type 1112 et quatre marmites: deux de type 1831, une de type 1351, une de type 1832. Pour ces dernières, les variantes morphologiques se situent surtout au niveau des lèvres et des fonds, mais la forme générale reste la même : panse généralement globulaire et deux anses verticales opposées qui se rattachent sur la lèvre et le milieu de la panse. Quant à la famille B1, elle ne livre que des tessons de panse et des fonds.

\section{La fosse 901}

Elle est située dans la maison du Merle Blanc ainsi que la suivante. Elle compte un total de 183 tessons, répartis en 6 familles : 1 en faïence F, 2 en verte sur engobe E1, 26 en commune grise glaçurée $\mathrm{G} 1,121$ en commune rouge $\mathrm{R}, 178$ en commune rouge glaçurée $\mathrm{R} 1$ et 855 en commune grise $\mathrm{G}$.

135 Ce dernier lot est extrêmement intéressant : en effet, il regroupe des exemplaires de marmites types 1311, 1441 et 1431, avec d'autres, non connus jusqu'alors, mais dont il faut noter les différences morphologiques, telles que l'absence de col et les anses sur la lèvre (10122), ou la présence de col avec les anses sur la lèvre (10231) ou sur le haut de la panse (10211). Il s'agit en fait de l'addition de plusieurs caractéristiques typologiques que l'on avait notées dans les couches 1688 et 1669 de l'Ilot 24, où, d'ailleurs se trouvent plusieurs exemplaires de marmites 1441. Il n'en reste pas moins que la présence de ces différents types de marmites en famille $G$ demeure d'un grand intérêt.

136 En céramique glaçurée à pâte rouge, famille R1, on retrouve les marmites de la famille $G$, mais cuites en mode oxydant : types 1441, 10131, oule de type 1371 et surtout une marmite entière sans doute de type $\mathbf{1 3 1 1}$; les anses, incomplètes ne permettent pas de le certifier. Mentionnons aussi des cruches 11061 et une cruche 11051. Les fragments de verte sur engobe El et de faïence ne permettent pas d'identification.

\section{La fosse 902}

137 Elle fournit 450 tessons, répartis en 8 familles : 1 exemplaire pour les familles F, E4, E7, 5 attribués au service vert B1, 21 en verte sur engobe El, 27 en commune rouge R, 122 en commune rouge glaçurée $\mathrm{R} 1$ et 272 en commune grise $\mathrm{G}$.

On remarque, pour cette dernière famille, une forte présence de marmites type 1311, des bassins type 3211 et des marmites type 1441. On trouve également des exemplaires de marmites types 1411 et 1421 en céramique glaçurée à pâte rouge R1. La seule lèvre de famille R n'est malheureusement pas identifiée.

139 Les rares exemplaires d'assiettes creuses, de type 3311 et d'écuelles à oreilles, de type 3411 appartiennent à la famille El, ainsi qu'un lèchefrite de type 3111, de même qu'un petit pot, qui, par sa taille, doit appartenir à une dînette.

140 Les familles $\mathrm{B} 1$ et $\mathrm{F}$ ne fournissent que des fragments non identifiables. 


\section{La fosse 801}

141 tout au début du XVIe s. En effet, il est curieux de constater le mélange de céramiques bien datées du XVIe, telles que les assiettes, les écuelles ou les marmites à anses coudées avec des vases que l'on a plutôt tendance à trouver à des époques antérieures, comme les marmites 1441, les cruches 11061, les pichets 11212. Ce mélange est la caractéristique du remplissage des fosses de l'Hôtel-Dieu et il est trop systématique pour ne voir qu'un fait dû au hasard: il faut le considérer comme révélateur d'une époque de transition entre vaisselier médiéval et vaisselier moderne. Ce site est d'ailleurs le seul à proposer un tel éventail, comme le montre la suite de l'étude. Il faut 
ajouter que le faible pourcentage de la famille B1 plaide également en faveur du début du XVIe s.

\section{Dans la première moitié du siècle}

147 Les éléments de datation absolue restent relativement rares pour cette époque; heureusement, certaines fosses de la fouille du quartier Saint-Vincent ne sont pas dépourvues de monnaies et permettent de poser des jalons chronologiques.

\section{La fosse 129-134}

Elle regroupe les couches 130,135, 156, 169, 171, 175, et compte 1259 tessons qui se répartissent en 7 familles : 2 pour la jaune décorée $E 5,5$ pour la faïence $F, 8$ attribués au service vert $\mathrm{B} 1,11$ pour la verte sur engobe $\mathrm{El}, 25$ pour la commune grise glaçurée $\mathrm{G} 1$, 69 pour la commune rouge glaçurée R1 et 1139 pour la commune grise G. Le recollage montre de nombreuses liaisons entre ces diverses couches et permet de considérer et d'étudier le matériel comme un tout homogène.

Très peu de types sont présents en famille $G$ dans cette fosse, mais on rencontre 120 exemplaires de marmites à anses coudées de type $\mathbf{1 3 1 1}$; le reste du matériel se répartit entre cruche à bec ponté de type 11051, bassins de type 3211, un récipient à fond plat et paroi évasée rectiligne, que l'on va retrouver fréquemment en commune grise et pots de type 10172; malheureusement, ce dernier reste incomplet et on ne peut trancher entre marmite et coquemar.

En commune rouge glaçurée R1, on trouve des exemplaires de la marmite type 1411, aussi fréquente dans cette famille que peut l'être le type 1311 en commune grise. Les formes 141 et 142 se distinguent par leur deux anses plates opposées qui s'attachent sur le haut et le milieu de la panse et par leur fond hémisphérique.

151 C'est en verte sur engobe E1 que l'on a le plus de types différents : lèchefrites 3111, reconnaissables à leurs parois verticales, assiettes creuses 3311, réchaud de type $\mathbf{7 1 1 2}$ (fig. 131), écuelles de type 3411, avec leur tenons de préhension ou « oreilles », cruche 1141 à bec tubulaire et cruche de type $\mathbf{1 1 0 1 1}$ à anse en panier qui, pour l'instant, n'est connue qu'en commune grise. 


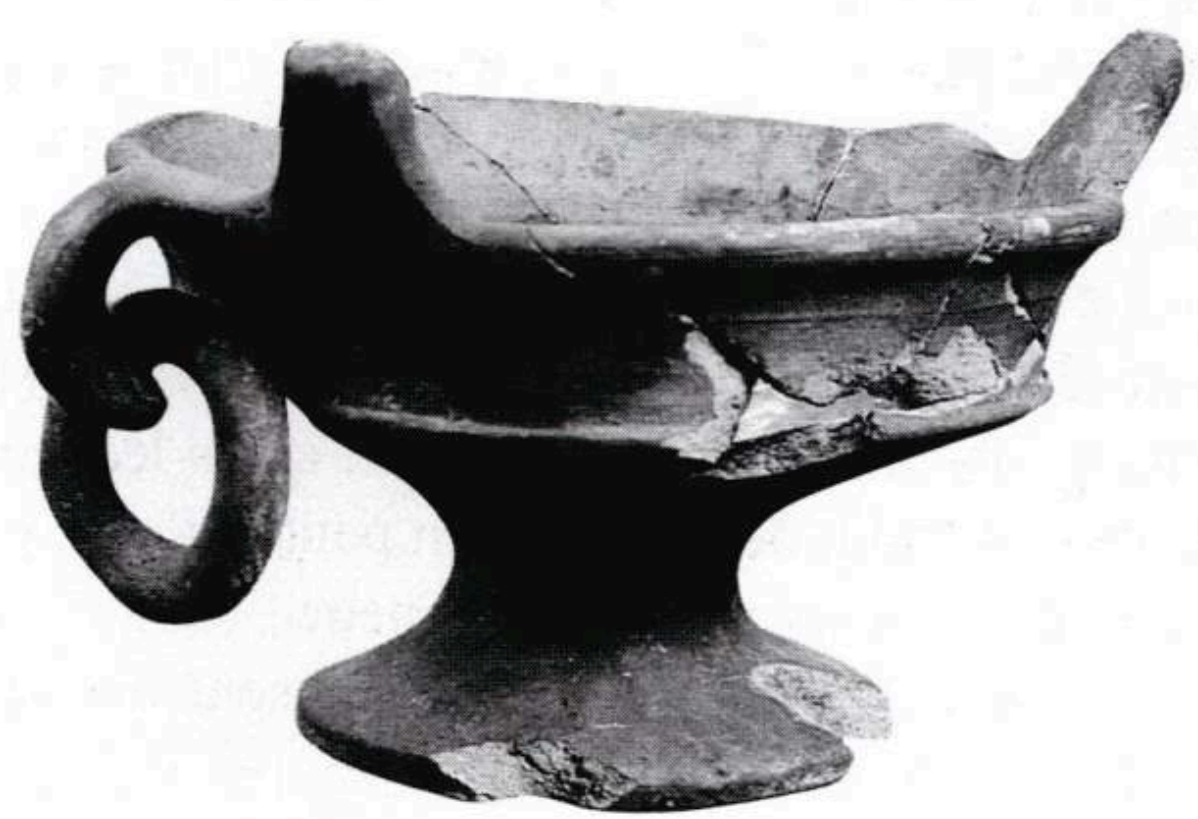

En faïence F, il n'y a aucune forme identifiée à partir des lèvres présentes, ni pour le service vert B1, mise à part une minuscule assiette creuse $\mathbf{4 3 1 1}$ qui s'apparente plutôt à une dînette.

La datation est proposée ci-dessous, après étude de la fosse suivante, en raison des relations existant entre les deux structures.

\section{La fosse 131}

Cette fosse regroupe les couches 131, 184, 185 et fournit un total de 328 tessons, répartis en 4 familles : 1 tesson attribué au service vert B1, 9 en verte sur engobe E1, 16 en commune rouge glaçurée R1 et 302 en commune grise G. Le recollage montre de nombreuses liaisons entre ces diverses couches et autorise une étude d'ensemble.

Nous retrouvons ici, en famille $G$, une nette majorité de marmites à anses coudées de type 1311 avec 22 vases; les exemplaires restants sont identifiés comme des pots de type 10172. Avec seulement quelques marmites de type 1411, la fosse ne livre que peu de matériel en famille R1. Par contre, la céramique verte sur engobe, famille El, procure une grande variété de types : lèchefrites 3111, écuelle 3411, assiettes creuses 3311 et cruches de type 1141. Il ne faut pas oublier l'unique tesson en famille Bl.

De nombreux fragments issus de cette fosse recollent avec la fosse 129/134. On peut donc les considérer comme contemporaines. La fosse 129/134 a livré deux monnaies : un jeton de Nuremberg de la fin XVe s. et un double tournois de Louis XII, du début du XVIe s.; en ajoutant, par ailleurs, une datation début XVIe s. du matériel en verre (Auger 1990), c'est donc à cette époque qu'il faut placer le lot de céramique. Si l'on se réfère aux découvertes des Terreaux, la rareté de la faïence, de la famille B1 et de la famille E5, ainsi que l'absence de rouge décorée E2, corroborent cette datation. Il faut toutefois préciser que le remplissage de ces deux fosses est postérieur à celui de l'HôtelDieu, comme tend à le démontrer l'absence de céramiques de tradition médiévale, tels 
que les types 1441 ou 11061 ; dans son ensemble, le matériel des fosses 129 et 131 possède plus d'affinité avec le milieu du XVIe s.

\section{La fosse 158}

157 Elle n'est composée que de la couche 177 qui compte 415 tessons, répartis en 5 familles : 2 en faïence F, 6 en service vert B1, 9 en verte sur engobe E1, 60 en commune rouge glaçurée R1 et 338 en commune grise $\mathrm{G}$.

Une nouvelle fois, les marmites de type 1311 en commune grise tiennent la vedette, ici avec 43 exemplaires, auxquels viennent s'ajouter des pots de type 10172. Dans la famille R1, il n'y a pas de surprise avec les marmites de type $\mathbf{1 4 1 1}$; toutefois, le matériel est un peu plus important en E1 avec des écuelles 3411, des assiettes creuses 3311 et une jatte de type $\mathbf{3 2 2 1}$ à fond plat et deux anses verticales opposées. Ce lot ne serait pas complet sans les deux tessons de faïence et les six en famille B1 qui, malheureusement, ne reconstituent aucun vase.

159 Cette fosse est importante, puisqu'elle fournit deux monnaies : un denier tournois de Louis XII, fin XVe - début XVIe et un double tournois de François Ier de la première moitié du XVIe s. C'est donc au moins à cette date qu'il faut placer ce lot. Le matériel, peu abondant, est typologiquement identique à celui des fosses précédentes, ce qui pourrait suggérer une certaine stabilité des types entre le début et le milieu du XVIe s.

\section{La fosse 176}

160 Elle comprend la couche 159 qui contient 431 tessons, répartis en 6 familles : 1 en glaçure jaune sur engobe blanc E4, 2 en faïence F, 9 en verte sur engobe El, 30 en famille B1, 63 en commune rouge glaçurée R1 et 326 en commune grise G.

Très peu de vases demeurent identifiables dans cette fosse, en famille $G$, malgré l'importance du lot, essentiellement des fragments de panse. On possède des marmites de type 1311 et un pot de type 10172. Même chose pour R1 où les 63 tessons fournissent une seule marmite type 1411. En service vert B1, sur trois fragments de lèvre, on rencontre enfin un type identifiable : 1521 ; il s'agit d'un pot à cuire pourvu d'un fond plat, d'une panse ovoïde haute et muni de deux anses opposées de section ovale qui s'attachent sur la lèvre et le milieu de la panse. La faïence ne donne qu'un seul tesson, non identifié, et la production glaçurée sur engobe ne comprend que deux familles et deux types de récipients: des écuelles $\mathbf{3 4 1 1}$ en famille El et E4, cette dernière assez discrète, sans oublier une jatte de type 3221 en E1.

Le remplissage de la fosse a livré quelques monnaies : un denier tournois de Louis XII de la fin XVe - début XVIe s. et deux monnaies de François Ier, de la première moitié du XVIe s. Ces datations confirment celles des fosses précédentes.

163 L'étude des structures ci-dessus permet de placer chronologiquement un certain nombre de types de céramiques. Malheureusement, la majorité des dépotoirs ne fournit pas d'élément de datation absolue. Nous poursuivons ce travail par l'étude de fosses, tous chantiers confondus, qui ne possèdent aucun élément de datation, mais enrichissent et complètent notre typologie par l'apport de nouveaux types. 


\section{La fosse 136}

1113 en famille E5, décorée de filets rouges et verts; dans la production de Meillonnas, on trouve une marmite de type 1811 à panse globulaire et fond plat avec deux anses ovales verticales opposées qui s'accrochent sur le milieu de la panse et sur la lèvre ; en faïence, les rares tessons fournissent pourtant une sorte de soucoupe, de type $\mathbf{4 3 2 1}$ avec un décor de cercles concentriques sur le marli, bleus et orange, qui entoure un motif floral stylisé relativement élaboré ; en famille $\mathrm{G}$, enfin, il faut signaler une cruche de type 11011, pourvue d'un bec tubulaire ponté opposé à une anse plate verticale, le tout relié par une anse en panier, ainsi que deux fragments de lèvres en bandeau appartenant sans doute à une oule de type 1371, que l'on peut considérer ici comme matériel résiduel.

170 En effet, la datation proposée s'éloigne beaucoup de l'époque des oules ; la présence de la faïence, des marmites 1311, des familles Bl, E4 et E5 nous place dans le XVIe s., l'absence de la famille E2, dans sa première moitié. 


\section{La fosse 648}

171 Dans le quartier Saint-Vincent, elle ne comprend que la couche 681 qui contient 103 tessons, répartis en 4 familles : 1 en faïence $F, 3$ en commune rouge glaçurée R1, 8 en verte sur engobe E1 et 91 en commune grise G. Après collage, nous obtenons un total de 7 vases.

Un nouveau type apparaît en commune grise : il s'agit d'une marmite de type 1321, à fond bombé, panse globulaire, col court évasé et à deux anses plates verticales et opposées. Cette fosse livre deux exemplaires entiers. En verte sur engobe, famille El, le mobilier n'offre guère de surprises, si ce n'est son excellent état de conservation : jatte de type 3231, assiette creuse 3311 et écuelles 3411.

173 La fréquence de ces types dans la première moitié du XVIe s. conduit à formuler, sur ces bases minces, une proposition de datation équivalente, faute d'autres éléments chronologiques.

\section{La fosse 4039}

174 Toujours dans le quartier Saint-Vincent, la fosse 4039 ne contient que la couche 4040 avec ses 97 tessons, répartis en 3 familles : 1 fragment attribué au service vert B1, 7 en commune rouge glaçurée R1 et 89 en commune grise G. Le remplissage n'est pas important, mis à part la coexistence des cruches de type 11011, à anse en panier, en $G$ et d'un nouveau type à bec tubulaire, 1141, en R1; le reste se présente sous l'aspect de marmites de type 1311.

175 En l'état actuel des connaissances, cet ensemble peut être placé dans la première moitié du XVIe s.

\section{La fosse 1434}

176 Située rue de la Monnaie (îlot 24), la fosse 1434, remplie par la couche 1435, présente comme particularité d'être l'une des rares fosses de toute cette étude où aucun tesson de commune grise ne fut trouvé. Cela ne signifie pas pour autant un arrêt de production de cette famille, puisqu'on la retrouve sur d'autres sites de même époque, mais indique qu'il s'agit d'une caractéristique de ce remplissage. Le nombre total de tessons, 139, se répartit ainsi : 6 en commune grise glaçurée $G 1,6$ en faïence $F, 11$ en divers E8, 8 en verte sur engobe $\mathrm{El}, 11$ en commune rouge $\mathrm{R}$ et 97 en commune rouge glaçurée R1.

177 On ne peut malheureusement pas identifier les deux marmites qui appartiennent à la famille Gl. En céramique à pâte rouge non glaçurée, famille $R$, un fond bombé a été identifié, presque plat, ainsi qu'une moitié de panse qui pourrait correspondre à une cruche de type 1131, dont la caractéristique réside dans le bec tubulaire perpendiculaire à deux anses plates verticales, mais aucun élément ne permet d'étayer cette supposition.

178 La famille la plus représentée avec 19 récipients répertoriés, dont 2 non identifiés, est sans conteste R1, commune rouge glaçurée, où les marmites jouent un rôle prépondérant avec plusieurs individus de type 1422, dont la lèvre est réduite à un simple épaississement externe, de type 1411 ou 1412-une variante, au niveau de la lèvre, du précédent-et de type 1831, avec les deux anses plates verticales qui 
s'accrochent sur la lèvre et le milieu de la panse. On a également, dans la classe des vases bas fermés, deux nouveaux types, 2211 et 2311, assimilés à des pots de stockage dépourvus d'élément verseur; bien que des variantes soient notables au niveau de la panse ou du fond, ils montrent tous deux le même col court convergent et deux anses verticales opposées, accrochées sur le haut et le milieu de la panse. Il faut également mentionner, dans la même famille un lèchefrite, de type $\mathbf{3 1 1 1}$ qui se présente comme un récipient circulaire, à paroi cylindrique, de taille basse $(5,5 \mathrm{~cm})$, avec deux anses opposées perpendiculaires à un bec pincé. Deux nouveaux types de jatte : 30311 et $\mathbf{3 2 2 2}$ sont typologiquement assez semblables au précédent, mais de taille plus haute : 8 et 6,6 $\mathrm{cm}$. Par contre, on ne peut rien dire sur le profil du fond, ni même sur l'éventuelle présence d'élément de préhension du dernier type, 30111, incomplet : la paroi, de toute évidence plutôt évasée courbe que cylindrique, le classe éventuellement parmi les jattes.

En ce qui concerne les cruches appartenant à cette famille, on possède plusieurs exemplaires, dont l'un, de type 11051, est plutôt de facture archaïque, avec son bec ponté ; l'autre, incomplet, de forme 191, présente quand même une panse surbaissée. Il reste une cruche à bec pincé type $\mathbf{1 1 1 2}$ à laquelle manque le fond plat, et une cruche à bec tubulaire, type 1141, de petites dimensions $(10,5 \mathrm{~cm}$ de haut) avec une anse qui s'accroche sur la lèvre et le milieu de la panse. Une tasse, type 3261, à paroi évasée rectiligne et un pot de chambre, 10511, viennent compléter les récipients glaçurés à pâte rouge. Signalons toutefois que l'attribution « pot de chambre » n'est pas définitive, le caractère incomplet du vase ne permet pas une identification certaine.

Deux récipients, dont l'un inédit, sont présents dans la famille E1 : un biberon, type 11021 avec une anse verticale perpendiculaire à un bec tubulaire très fin et un lèchefrite (fig. 132), 3111, identique au modèle à pâte rouge glaçurée à deux anses et bec pincé. Dans la catégorie E8, on trouve un creuset en pâte blanche et une écuelle à glaçure vert sombre sur engobe brun de type 3411, maintenant bien connu.

132 - Lyon, lèchefrite (type 3111 )

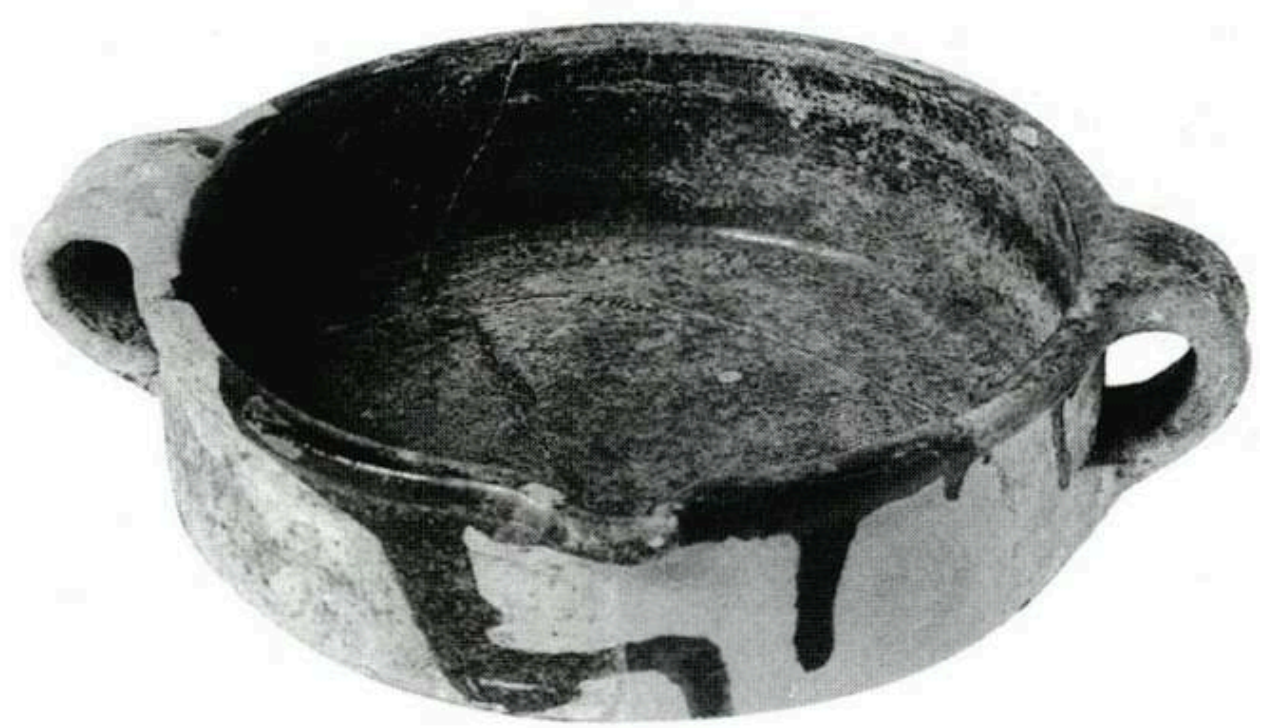

181 Au sujet de la datation, on sait, par l'absence de céramique commune grise, que le matériel de cet ensemble ne reflète pas son époque; par conséquent, l'absence de 
production de Meillonnas doit-elle être considérée comme un facteur déterminant? de même celle des familles E2, E5 et E7 ? Sans répondre à ces questions, nous pouvons déjà dire que l'ensemble des types présents correspond bien à ce qu'on trouve dans la première moitié du XVIe s. Ainsi la famille El apparait à cette époque, de même que les écuelles ou les lèchefrites; les marmites du groupe 14 sont, elles, bien assimilées au XVIe s. et ne se retrouvent pas après. Il faut conclure en insistant sur le caractère particulier de ce remplissage; on peut proposer, en l'absence de données archéologiques et en s'appuyant uniquement sur les comparaisons typologiques, la première moitié du XVIe s. comme datation. Le remplissage de cette fosse est surtout intéressant par l'apport de nouveaux types.

\section{La fosse 1612}

Nous avons vu précédemment que le comblement inférieur de la fosse 1612 (couches 1669 et 1688), située à Lyon, rue de la Monnaie (îlot 24), appartenait à la période médiévale. Pour le comblement supérieur, rappelons que la caractéristique de cette fosse est d'être coupée par un mur moderne : la fouille a dégagé les couches supérieures de la fosse de part et d'autre de ce mur; ainsi 1606 correspond à 1595. Elles seront traitées comme un ensemble. Le nombre total de fragments, 169, reste assez faible et se répartit de la manière suivante : 2 en commune rouge $R, 9$ en faïence $F, 47$ en commune rouge glaçurée RI, 106 en commune grise G, 1 en verte sur engobe El, 2 en service vert B1 et 6 en sgraffito E7.

Si l'on excepte deux exemplaires non identifiés de famille $G$ et un bassin de type 3211, les 15 types restants sont des marmites à anses coudées type 1311. Dans la catégorie R1, c'est-à-dire la commune rouge glaçurée, on a un lot de marmites identiques de type 1421. En ce qui concerne la classe 3 , les vases bas ouverts, un récipient, 30211, montre un caractère si incomplet qu'il ne peut être identifié avec certitude : on ne connait que le fond plat, la paroi évasée rectiligne et un rebord sans inflexion; un deuxième récipient est identifié comme un bassin de type 3211, à deux anses opposées qui s'accrochent sur la lèvre et le milieu de la paroi.

Les trois familles restantes ne fournissent que peu de matériel : en famille B1, un seul vase existe, de type 3111, qui s'apparente à un lèchefrite; on a aussi, avec le type 10351, un fragment de cruche ou de pichet en sgraffito, famille E7, qui possède une anse attachée au sommet de la lèvre; en faïence, les quelques tessons recensés n'apportent aucune donnée, si ce n'est celle de leur présence dans cette couche. Constatation identique pour le fragment de verte sur engobe E1.

185 La présence des familles B1, E1, E7 et F, ainsi que des marmites à anses coudées, permet de placer cette couche dans la première moitié du XVIe s.

\section{La fosse 1687}

186 Située à Lyon, rue de la Monnaie (îlot 24) elle-ne fournit que très peu de matériel : seulement 18 fragments, 2 en famille $G$ et le reste en commune rouge glaçurée R1. Dans la première famille, une seule marmite est présente : il s'agit d'un nouveau type, 1423, à panse globulaire et fond sans doute hémisphérique ; deux anses verticales opposées s'attachent sur le haut et le milieu de la panse et la lèvre est simplement évasée, sans col. Cette marmite, d'un profil inhabituel en commune grise, s'apparente plutôt aux récipients de la famille RI, à laquelle appartiennent d'ailleurs les quatre marmites 
restantes, toutes du groupe 14 : types 1411,1412 et 1422 . Il faut également mentionner un vase bas ouvert, le lèchefrite de type $\mathbf{3 1 1 1}$.

Le faible éventail typologique ne permet pas une datation précise ; toutefois, on sait que les vases du groupe 14 sont présents dans la première moitié du XVIe s. ; c'est donc à cette époque qu'il faut placer ce comblement.

\section{La fosse 153}

A l'îlot Vieille Monnaie, rue René Leynaud, elle ne livre que 197 tessons, répartis en 6 familles : 1 en commune rouge $R, 4$ en faïence $F, 10$ attribués au service vert B1, 23 en glaçure verte sur engobe $\mathrm{El}, 59$ en commune rouge glaçurée R1 et 100 en commune grise $\mathrm{G}$.

Cette dernière famille est représentée par deux types déjà connus : les marmites 1311 et 1321 et par un coquemar de type 1741, qui possède un fond plat, une panse droite surmontée d'une lèvre sans inflexion et une seule anse plate verticale attachée sur la lèvre et le haut de la panse ; il s'agit d'un profil peu banal qui tranche avec le reste de la production en céramique commune grise.

190 La céramique glaçurée à pâte rouge n'offre également que peu de vases : une marmite de type 1411 avec un décor de bande d'argile digitée sur le haut de la panse, une tirelire de forme 731, et un nouveau type, 1841, coquemar à col court évasé et fond plat.

191 En céramique de Meillonnas et en faïence, deux vases incomplets sont identifiés : il s'agit, en B1, d'une cruche de forme 111, et en F, de deux éléments de cruche dont on ne peut déterminer le profil.

192 Quant à la céramique glaçurée sur engobe, de famille $\mathrm{El}$, nous retrouvons les écuelles à oreilles, les assiettes creuses, et un chauffe-plats, type 7113, avec un grand pied douche, deux anses plates verticales attachées sous le rebord et le bas de la paroi ; ce récipient est également muni de trois supports, disposés en triangle, sur le rebord. Le dernier vase est plus singulier, puisqu'il s'agit d'une cruche de type 1911 à fond plat, base étalée, panse surbaissée, pourvue d'un col d'abord cylindrique puis évasé ; le bec pincé est opposé à une anse de section ovale.

En ce qui concerne, la datation, la présence de la famille B1, de faïence et de marmites à anses coudées se situe dans la première moitié du XVIe s.

194 Les deux dernières fosses ne présentent ni élément de datation absolue ni nouveau type de céramique : leur étude permet toutefois de confirmer la coexistence de divers types et de bénéficier de nouvelles données concernant les pourcentages des différentes familles.

\section{La fosse 714}

C'est en fait une fosse d'aisance du quartier Saint-Vincent : le matériel se situe dans une couche de faible épaisseur sous plusieurs mètres de sable destiné à assainir la fosse après abandon. Comme c'est souvent le cas dans ce genre de contexte archéologique, le mobilier est en excellent état de conservation; il compte 120 tessons, répartis en 5 familles : 1 fragment attribué au service vert B1, 2 en faïence F, 4 en commune rouge glaçurée R1, 23 en verte sur engobe $\mathrm{E} 1$ et 90 en commune grise $\mathrm{G}$. 
196 Toujours les mêmes types en céramique commune grise : marmites de type 1311, chauffe-plats de type 7111, bassin de type 3211 et pot de type 10172. La famille Bl ne fournit qu'une assiette creuse 3311, mais avec une remarquable marque en creux sur le fond, face externe : cette "signature » est la seule jamais rencontrée dans toute la production de service vert; pour cette raison, elle semble plus être un indice de propriété qu'une marque de potier. En verte sur engobe $\mathrm{El}$, on a un lèchefrite de type 3111, des écuelles à oreilles de type $\mathbf{3 4 1 1}$ et des assiettes creuses 3311. Nous ne pouvons tirer aucun renseignement des tessons en commune rouge glaçurée R1 ou en faïence.

L'homogénéité du lot, la présence de faïence et de la famille B1 plaident pour un contexte de la première moitié du XVIe s.

\section{La fosse 139}

Toujours située dans le quartier de Saint-Vincent, elle regroupe les couches 140 et 141 qui fournissent 104 tessons, répartis en 7 familles : 1 fragment pour les familles jaune décorée $\mathrm{E} 5$ et la faïence $\mathrm{F}, 2$ en jaune sur engobe $\mathrm{E} 4,3$ en verte sur engobe $\mathrm{El}, 7$ en commune rouge glaçurée RI, 9 attribués au service vert B1 et 81 en commune grise G. Les deux couches recollent entre elles et sont étudiées ensembles.

199 Un seul type de vase est représenté en $\mathrm{G}$, il s'agit toujours de marmites à anses coudées de type 1311, ici en 19 exemplaires. La famille B1 ne livre que neuf tessons, non identifiables. Les productions à glaçure sur engobe ne sont pas non plus très présentes avec trois familles et deux types : des assiettes creuses 3311 en El, en E4 et en E5, ainsi qu'une jatte de forme 322 ou 324 en El; quant au tesson de faïence et aux sept fragments en commune rouge glaçurée R1, ils ne permettent pas d'identification.

200 Sans indice de datation absolue, la typologie place cet ensemble dans la première moitié du XVIe s.

\section{Le milieu du XVle siècle}

Le matériel issu de la fouille de la place des Terreaux, est une référence incontournable pour le milieu du XVIe s. (fig. 133). On ajoute, à cet ensemble, le matériel de la fosse 661 du quartier Saint-Vincent. 


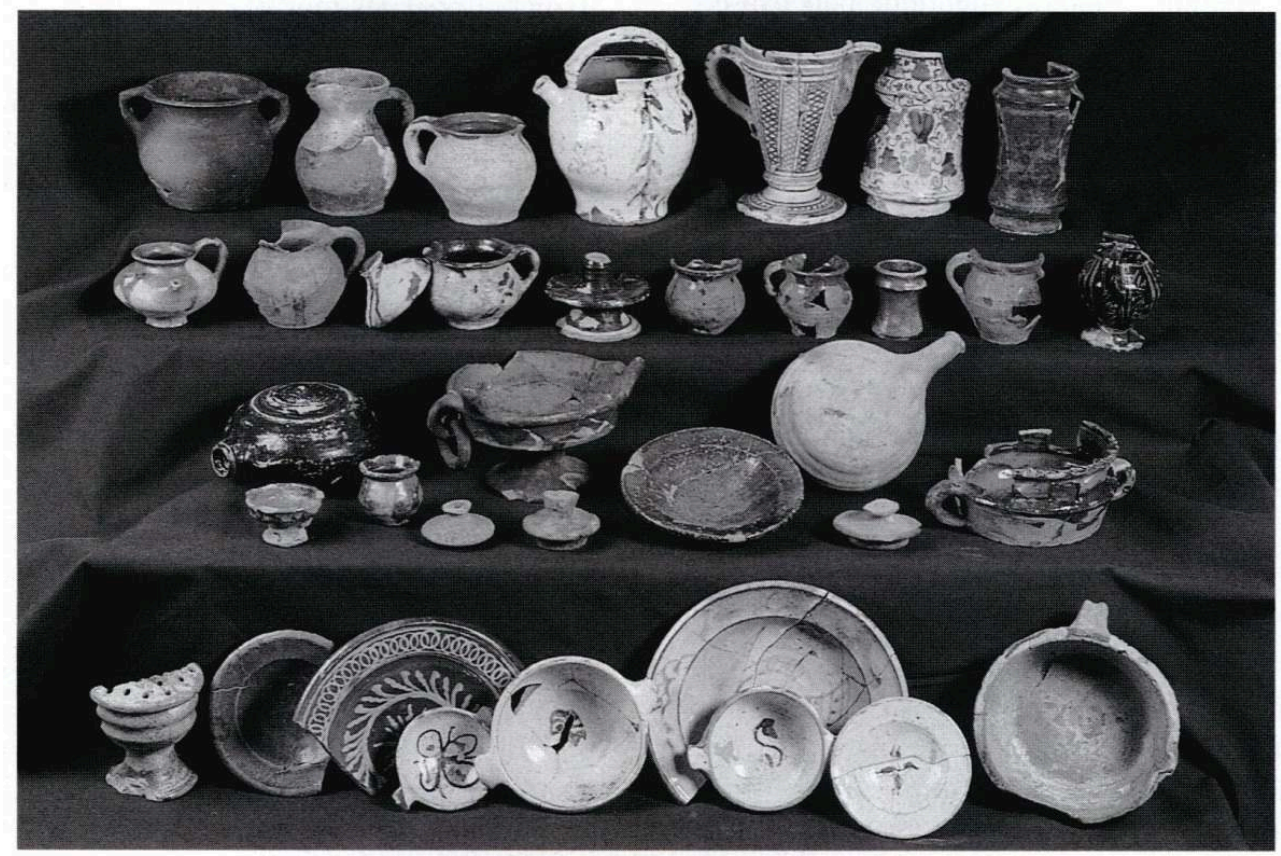

\section{La place des Terreaux}

Elle est installée sur le comblement d'un tronçon des anciens fossés de Lyon, lesquels ont été remblayés progressivement, mais dans un laps de temps très court, au milieu du XVIe s., comme l'attestent les archives et la quantité impressionnante de monnaies recueillies (Rapport de fouille, C. Arlaud, 1991-94). Les 56000 tessons retrouvés dans ce contexte apportent de nouvelles données pour une période mal représentée jusqu'alors. En commune grise $G$, les marmites à anses coudées de type 1311, côtoient les marmites 1321, les réchauds 7111, les bassins 3211. La production en jaune décorée E5, fournit une grande quantité d'assiettes 3311, d'écuelles 3411, de réchauds 7112 ou 7113, tandis que les sgraffito $\mathrm{E7}$, également très présents, ne montrent que des écuelles et des assiettes creuses. Les familles à glaçure verte sur engobe El, la faïence $\mathrm{F}$, la commune rouge glaçurée $\mathrm{R} 1$, le service vert B1 tiennent également une place importante, tant par leur quantité que par la diversité des types. Mais la grande nouveauté réside dans la présence de nombreuses céramiques à engobe rouge et décor à la barbotine blanche : la famille E2. Cette production, que l'on plaçait plutôt au XVIIe s. est, en fait, en pleine diffusion dès le milieu du siècle précédent, avec des écuelles, des assiettes creuses, des réchauds, des albarelli, des chevrettes, et on note même l'apparition des premières assiettes plates de type 4111. Par contre, on ne trouve aucune trace des jattes 3251, ni de la famille jaspée E3, qui restent, semble-t-il, l'apanage du XVIIe s. Le matériel de la place des Terreaux pose un jalon extrêmement important pour notre compréhension de la céramique de cette époque charnière, où se met en place le vaisselier diversifié des temps modernes. Bien que ce site ne soit pas inclus dans les études ci-après, force est de tenir compte des informations qu'il a fournies. 


\section{Le quartier Saint-Vincent, la fosse 661}

l'une d'elles, le comblement d'un puits, est fondamentale pour la typochronologie de cette période.

\section{Le quartier Saint-Vincent}

Le comblement d'un puits, de $80 \mathrm{~cm}$ de diamètre, a été fouillé sur une profondeur de six mètres environ. Pour des raisons de sécurité, le travail s'est arrêté à ce niveau, sans toutefois atteindre le fond. Nous avons répertorié dix-neuf unités stratigraphiques, présentées dans l'ordre chronologique, de haut en bas : 544, 531, 532, 551, 554, 561, 560, $562,569,571,978,979,988,993,995,1001,1002,1036$, et 1092 qui fournissent 10452 tessons de céramique avant collage (fig. 134). 
134 - Lyon, quartier Saint-Vincent

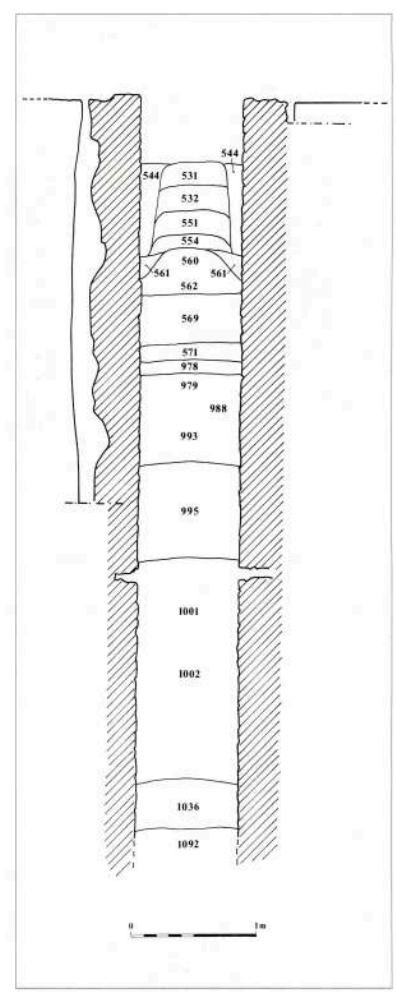

Coupe stratigraphique à l'intérieur du puits ; identification des couches de remplissage

209 Tout d'abord, en face d'une telle quantité de matériel, il convient de s'interroger sur le mode de remplissage : peut-on le considérer comme un tout homogène et le traiter en tant que tel, ou peut-on discerner plusieurs phases de comblement? Pour répondre à une telle question, nous utiliserons deux méthodes: la présence/absence de types identiques dans les différentes couches de remplissage et les renseignements apportés par les collages.

210 Pour chaque famille, un tableau représente en ordonnée les couches dans l'ordre chronologique, et en abscisse les différents types de céramique (tableau 3). La lecture de ces tableaux atteste que, toutes familles confondues, la très grande majorité des types perdure sur toute la durée du remplissage, malgré quelques absences dans certaines couches. Bien que l'on ne connaisse pas la durée de vie de chaque type, ces tableaux suggèrent déjà que le remplissage du puits forme un tout homogène. 
Tableau 3. Quartier Saint-Vincent, graphique de présence-absence des types de céramiques dans le puits, classés par famille

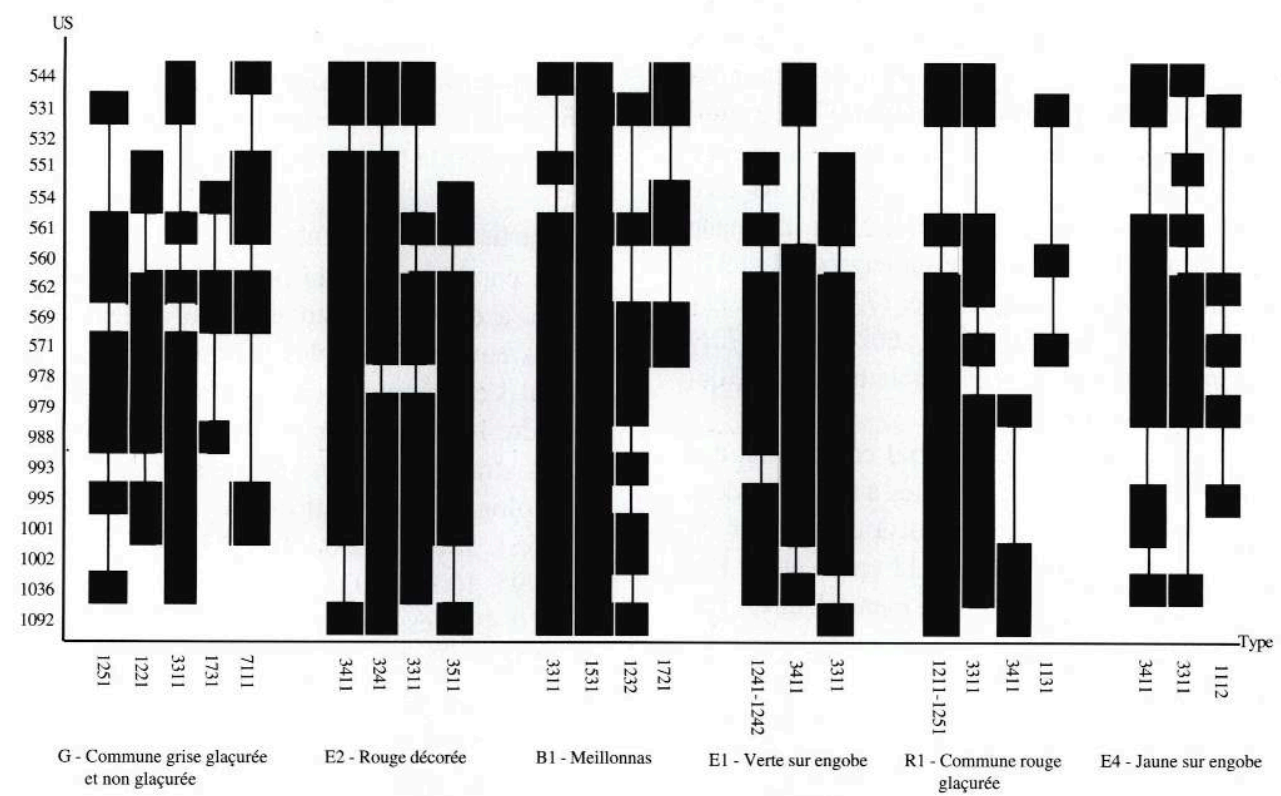

211 Puisque le recollage des tessons montre souvent les rapports des couches entre elles, il suffit de visualiser cette opération sous forme de tableau (tableau 4). Celui-ci regroupe 89 récipients, issus de quatre familles (commune grise G, commune rouge glaçurée R1, service vert B1 et rouge décorée E2) et affiche, en ordonnée, les couches dans l'ordre chronologique. Chaque trait vertical représente un vase et chaque point noir, un ou plusieurs fragments lui appartenant; ainsi la répartition dans le remplissage du puits est immédiatement perceptible, les vases étant classés par ordre chronologique d'apparition.

Tableau 4. Quartier Saint-Vincent, détail des recollages des récipients dans le remplissage du puits

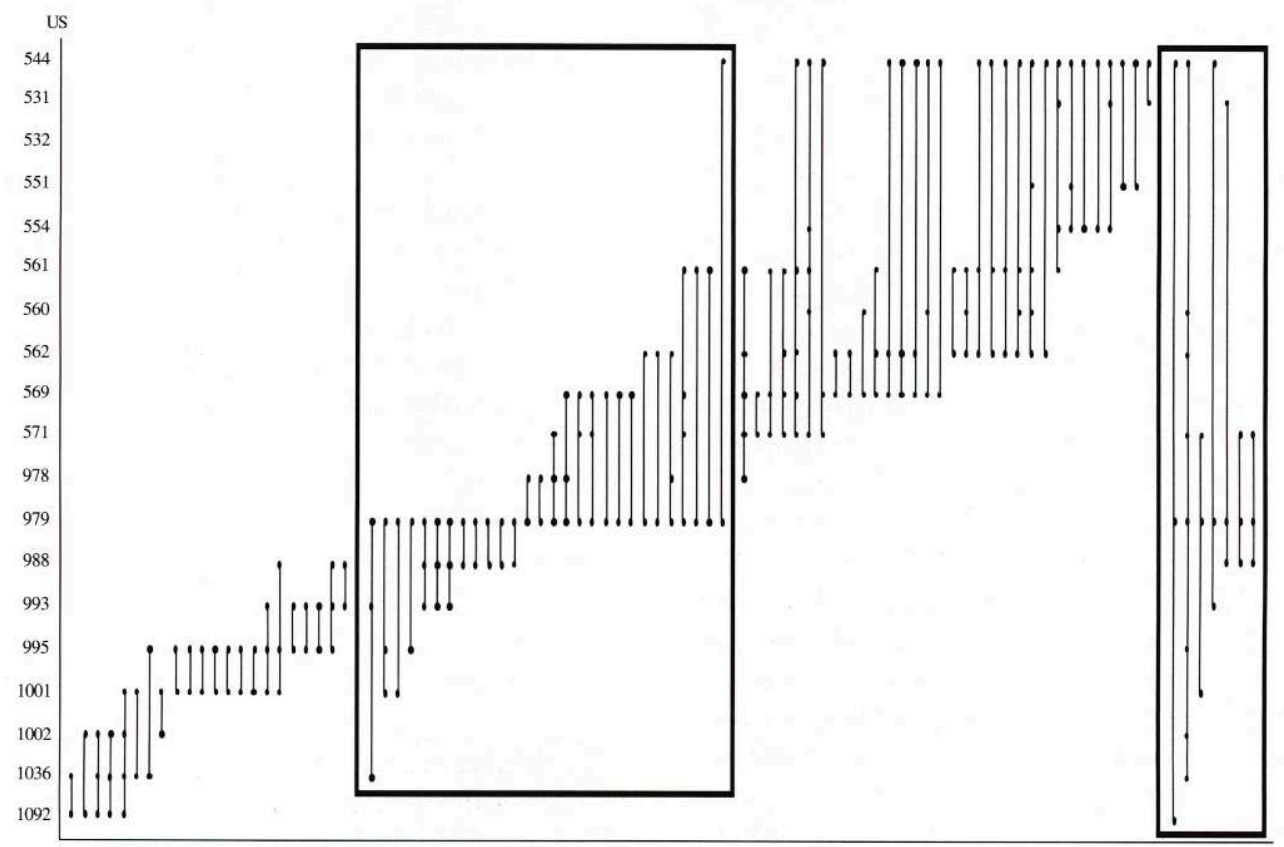


La lecture du tableau met en évidence trois groupes :

- le premier groupe montre un remplissage régulier à partir de la couche 1092 jusqu'à la couche 979. Celle-ci semble correspondre à un arrêt du remplissage : douze vases issus des couches antérieures s'arrêtent à ce niveau et seize autres en repartent.

- le deuxième groupe concerne le remplissage, qui s'effectue de manière régulière, de la couche 979 jusqu'à la couche 544.

- le troisième groupe se situe à part : il s'agit de sept vases dont les fragments s'échelonnent de part et d'autre de la couche 979.

Ces observations, conjuguées avec les renseignements fournis par les tableaux de présence-absence des types, montrent que le puits a été comblé rapidement, mais avec un arrêt au niveau de l'US 979. D'autre part, la présence du troisième groupe suggère que, parallèlement au remplissage observé, un second, plus ponctuel, ne tient pas compte de l'interruption; mais certains vases, qui se répartissent sur toute la hauteur du puits, confirment que l'opération s'est effectuée dans un laps de temps très court et que le matériel forme un tout homogène et indissociable.

214 Ce point étant acquis, on peut avoir une vue d'ensemble du mobilier céramique : un tableau permet d'appréhender, en ordre croissant, la proportion des familles à l'intérieur du remplissage : la commune rouge $\mathrm{R}$ et la jaune décorée sur engobe $\mathrm{E} 5$ sont vraiment minoritaires avec 48 et 55 tessons. Ensuite, un lot regroupe la faïence $\mathrm{F}$, la jaune sur engobe $\mathrm{E} 4$, les divers $\mathrm{E} 8$, la jaspée $\mathrm{E} 3$, la beige décorée $\mathrm{E} 6$ et la commune rouge glaçurée G1 s'étageant entre 131 et 326 fragments. Vient ensuite un groupe situé dans une fourchette de 992 et 1593 tessons, comprenant la commune rouge glaçurée R1, la verte sur engobe E1, la rouge décorée E2 et la commune grise G. Enfin, loin devant, la production attribuée au service vert B1 culmine avec 3749 fragments.

215 Malgré un nombre imposant de fragments, la commune grise $G$ ne propose qu'un éventail restreint de types. Outre les 37 exemplaires de réchauds, type 7111, on ne trouve que des bassins 3211, bien connus depuis la fouille d'Antonin Poncet et des marmites 1221, en grande quantité, il est vrai. Un des avantages du remplissage de ce puits est de fournir de nombreux vases entiers ou du moins, reconstituables, ce qui permet, par exemple, de compenser le manque de variété des types en $G$ par la présence remarquable de céramiques communes grises glaçurées. Cette famille, G1, jusque-là plutôt minoritaire, prend ici une place importante avec 39 assiettes creuses, 6 écuelles, 1 vase de stockage 1731 et quelques marmites 1221 . On remarque que la famille G1 puise aussi bien dans la production en commune grise que dans celle à cuisson oxydante. Cette dernière, avec la famille R1, mis à part les assiettes creuses, écuelles et bassins, fait preuve d'originalité avec trois types : 1122, 1211 et 6211 . Le premier renvoie à une cruche un peu particulière avec son bec tubulaire relié à une anse en panier; l'état du vase ne permet pas de savoir s'il existe une anse plate verticale dans le même axe. Le deuxième type concerne une marmite tripode qui possède la particularité d'offrir une grande variété dans son système de préhension: deux anses plates verticales, parfois opposées, parfois accolées, ou une seule anse plate verticale qui transforme le récipient de marmite en coquemar. Enfin, il s'agit, pour le troisième, d'un couvercle de grande dimension, mais qui laisse planer un doute sur sa facilité d'utilisation, car il n'est pourvu d'aucun système de préhension. En famille R, la production oxydante nous gratifie d'un récipient étonnant: une sorte de réchaud de table, cylindrique dans sa partie basse, puis légèrement évasé, muni à sa base d'une 
ouverture dans la paroi et, à l'intérieur, d'un ressaut à mi-hauteur; le récipient est incomplet et on ne possède pas son rebord.

216 Le service vert B1 apporte aussi son lot de nouveautés, puisqu'à côté des assiettes creuses, des écuelles et des pots à cuire 1511 et 1521 (vases typologiquement semblables, la seule différence provient de l'emplacement des attaches d'anses; cette particularité n'a pas d'incidence sur la fonction: les deux exemplaires montrent des traces d'utilisation au feu sur le fond et les parois), il y a quelques vases peu banals. Ainsi le type 1711 :c'est un vase à panse rectiligne, fond plat, tripode, à deux anses ovales verticales opposées, possédant un col court convergent et une lèvre à une inflexion externe oblique vers le haut. Par sa morphologie, ce vase sort de l'ordinaire, mais de plus, un des exemplaires présents fait l'objet d'une réutilisation: une série d'ouvertures, rondes ou carrées, disposées en deux registres superposés, ont été percées dans la partie supérieure de la panse, peut-être pour le transformer en chaufferette. Un deuxième type, 1721, mérite un regard aussi attentif: panse droite, tripode, col court, lèvre à une inflexion externe font de ce type une sorte de copie du précédent; pourtant l'état du vase ne permet pas de déterminer son système de préhension. Enfin, une série de coquemars type $\mathbf{1 8 2 1}$ clôt cette production du service vert ; ces vases sont reconnaissables à leur anse de section ovale, très développée.

217 Par comparaison, la faïence fait figure de parent pauvre : en effet, les 6 lèvres présentes ne sont pas identifiables, de même qu'une cruche, incomplète. Avec 131 fragments, le nombre de tessons provenant du remplissage du puits reste très faible. Ce problème sera abordé dans le chapitre de synthèse consacré à cette famille.

218 En abordant les productions à pâte rouge glaçurée sur engobe, on constate la présence de nouvelles familles : la jaspée E3, qui renvoie à une production décorée d'un mélange d'engobes blanc et rouge; la beige décorée E6 qui ne concerne que des cruches à pâte beige et possédant un décor situé autour du goulot. En tout, pas moins de six familles sont représentées, mais avec bien des types communs. Un simple tableau (tableau 5) exprime cette observation. 
Tableau 5. Lyon, quartier Saint-Vincent, puits : répartition par types et par famille des productions engobées

\begin{tabular}{|l|c|c|}
\hline Cruche & $1111 / 1112$ & E1 \\
\hline Cruche & 1111 & E2 \\
\hline Cruche & 1112 & E4, E5 \\
\hline Cruche & 1114 & E6 \\
\hline Cruche & $1121 / 1113$ & E2, E3 \\
\hline Cruche & 1131 & E6 \\
\hline Pot de chambre & 1231 & E1, E8 \\
\hline Pot de stockage & 2111 & E8 \\
\hline Jatte & $3221 / 3241$ & E1 \\
\hline Jatte & 3251 & E2 \\
\hline Assiette creuse & 3311 & E1, E2, E3, E4, E5, E8 \\
\hline Ecuelle & 3411 & E1, E2, E3, E4 \\
\hline Tasse & 3421 & E1, E2, E3 \\
\hline Coupelle & 3431 & E1 \\
\hline Assiette plate & 4111 & E2, E3, E8 \\
\hline Gobelet & 5111 & E2 \\
\hline Cruche de stockage & 10711 & E2 \\
\hline
\end{tabular}

219 Certains types existent dans de nombreuses familles; c'est le cas des assiettes creuses, de type 3311, des écuelles type 3411, des tasses type 3421, des assiettes plates type 4111, des cruches types 1111, 1112, 1113 et 1114, qui ne diffèrent que par la lèvre.

Par contre, d'autres types n'appartiennent qu'à peu de familles, voire à une seule : les pots de chambre de type 1231; les cruches type 1121: il s'agit de cruches à bec tubulaire, anse en panier et anse plate verticale; les jattes types 3221 et 3241 et les jattes type 3251, avec leurs extraordinaires décors à la barbotine blanche.

221 Enfin, il existe des types rares, qu'on ne retrouve pas sur d'autres sites, tels le pot de stockage de type 2111, en E8 avec ses lignes anguleuses, ses tenons de préhension et son décor sur la panse ; la coupelle type 3431, en E1, sorte d'écuelle en réduction, sans système de préhension; la cruche de stockage type 10711, en E2, malheureusement incomplète, avec une panse surbaissée, presque hypertrophiée et un décor magistral à la barbotine blanche; le gobelet type 5111, en E2, décoré de l'inscription religieuse I.H.S. Ce dernier récipient est le seul dont la fonction se rapproche de la production en verre.

Par bonheur, les éléments de datation ne manquent pas. Ainsi, la fouille du puits a livré six monnaies ${ }^{9}$ : trois sont frappées dans le premier quart du XVIIe s., une en 1639, une entre 1627 et 1650 et une en 1653.

D'autre part, une parcelle dont nous pouvons restituer les limites par les murs avait pour mention dans les archives, en 1685, "d'un vieux puys comblé entre deux de soir »; cette structure peut correspondre à celle dont le remplissage est étudié ici.

Tous ces éléments nous conduisent à proposer une fourchette chronologique du remplissage, entre 1653 et 1685 . De plus, l'absence, sur 10452 tessons, de céramique du service jaune B2 de Larnage, interdit, à notre avis, une datation plus basse, de même 
que l'absence de marmites à anses coudées, une datation XVIe s. En ce qui concerne la comparaison purement typologique, il faut noter que ce matériel est semblable à celui trouvé place Antonin Poncet et daté de la deuxième moitié du XVIIe s.

Cette chronologie est d'autant plus précieuse que la fouille de la tranchée de fondation du puits a livré un matériel intéressant. Il s'agit de la couche 327 qui comprend 223 tessons : 212 pour la commune grise $G, 6$ pour la verte sur engobe $\mathrm{El}, 2$ en commune rouge glaçurée R1, 2 attribués au service vert B1 et 1 en commune grise glaçurée G1. Après recollage, on obtient, en famille $G$, vingt-huit exemplaires de marmites à anses coudées. La datation de ce lot est à placer plutôt au XVIe s. et l'absence de marmites 1311 dans le puits devient alors un élément très important : on sait maintenant que ces marmites apparaissent fin XVe s. (Rapport de fouilles, C. Arlaud, 1990) et n'existent plus au milieu du XVIIe s. L'étude de la structure suivante permet d'affiner cette proposition.

\section{Le quartier Saint-Vincent, la fosse 4109}

Elle regroupe deux couches: 4110 et 4167 qui comptent respectivement 242 et 52 tessons, que l'on peut considérer comme un ensemble homogène. Les 294 fragments se répartissent en 9 familles : 1 fragment pour les familles grise glaçurée G1, service vert B1, faïence $F$, jaune sur engobe E4 ; 3 fragments pour la verte sur engobe E1, 5 pour la commune rouge $\mathrm{R}, 6$ pour la famille divers E8, 72 en commune rouge glaçurée R1 et 204 en commune grise $\mathrm{G}$.

La céramique commune grise $G$ se présente comme un lot de dix-neuf marmites de type 1311. Nous trouvons également une écuelle $\mathbf{3 4 1 1}$ en verte sur engobe El, et des marmites 1331 en commune rouge glaçurée R1. L'intérêt de cette fosse réside dans la présence d'une monnaie, un liard de Trévoux, daté de 1608-1626, qui suggère que les marmites à anses coudées sont encore en service au début du XVIIe s. Leur disparition se fait donc entre 1626 et 1653, date de la plus récente monnaie du puits.

\section{L'îlot Vieille-Monnaie, la fosse 433}

Le remplissage fournit 362 fragments : 1 en jaune sur engobe $E 4,3$ en jaune décorée sur engobe E5, 5 en beige décorée E6, 9 en rouge décorée E2, 10 en jaspée E3, 31 en commune rouge glaçurée R1, 57 en verte sur engobe El, 102 en commune grise G et 149 attribués au service vert B1.

Malgré le nombre important de tessons en commune grise, il y a très peu de récipients identifiés dans cette fosse: quelques marmites et un coquemar de type 1221, ainsi qu'un couvercle 6111. La même référence pour la marmite et le coquemar a été maintenue : en effet, ces deux vases sont typologiquement identiques si ce n'est le nombre d'anses; or, beaucoup de céramiques restent incomplètes, même après recollage, et il est difficile parfois de différencier une marmite d'un coquemar pour ce type particulier. Ainsi, en céramique glaçurée à pâte rouge R1, un seul récipient est présent, mais sans identification ; on peut toutefois suggérer un fragment de coquemar. En ce qui concerne le service vert B1, plusieurs vases sont répertoriés : pots à cuire de types 1521 et $\mathbf{1 5 1 1}$, assiette creuse 3311 et poêlon 3832. Ce dernier est un type peu courant, dont le fond manque; toutefois, on remarque un fond plat sur un autre exemplaire. La céramique glaçurée sur engobe est aussi présente dans quatre familles, et le mobilier ne brille pas par son originalité avec trois types différents : les assiettes 
creuses 3311 en verte sur engobe $\mathrm{El}$, en rouge décorée E2, en jaspée E3 et en jaune décorée $\mathrm{E} 5$; les écuelles à oreilles $\mathbf{3 4 1 1}$ en E2, E3 et E5 et pour finir un coquemar 1841 en E1.

En l'absence de critères de datation absolue, on doit se contenter de la typologie pour établir une datation. Or cette dernière évolue ; ainsi la présence de la famille E2, et du type 1221 était considérée comme un critère typique du XVIIe s. Depuis peu, les fouilles de la place des Terreaux montrent que ces éléments appartiennent aussi au XVIe s. et prouvent, par ailleurs, que la famille E3, à décor jaspé, reste typique du XVIIe s. ; c'est au milieu de ce siècle qu'il faut placer le remplissage de la fosse 433, si l'on se base également sur l'absence du service jaune B2.

\section{Période charnière : deuxième moitié du XVIle - début XVIIle siècle}

Il est temps maintenant d'évoquer les découvertes de la place Antonin Poncet (Becker et alii 1989, pp. 137 à 186) (fig. 135).

135 - Lyon, place Antonin Poncet : quelques vases issus des dépotoirs

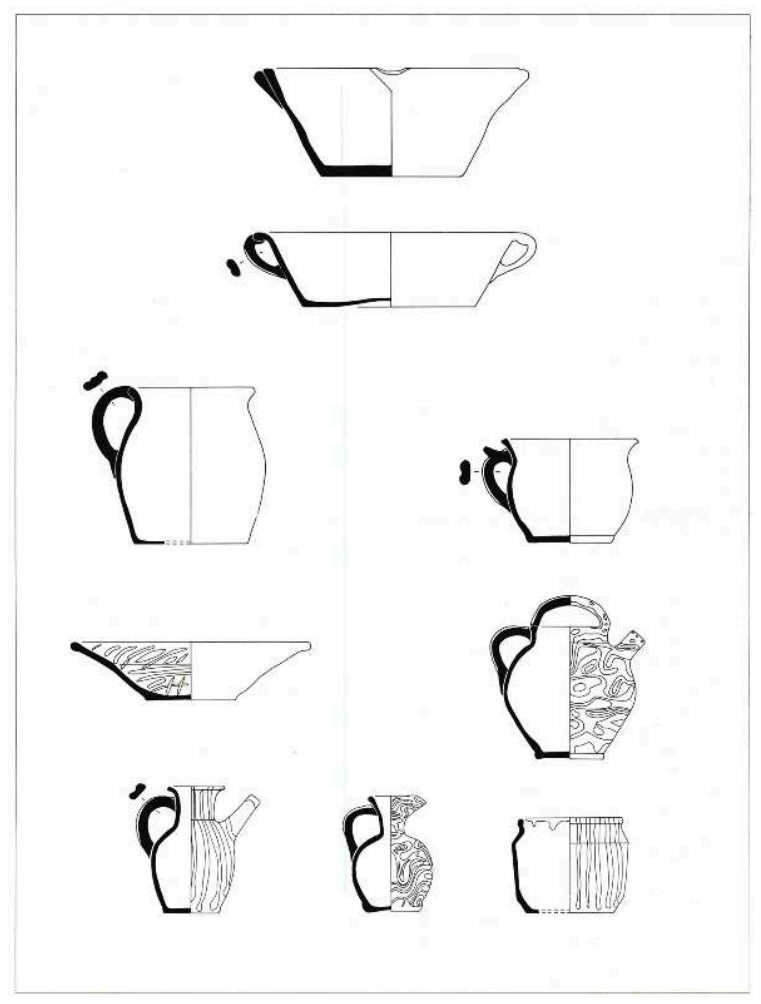

La fouille, dans la zone 1, du comblement d'une fosse d'aisance et d'un puits a permis la mise au jour d'un lot important de céramiques et de verres, datés, d'après les sources écrites, de la seconde moitié du XVIIe s., entre 1677 et 1680 . Quelles sont les caractéristiques de ce mobilier? Les marmites et les pots à cuire sont représentés, en commune grise $G$, par le type 1221 ; en service vert B1, par le type 1521, ainsi que par un autre vase, tripode; en service jaune B2, par le type 1341. Les coquemars, de forme traditionnelle, se trouvent en familles B1 et R1. Un seul exemplaire de poêlon est recensé, en commune grise, ainsi qu'un vase de stockage, muni de deux tenons de préhension : ces deux vases possèdent le col convergent propre aux types 2211 et 1731. Les assiettes creuses, de type $\mathbf{3 3 1 1}$, sont présentes dans de nombreuses familles, à la 
différence des assiettes plates, de type 4111, produites en E2 et E5. On trouve également une grande quantité d'écuelles de type 3411, des bassins de type 3211, en commune grise, des jattes de type $\mathbf{3 2 5 1}$ en E2 et de type $\mathbf{3 2 4 1}$ en R1, des chauffe-plats, de type 7111 en commune grise, des pots de chambre, des plats en faïence, et, bien sûr, de très nombreuses cruches à bec pincé ou tubulaire, de types 1111, 1112, 1114, 1121, 1131. Ce remplissage est surtout important par la présence du service jaune B2, qui jouera un grand rôle par la suite et que l'on trouve pour la première fois.

233 Cinq fosses, toutes issues de Saint-Vincent, concernent cette même période, c'est pourquoi on ne reviendra pas sur la datation de chaque structure.

\section{Les fosses 108 et 106}

Elles regroupent, pour la première, les couches 109, 393, 395 et 392 qui fournissent un total de 555 fragments, et pour la deuxième, les couches 107, 391, 474, 475 qui totalisent 231 fragments. Les collages entre couches montrent qu'il s'agit, à chaque fois, d'un tout homogène. Diverses céramiques provenant des deux fosses recollent ensemble et permettent d'envisager une étude globale. Les 786 tessons se répartissent de la manière suivante : 3 en jaune décorée E5, 9 en commune rouge $R, 13$ en jaspée E3, 14 en jaune sur engobe $\mathrm{E} 4,20$ en faïence $F, 48$ attribués au service vert B1, 57 en verte sur engobe El, 78 attribués au service jaune B2, 96 en commune rouge glaçurée R1, 98 en rouge décorée $\mathrm{E} 2,105$ en commune grise $\mathrm{G}$ et 249 en divers E8.

Malgré ses 105 tessons, la céramique commune grise $G$ n'affiche que 4 lèvres, et de plus, non identifiées. En famille R1, le lot se compose de marmites de type 1211, d'assiettes creuses de type $\mathbf{3 3 1 1}$ et d'un couvercle. En service vert B1, le matériel n'est guère abondant avec 5 assiettes $\mathbf{3 3 1 1}$ et la faïence n'apporte que 6 tessons non identifiés. Quant à la famille B2, la jatte de type 3252, récipient sans marli ni élément de préhension, voisine avec de classiques assiettes creuses 3311. La diversité viendrait-elle des productions glaçurées sur engobe? On peut le penser au vu des 5 familles représentées, mais les types restent bien connus: des assiettes ou plats creux de type 3311 en famille verte sur engobe El, en famille rouge décorée E2, en divers E8 et en famille jaune sur engobe E4; des écuelles de type 3411 en E2 ainsi qu'une tasse de type 3421 et des jattes de type $\mathbf{3 2 5 1}$; une cruche de type $\mathbf{1 1 2 1}$ et une de type 1113 en famille jaspée E3, assorties de 16 autres incomplètes, de forme 111 en divers E8. Il faut ajouter à ceci toute une série de lèvres non identifiées dans des familles diverses. Dans l'ensemble, ce lot n'apporte pas de nouveauté ; il reste homogène dans sa banalité.

\section{La fosse 61}

236 Elle regroupe les couches $66,90,339,340$ et 343 qui donnent un total de 276 fragments répartis entre 9 familles : 1 fragment pour le service jaune B1 et la jaune sur engobe E4, 4 en rouge décorée E2, 5 en verte sur engobe E1, 6 attribués au service jaune B2, 9 en jaune décoréé $\mathrm{E} 5,25$ en divers $\mathrm{E} 8,47$ en commune rouge $\mathrm{R}$ et 178 en commune rouge glaçurée R1.

Cet important total de vases en R1 s'explique par l'abondance des fragments de canalisation contenus dans la fosse, qui de plus, n'offrent pratiquement aucun recollage: 55 bords ont été trouvés et 54 vases obtenus; ils sont en pâte rouge grossière, glaçurés sur leur face interne. Le reste du matériel n'offre aucune surprise : 
écuelle de type 3411 en El, en B2; assiette creuse de type 3311 en E5, de type $\mathbf{3 8 1 4}$ en R1 ; jatte de type 3251 en E2, cruche incomplète de forme 111 en E5.

\section{La fosse 1052}

Elle ne contient que 46 fragments répartis en 7 familles, qui fournissent 9 vases entiers : 1 en service jaune B2, 2 en service vert B1, 4 en divers E8, 6 en jaune décorée E5, 8 en commune grise $\mathrm{G}, 11$ en jaune glaçurée $\mathrm{E} 4$ et 14 en rouge décorée $\mathrm{E} 2$.

La plus grand partie de ce comblement n'apporte pas d'élément nouveau: assiette creuse de type $\mathbf{3 3 1 1}$ et de type $\mathbf{3 8 1 1}$ en E2, assiettes plates de type 4111 en E5, en E2, écuelle de type 3411 en E2, en B2 et enfin 1 fragment non identifié en famille G. En fait, l'intérêt de ce remplissage tient dans un seul récipient : il s'agit, en E5, d'un plat creux de type 3813 qu'on retrouve dans l'US 438 d'îlot Vieille-Monnaie. Ce plat possède un rebord à inflexion externe oblique vers le bas, qu'on peut aussi nommer lèvre pendante ; ce profil semble copié directement sur les plats en faïence si on se réfère à ceux trouvés place Antonin Poncet (Vicard 1989).

\section{La fosse 446}

240 Elle est composée de l'US 447, compte 250 tessons, dont 1 en commune rouge $\mathrm{R}$ et en jaspée E3, 2 en commune rouge glaçurée R1 et en service jaune B2, 3 en commune grise G, 4 en faïence F, 5 en jaune décorée E5, 9 en verte sur engobe E1, 11 en service vert B1, 19 en jaune sur engobe E4, 22 en rouge décorée E2, 70 en beige décorée E6 et 101 en divers E8. Après collage, vingt vases sont répertoriés; il s'agit de types devenus classiques maintenant : écuelles de type $\mathbf{3 4 1 1}$ en E3 ; assiettes creuses de type $\mathbf{3 3 1 1}$ en B2, R1, B1 et en E1; jattes de type 3221 en El et de type 3251 en E2 et, pour finir, marmites 1211 en famille R1. Il faut quand même faire mention des 70 tessons de panses en famille E6 qui ne fournissent aucun vase reconstituable : c'est d'autant plus regrettable lorsqu'on sait que le répertoire de types dans cette famille est très limité.

\section{La fosse 4053}

241 Le comblement de cette fosse septique comporte 3 couches: 4053,4687 et 4688, montrant de nombreux collages entre elles, ce qui conduit à les considérer comme un tout homogène. Le total de 445 tessons se répartit ainsi : 8 fragments en jaspée E3, 4 en commune grise glaçurée $\mathrm{G} 1$ et en sgraffito $\mathrm{E} 7,5$ en commune rouge, 8 en jaune décorée E5, 13 en rouge décorée $\mathrm{E} 2,16$ en commune rouge glaçurée, 22 attribués à Larnage, 26 en beige décorée E6, 27 en faïence, 30 attribués à Meillonnas, 34 en jaune sur engobe E4, 40 non identifiés, 51 en verte sur engobe $\mathrm{El}, 54$ en commune grise et 103 en divers E8.

Ce lot, relativement important, permet de recenser 66 vases : un tel chiffre s'explique par le très bon état de conservation du matériel, du fait de la nature des couches archéologiques. La variété des types présents rend également intéressant ce remplissage. On retrouve, bien sûr, des vases connus, telles que les assiettes creuses de type 3311 présentes dans les familles B2, R1, El, E2 et E3, ou les assiettes plates de type 4121 en famille E7, ou encore les écuelles de type 3411 en famille El et en E2, ou même, dans cette dernière famille, les jattes de type 3251. Dans la classe des vases hauts fermés, on reconnaît les marmites de type 1221 en famille $G$, de même que le pot à cuire de type 1711, en famille B1, déjà rencontré lors du comblement du puits, où l'on 
trouve aussi les même cruches que cet exemplaire 1121 en famille jaspée E3. La cruche 1142 en jaune décorée E5, elle, ne diffère du type $\mathbf{1 1 4 1}$ de l'îlot 24, que par le profil de sa lèvre. Les pots de chambre, qu'ils soient de type 3711, en jaune sur engobe E4, ou de type 1231, en El, nous sont aussi familiers. Même constatation pour le coquemar de type 1541, en verte sur engobe El, ou le type 1821 en service vert B1. Le pot à conserves, de type 3531, famille E3 est identique à celui de l'îlot Vieille-Monnaie, tout comme le pot de fleurs de type 5211, en E1. Il faut aussi noter les couvercles, de type 6111 ou 6121, en famille R1.

La nouveauté réside dans certaines variantes de vases : ainsi les écuelles de type 3511, en El, ou de type 3521, en E8 peuvent être considérées comme héritières du type $\mathbf{3 4 1 1}$ avec cette paroi rectiligne légèrement évasée ou ce petit pied cylindrique qui ne va pas sans rappeler les faïences.

\section{Le XVIIle siècle}

Les fouilles à Lyon n'ont livré que deux fosses de cette époque, l'une au quartier SaintVincent (f. 28) et l'autre de l'îlot Vieille-Monnaie (f. 438).

\section{La fosse 28}

245 Elle ne possède qu'une couche, la 295 et fournit 314 tessons répartis de la manière suivante : 1 en sgraffito E7, 2 en commune grise glaçurée $\mathrm{G} 1$ et en verte sur engobe El, 3 en jaune sur engobe E4, 14 en jaspée E3, 25 en faïence $F, 28$ en rouge décorée E2, 38 attribués au service vert B1, 52 au service jaune B2 et 149 en divers E8.

Ce qui frappe dans la composition de ce lot, c'est l'absence de commune grise $G$, de commune rouge glaçurée $\mathrm{R} 1$ et la très faible présence du service vert B1, représenté par un seul vase, malgré 38 tessons avant collage : il s'agit sans doute d'un pot à cuire d'un type peu fréquent, 1531, à deux anses opposées et à fond tripode, à la morphologie très particulière qui tranche avec le reste des autres productions. Le service jaune B2 n'est constitué que de jattes de types 3821 et 3254 et d'un poêlon de type $\mathbf{3 8 3 1}$; on ne trouve aucune trace des assiettes creuses et des marmites généralement présentes dans cette famille. Par contre, la faïence offre un remarquable ensemble de récipients décorés de motifs floraux stylisés, de couleur bleue ou dorée (fig. 136) : une cruche type 1151 à bec pincé, une chocolatière type 1161 à bec tubulaire orné de traits horizontaux superposés; dans cette même famille, on rencontre des assiettes plates de type 4211, au marli souvent pourvu d'un trait de couleur bleue et une pièce en tout point unique: un taste-vin de type 3441, décoré sur sa face externe et portant une inscription sur sa face interne, dans un français approximatif : «Lamour ma réduit ou je suit », suivi de la date 1744 . 


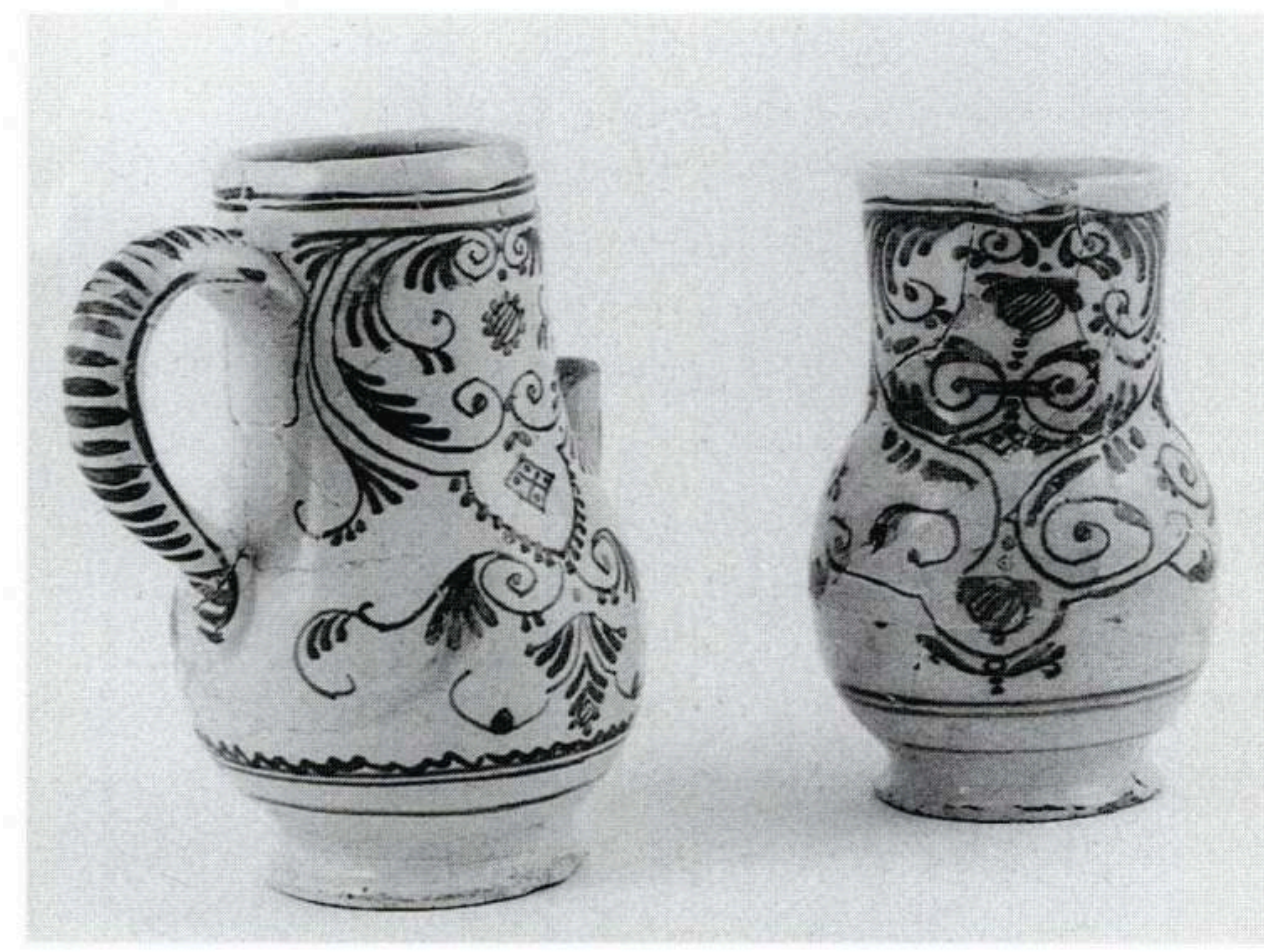

En ce qui concerne les productions de céramique à glaçure sur engobe, pas moins de 6 familles sont représentées: en verte sur engobe famille $\mathrm{El}$ on trouve les désormais inévitables assiettes creuses de type 3311, un pot de chambre de type 3711 et un pot de fleurs 3541 ; en rouge décorée famille E2, une seule jatte de type 3253 est présente ; en jaspée famille E3, des écuelles à oreilles de type $\mathbf{3 4 1 1}$; en jaune sur engobe famille E4, on a un plat de type 3812, sans marli et à paroi évasée courbe, agrémenté de taches vertes; en divers famille $\mathrm{E} 8$, une assiette plate de type 4121, reconnaissable à son absence de paroi et au marli à face interne convexe, voisine avec des assiettes plates de type 4111, de factures plus traditionnelles. On remarque toutefois l'absence de récipient en famille E5, pâte rouge, glaçure jaune et décor à l'engobe.

Pour cette fosse, le problème de la datation est en grande partie résolu par la date inscrite sur la faïence, 1744 ; si l'on ajoute à cela la présence de la famille B2, celle de faïence typiquement XVIIIe s., telles les assiettes $\mathbf{4 2 1 1}$ avec leur liseré bleu, nous pouvons donc proposer la deuxième moitié du XVIIIe s. On gardera bien en mémoire l'absence des familles G, R1, E5 et la faible présence de B1.

\section{La fosse 438}

Elle fournit un total de 808 fragments, répartis en 13 familles : 1 tesson en commune grise glaçurée G1, 4 en sgraffito E7, 23 en jaspée E3, 39 en commune grise $G, 40$ en faïence $\mathrm{F}, 42$ en beige décorée $\mathrm{E} 6,46$ en jaune sur engobe $\mathrm{E} 4,47$ en jaune décorée $\mathrm{E} 5,49$ en rouge décorée E2, 54 en verte sur engobe $\mathrm{El}, 85$ en divers E8, 151 attribués au service vert B1 et 227 au service jaune B2.

La famille $G$ n'apporte que peu de types : un bassin type $\mathbf{3 2 1 1}$ et des fragments de fond de marmite 1221. Il faut aussi ajouter un autre fragment de fond en commune grise glaçurée, famille G1. 
251 Le service vert B1 est un peu plus prolifique avec une assiette de type 3311, des marmites de type 1521, un pot de type 1531, un coquemar de type 1821 et un couvercle. Il faut remarquer le souci qu'ont les potiers de Meillonnas de se démarquer des produits standard présents dans de nombreuses autres familles, en créant de nouveaux profils d'assiettes, de marmites, de coquemars.

La famille B2 est la plus nombreuse, mais la production se limite en général à quatre ou cinq types ; ici, la fosse 438 donne 24 marmites de type 1341, une assiette de type $\mathbf{3 3 1 1}$ et un pot de fleurs de type 3541. La marmite 1341 est typique de la production de Lamage : il s'agit d'un vase tripode, possédant deux anses plates verticales opposées et perpendiculaires à un manche creux attaché sur le haut de la panse. Ces marmites, après utilisation au feu, sont généralement recouvertes de suie sur leur partie inférieure et la pâte devient noire. Quant aux assiettes, elles sont semblables à celles d'autres productions.

Les fragments de faïence permettent de reconstituer des assiettes de type $\mathbf{4 2 1 1}$ avec leur marli peu évasé à face interne concave, souvent décoré d'un trait de couleur bleue ; le reste du récipient est de couleur blanche ou légèrement grise.

La production de céramique à glaçure sur engobe est particulièrement abondante avec huit familles représentées, bien que la plupart des types soient déjà bien connus.

La famille verte sur engobe El est représentée par les assiettes creuses de type 3311, une assiette plate de type 4111, un pot de chambre de type 1231, d'autres de type 3711 et un pot de fleurs de type 5211. Ce dernier est pourvu d'un pied annulaire, d'une paroi haute et évasée et d'un rebord à épaississement externe. C'est exactement ce type de vase que l'on peut encore acheter aujourd'hui chez des artisans du Midi de la France. Pour les pots de chambre, la différence tient dans la forme de la panse : l'une, 1231, est ovoïde et surmontée d'un col court, l'autre, 3711, est haute et légèrement évasée, sans col. Le reste du récipient ne diffère pas d'un type à l'autre.

Un plat creux de type 3311, des écuelles à oreilles de type 3411, une jatte de type 3251, une cruche de type 1111 font partie de la rouge décorée E2. La jatte 3251 est caractéristique de cette famille avec une paroi évasée rectiligne, l'absence de marli et un rebord à une inflexion externe horizontale; le récipient est décoré sur sa face interne de motifs à la barbotine blanche.

257 Le décor jaspé de la famille E3 se retrouve sur quatre écuelles à oreilles de type 3411 et sur des pots à conserves de type 3531. Il s'agit d'un récipient à paroi rectiligne légèrement évasée, sans marli, sans élément verseur ou de préhension, avec un rebord qui montre une gorge sous un épaississement externe. Contrairement aux écuelles, le pot à conserves montre une ornementation externe, tandis que la face interne est revêtue d'une glaçure sur engobe ; de même, le décor jaspé, d'un aspect un peu fruste, ne donne pas l'impression d'une technique maitrisée, ou d'une grande application.

Des récipients bien connus sont identifiés jaunes sur engobe $\mathrm{E} 4$ : assiettes creuses de types 3612 et 3311 , assiette plate de type 4111, écuelle de type 3411, cruche de type 1111 et un pot de chambre de type 1231. Ces vases sont identiques à ceux rencontrés dans d'autres familles.

259 La jaune décorée E5 est l'une des familles les plus fournies en vases après collage avec seulement 47 tessons d'origine. Nous avons répertorié 17 récipients: une écuelle à oreilles de type 3511, d'autres, de type 3411, plusieurs assiettes creuses type 3311, une assiette plate type $\mathbf{4 1 1 1}$, un pot de chambre de type $\mathbf{3 7 1 1}$, des plats creux de type $\mathbf{3 8 1 3}$, 
des cruches type 1112 et un couvercle non identifié. Ces types sont, pour la plupart, déjà connus ; l'écuelle 3511 est à paroi rectiligne légèrement évasée et le plat $\mathbf{3 8 1 3}$, à paroi évasée courbe, sans marli, possède un décor de taches vertes disséminées sur sa face interne.

La catégorie de la famille E6 est un peu spéciale, car seulement deux types de vases ont été recensés jusqu'à présent : dans le cas présent, il s'agit de cruches de type $\mathbf{1 1 3 1}$ qui possèdent chacune deux anses plates verticales opposées, perpendiculaires à un bec tabulaire autour duquel s'étale une glaçure sur engobe.

Un rebord d'assiette plate de type 4121, sans paroi et à marli, typique de cette famille, est le seul élément présent en sgraffito E7, tandis qu'en divers E8, nous trouvons des récipients connus : pots de chambre type 3711 à glaçure externe brune, assiette plate type 4111, tasse type 3421 et écuelle type 3411.

Une fois n'est pas coutume : le comblement de cette fosse a livré un jeton de la fin XVIIe s., mais c'est la comparaison typologique qui permet de préciser un peu plus la chronologie, puisque les spécialistes de la faïence s'accordent sur le fait que les assiettes à bande bleue, type 4211, sont typiques du XVIIIe s. : il est vrai qu'on ne les trouve jamais dans des contextes archéologiques datés du siècle précédent. C'est pourquoi, la première moitié du XVIIIe s. peut être retenue comme datation pour le comblement de cette fosse, d'autant plus que les ateliers de Meillonnas abandonnent la production du service vert dans le courant du XVIIIe s. pour d'autres catégories de poteries glaçurées moins originales.

\section{NOTES}

1. Cette pièce n'est pas codée car trop incomplète.

2. La phase A fournit, pour l'US 7.15, 3 verres à tige, 1 flacon ou petite bouteille, 1 gourde; pour l'US 7.13, 1 verre à tige ; pour l'US 7.11, 1 verre à tige. La phase B fournit, pour l'US 7.10, 1 verre à tige. La phase C fournit, pour l'US 7.9, 1 verre à tige ; pour l'US 7.8, 1 verre à tige ; pour l'US 7.7, 2 verres à tige, 1 gobelet décoré d'un filet bleu rapporté et de godrons et pour l'US 7.6, 1 verre à tige.

L'ensemble de ces verres est daté actuellement de la fin du XIVe s., par comparaison avec le matériel issu des fouilles de la rue Tramassac. Evidemment, cette datation pose un problème, car, si elle peut, à la rigueur, aller avec la phase $\mathrm{C}$ de $\mathrm{S} 16$, il est hors de question de placer la phase $\mathrm{A}$ au XIVe s., puisqu'on possède des éléments précis qui la situent tout au début du XIIIe s. L'étude céramologique suggère donc que les formes de verre à tige utilisées au XIVe le sont déjà depuis le début du XIIIe s.

Par contre, en ce qui concerne la deuxième période de remplissage de $\mathrm{S} 16$, datée du XVIe s., l'étude des verres nous apporte une confirmation; en effet, l'US 7.5 fournit un gobelet à décor de cordons rapportés et l'US 7.3, un autre gobelet, mais à décor de pastilles rapportées; ces deux formes sont utilisées dès le XVe $\mathrm{s}$.

3. On peut aussi évoquer un dépotoir lié à une cuisine ; or il y a une cheminée, pas très loin, contre le mur 1. 
4. Dans cette fosse, le matériel en verre fournit 4 fonds de gobelets avec quelques fragments de panse et 2 verres à tige. Si ces derniers, datés d'après Tramassac, n'apportent rien de neuf, il en va autrement des gobelets qui peuvent être comparés avec du matériel provenant de la bastide de Gironville (Rapport de fouilles, J.-M. Poisson, 1984). Ce site, dans l'Ain, près d'Ambronnay, est une «fortification de terre entourée de deux fossés qui a été érigée lors de la guerre entre la Savoie et le Dauphiné ». On a la chance de posséder la date exacte de la construction, 1324, ainsi que celle de son abandon, entre 1330 et 1337 . Cette fourchette chronologique précise ne signifie pas pour autant que les gobelets de la fosse 35 datent du XIVe s.: nous ne possédons aucun renseignement sur la date d'apparition de cette forme. Ici non plus, l'étude du verre ne peut nous aider.

5. Une forme en verre a été identifiée dans la fosse 934 : il s'agit d'une gourde décorée datée du XIVe s., d'après la fouille de Tramassac; rappelons que la fourchette chronologique du verre proposée pour ce chantier est loin d'être sûre; il suffit de regarder les problèmes posés par Anse pour en être convaincu.

6. On peut également la comparer avec les marmites de la période 13 de Tramassac (MaccariPoisson 1994, fig. 91 n²), hormis une légère différence dans la lèvre.

7. Si le col représente un visage humain, on peut s'interroger sur les motifs décoratifs de la panse : il s'agit peut-être d'un vêtement.

8. Cet élément n'est pas codé, car trop incomplet.

9. Les monnaies sont étudiées par B. Claret dans l'annexe du rapport préliminaire de la Z.A.C Saint-Vincent, 1986 


\section{Chapitre 3. L'évolution du vaisselier régional du XII ${ }^{\mathrm{e}}$ au XVIII ${ }^{\mathrm{e}}$ siècle}

1 Il est temps, maintenant, de procéder à une synthèse générale de la céramique à Lyon et ses environs, pour une période comprise entre la fin du XIIe s. et le XVIIIe s. Cette démarche, novatrice pour la région, est maintenant possible pour plusieurs raisons : en amont, il faut évoquer la quantité de mobilier disponible, son extrême variété et le fait qu'il couvre une période de près de sept siècles; mais le plus important reste l'établissement d'un code typologique qui permette de classer toutes ces céramiques et de les étudier en même temps et selon les mêmes normes. Nous avons donc à notre disposition une véritable banque de données, qu'il suffit d'utiliser.

2 Un document utile aux archéologues: c'est évidemment le but premier de cette démarche. Dans le souci d'éviter le piège de la "spécialisation» à outrance, de la description systématique de la moindre petite lèvre, du moindre changement d'orientation dans un col ou une panse, nous avons opté, la plupart du temps, pour une description littéraire des céramiques; le renvoi indispensable aux codes des types se fait entre parenthèses.

3 Mais la demande des chercheurs est multiple dans ce domaine : précision typologique, technologique, ou vue d'ensemble sur une période donnée; trois axes de recherches sont proposés, trois éclairages différents, mais néanmoins complémentaires: une synthèse des fonctions, dont les termes sont décrits en chapitre 1 , une synthèse par groupe technique-les familles-, et une synthèse par siècle.

4 Évidemment, une telle démarche ne peut éviter certaines répétitions; si les trois synthèses donnent une vue globale de ce matériel, et surtout de son évolution à travers le temps, chacune d'entre elles peut néanmoins être lue indépendamment.

\section{Synthèse fonctionnelle}

5 Pour faciliter l'approche, les vases sont présentés dans chaque famille, par fonction, tout en respectant l'évolution chronologique. 


\section{Oule, marmite et pot à cuire}

6 Produite en commune grise G, l'oule (1371) est un vase bien connu depuis la publication du matériel de Lyon et de Vienne (Reynaud 1975 ; Boucharlat 1978). L'élaboration de ce récipient ne change pratiquement pas du Xe s. jusqu'au début du XIIIe s.: les oules de la phase A, silo S 16, du château d'Anse sont pratiquement identiques à celles de Saint-Georges de Vienne ou du Groupe Episcopal de Lyon : fond bombé, panse globulaire, absence de col et d'élément de préhension et, bien sûr, l'omniprésente lèvre en bandeau qui termine, au début du XIIIe s., une carrière commencée quelques huit siècles plus tôt (fig. 137). Il convient de constater l'absence de marmites sur les sites des XIe, XIIe s., ainsi que sur la fouille de la rue Palais-Grillet. Mais on peut les trouver, mélangées avec les oules, peut-être dès la phase A de $S 16$ à Anse, et en tout cas dans la phase $B$; ce phénomène est également perceptible sur le site de la place de la Bourse, où pas moins de quatre types de marmites sont recensés : c'est donc dans le premier quart du XIIIe s. qu'il faut placer leur apparition. La marmite et l'oule coexistent quelque temps, puis la seconde disparaît au bénéfice de la première : au milieu du XIIIe s., tout est joué. A partir de là, il devient impossible de distinguer une évolution de ce récipient, d'autant plus que bon nombre d'exemplaires sont incomplets. Le profil de la panse, celui du fond, l'emplacement des anses et la présence de col ne constituent pas des critères de datation et tous les cas de figure cohabitent : l'absence de col peut être liée à des anses accrochées sur la lèvre (10121), comme son absence, à des anses positionnées à un endroit identique (10191), voire même sur le col $\mathbf{( 1 0 1 4 1 , 1 0 2 2 1 )}$. En règle générale, pour l'ensemble des marmites du XIIIe s., les fonds bombés sont majoritaires, mais on note quelques exemplaires hémisphériques ; par contre, le fond plat semble inconnu. D'autre part, on remarque que le profil des lèvres tend à se simplifier.

137

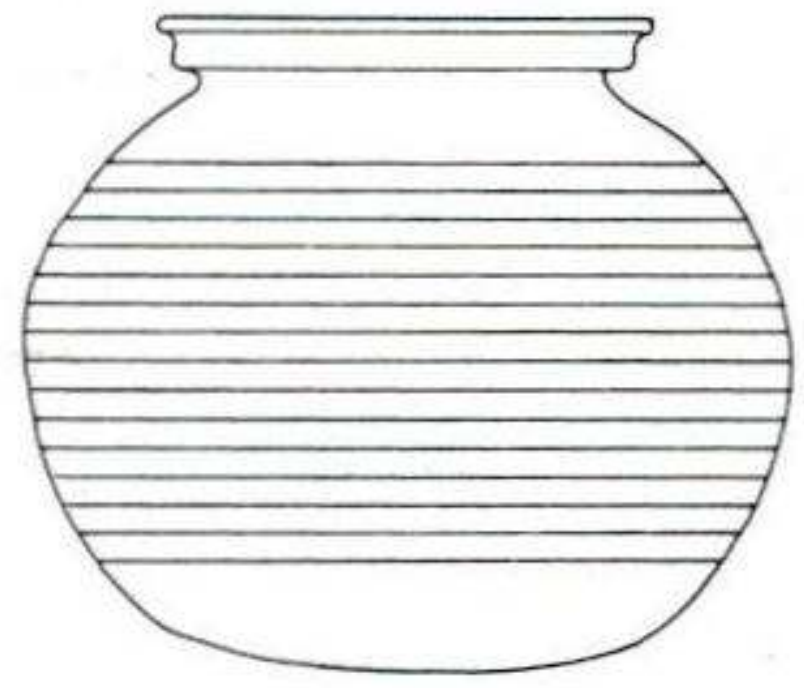

7 Sans passer en revue l'ensemble de ces marmites, il faut attirer l'attention sur certains exemplaires : ainsi, un vase montre un départ d'anse à la jonction d'un col rectiligne et d'une panse globulaire, un profil et un emplacement que l'on ne retrouvera plus par la suite (10161). Un autre récipient, dont on ne connaît pas le profil complet, mais 
pourvu, lui aussi d'un col, est signalé sur plusieurs sites d'époque médiévale : on a peutêtre là un repère chronologique, inexploitable pour l'instant (10321). Problème identique pour une marmite à lèvre horizontale et col court droit d'où partent deux anses plates opposées reconnue sur divers sites, et qui pourrait servir de critère de datation (1441).

Le XVe s. est plutôt avare en marmites entières de famille $G$; on trouve toujours les fonds bombés ou hémisphériques, les panses globulaires et les petits cols évasés. Les anses s'attachent aussi bien sur le col que sur la lèvre, qui, dans l'ensemble, demeure de conception simple.

138

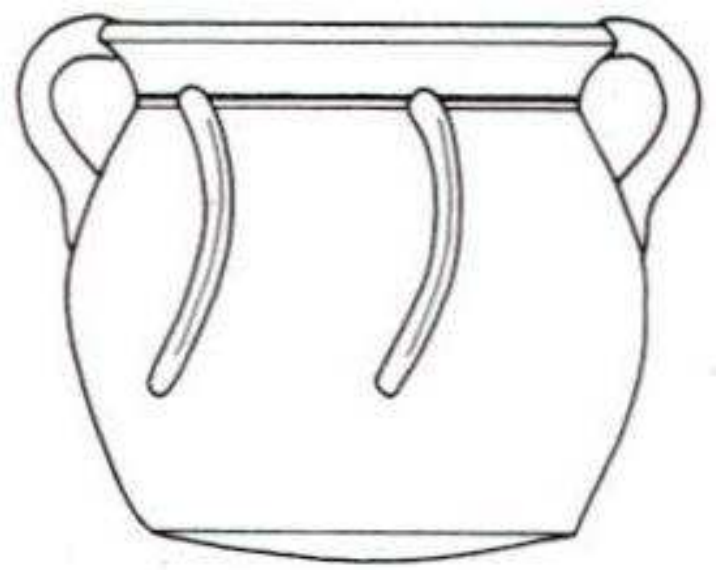

9 Au début du XVIe s., la production en commune grise reste encore bien imprégnée de tradition médiévale (fig. 138). L'observation des huit types de marmites à notre disposition pour cette période montre, une nouvelle fois, que l'emplacement des anses, la présence ou l'absence de col, le profil de la panse et celui du fond ne constituent pas des critères de datation. Tout au plus, on remarquera l'absence de fonds plats. Par contre, un élément se détache de cet ensemble : il s'agit d'une marmite qui, avec ses anses coudées de section ronde, imite les récipients en métal (1311). Cette particularité en fait un bon repère chronologique, puisque ce vase commence sa carrière sans doute à la fin du XVe s. et perdure jusqu'à la fin du XVIe s., et même jusqu'au début du siècle suivant. Dans la fosse 4109 de Saint-Vincent, qui contient 19 marmites à anses coudées, un liard de Trévoux, daté de 1608-1626, trouvé dans le remplissage, suggère que le type 1311 est encore utilisé à cette époque. Cette information n'est pour l'instant pas vérifiée par d'autres découvertes et doit être considérée avec toutes les précautions d'usage. En ce qui concerne la date de disparition de ces marmites, les 1593 fragments de commune grise trouvés dans le remplissage du puits de Saint-Vincent, montrent qu'au milieu du XVIIe s., le type $\mathbf{1 3 1 1}$ n'est plus en service.

Pour la première moitié du XVIe s., le remplissage de quatorze fosses permet de mettre en évidence la disparition de nombreux types propres à l'époque médiévale, au profit d'un catalogue plus que restreint, dominé par les marmites à anses coudées (1311); celles-ci monopolisent pratiquement toute la production, secondées par quelques marmites de conception plus ordinaire (1321). La fouille de la place des Terreaux, ainsi que celle d'une fosse dépotoir à Saint-Vincent, démontrent que cet état de fait ne change pas au milieu du XVIe s. 
11 Dans la première moitié du XVIIe s., la situation se simplifie encore : la production en commune grise ne fournit qu'un type de récipient, lequel apparait d'ailleurs à cette époque (1221). Il diffère par son fond plat et sa panse ovoïde, presque droite ; les anses, relativement réduites, sont consolidées par des bandes d'argile verticales à décor digité. Ce type va être le seul représentant de la commune grise G jusqu'au XVIIIe s. : pour cette production, le règne de la marmite globulaire est terminé; il faut maintenant parler de pot à cuire.

12 L'apparition de marmites en pâte rouge glaçurée R1, sur les sites du château des Tours, à Anse (dépotoir 35, type 1391), et rue de la Monnaie, à Lyon (types 1381 et 1441) reste, pour le milieu du XIIIe s., l'une des grandes surprises. Ces récipients ne sont présents qu'en nombre extrêmement limité, de Tordre d'un seul exemplaire par type. On remarque, d'ailleurs, qu'on s'est souvent contenté de cuire en mode oxydant des vases existant en commune grise (1381, 1441). Mais la volonté de se démarquer de la production sombre est bien présente : ainsi, certains vases sont bien les précurseurs des marmites du XVIe s. (1441). Par contre, le manque d'information relatif au XVe s. ne nous permet pas de suivre l'évolution de ces récipients ${ }^{1 .}$ On constate cependant qu'au XVIe s., le catalogue s'est considérablement enrichi, puisqu'on recense plus d'une dizaine de types. Quelles sont les caractéristiques de ces marmites?

- Une série à panse ovoïde, à fond bombé, sans col, aux anses partant de la lèvre pour s'accrocher au milieu de la panse (1351 et 1352).

- Une série à panse globulaire, à fond plat, à col court et aux anses accrochées sur la lèvre et le milieu de la panse (1831 et 1832).

- Une série à panse globulaire, à fond hémisphérique, avec ou sans col, aux anses attachées sur le haut et le milieu de la panse (1411, 1412, 1421 et 1422).

- Une série qui reprend les caractéristiques des marmites en famille $G(1311,1441,10131)$.

- Un vase qui mélange plusieurs tendances : panse ovoïde, fond bombé, col court évasé, deux anses opposées sur le haut et le milieu de la panse (1331).

- Un vase à panse surbaissée, à fond bombé, considéré comme une variante des formes 141 et 142 (1611).

13 Tout ces vases montrent qu'en famille R1, la production tend également vers une certaine diversité en ce qui concerne les panses, les emplacements des anses et les fonds; il faut noter, pour ces derniers, la présence de fonds plats, contrairement à la famille G. Les lèvres sont, en général, de facture simple, sans inflexion, ou simplement évasées, à simple inflexion externe, bien qu'un type se singularise par une double inflexion externe (1352). On retiendra, pour cette époque, les marmites de formes 141 et 142 qui sont un bon repère chronologique pour le XVIe s.

Dans la première moitié du XVIIe s., la production en commune rouge glaçurée R1 s'est considérablement réduite, à l'instar de la commune grise $G$, puisqu'on ne dénombre que deux types. L'un est déjà connu (1331) et l'autre, à panse ovoïde et fond plat tripode, se décline en plusieurs versions : coquemar à une anse, ou marmite à deux anses opposées ou accolées (1211) (fig. 139). 


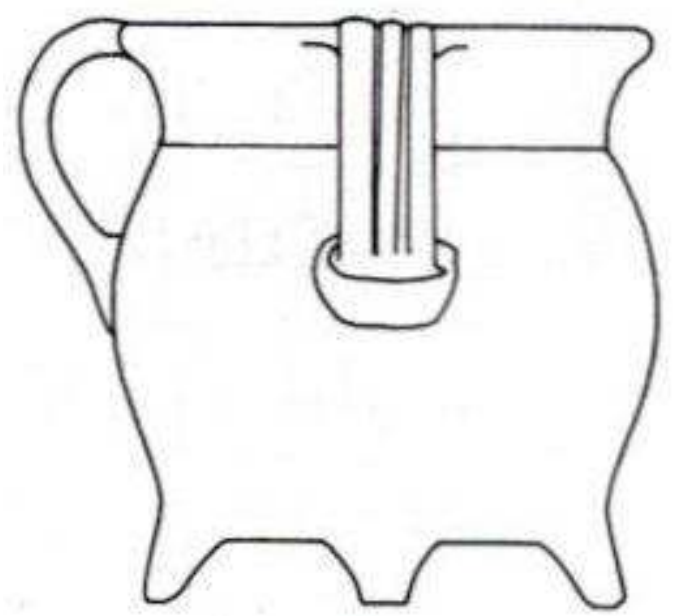

Il semble, à partir des données de fouille, que la production en commune rouge glaçurée R1 n'existe plus au XVIIIe s. : les 1122 tessons recensés pour cette époque, qui donnent 152 vases, n'en fournissent aucun exemplaire. Les fouilles récentes de Condrieu confirment cette hypothèse, pour un contexte archéologique du milieu de ce même siècle (Rapport de fouilles, Feuillet, 1991).

Le service vert B1 produit également des récipients destinés à la cuisson, mais c'est seulement pour la première moitié du XVIe s. que nous identifions une marmite, ronde et massive, guère différente des autres productions (1811). Il s'agit sans doute d'une des rares concessions faites par le service vert à la forme globulaire, puisqu'à la même époque, apparaitt un autre type de récipient (1521), à base étalée assortie d'une panse ovoïde haute et d'anses s'élèvant bien au-dessus du niveau de la lèvre, et qui, avec une variante (1511), perdure jusqu'au XVIIIe s. Peut-être pouvons-nous déjà parler de pots à cuire ? C'est en tout cas l'option choisie par cette production au XVIIe s. (1711 et 1721) ou au XVIIIe s. (1531). L'originalité du service vert tient dans le fait qu'à fonction égale, il propose des profils différents des autres productions.

C'est dans la deuxième moitié du XVIIe s. que le service jaune B2 produit, dans le contexte culinaire qui nous intéresse ici, une marmite qui mélange l'archaïsme - panse ovoïde, col moyen évasé, deux anses opposées - et la nouveauté, avec un fond tripode et un manche creux perpendiculaire aux anses (1541). Ce récipient se retrouve également au XVIIIe s.

Que conclure de cette vue d'ensemble ? Jusqu'au début du XIIIe s., la vaisselle de cuisine est dominée par les ouïes; puis apparait la marmite et l'on assiste, du XIIIe s. au début du XVIe s., à un foisonnement de types divers. Le grand nombre de marmites-la plupart $\mathrm{du}$ temps présentes en unique exemplaire-et leurs caractères souvent incomplets empêchent l'établissement d'une évolution chronologique, du moins en commune grise G. Mais dès la fin du XVe s. ou le début du XVIe s., la marmite à anses coudées (1311) en famille $\mathrm{G}$ et les formes 141 et 142 en famille R1 peuvent servir de critères de datation. Le service vert B1 se démarque avec des produits différents, de haut niveau, quelle que soit l'époque. Le XVIIe s. reste marqué par une transformation radicale des récipients culinaires, sans doute liée à de nouvelles pratiques, avec, par exemple, l'apparition du potager, cet équipement qui permet de contrôler plusieurs feux de cuisson. Les 
nouveaux types présents à cette époque, en famille $G$, R1 et même B2 pour la fin de ce siècle, constituent également de bon critères chronologiques.

\section{Coquemar}

140

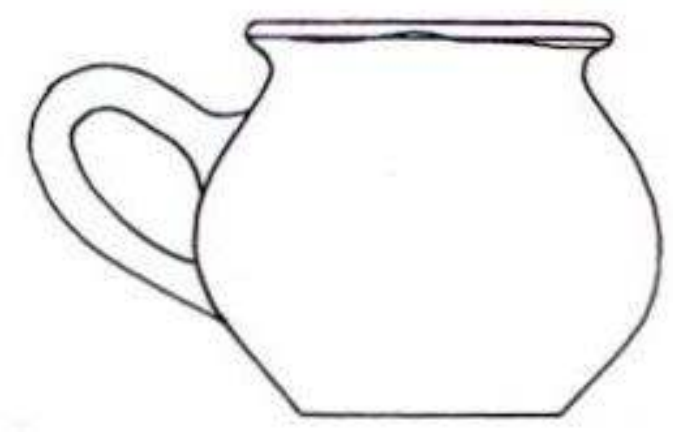
répertorié dans le cadre de cette étude (10131). Ce vase à une seule anse, qui ressemble à certains récipients de même époque $(10121,1381,11051)$, est encore sous l'influence du profil des marmites, comme le montrent d'autres exemplaires, en provenance de la fouille de Tramassac, qui hésitent entre fond hémisphérique et fond plat (MaccariPoisson 1994, pp. 93-116). possède déjà ses caractéristiques propres : fond plat, panse ovoïde, col court et anse unique s'attachant sur la lèvre et le milieu de la panse ; il est fabriqué exclusivement en commune grise G. Il faut noter le fond plat, à une époque où les marmites ne montrent que des fond bombés ou hémisphériques ; le coquemar est vraiment destiné à être posé au coin du feu.

21 Pour le début du XVIe s., les fouilles ne restituent que deux exemplaires, de tradition médiévale, en commune grise $G$ : l'un est déjà connu (10131), mais sur l'autre, le col brille par son absence; de plus, il s'agit du seul exemplaire de coquemar pourvu d'un fond bombé! (1361).

Dans la première moitié du XVIe s., on retrouve les caractéristiques des coquemars de Tramassac, mais, cette fois, produits en commune rouge glaçurée R1 (1841), ou en commune grise $G$ (10172). Il faut mentionner un vase particulier, en provenance de la fouille de l'îlot Vieille Monnaie, à Lyon : le fond plat et l'anse unique n'étonnent pas, mais la panse rectiligne et l'absence de col sont l'expression d'une version originale du coquemar, jamais renouvelée par la suite, du moins d'après nos connaissances (1741).

Le milieu du XVIe s. n'apporte guère de nouveauté ; la fouille des Terreaux montre que le même type est disponible, en commune grise $G$ ou en commune rouge glaçurée R1 (1841), tandis que le service vert B1 produit un récipient à fond plat, panse globulaire et anse unique, de facture classique.

$\mathrm{Au}$ XVIIe s, c'est au tour de la production verte sur engobe E1, de proposer un coquemar, copié sur d'autres familles, mais avec, comme particularité, une tache de glaçure qui s'étale sur la paroi et la lèvre, du côté opposé à l'anse (1841). Cette époque est marquée par l'arrivée de plusieurs marmites, qui se déclinent aussi en mode 
coquemar (1211 en R1 et 1221 en G). C'est également à la même période que le service vert $\mathrm{B} 1$ inonde le marche avec une conception originale de ce récipient: le fond reste plat, la panse oscille entre un profil globulaire ou ovale; dans les deux cas, le col est absent et l'anse, de section ovale, s'attache sur le haut et le milieu de la panse, après avoir formé une boucle qui remonte jusqu'au niveau de l'ouverture (1821) (fig. 140). Ce vase amorce une longue carrière qui le conduira jusqu'au XVIIIe s., époque où il reste seul en service. On note, à la charnière des XVIIe et XVIIIe s., l'apparition unique et anecdotique d'un récipient, en verte sur engobe E1, qui reprend les caractéristiques du coquemar, avec cependant une panse ovoïde dont le diamètre maximum se situe dans la partie supérieure (1541).

En résumé, si le coquemar n'évolue pratiquement pas en 400 ans, il est, par contre, produit en diverses familles : commune grise $G$, puis commune rouge glaçurée R1; il passe ensuite en verte sur engobe E1 et surtout en service vert B1. C'est d'ailleurs la seule famille qui le garde au catalogue, au XVIIe s., au moment où la marmite se transforme en pot à cuire.

\section{Poêlon}

141

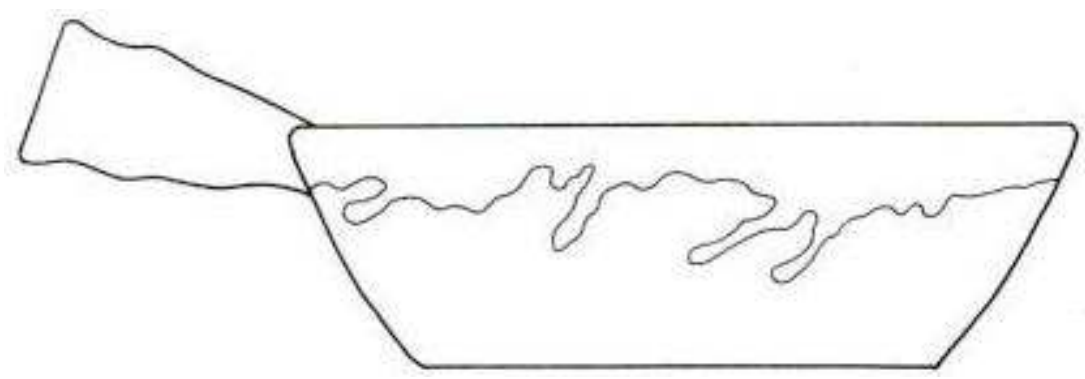

Il s'agit d'un récipient relativement minoritaire; on en signale au XVe s., issu du dépotoir de la Bourse, à fond plat, paroi évasée, manche creux opposé à un bec pincé, produit en commune rouge glaçurée R1. La fouille de l'Hôtel-Dieu fournit un exemplaire, sans élément verseur, pour le début du XVIe s., pourvu d'un fond plat surmonté d'une paroi évasée courbe et terminé par un rebord sans inflexion où s'attache un manche creux (3831) (fig. 141). La fouille des Terreaux montre qu'au milieu de ce siècle, il existe un type, en service vert B1, assez semblable au précédent, si ce n'est un rebord à une inflexion externe horizontale, et que Ton retrouve aussi en plein XVIIe s. (3832). Pour la deuxième moitié de ce siècle, un nouveau type en commune grise G, issu d'Antonin Poncet, enrichit le catalogue ; le récipient, muni d'un manche creux opposé à un tenon de préhension, possède également un fond plat et une paroi légèrement évasée, mais celle-ci est suivie d'un col convergent (Vicard 1989, p. 159, fig. 10). Au XVIIIe s., l'exemplaire rencontré à l'Hôtel-Dieu ressurgit, mais cette fois en service jaune B2 (3831); cette pérennité de profil est liée aux contraintes fonctionnelles de ce récipient, qui ne prédisposent pas aux innovations morphologiques. On peut aussi se demander dans quelle mesure cette faible représentation des poêlons n'est pas due aux hasards des découvertes, plutôt qu'à un désintérêt de la part de l'utilisateur : pour répondre à cette question, il suffit d'évoquer la masse considérable de marmites à anses coudées présentes dans chaque contexte du 
XVIe s. : une utilisation massive de poêlons laisserait des traces identiques. Ceci dit, on ne connaît pas la part prise, dans le mobilier de cuisine, par les poêles en métal.

\section{Lèchefrite}

142

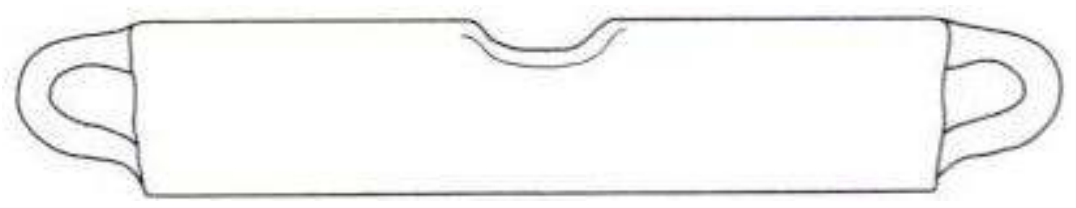

Ce récipient a une curieuse destinée : il apparait au début du XVIe s. avec un type à paroi rectiligne et à deux anses opposées, perpendiculaires à un bec pincé, produit en commune rouge glaçurée R1 ou en verte sur engobe El (3111) (fig. 142). On le trouve jusqu'au milieu de ce siècle, parfois en service vert B1, puis il disparaît complètement. La fouille des Terreaux montre qu'à cette même époque, des lèchefrites en commune grise $G$ sont utilisés, phénomène dont on se doutait grâce à des fragments recueillis sur d'autres chantiers. Le profil est identique au type précédent, mais le récipient est ovale et non plus circulaire; deux manches creux coexistent sur un des côtés et un bec pincé est présent sur chaque largeur; le choix d'une cuisson réductrice et l'absence de glaçure semblent étranges pour un vase où chaque utilisation fait pénétrer la graisse dans l'argile, qui en garde ainsi le goût. Ce récipient ne semble pas avoir été retrouvé pour des périodes postérieures. On sait pourtant, grâce au musée des A.T.P, que des lèchefrites identiques sont encore utilisés au XIXe s., mais, pour la région, entre le milieu du XVIe et le XVIIIe s., les découvertes archéologiques restent muettes.

\section{Cruche, pichet et biberon}

Dès les premiers niveaux médiévaux du site de Palais-Grillet, on trouve des traces de pichets en commune rouge glaçurée R1, en faible quantité, il est vrai. La date de cette apparition reste encore mal connue, mais se situe vraisemblablement à la fin du XIIe s. La quantité et la qualité des exemplaires trouvés à Anse montrent qu'au début du XIIIe s., il ne s'agit pas d'un événement marginal, mais bien d'une production de série. On détermine quatre types de pichets, qui, s'ils ne coexistent pas sur un même site, n'en sont pas moins considérés comme contemporains; en effet, dans l'état actuel de nos connaissances, il n'est pas possible d'établir une chronologie des pichets, bien que certains éléments laissent supposer une évolution. Le type le plus connu et le plus représenté reste le pichet décoré de bandes moletées et/ou de pastilles d'argile, à pied haut et à grand col; on le retrouve sur les cinq sites étudiés (fig. 144) (11121). Son profit général ne change guère, bien que certains montrent des pieds plus proéminents (cf. place de la Bourse) ou plus élancés (Rapport de fouilles, Monnoyeur 1992). 


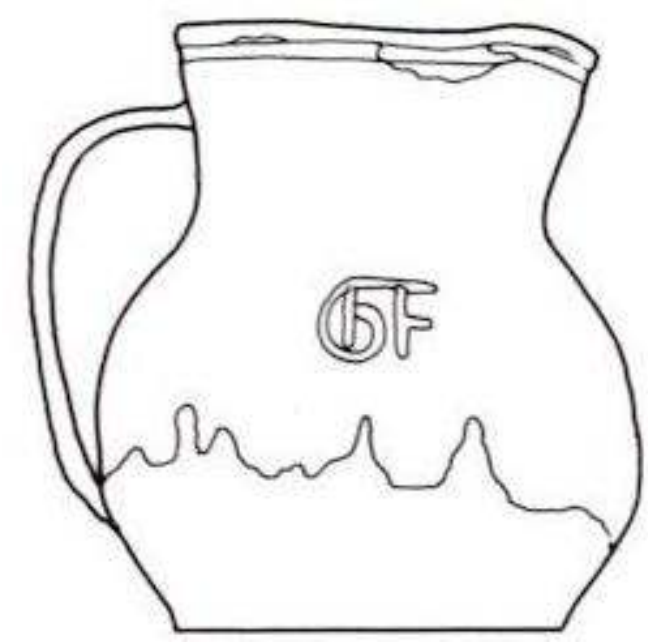

144

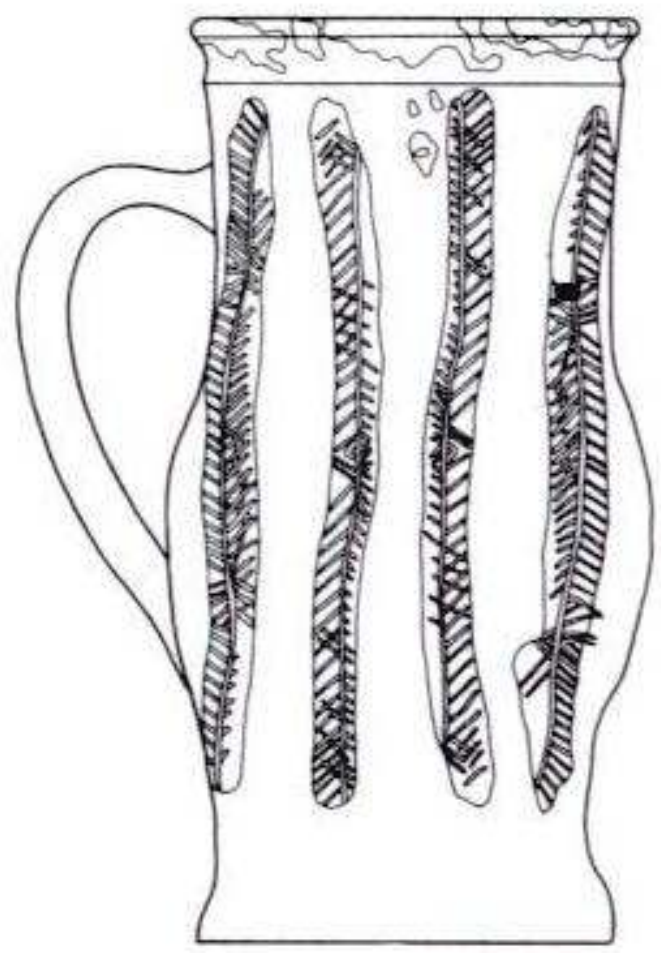

Les sites du château des Tours, à Anse et de la place de la Bourse, à Lyon, fournissent un autre pichet, plus simple, différent du précédent, avec une base étalée et un col peu prononcé (11111). D'après les données apportées par la fouille d'Anse, ce type aurait une durée de vie beaucoup plus courte que son homologue et se cantonnerait dans le tout début du XIIIe s., mais le manque de références ne permet pas de confirmer cette hypothèse. Les chantiers du quartier Saint-Vincent et de la rue de la Monnaie (îlot 24), à Lyon, ont permis la découverte d'un troisième type de pichet, dont le profil change beaucoup par rapport à ceux étudiés plus haut : panse surbaissée, fond plat sans pied, avec toutefois un col haut et rectiligne (11211). Les parentés avec les cruches à bec pincé (11061) sont plus qu'évidentes. Ces exemplaires, souvent anthropomorphes, 
imitent également les cerclages de tonnelets en bois par des bandes horizontales d'argile rapportées. On les trouve aussi sur les sites de Clément V (Rapport de fouilles, Monnoyeur 1992) ou de Tramassac (Maccari-Poisson 1994), mais ils sont absents de la Bourse-ce qui peut être expliqué par la faible quantité de matériel-et également du château d'Anse, ce qui est plus troublant. Il s'agit peut-être d'un indice chronologique, que nous ne sommes pas en mesure, par manque de critères de datation absolue, de clarifier pour l'instant. Le dernier type de pichet n'a jamais été trouvé complet : on sait quand même qu'il possède un col rectiligne et surtout une panse surbaissée, dépourvue de décoration ; sa faible représentation dans les sites étudiés ne permet pas de le situer par rapport à ses confrères (11212).

Il semble, en conclusion, qu'on puisse risquer une hypothèse d'évolution des pichets : dans un premier temps, on a un pichet à base étalée et col court évasé (11111), d'une durée de vie très courte (phase $\mathrm{A}$, dépotoir S16 à Anse), contemporain de l'exemplaire pourvu d'un pied et d'un grand col haut (11121) qui restera plus longtemps en circulation, peut-être en raison de son décor. Quand ce type tombe en désuétude, à peu près au milieu du XIIIe s., et au moment où il va être remplacé par la cruche à bec pincé (11061), un nouveau pichet à panse surbaissée-une sorte de précurseur de la cracheentre en jeu (11211). Quant au dernier type, on ne connaît pas sa place dans cette évolution (11212). Bien sûr, il faut prendre ce scénario avec toute les précautions d'usage par manque de critères chronologiques absolus; quoi qu'il en soit, tout ceci a dû se passer dans une période extrêmement brève, entre la fin du XIIe s. et la deuxième moitié du XIIIe s.

31 A cette même époque, on trouve encore quelques cruches à bec ponté, qui péricliteront vite, face à la montée des productions en commune rouge glaçurée (11051). Les profils n'ont pas bougé depuis le Xe s., mais, semble-t-il, les récipients ont gagné en dimension.

Responsable en grande partie de la disparition du pichet, la crache à bec pincé (11061) fait une entrée en force, en commune rouge glaçurée R1, à peu près au milieu du XIIIe s. : plus simple d'aspect, plus stable, de plus grande capacité, de facture plus sobre, en un mot, plus fonctionnelle, elle s'impose et se maintient, presque inchangée, jusqu'au XVIe s. (fig. 143). Il s'agit aussi probablement d'une utilisation différente: on peut boire dans un pichet, ou servir à boire; la crache, elle, sert uniquement à verser du liquide, son bec pincé est là pour le rappeler. Le profil de cette crache ne change pas, seule la lèvre subit quelques variantes, tout en restant simple. La quasi totalité des panses n'offre aucune trace d'ornementation, si ce n'est quelques graffitis ou lignes ondulées, tracées en creux dans la pâte, avant cuisson.

$\mathrm{Au}$ XVe s., la production en commune rouge glaçurée R1, n'est toujours pas avare de ce récipient ; le dépotoir de Tramassac et celui de la Bourse en fournissent de nombreux exemplaires, souvent rapidement décorés de bandes d'engobe. Il est à noter que, sur ces deux sites, ces craches voisinent avec les pichets surbaissés, autres rescapés de l'époque médiévale (11212).

34 Au début du XVIe s., ces deux récipients arrivent en fin de carrière. Un vase, incomplet, suggère que la crache à bec pincé (11061) fut fabriquée en verte sur engobe El, mais cette hypothèse ne peut pas être confirmée.

Curieusement, c'est à cette époque que réapparaît la cruche à bec ponté (11051) ; précisons tout de suite que ce type n'a rien à voir avec son homologue médiéval. Certains dépotoirs de la fin du XVe s., ou du début du siècle suivant, fournissent quelques exemplaires de craches à bec ponté, de très grande dimension, en commune 
grise $\mathrm{G}$, en commune rouge glaçurée R1 ou en verte sur engobe $\mathrm{El}$; les exemplaires appartenant à cette dernière famille ont souvent une cloison, percée de nombreux trous, située entre la panse et le bec. Malgré la présence de la famille El, on pourrait penser qu'il s'agit là de matériel résiduel, mais les fouilles récentes de la place des Terreaux, zone IX, confirment l'utilisation de ces vases à cette époque. Il s'agit d'un phénomène que nous pouvons difficilement appréhender pour l'instant.

C'est donc au début du XVIe s. que se fait la transition entre la cruche d'époque médiévale et celle d'époque moderne (1112), qui va connaître une brillante destinée jusqu'au XVIIIe s. Ce type est un peu le prolongement du précédent; il gagne en hauteur du fait de sa panse ovoïde, le col cylindrique se resserre et le fond montre une base étalée, parfois une amorce de pied (on se souvient que le type médiéval en était dépourvu); la lèvre reste simple, à faces parallèles, sans inflexion ; l'anse s'attache sur le col et le milieu de la panse, à l'opposé d'un bec pincé, parfois fortement marqué. Ce type est produit en service vert $\mathrm{B}$, en commune rouge $\mathrm{R}$, en commune rouge glaçurée R1, sans décor, excepté pour un exemplaire, orné de traits à la barbotine, puis en verte sur engobe El au milieu du XVIe s. et, enfin, en jaune décorée E5 au XVIIIe s.

Au cours des époques, les cruches sont sujettes à de nombreuses variantes. Certaines ne concernent que le profil de la lèvre (1113), d'autres celui de la panse (1119); dans la première moitié du XVIe s., le bec pincé est parfois remplacé par un bec tubulaire (1141), dont on trouve déjà quelques fragments sur des sites d'époque médiévale; au XVIIIe s., une anse en panier peut être ajoutée sur le rebord, afin d'accroître la prise en main $(\mathbf{1 1 2 1})^{2}$. La faïence, plutôt absente, se démarque, au XVIIIe s., par des récipients extrêmement décorés (1151 et 1152).

Il est difficile d'avoir une vue d'ensemble de l'évolution des cruches, particulièrement à l'époque moderne : chaque période voit son lot de nouveautés et de nombreux types ne sont présents qu'en un seul exemplaire.

Cependant, pour le Moyen Age, deux récipients servent de fil conducteur : il s'agit de la cruche à bec pincé de type $\mathbf{1 1 0 6 1}$ qui se rencontre dès le milieu du XIIIe s. et perdure jusqu'au XVIe s., et de la cruche à bec ponté de type $\mathbf{1 1 0 5 1}$ qui elle, connaît une carrière singulière, du Haut Moyen Age, jusqu'à l'aube de l'époque moderne.

Quant aux biberons (fig. 145), qui se distinguent par une taille réduite et un mince bec tubulaire, de rares exemplaires nous parviennent de la fouille de l'Hôtel-Dieu, datés du début du XVIe s. : l'un, en commune grise glaçurée G1, possède un fond plat, et une anse posée perpendiculairement au bec (11031), contrairement au second, en divers E8, dont l'anse se situe à l'opposé de l'élément verseur (11041). On trouve, dans la première moitié du XVIe s., un type à col court évasé (11021), une variante du type 11031. En ce qui concerne les autres périodes, aucune trace de ce récipient n'est visible, du moins, dans le cadre de cette étude : on sait pourtant, grâce à la fouille des Terreaux, que certains sont disponibles en familles E1 et B1, pour le milieu du XVIe s. 


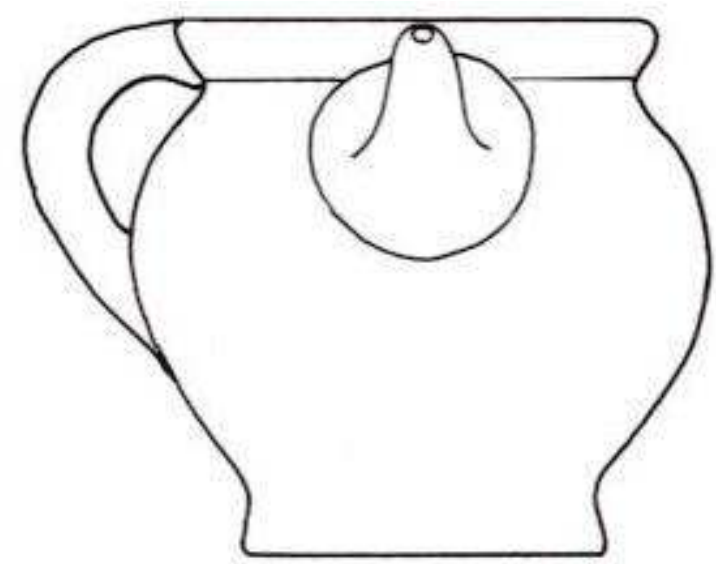

\section{Assiette et plat creux}

146

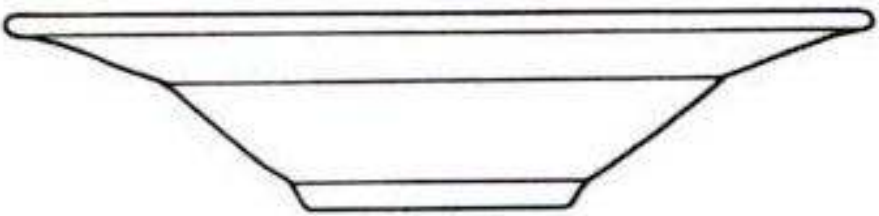

147

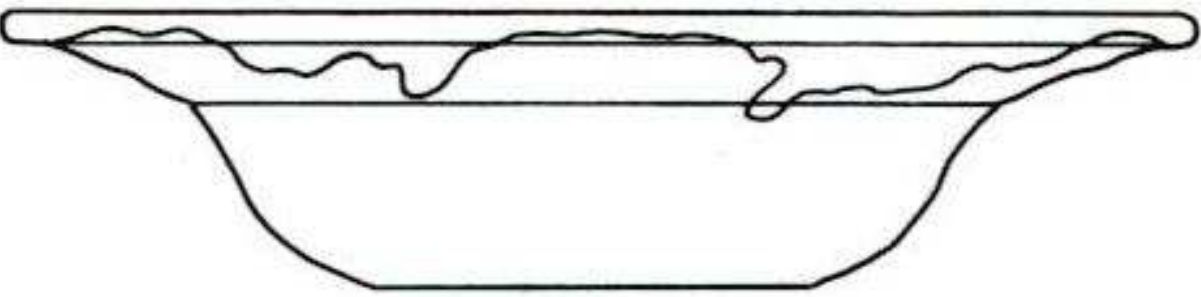

41 La différence entre une assiette individuelle et un plat réside généralement dans leurs dimensions ; mais la limite reste difficile à appréhender ; c'est pourquoi, dans cette étude, ces deux genres d'ustensiles seront abordés simultanément.

L'assiette apparaît timidement dès la fin du XVe s. (Terreaux, zone IX), en commune rouge glaçurée $\mathrm{R} 1$; le fond plat, la paroi évasée plutôt rectiligne et la présence d'un marli composent un profil qui ne change guère jusqu'à nos jours (3311) (fig. 146, 147). $\mathrm{Au}$ début du XVIe s., on trouve des assiettes en verte sur engobe El, puis, dans la première moitié de ce siècle, en familles $\mathrm{E} 4, \mathrm{E} 5, \mathrm{~B} 1$; cette dernière propose même une minuscule assiette, que Ton peut considérer comme de la dînette (4311), ainsi qu'un exemplaire de plat creux, également visible à la charnière des XVIIe et XVIIIe s. (3811).

Le milieu du XVIe s. n'apporte aucune surprise : l'assiette creuse (3311) continue sa carrière, présente dans de nombreuses familles (en E1, B1, R1, E2, E5, E7 et F, d'après les découvertes faites aux Terreaux). 

beige décorée $\mathrm{E} 6$, en commune grise $\mathrm{G}$ et en commune rouge $\mathrm{R}$. Il n'est guère étonnant de constater que toutes ces assiettes se ressemblent, mises à part celles du service vert B1, caractérisées par un marli très incliné, dans le prolongement de l'axe de la paroi, ce qui donne au récipient une plus grande contenance. La deuxième moitié du XVIIe s. ne voit aucun changement, si ce n'est deux curieux exemplaires à fond hémisphérique, issus de la place Antonin Poncet et qui s'apparentent plutôt à des bassines, destinées à être posées sur un support (Vicard 1989, p. 171, fig. 35).

A la charnière des XVIIe et XVIIIe s., quelques nouveautés viennent enrichir le vaisselier : tout d'abord, il faut noter l'apparition du service jaune B2, qui propose des assiettes de facture classique (3311) ; on remarque aussi de nouvelles morphologies: sur certaines assiettes, la paroi se relève et devient légèrement évasée, presque droite (3611) ; sur d'autres, le rebord montre une inflexion externe oblique vers le bas (3813) ou un épaississement externe et interne (3813). familles (F, El, B1, B2, E4, E5, E2). Dans la série des formes 381, on peut rajouter un type, à une inflexion externe oblique vers le haut (3812), et la forme 361 s'enrichit d'un autre, à une inflexion externe horizontale (3612).

En résumé, il semble que les productions d'assiettes creuses ne s'appuient que sur un seul type, qui dure du XVIe s. jusqu'au XVIIIe s. (3311). A partir de la fin du XVIIe s., de nouveaux récipients, pourvus de profils différents, viennent en appoint.

\section{Assiette plate}

148

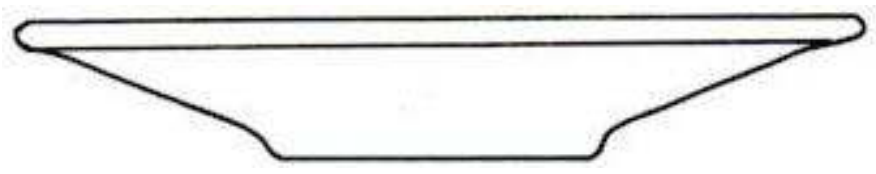

La première apparition de ce genre d'assiette se situe au milieu du XVIe s. Il s'agit d'un récipient à fond plat, sans paroi, à marli évasé, caractérisé par une face interne convexe et un rebord à épaississement interne, disponible en sgraffito E7 et en rouge décorée E2 (4121) (fig. 148).

Dès le XVIIe s., la rouge décorée E2, la jaspée E3 et les divers E8 produisent un type-avec un fond plat suivi d'un marli rectiligne très évasé-qui devient la référence pour les assiettes plates (4111).

Entre le XVIIe et le XVIIIe s., on ne note aucun changement ; les deux types précédents (4121 et 4111) sont toujours en service, de même qu'au XVIIIe, le premier en familles E8 et E7 et le second en familles E1, E4, E5, E8. C'est à cette époque qu'il faut leur adjoindre une assiette un peu particulière, avec une courte paroi évasée courbe, suivie d'un marli à face interne concave : c'est la caractéristique des assiettes en faïence blanche à liseré bleu, typiques du XVIIIe s. (4211).

51 Les assiettes plates ne sont donc représentées que par deux types, dont l'un semble être l'apanage de la famille E7 (4121). La faïence se réserve, à partir du XVIIIe, son propre type (4211). Il faut noter que certaines familles ne montrent pas d'assiettes plates dans 
leur catalogue : c'est le cas de la verte sur engobe El, des services vert et jaune B1 et B2, des communes rouge et grise glaçurées R1 et G1 : c'est-à-dire les seules productions non décorées.

\section{Écuelle et tasse}

149

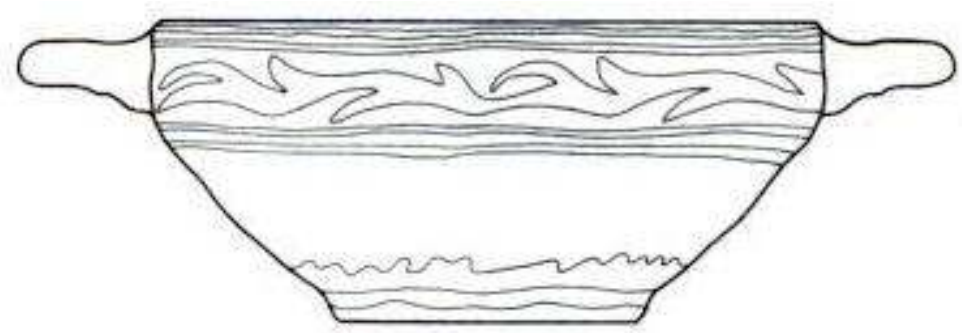

150

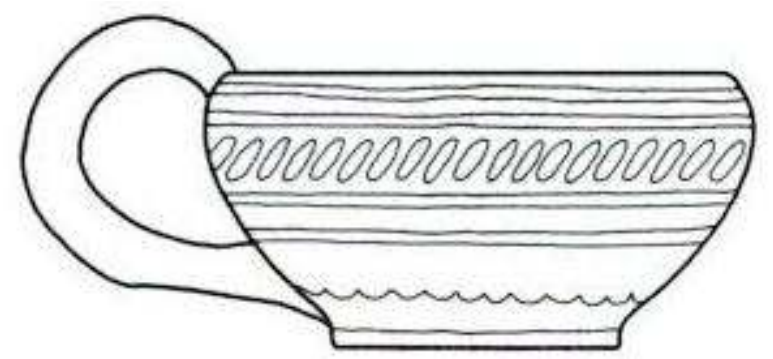

S'il existe un récipient qui semble sortir d'une production d'usine tant les exemplaires sont identiques, c'est bien l'écuelle. Il suffit de superposer de nombreux profils pour en être convaincu ${ }^{3}$.

L'écuelle se trouve, dès le XVe s., dans le dépotoir de Tramassac: elle possède un fond plat, une paroi rectiligne évasée, sans système de préhension et existe en commune rouge $\mathrm{R}$ ou glaçurée R1; mais c'est au début du XVIe s. qu'apparaissent certaines caractéristiques qui vont perdurer jusqu'au XVIIIe s. : fond plat, léger pied droit, paroi hémisphérique avec ou sans carène, rebord sans inflexion où s'attachent deux oreilles horizontales opposées, le seul segment qui se permette quelques variations de profils (3411). Au début du XVIe s., elle n'est disponible qu'en verte sur engobe $\mathrm{El}$; dans la première moitié de ce siècle, la jaune sur engobe E4 et les divers E8 en produisent également et au milieu du XVIe s., la jaune décorée E5, la rouge décorée E2 (fig. 149) et la faïence F. Au XVIIe s., c'est au tour de la commune grise glaçurée G1 et du service vert B1 de proposer leurs écuelles: on note, que, pour une fois, cette dernière production s'aligne sur les produits existants et ne se démarque pas par de nouveaux profils. Entre le XVIIe et le XVIIIe s., la jaspée E3 et le service jaune B2 s'ajoutent à cette longue liste. Pourtant, à cette époque, deux nouveaux types sont disponibles : l'un à paroi rectiligne légèrement évasée (3511) et l'autre, pourvu d'un petit pied cylindrique qui imite les productions en faïence (3521). Au XVIIIe s., certains types existent toujours, mais avec une carène plus prononcée et des oreilles davantage obliques (3411 et 3511). 

premier exemplaire apparaît au cours de la première moitié du XVIe s.; il s'agit d'un type fabriqué en commune rouge glaçurée R1, à fond plat, paroi évasée rectiligne, pourvu d'une anse qui s'accroche sur le rebord et le bas de la paroi (3261). A cette époque, il existe aussi un récipient, incomplet, qui possède sans doute les mêmes caractéristiques (30211). Au milieu du XVIe s., seul le premier type est disponible et il faut attendre le milieu du XVIIe s. pour découvrir une nouveau profil ; il s'agit en fait d'une petite écuelle, pourvue d'une anse dont la courbure dépasse largement au dessus du rebord; ce récipient est fabriqué en verte sur engobe E1, en rouge décorée E2 (fig. 150) et en jaspée E3 (3421). A cette même époque, un autre vase, présent en unique exemplaire et produit en E1, s'apparente plutôt à une dînette et ne comporte aucun système de préhension, même s'il ressemble à une écuelle (3431). La tasse de type 3421 continue a être disponible au XVIIIe s., en rouge décorée E2 et en divers E8. Les fouilles livrent aussi, pour cette période, le seul exemplaire de taste-vin rencontré dans toute cette étude, à paroi hémisphérique, pied annulaire, muni d'une seule oreille qui surmonte un anneau de préhension: le modèle n'est guère différent de nos taste-vin actuels (3441).

\section{Vases de transport, de stockage et de conservation}

Malgré le peu d'exemplaires étudiés, il est facile d'identifier les vases de transport grâce à l'anse en panier, commune aussi bien aux pots qu'aux cruches. Pour la période comprise entre la fin du XIIe s. et le milieu du XIIIe s., les fouilles de la place de la Bourse et de la rue Palais-Grillet ont le mérite de révéler un pot de transport, qui reprend les caractéristiques de l'ouïe à lèvre en bandeau, mais muni d'une anse en panier accrochée sur le rebord (10112), lequel montre parfois un profil sans inflexion, à faces parallèles (10111). Ce genre de récipient ne se retrouve qu'au début du XVIe s., légèrement différent dans la conception et dans la famille de production (10341).

De rares cruches de transport sont attestées à partir de la première moitié du XVIe s. Un exemplaire, malheureusement incomplet, produit exclusivement en commune grise G, ne manque pourtant pas d'intérêt, avec la présence d'une double anse en panier qui part du sommet de l'anse verticale, rejoint à l'opposé la lèvre et de là, par un deuxième rebond, vient se souder au bec tubulaire. Tout, dans cet agencement, indique un renforcement du système de préhension : l'anse en panier pour porter, l'anse verticale pour aider à verser (11011); ce type se retrouve au milieu du XVIe s., dans la fouille de la place des Terreaux. Dans ce même registre, on peut inclure un autre vase, en commune rouge glaçurée R1, marqué par une lèvre imposante et par le même genre d'anse (1122).

En ce qui concerne la conservation et le stockage, on rencontre également des cruches et des pots. Les premières sont faiblement représentées ; un exemplaire à bec tubulaire perpendiculaire à deux anses plates peut entrer dans cette catégorie, du fait de ses grandes dimensions (1131). Il apparaît, semble-t-il, au XVIIe s. (quoiqu'une étude plus approfondie du matériel de la place des Terreaux pourrait remettre en cause cette observation) et perdure jusqu'au XVIIIe s., époque où une variante, munie d'une lèvre différente, enrichit le catalogue (1132). A l'extérieur du vase, la glaçure, qui forme une tache autour du goulot, sert souvent de support à un décor. Quant à l'exemplaire unique, richement orné, produit en rouge décorée $\mathrm{E} 2$, son caractère incomplet enlève 
une bonne partie des informations. Le fond plat, la panse surbaissée, le col extrêmement resserré et deux anses plates opposées, fichées sur le haut de la panse placent sans hésiter ce récipient dans la catégorie des cruches de stockage (10711).

On peut penser, à partir du matériel recueilli lors des fouilles, que les pots de stockage et de conservation ne sont guère prisés des consommateurs. Ils apparaissent dans la première moitié du XVIe s. ; ce sont des vases bas, fermés, produits en famille R1, à fond bombé (2211) ou plat (2311) et à panse évasée courbe, surmontée d'un col convergent et flanquée de deux anses verticales. Il faut se tourner vers les Terreaux pour découvrir, au milieu du XVIe s., un type semblable, si ce n'est l'axe horizontal des anses et la famille de production, en l'occurrence, la commune grise $\mathrm{G}$. Les rares exemplaires trouvés lors de cette fouille confirment le peu d'intérêt pour ce récipient. Au XVIIe s., ces produits disparaissent, mais leur influence se fait sentir, dans un vase bas fermé, en divers E8, composé d'angles et de lignes droites (2111), ou dans un autre, de grande taille, en commune grise glaçurée G1, qui reprend les éléments propres aux vases de stockage (1731). C'est à la fin du XVIIe et tout au long du siècle suivant qu'on peut alors trouver un récipient du même genre en jaspée $\mathrm{E} 3$, mais en plus réduit : le col est absent et la liaison avec le rebord passe par une gorge interne fortement marquée (3531).

Si la caractéristique des récipients de transport reste l'anse en panier, celle des pots de stockage réside, non dans le système de préhension, mais dans le col, convergent ou pourvu d'une gorge : cet élément, permet en effet, l'utilisation d'un lien pour maintenir un couvercle souple en tissu ou parchemin.

\section{Jatte et bassin}

151

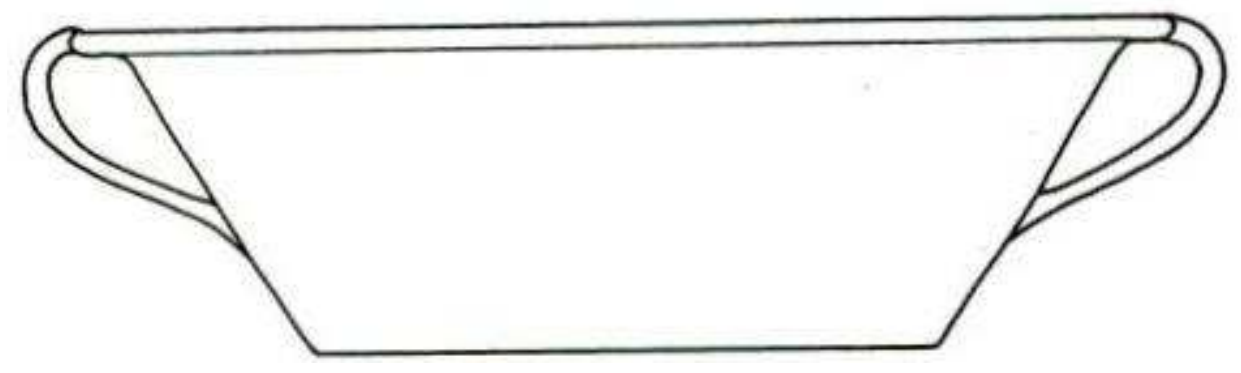

152

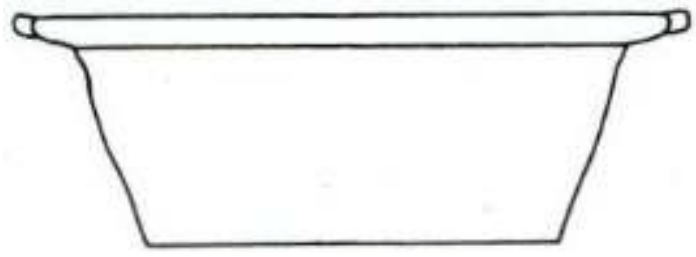

Dans le cadre de cette étude, les bassins apparaissent dès la fin du XVe s., comme le soulignent les découvertes de la place des Terreaux, à l'emplacement de la fontaine, zone IX. Un seul type existe, en commune grise G. Il s'agit d'un récipient à fond plat, sans pied, à paroi évasée rectiligne, sans marli ; les deux anses verticales sont parfois remplacées par deux tenons horizontaux fixés sur le rebord; l'ensemble reste dépourvu 
d'élément verseur (3211). Précisons que ce type n'évolue pas et perdure du XVIe s. jusqu'au XVIIIe s. On le trouve parfois, à partir du XVIe s., en familles R ou R1 (fig. 152).

61 Les jattes demeurent un des récipients les plus utilisés et montrent une grande variété de profils : du XVe au XVIIIe s., on ne compte pas moins de treize types différents (fig. 151).

62 Tout d'abord, il faut signaler, pour la fin du XIIe s., de rares fragments de récipients ouverts, en commune grise $G$, qui peuvent être apparentés à des jattes.

63 Examinons maintenant les vases en commune grise $G$, datés du XVe s., en provenance du dépotoir de Tramassac: ils montrent un profil globulaire aplati et un fond hémisphérique ; la paroi, juste avant le rebord, subit un fort étranglement ; le système de préhension comprend deux anses qui s'accrochent sur le rebord et le milieu de la paroi ou deux tenons horizontaux fixés sur le rebord. Ce profil de jatte reste fondamentalement différent de tous les exemplaires trouvés sur d'autres sites postérieurs; le plus surprenant réside surtout dans le fond hémisphérique, mais on sait, depuis les fouilles de clément $\mathrm{V}$, qu'il existe des trépieds en céramique et l'iconographie médiévale et moderne en montre souvent en métal. Ces jattes ressemblent à de grosses marmites, dont on aurait démesurément agrandi le diamètre d'ouverture ${ }^{4} L^{\prime}$ hypothèse la plus probable reste l'imitation de récipients en métal.

C'est au début du XVIe s. qu'apparaissent les premières jattes à fond plat, dont on recense trois types différents, tous produits en verte sur engobe $\mathrm{El}$ : le premier est doté systématiquement d'anses verticales opposées et les exemplaires étudiés ne montrent aucun système verseur (3221). Le second reprend également les même éléments de base, mais on trouve, à la place des anses, deux larges tenons horizontaux, perpendiculaires à un bec pincé (3241). Le troisième récipient demeure incomplet, mais le rebord montre une gorge interne, qui suggère l'utilisation d'un couvercle (30221).

Dans la première moitié du XVIe s., on découvre encore quatre nouveaux types: certains sont dépourvus de système verseur et possèdent des anses qui s'attachent sur le haut et le bas de la paroi (3231), d'autres montrent un profil de rebord différent (3222) ; les deux derniers demeurent incomplets (30311 et 30111). Au milieu du XVIe s., le type 3231 continue sa carrière, alors qu'apparait un nouveau récipient, muni de deux anses horizontales perpendiculaires à un bec pincé (3841). Signalons aussi que cette fouille confirme la pérennité du type 3221, mais en R1, et permet de découvrir un grand nombre de nouveautés, dont les plus inattendues restent certainement les exemplaires en service vert B1, à fond bombé et paroi courbe.

$66 \mathrm{Au}$ XVIIe s., la rouge décorée E2 produit une jatte dont l'absence systématique d'élément de préhension et d'élément verseur en font un vase caractéristique et un excellent élément chronologique (3251). Il faut noter que la présence de riches décors internes ainsi que celle de trous de fixation sur le marli réservent ce récipient à une utilisation autre que culinaire.

67 Entre le XVIIe et le XVIIIe s., le service jaune B2, propose, à son tour, une jatte, mais dépourvue d'élément verseur, de préhension et de marli : le moins qu'on puisse dire est que cette famille fait dans la simplicité (3252).

Au XVIIIe s., trois nouveaux types entrent en scène : l'un des deux exemplaires produits en service jaune B2 est pourvu d'un rebord à inflexion externe très oblique vers le bas (3254), tandis que l'autre réintroduit la paroi évasée courbe, sans marli, avec deux 
tenons (3821) ; le dernier, en rouge décorée E2 (3253), se rapproche plutôt du type 3251 de cette même famille.

La multitude de types de jattes et le fait qu'un certain nombre n'existe qu'en exemplaire unique rendent difficile un essai d'évolution chronologique. Il ressort pourtant que le type $\mathbf{3 2 2 1}$ constitue l'ossature de cette catégorie, puisqu'on le trouve du XVIe jusqu'aux XVII-XVIIIe s. : il va sans dire que sa présence dans une couche ne constitue pas un indice de datation! Par contre, la jatte produite en rouge décorée (3251), qui apparaît courant XVIIe et perdure au siècle suivant, constitue un bon repère chronologique. Le reste des types étudiés apparait de manière ponctuelle, suivant les époques: leur présence est trop dispersée pour en tirer des informations. La même conclusion peut s'appliquer aux système de préhension: du fait de leur variété, la présence ou l'absence d'anses ou de tenons, leur emplacement sur la paroi ne constituent pas une référence chronologique.

\section{Pot de chambre}

153

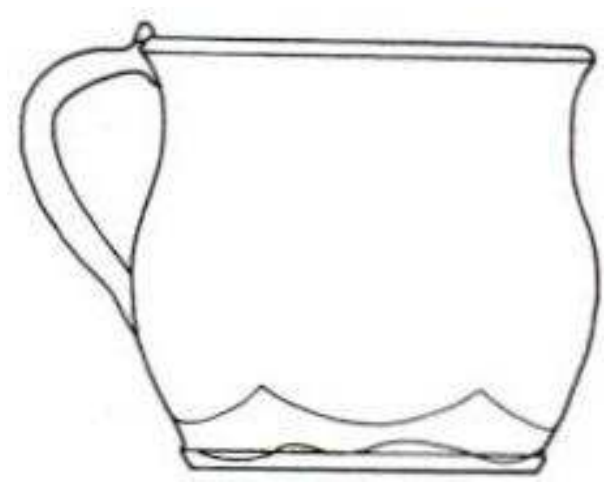

Ce récipient demeure peu fréquent dans les découvertes archéologiques. Il faut mentionner, sous toutes réserves, pour la première moitié du XVIe $s$, un vase, incomplet, qui peut s'apparenter typologiquement à un pot de chambre (10511). Pourtant, l'incontournable référence de la fouille des Terreaux, avec ses 56000 tessons n'en fournit aucun exemplaire pour le milieu du XVIe s., pas plus d'ailleurs que tous les autres sites de cette époque. L'apparition du pot de chambre au XVIe reste donc une hypothèse sous haute surveillance.

71 Par contre, son utilisation au XVIIe s. est assurée par la présence d'un vase haut, muni d'une anse verticale, souvent agrémentée d'un poucier (1231). Ce type, produit en verte sur engobe E1 et en divers E8 (fig.153), perdure jusqu'au XVIIIe s. A la charnière des XVIIe s. et XVIIIe s., apparaît un autre pot de chambre, quelque peu différent : en effet, la paroi devient plus rectiligne, impression accentuée par la disparition du col (3711). Ce type est produit en jaune sur engobe E4, puis, au XVIIIe s., en verte sur engobe El, en jaune décorée $\mathrm{E} 5$ et divers $\mathrm{E} 8$, tandis, qu'à cette époque, le type 1231 se trouve en famille E1 et E4.

On ne peut terminer ce bref tour d'horizon des pots de chambre, sans signaler que ce récipient, si bien adapté à sa fonction, n'évoluera pratiquement pas jusqu'à la première moitié du XXe s., où on le retrouve en faïence et en émail. 


\section{Couvercle}

154
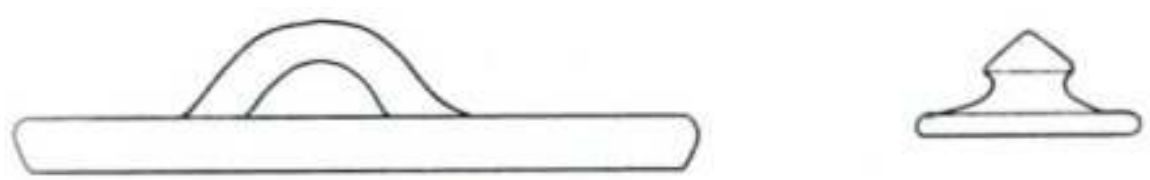

Au XIIIe s., il n'existe qu'un type de cet objet fonctionnel, creux, aux parois obliques, muni d'un tenon de préhension central (6221). Le couvercle plat semble encore inconnu à cette époque. Il faut attendre le milieu du XVIe s. pour retrouver des couvercles en contexte archéologique. C'est encore la fouille de la place des Terreaux qui en fournit le plus grand nombre : couvercles plats en commune grise $G$ (fig. 154) et en commune rouge glaçurée $\mathrm{R} 1$, reconnaissables à leur anse centrale horizontale, de section ronde (6111), mais également toute une variété de couvercles creux, issus du type 6221. Au chapitre des nouveautés, il faut citer les couvercles plats, en forme de cœur, muni d'un poucier percé à sa base d'un axe horizontal ; ce genre d'élément, produit en jaune décorée $\mathrm{E} 5$, s'attache sur des anses de cruches imitant les aiguières en étain. Mentionnons également des couvercles creux en commune rouge $\mathrm{R}$, avec un ressaut important, destinés à s'encastrer dans un récipient et fréquemment percés d'une ouverture à leur sommet afin d'évacuer la vapeur. Au XVIIe s., le couvercle plat à anse horizontale (6111) est toujours en service, accompagné d'un unique exemplaire, en famille R1, de couvercle creux, bas, dépourvu de système de préhension (6211). A la charnière des XVII et XVIIIe s., on trouve également une variante du couvercle plat, mais pourvu d'un tenon de préhension central rond (6121).

\section{Chauffe-plat et réchaud}

155

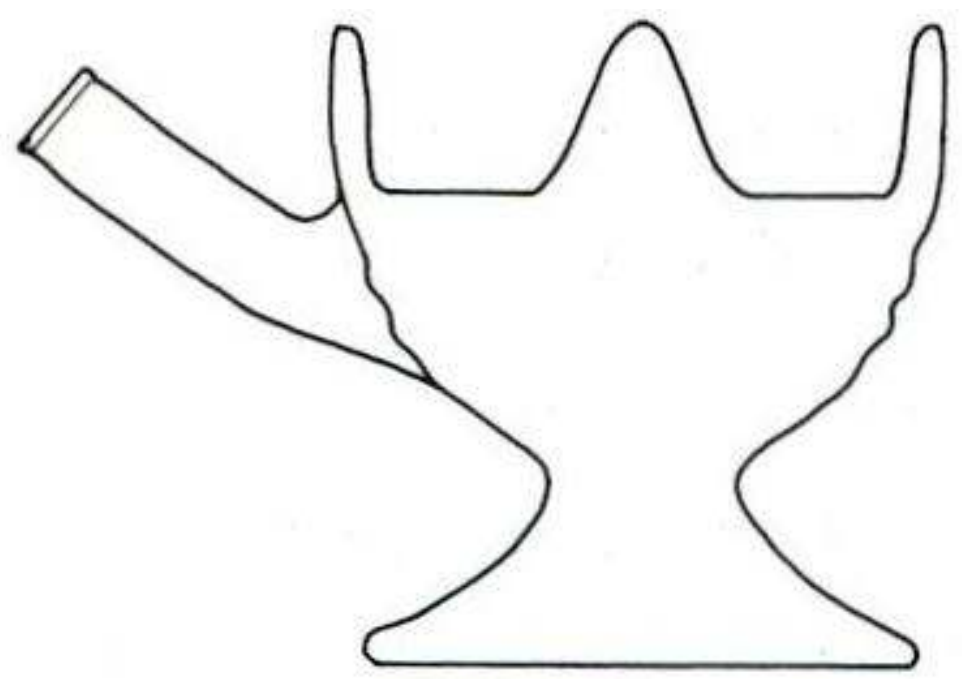

74 C'est dans la première moitié du XVIe s. qu'apparaissent pour la première fois les chauffe-plats, certains produits en commune grise $G$ (7111) (fig. 155) et d'autres en verte sur engobe $\mathrm{El}$ (7112 et 7113). Il s'agit d'un récipient à grand pied douche, à paroi 
évasée courbe, muni de deux anses plates verticales opposées. Trois tenons verticaux sont disposés en triangle sur le rebord : ils sont destinés à soutenir un récipient. Notons ici une particularité intéressante: les tenons des chauffe-plats produits en $G$ sont systématiquement hauts, de profit triangulaire et lisses, alors que les autres productions offrent des tenons bas, ronds, en forme de boules. Au chapitre des différences, on remarque également que les exemplaires en commune grise sont nettement plus volumineux que leurs homologues en verte sur engobe.

Au milieu du XVIe s., les chauffe-plats sont toujours en service ; la jaune décorée E5 et le service vert B1 en proposent également (7112). On les retrouve, en commune grise $G$, au cours du XVIIe s., puis cet ustensile disparait totalement, du moins d'après les découvertes archéologiques. Peut-être n'est-il plus fabriqué ? Quant à l'utilisation de ce récipient, la tradition veut qu'il soit rempli de braises; or, un simple regard sur les exemplaires en notre possession montre que les fonds internes ne présentent aucune trace de brûlé, ni décoloration de la pâte ou de la glaçure. Il faut plutôt imaginer un récipient rempli d'eau chaude ou une petite bougie posée au fond ou même une mèche trempant dans de l'huile. A l'appui de ces hypothèses, on peut citer deux observations archéologiques : certaines assiettes montrent sur leurs fonds externes des traces très importantes de brûlé, mais pas sur les parois, ce qui correspond bien à l'utilisation d'une petite flamme à effet centralisé ; d'autre part, toutes les marmites entières que l'on pose sur des chauffe-plats s'enfoncent profondément dedans; les tenons ne coincent le récipient qu'à mi-panse, ce qui interdit l'utilisation d'une flamme mais pas celle de l'eau chaude : le fond de la marmite, immergé, permet alors de réchauffer les aliments. On peut donc utiliser le chauffe-plats de deux manières, suivant le récipient posé dessus.

76 Les réchauds ne sont trouvés que dans des contextes XVIIe s. Ils sont produits uniquement en commune rouge famille $\mathrm{R}$. Il s'agit d'ustensiles à fond plat, à paroi droite puis légèrement évasée, munis dans leur partie basse, d'une ouverture rectangulaire ou en ogive et, un peu plus haut, d'un ressaut interne destiné à recevoir un récipient : celui-ci est donc en grande partie enveloppé par les parois du réchaud (7211). Malheureusement, aucun exemplaire n'est complet, ce qui nous prive de la hauteur réelle du récipient.

\section{Autres}

77 Dans cette catégorie sont regroupés tous les récipients trouvés en peu d'exemplaires; même si on ne peut les ordonner dans un schéma évolutif, leur présence contribue à la compréhension du mobilier des époques étudiées.

\section{Dînette}

78 A partir du XVIe s., on trouve assez souvent, en cours de fouille, des céramiques, de taille réduite, qui imitent de vrais récipients : cruche, soucoupe, assiette, chauffe-plats, écuelle, produits en familles El ou E5. Il faut évoquer la qualité de travail de ces modèles réduits : engobe, glaçure, décor, tout est à l'image des pots de taille normale. S'agit il de jouets, ou, à l'image de la faïence, de reproductions miniatures placés dans les fours pour contrôler le déroulement de la cuisson? 


\section{Tirelire}

79 La première tirelire, datée du XIIIe s., provient du site du quartier Saint-Vincent et n'offre qu'un intérêt anecdotique (731) ; on remarquera pourtant que les exemplaires de l'îlot Vieille Monnaie, et des Terreaux, datés du XVIe s., sont pratiquement identiques : pourquoi changer lorsque l'objet est bien adapté à sa fonction?

\section{Gobelet}

Deux exemplaires seulement de gobelets ont été trouvés sur l'ensemble des céramiques étudiées ici. Il s'agit d'un récipient à pied court tronconique, à paroi rectiligne légèrement évasée, démuni de système de préhension (5111). Cette faible représentation s'explique par l'industrie du verre qui possède, pour le XVIIe s., un important catalogue de formes; or la céramique ne fait pas concurrence au verre, les deux artisanats sont plutôt complémentaires. Ces deux gobelets détonnent dans la production céramique. Sur l'un d'eux, une inscription incomplète renvoie sans doute au monogramme christique IHS et suggère, peut-être, un récipient lié au culte? Cette hypothèse est à considérer avec prudence, car ce même monogramme est quelquefois présent sur des assiettes ou des écuelles.

\section{Gourde}

81 Nous possédons, pour le XIIIe s., un unique exemplaire de gourde, incomplet, qui présente, comme particularité, un tenon adossé au goulot. Celui-ci est placé sur un axe horizontal (741). On ne retrouve ce récipient qu'au XVIe s., avec un profit différent: l'objet possède une base plate, une panse ronde fermée; la partie supérieure est bombée ; deux anses plates opposées sont fixées de part et d'autre d'un goulot selon un axe horizontal. La production est assurée par la famille R1, mais également par le service vert $\mathrm{B} 1$, qui propose, à son habitude, un récipient répondant aux même exigences fonctionnelles mais d'un profit différent (Cliché en dos de couverture) (Rapport de fouilles, Arlaud 1991-1994).

\section{Vases pharmaceutiques}

Ces récipients sont généralement produits en faïence ; à ce titre, ils sont étudiés dans le cadre d'un diplôme de maîtrise sur la faïence lyonnaise. Il nous suffit de dire qu'ils apparaissent au début du XVIe s., avec l'arrivée des faïenciers italiens à Lyon. Ce qui est plus intéressant, c'est de constater que ce genre de vase a été copié par d'autres productions, telle que la rouge décorée E2 et peut être même la jaune décorée E5.

On peut citer les plus connus :

- Albarello, souvent de grande taille (plus de $20 \mathrm{~cm}$ ) ou plus modeste $(10 \mathrm{~cm})$, entièrement décoré sur la face externe ou complètement blanc (Rapport de fouilles, Arlaud 1991-1994).

- Chevrette de grande taille, munie d'une anse opposée à un bec tubulaire surmonté d'un anneau ; les exemplaires recensés sont tous décorés sur la face externe, parfois de manière excessive, et le nom du produit quelquefois marqué sur la panse ; (cf. idem).

- Cruche toujours décorée sur sa face externe, munie d'un pied et d'une paroi rectiligne évasée, d'une anse verticale de section ronde opposée à un long bec ponté (cf. idem).

- Récipient bas ouvert, décoré sur sa face externe; le col court convergent suggère l'emploi d'un couvercle ; il en existe de différentes tailles et la fonction, qui reste la conservation, est 
multiple : de la simple boîte au pilulier, en passant par la bonbonnière et le drageoir (cf. idem).

\section{Vases exceptionnels}

84

Dans cette catégorie ont été inclus; un vase décoratif, orné de godrons et réalisé en grès céladon, des fragments de tasses en porcelaine chinoise, à décor bleu, ainsi qu'un impressionnant récipient, à décor marbré, qui ressemble à une hydrie grecque (cf. idem).

\section{Synthèse technologique}

En toute logique, la synthèse technologique, c'est-à-dire l'évolution des familles du XIIe au XVIIIe s. complète celle des fonctions. Après une vision globale du mobilier, un regard sur les différentes productions ne peut qu'apporter de nouveaux éléments. A ce titre, chaque famille bénéficie d'un tableau de quantités, par époque ; les chiffres sont calculés à partir du nombre de fragments avant collage, mais le tableau les retranscrit sous forme de pourcentage.

En guise d'avertissement, il serait malhonnête de passer sous silence le principal handicap de cette synthèse : les rapports des familles entre elles et les hypothèses qui en découlent ne tiennent pas compte de la nature des sites fouillés, de leur fonction, du rang social des utilisateurs, de leur nombre, etc., toutes une série d'informations que l'archéologie ne révèle pas, ou de manière tronquée. C'est pourquoi les études suivantes sont à prendre avec toutes les précautions d'usage.

\section{La commune grise, famille $\mathrm{G}$}

Pendant longtemps, cette production constitue l'ossature du mobilier céramique, d'un point de vue purement quantitatif; elle est essentiellement axée sur le vaisselier culinaire, c'est-à-dire le matériel de base de l'aménagement d'une cuisine, aussi modeste soit-elle.

Diverses études (Faure-Boucharlat 1978) ont montré que la commune grise accapare la totalité du marché aux Xe, XIe et XIIe s.; à la fin de ce dernier siècle, elle représente encore $96 \%$ du mobilier de la fouille rue Palais-Grillet, sous forme d'oules, de cruches à bec ponté et d'oules à anse en panier : un éventail plutôt restreint, hérité des époques précédentes et qui correspond bien aux goûts culinaires en vigueur (A la Fortune du Pot 1990). Au début du XIIIe s., la production amorce une baisse de quantité, puisqu'elle ne totalise plus que $66 \%$ de l'ensemble des fragments recueillis en fouille. Cette baisse est à mettre en relation avec deux phénomènes :

- La montée de la production en commune rouge glaçurée, famille R1, qui se limite, pour l'instant, au vaisselier de table. On peut quand même souligner que la disparition des cruches à bec ponté est sans doute liée à l'apparition des pichets.

- L'apparition des premières marmites et l'abandon des oules; ce changement est apparu au début du XIIIe s. et est consommé au milieu de ce siècle : l'oule n'existe plus et la marmite règne en maitre, les nombreux types recensés sont là pour le prouver.

C'est donc à ce moment, où les types de marmites se multiplient, que la production de commune grise, après une baisse au début du XIIIe s., se stabilise aux alentours de $60 \%$ 
du mobilier, phénomène que l'on rencontre tout au long du XIIIe s. et peut-être même après, bien que les données pour le XIVe s. nous fassent cruellement défaut. On remarque également une sorte de statu quo dans les rapports entre commune grise $\mathrm{G}$, qui fournit la vaisselle de cuisine et commune rouge glaçurée R1, la vaisselle de table : pour l'instant les deux familles ne sont pas en concurrence. Cet aspect de la question ne peut pas être davantage détaillé, en l'absence de fouille de sites producteurs.

90 A la fin du XVe s., le remplissage du dépotoir D1 du site de la Bourse montre que l'équilibre évoqué plus haut se maintient, fragile, pour cette époque : $64 \%$ de commune grise pour $35 \%$ de commune rouge glaçurée. On constate pourtant que cette dernière production est déterminée à prendre pied dans le domaine culinaire (marmites, coquemars, poêlons). Malgré ces incursions dans son domaine, la famille $G$ reste largement en tête au niveau de la quantité, sans pour autant introduire de nouveaux récipients, la marmite étant, dans toute ses variantes, le vase de référence.

91 Cette position privilégiée, la commune grise arrive à la garder, dans la première moitié du XVIe s. -ce qui est un tour de force-face à la concurrence déjà en place et face à l'arrivée de nouvelles productions. Celles-ci ne se spécialisent pas toutes dans la vaisselle culinaire, mais deux sont particulièrement actives dans ce domaine : il s'agit évidemment de la commune rouge glaçurée R1, qui produit un certain nombre de marmites standardisées, avec néanmoins de nombreuses variantes (types 1411, 1412, 1421,1422 et 1611) et surtout de la production du service vert B1, qui propose des marmites, coquemars, aux formes originales, de bonne qualité et glaçurées.

La commune grise garde quand même un certain nombre d'atouts, comme le prouve la quantité de mobilier recueilli en fouille : $69 \%$ au début du XVIe s., $77 \%$ dans la première moitié, et $75,5 \%$ au milieu du siècle; le produit est "rustique", sans décoration et c'est ce qui fait sa force : fabriqué facilement en grande quantité, son coût ne doit pas être élevé. Tout au long du XVIe s., cette famille bénéficie avec la marmite à anse coudée (1311) -une imitation des chaudrons en métal d'un élément porteur, de très grande diffusion : 90,5\% des marmites recensées sont à anses coudées. Cette mode entraîne une raréfaction des autres types de marmites.

Dans le courant de ce siècle, la commune grise fait un gros effort de diversification: bassins, cruches de stockage à anse en panier, coquemars, vases de transports, réchauds, lèchefrites rectangulaires à deux manches, ainsi que d'autres vases, plus rares, tels le pot à cuire les châtaignes, ou le coquetier (Rapport de fouilles, Arlaud 1991-1994). Ceci doit être perçu comme un effort pour garder une part de marché, sans doute sans cesse menacée ; cette politique ne semble pas porter ses fruits, puisque dès la seconde moitié du XVIe s., la production de commune grise amorce un net recul, perçu dans les comptages du matériel mis au jour lors de la fouille des Terreaux : la famille $G$ ne totalise que $25 \%$ de l'ensemble du mobilier. A partir de cette époque, cette production n'arrive plus à se maintenir en première place: milieu XVIIe s., elle ne totalise que $17 \%$ du mobilier, fin XVIIe s., $22 \%$ pour la place Antonin Poncet ; ce chiffre descend à 9,6 \% à la transition des XVIIe et XVIIIe s., et au XVIIIe s., à 3,5\%.

Quelles raisons peut-on évoquer pour comprendre ce phénomène? Rappelons qu'au XVIIe s., on assiste à un changement dans la manière de cuire, avec l'apparition du potager; en relation avec cette nouveauté, on s'aperçoit que les marmites disparaissent, remplacées de plus en plus par les pots à cuire, à fond plat : un créneau où le service vert $\mathrm{B} 1$ excelle et concurrence directement la commune grise, en proposant de nombreux types différents, originaux et de très bonne qualité. A cette 
époque, la famille $G$ ne fournit qu'un type de pot à cuire, alors que le service vert en aligne une bonne demi-douzaine. De plus, il y a sans doute un phénomène de mode qui joue, difficilement perceptible d'un point de vue uniquement céramologique; il est pourtant certain qu'au XVIIe s., la table est extrêmement colorée; ce souci de décoration, que l'on perçoit bien dans le matériel avec les familles à décor sur engobe (E2, E3, E4, E5, E7), n'est sans doute pas réservé à la salle où l'on mange et peut gagner la cuisine : dans cette optique, on préférera le service vert, avec sa belle glaçure verte à une céramique grise, plus austère. En suivant cette idée, dans la deuxième moitié du XVIIe s., une nouvelle famille profite de la baisse d'intérêt pour la commune grise pour placer ses produits : il s'agit du service jaune B2 qui propose une marmite/pot à cuire tripode et pourvu d'un manche, revêtu d'une glaçure jaune. Service vert et service jaune sont bien résistants au feu tout en étant agréables à l' œil. Il faut citer enfin les marmites et autres ustensiles culinaires en métal : un phénomène que l'on ne peut pas appréhender à partir des découvertes archéologiques, mais qui doit jouer énormément dans la disparition de la commune grise : dans le catalogue de l'exposition (A la Fortune $d u$ Pot 1990), les deux tableaux dépeignant un intérieur de cuisine du XVIIIe s. (Pl. VI) et du XIXe s. (Pl. IX) montrent deux potagers et un matériel de cuisine composé essentiellement de casseroles et de marmites en métal. Tout ces éléments combinés marquent la fin de cette production à cuisson réductrice, après de nombreux siècles de suprématie.

\section{La commune grise glaçurée, famille $\mathrm{G} 1$}

Il s'agit d'une production que l'on peut qualifier de marginale; en effet, elle est représentée de façon minoritaire, quelles que soient les époques concernées. On en trouve $1,2 \%$ dès la fin du XIIe s., puis $0,1 \%$ dans la première moitié du XIIIe s., et $1 \%$ au milieu de ce siècle. Les seuls vases identifiés dans cette famille renvoient à une marmite et une cruche à bec ponté.

C'est au début du XVIe s., que l'on retrouve la trace de la commune grise glaçurée, toujours en très faible proportion: $1,7 \%$ du matériel recueilli pour cette époque: marmite à anses coudées (1311), aussi rare qu'inattendue et biberon (11031). Dans la première moitié du XVIe s., la quantité de cette production n'évolue pas et stagne aux alentours de $1 \%$, ce qui correspond encore à des fragments de marmites. Au milieu de ce siècle, l'observation reste identique, et même la fouille des Terreaux avec ses 56000 tessons ne fournit que 57 fragments en $\mathrm{G} 1$, soit $0,1 \%$ du total ; de plus, aucun vase n'est identifié. Au milieu du XVIIe s., on note une petite hausse d'utilisation, due à la présence d'un certain nombre de vases de stockage (1731) dans un comblement de puits, à Saint-Vincent. Par la suite et jusqu'au XVIIIe s., la présence de G1 diminue fortement, vers les 0,4 et $0,2 \%$; pour ces époques, aucun vase n'est identifié.

Ces rares observations nous conduisent à penser qu'il n'existe pas de production spécifique, mais plutôt un glaçurage ponctuel de certaines pièces produites en commune grise $\mathrm{G}$.

\section{La commune rouge glaçurée famille $\mathrm{R} 1$}

Après une éclipse de plusieurs siècles, cette famille réapparait de manière ponctuelle dans le courant du XIIe s., mais c'est à la fin de ce siècle que l'on trouve les premiers 
fragments de vaisselle de table, essentiellement des pichets. La proportion par rapport à la commune grise reste encore bien mince, puisqu'elle n'atteint que $2,8 \%$. La séparation entre vaisselle de cuisine et de table et l'existence d'une production en commune rouge glaçurée sont mises en évidence dès le début du XIIIe s., grâce au matériel mis au jour lors de la fouille du château d'Anse, où elle totalise $34 \%$ de l'ensemble du mobilier.

99 A cette époque, la production en R1 fournit des pichets, décorés ou non. La glaçure plombifère, sans engobe, en saupoudrage sur le vase préalablement enduit d'une colle végétale ou animale, présente, après cuisson, une surface rugueuse, parsemée de trous d'épingles, bien caractéristique de cette technique. Les décors sont constitués de bandes d'argile appliquées verticalement, parfois décorées à la molette, souvent intercalées de pastilles d'argile frappées d'un poinçon. On trouve aussi quelques décors d'écaillés couvrant l'ensemble du vase. Les pichets non décorés montrent, au niveau du col, de nombreuses stries de tournage bien prononcées. La palette de couleur n'est pas très étendue, allant du vert à l'orange, avec, parfois, quelques touches jaunes.

Dans la première moitié du XIIIe s., la production en R1 fournit 39 \% du mobilier, 33,4 \% pour le milieu de ce siècle et $36 \%$ pour une période située dans la deuxième moitié du XIIIe s. et peut-être le début du XIVe s. A ces époques, la technique de glaçurage ne change pas ; on constate simplement une désaffection pour les pichets décorés au profit de cruches non décorées, de conception plus simple : il faut citer le type $\mathbf{1 1 0 6 1}$ qui va perdurer jusqu'au début du XVIe s. L'éventail des couleurs ne change pas. La quasi totalité de la production concerne la vaisselle de table, mais on commence à trouver quelques marmites. Un bref calcul montre que le taux de présence de la famille R1, pour une période allant de la fin du XIIe s. jusqu'à la fin du XIIIe s. et peut-être même le début du XIVe s., est de $31 \%$.

Après le hiatus du XIVe s., nous retrouvons cette production à la fin du XVe s. On constate que le phénomène perçu pour la commune grise se répète pour la famille R1 : le rapport entre ces deux familles reste identique de la fin XIIIe s. jusqu'au XVe s., puisque la commune rouge glaçurée totalise $36 \%$ du mobilier de cette époque. L'éventail des vases n'évolue pratiquement pas ; le dépotoir de la Bourse, comme celui de Tramassac, ne fournit que de la vaisselle de table : les timides essais de marmites en R1, à l'époque médiévale sont restés sans suite, du moins dans l'état actuel des découvertes. La glaçure est toujours de type plombifère, saupoudrée comme le montre l'aspect "peau d'orange " et la palette de couleurs n'a pas changé; tout au plus remarque-t-on une diminution des surfaces glaçurées, un peu comme si l'on posait le produit à l'économie.

Au début du XVIe s., la quantité de commune rouge glaçurée baisse, puisqu'elle ne représente que 16,8 \% du mobilier, ce qui ne l'empêche pas d'être en seconde position, après la commune grise. Son catalogue s'élargit : elle produit maintenant différents types de marmites, ainsi que des lèchefrites et des jattes. La glaçure est désormais effectuée par trempage dans une "fritte" liquide qui couvre plus efficacement les vases. La palette de couleurs se cantonne dans les verts et rouges, ce qui est normal, puisque le plus gros handicap d'une glaçure posée sans engobe est de réagir pendant la cuisson en fonction des oxydes métalliques présents dans l'argile du vase.

Dans la première moitié du XVIe s., la famille RI1 se maintient en seconde position derrière la commune grise, mais avec $12 \%$ du mobilier. Elle produit toujours des marmites, avec une prédilection pour les récipients aux anses attachées à la panse 
$(1411,1412,1421,1422,1611) ;$ il s'agit sans doute de la réponse face à la quantité grandissante de marmites à anses coudées disponibles en commune grise. Il est d'ailleurs curieux de constater combien ces deux familles restent dans leur créneau respectif en proposant des types de marmites différents : il n'y a pas de concurrence directe, plutôt une sorte de complémentarité. Par contre, lorsque la famille R1 produit des coquemars, des jattes, des lèchefrites, quelques tasses et pots de stockage, elle se trouve directement opposée à la commune grise et surtout à la verte sur engobe E1, qui se lance à fond dans la vaisselle de table. A ce niveau, la commune rouge glaçurée R1 ne fait pas le poids : ses produits sont de qualité nettement inférieure.

Au milieu du XVIe s., la commune rouge glaçurée n'arrive qu'en troisième position avec $5 \%$ du mobilier : on trouve quelques cruches et couvercles. L'image la plus proche de la réalité vient sans doute de la fouille des Terreaux: la famille R1 ne se situe qu'en quatrième position, avec $13 \%$ du mobilier, après le service vert B1, la verte sur engobe E1 et la commune grise G. Une vingtaine de types sont présents : des marmites, des cruches à becs pincés ou tubulaires, des jattes, des assiettes creuses, quelques vases de stockage et réchauds et de rares gourdes ou albarelli. On s'aperçoit, au regard de cette énumération, que la commune rouge glaçurée R1 copie beaucoup sur les autres productions : sur la faïence $\mathrm{F}$ avec l'albarello, la verte sur engobe $\mathrm{El}$ avec la jatte et l'assiette, la commune grise $G$ avec le réchaud; il n'y a guère que la cruche et les marmites de formes 141 et 142 qui possèdent des antécédents lointains ou plus récents. Le handicap de la famille R1 réside dans la multiplication des productions à cette époque ; la plupart proposent un mobilier de meilleure qualité, revêtu d'une glaçure sur engobe, et la commune rouge glaçurée, face à ces concurrents, fait plutôt figure de bas de gamme. Une brève addition de l'ensemble des fragments pour la totalité du XVIe s. donne 68879 tessons, toutes familles confondues, dont 12,8\% sont composés de commune rouge glaçurée; ce chiffre est à comparer avec celui obtenu pour l'époque médiévale : la baisse de production de la famille R1 est nettement perceptible.

Au milieu du XVIIe s., le taux de présence est de $10 \%$. Sur la fouille de la place Antonin Poncet, dans la deuxième moitié de ce siècle, il n'est que de $4 \%$, puis à la charnière des XVIIe et XVIIIe s., il remonte à 16,5\%. Lorsqu'on calcule en vases reconstitués, les taux de présence donnent, pour les mêmes époques : 7,7\%,6,5\% et 10,2\%. Sous forme de tableau, ces deux modes de calcul montrent le même tracé, avec une courbe plus accentuée pour les fragments. Si l'on additionne le total des fragments pour l'ensemble du XVIIe s. (soit cinq remplissages de structures), on dénombre 15216 tessons, ce qui fait $8,3 \%$ du mobilier : une nouvelle baisse très nette par rapport au chiffre obtenu pour le XVIe s.: petit à petit la production de la famille R1 diminue. Malgré cela, l'éventail des types disponibles demeure relativement large : les céramiques issues des comblements de structures de cette époque montrent que l'on peut disposer de marmites, coquemars, cruches diverses, assiettes creuses, écuelles, bassins et couvercles, sans compter les innombrables fragments de canalisations qui prouvent que la famille R1 avait pratiquement le monopole de cette fabrication.

$\mathrm{Au}$ XVIIIIe s., la production de commune rouge glaçurée a complètement disparu : c'est du moins l'image que nous renvoient les 1122 fragments recensés pour cette époque, soit 152 vases identifiés. Les résultats de la très récente fouille de Condrieu pour un contexte archéologique du milieu de ce siècle, montrent également une absence totale de fragments appartenant à la famille R1 (Rapport de fouilles, Feuillet, 1991). De nouvelles fouilles de structures du XVIIIe s. permettront de valider cette hypothèse. 
107 L'histoire de la commune rouge glaçurée reste classique : elle apparaît au début du XIIIe s. comme une nouveauté face à la commune grise $G$, mais finit comme céramique commune, au XVIIe s., perdue au milieu d'autres productions. Il faut lui reconnaître plusieurs points forts, avec certains types de marmites (formes 141 et 142) et de cruches à bec pincé (11061). En fait, c'est peut-être la mise en service de cette cruche, au milieu du XIIIe s., qui a amorcé son déclin : en abandonnant les pichets décorés, donc, la céramique de luxe, au profit d'un vase plus sobre, fabriqué en grande série, elle banalise sa production. A ce sujet, on peut envisager deux hypothèses : soit les artisans potiers suivent la mode, en copiant sur des productions d'autres régions, soit ils la suscitent, en décidant d'exploiter un marché en pleine ouverture : il suffit alors de baisser le prix de revient du produit en le simplifiant, c'est-à-dire en supprimant les décors et en réduisant la glaçure. On peut aussi penser que la mode des céramiques décorées est passée et que les acheteurs désirent des pièces plus sobres : à cela, il faut répondre que la durée de cette mode aura été bien courte, comparée à d'autres, telles que celle des marmites à anses coudées, ou des cruches à bec pincé, qui remplacent le pichet. Quoi qu'il en soit, à partir du XVIe s., la commune rouge glaçurée R1 n'est pas de taille à lutter contre la montée des autres productions et décline doucement.

\section{La commune rouge non glaçurée, famille $R$}

108 Cette famille pose les mêmes problèmes que la commune grise glaçurée : on en trouve épisodiquement, suivant les époques, mais en faible quantité, avec de rares types identifiés, à tel point que l'on se demande si cette production existe réellement. En effet, à l'époque médiévale, la plupart des vases en R1 ne sont pas glaçurés entièrement, d'où un problème de fiabilité dans les comptages.

109 Jusqu'au milieu du XIIIe s., la production de commune rouge est nulle. A cette époque, on recense 191 tessons, soit 7,3\% du mobilier. Le décompte détaillé de ces fragments montre qu'ils proviennent de panses et d'anses de cruche, c'est-à-dire des seuls endroits du vase où la glaçure n'est pas systématiquement posée : il suffit de regarder les exemplaires entiers pour en être convaincu. D'autres fragments concernent les couvercles : certains sont produits en commune rouge, mais cette part reste minime.

$110 \mathrm{Au} \mathrm{XVe} \mathrm{s.,} \mathrm{il} \mathrm{existe} \mathrm{un} \mathrm{seul} \mathrm{exemple} \mathrm{de} \mathrm{céramique} \mathrm{en} \mathrm{commune} \mathrm{rouge} \mathrm{:} \mathrm{il} \mathrm{s'agit} \mathrm{d'une}$ marmite en provenance de Tramassac; le dépotoir D1 de la Bourse n'en fournit aucun fragment.

$111 \mathrm{Au}$ début du XVIe s., la quantité de commune rouge grimpe en flèche avec 430 tessons, soit $9 \%$ du mobilier; le problème posé reste pourtant identique : le faible nombre de vases reconstitués ne prouve pas l'existence d'une production; témoin cette cruche décorée de bandes d'engobe, mais non glaçurée; ces décors confirment la présence d'un revêtement: il s'agit là, soit d'un oubli du potier, soit d'un manque de matière première, mais l'artisan a quand même cuit le récipient tel quel. Il faut rapprocher de cette observation, la présence, place des Terreaux, de nombreuses écuelles engobées mais non glaçurées, sans doute en verte sur engobe $\mathrm{E} 1$ : ces écuelles ont été cuites sans glaçure, sans doute pour les mêmes motifs que la cruche évoquée précédemment. Cette façon de procéder suggère bien évidemment la présence d'acheteurs potentiels pour ce genre de produits.

112 Dans la première moitié du XVIe s. et au milieu de ce siècle, la quantité de commune rouge présente oscille entre 1 et $0,2 \%$ et on identifie une marmite et une tirelire; par 
contre la fouille des Terreaux fournit un grand nombre de couvercles, une marmite et une gourde, sans élément de préhension, sans doute logée dans un étui tressé ou en cuir, ce qui explique l'absence de glaçure.

$\mathrm{Au}$ milieu et à la fin du XVIIe s., la place de la commune rouge se tient entre 0,5 et 0,1\%. Dans les deux cas, ces chiffres sont dus à la présence de réchauds de table (7211).

Dans la période comprise entre le XVIIe et le XVIIIe s., on compte 3,3\% de commune rouge sur l'ensemble du mobilier. Cette fois nous n'identifions aucun type.

$\mathrm{Au}$ XVIIII s., la famille R disparaît complètement.

116 En conclusion, on peut accréditer l'hypothèse d'une absence de production en commune rouge: les rares vases fabriqués selon cette technique le sont de manière ponctuelle, sans suivi. Par contre, la production de réchauds au XVIIe s. semble être une réalité : les exemplaires proviennent de sites et de datation différents.

\section{Le service vert, famille B1}

117 La première apparition de cette famille à Lyon se situe à la fin du XVe s., d'après les découvertes des Terreaux, zone IX. Aucun type de vase ne peut être identifié. Le service vert ne totalise que 4,5\% du mobilier (Rapport de fouilles, Arlaud 1991-1994). Au début du XVIe s., sur le site de l'Hôtel-Dieu, la production de Meillonnas reste minoritaire avec $1,8 \%$ du mobilier; nous n'identifions qu'un vase, une cruche de type 1112, identique à celles produites dans d'autres familles: il s'agit d'un des deux seuls exemplaires de ce type trouvés sur les sites lyonnais et le seul, d'ailleurs, qui offre une affinité morphologique avec des vases d'autres productions.

Dans la première moitié du XVIe s., la quantité de service vert ne progresse guère: $3,5 \%$ du mobilier. Ce chiffre peut paraitre dérisoire, mais situe le service vert en troisième position, derrière les familles R1 et $\mathrm{G}$. Un regard sur le matériel permet de découvrir des marmites (1521 et 1811), des assiettes creuses (3311) et deux récipients dont l'un peut s'apparenter, en émettant quelques réserves, à un lèchefrite (3111), et l'autre à une soucoupe ou une « dînette » (4311), sans oublier un fragment de cruche à bec pincé. Dès cette époque, la ligne de conduite des potiers bressans est relativement claire : ils misent aussi bien sur l'aspect culinaire que sur celui de la vaisselle de table ; toutefois on remarque déjà un savoir-faire indéniable et une originalité qui ne feront jamais défaut : ainsi la hauteur des marmites et leur paroi extrêmement mince, ou le marli très évasé des assiettes, dans l'axe de la paroi, qui suggère une grande contenance.

119 Au milieu du XVIe s., cette famille représente 14,6\% du mobilier des sites étudiés, en incluant les résultats de la fouille des Terreaux. L'éventail des types s'est largement diversifié : marmites, coquemars, biberons, vases de stockage, pots à cuire, écuelles, assiettes creuses, jattes, réchauds, poêlons, couvercles, gourdes, sans doute aussi de grands lèchefrites rectangulaires, carreaux de poêle et même un gobelet. Le service vert, en produisant ces récipients, concurrence plusieurs autres familles : la commune grise $G$, la commune rouge glaçurée R1, la verte sur engobe E1. Son principal atout réside dans des profils différents par rapport aux autres productions pour un même ustensile: phénomène bien visible en ce qui concerne les marmites, coquemars, gourdes, jattes et même les couvercles; par contre, d'autres, comme les écuelles, demeurent identiques. 
120 C'est au XVIIe s. que le service vert atteint son apogée avec $35 \%$ du mobilier et supplante la commune grise en se plaçant en première position. Cette situation reste stable pour la deuxième moitié de ce siècle ; le service vert représente $26 \%$ du matériel issu de la place Antonin Poncet, et garde sa première place devant la famille G. Pour comprendre cet engouement, il faut se souvenir que la commune grise ne propose qu'un type de pot à cuire, alors que le catalogue de la famille B1 s'enrichit constamment. On peut toutefois se demander si le service vert prend une place laissée vacante, ou si sa vitalité contribue à la baisse d'intérêt des utilisateurs pour la commune grise.

Dans la période comprise entre le XVIIe et le XVIIIe s., on constate pourtant un net recul de la famille B1, qui descend à $5,2 \%$ : sur les 273 vases recensés, seulement 7 récipients appartiennent au service vert. Dans le courant du XVIIIe s., la famille B1 enregistre également une baisse importante au niveau de la quantité du matériel, avec $17 \%$ du mobilier. La fouille récente de Condrieu (Rapport de fouilles, Feuillet 1991) témoigne, pour le milieu de ce siècle, d'une présence du service vert de l'ordre de 0,1\%. Quelles en sont les causes? Un regard sur le tableau récapitulatif des familles à cette époque met en évidence un net déclin des productions concurrentes de la famille B1; par contre, le service jaune B2 et les divers E8 sont en pleine expansion. Leur étude montre que le service vert subit, au XVIIIe s., le contrecoup d'un changement radical du mobilier céramique. Cela dit, les éléments recueillis ne reflètent peut être pas toute la réalité économique des ateliers bressans : l'hypothèse d'un déclin de la production du service vert à partir du XVIIIe s. est à prendre avec toutes les précautions d'usage.

\section{Le service jaune, famille B2}

C'est la fouille du dépotoir 1 (US 53) de la place Antonin Poncet qui permet de situer, avec $1,7 \%$ du mobilier, l'apparition du service jaune, dans le dernier quart du XVIIe s. Cette famille qui arrive tardivement ne propose que peu de types: assiettes creuses (3311) et marmites (1341), sans oublier une sorte de moutardier aux parois verticales.

123 A la charnière des XVIIe et XVIIIe s., le service jaune totalise 6,2 \% de l'ensemble du mobilier. Aux assiettes creuses, s'ajoutent des écuelles (3411), une jatte (3252) et d'autres assiettes (3611).

$\mathrm{Au}$ XVIIIe s., la diffusion du service jaune augmente considérablement et constitue $25 \%$ du mobilier. Deux nouveaux types de jattes (3254 et 3821), ainsi qu'un poêlon (3831) s'ajoutent aux vases déjà connus.

Les fouilles récentes de Condrieu font état, pour le milieu du XVIIIe s., d'un taux de présence de 46,7\%. Les types restent identiques, avec, comme nouveauté, la présence de couvercles plats et de vases à panse sphérique, sans col, pourvus, près de la lèvre, d'un rebord externe saillant, en forme de collerette horizontale.

On peut s'interroger sur l'opportunité d'introduire une nouvelle production à une époque qui semble saturée de vases de tous types. Cette abondance cache en fait une désaffection pour les céramiques culinaires; la production en commune grise est en chute libre et le service vert inonde le marché de ses produits depuis près de deux siècles. Le service jaune s'engouffre dans ce créneau avec ses marmites tripodes, poêlons, jattes et assiettes. Le choix de ces deux derniers récipients peut paraître étrange, puisqu'à la fin du XVIIe s., pratiquement toutes les familles en fabriquent, mais 
il s'inscrit dans une logique, afin de proposer une gamme complète, essentiellement utilitaire. Cette volonté de ne pas diversifier les récipients donne vraiment l'impression d'une étude de marché préalable, destinée à cibler les produits dans un domaine ou la concurrence reste rude. Cela dit, il faut rappeler la qualité particulière des argiles kaoliniques, qui, après cuisson, deviennent réfractaires et sont donc bien adaptées à la vaisselle de cuisine.

\section{La céramique glaçurée verte sur engobe, famille E1}

Cette famille apparaît timidement au début du XVIe s. (1,3\%), assez loin derrière la commune grise $\mathrm{G}$, la commune rouge glaçurée R1 et le service vert B1. Au cours de la première moitié de ce siècle, la diffusion de cette famille progresse lentement $(3,5 \% \mathrm{du}$ mobilier), toujours précédée des familles G, R1 et B1. C'est au milieu du XVIe s. qu'elle prend sa vraie dimension avec $12 \%$ du mobilier, juste derrière la commune grise. Il faut souligner que la fouille de la place des Terreaux donne un résultat équivalent, avec $15 \%$, à la même place. Au cours du XVIIe s., la famille El maintient sa position et totalise $11 \%$ (14, $5 \%$ pour la fouille de la place Antonin Poncet), mais se situe toujours derrière la commune grise, voire le service vert et parfois même la rouge décorée E2. Le déclin s'amorce à la charnière des XVIIe et XVIIIe s. avec $7 \%$ du mobilier et seulement $5 \%$ pour le XVIIIe s. Au milieu de ce siècle, elle est totalement absente sur la fouille de Condrieu (Rapport de fouilles, Feuillet 1991).

Quelles caractéristiques peut-on retenir pour cette famille? Tout d'abord une extraordinaire aptitude à la diversité, puisqu'en deux siècles, on ne recense pas moins d'une quarantaine de types différents. Ce phénomène est certainement lié au fait que la famille E1 a su le plus souvent éviter le domaine culinaire-sans doute s'est-elle adaptée à son argile calcaire, peu réfractaire-et s'est orientée vers la vaisselle et les accessoires de table, une option qui lui permet d'assurer une base solide avec les cruches, assiettes, écuelles et diverses jattes, tout en faisant preuve d'une certaine liberté dans le reste de sa production.

Dès son apparition, la famille El propose un éventail de types assez conséquent : jatte, assiette creuse, écuelle, pot de transport, dînette et même lèchefrite. Ce genre de récipient reste l'unique concession qu'a faite la famille $\mathrm{El}$ au domaine culinaire, sans pour autant courir de risques : en effet, les lèchefrites sont plutôt le monopole de la commune grise, avec une morphologie complètement différente de nos exemplaires en El. Au cours de la première moitié du XVIe s., s'ajoutent, aux vases déjà recensés, divers types de cruches, de jattes, ainsi que des biberons et des réchauds. Le milieu du XVIe s. nous permet, grâce aux découvertes de la place des Terreaux, d'enrichir notre vision de cette production: jattes de tous types, à parois cylindriques ou évasées, assiettes creuses dont l'une possède le seul décor jamais remarqué sur un récipient en El (il s'agit d'une scène figurative, incisée avant cuisson), premiers exemplaires de tasses, à paroi évasée rectiligne, lèchefrites, cruches de table ou de stockage, biberons, réchauds, albarelli aux profils copiés sur la faïence, gourdes, chaufferettes, pique-fleurs, bougeoirs, dînettes en tous genres; cette simple énumération montre bien le dynamisme de cette famille au milieu du XVIe s.

Pour le XVIIe s., les découvertes n'ont pas l'ampleur de celles de la place des Terreaux, mais permettent de remarquer quelques nouveaux récipients, tasses, coupelles, pots de chambre, parallèlement à la production des jattes, assiettes et écuelles. 
Cette production continue à la charnière des XVIIe et XVIIIe s. Pour le XVIIIe s., les fouilles montrent un mobilier légèrement différent : des vases rencontrés jusqu'alors, il ne reste que les assiettes creuses, assorties de nouveautés : pot de chambre, assiette plate, pot de fleurs. Ces inédits arrivent pourtant en pleine période de déclin pour la famille El, déclin sans doute imputable à l'ascension des divers E8, qui envahissent le créneau de la vaisselle de table. A partir de ces constatations, on ne peut que formuler des hypothèses : ainsi, on peut penser que la famille E1 est restée fidèle à sa politique de diversification et a produit des nouveautés jusqu'au bout. Il est préférable d'imaginer qu'une partie de la céramique classée en divers E8 provienne des mêmes centres de potiers, qui ont ainsi assuré, en se renouvelant, une continuité dans leur production, suivant les désirs des consommateurs, lassés par deux siècles de vases à glaçure verte. D'autre part, lorsqu'on compare les catalogues des familles B1 et El, on s'aperçoit qu'ils sont complémentaires et que ces deux productions couvrent, aux XVIe et XVIIe s., l'ensemble des besoins en vaisselle de table ou culinaire.

\section{La rouge décorée, famille E2}

Nous abordons ici l'étude d'une de ces productions où la décoration prime sur l'aspect fonctionnel du récipient. La majeure partie des récipients de cette famille appartient aux formes ouvertes, où l'artisan peut s'exprimer sur de larges surfaces (fig. 156).

La grande surprise du mobilier de la place des Terreaux réside dans le fait que cette production est en pleine activité au milieu du XVIe s. ${ }^{5} \mathrm{~A}$ cette époque, la famille E2 ne compte que $3 \%$ du mobilier, mais progresse pour totaliser $12 \%$ du matériel au milieu du XVIIe s. De la fin de ce siècle jusqu'à la moitié du XVIIIe, elle oscille entre 6 et 8,5\%.

156 - Assiette au décor clair sur fond rouge (E2)

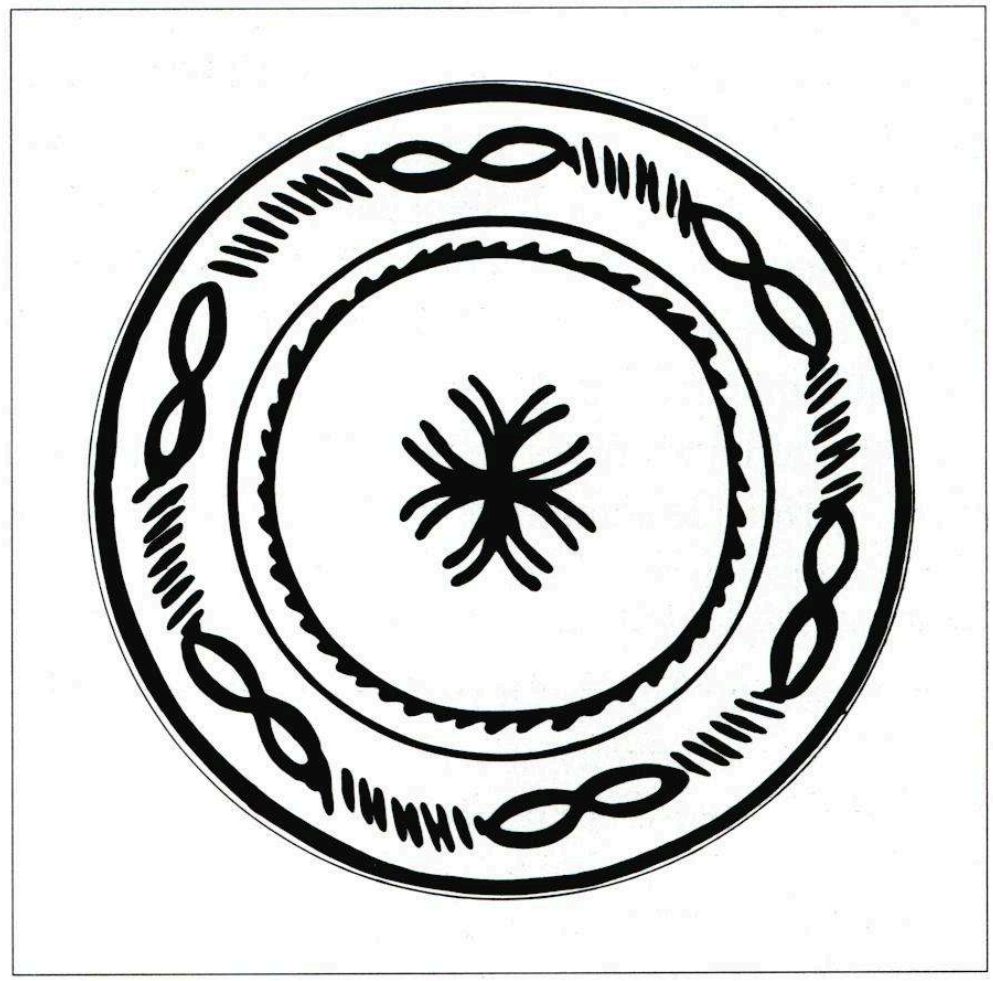


134 Au XVIe s., le mobilier comprend des assiettes creuses, des écuelles à oreilles, quelques assiettes plates (4121) et de rares chevrettes, copiées sur la faïence. Au siècle suivant, l'éventail des vases décorés s'accroît: cruches, tasses, assiettes plates et même un gobelet ou une énorme cruche de stockage. C'est à cette date qu'il faut également placer l'apparition de nouvelles jattes (3251), un bon repère chronologique pour cette famille : en effet, ce type de jatte, totalement absent pour le XVIe s., assure, du fait de sa présence, une datation du contexte archéologique au moins du XVIIe s. De la fin du XVIIe au XVIIIe s., on ne peut que rajouter un nouveau type d'assiette (3811) à cette énumération. Au XIXe s., cette famille poursuit sa carrière en assurant la décoration de très grosses cruches de stockage (Poteries tradionnelles du Val de Saône Mâconnais, 1984, Mâcon).

Les décors à eux seuls mériteraient un chapitre entier. Il n'est pas possible ici d'en donner le catalogue exhaustif ; on se bornera à des constatations générales.

Au XVIe s., l'ornementation est résolument concentrée sur la face interne; pour les assiettes et plats, une frise court sur le marli entre deux traits; ensuite, une deuxième frise occupe l'emplacement immédiatement au sommet de la paroi; puis vient, sur le fond, le motif central. Evidemment, ce schéma subit quelques modifications au gré des réalisations : certaines frises de marli ne sont pas encadrées, parfois, le sommet de la paroi est exempt de décor, mais dans l'ensemble, l'association des deux frises et du décor central reste la solution la plus employée. En ce qui concerne les écuelles, le procédé est relativement identique: une frise sur le haut de la paroi et un motif central, sur le fond. Pour l'ensemble des récipients, le choix des motifs de frise se cantonne dans une inspiration géométrique faite de traits et de rubans ondés; celui des motifs de fond offre une plus grande variété : géométrique, floral, animalier et même héraldique avec un plat aux armes du Dauphiné.

Du XVIIe s. au XVIIIe s., on remarque, sur la face interne des assiettes creuses, un motif central, simple et isolé : une croix ancrée à branches multiples, une svastika à branches multiples coudées à gauche, ou même une fleur à sept pétales. Souvent, à la jonction du marli et de la paroi, un ruban ondé sert de transition, quand ce n'est pas une frise de barettes. Sur le marli, on trouve une frise géométrique entre deux cercles: fuseaux couchés, intercalés de barettes, ou barettes surmontées d'un demi-cercle, ou ruban ondé tout simple. L'ornementation est dépouillée, inscrite sur la face interne du vase.

Les assiettes plates offrent au potier une surface plus uniforme, propice au développement d'un décor plus homogène, essentiellement d'inspiration géométrique, et toujours situé face interne. Au centre, on peut trouver une frise d'entrelacs de cercles, disposés en rond, ou une croix inscrite dans un losange. La jonction entre le marli et le fond sert de support à un ruban ondé en cercle. Sur le marli, le décor peut reprendre le premier thème, par exemple les entrelacs de cercles, ou l'évoquer par une série de cercles indépendants, disposés en rond, ou encore rediviser l'espace par un octogone ou même l'agrémenter d'une frise de barettes.

Les écuelles présentent des décors variés, des plus simples aux plus complexes. Les premiers peuvent prendre la forme d'un groupe ou d'un entrelacs de cercles ou d'une ligne double divisant l'espace en plusieurs parties, occupées par un décor de barettes. Les motifs complexes sont toujours d'inspiration florale, ils diffèrent sensiblement de ceux du XVIe s. par leur composition et par leur situation, aussi bien sur la face externe que sur la face interne du vase. Sur cette face, le décor se développe selon un ou plusieurs axes de symétrie : une fleur peut diviser l'espace en deux moitiés, chacune 
composée d'un bourgeon et d'une feuille. Sur la face externe, la décoration s'organise sur deux registres : celui du bas est généralement un ruban ondé, celui du haut, près du rebord, consiste en une frise encadrée de deux doubles traits. On trouve même parfois un décor sur le fond, face externe, de trois lignes parallèles se croisant à angle droit. Les oreilles sont également ornées de traits parallèles.

Les tasses suivent le même schéma que les écuelles : soit un décor simple face interne, composé de cercles ou d'entrelacs de cercles, soit un décor complexe, de style végétal à l'intérieur et géométrique à l'extérieur.

Les cruches offrent deux types d'ornementation, florales ou géométriques. Les motifs géométriques sont réservés aux cruches de transport ou de stockage appartenant à la famille beige décorée E6. Ils se concentrent en une large zone circulaire entourant le bec pincé : frises de barettes et rubans ondés, encadrés de deux traits, ou simples traits verticaux d'engobe blanc sur la panse. Les motifs floraux sont beaucoup plus élaborés ; ils se situent sous le bec verseur et se développent de part et d'autre d'un axe vertical. Il s'agit toujours de bourgeons avec feuilles, ou de fleurs avec bourgeons et feuilles. Ces motifs sont flanqués de part et d'autre de triples traits verticaux et fermés en haut et en bas par des traits horizontaux qui délimitent ainsi l'espace dans lequel se place le décor. La cruche de stockage type $\mathbf{1 0 7 1 1}$ ne se plie pas à cette règle : le décor floral se répète dans un espace libre d'encadrement; la forme du récipient permet effectivement de s'en affranchir.

Les jattes sont décorées uniquement face interne, sur le rebord, la paroi et le fond. Sur ce dernier, le motif est essentiellement floral : une combinaison de fleurs, de bourgeons et de feuilles. La paroi, de par sa forme circulaire, se prête aux motifs répétitifs, géométriques (doubles sinusoïdes croisées, fuseaux) ou floraux (rameaux, palmettes). Sur le rebord, le décor s'inscrit entre deux doubles traits; dans cet espace restreint, le motif reste simple, généralement une frise géométrique.

143 Lorsqu'on compare cette famille avec d'autres, telles que la jaune décorée E5 et les sgraffito E7, on s'aperçoit que l'utilisation de l'espace est différente: le décor est essentiellement linéaire et laisse de grandes parties vierges, ce qui donne une impression de grandeur; de plus, l'utilisation de barbotine claire sur fond sombre accentue un effet de relief, mis en valeur par la qualité excellente de la glaçure.

\section{La céramique jaspée, famille E3}

144 On trouve la famille E3 pour la première fois au milieu du XVIIe s., où elle totalise 2,5\% du mobilier. Dans le dernier quart de ce même siècle, elle montre des proportions équivalentes, pour la place Antonin Poncet. A la charnière des XVIIe et XVIIIe s., elle ne compte plus que $1,2 \%$ du total des fragments recueillis et au XVIIIe s., $2 \%$. Pour mémoire, rappelons que la fouille de Condrieu, milieu XVIIIe, n'en fournit aucun exemplaire, mais qu'au XIXe s., certaines pièces continuent la tradition du décor jaspé.

Le décor jaspé ou «baroque " se retrouve essentiellement sur les assiettes creuses ou plates, les écuelles, les tasses ou les cruches. Sur ces dernières et sur plusieurs assiettes, il s'agit surtout d'aspersion d'engobe blanc sur une couche rouge plus ou moins sèche : l'effet est parfois peu réussi. Par contre, certains potiers maitrisent admirablement bien cette technique décorative et ont produit des pièces remarquables, en utilisant au mieux la forme du vase : ainsi, une goutte d'engobe posée sur le marli descend le long de la paroi jusqu'au fond et se subdivise en plusieurs grosses gouttes blanches. Cette 
manipulation est reprise pour quelques assiettes plates ; parfois le marli est aspergé de taches d'engobe qui se réunissent sur le fond en un tourbillon. On trouve également des traînées bien nettes d'engobe qui partent du marli et se dirigent vers le fond, où elles sont finement mélangées à la plume (fig. 157). Sur les écuelles, le décor part du centre et s'enroule autour de la paroi en de multiples volutes. On remarque toutefois qu'à partir du milieu du XVIIe s., la qualité de la réalisation diminue : il n'est pas rare de trouver des récipients où la glaçure et l'engobe se délitent en larges plaques, phénomène que l'on ne constate pas aux époques précédentes.

157 - Assiette au décor jaspée (E3)

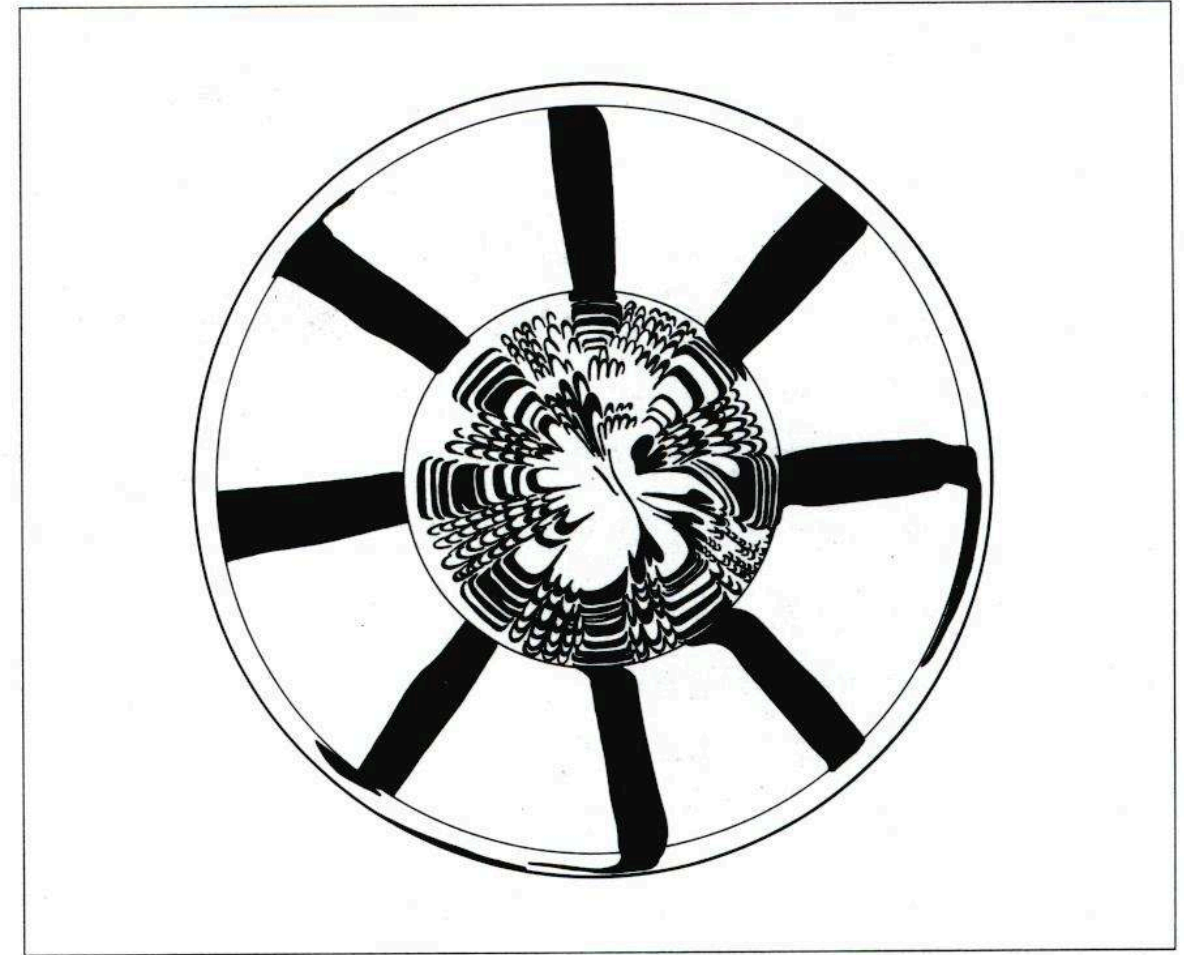

\section{Les céramiques glaçurées jaune sur engobe, famille E4 et jaune décorée, famille E5}

La famille E5 est présente dès le début du XVIe s. et perdure jusqu'au XVIIIe s. La famille E4 n'est formellement attestée qu'à partir du milieu du XVIe s., grâce à la fouille de la place des Terreaux, qui en restitue de rares exemplaires intacts.

Sans recollage des fragments, les deux familles sont parfois difficiles à distinguer l'une de l'autre; c'est pourquoi ils sont associés dans les calculs de fréquence. Pendant toute la première moitié du XVIe s., le taux de présence se situe entre 0,7 et $0,6 \%$. Au milieu de ce siècle, il monte à $10,7 \%$, mais les résultats tiennent compte de la fouille des Terreaux. Du XVIIe au XVIIIe s., ce taux se situe entre 2,7 et 9,5\%. A Condrieu, pour le milieu XVIIIe s., il n'est que de 1,7\%. Les taux de fréquence de cette production sont nettement inférieurs à ceux de la famille E2 et ce, pour toutes les époques; ces familles tiennent donc une place minoritaire dans le vaisselier moderne.

Un regard sur l'éventail des types permet de nuancer cette affirmation. 
Pour le XVIe s., en formes fermées, nous trouvons des cruches à bec pincé, ainsi que d'autres, à une seule anse en panier, dans l'axe d'un bec tubulaire. Il faut mentionner, en association avec les cruches, une variété de couvercles, plats, munis à une extrémité d'un important poucier et d'une paroi plate, percée d'un trou. Ce couvercle s'adapte à une anse verticale, de section ovale, qui possède une charnière dans sa partie supérieure. Malheureusement, le reste du récipient n'est pas connu; il doit sans doute s'agir d'une cruche à bec pincé, copiée sur des modèles en étain ${ }^{6}$ Un dernier vase répertorié s'apparente à un récipient de stockage (Rapport de fouilles, Arlaud 19911994). En formes ouvertes, le catalogue des types est quelque peu limité : assiettes creuses, écuelles à oreilles et une variété de petits récipients bas ouverts, ainsi que quelques réchauds.

On note également la présence de "dînettes", qui reprennent des profils propres à cette famille.

Le XVIIe s. n'apporte aucune nouveauté ; par contre, à la charnière de ce siècle et du suivant, apparaissent de nouveaux plats creux, cruches et pots de chambre. Au XVIIIe s. également, un certain nombre de nouveautés étoffent le catalogue et offrent de bons repères chronologiques, avec des plats $\mathbf{( 3 8 1 2 )}$, des cruches $(\mathbf{1 1 1}, \mathbf{1 1 1 2})$, des pots de chambre (1231), des assiettes creuses (3612), des écuelles (3511) et des assiettes plates (4111). Malgré son faible taux de présence, cette production donne l'impression d'un certain dynamisme dans l'élaboration des types.

Quant aux décors, qui constituent la caractéristique principale, un bref regard suffit pour comprendre qu'au XVIe s., les motifs ne sont guère élaborés. Le sentiment qui domine lorsqu'on les examine est une impression de flou qui vient du manque de soin dans la réalisation. La quantité de barbotine utilisée pour tracer les décors n'est pas égale : le fond d'engobe blanc qui recouvre la totalité du vase apparaît souvent et dilue le contour du motif, qui ne ressort pas avec netteté. La plupart du temps, il s'agit de traits qui forment des figures indéfinies, d'inspiration géométrique. Quelques sujets émergent quand même du lot: un visage sur une assiette avec les yeux, le nez et la bouche esquissés et un chapeau rudimentaire posé sur une face ronde ; une fleur de lys sur une écuelle; une sorte de pétale de fleur, stylisé, sur plusieurs écuelles : tous ces motifs reconnaissables sont agrémentés volontairement de taches d'engobe ou d'oxyde qui rendent la lecture difficile et parfois incompréhensible. Un seul récipient possède un décor soigné, mais son caractère incomplet empêche toute identification. Il faut mentionner aussi une assiette creuse, à laquelle manque toute la partie centrale et dont le marli présente un motif de traits agrémentés de rubans ondés, à la finition toujours imparfaite, mais d'une belle couleur bleu foncé, ce qui en fait un exemplaire unique.

Aux XVIIe et XVIIIe s., les observations sont identiques ; pourtant, certains exemplaires sortent du lot : des écuelles avec des taches marron entourées de points verts; d'autres, avec comme élément central une svastika à branches multiples, sont complétés soit par une frise sur le rebord, composée de traits courbes s'accrochant ensemble, soit par un espace carré défini par quatre lignes de barettes soulignées d'un trait. Sur certaines assiettes, un même motif - des points verts entourant une tâche brune - se trouve répété en cercles concentriques; sur une autre, un motif floral central, disposé en cercle, répond à une frise de palmes sur le marli. Enfin, il faut citer le seul exemplaire, malheureusement incomplet, de décor animalier: un paon faisant la roue, traité tout en finesse sur la surface entière du récipient (fig. 158). L'animal, en barbotine marron, a le corps découpé en petites cases agrémentées d'un point vert ; la roue, également de 
couleur marron est doublée d'une seconde, verte. Autour de l'animal, se trouvent des motifs appartenant à un agencement complexe qui nous échappe. Un fragment de cruche montre également un décor très élaboré : deux ovales allongés se croisent à angle droit par leur milieu, tout en étant inscrits dans un carré ; l'espace central est occupé par une croix (fig. 159). Tout autour, de multiples points verts renforcent le motif. L'ensemble est circonscrit dans un cadre de traits verticaux et horizontaux.

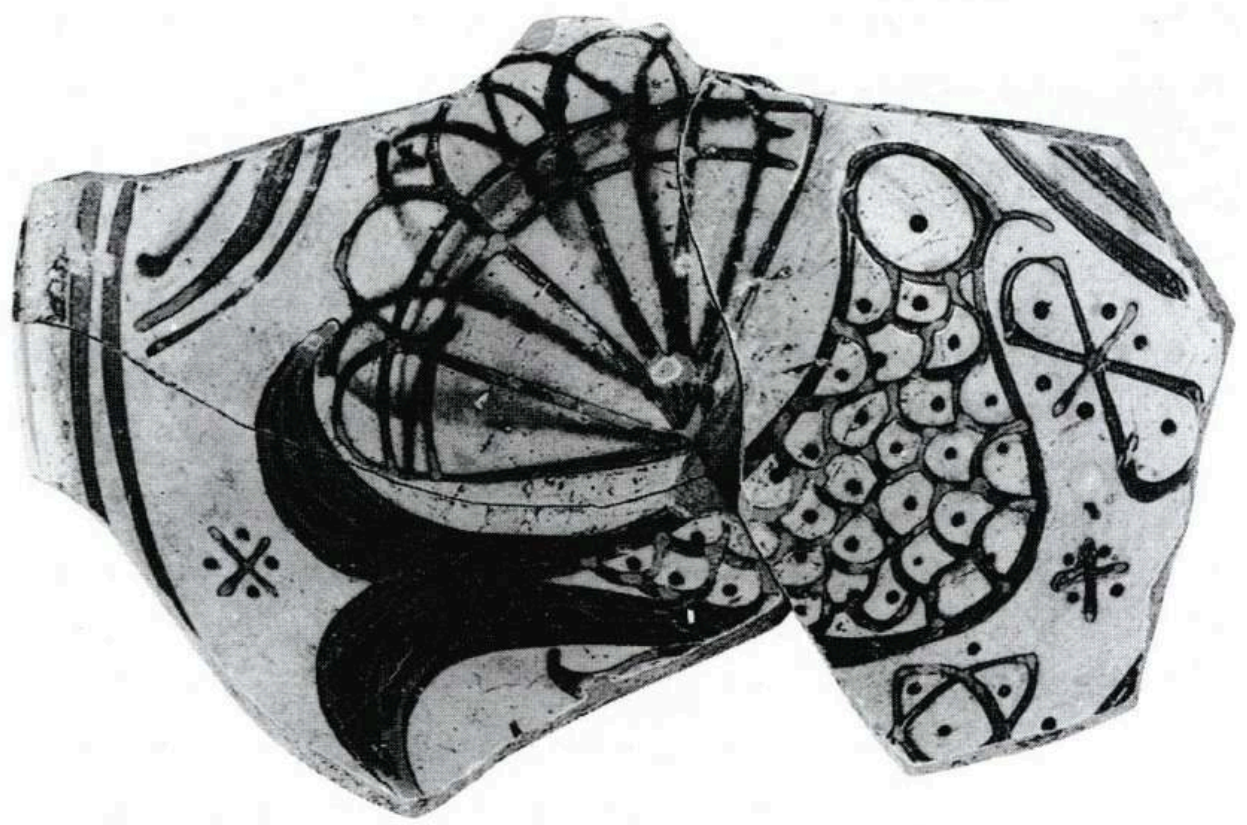




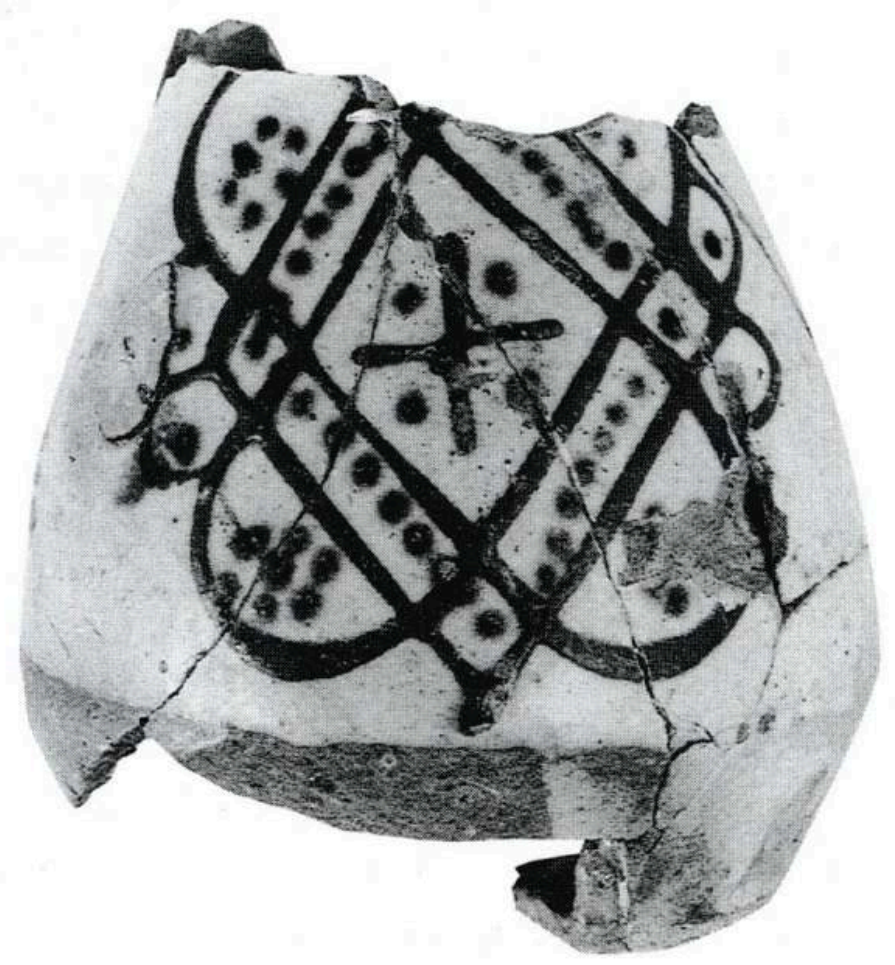

Peut-on distinguer les époques simplement au vu des décors? Il semble qu'aux XVIIe et XVIIIe s., les motifs soient traités avec une barbotine plus épaisse, ce qui donne un léger relief aux traits. On remarque aussi que les cercles marron, entourés de points verts, ne se rencontrent pas au XVIe s., mais sont l'apanage des époques postérieures.

En conclusion, la vision d'ensemble qui se dégage de la famille E5 reste ambivalente : elle n'est pas présente en grande quantité, mais l'éventail des types fait preuve d'un certain dynamisme; la qualité des décors demeure souvent médiocre, lorsqu'on la compare aux autres familles, mais certaines pièces tranchent sur le reste de la production par le soin apporté à leurs finitions, preuve que ces artisans possédaient un réel «savoir-faire». On a l'impression d'une production de série, avec, ici et là, des vases mieux finis, peut-être l'objet de commandes particulières.

\section{Les « sgraffito », famille E7}

Si la présence des familles E4 et E5 est jugée minoritaire, on peut alors dire que celle de la famille E7 est quasi confidentielle. Elle apparaît à l'extrême fin du XVe s. (dépotoir D1, place de la Bourse) et perdure jusqu'au XVIIIe s. (fosse 28, quartier Saint-Vincent). Malgré une présence de plus de trois siècles, elle ne totalise qu'entre 0,2 et $1 \%$ du mobilier suivant les époques. L'éventail des vases reste mal connu ; la faible quantité de fragments recueillis empêche souvent le recollage et l'identification. Les types concernent majoritairement les formes ouvertes: assiettes et plats creux (3311), écuelles à oreilles (3411), assortis de rares fragments de cruches (10351) pour le milieu du XVIe s., assiettes plates (4121) à partir de cette date. 


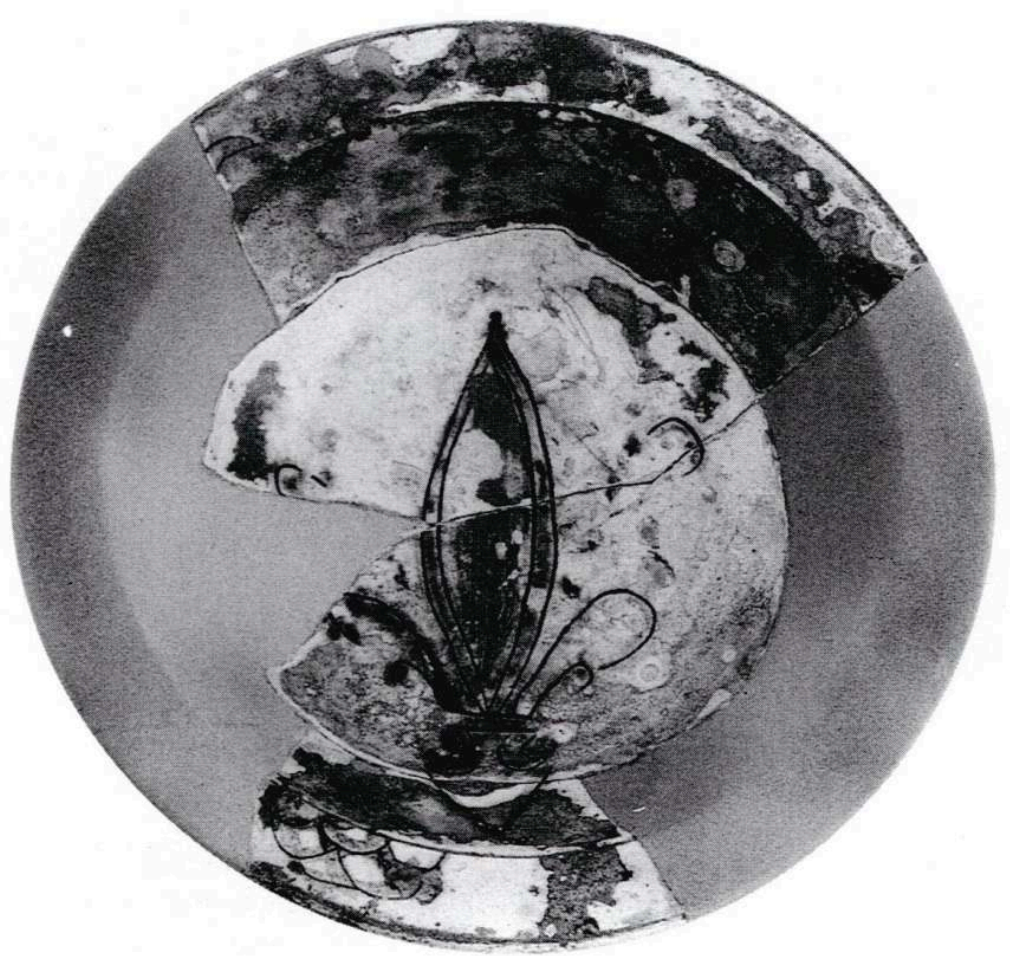

157 Ce principe décoratif est bien répandu dans le Midi de la France et dans d'autres pays $\mathrm{du}$ Sud depuis longtemps; son arrivée dans la région lyonnaise se fait donc tardivement. La faible représentation des types est largement compensée par l'ornementation qui impressionne par sa qualité et sa diversité, ce qui ne permet pas de dresser ici un répertoire des motifs. On peut toutefois en évoquer les aspects généraux : le décor peut être d'une grande sobriété, avec juste un motif central isolé, agrémenté d'une frise de conception simple; ou alors d'une étonnante complexité, avec, sur le fond, un motif principal entouré de nombreux registres circulaires aux décors variés et sur les parois et le marli - dans le cas d'assiette ou de plat-d'une série de frises superposées, aux décors géométriques ou floraux. Dans les deux cas, les artisans font preuve d'une grande maîtrise de l'espace. On peut citer des fleurs de lys (fig. 160), des rosaces, des croix pattées, des poissons, une esquisse de visage et, sur l'unique fragment de cruche, un noeud de Salomon. Les motifs présents sur les parois et les marlis sont plutôt d'inspiration géométrique ou florale.

A l'intérieur de cette production, on trouve également des réalisations de facture relativement grossière : lignes tremblées, motifs imprécis, couleur mal maîtrisées. Ce fait est plutôt constaté pour les XVIIe et XVIIIe s., sans que l'on sache s'il est dû à un déclin ou à un atelier différent.

\section{La beige décorée, famille E6}

La première apparition de cette famille a lieu au cours du XVIIe s., où elle totalise $3 \%$ $\mathrm{du}$ mobilier. Elle maintient un taux de présence assez bas aux époques suivantes : 2,6\% pour la place Antonin Poncet, dans le dernier quart du XVIIe, 5,4 \% à la charnière des XVIIe et XVIIIe s. et $4 \%$ au XVIIIe s. La caractéristique de cette production réside dans 
l'éventail, plus que réduit, du vaisselier: il s'agit de cruches de transport ou de stockage, à bec pincé opposé à une anse verticale (1114) ou à bec tubulaire perpendiculaire à deux anses verticales opposées (1131 et 1132). Dans le cas du premier type, le décor, réduit à sa plus simple expression, se situe autour de l'élément verseur, sur une couche d'engobe foncé : des traits verticaux de barbotine blanche sont appliqués en arcs de cercle, alternés de rubans ondés. Les cruches à bec tubulaire sont exemptes de motifs décoratifs; la glaçure, posée sur l'engobe lie-de-vin, forme une grosse tache qui englobe le rebord, le col et l'élément verseur.

Dans l'état actuel des connaissances, cette famille constitue déjà un bon repère chronologique.

\section{Les divers, famille E8}

161 Cette famille regroupe tous les «inclassables », c'est-à-dire toutes les céramiques qui n'appartiennent à aucune des autres familles étudiées et trouvées en faible quantité. Cette famille est appelée à disparaître au fur et à mesure qu'augmentent les connaissances dans ce domaine. A titre d'exemple, on peut citer l'étude faite sur le matériel de la place Antonin Poncet (Vicard 1989), où les familles E4 et E5 étaient assimilées aux divers. Malgré son caractère disparate, cette famille reflète une certaine réalité. Jusqu'au milieu du XVIe s., elle ne totalise qu'entre 0,02 et $1 \%$ du mobilier ; ce chiffre peut monter jusqu'à $13 \%$ pour le matériel issu de la fouille de la place des Terreaux et retomber à $2,5 \%$ pour le XVIIe s. En fait, du XVIe au XVIIe s., peu de productions restent inconnues, ce qui explique les faibles pourcentages. A ce titre, il faut revenir sur le mobilier des Terreaux, qui montre un taux élevé de famille E8 :

- un premier lot concerne une production à pâte rose-beige et à glaçure noire sans engobe. Il s'agit, semble-t-il, de grosses cruches de stockage, à deux anses verticales opposées, perpendiculaires à un bec tubulaire, et peut-être d'un autre type, une sorte de grande jarre. Aucun exemplaire n'est remonté, ni même complet.

- le deuxième lot regroupe des céramiques à engobe rouge foncé ou lie-de-vin, avec un décor à la barbotine blanche rehaussé d'oxyde de cuivre. Après le glaçurage de la pièce, le fond ressort brun vert sombre et les décors, vert plus clair ; un type est identifié : une cruche 1112.

- le plus curieux reste quand même un lot de céramiques engobées, mais non glaçurées, appartenant sans doute à la famille verte sur engobe E1, du fait de l'absence de décor à la barbotine. Ces vases ont été volontairement cuits sans glaçure, et, sans doute, vendus tels quels.

On peut également placer, en divers E8, plusieurs vases hors du commun :

- un vase décoratif qui ressemble à une œnochoé grecque, moulé et non tourné ; la technique décorative sort de l'ordinaire : il s'agit d'épaisses couches d'engobes, de couleurs diverses : brun, rouge, jaune, marron, intercalées et mélangées. Le résultat donne un décor marbré, constitué de multiples stries colorées, très fines. Une glaçure transparente recouvre l'ensemble. Une vue en coupe montre d'ailleurs qu'à certains endroits du vase, l'engobe remplace totalement l'argile, avec pour conséquence, un affaissement de la lèvre et du col.

- une série de fragments d'assiettes creuses, dont la techique décorative se fait par retrait de l'argile. La binoculaire permet nettement de discerner de minuscules rigoles, laissées par l'outil de l'artisan. Le motif ressort alors en relief: il s'agit d'un thème floral, avec de multiples rinceaux, dans un agencement complexe, qui couvre toute la surface interne du 
vase ; il est recouvert très soigneusement de barbotine blanche, puis l'ensemble du vase est glaçuré : dans les cavités, la glaçure devient orange au contact de l'argile et reste blanche sur le décor.

- technique identique pour une autre assiette creuse, avec, sur le marli, un décor géométrique et sur le fond et la paroi, des feuilles parfaitement ciselées. La glaçure, d'une qualité et d'une finition extraordinaires, offre une palette de couleurs étonnante : bleu, vert, jaune, marron, noir, rose; son application, parfaitement maîtrisée, permet par exemple, de colorier l'intérieur d'un quadrillage en marron et l'extérieur, d'un mélange de jaune, de vert et de rose.

163 A la charnière des XVIIe et XVIIIe s., les divers E8 atteignent 27,3\% du mobilier et au XVIIIe s., $21 \%$. Ces chiffres peuvent paraitre impressionnants pour ces époques bien connues, mais s'expliquent par l'émergence de toute une gamme de produits qui vont connaître une énorme diffusion au cours du XIXe s. Le XVIIIe s. apparaît de plus en plus comme une époque de transition: pour bien comprendre la famille E8, il faudrait étudier le matériel du XIXe s., un travail qui n'est pas envisagé actuellement.

\section{La faïence, famille $F$}

Cette famille apparaît à la fin du XVe s., mais ne totalise que 0,5\% du mobilier. Il s'agit de céramique d'importation en provenance d'Italie ou d'Espagne, essentiellement des écuelles ou des assiettes creuses. Au début du XVIe s., date où les premiers faïenciers italiens installés à Lyon commencent leurs productions, le taux de présence reste faible, de l'ordre de $0,1 \%$ et ne varie guère jusqu'au milieu de ce siècle, où il totalise $4 \%$ place des Terreaux. Pourtant, le catalogue des vases s'élargit considérablement, puisque la caractéristique, voire le monopole de la faïence, reste le pot pharmaceutique.

$\mathrm{Au}$ XVIIe s., la faïence est quasi-absente du mobilier archéologique. Du XVIIe au XVIIIe s., elle ne compte qu'entre 1 et $5,8 \%$ du mobilier céramique. Tout au plus trouvonsnous quelques pièces, tasse ou cuvette, importées de Nevers. Pour expliquer ce phénomène, nous ne pouvons que mettre en avant la terrible peste de 1628, responsable de l'éclipsé des faïenciers lyonnais. Pendant ce temps les centres de productions concurrents ne sont pas restés inactifs, et, au début du XVIIIe s., lorsque l'activité renaît à Lyon, les artisans ont dû surmonter ce handicap, en s'orientant vers un genre plus luxueux (fig. 161), mais aussi vers des produits plus communs, telles ces assiettes blanches à filets bleu, si fréquents à cette époque. La fouille récente d'un atelier de faïenciers du XVIIIe s. à Lyon, rue Gilbert Dru, permet de compléter nos connaissances de cette famille, qui, à cette époque, délaisse complètement le marché des pots pharmaceutiques : ce phénomène était déjà perceptible dès le XVIIe s. (Ayala 1992). 
161 - Déroulé de décor bleu et doré sur une cruche en faïence blanche

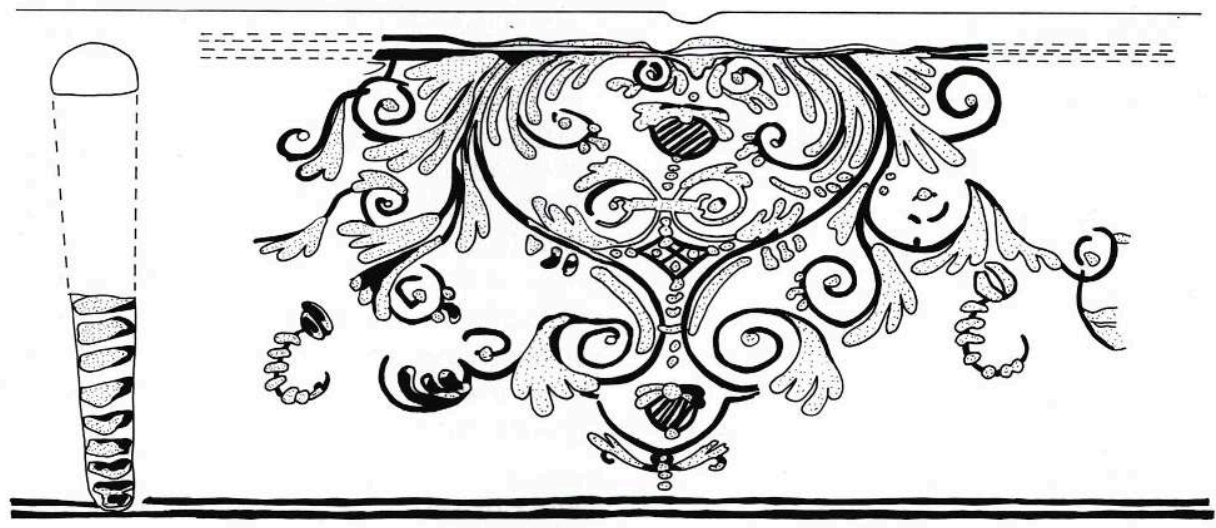

L'histoire de la faïence lyonnaise souffre, paradoxalement, du trop grand intérêt que les historiens d'art lui accordent ; dans la grande majorité des cas, ceux-ci ne se basent que sur les décors; or, la faïence ne peut être comprise qu'en prenant en compte l'origine des productions et, à ce niveau, seule l'analyse des pâtes en laboratoire peut faire avancer notre compréhension ${ }^{7}$.

\section{Le grès, famille GR}

Cette catégorie ne recouvre que très peu de matériel. Pour toute la période médiévale et moderne, seuls cinq fragments, datés du milieu XVIe s., en provenance sans doute d'Europe du Nord, ont été mis au jour lors de la fouille des Terreaux. Ces quelques vestiges ne permettent aucune interprétation, sinon l'extrême rareté du produit, à des époques où il est fréquent d'en trouver dans d'autres régions. Il faut attendre le XIXe s. pour voir d'autres grès apparaître à Lyon, du moins d'après les découvertes archéologiques.

Il faut citer également, pour le milieu du XVIe s., quatre fragments de grès vert céladon, sans doute en provenance de chine.

\section{La porcelaine, famille $P$}

Cette famille est assez fréquente dans les contextes archéologiques du XIXe s. Pour les époques antérieures, il faut se reporter aux onze fragments blancs à décors bleus de porcelaines orientales ou extrême-orientales, peut-être chinoises, période Ming, trouvés place des Terreaux.

\section{Synthèse chronologique}

La synthèse par époque reste délicate à écrire pour ne pas apparaître comme une répétition, agencée de manière différente, des études précédentes. Afin d'éviter un texte fastidieux et redondant, l'aspect visuel est privilégié, au moyen de divers tableaux 
et diagrammes, qui, en s'appuyant sur les données existantes, mettent en relief les points importants aussi bien au niveau technologique que typologique.

\section{De la fin du XIle s. à la fin du XIIle siècle}

171 Sur l'ensemble de cette période, on dispose de 7437 fragments, lesquels fournissent 67 récipients pour la fin du XIIe s. et 286 pour le XIIIe s. L'ensemble se divise en 31 types différents (tableau 6).

Tableau 6. Total des types aux XIIe-XIIle siècle

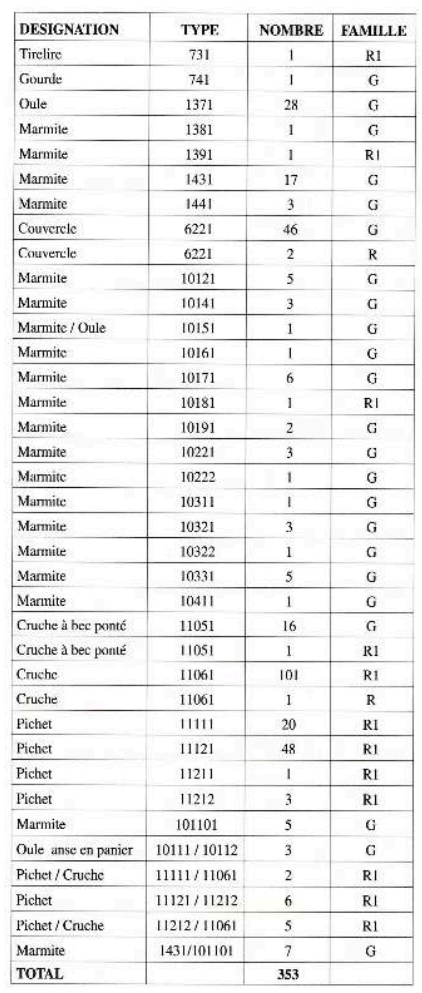

172 Entre le IXe s. et le début du XIIe s., les productions de céramiques montrent une remarquable homogénéité dans la région Rhône-Alpes, tant au niveau de la cuisson en mode réducteur (famille $\mathrm{G}$ ), qu'au niveau des vases: oules et cruches à bec ponté constituent l'ossature d'un répertoire extrêmement réduit et servent essentiellement pour la cuisine, comme le démontrent les panses noircies de suie.

173 Qu'en est-il à la fin du XIIe s. ? $96 \%$ du mobilier est produit en commune grise G et $2,8 \%$ en commune rouge glaçurée R1 ; mais au début du XIIIe s., cette dernière atteint les $34 \%$, tandis que la famille $G$ passe à $66 \%$ : cette nouvelle répartition ne changera guère tout au long de ce siècle.

174 Un éclairage différent sur le mobilier de ces époques permet de mieux comprendre l'évolution du vaisselier. A la fin du XIIe s., $76 \%$ des récipients sont consacrés à la cuisson, $11 \%$ au transport, $10 \%$ au service des boissons et $3 \%$ à la préparation des aliments. Ces $10 \%$,-les quelques fragments de pichets à boire-reflètent un grand bouleversement: ils prouvent, en effet, l'émergence d'une production oxydante glaçurée, décorée de surcroît, ainsi que la séparation entre vaisselle de table et de cuisine, phénomène confirmé par le XIIIe s., où les récipients associés à la cuisson ne 
totalisent que $42 \%$ de l'ensemble, alors que ceux utilisés pour le service des boissons atteignent $54 \%$.

Toutes ces transformations sont évidemment perceptibles au niveau des types de céramiques. Ainsi, à la fin du XIIe s., le paysage semble inchangé par rapport aux époques précédentes : les mêmes vases, en commune grise $G$, utilisés pour la cuisine, tiennent toujours une place de choix; on note également des récipients de transport, sous forme d'oules à anses en panier et de rares fragments de jattes; par contre, on trouve maintenant quelques fragments de pichets, en famille R1. Au début du XIIIe s., les oules, encore très présentes, cèdent petit à petit le pas aux marmites et les cruches à bec ponté aux pichets, eux-mêmes bientôt supplantés par les cruches à bec pincé. La technique de glaçurage par saupoudrage est de mieux en mieux maitrisée, comme le montrent certaines pièces, que Ton peut qualifier de luxueuses, recouvertes d'un vernis épais et brillant. Dans la première moitié du XIIIe s., le clivage est définitivement consommé : les marmites sont maintenant majoritaires avec une gamme étendue de types et les cruches à bec pincé se sont définitivement imposées, en tant que production de grande série, face aux pichets (fig. 162). A partir de la deuxième moitié du XIIIe s., ce schéma demeure relativement stable. Il faut pourtant noter l'apparition de marmites en commune rouge glaçurée R1, un timide essai de changement qui ne prendra une véritable expansion qu'à partir du XVIe s.

162 - Ensemble de céramiques du XIIle s. (région Lyonnaise)

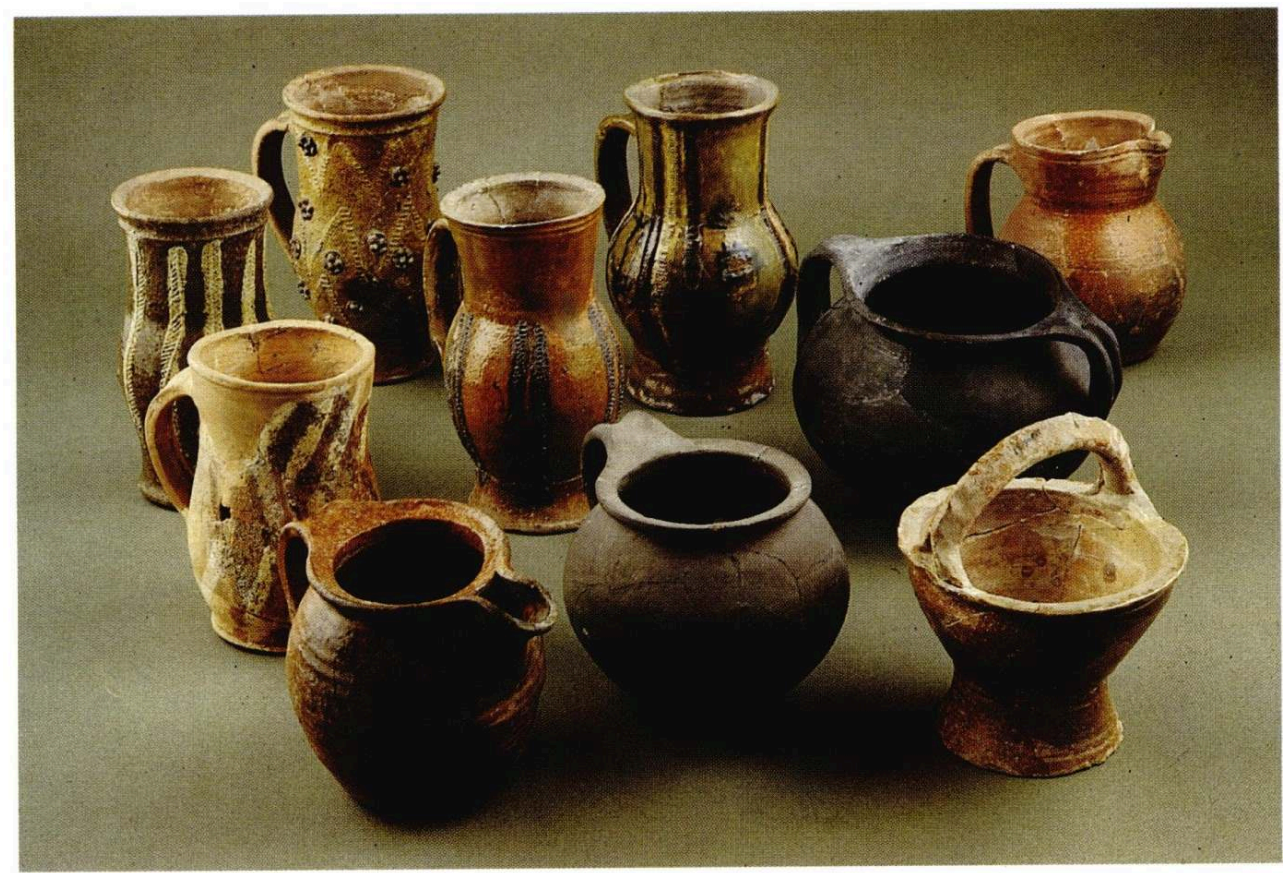

176 Ces nouveautés sont l'expression d'un changement de mentalité, d'une évolution des goûts, et l'on peut avancer, sans trop de risque, l'hypothèse d'une influence extérieure à la région, sur laquelle on ne possède, pour l'instant, aucun renseignement. On sait pourtant qu'à quelques décennies près, ce phénomène est général à l'Europe du NordOuest ; il semble apparaître même assez tôt dans notre région. 


\section{Le XVe siècle}

177 Le manque d'informations sur le XIVe s. concerne également une grande partie du XVe s. De rares données archéologiques nous sont accessibles pour la fin de ce siècle, grâce à la mise au jour de trois structures, issues de sites lyonnais. Cette époque apparaît donc comme une période de transition, encore imprégnée de tradition médiévale comme le démontrent les nombreuses marmites en famille $G$ et les cruches à bec pincé en famille R1, tout en annonçant les bouleversements du XVIe s. avec la présence de nouvelles familles, tels que le service vert B1, les faïences d'importation et, semble-t-il, les sgraffitos E7. Ces nouvelles productions vont de pair avec une légère amorce de renouveau pour les types de céramiques, principalement en formes ouvertes : assiettes, jattes, écuelles.

\section{Le XVle siècle}

178 Pour l'ensemble de ce siècle, on dispose de 9598 fragments, lesquels fournissent 740 vases répertoriés. L'étude de cet ensemble donne l'image d'un XVIe s. en pleine mutation, propice aux changements des goûts et des mentalités (tableau 7) (fig. 163).

$179 \mathrm{Au}$ début du siècle, la présence de nouvelles productions renvoie à certaines innovations techniques: la disparition progressive de la glaçure par saupoudrage, remplacée par une fritte liquide dans laquelle on plonge le récipient, est peut-être en relation avec une baisse du prix des produits de base, mais surtout avec l'apparition de la technique d'engobage; ce revêtement crée une zone neutre et permet la pose de glaçures de bonne qualité et de couleurs diverses. C'est ainsi qu'apparaisent, au début du siècle, la verte sur engobe $\mathrm{E} 1$, la jaune décorée $\mathrm{E} 5$ et, issue d'une technique différente, la faïence lyonnaise, grâce à l'arrivée de potiers italiens. Au milieu de ce même siècle, la présence de la rouge décorée E2 est attestée, ainsi que celle de la jaune sur engobe $\mathrm{E} 4$. 
163 - Ensemble de céramiques du XVle s. (région Lyonnaise)

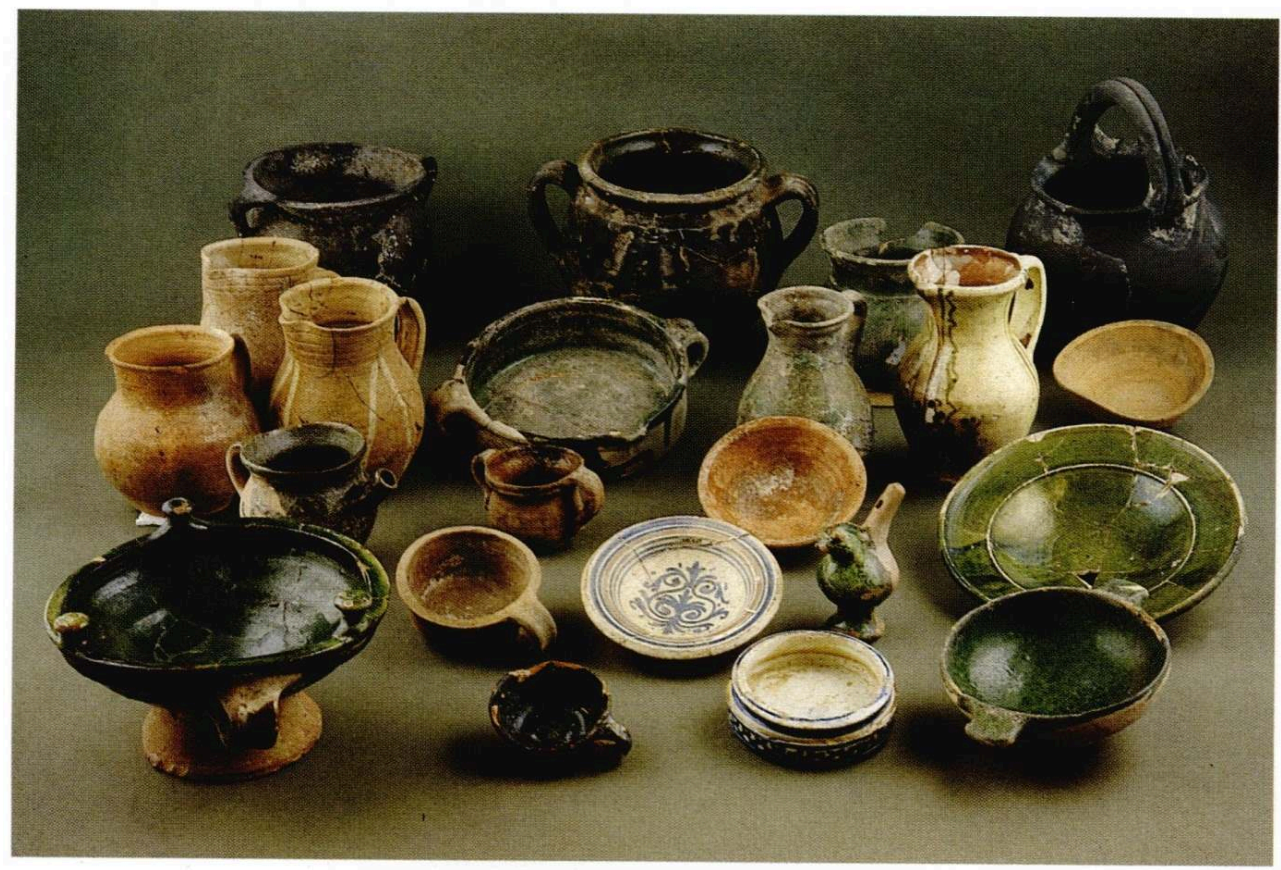

Tableau 7. Total des types au XVIe siècle
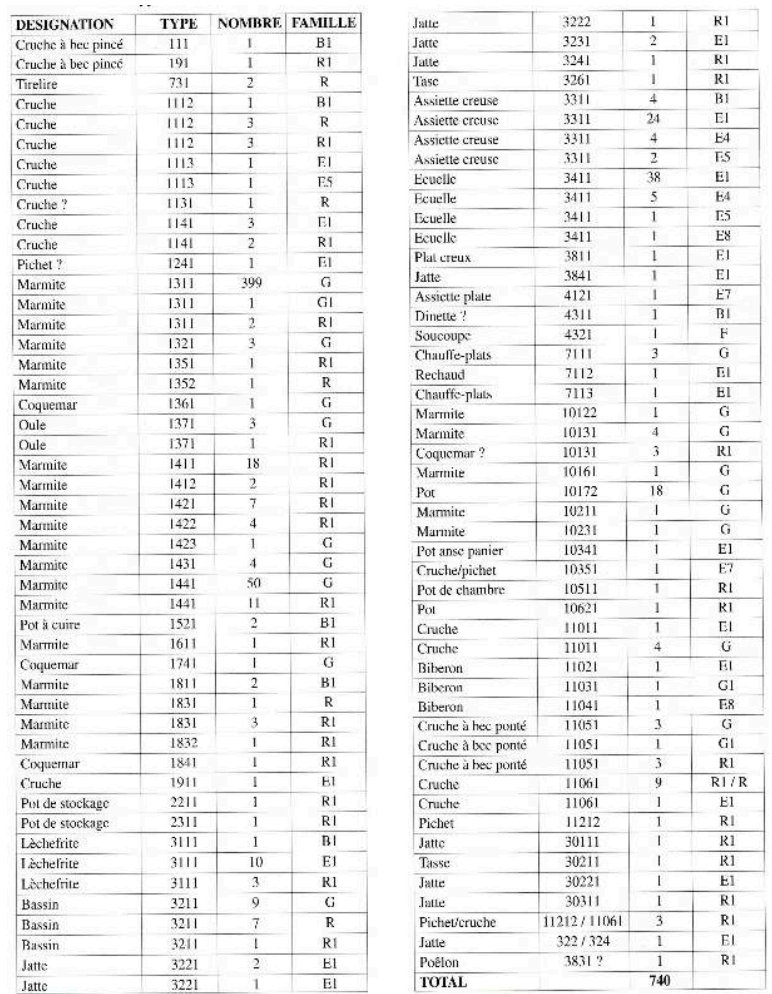

180 Quelle est la place prise par chaque famille, pour une période comprise entre le début et le milieu du XVIe s. ? La commune grise G garde la première place avec $73 \%$ du mobilier, suivie par la commune rouge glaçurée R1 avec $14 \%$; viennent ensuite la commune rouge $\mathrm{R}$ avec $5 \%$, la verte sur engobe $\mathrm{E} 1$ et le service vert B1 avec $3 \%$ et la commune grise glaçurée avec $1,5 \%$; la faïence $\mathrm{F}$ et les productions décorées forment un 
dernier groupe qui ne dépasse pas la barre des $1 \%$. L'arrivée de nouvelles productions compromet fortement l'équilibre instauré au Moyen Âge entre la commune rouge glaçurée R1 et la commune grise $\mathrm{G}$, mais cette dernière garde sa situation de monopole, puisque l'ensemble des autres familles ne totalise que $27 \%$ du mobilier !

Cette répartition est à comparer avec celle élaborée pour les Terreaux, à partir d'un matériel daté du milieu du XVIe s. : la commune grise $G$ est encore majoritaire $(28,5 \%)$, suivie de la verte sur engobe El $(17,5 \%)$ et du service vert B1 (16,5\%); la commune rouge glaçurée vient donc en quatrième position avec $14,5 \%$ du mobilier; on trouve ensuite la jaune décorée E5 (11 \%) et la faïence F (4\%); et enfin, le reste des productions décorées.

Les chiffres montrent la montée des nouvelles familles, telles que le service vert B1 et celui sur engobe E1, au détriment de la commune rouge glaçurée R1, mais aussi de la commune grise, qui commence peut-être ici son lent déclin. Il faut noter également la place importante de la jaune décorée $\mathrm{E} 5$, sans que l'on puisse dire s'il s'agit d'une caractéristique du remplissage du fossé des Terreaux ou de la pleine période de diffusion de cette famille.

183 La présence de nouvelles familles va de pair avec un changement des types de céramiques. On peut noter, pour le début du XVIe s., la persistance ou le renouveau des cruches à bec ponté en $\mathrm{G}$ ou R1; l'apparition des marmites à anses coudées en $\mathrm{G}$ (1311) et des marmites à deux anses en G ou R1 (de formes 141 et 142); l'apparition des lèchefrites en El et R1 (3111), des jattes en El et R1, des écuelles et des assiettes en El (3411 et 3311), des cruches (1112) avec toutefois une persistance de types anciens (11061 ou pichets 11212). On trouve aussi les premiers poêlons en R1 et quelques coquemars. Dans la première moitié du XVIe s., on note une diversification des cruches à bec pincé ainsi que la disparition des types anciens et des pichets 11212 ; la présence de cruches à bec tubulaire est également constatée, tout en gardant en mémoire, pour le Moyen Âge, les fragments de système verseur identiques, trouvés en cours de fouille sans pour autant définir de forme complète. La deuxième moitié du XVIe s. est aussi une époque de grande expansion pour les marmites en $G(\mathbf{1 3 1 1})$ et en R1 $(\mathbf{1 4 1}, \mathbf{1 4 2})$; parallèlement, on remarque la présence de marmites en service vert $B 1$, d'un pot de stockage en R1, de lèchefrite en El, B1 et R1. Les jattes se diversifient en de nombreux types; les assiettes creuses et les écuelles sont maintenant produites en de multiples familles; la présence d'accessoires de service tels que les chauffe-plats est un fait acquis, de même que celle des pots de chambre, des coquemars, des tasses (30211) et surtout, des premières assiettes plates en famille E2.

Les répartitions élaborées à partir des usages de chaque récipient permettent également de mieux saisir l'importance du XVIe s. dans l'histoire de la céramique : $76 \%$ du vaisselier est consacré à la cuisine, $8 \%$ au service des boissons, $4 \%$ pour la préparation des aliments sous forme de jattes et de bassins ; $0,5 \%$ pour la conservation et le transport. Ces chiffres sont assez proches de ceux établis pour la fin du XIIe s.; mais, à la différence du Moyen-Âge, ils ne comptabilisent ici qu'une partie du mobilier : le XVIe s. voit l'émergence de nouveaux usages ; ainsi, $10 \%$ du matériel est consacré au service et à la consommation des aliments (assiettes, plats, écuelles), 0,6\% à la consommation des boissons (tasses), 0,6 \% aux accessoires de service (chauffe-plats) et $0,1 \%$ à l'hygiène, sous forme de pots de chambre. 


\section{Le XVIle siècle}

Pour l'ensemble de ce siècle, nous disposons de 11541 fragments, lesquels fournissent 1250 vases répertoriés (tableau 8).

Tableau 8. Total des types après collage au XVIle siècle

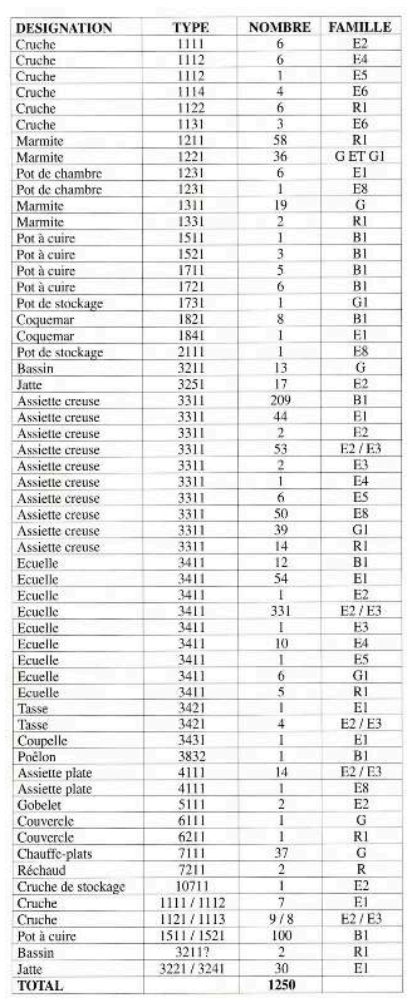

Par rapport au siècle précédent, la répartition par familles souligne un certain nombre de changements. Pour la première fois, la commune grise $G$ n'est plus en situation de monopole $(17 \%)$ et cède la place au service vert B1 (35\%); le XVIIe s. semble être une période faste pour la rouge décorée E2 (12\%), qui dépasse même la verte sur engobe $\mathrm{El}$, stabilisée à $11 \%$. La commune rouge glaçurée n'est cependant guère mieux lotie, mais dans l'ensemble, ces quatre dernières familles fournissent, après le service vert $B 1$, l'essentiel du mobilier du XVIIe s. Les autres productions décorées, la faïence, la commune grise glaçurée ne dépassent pas la barre des $3 \%$ et restent quasi confidentielles. On note le déclin évident de la jaune décorée E5 et de la faïence, la présence des divers E8 et l'apparition de nouvelles familles, la beige décorée E6 et la jaspée E3, qui totalisent respectivement 3 et $2,5 \%$ : le catalogue de la première ne compte que quelques types de cruches, tandis que la seconde s'oriente plutôt vers les formes ouvertes.

Au niveau des types, on retiendra la présence, en famille rouge décorée E2, de jattes de type 3251, qui sont un bon repère chronologique. Le début du siècle voit la disparition des marmites à anses coudées (1311) en $G$, ainsi que celles appartenant aux formes 141 et 142 en $\mathrm{G}$ ou R1. En règle générale, les marmites à panses globulaires cèdent la place aux pots à cuire pourvus de panses plus rectilignes. 
164 - Ensemble de céramiques du XVIle s. (région Lyonnaise)

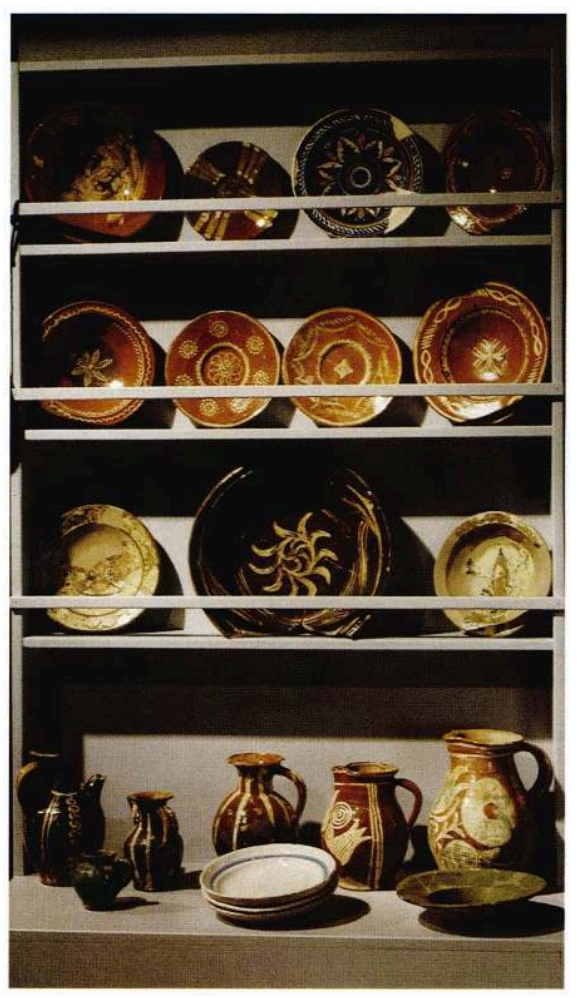

La répartition par usage montre que sur l'ensemble des vases, $67,5 \%$ concerne le service et la consommation; $19 \%$ la cuisson ; $5 \%$ la préparation ; $4 \%$ le service des boissons ; 3 \% les accessoires de service ; 0,5 \% la consommation des boissons ; 0,5 \% la conservation et le transport et $0,5 \%$ l'hygiène. Une comparaison avec l'époque antérieure fait ressortir la surprenante inversion des proportions en ce qui concerne la cuisson et le service/consommation des aliments : la première passe de $76 \%$ à $19 \%$ et la seconde monte de $10 \%$ à $67,5 \%$. Comment peut-on expliquer ces phénomènes? Le XVIIe s. est une période où les arts culinaires retiennent l'attention; il est donc hors de question de voir, dans la baisse d'utilisation de récipients destinés à la cuisson, une désaffectation de la cuisine. Au contraire, il s'agit peut-être des conséquences d'un besoin de produits identiques, mais en d'autres matériaux, tels que le fer ou le cuivre, comme par exemple la poêle, inconnue en céramique. L'augmentation des récipients destinés au service et à la consommation des aliments prend sa source sans doute dans un changement de mentalité ; à cette époque, la séparation entre la cuisine et la salle à manger est effective et le besoin d'agrémenter cette dernière se fait sentir, d'où un éventail accru de nouvelles formes, souvent décorées, disponibles pour satisfaire la demande des utilisateurs (fig. 164). En fin de compte les deux phénomènes sont liés : pour l'artisan, la baisse d'intérêt des récipients de cuisson signifie baisse des ventes donc des bénéfices, ce manque à gagner doit donc être compensé par des achats d'autres produits, d'ou la grande variété de production d'assiettes et d'écuelles constatée pour cette époque. Cela dit, on ne connaît pas la place prise par d'autres matériaux : le bois ne doit pas inquiéter les artisans potiers; la difficulté du travail limite les formes aux assiettes et autres récipients plats ; l'industrie du verre reste axée sur les récipients servant au transport, au service et à la consommation des boissons et n'entre pas en concurrence avec la céramique ; quant au métal, le manque de référence 
ne permet pas de le prendre en considération : c'est pourtant le seul matériau qui peut empiéter sur le domaine des productions céramiques.

\section{Période charnière : deuxième moitié du XVIIe, début du XVIIle siècle}

Pour cette période, nous disposons de 1803 fragments, lesquels fournissent 131 vases répertoriés (tableau 9). Il faut se souvenir que cette période est difficile à appréhender, par manque de critères de datation absolue; on s'aidera donc de l'étude de deux remplissages de fosse, mis au jour lors de la fouille de la place Antonin Poncet, à Lyon, et datés du dernier quart du XVIIe s. : ce lot fournit 333 vases pour 4331 fragments.

Tableau 9. Total des types après collage pour la période charnière XVIIe-XVIIIe siècle

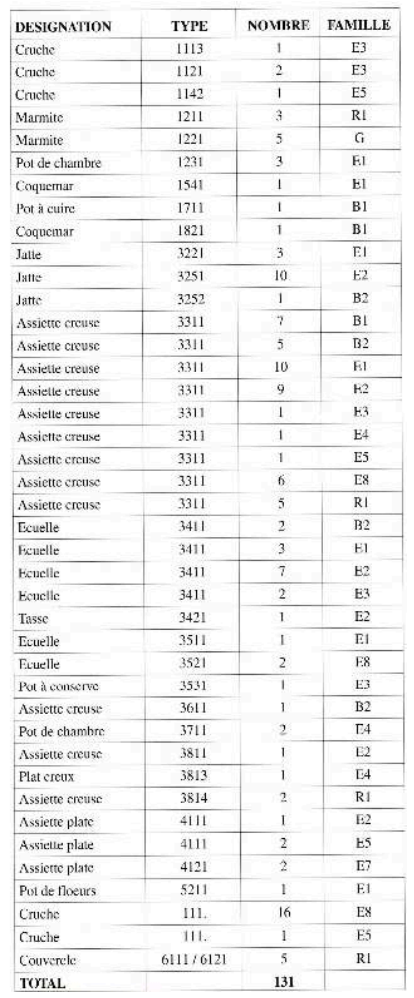

190 La répartition des familles concernant le matériel d'Antonin Poncet offre certaines analogies avec l'époque précédente : prédominance du service vert B1 (26\%), suivi de près par la commune grise $G(22 \%)$; puis vient la verte sur engobe $(14,5 \%)$, la rouge décorée $(6 \%)$ et enfin les autres productions. Deux faits marquants sont à retenir ici : d'une part, la présence, en troisième position, des divers E8 avec $14,5 \%$ et d'autre part celle du service jaune B2, dont c'est la première manifestation, avec $3,5 \%$. Les calculs effectués dans le cadre de cette étude permettent de nuancer cette image: la place prise par les divers E8 est beaucoup plus marquée avec $27,3 \%$ du mobilier, de même que celle du service jaune B2 (6\%), et de son homologue, le service vert B1 (5\%). La verte sur engobe $\mathrm{El}(7 \%)$, la rouge décorée $\mathrm{E} 2$ (9\%) et la commune grise $\mathrm{G}(10 \%)$ restent toujours d'actualité, même si, individuellement, elles montrent une baisse sensible. La place importante de la commune rouge glaçurée, avec 16,5\% du mobilier, n'est pas significative: ce chiffre est faussé par la présence de multiples fragments de canalisations. 
191 En ce qui concerne le domaine des types de céramiques, l'époque est plutôt pauvre en innovations; il s'agit plutôt de variantes de types déjà existants : assiettes creuses (3611 et 3814) ou plates (4121), pots de chambre (3711), écuelles $(3511,3521)$, plats creux (3811 et 3813), pot à conserves (3531).

192 Le classement par usage montre que $50 \%$ du mobilier concerne le service et la consommation des aliments ; $19,5 \%$, le service des boissons ; $12,6 \%$, la préparation des aliments ; $12,6 \%$, la cuisson ; $4 \%$, l'hygiène ; $0,7 \%$, la conservation et le transport et $0,7 \%$ classé en rubrique divers, qui renvoie en fait à des pots de fleurs. Ces chiffres sont légèrement différents de l'époque précédente: on retrouve la prépondérance des céramiques destinées au service et à la consommation des aliments, mais le service des boissons prend le pas sur la cuisson, laquelle fait jeu égal avec la préparation des aliments.

\section{Le XVIIIe siècle}

193 Les quelques 1122 fragments à notre disposition qui fournissent 133 vases répertoriés, ne peuvent que donner une image incomplète de cette époque (tableau 10).

Tableau 10. Total des types après collage au XVIIle siècle

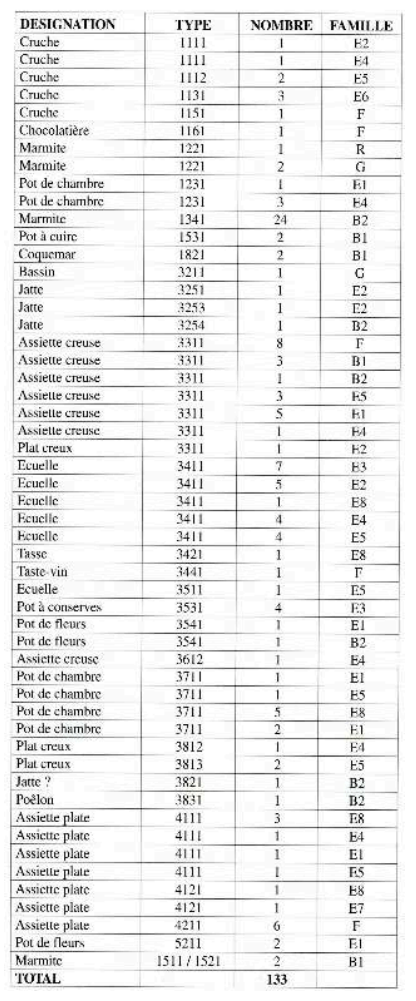

194 Le calcul de répartition des familles souligne la prédominance du service jaune B2 $(25 \%)$ et des divers E8 $(21 \%)$, suivis de près par le service vert B1 (17\%). Toutes les autres productions sont comprises dans les $37 \%$ restants : entre $0,2 \%$ pour la commune grise glacurée et $7 \%$ pour la décorée aux engobes E2, on remarque la disparition de la commune rouge glaçurée R1 et la place minime occupée par la commune grise $\mathrm{G}$ $(3,5 \%)$. 
$\mathrm{Au}$ niveau des types, quelques variantes de cruches (1131, 1151), de pots (1531), de

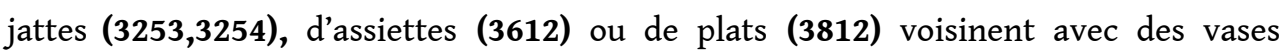
entièrement nouveaux, tels que la chocolatière 1161 ou le taste-vin $\mathbf{3 4 4 1}$; mais la fouille réçente, rue Gilbert Dru, de l'atelier du faïencier Joseph Combe, qui œuvra de 1732 à 1737, fournit un catalogue de formes inconnues jusqu'alors: force est de constater qu'on manque de matière première pour avoir une idée précise du mobilier en usage à cette époque.

La classification par usage montre que $44 \%$ du mobilier concerne le service et la consommation des aliments; $27 \%$ la cuisson; $10 \%$ l'hygiène; $7 \%$ le service des boissons ; $4,5 \%$ la préparation des aliments ; $3 \%$ la conservation ; $3 \%$ classés en rubrique divers, renvoient toujours aux pots de fleurs et les $1,5 \%$ restant concernent la consommation des boissons. Le service et la consommation des aliments restent toujours en première place, suivis par la cuisson, qui bénéficie de la mise en circulation des marmites en service jaune B2. L'hygiène est de plus en plus présente et la préparation reprend une place équivalente à celles des XVIe et XVIIe s.

Le XVIIIe s. pose un certain nombre de questions difficiles à résoudre sans connaître le XIXe s. A ce sujet, on peut citer la place de plus en plus importante prise par la famille E8, qui reflète, en fait, un certain manque dans nos connaissances. Le parti pris d'arrêter l'étude au XVIIIe s. prive d'un certain nombre d'informations. Cela dit, un bref regard sur le mobilier du XIXe s., trouvé dans les quelques dépotoirs mis au jour, laisse imaginer l'ampleur du travail : le XIXe s. n'est pas une période que l'on peut étudier simplement à partir de la céramique, mais nécessite une vision globale incluant les autres catégories de matériaux, tels que le métal ou le verre, pour lesquels la documentation est abondante, à la différence des époques antérieures (fig. 165).

165 - Ensemble de céramiques du XVIIle s. (région Lyonnaise)
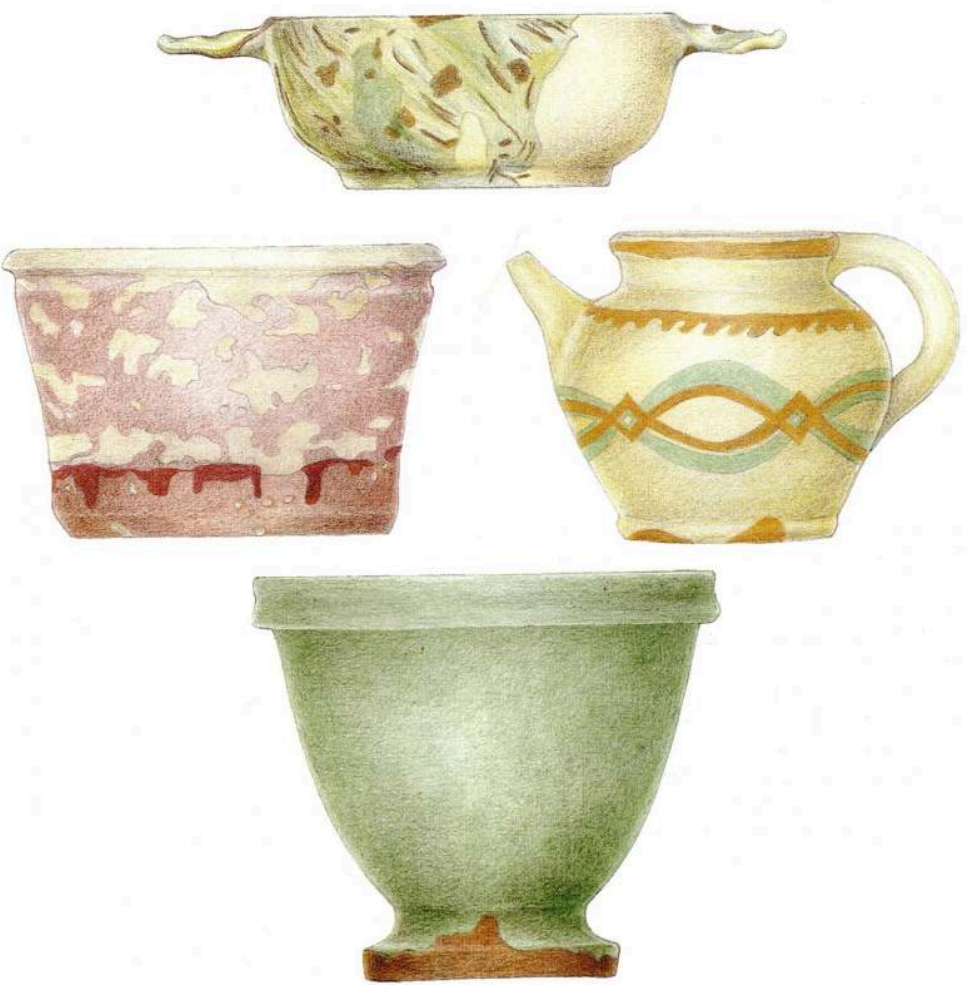


\section{NOTES}

1. Certaines fouilles datées fin XVe, comme par exemple la zone IX des Terreaux, prouvent l'existence de marmites en R1, mais ne fournissent pas de vases entiers.

2. Signalons que ce dernier type pourrait être assimilé à une cruche de transport; ses dimensions réduites conduisent à l'intégrer dans les cruches de table.

3. Il s'agit de l'enveloppe de Clive R. Orton (Orton 1987) : il suffit de superposer tout les dessins d'une même forme et de tracer le contour de l'ensemble : plus le dessin de la somme des vases (l'enveloppe) se rapproche d'un exemplaire, plus la production est standardisée ; dans le cas des écuelles, les contours de l'enveloppe sont extrêmement resserrés.

4. Les marmites de ce dépotoir sont d'ailleurs dotées de fonds identiques.

5. La chronologie proposée dans le catalogue "A la Fortune du Pot" est maintenant dépassée : on pensait alors que cette production était typique du XVIIe s.

6. Par exemple, l'exemplaire p. 161 photo 803, dans le Dictionnaire des Objets Civils et Domestiques.

7. L'étude de la faïence est volontairement laissée succincte ; un diplôme de maîtrise est en cours sur le sujet par A. Horry et comprend également des analyses de pâte en laboratoire. 


\section{Annexe}

\section{Analyse morphologique du corps du vase}

1 Il s'agit de la description de la section méridienne du vase, dont l'axe de symétrie est toujours vertical.

\section{Les classes}

2 Le premier rapport tient compte de la hauteur totale du récipient (H) et de son diamètre d'ouverture $(d)$ :

forme haute $\mathrm{si} \mathrm{H} / \mathrm{d}>1$

forme basse si $1 / 3<\mathrm{H} / \mathrm{d}<1$

forme plate $\mathrm{si} / \mathrm{H}<1 / 3$

3 Le second rapport concerne le diamètre du col (C) et le diamètre maximum (D) :

forme fermée si $C / D<0,9$

forme ouverte si $C / D>1$. Pour cette dernière distinction, lorsque $C / D$ est compris entre les deux mesures, la morphologie du col entre en ligne de compte : la forme est fermée si ce segment présente un profil convergent.

4 Cette combinaison de critères donne cinq classes.

\section{Les groupes}

$5 \quad$ Il ne faut pas oublier que les vases de la classe 1 sont des formes fermées, c'est-à-dire que dans tout les cas de figure, la panse se rétrécit en arrivant au niveau du col ou de la lèvre. La panse est donc qualifiée de globulaire lorsque son diamètre maximum est plus ou moins équivalent à sa hauteur; ovoïde haute, quand le diamètre maximum est situé dans sa partie supérieure; surbaissée, quand il se situe dans sa partie inférieure; cylindrique, quand les deux faces sont rectilignes et parallèles. Le terme ovoïde est utilisé quand aucune des autres conditions ne sont remplies; le diamètre maximum de la panse se situe dans la partie centrale, mais il est inférieur à sa hauteur. 
6 Le fond plat ne pose pas de problème de description; par contre, un fond est dit bombé ou lenticulaire, lorsque le profil convexe de cet élément montre une arête dans sa liaison avec la panse ; hémisphérique, lorsque cette-ci disparaît.

Dans la classe 2, un seul changement intervient dans la morphologie de la panse, divisée en évasée rectiligne et évasée courbe.

Dans la classe 3, la paroi est dite cylindrique quand son axe est parallèle à l'axe vertical médian du vase, évasée ou légèrement évasée, lorsque la paroi s'écarte à l'extérieur de cet axe vertical, hémisphérique, lorsqu'il s'incline en direction de cet axe, selon un profil courbe ; c'est pourquoi ce terme n'entraîne pas une description du profil de la paroi.

Ces distinctions de paroi sont combinées avec la description de son profil: les appellations rectiligne et courbe n'appellent pas de commentaire particulier; mais la paroi est dite carénée lorsqu'on note un changement brusque dans son axe.

La classe 4 reprend les mêmes descriptions.

11 La classe 5 ajoute la morphologie du pied : celui-ci est tronconique lorsqu'il présente un profil en tronc de cône renversé, ou annulaire, lorsqu'un segment en forme d'anneau est ajouté sur le fond.

\section{Les formes}

En classe 1, quatre critères sont utilisés :

- la présence ou l'absence d'un col ainsi que sa morphologie : ce segment est défini comme étant la partie du vase située entre la panse et la lèvre ; le passage de la panse au col se fait par un changement de courbure ou d'inclinaison du profil. Pour déterminer la présence ou l'absence du col, de même que sa taille, il paraît plus simple de se référer aux conventions du Code de Marie Leenhardt (chapitre E), plutôt que d'inventer une nouvelle version. Quant à son profil, les termes employés cylindrique ou évasé sont déjà connus.

- la description de l'élément verseur : un bec pincé est obtenu par pincement de l'argile encore molle au niveau de la lèvre ; un bec ponté est un segment d'argile rapporté, collé et mis en forme sur le vase au niveau du col, percé à cet endroit; la lèvre n'est pas interrompue à l'emplacement du bec et forme un petit pont pardessus ce dernier. Un bec tabulaire est un segment d'argile de forme tubulaire et de section ronde rapporté et collé sur le vase, généralement sur la partie haute de la panse, percée à cet endroit.

- la description de l'élément de préhension : anse verticale, en panier, horizontale, de section plate, circulaire ou ovale et son emplacement : sur la lèvre ou le col, sur le haut, le milieu ou le bas de la panse.

- la présence ou l'absence et la morphologie du pied : de la même manière que pour le col, les conventions du code de Marie Leenhardt (chapitre C) sont utilisées pour décrire ce segment.

Quant aux autres classes, les termes employés ne nécessitent pas de commentaire.

\section{Les types}

Dans tout les cas de figure (ou presque : ainsi un vase complètement fermé tel que la tirelire ne possède pas de lèvre), la paroi du vase s'achève, au-dessus du col ou de la panse par un segment appelé lèvre ou rebord et dont le profil détermine le type.

Toujours dans le même esprit de facilité, le Code de Marie Leenhardt est encore mis à contribution (chapitre F) : nous gardons les conventions concernant la présence ou 
l'absence d'une ou plusieurs inflexions ainsi que la description des faces et de l'extrémité. Par contre, une simplification du degré d'inclinaison (qui correspond à l'angle formé par l'axe de la lèvre avec l'axe vertical du vase) s'avère nécessaire sous peine de multiplication abusive des types:

16 La lèvre est donc verticale, s'incline de plus en plus, et devient alors oblique vers le haut puis horizontale. Passé ce cap, elle se définit comme oblique vers le bas.

17 T.V. 


\title{
Conclusion
}

\author{
Tommy Vicard
}

1 A l'issue de ce tour d'horizon de plus de cinq siècles de vaisselle céramique, un certain nombre des buts fixés à l'origine a été atteint : rassembler les lots de céramiques des différents sites fouillés sur Lyon, établir une typo-chronologie et tracer les grands axes d'une évolution du mobilier médiéval et moderne.

2 Entre le XIIe et le XVIIIe s., il y a deux points forts dans l'évolution du mobilier céramique, qui renvoient aussi bien à des nouveautés typologiques, technologiques qu'à des changements de mentalité. Les causes en sont difficilement accessibles à partir de cette seule étude, mais les potiers sont soumis aux mêmes lois économiques que n'importe quel autre corps de métier: pour vivre, ou même survivre, l'artisan doit vendre sa production, donc attirer le client, soit par le prix de sa marchandise, soit par sa qualité, son apparence ou sa fonction. Dans cette optique, deux mécanismes fondamentaux s'identifient facilement.

3 Le premier concerne les innovations techniques, qui n'ont, en fait, d'influence sur la production que si elles sont durables. Ainsi, une transformation progressive, mais générale des types de vases s'opère à la fin du XIIe ou au début du siècle suivant, liée à la redécouverte de la cuisson oxydante, à la généralisation de la glaçure plombifère et à la distinction entre vaisselle de cuisine et vaisselle de table. Une seconde transformation intervient dès le début du XVIe s. avec l'apparition de nouvelles techniques, donc de nouvelles productions, qui bouleversent le paysage en profondeur et reflètent le passage du Moyen Âge à l'époque moderne.

4 Le deuxième mécanisme renvoie aux effets de la concurrence : l'arrivée, au début du XVIe s., des faïenciers italiens a dû secouer le monde des artisans potiers régionaux, plutôt immobile. En effet, les Italiens apportent avec eux, non seulement un savoirfaire nettement supérieur, mais également, sans aucun doute, un catalogue de formes, voire de décors inconnus jusqu'alors. L'étude de la céramique de cette époque montre, que loin de se laisser abattre, les artisans régionaux se sont adaptés en améliorant leurs produits et en les diversifiant. Un choix important est donc proposé aux clients ; par conséquent et sans même connaître l'origine exacte de toutes ces productions, il est facile de déduire qu'elles entrent toutes en concurrence; pourtant chacune d'elles a ses propres atouts : la commune grise se consacre à la vaisselle de cuisine, le service vert 
joue sur la qualité et l'originalité et couvre aussi bien la vaisselle de table que les récipients de cuisine, la verte sur engobe, plutôt axée sur la vaisselle de table, mise sur la diversité avec certains types spécifiques, etc. La concurrence développe également la prolifération de types comparables d'une production à l'autre; les cas les plus représentatifs concernent les réchauds, qu'on retrouve en famille G, B1, El, R1 et E5., ou les assiettes creuses, voire même les écuelles et les pots de chambre. La spécialisation des produits peut être imputée au même phénomène ; une mention spéciale concerne la production de faïence, cantonnée en grande partie dans l'hygiène et les pots pharmaceutiques. Il est d'ailleurs curieux de constater, au niveau des types de céramique, qu'il n'y a pas la volonté, de la part des productions décorées, de concurrencer directement la faïence, comme le démontrent les rares exemples de chevrettes en famille E2.

Ces deux mécanismes, perceptibles à partir de l'étude de la céramique, possèdent une dynamique interne qui engendre à son tour des effets secondaires, dont le plus frappant, celui de la vulgarisation des produits, se traduit aussi bien par la version populaire d'objet de luxe que par l'imitation d'objets existant dans d'autres matériaux. La marmite à anses coudées copie le métal, certains pichets, les tonnelets en bois ; d'autres sont décorés à la manière des verres; les décors aux engobes plagient parfois la faïence. La vulgarisation d'un produit sous-entend sa diffusion abondante, donc, à plus ou moins brève échéance, sa dégradation : ce fait est particulièrement visible en ce qui concerne les pichets, dont les décors rapportés, de grande qualité, se banalisent et s'appauvrissent, par la suite, sur les cruches.

6 L'évolution du mobilier céramique est donc l'aboutissement d'un grand nombre de facteurs qui agissent les uns sur les autres tout en étant eux-même soumis à des phénomènes de plus grande ampleur, dans des contextes économiques ou historiques. En partant de l'hypothèse qu'il s'agit de mécanismes récurrents à d'autres régions, les conditions de mise en place seront différentes et le résultat - les types de céramiqueségalement.

7 Ces constatations invitent à une utilisation prudente de la typologie publiée ci-dessus pour la datation de nouvelles découvertes, surtout hors du site de référence ${ }^{1}$ Afin de pallier ces difficultés qui entraîneraient à terme un blocage de la recherche, il s'avère indispensable d'évoquer l'aire de validité de cette typologie.

Ce terme nécessite quelques explications et mises en garde : il ne faut pas oublier que pour cette étude, Lyon n'a pas été envisagé comme site de production ${ }^{2}$, mais comme site de consommation; déterminer une aire d'utilisation ne revient pas à définir une zone de diffusion, à l'instar du travail effectué pour les productions de MeillonnasTreffort et de Larnage, dans la première partie de cet ouvrage. Il s'agit simplement de fournir quelques points de repère en comparant avec les productions d'autres régions. Il va sans dire que ce travail n'est pas exhaustif, surtout dans l'état actuel de nos connaissances; ces comparaisons sont pour l'instant plus faciles à effectuer pour l'époque moderne que pour le Moyen Âge, où nous manquons de référence en raison du hiatus des XIVe et XVe s.

Lorsqu'on se tourne vers le sud de Lyon, deux sites relativement proches, Vienne et Condrieu ${ }^{3}$, fournissent de la céramique des XVIIe et XVIIIe s. comparable à notre matériel, tant au niveau des types qu'à celui des productions. Il est d'ailleurs intéressant de constater que le site de Condrieu dispense également des céramiques datables de la fin du Moyen Âge, dont des marmites en commune grise pratiquement 
analogues à la production du four de Surieu ${ }^{4}$, ainsi qu'un rebord d'une grande coupe, sans doute d'origine méridionale, qui illustre bien le problème des relations de Lyon avec cette région.

10 En effet, la bibliographie récente ${ }^{5}$ nous amène à constater que les récipients et les productions du sud de la France sont extrêmement différents de ce que Lyon peut offrir, tant au niveau des profils de vase que des décors et des revêtements. Pourtant, les grands axes demeurent sensiblement les mêmes : disparition pendant près de cinq siècles de la notion de céramique de luxe, réapparition de la glaçure et de la cuisson oxydante au cours du XIIIe s., ainsi que de la vaisselle de table. Mais l'ouverture des régions sud au bassin méditérranéen a sans doute favorisé les échanges et contribué à diversifier le vaisselier.

11 Malgré ceci, quelques similitudes sont à noter pour l'époque moderne, illustrées par la vaisselle trouvée dans l'église de Sainte-Anne de Boulbon, dans les Bouches-du-Rhône (Betton 1990). Ce lot du XVIIe s. est composé de 200 pièces, dont 184 écuelles à oreilles, issues d'ateliers proches (Avignon, Tarascon, Uzège). Certaines sont réellement identiques aux exemplaires provenant des fouilles lyonnaises, tant d'un point de vue typologique que décoratif. Ce qui est intéressant ici, c'est de replacer ce lot dans son contexte typo-chronologique régional (Abel 1987 et 1988; Carraze 1987; Démians d'Archimbaud 1980; Pasqualini 1988; Carru 1989), qui présente des récipients et une évolution différente de Lyon. Cette observation s'applique également à la céramique des XVIe et XVIIe s. trouvée à Marseille (Abel 1987 et 1988 ; Carraze 1987). Elle provient d'ateliers régionaux ou extra-régionaux : Ligurie, Fréjus, Pise, Montelupo, Uzège, Biot, Vallauris, mais plusieurs vases, surtout dans les formes ouvertes, ainsi que certains décors aux engobes, montrent de belles affinités avec les céramiques "lyonnaises", alors que le reste du mobilier demeure spécifique au Sud de la France, notamment en ce qui concerne les "toupins" et les marmites. Par contre, la céramique du XVIe s. découverte à Avignon, rue Racine (Carru 1989), ne possède aucune parenté morphologique et technologique avec celle des fouilles lyonnaises ${ }^{6}: 23 \%$ du mobilier est d'importation italienne ou espagnole, le reste étant de fabrication régionale.

Ces exemples montrent que la comparaison ne doit pas se faire sur un ou plusieurs types de vases, mais sur l'ensemble du mobilier disponible à une époque donnée. De ce fait, la typo-chronologie établie à Lyon demeure globalement différente de celle constatée pour le Sud de la France. Les quelques analogies ponctuelles ne sont pas attribuées, pour l'instant, à des origines identiques ${ }^{7}$, mais plutôt à des phénomènes de mode $^{8}$. La plupart des productions méridionales n'atteignent pas notre région, ou alors de manière anecdotique ${ }^{9}$.

13 A l'ouest de Lyon, les sites fournissant du matériel bien daté ne sont pas très nombreux. Passés les monts du Beaujolais, une des rares références reste le château d'Essertines situé à huit kilomètres de Montbrison, au pied des monts du Forez. En effet, la fouille de ce site livre un mobilier qui s'échelonne du moyen-âge jusqu'à l'époque moderne, tant en provenance du château (Piponnier 1993) que du village. Le revers de la médaille réside dans l'extrême fragmentation des céramiques, donc dans la pauvreté du catalogue, qui rend les comparaisons difficiles. Seules trois familles sont présentes ${ }^{10}$, la commune grise $G$, souvent décorée de bandes rapportées, avec de grands pots globulaires de cuisine ou de stockage, des marmites à fond lenticulaire et même des cruches à panse globulaire ; la commune rouge $\mathrm{R}$ qui renvoie à une vaisselle de table en pâte fine et à des pots de stockage en pâte plus grossière et enfin, la commune rouge 
glaçurée R1 avec des coquemars, des pichets décorés et des marmites à anses. L'étude des provenances montre un ravitaillement purement régional, en ce qui concerne la quasi-totalité de la vaisselle commune : le bourg d'Essertines n'est pas loin de plusieurs villes foréziennes connues pour leurs marchés aux pots : Montbrison, Feurs, Sury-leComtal, etc. Cette origine locale n'est agrémentée que de quelques céramiques d'importation en provenance du Sud de la France, de la Bourgogne, mais « il ne paraît pas cependant, que la poterie de terre forezienne ait donné lieu à un trafic exterieur au comté » (Fournial 1967, p. 207). Voilà qui, non seulement justifie une étude comparative du matériel d'Essertines avec celui de Lyon, mais donne une nouvelle piste de recherche vers l'Auvergne.

14 La zone située à l'est de Lyon englobe le département de l'Ain et une partie de la HauteSavoie. Dans ce département, le château de Vuache, à Vulbens (Raynaud 1992), fournit quelques exemplaires de pichets comparables à ceux d'Anse pour une période qui comprend le XIIIe et le XIVe s. De cette époque, la bastide de Gironville, dans l'Ain livre des cruches à bec pincé en commune rouge glaçurée et des marmites en commune grise, toujours comparables à nos céramiques lyonnaises. Par contre, pour le XVIe s., le matériel en service vert, issu des châteaux de Vulbens et de Pierre (Collonges, dans l'Ain) montre quelques particularités étonnantes. Sur ce dernier site ${ }^{11}, 97 \%$ du mobilier appartient au service vert, dont $50 \%$ sous forme de marmites à anses coudées, un type jamais présent à Lyon en famille B1. La plus grande partie des $50 \%$ du mobilier restant, marmites tripodes, casseroles hautes et basses, cruches à bec tubulaire, albarello et couvercles creux est également quasi-inexistante à Lyon et il n'y a guère de comparable, entre les deux sites, que les marmites ovoïdes, les réchauds et les assiettes creuses. Les quelques vases de la même famille, trouvés à Vulbens, offrent des caractéristiques identiques (Raynaud 1992, pp. 106108). Ce phénomène se répète pour le XVIIe s. : la fouille d'un dépotoir et d'une latrine au château de Nerciat ${ }^{12}$, dans l'Ain, indique que le service vert compte pour environ $90 \%$ de la totalité du mobilier; la plupart des formes fermées - cruches à bec pincé ou tubulaire, à anse en panier, marmites ovoïdes ou cylindriques - sont absentes des fouilles lyonnaises, de même que certaines formes ouvertes, panier, jattes, casseroles basses ; de plus, une vingtaine de vases à pâte blanche et glaçure jaune copie ce répertoire typologique tout en n'étant pas du service jaune. Par contre, les récipients appartenant aux productions décorées aux engobes et jaspées (E2 et E3) ne présentent pas de nouveautés typologiques. Cette particularité du service vert se retrouve souvent sur des sites extra-lyonnais ${ }^{13}$; il faut admettre que l'ensemble du catalogue de chaque production n'est pas représenté dans sa totalité dans les lots lyonnais. Pour certains potiers, Lyon n'est qu'un point de vente parmi d'autres et des types de vases présents ou absents à une époque donnée, peuvent se retrouver dans d'autres villes, dans un autre contexte, voire à une époque différente.

Au nord de Lyon, le service vert s'est diffusé jusqu'à Chalon-sur-Saône. Cette ville demeure un point important dans l'établissement d'une aire d'utilisation de la typologie lyonnaise. A quelques kilomètres au sud, se trouve le village de Sevrey, connu pour l'intense activité de ses ateliers de potiers au Moyen Âge et à l'époque moderne (Renimel 1974). Entre ces deux points, un lieu, Port Guillot, en bord de Saône, a fait l'objet de fructueuses prospections et fouilles subaquatiques (Bonnamour 1985-1987). Qu'en-est-il du mobilier récolté ? Il s'agit en fait du catalogue complet des céramiques en commune grise trouvées à Lyon pour les XVIe et XVIIe s. : marmites à anses coudées, réchauds, bassins, cruches à anse en panier, pots à cuire, faisselles ${ }^{14}$, sans compter quelques vases décorés aux engobes, de famille E2, en tout point semblables à nos 
exemplaires lyonnais. Il semble que ces céramiques en commune grise proviennent de l'atelier de Sevrey. Un deuxième exemple, toujours à Chalon-sur-Saône, concerne un lot des XVIIe et XVIIIe s., provenant de la fouille de la clinique Sainte Marie (Les Saintes Maries, les Visitandines à Chalon-sur-Saône 1993). Une fois encore, la similitude de certains types avec les découvertes lyonnaises est frappante; c'est notamment le cas des cruches décorées aux engobes, des écuelles et des assiettes de la même famille, des chauffe-plats et des marmites en céramique commune grise. Par contre, les pots à cuire, les poêlons et les pots à conserves ne montrent aucune affinité avec le matériel lyonnais. L'essentiel de ce mobilier est attribué aux ateliers de Sevrey, le reste se répartissant entre Meillonnas-Treffort, Larnage et Étrepigney dans le Jura, pour la seconde moitié du XVIIIe s. Pourtant, la découverte récente d'ateliers comparables plus près de Lyon, dans la vallée de la Saône (cf. supra 1ère partie, chap. 3) pourrait nuancer cette hypothèse.

L'aire géographique d'utilisation se dégage donc lentement, au gré des découvertes archéologiques. Par manque de références, la limite sud reste encore à préciser : malgré quelques affinités, il semble que les productions soient bien différenciées et la zone de transition, à la latitude de Valence, doit être circonscrite. La façade ouest ne peut pas être exploitée pour l'instant, toujours par manque de données; une étude doit être entreprise sur d'éventuels lots de céramiques au-delà des monts du Beaujolais. Les secteurs est et nord offrent plus de promesses; une partie du travail a été effectuée pour la production de Meillonnas-Treffort et donne un cadre à l'utilisation de la typologie. La comparaison méthodique des céramiques communes lyonnaises avec les découvertes de Chalon-sur-Saône et du Val de Saône (ateliers de Sevrey ou autres), accompagnée d'analyses de pâte, devient pratiquement inévitable pour répondre à ces questions; c'est d'ailleurs dans cette direction que doivent s'orienter les efforts : à peine un travail achevé, que s'ouvrent de nouvelles pistes de recherches.

\section{NOTES}

1. A cela s'ajoutent des problèmes intrinsèques à la typologie : fiabilité des indices de datation, détermination de la durée d'existence des types de céramiques, aléatoire dans la plupart des cas, qui entraîne le problème du matériel résiduel, ou encore, manque de mobilier archéologique pour des périodes plus ou moins longues qui contraint l'archéologue à de nombreuses spéculations.

2. Les archives lyonnaises comportent de nombreuses mentions de potiers, mais aucun atelier n'a été pour l'instant découvert.

3. La fouille de Vienne a été dirigée par M. Zanettaxi et celle de Condrieu, par M.-P Feuillet, l'étude de la céramique a été réalisée par B. Poisson.

4. Cet endroit se trouve à $20 \mathrm{~km}$ au sud de Vienne et la fouille fut dirigée par M. Jannet-Vallat (Faure-Boucharlat; Vicard 1986).

5. Poterie d'Oc, céramiques languedociennes VIIe-XVIIe s 1995 ; Archéologie et vie quotidienne aux XIIIeXIVe s. en Midi-Pyrénées 1990 ; Terres de Durance 1995 ; Aujourd'hui le Moyen Age 1981 ; Le vert et le brun 1995 ; De l'Orient à la table des Papes 1995. 
6. Même constatation pour le matériel XIVe-XVe s., issu des fouilles de l'hôtel de Brion, dans la même ville (Démians d'Archimbaud 1980).

7. Ce point ne peut être résolu que par une analyse de pâte en laboratoire.

8. C'est pourquoi, par exemple, on peut trouver de la céramique décorée aux engobes aussi bien dans le Pas-de-Calais qu'à Marseille. Cela dit, il doit exister, entre Avignon et Valence, une zone géographique où s'arrête la diffusion et l'influence des productions du Midi ; il serait intéressant de voir si les céramiques "lyonnaises" y sont présentes.

9. Il s'agit généralement de fragments de céramique verte et brune.

10. Respectivement, groupe C, B et A dans le classement établi pour Essertines.

11. Fouille dirigée par Sylvain Motte, étude de la céramique par A. Horry.

12. Idem note 11 .

13. On peut également citer l'étude de la production du four Giroud, en première partie de cet ouvrage.

14. Cette dernière forme était absente du catalogue lyonnais jusqu'à la récente découverte d'un exemplaire entier en provenance de la fouille, rue du Dr. Horand, (Lyon 69009) dirigée par C. Bellon, été 1995. 


\section{Bibliographie}

Catalogue de l'exposition : Aujourd'hui le Moyen Age : Archéologie et vie quotidienne en France Méridionale. Aix-en-Provence, 1981-1983, 125 p.

Catalogue de l'exposition : Poteries traditionnelles du Val de Saône Mâconnais. Macon, Musée des Ursulines, 13 janvier, 11 mars 1984, $30 \mathrm{p}$.

Catalogue de l'exposition: Bourgogne médiévale, la mémoire du sol, 20 ans de recherches archéologiques. Dijon, Auxerre, 1987, 1988. Mâcon, 1987, 255p.

Catalogue de l'exposition: Se nourrir à Besançon au Moyen Age : À la table d'un vigneron de Battant, Musée des Beaux-Arts et d'Archéologie de Besançon, 10 mars-10 juin 1990, 83 p.

Catalogue de l'exposition: Archéologie et vie quotidienne aux XIIIe-XIVe s. en Midi-Pyrénées, Musée des Augustins, Toulouse, 1990, 195 p.

Catalogue de l'exposition: A la Fortune du pot; la cuisine et la table à Lyon et à Vienne (XeXIXe s.). Lyon-Vienne, 1990-1991, 235 p.

Catalogue de l'exposition : Plaisirs et manières de table aux XIVe et XVe s. Musée des Augustins, Toulouse, 1992, 347p.

Catalogue de l'exposition : $20000 \mathrm{~m} 3$ d'histoire, les fouilles du parking de la mairie à Besançon. Musée des Beaux Arts et d'Archéologie de Besançon, 1992, 399 p.

Catalogue de l'exposition : Les Saintes Maries, les Visitandines à Chalon-sur-Saône aux XVIIe et XVIIIe s. Chalon-sur-Saône, 1993, 273 p.

Catalogue de l'exposition : La faïence de Meillonnas (1760-1845). Brou et Sèvres, Musée de Brou, Adam Biro, Tours, 1993, 235p.

Catalogue de l'exposition: Tupins et carrons. Musée des Pays de l'Ain. Musée du Revermont, conservation départementale des musées des Pays de l'Ain, 1994, 81p.

Catalogue de l'exposition: Ex pots, céramiques médiévales et modernes en Franche-Comté. Musée des Ducs de Wurtemberg, Montbéliard, 1995, 247p.

Catalogue de l'exposition: Poteries d'Oc, céramiques languedociennes, VIIe-XVIIe s. Musée archéologique de Nîmes, oct. 95-fev. 96, Narrations éditions, 1995, 144 p.

Catalogue de l'exposition: De l'Orient à la table des Papes, l'importation des céramiques méditerranéennes dans la région d'Avignon aux XIVe-XVIe s. Musée Vouland, Avignon, 1995.

Catalogue de l'exposition : Le vert et le brun, de Kairouan à Avignon, Céramiques du Xe au XVe s. Musée de Marseille, Réunion des Musées nationaux, Marseille, 1995, 246 p. 
Catalogue de l'exposition: Terres de Durance, céramiques de l'Antiquité aux Temps modernes. Musées de Digne et de Gap, 1995, 160 p.

La céramique médiévale et post-médiévale dans le nord de la France 1988: La céramique médiévale et post-médiévale dans le nord de la France - Travaux du groupe de recherches et d'études sur la céramique dans le Nord-Pas-de-Calais. Actes du colloque de Lille (26-27 mars 1988), numéro hors-série de Nord-Ouest Archéologie, 1989, 272 p.

La céramique du Ve au Xe s. dans l'Europe du Nord-Ouest 1993 : La céramique du Ve au Xe s. dans l'Europe du Nord-Ouest - Travaux du groupe de recherches et d'études sur la céramique dans le Nord-Pas-de-Calais. Actes du colloque d'Outreau (10-12 avril 1992), numéro hors-série de Nord-Ouest Archéologie, 1993, 431p.

Abel 1987 : ABEL (V) - La céramique commune à Marseille au XVIIe s. : l'exemple de dépotoirs domestiques du site de la Charité, Archéologie du Midi Médiéval, t. 5, 1987, pp. 153-165.

Abel 1988 : ABEL (V) - La céramique du XVIe s. sur le site de la Bourse : premiers éléments pour une typologie à Marseille. Archéologie du Midi Médiéval, t. 6, 1988, pp. 161-172.

Amouric et alii 1986 : AMOURIC (H.), CHEMORIN (M.-B), DEMIANS D'ARCHIMBAUD (G.), PICON (M.) - Une enquête sur les centres de production céramique dans la région rhodanienne: approches globales, localisations et structures. In: La ceramica medievale nel mediteraneo occidentale. Congrès de Sienne-Faenza, 1984. Fireze, 1986, pp. 279-292.

Amouric 1986 : AMOURIC (H.) - Les origines de l'industrie céramique à Apt : l'apport des sources écrites, XIVe-XVe s. Archéologie du Midi Médiéval, t. 4, 1984, pp. 31-35.

Amouric 1987 : AMOURIC (H.) - La diffusion des produits céramiques en Provence : XIVe-XIXe s. Flux, diffusion marginale, aléatoire, immédiate et médiate. In: La céramique (Ve-XIXe s.). Fabrication. Commercialisation. Utilisation. Actes du 1er Congrès international d'archéologie médiévale, 1987, pp. 227-243.

Arlaud et alii 1994 : ARLAUD (C.), BURNOUF (J.), BRAVARD (J.-P-), LUROL (J.-M.), VEROTBOURRELY (A.) - Lyon Saint-Jean, les fouilles de l'îlot Tramassac. Lyon, Service régional de l'archéologie, D. A. R. A. n 10, série lyonnaise nº 4, 1994, pp. 93-116.

Armand-Caillat 1946 : ARMAND-CAILLAT (L.) - La poterie de Sevrey en Chalonnais. Artisans et Paysans de France, t. 1, 1946, pp. 111-117.

Auger 1990 : AUGER (M.) - Lyon Saint-Jean, quartier Saint Vincent : verres des XVe-XVIIIe s. In : Verrerie de l'Est de la France, 13-17e s. : fabrication et commercialisation. Revue Archéologique de l'Est et du Centre Est, 1990, p. 277.

Ayala 1992: AYALA (G.) - Rue Palais Grillet, une intervention archéologique au cœur de la presqu'île lyonnaise. Revue Archéologique de l'Est et du Centre Est, 1992, pp. 233-305.

Ayala 1994 : AYALA (G.) - Les éléments de la culture matérielle, la céramique gallo-romaine. In : ARLAUD (C.) et alii. Lyon Saint-Jean, les fouilles de l'îlot Tramassac. Lyon, Service régional de l'archéologie, D. A. R. A. $n^{\circ}$ 10. série lyonnaise $n^{\circ} 4$, 1994. pp. 79-92.

Becker et alii 1989: BECKER (C.), MACE (S.), MANDY (M.-O.), AUGER (M.), VICARD (T.) - Les fouilles de la place Antonin Poncet à Lyon. Archéologie du Midi Médiéval, t. 7, 1989, pp. 137-186.

Bertin 1977: BERTIN (J.) - Le graphique et le traitement graphique de l'information. Flammarion, nouvelle bibliothèque scientifique 1977, $264 \mathrm{p}$.

Betton et alii 1990 : BETTON (F.), BURAVAND (V.), VALLAURI (L.) - Un lot de vaisselle moderne déposé dans l'église Sainte-Anne de Boulbon. Archéologie du Midi Médiéval, t. 8-9, 1990-1991 pp. 155-168

Bizot et Serralongue 1988 : BIZOT (B.), SERRALONGUE (J.) - Un édifice funéraire du haut Moyen Age à Seyssel, Albigny (Haute-Savoie). Archéologie du Midi médiéval, t. 6, 1988, pp. 25-50. 
Blieck 1989: BLIECK (G.) - Potiers de terre du XVIIe s. à Lille. In: Travaux du groupe de recherches et d'études sur la céramique dans le Nord-Pas-de-Calais. Actes du colloque de Lille (mars 1988), Nord-Ouest Archéologie, hors-série, 1989, pp. 133-151.

Bonhoure et Marchesi 1993 : BONHOURE (I.), MARCHESI (H.) - Le site du Pont Julien à Bonnieux (Vaucluse); un four de potiers médiéval et sa production de céramiques grises. Archéologie du Midi Médiéval, t. 11, 1993 pp. 99-108.

Bonnamour 1985-1987 : BONNAMOUR (L.) - Chronique archéologique. Bulletin de la Société d'Histoire et d'Archéologie de Chalon-sur-Saône, t. 55, 1985-1986, pp. 23-70 et t. 56, 1987, pp. $15-20$.

Boüard 1976 : BOÜARD (M. de) - La céramique de Doué-la-Fontaine (IXe-XIe s.). Fouilles de la motte de la Chapelle (Maine-et-Loire). Archéologie Médiévale, VI, 1976, pp. 247-271.

Boüard et alii 1987: BOÜARD (M. de), MEYER (N.), RANDOIN (B.) - Le traitement de la céramique, rapport introductif. In : La céramique (Ve-XIXe s.). Fabrication. Commercialisation. Utilisation. Actes du 1er Congrès international d'archéologie médiévale, Paris 1985. Caen, Société d'Archéologie Médiévale, 1987, pp. 9-15.

Bouvier et alii 1992 : BOUVIER (A.), FAURE-BOUCHARLAT (E.), MONNIER (J.) - La motte castrale de Décines-Charpieu (Rhône). Archéologie Médiévale, t. XXII, 1992, pp. 231-307.

Bouchu 1978 : BOUCHU - Déclarations des biens des communautés 1665-1670. 2 tomes, Lyon 1978.

Bucur et alii 1989 : BUCUR (I.), DUFOURNIER (D.), FAJAL (B.), LEVALET (D.) - Un four de potier médiéval à Saint-Georges-de-Rouelley (Manche), les premiers grès bas-normands. Archéologie Médiévale, XIX, 1989, pp. 215-241.

Carraze 1987: CARRAZE (F.) - La poterie commune à décor baroque dans l'arrière pays marseillais. Bulletin de l'association Polypus, 1987, $37 \mathrm{p}$.

Carru 1989 : CARRU (D.) - Céramiques d'un dépotoir du XVIe s. à Avignon. Archéologie du Midi Médiéval, t. 17, 1989 pp. 187-209.

CATHMA 1986 : Association CATHMA - La céramique du haut Moyen Age en France méridionale : éléments comparatifs et essai d'interprétation. In: La ceramica medievale nel mediterraneo occidentale. Congrès de Sienne-Faenza 1984. Fireze, 1986, pp. 27-50.

CATHMA 1993 : Association CATHMA - Céramiques langue-dociennes du haut Moyen Age (VIIeXIe s.). Etudes microrégionales et essai de synthèse. Archéologie du Midi Médiéval. t. 11, 1993, pp. 111-228.

Cattin 1979 : CATTIN (P.) - Guide des Archives de l'Ain. Bourg-en-Bresse, 1979.

Cattin 1984 : CATTIN (P.) - Histoire des communes de l'Ain. Roanne, 1984.

Cattedu 1992: CATTEDU (I.) - L'habitat rural mérovingien de Genlis (Côte d'Or). Revue Archéologique de l'Est et du Centre-Est, t. 43, 1992, pp. 39-98.

Chami 1963 : CHAMI (E.) - L'art céramique du Beauvaisis. Cahier de la céramique et des arts du feu, $\mathrm{n}^{\circ} 30,1963$.

Chapelot 1970 : CHAPELOT (J.) - Un centre de fabrication de la poterie aux VIIIe-IXe s. Revue archéologique du Centre, IX, fasc. 1, 1970, pp. 8-12.

Chapelot 1971 : CHAPELOT (J.) - Un atelier céramique d'époque carolingienne; Saran (Loiret). Revue archéologique du Centre, X, fasc. 1-2, 1971, pp. 3-10.

Chapelot 1975 : CHAPELOT (J.) - Potiers de Saintonge, huit siècles d'artisanat rural, Paris, catalogue d'exposition. Editions des Musées Nationaux, 1975, 127 p. 
Chapelot 1987: CHAPELOT (J.) - Introduction. In: La céramique (Ve-XIXe s.). Fabrication. Commercialisation. Utilisation. Actes du 1er Congrès international d'archéologie médiévale, Paris 1985. Caen, Société d'Archéologie Médiévale, 1987, pp. 7-8.

Chapelot et alii 1987 : CHAPELOT (J.), GALINIE (H.), PILET-LEMIERE (H.) - La céramique (Ve-XIXe s.). Fabrication. Commercialisation. Utilisation. Actes du 1er Congrès international d'archéologie médiévale, Paris 1985. Caen, Société d'Archéologie Médiévale, 1987, 259 p.

Chemorin 1984: CHEMORIN (M.-B.) - Implantation et permanence des lieux de production céramique dans le département du Rhône de l'Antiquité au XIXe s. Thèse de doctorat de 3e cycle, dactylographiée. Université Lyon 2, 2 vol.

Cochard 1814-1816 : COCHARD (N.-F.) - Notice historique sur Loire. Almanach de Lyon 1814-16, pp. K à LV.

Colardelle 1983 : COLARDELLE (M.) - Sépultures et traditions funéraires du Ve au XIIe s. ap. J.-C. dans les campagnes des Alpes françaises du Nord. Société Alpine de Documentation et de Recherche en Archéologie Historique. Grenoble, 1983, 465 p.

Cotton 1984 : COTTON (F) - La vie rurale à Treffort en Revermont au Moyen Age. Bourg-enBresse, 1984.

Darnand 1989 : DARNAND (P.) - La terre de Meillonnas. In : Meillonnas à la recherche de son passé. Soret (S.) (sous la dir. de). Bourg-en-Bresse, 1989.

Debord et Leenhardt 1975: DEBORD (A.) et LEENHARDT (M.) - La céramique d'Andone (Charente). Archéologie Médiévale, V, 1975, pp. 209-242.

Démians d'Archimbaud et alii 1980 : DÉMIANS D'ARCHIMBAUD (G.), VALLAURI (L.), THIRIOT (J.) - Céramiques d'Avignon: les fouilles de l'hôtel de Brion et leur matériel. Académie du Vaucluse, fasc. hors série, 7ème série, I, 1980, 185p.

Démians d'Archimbaud 1980 : DEMIANS D'ARCHIMBAUD (G.) - Céramique et stratigraphie. L'évolution de la vaisselle commune en Provence aux XIIIe-XVe s. d'après les fouilles de Rougiers. In : La céramique médiévale en Méditérranée occidentale, Xe-XVe s. Congrès de Valbonne 1978, Paris, Editions du CNRS, 1980, pp. 441-456 (Colloques internationaux du CNRS, n 584).

Démians d'Archimbaud 1982 : DEMIANS D'ARCHIMBAUD (G.) - L'équipement céramique d'une maison méridionale au bas Moyen Age: sources écrites et archéologiques. In: Mélanges d'archéologie et d'histoire médiévales en l'honneur du Doyen Michel de Boüard. Mémoires et documents, XXVII. Société de l'Ecole des chartes, Genève-Paris, Droz, 1982, pp. 105-112.

Démians d'Archimbaud et Picon 1987 : DEMIANS D'ARCHIMBAUD (G.), PICON (M.) - Céramiques d'habitat. Réflexion critique sur les données acquises lors des fouilles de Rougiers. In: La céramique (Ve-XIXe s.). Fabrication. Commercialisation. Utilisation. Actes du 1er Congrès international d'archéologie médiévale, Paris 1985. Caen, Société d'Archéologie Médiévale, 1987, pp. 245-258.

Dubois 1932 : DUBOIS (G.) - Une enquête de l'Intendant Fontanieu : mémoires sur les productions et le commerce du Dauphiné. Grenoble, 1932.

Dufournier 1989: DUFOURNIER (D.) - Céramologie, technologie céramique. In: Travaux du groupe de recherches et d'études sur la céramique dans le Nord-Pas-de-Calais. Actes du colloque de Lille (mars 1988), Nord-Ouest archéologie, hors série, 1989, pp. 9-16.

Dufournier et Flambard 1987 : DUFOURNIER (D.), FLAMBARD (A.-M.) - Reflexion à propos de l'apparition du grès en Europe occidentale. In: La céramique (Ve-XIXe s.). Fabrication. Commercialisation. Utilisation. Actes du premier Congrès international d'archéologie médiévale, Paris 1985. Caen, Société d'Archéologie Médiévale, 1987, pp. 139-147. 
Esquieu 1988 : ESQUIEU (Y) (sous la dir. de) - Viviers, cité épiscopale. Lyon, Service Régional de l'archéologie, D.A.R.A. $\mathrm{n}^{\circ} 1,1988,127$ p.

Faure-Boucharlat et alii 1978 : FAURE-BOUCHARLAT (E.), COLLARDELLE (M.), FIXOT(M.), PELLETIER (J.-P.) - Eléments comparatifs de la production céramique du XIe s. dans le bassin rhodanien. In: La céramique médiévale en Méditerranée occidentale (Xe-XVe s.), Congrès de Valbonne 1978. Paris, Colloque international du CNRS, n 584. Editions du CNRS, 1980, pp. 429-440.

Faure-Boucharlat 1980 : FAURE-BOUCHARLAT (E.) - La céramique médiévale en Lyonnais et Dauphiné, recherches sur les moyens de production. Thèse de doctorat de 3e cycle, Université de Lyon 2, 1 vol. dactylographiée, 383 p., 1 vol. planches.

Faure-Boucharlat et Reynaud 1986 : FAURE-BOUCHARLAT (E.), REYNAUD (J.-F.) - Les vases funéraires de la nécropole Saint-Laurent de Lyon. Archéologie Médiévale, XVI, 1986, pp. 41-64.

Faure-Boucharlat et Vicard 1986 : FAURE-BOUCHARLAT (E.), VICARD (T.) - La production de l'atelier de potier de Surieu à la fin du Moyen Age (Saint-Romain-de-Surieu, Isère). Archéologie du Midi Médiéval, t. 4, 1986, pp. 113-122.

Faure-Boucharlat et Tardieu 1986: FAURE-BOUCHARLAT (E.), TARDIEU (J.) - Sauvetage archéologique, place du pilori à Vienne. Bulletin de la société des amis de Vienne, $\mathrm{n}^{\circ}$ 81, fasc. 3 , 1986, pp. 47-60.

Faure-Boucharlat 1986 : BOUCHARLAT (E.) - Les vases funéraires du cimetière Saint-Georges de Vienne. Bulletin de la société des amis de Vienne, $n^{\circ} 81$, fasc. 3, 1986, pp. 39-46.

Faure-Boucharlat 1990 : FAURE-BOUCHARLAT (E.) - Les ramassages de surface sur des sites d'ateliers : trois exemples français. In : Fours de potiers et testares médiévaux en méditerranée occidentale. Colloque de la Casa Velasquez 1987. Publications de la Casa Velasquez, série archéologique XIII. Madrid 1990, pp. 157-168.

Faure-Boucharlat et Maccari-Poisson 1993 : FAURE-BOUCHARLAT (E.), MACCARI-POISSON (B.) - Le mobilier Céramique. In : Les habitats du lac de Paladru (Isère), dans leur environnement, sous la dir. de Collardelle (M.), Verdel (E.). Paris, Maison des Sciences de l'Homme, DAF, n 40, 1993, $416 \mathrm{p}$.

Feuillet et Guilhot 1985 : FEUILLET (M.P), GUILHOT (J.O) - Anse, château des Tours, 5 ans de recherches. Rapports archéologiques préliminaires de la région Rhône-Alpes, Lyon, 1985, 177 p.

Fournial 1967 : FOURNIAL (E.) - Les villes et l'économie d'échange en Forez aux XIIIe et XIVe s. Paris, 1967.

Gairaud 1975 : GAIRAUD (R.-P.) - La céramique médiévale de Condorcet (Drôme). Archéologie Médiévale, V, 1975, pp. 307-369.

Garneret 1958: GARNERET (J.) - Etrepigney. Barbizier, revue régionale d'ethnologie franccomtoise. 1958 , pp. 45-60.

Haldimann 1994: HALDIMANN (M.-A.) - Le haut Moyen Age: une continuité méconnue? Keramik zwischen den Epochen. Funktion. Formenwandel. Technick. Centre national d'information pour la conservation des biens culturels, Bern, Août 1994, pp. 56-63.

Hanusse 1982 : HANUSSE (C.) - L'outillage du potier de terre aux XVIIe et XVIIIe s. à Sadirac (Gironde), d'après les sources écrites. Archéologie Médiévale, XII, 1982, pp. 289-296.

Hanusse 1987 : HANUSSE (C.) - La relation four-atelier d'après les sources écrites : l'exemple de Sadirac (Gironde) du XVIe au XVIIIe s. In: La céramique (Ve-XIXe s.). Fabrication. Commercialisation. Utilisation. Actes du 1er Congrès international d'archéologie médiévale, Paris, 1985. Caen, Société d'Archéologie Médiévale, 1987, pp. 101-105. 
Hesse 1980 : HESSE (A.) - La reconnaissance des sites archéologiques à partir de l'échantillonage des vestiges de surface : problèmes de méthodes et exemples. In : Préhistoire du Levant. Colloque international du CNRS n 598, Lyon 1980, pp. 513-521.

Inventaire Général des monuments et des richesses artistiques de la France 1984 - Objets civils domestiques, principes d'analyse scientifique, vocabulaire. Paris 1984, 632p.

Jeanton 1943 : JEANTON (G.) - Les arts populaires en Bresse et en Maçonnais : la céramique rustique. Mâcon, 1943.

Leenhardt 1969 : LEENHARDT (M.) - Code pour le classement et l'étude des poteries médiévales (Nord et Nord-Ouest de l'Europe). Centre de Recherches Archéologiques Médiévales. Caen, 1969, $45 \mathrm{p} ., 30 \mathrm{pl}$.

Maccari-Poisson 1980 : MACCARI-POISSON (B.) - Méthodes archéologiques de relevé et d'étude de la céramique pour restituer l'espace intérieur des maisons médiévales (Brucato, Sicile). In : La céramique médiévale en Méditérranée occidentale, Xe-XVe s. Congrès de Valbonne 1978. Paris, Colloque international du CNRS, $\mathrm{n}^{\circ}$ 584. Editions du CNRS, 1980, p. 167-174.

Maccari-Poisson 1988 : MACCARI-POISSON (B.) - Un dépotoir du Bas Moyen Âge dans le quartier Saint-Jean à Lyon. Archéologie Médiévale, XVIII, 1988, pp. 215-237.

Maccari-Poisson 1991 : MACCARI-POISSON (B.) - Contribution à l'étude des poteries du haut Moyen Âge : le quartier Saint-Jean à Lyon (IXe-Xe s.). In : A cerâmica medieval no mediterrâneo occidental. Congrès de Lisbonne 1987. Mertola 1991, pp. 147-160.

Maccari-Poisson 1994 : MACCARI-POISSON (B.) - Céramique Médiévale et Moderne. In : ARLAUD (C.) et alii. Lyon, Saint-Jean, les fouilles de l'îlot Tramassac. Lyon, Service Régional de l'archéologie, D. A. R. A. $n^{\circ}$ 10, série lyonnaise $n^{\circ} 4,1994$.

Nicourt 1974 : NICOURT (J.) - Productions médiévales des potiers de terres parisiens. Les Dossiers de l'archéologie, 1974, 7, pp.117-130.

Nicourt 1986 : NICOURT (J.) - Céramiques médiévales parisiennes, classification et typologie. Ass. Jeunesse Préhistorique et Géologique de France. Paris, 1986, 366 p.

Oriol 1945 : ORIOL (J.) Les poteries de Bans. Le Grand Givors, n 42, 6 juil. 1945.

Orton 1987: ORTON (C.) - The "envelope": un nouvel outil pour l'étude morphologique des céramiques. In : La céramique (Ve-XIXe s.). Fabrication. Commercialisation. Utilisation. Actes du 1er Congrès international d'archéologie médiévale, Paris 1985. Caen, Société d'Archéologie Médiévale, 1987, pp. 33-41.

Pasqualini et Vallauri 1988 : PASQUALINI (M.), VALLAURI (L.) - Fouilles de Toulon. Quartier de Besagne : périodes médiévale et moderne. Archéologie du Midi Médiéval, t.6, 1988, pp. 173-183.

Pesez 1982 : PESEZ (J.-M.) - Archéologues et historiens. Mélanges d'archéologie et d'histoire médiévale en l'honneur du Doyen Michel de Boüard. Mémoires et documents, XXVII, Société de l'Ecole des chartes. Genève-Paris, Droz, 1982, pp. 295-317.

Philipon et alii 1913 : PHILIPON et alii - Dictionnaire topographique du département de l'Ain. Paris, 1913.

Philippe 1925 : PHILIPPE (L.) chanoine - Les carreaux plombés de Treffort. Rhodania, compterendu du 7e Congrès de Bourg-en-Bresse. 1925, n 1001 à 1066, pp. 72-75.

Picon 1973 : PICON (M.) - Introduction à l'étude technique des céramiques sigillés de Lezoux. Centre de recherche sur les techniques gréco-romaines, Dijon, $\mathrm{n}^{\circ}$ 2, 1973, pp. 51-75.

Picon 1984a : PICON (M.) - Le traitement des données d'analyses. In : Datation - Caractérisation des céramiques anciennes, PACT 10, Cours intensif européen. 1984, pp. 379-399. 
Picon 1984b: PICON (M.) - Problème de détermination de l'origine des céramiques archéologiques. In : Datation - Caractérisation des céramiques anciennes, PACT 10, cours intensif européen. 1984, pp. 425-433.

Pilot de Thorey 1899 : PILOT DE THOREY (J.) - La céramique en Dauphiné. Revue Dauphinoise, t. 1, 1899.

Piponnier 1987: PIPONNIER (F.) - La céramique dans son contexte quotidien d'après les inventaires bourguignons (XIVe-XIXe s.). In: La céramique (Ve-XIXe s.). Fabrication. Commercialisation. Utilisation. Actes du 1er Congrès international d'archéologie médiévale, Paris 1985. Caen, Société d'Archéologie Médiévale, 1987, pp. 235-244.

Piponnier 1993 : PIPONNIER (F.) (sous la dir. de) - Le château d'Essertines, Loire. Lyon, Service régional de l'archéologie, D. A. R. A. n 8, 1993, pp. 73-118.

Pleszczynska et Tabaczynski 1978: PLESZCZYNSKA (E), TABACZYNSKI (S.) - Séquences stratigraphiques et chronologie des types céramiques: essai d'établissement d'un modèle de traitement. In : La céramique Médiévale en Méditerranée Occidentale Xe-XVe s. Congrès de Valbonne 1978. Paris, Colloque international du CNRS, $n^{\circ}$ 584. Editions du CNRS, 1980, pp. 59-63.

Potiers et poteries du pays de Dieulefit 1986 - Potiers et poteries du pays de Dieulefit du Moyen-Age à nos jours. Dieulefit, Association patrimoine potier, 1986, $28 \mathrm{p}$.

Raynaud 1992: RAYNAUD (F.) - Le château et la seigneurie-du Vuache (74). Lyon, Service régional de l'archéologie, D. A. R. A. n 6, pp. 106-108.

Renimel 1974 : RENIMEL (S.) - L'atelier céramique de Sevrey (IXe-XIXe s.). Un millénaire de tradition céramique en Chalonnais. Publication de la Société d'Histoire et d'Archéologie, Chalonsur-Saône, 1974, 70 p.

Reynaud et alii 1975 : REYNAUD (J.-F.) et alii - Etude d'une céramique régionale : les vases à fond marqué du XIe s. dans la région Rhône-Alpes. Archéologie Médiévale, V, 1975, pp. 245-285.

Rosen 1993 : ROSEN (J.) - La faïence de Meillonnas 17601845, Lyon, thèse de doctorat d'histoire de l'art et d'archéologie, 4 vol., Université de Bourgogne, Dijon, 1993, 1129 p.

Tardy 1971 : TARDY - Les poteries et les faïences françaises, Paris, 3 vol., 1971, 1646 p.

Thiriot 1985 : THIRIOT (J.) - Les ateliers de potiers postmédiévaux de Saint-Quentin-la-Poterie (Gard) : état de la recherche. Archéologie du Midi Médiéval, t. 3, 1985, pp. 123-150.

Thiriot 1987 : THIRIOT (J.) - Les ateliers médiévaux de poterie grise dans l'Uzège et le Bas-Rhône. Premières recherches de terrain. Paris, Maison des Sciences de l'Homme, D. A. F. nº 7, 1987, 147 p.

Thiriot 1990 : THIRIOT (J.) - Les fours de potiers, problèmes de méthode. In : Fours de potiers et "testares" médiévaux en Méditerranée occidentale. Méthodes et résultats. Table ronde, Colloque de la Casa Velasquez 1987. Publications de la Casa Velasquez, série archéologie XIII. Madrid 1990, pp. 169-200.

Vaginay et Guichard 1988 : VAGINAY (M.), GUICHARD (V.) - L'habitat gaulois de Feurs (Loire). Paris, Maison des Sciences de l'Homme, D. A. F. n 14, 1978-1981, pp. 36-190.

Vayssettes 1987 : VAYSSETTES (J.-L.) - Les potiers de terre de Saint-Jean-de-Fos. Millau. 1987, $447 \mathrm{p}$.

Verhaeghe 1985 : VERHAEGHE (F.) - La céramique en Flandre (XIIIe-XVe s.) : quelques aspects de l'évolution et de la concurrence. In : La céramique (Ve-XIXe s.). Fabrication. Commercialisation. Utilisation. Actes du 1er Congrès international d'archéologie médiévale, Paris 1985. Caen, Société d'Archéologie Médiévale, 1987, pp. 203-226.

Vicard 1984 : VICARD (T.) - Principes pour une évolution de la céramique régionale. Le XIIIe s. dans le département du Rhône. Mémoire de maîtrise, Université de Lyon 2, 1984, 1 vol., dactylographié, 228p. 
Vicard 1984 : VICARD (T.) - La céramique moderne de la place Antonin Poncet. In : Les fouilles de la place Antonin Poncet à Lyon. Archéologie du Midi Médiéval, t. 7, 1989.

Vindry 1976: VINDRY (G.) - Une céramique mal connue, les sgraffito français méridionaux tardifs. In : Atti del IXe convegno internationale della ceramica, Albisola, 1976, pp. 199-208. 


\section{Crédits illustrations}

\section{DESSINS}

1 M.-N. Baudrand : fig. 1, 2, 39 à 47, 49, 51, 56, 63 à 66, 81, 83 à 91, 94 à 96, 117, 157.

T. Vicard et M.-N. Baudrand : fig. 124, 137 à 155.

G. Ayala et M.-N. Baudrand : fig.119.

A. Maitre : fig. 3, 55, 57, 75, 82.

M.-P. Feuillet et J.-O. Guilhot : fig. 120.

G. Ducomet et P. Druelle (AFAN) : 98 à 108.

Ch. Laporte : fig. 121.

P. Darnand : fig. 5.

T. Vicard : fig. 22, 127, 134, 135, 156.

M. Vichy : fig. 52 à 54,73 .

C. Toti-Tissot : fig. 161, 165 (couleur M.-N. B.).

Y. Baudouin : fig. 68, 69.

B. Maccari-Poisson (mise au net M.-N. B.) : fig. 11 à 15, 17, 18, 20, 23, 24, 26, 29 à 32, 34 à 37, 71, 72.

B. Maccari-Poisson et T. Vicard : fig. 21, 25, 27.

B. Maccari-Poisson et A. Horry : fig. 19, 28, 33.

B. Maccari-Poisson et Y. Baudoin : 109 à 116.

Equipe de fouille, U.R.A. 26 : fig. 125.

S.A.M. : fig. 118, 129, 130.

2 Les dessins de la typologie ont été effectués par T. Vicard et A. Horry.

Sauf indication contraire, les céramiques sont réduites au 1/4.

\section{CLICHÉS PHOTOGRAPHIQUES}

3 E. Faure-Boucharlat : fig. 4, 38, 50, 60, 62, 67, 92, 93, 97.

H. Savay-Guerraz : fig. 61.

Ch. Thioc (MCGR) : 1ere de couverture et fig. 16, 22, 48, 80, 122, 123, 128, 132, 136, 158, 159, 160, 162, 163, 164. 
P. Plattier : fig. 58, 70.

A. D. Rhône : fig. 59.

A. D. Drôme : fig. 76, 79.

A. D. Ain : fig. 10.

F. Leyge (MCGR) : fig. 77.

Musée Dauphinois : fig. 78.

Equipe de fouille, Bourse : fig. 126.

Equipe de fouille, Terreaux : fig. 131, 133 et quatrième de couverture. 